\title{
UUUNIVERITAT JAUME•I
}

Escuela de Doctorado

\section{LO IMPORTANTE AQUÍ ES NO MORIRSE}

Azúcar, Esclavitud y Mortalidad en Cuba (1840-1886)

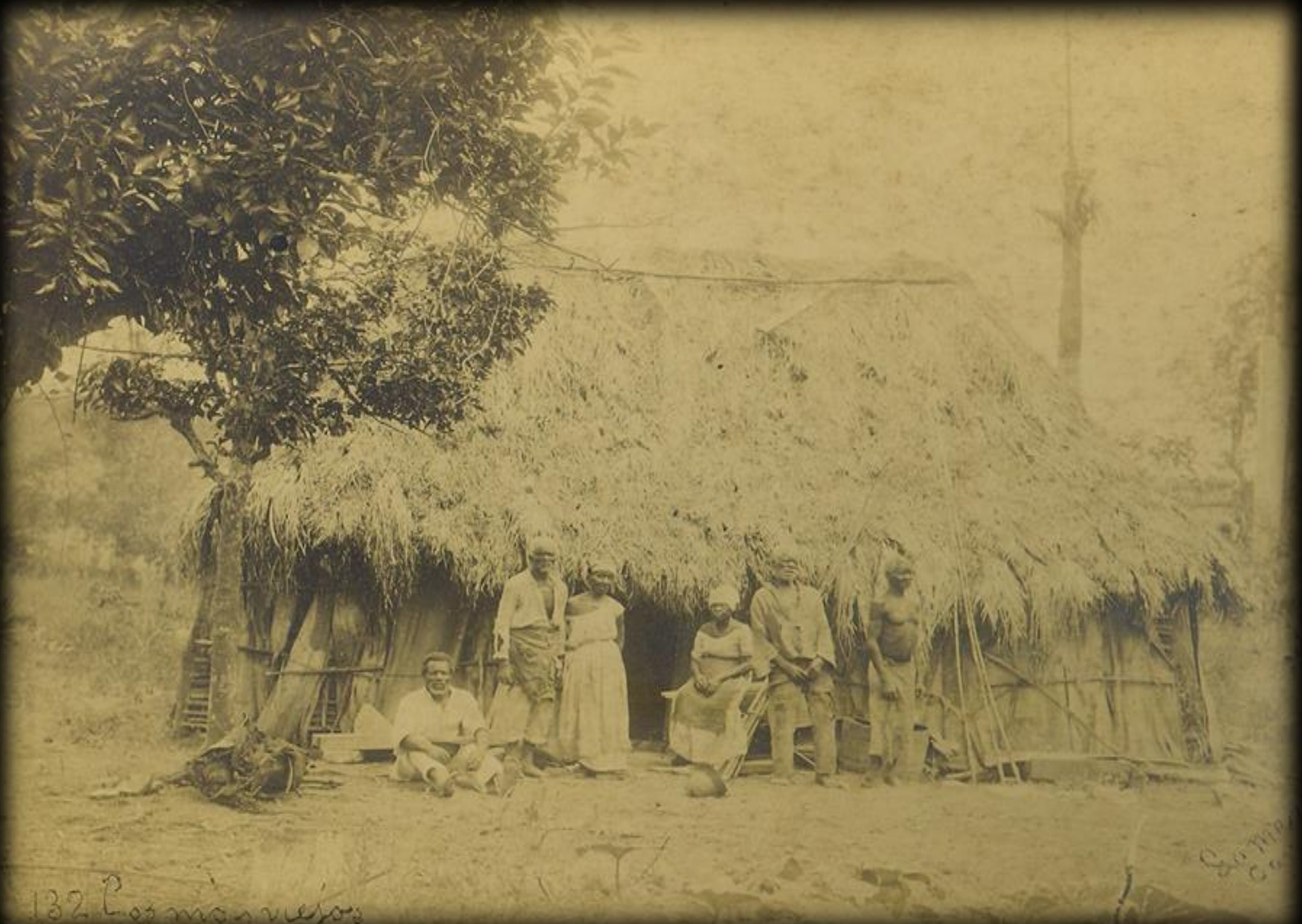

Tesis Doctoral

Presentada por: Reinier Borrego Moreno Dirigida por: Dr. José Antonio Piqueras Septiembre, 2019 



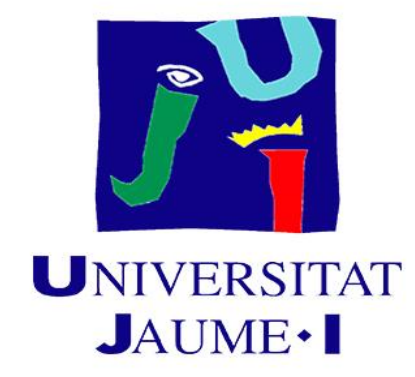

Programa de Doctorado en Historia y Estudios Contemporáneos

Escuela de Doctorado de la Universitat Jaume I

\section{LO IMPORTANTE AQUÍ ES NO MORIRSE Azúcar, Esclavitud y Mortalidad en Cuba (1840-1886)}

Memoria presentada por Reinier Borrego Moreno para optar al grado de doctor por la Universitat Jaume I

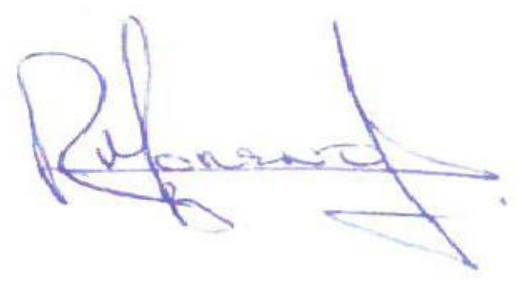

Doctorando:

Reinier Borrego Moreno

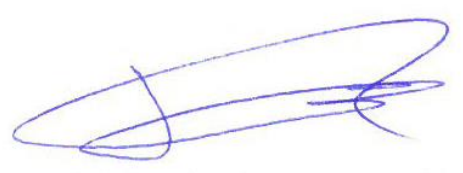

Director:

Dr. José Antonio Piqueras Arenas

Castellón de la Plana, septiembre de 2019 

Para el desarrollo de esta tesis he contado con financiamiento de la Generalitat Valenciana a través del Programa Santiago Grisolía, del cual fui becario entre los años 2014 y 2017. He recibido también ayudas económicas y recursos provenientes de los proyectos "La sociedad creada por la plantación: lógicas confrontadas, consenso y disenso colonial (Cuba 1783-1898)"-HAR201236481- y "Segunda esclavitud, producción para el mercado mundial y sistemas laborales en Cuba (1779-1886)" -HAR2016-78910-P-, financiados por el Ministerio de Economía y Competitividad y siendo José Antonio Piqueras el investigador principal. 

A Martha y René

A mis hermanos

A Claudia 

"Vencido el siglo XVIII y con él los patrones de proyecto de país sobre el criterio de sumas orgánicas de entidades locales más o menos autosuficientes, la plantación inaugurada traía los componentes de una nueva situación límite y con ella desconocidas variantes y versiones de la muerte y de las imágenes de ellas desprendibles y desprendidas. La esclavitud es la muerte colectiva, institucionalizada e inscrita como normalidad dentro de la normalidad social misma. Lo más horrible de la variante esclavista de la emergencia del capitalismo plantacionista en Cuba --y en general en el Caribe-- estriba en su carencia de capacidad para mover no ya a la solidaridad humana sino ni siquiera a conmiseración o lástima. La esclavitud se implanta y se mantiene por consenso --y es un consenso en el cual participa la casi totalidad de los sectores integrantes de la sociedad-- y su significado como pérdida de esencias humanas, como muerte total o como muertes individuales, es recibida con indiferencia consensual; sin respaldo, para las víctimas de calor humano alguno. Así la esclavitud inaugura para el registro emocional del cubano la soledad y la impotencia como referencia colectiva, y ambos extremos son expresiones de la muerte. Pero también inaugura un soterramiento de la protesta y la rebeldía; una búsqueda paciente de camino para la expresión frente a lo imposible; y todo son expresiones de lucha contra la muerte y, por tanto, de defensa para la vida."

La muerte en Cuba

Joel James Figarola 



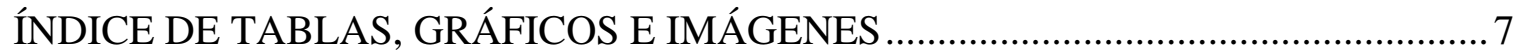

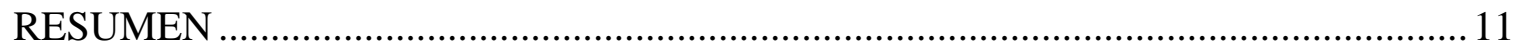

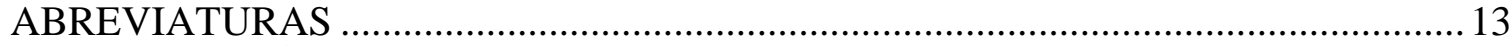

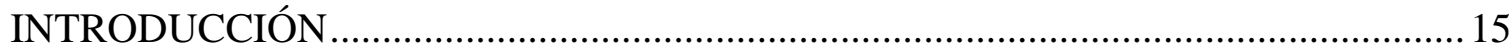

CAPÍTULO I: ESCLAVITUD Y SALUD EN LA HISTORIOGRAFÍA

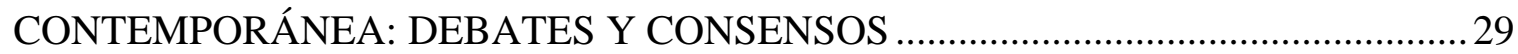

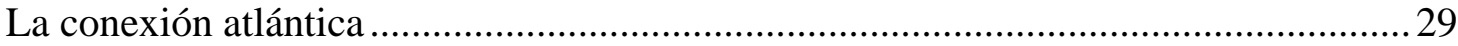

Alimentación y salud en la plantación .............................................................................36

Esclavitud y salud en la historiografía sobre Cuba ......................................................... 46

CAPÍTULO II: EL CICLO DEMOGRÁFICO DEL AZÚCAR ………………….............59

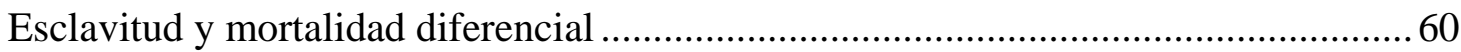

Familia esclava y mortalidad …………………………………………………..... 76

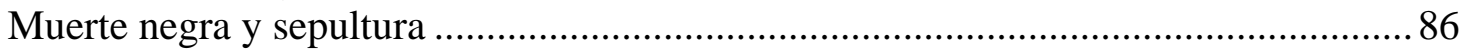

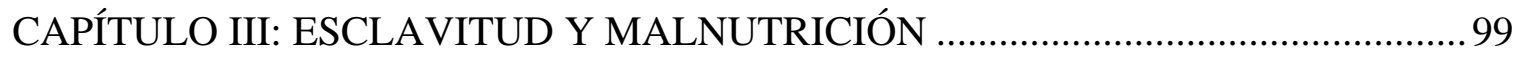

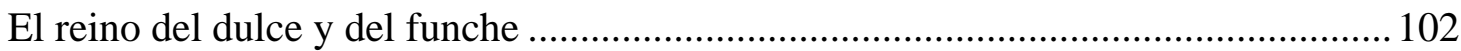

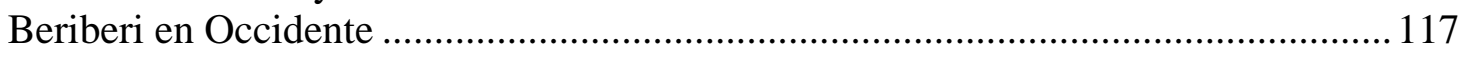

CAPÍTULO IV: ESCLAVITUD Y EPIDEMIOLOGÍA HISTÓRICA ................................. 137

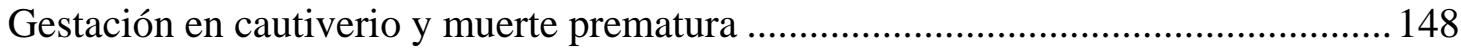

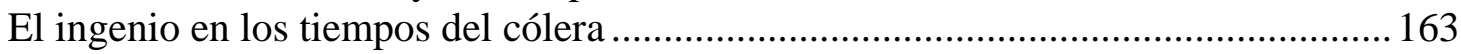

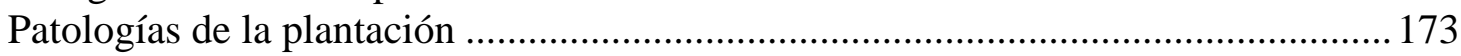

Cuerpos cautivos y nematodos libres...................................................................... 192

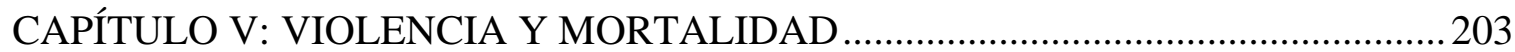

La isla del "dulce trato": reglamentación y slave agency ...........................................2205

Violencia externa y pericia judicial ............................................................................220

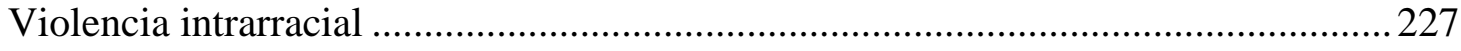

Morir, a pesar de nosotros y contra ellos .................................................................... 238

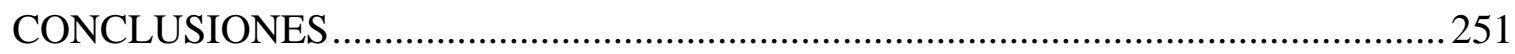

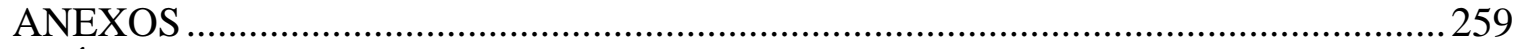

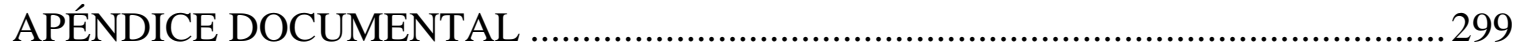

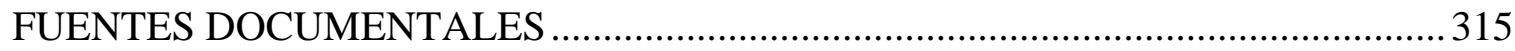

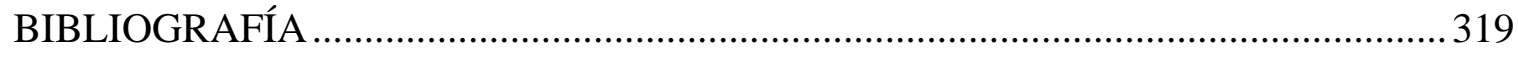


ÍNDICE DE TABLAS, GRÁFICOS E IMÁGENES

TABLA 1: Cuba. Relación entre producción azucarera y concentración de esclavos

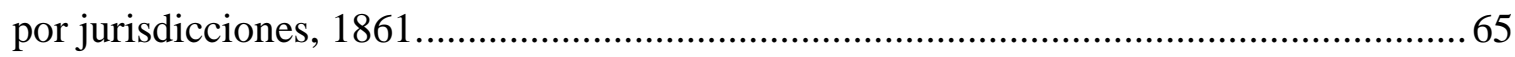

TABLA 2: Cuba. Mortalidad y natalidad comparada por jurisdicciones y raza, 1862 .... 69

TABLA 3: Raza y mortalidad comparada en varios territorios cubanos.

TABLA 4: Raza y mortalidad comparada en varias ciudades-puertos de Cuba, 18761878.

TABLA 5: Resumen de la mortalidad civil por enfermedades en La Habana, 18721881. 73

TABLA 6: Cuba. Estado civil de la población, 1869...................................................... 81

TABLA 7: Cuba. Mortalidad por raza y estado civil, 1879............................................. 83

TABLA 8: Bautismos y entierros de pardos y morenos en los registros de la iglesia parroquial de San Carlos de Matanzas, 1860-1870.

TABLA 9: Distribución étnica de los enterramientos de población de origen africano, 1850-1869. 93

TABLA 10: Esclavos fallecidos en un ingenio propiedad de Guadalupe del Junco Gener en 1850 y registrados en la iglesia parroquial de San Carlos de Matanzas. 95

TABLA 11: Cuadro comparativo del valor nutritivo de varios alimentos cubanos. 114

TABLA 12: Ración alimenticia de obreros de trabajos fuertes en varios países de clima tropical.

TABLA 13: Una estimación del estado nutricional de los esclavos del Caribe siguiendo el análisis de dos tipos de dietas "ideales" de esclavos. 116

TABLA 14: Tipos y fuentes principales de nutrientes. 118

TABLA 15: Cuadro de la epidemia de "hinchazón" estudiada por Henri Dumont en varias fincas de Matanzas, 1865 
TABLA 16: Cuba. Crecimiento vegetativo, por raza y provincia, 1879.

TABLA 17: Cuba. Registro sobre la epidemia de cólera, 1850-1854.

TABLA 18: Registro sobre la epidemia de cólera en Matanzas, 1853.

TABLA 19: Tipos de malaria examinados en el hospital del central Preston.

TABLA 20: Mortalidad en Matanzas, por causas registradas, raza, sexo y condición social, 1879

TABLA 21: Foco de dracunculiasis observado en el ingenio España, 1866.

TABLA 22: Número de patrocinados que por los conceptos que se expresan adquirieron la libertad durante el tercer año de abolida la esclavitud.

TABLA 23: Cuba. Delitos contra las personas registrados, 1857 a 1875.

TABLA 24: Estadística criminal seleccionada, con indicación de los casos de sevicia a esclavos en las principales jurisdicciones esclavistas, 1861/1862

TABLA 25: Cuba. Casos registrados como suicidios, homicidios y muertes violentas, 1879 .

TABLA 26: Cuba. Mortalidad registrada por enfermedades del corazón, 1879. 235

TABLA 27: Cuba. Muertes registradas por suicidios, 1879. 242

TABLA 28: Cuba. Estadística criminal seleccionada de la población china, 18591875 . 247

GRÁFICO 1: Cuba. Correlación entre azúcar y población, 1792-1887

GRÁFICOS 2 Y 3: Cuba. Evolución en números absolutos y porcentual de los principales componentes raciales de la población, 1792-1887.

GRÁFICO 4: Cuba. Proporción (\%o) de la mortalidad de viudos sobre casados, por raza y grupos específicos de edades, 1879.

GRÁFICO 5: Estructura por grupos de edades de los 2.206 enterramientos “de color" procesados, 1850-1869.

GRÁFICO 6: Estructura por grupos de edades de los 925 enterramientos de esclavos procesados, 1850-1869.

GRÁFICO 7: Estructura comparada de los enterramientos procesados atendiendo a la edad y condición social, 1850-1869. 
GRÁFICO 8: Cuba. Relación entre el volumen (tm) de las exportaciones de azúcar y las importaciones de arroz, 1827-1862.

GRÁFICO 9: Frecuencia con la que se daban varios alimentos a la dotación en ingenios de Julián Zulueta.

GRÁFICO 10: Cuba. Correlación entre número de ingenios y mortalidad por beriberi, 1879 .

GRÁFICO 11: Cuba. Mortalidad por beriberi y condición social de los atacados, 1879 .

GRÁFICO 12: Cuba. Relación (\%) entre población “de color", ingenios y mortalidad, 1879 .

GRÁFICO 13: Cuba. Participación (\%) de cada provincia en las principales causas de mortalidad, 1879.

GRÁFICOS 14 Y 15: Cuba. Nacimientos y defunciones de cada raza, 1793-1879...... 145

GRÁFICO 16: Cuba. Mortalidad por raza y grupo etario, 1879.

GRÁFICO 17: Cuba. Nacimientos por 100 habitantes de cada raza, 1793-1879.

GRÁFICO 18: Cuba. Mortalidad comparada por accidentes del parto en cada raza y provincia en relación (\%o) al número de nacimientos registrados, 1879.

GRÁFICO 19: Distribución de los casos de malaria estivo-otoñal examinados en el hospital del central Preston.

GRÁFICO 20: Estacionalidad de la mortalidad en Matanzas, por raza y condición social, 1879.

GRÁFICO 21: Causas de muerte identificadas en los registros de enterramientos procesados, 1855-1869.

GRÁFICO 22: Registro de la población enferma en ingenios de Julián Zulueta, $1875-1876$

GRÁFICO 23: Cuba. Evolución de los delitos contra las personas, 1857-1875.

GRÁFICO 24: Cuba. Correlación porcentual entre esclavitud y mortalidad por enfermedades del corazón, 1879. 
IMAGEN 1: Croquis de una plantación en el que se indica la enfermería, un

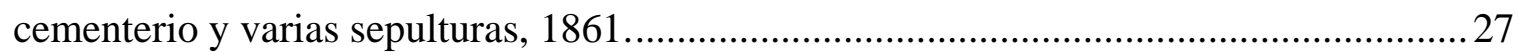

IMAGEN 2: Cuba. Esclavos a la espera de su ración de alimentos, 1866...................... 106

IMAGEN 3. Mapa publicado a fines del siglo XIX en el que se observa la distribución geográfica del beriberi y su incidencia en Cuba......................................... 122

IMAGEN 4: Anuncio de un remedio contra el beriberi en la prensa cubana, $1879 \ldots \ldots . . .128$

IMAGEN 5: Distintos aspectos de lesiones cutáneas en dos menores enfermos

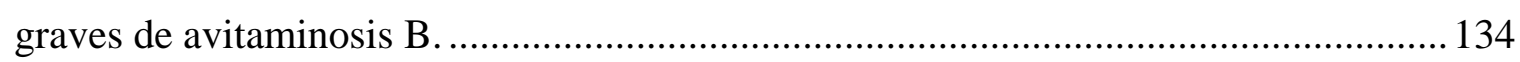

IMAGEN 6: Nota en la que se certifica el fallecimiento de Coleta conga, de 46

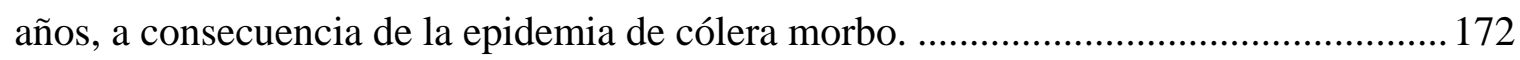

IMAGEN 7: Nota en la que el licenciado Francisco de P. Grima comunica al capitán pedáneo del partido de Santa Ana la defunción de Ambrosia mina a consecuencia de una disentería.

IMAGEN 8: Portada de la publicación titulada Tratado sobre las enfermedades que producen las lombrices en el cuerpo humano, dirigida a los hacendados $\mathrm{y}$

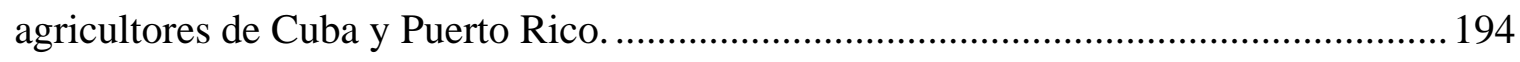

IMAGEN 9: Domingo Fernández, congo, 32 años, enfermo de "hernia disforme". ...... 200 IMAGEN 10: Hombre con elefantiasis del escroto. África oriental alemana (Tanzania), 1906-1914. 


\section{RESUMEN}

La investigación que desarrollamos analiza cómo los cambios que se producen en la economía cubana en el contexto de lo que el historiador Dale W. Tomich conceptuó como "segunda esclavitud" afectaron la salud de la población cautiva. Por su naturaleza coercitiva y caracteres específicos, la plantación esclavista configuró uno de los ambientes laborales más hostiles en la historia económica de la isla. Al término de la esclavitud en 1886, el legado demográfico de esa población acusa un desequilibrio que no puede explicarse al margen de la sobremortalidad inherente al régimen de producción en las plantaciones azucareras y el entorno social creado por las mismas. Los efectos biodemográficos y sociales de ese fenómeno trascienden el marco histórico de esta tesis, y son de gran valor para comprender el devenir de las relaciones raciales en Cuba. 


\section{ABREVIATURAS}

$\begin{array}{ll}\text { ANC } & \text { Archivo Nacional de Cuba } \\ \text { AHN } & \text { Archivo Histórico Nacional (Madrid) } \\ \text { AHPM } & \text { Archivo Histórico Provincial de Matanzas } \\ \text { BNC } & \text { Biblioteca Nacional de Cuba } \\ \text { BNE } & \text { Biblioteca Nacional de España } \\ \text { SSDA } & \text { Slave Societies Digital Archive }\end{array}$




\section{INTRODUCCIÓN}

"Y en verdad, de toda la dotación que yo había conocido en los primeros años de mi vida, pocos eran los esclavos que aun existían".

El cementerio del Ingenio Anselmo Suárez y Romero

Cuando en 1864 el costumbrista Anselmo Suarez y Romero publicó El cementerio del ingenio, ${ }^{1}$ la isla de Cuba era una gran metáfora de su particular relato. Las muertes de Pedro macuá y el mina Rogerio, del escurridizo Teodoro y la pretendida Gertrudis, del triste Fernando y el criollito Wenceslao, son el resultado del funcionamiento de un potente "complejo económico y social" especializado en transformar vidas humanas en azúcar para el mercado mundial. En los límites del ingenio, los amontonados nichos de generaciones de esclavos devorados con preocupante celeridad delataban la esencia mortífera del tándem compuesto por un refinado sistema de cuerpos cautivos y una geografía comercial desplegada en kilómetros de tierras y miles de imponentes fábricas de azúcar.

El relato de Suarez y Romero es una de las tantas evidencias que remiten a la muerte como piedra angular de la dinámica esclavista en la colonia cubana. Un croquis realizado en 1861 de una plantación matancera, encontrado en el Archivo Nacional de Cuba durante nuestra investigación, descubre la jerarquía que la última morada tuvo en la configuración de estos espacios. A los extremos del camino real que separaba los perímetros del ingenio y la casa de viviendas se observa el trazado de varias sepulturas. La "sacarocracia" cubana, como sus similares en otras áreas de la moderna economía atlántica, eran conscientes de lo que el historiador Vincent Brown definió con extrema lucidez: "El azúcar era una mercancía asesina". ${ }^{2}$ En tal sentido, igual de lapidaria es la

\footnotetext{
${ }^{1}$ Anselmo Suarez y Romero, El cementerio del ingenio, en: Costumbristas cubanos del siglo XIX, Biblioteca Ayacucho, Caracas, pp. 337-342.

${ }^{2}$ Vincent Brown, "Eating the Dead: Consumption and Regeneration in the History of Sugar", Food and Foodways, vol. 16, No. 2, 2008, p. 117. Este artículo puede leerse como un complemento metodológico de la investigación capital de Vincent Brown, The Reaper's Garden
} 
afirmación de la antropóloga Nancy Scheper-Hughes: "la historia de la plantación azucarera nordestina es una historia de violencia y destrucción inscrita en la ocupación implacable de tierras y cuerpos." 3

Las valoraciones de Vincent Brown y Scheper-Hughes, autores de sendos estudios sobre las implicaciones del azúcar en la historia social de Jamaica y Brasil, respectivamente, se inscriben en una de las tendencias más renovadoras de la historiografía contemporánea sobre los sistemas de plantación esclavista desarrollados en América. En las últimas décadas, con instrumentos teóricos y metodológicos resultantes de la combinación de distintas disciplinas, se ha profundizado en el análisis de las condiciones de vida de los esclavos y sus consecuencias sociodemográficas, destacando la importancia que los procesos de morbilidad y mortalidad de esta población tienen para el análisis de la salud del trabajo en la historia de la moderna economía-mundo.

Algunas de las preguntas que han orientado las investigaciones al respecto fueron formuladas por A. Meredith John en un artículo publicado en 1988: ¿Cuántos años vivió el esclavo promedio de plantación? ¿Las mujeres vivieron más que los hombres? ¿Qué proporción de esclavos recién nacidos llegaba a celebrar su primer año? ¿Qué proporción de esclavos nacidos sobrevivieron para convertirse en adultos? ¿Cuál fue el número promedio de años que un esclavo adulto fue productivo? ¿Fue la mortalidad de los esclavos criollos diferente a la de los esclavos traídos de África? ¿Había mayor mortalidad en las plantaciones de azúcar que en otros lugares? ¿Es cierto que los propietarios de esclavos católicos eran más humanos en su trato a los esclavos que los protestantes? ${ }^{4}$ En la medida que la documentación disponible para cada territorio lo ha permitido, estas y otras interrogantes han sido abordadas, siendo quizás el caso cubano, de entre las grandes sociedades esclavitas del continente, la que presenta los avances más tímidos en esta dirección.

En consecuencia, la investigación que desarrollamos analiza cómo los cambios que se producen entre 1840 y 1886 en la agroindustria azucarera de la colonia cubana afectaron la salud de la población africana cautiva y sus descendientes. Como hipótesis, consideramos que el contexto de la "segunda esclavitud" transformó radicalmente el

\footnotetext{
Death and Power in the World of Atlantic Slavery, Harvard University Press, Cambridge, 2010.

${ }^{3}$ Nancy Scheper-Hughes, La muerte sin llanto. Violencia y vida cotidiana en Brasil, Ariel, Barcelona, 1997, p. 46.

${ }^{4}$ A. Meredith John, "Plantation Slave Mortality in Trinidad", Population Studies, vol. 42, №. 2 , julio, 1988, pp. 161-182.
} 
panorama demográfico y epidemiológico de la isla, situando la mortalidad esclava en el centro de conexos debates económicos, sociales y científicos. Entonces, el ingenio configuró uno de los ambientes laborales más hostiles en la historia económica y social de la isla. Su funcionamiento dependió de un remplazo sistemático de las fuerzas productivas. Este hecho por lo general no se ha cuestionado, aunque las explicaciones al respecto son divergentes. En nuestro análisis, enfatizamos en que la mortalidad fue un elemento fundamental del fracaso demográfico asociado a la "segunda esclavitud" en Cuba, y que ello fue el resultado de la acción combinada de un conjunto de factores. De acuerdo con los demógrafos Juan Carlos Albizu y Fabián Cabrera, la manera en la que un determinado grupo humano muere revela los niveles de exposición a contraer ciertas enfermedades, las agresiones de las que son víctimas o los fundamentos de las decisiones autodestructivas que pudieran tomar a lo largo de sus vidas. ${ }^{5}$

En efecto, existe una fuerte correlación, no estudiada en profundidad por la historiografía contemporánea sobre Cuba, entre la dinámica socioeconómica y los patrones de salud de su población. Indicadores globales de morbilidad y mortalidad aparecen en estudios que priorizan otras temáticas, pero, al margen de observaciones puntuales, no se han desarrollado análisis sistemáticos sobre el modo en el que la dinámica socioeconómica de la colonia cubana influyó en la capacidad de supervivencia de su población. En parte, este déficit responde a la construcción de un relato demasiado optimista sobre la historia médica de la isla.

El sistema esclavista en Cuba, uno de los más prolongados del continente, comportó cambios significativos en su desarrollo. Aunque desde el siglo XVI se utilizó trabajo cautivo en diversas labores, no fue hasta el XIX que la isla se transformó en una de las principales sociedades esclavistas del continente. Entre las diferencias sustantivas que existen entre la "segunda esclavitud" y la etapa anterior destacan los cambios en la dinámica demográfica asociados al auge azucarero, no solo por el monto de la inmigración que acarreó la explotación de ese cultivo, sino además por la manera en la que condicionó un particular ciclo de vida y muerte en la plantación.

Hacia la década de 1840 la estructura demográfica de la isla se había transformado sustancialmente. Su población pasó de poco más de 171.000 habitantes en

\footnotetext{
5 Juan Carlos Albizu-Campos Espiñeira y Fabián Cabrera Marrero, "La mortalidad en Cuba según el color de la piel", Novedades en población, Año. X, No .20 , julio-diciembre, 2014, p. 38.
} 
1774 a cerca de 900.000 en 1846 . Crecimiento que estuvo determinado por un fuerte componente externo: europeo y africano principalmente. Durante la primera mitad del siglo XIX fueron desembarcados en Cuba más de dos tercios de los ochocientos mil africanos traídos mediante la trata transatlántica. El cenit de este proceso se alcanzó en 1841, cuando la población cautiva alcanzó una mayoría estimada en 436.495 personas. Ahora bien, al término de la esclavitud en 1886, el legado demográfico de esa población acusa un desequilibrio que no puede explicarse al margen de la sobremortalidad ${ }^{6}$ inherente al régimen de producción en las plantaciones azucareras y el entorno social creado por las mismas. En este contexto, el binomio azúcar y población se instaló en múltiples debates y las desigualdades en salud, sustanciadas en indicadores diferenciales de mortalidad, adquieren relieve como problema social. Esto no significa que las élites económicas y políticas de la isla desconocieran que la plantación esclavista azucarera estaba asociada a niveles elevados de mortalidad. Así lo confirmó tempranamente la experiencia demográfica de sistemas desarrollados en otras áreas del Caribe y Brasil. Por ejemplo, ya en los primeros años del siglo XVII, Diogo de Meneses e Sequeira, gobernador de Bahía entre 1608 y 1612, expresó su preocupación por la alta mortalidad de la fuerza de trabajo cautivo y el costo consecuente para los plantadores. ${ }^{7}$

Expresión de la importancia que la mortalidad esclava estaba teniendo en el desempeño del sistema hacia mediados del siglo XIX fue la aparición de Sociedades de Seguros Mutuos sobre la vida y valores de los esclavos. Las pesquisas realizadas hasta la fecha por varios investigadores interesados en el funcionamiento de estas instituciones revelan que la información conservada es escasa. No obstante, la fragilidad de la vida en la plantación azucarera queda patente cuando en los estatutos de La Providencia, las más importante de las que llegaron a funcionar, se lee que entre los grados de peligro a los que están expuesto los esclavos según el trabajo al que están destinado, los que realizan diversas tareas en el ingenio corresponden a las peores posiciones. ${ }^{8}$ El drama de la mortalidad esclava en el contexto estudiado no emana solo

\footnotetext{
${ }^{6}$ Utilizamos el concepto sobremortalidad en dos sentidos. En ocasiones para indicar la mayor mortalidad de un grupo en comparación con otro. Por ejemplo, la mortalidad de la población "de color" en relación a la blanca, la de los esclavos respecto a la población libre, o la de los trabajadores de ingenios respecto a la de los trabajadores de otros entornos. En segundo lugar, para referirnos a etapas en las que la mortalidad de un grupo supera a la natalidad del mismo, determinando un decrecimiento vegetativo de esa población.

${ }^{7}$ Stuart B. Schwartz, Sugar plantations in the formation of Brazilian society: Bahia, 1550-1835, Cambridge University Press, Cambridge, 1985, p. 364.

${ }^{8}$ En 1855, un año después de su fundación, La Providencia tenía asegurados 25.628 esclavos. A principio de la década de 1860 funcionaban en la isla otras tres sociedades de este tipo: La
} 
de su confrontación con las necesidades de la dinámica productiva, sino además de que esa realidad, regularmente rebajada a mera cuestión de números, está en permanente conflicto con la corriente abolicionista.

Dos son los conceptos fundamentales que articulan nuestra investigación: "segunda esclavitud" y epidemiología histórica. El primero de ellos, propuesto por el historiador Dale W. Tomich en una publicación de 1988, ${ }^{9}$ precisa el nexo existente entre las nuevas esclavitudes desarrolladas en América a fines del siglo XVIII y principios del XIX y la Revolución Industrial en Europa. Influenciado por el enfoque del "sistemamundo" de Inmanuell Wallerstein, la contribución teórica de Tomich es fundamental para analizar la inserción de la esclavitud atlántica en la moderna economía mundial. Aunque la esclavitud no fue una invención de la modernidad capitalista, si lo eran las lógicas económicas que la sustentaron en este nuevo marco histórico. Constituyó una de las diversas formas de control del trabajo para la reproducción del capital. El concepto de Tomich puede ser útil, además, como sugiere Marcel van der Linden, para conectar el trabajo forzado dentro de una "historia global del trabajo". De acuerdo con el historiador holandés, conviene potenciar el análisis de los problemas relativos al componente humano frente al estructuralismo dominante en los estudios tradicionales de la economía mundial. ${ }^{10}$ De este modo, al conjunto de transformaciones que el concepto "segunda esclavitud" engloba, integramos indicadores de salud que nos permiten evaluar la magnitud con la que el cuerpo del esclavo sustanció el proceso de reconversión económica hacia la producción azucarera a gran escala, asociado a transformaciones más generales del capitalismo europeo.

La muerte es un fenómeno natural e inevitable, pero el tiempo y las circunstancias en las que sucede están socialmente determinados. Lo que importa destacar entonces es que, en el contexto estudiado, las relaciones sociales serán cada vez más definitivas en la manera diferencial en la que las personan experimentan la vida y la

Protectora, El Iris y La Hereditaria. Ver: Claudia Varella, "El fracaso de las compañías de seguros de esclavos: Cuba a partir de la experiencia norteamericana", International Journal of Cuban Studies, vol. 10, №. 1, primavera, 2018, pp. 93-113.

${ }^{9}$ El artículo original fue reeditado como tercer capítulo en: Dale W. Tomich, Through the Prism of Slavery. Labor, Capital, and World Economy, Lanham, Rowman \& Littlefield, 2004. Para una revision contemporánea sobre el enfoque teórico y metodológico que propone el concepto, ver: Dale W. Tomich, "La segunda esclavitud y el capitalismo mundial: una perspectiva para la investigación histórica", Historia Social, No. 90, 2018, pp. 149-164.

${ }^{10}$ Marcel van der Linden, Workers of the world: essays toward a global labor history, Brill, Leiden y Boston, 2008. 
muerte. Como toda variable, los indicadores de morbilidad y mortalidad deben ser manejados con cuidado, pero ellos revelan mejor que otros las condiciones bajo las cuales las poblaciones viven, así como sus éxitos y fracasos en la lucha por la vida.

Comentamos ahora en qué sentido utilizamos el otro concepto fundamental de nuestra investigación: epidemiología histórica. En 1951, Kenneth F. Maxcy, entonces presidente del Departamento de Epidemiología de la Johns Hopkins University, definió la epidemiología como "el campo de la ciencia médica que se interesa por las relaciones de los diferentes factores y condiciones que determinan la frecuencia y distribución de un proceso infeccioso, una enfermedad o un estado fisiológico, en una comunidad humana". ${ }^{11}$ En las últimas décadas, la epidemiología humana ha destacado cada vez más la importancia de la persona y su entorno para comprender los procesos patógenos, consolidando su posición entre las ciencias biomédicas y las ciencias sociales. En biología, los gérmenes o microbios patógenos designan un conjunto de microrganismos -virus, bacterias, protistas y hongos- que, al invadir al ser humano, haciéndolos huésped de su reproducción, pueden producir una enfermedad y la muerte.

En consecuencia, nos interesamos por los patrones epidemiológicos registrados en el contexto de la "segunda esclavitud" en Cuba, y como la raza y la condición social funcionaron como catalizadores de la degradación biológica de la población residente en las plantaciones azucareras. Considerando la complejidad de las dinámicas que se establecen entre población-enfermedad, hemos priorizado el análisis de una de sus expresiones fundamentales, la mortalidad. Aspectos como la morbilidad o las discapacidades resultante de procesos de enfermedad requieren estudios más sofisticados que el que ahora proponemos. Si bien la ciencia contemporánea ha reconocido la importancia que en las inmunidades diferenciales tiene la genética humana $\mathrm{u}$ otros mecanismos esencialmente biológicos, en las enfermedades que analizamos son los estilos de vida -asociados a la estructura étnico-jurídica de la sociedad esclavista cubana- y desarrollados en entornos medioambientales propicios, las claves del fenómeno en cuestión. Insistimos en que el desarrollo de una enfermedad

\footnotetext{
${ }^{11}$ Gonzalo Piédrola Gil y otros, Medicina preventiva y salud pública, Masson S. A., Barcelona, 2002, p. 62. Karen Kruse Thomas, Health and Humanity: A History of the Johns Hopkins Bloomberg School of Public Health, 1935-1985, Johns Hopkins University Press, Baltimore, 2016.
} 
muy pocas veces tiene una explicación mono-causal, por lo general es el resultado de la combinación de factores diversos, en los cuales la actividad humana es decisiva. ${ }^{12}$

La investigación que hemos desarrollado está estructurada en cinco capítulos. Cada uno de estos presenta un problema de análisis particular con objetivos definidos que a su vez conectan con el problema fundamental que nos hemos planteado.

El primer capítulo ofrece un balance historiográfico sobre el binomio esclavitudsalud en las principales sociedades esclavistas de América y particularmente en Cuba. En este punto, dos han sido las áreas fundamentales de análisis: el pasaje medio y la plantación esclavista. En este segundo campo, más a fin a los objetivos que nos trazamos, se distinguen dos enfoques principales. El primero responde a interpretaciones próximas a la historia económica -sobre todo en su vertiente cliométrica- y la demografía histórica. Aquí la mortalidad esclava importa por sus implicaciones en el funcionamiento del sistema y se atiende fundamentalmente a tasas globales. En el segundo enfoque, sin ser ajeno a las preocupaciones antes comentadas, importan más las causas que determinaron la mortalidad esclava. Interpela las condiciones de vida y trabajo de este grupo desde una metodología más próxima a la historia social de la salud y la epidemiología histórica.

El segundo capítulo de la tesis ensaya sobre la transformación demográfica asociada a la segunda esclavitud en la isla y la forma en la que ese proceso determinó los niveles de mortalidad de la población sometida. Tasas dramáticamente altas de mortalidad, sobre todo infantil, combinadas con pobres niveles de natalidad definieron la esencia del sistema. Se confrontan diferentes posiciones historiográficas sobre el impacto de la esclavitud en la capacidad para formar familias, y se concluye que, en el caso cubano, la mortalidad esclava fue un evento demográfico determinante en los procesos de desarticulación de unidades familiares formadas con gran esfuerzo en el entorno de la plantación. Matrimonios extremadamente cortos y una proporción considerable de viudos sobre la población casada, fueron algunos de los resultados de la mortalidad regular entre la población cautiva, con las consecuencias que ese fenómeno imprimió a la sociedad cubana y en particular a la comunidad afrodescendiente.

\footnotetext{
${ }^{12}$ M. Szklo y J. Nieto, Epidemiología intermedia. Conceptos y aplicaciones, Ediciones Díaz de Santos, Madrid, 2003. Alfredo Morabia (ed.), A History of Epidemiologic Methods and Concepts, Birkhäuser Verlag, Boston, 2004.
} 
Considerando la influencia directa que la alimentación tuvo en la salud, el tercer capítulo se enfoca en los cambios que el auge de la plantación determinó en la alimentación regular de la población residente en esos espacios. En determinados períodos del contexto histórico analizado, no pocas defunciones de esclavos estuvieron determinadas por déficit severos en la nutrición. Unas de las expresiones más nítidas de ese fenómeno fueron las epidemias de beriberi, una enfermedad nutricional asociada a la carencia de vitamina B1. En esta línea, se discuten las posiciones historiográficas que han enfatizado en la capacidad de los esclavos de la isla para agenciarse suplementos alimentarios a través de diferentes mecanismos, como el conuco.

En el cuarto capítulo valoramos el panorama epidemiológico de la plantación esclavista en la isla a partir del examen de varias enfermedades que mantuvieron una incidencia regular en el contexto estudiado y fueron responsables de un alto porcentaje de la mortalidad esclava. Entre ellas incluimos el cólera, la disentería, la viruela, el paludismo, la tuberculosis, el tétanos y las enfermedades parasitarias. Sistemas inmunológicos debilitados por las exigencias de un trabajo intensivo padecieron con regularidad procesos infecciosos con fatídico desenlace.

Finalmente, el quinto capítulo analiza las expresiones de violencia que coexistieron en la plantación y cómo estas determinaron una parte importante de la mortalidad esclava. Por lo general, los estudios realizados hasta la fecha se han enfocado en el suicidio como expresión de la violencia intrínseca a la esclavitud, desconociendo eventos regulares cómo homicidios y agresiones entre los propios esclavos y sus compañeros de plantación. Aquí, nuestro análisis entronca con la propuesta que ha venido desarrollando en los últimos años el historiador norteamericano Jeff Forret en investigaciones como Slave Against Slave: Plantation Violence in the Old South $^{13}$, y discutimos una literatura tradicional demasiado optimista con la disciplina de la plantación y los resultados del supuesto "buen trato".

Ante las dificultades encontradas para realizar una cuantificación rigurosa de la mortalidad asociada a los problemas que analizamos, hemos potenciado un enfoque analítico más que descriptivo, que interpela más las causas y naturaleza del fenómeno en cuestión que la certeza estadística. Aunque creemos que en este último aspecto nuestra investigación también realiza avances significativos. La tesis incluye además un apéndice documental con parte de la base de datos que estamos desarrollando a partir de

${ }^{13}$ Jeff Forret, Slave Against Slave: Plantation Violence in the Old South, Louisiana State University Press, Baton Rouge, 2015. 
los registros de enterramientos de la población esclava y libre "de color" en varios territorios de Matanzas. El mismo se indica, cuando lo especifica la fuente, la fecha del entierro, nombre, nación, sexo, edad, color, condición social, propietario -en caso de ser esclavo-, vínculos familiares, y otras circunstancias de la muerte.

La tesis doctoral que hemos desarrollado comprende documentación disponible en diferentes archivos. Los fondos Junta Superior de Sanidad, Gobierno Superior Civil, Donativos y Remisiones, Miscelánea de Expedientes, Real Audiencia Pretorial de La Habana, y Reales Ordenes y Cedulas, todos del Archivo Nacional de Cuba han sido de particular importancia. Materiales de la Sala Cubana de la Biblioteca Nacional de Cuba, entre ellos manuscritos referidos a cuestiones diversas de la esclavitud en la isla y fuentes impresas especializadas en temas de salud, han sido de gran valor. Del Archivo Histórico Provincial de Matanzas he podido valerme de documentación muy precisa sobre la mortalidad de la población esclava, incluyendo centenares de registros de enterramientos realizados en diversos ingenios de esa región. No menos importante ha sido la documentación existente en los fondos del Ministerio de Ultramar conservados en el Archivo Histórico Nacional de España, así como en las hemerotecas de la Biblioteca Nacional y de la Real Academia de Medicina de España.

El trabajo de archivo en las instituciones antes mencionadas fue enriquecido con la consulta de la documentación al alcance en recursos disponibles online como el Centro de Documentación de la Universidad Jaume I, el Portal de Archivos Españoles (Pares), las bases de datos Voyages. The Trans-Atlantic Slave Trade Database, Baptismal Record Database for Slave Societies y The Human Mortality, las webs Archivo General de la Nación de Colombia, Biblioteca Digital Cubana, Cuban Heritage Collection, Our World In Data, Europeana Colletions, HathiTrust, Internet Archive, Biblioteca Virtual de la Real Academia Nacional de Medicina de España, Biblioteca del Congreso de los Estados Unidos, The New York Public Library-Digital Collections, Digital Public Library of America, y Archivos Nacionales del Reino Unido, entre otras.

Quiero destacar el proyecto Slave Societies Digital Archive, dirigido por la historiadora Jane Landers, docente en Vanderbilt University. A través de esa iniciativa se han digitalizado un número considerable de libros de enterramientos correspondientes a varias parroquias de la isla para los siglos coloniales, fundamentalmente para el XIX. Hablamos de una fuente poco explorada por la historiografía sobre la esclavitud en Cuba, y que por su dimensión cuantitativa y cualitativa en nuestra investigación ocupa un lugar relevante. Es una fuente 
particularmente valiosa para extraer conclusiones sobre el carácter de la dominación impuesta, el entorno epidemiológico, la edad, el sexo, las etnias africanas de procedencia, las relaciones familiares articuladas, entre otros factores que determinaron la capacidad de supervivencia en una región vital para el desempeño de la esclavitud y la economía atlántica en el siglo XIX.

Diversas instituciones y personas han sido fundamentales para el desarrollo de esta investigación. En primer lugar, quiero agradecer las ayudas económicas que me han brindado la Generalitat Valenciana a través del Programa Santiago Grisolía y la Universitat Jaume I. Su financiamiento me ha permitido la dedicación a tiempo completo en la tesis, la participación en actividades formativas, estancias de investigación, participación en congresos y seminarios internacionales, así como la publicación de los resultados alcanzados en cada etapa. La investigación que ahora presentamos ha sido desarrollada en el marco de los proyectos "La sociedad creada por la plantación: lógicas confrontadas, consenso y disenso colonial (Cuba 17831898)"-HAR2012-36481- y "Segunda esclavitud, producción para el mercado mundial y sistemas laborales en Cuba (1779-1886)" -HAR2016-78910-P-, financiados por el Ministerio de Economía y Competitividad y siendo José Antonio Piqueras el investigador principal. También quiero agradecer al Departamento de Historia, Geografía y Arte de la Universitat Jaume I que me ha facilitado todos los recursos a su alcance.

Mi incorporación en septiembre de 2014 al Grupo I+D Historia Social Comparada -Unidad Asociada del CSIC- mejoró considerablemente mi formación. Reconocido de Excelencia en diferentes convocatorias públicas de la Generalitat Valenciana, el grupo Historia Social Comparada constituye un nucleó de referencia para la historiografía iberoamericana. En su aval destaca la publicación de numerosos trabajos académicos, una participación activa de sus miembros en eventos científicos y la formación sistemática de doctores, varios de ellos reconocidos especialistas en diferentes áreas de la ciencia histórica. De toda esa experiencia acumulada he podido valerme durante los últimos cinco años. En especial, este trabajo ha sido posible gracias al apoyo y la confianza de mi tutor José Antonio Piqueras, director del Grupo. En septiembre de 2014 tuve la posibilidad de iniciar junto a él una rica trayectoria profesional que ha estado marcada, ante todo, por una profunda admiración a su persona. El rigor profesional 
y la dedicación con la que acometió la revisión de cada una de las entregas de esta tesis han sido imprescindibles para lograr los objetivos que nos hemos propuesto. Quiero mostrar también mi gratitud a los colegas del Grupo Historia Social Comparada, en especial a Imilcy Balboa, Juan Luis Bachero, Gwénaëlle Colez, Beatriz Joda, Amparo Sánchez, Claudia Varella y Andrés Ortí. Sin su colaboración, la trayectoria de estos años me hubiese resultado más difícil y desabrigada.

María del Carmen Barcia, Reinaldo Funes y Fernando Martínez Heredia avalaron en mayo de 2014 mi candidatura para emprender este proyecto. Estimo sinceramente la calidad humana y el compromiso intelectual que ellos representan. Siempre me sentiré orgulloso y muy agradecido por la posibilidad que me han brindado. Martínez Heredia falleció el 12 de junio de 2017, entonces me encontraba realizando una segunda estancia de investigación en Cuba. Recibí la noticia temprano en la mañana en el portal del ICIC Juan Marinello y, desde entonces, la memoria de las reflexiones compartidas ha estado presente en muchas de las jornadas de trabajo que hay detrás de esta tesis. Otras dos referencias para este trabajo han sido Oscar Loyola Vega y Gloria García, que también dejaron de estar físicamente entre nosotros mientras acometía la investigación.

En diferentes espacios, varias personas me han escuchado hablar de este proyecto, entre ellos Manuel Barcia, Consuelo Naranjo, Joan Casanova, Carlos Venegas, Marc McLeod, Josep M. Fradera, Berta Álvarez, Tomás Fernández Robaina, Mercedes García, Oilda Hevia, Bonnie A. Lucero, Yolanda Díaz, Camillia Cowling, Julio Cesar Guanche, Zuleica Romay, Alejandro L. Fernández y Josef Opatrný. Sus observaciones, con mayor o menor detenimiento, han servido para perfilar pasajes de la investigación que ahora presentamos.

Al graduarme de la licenciatura en 2012, tuve la suerte de pasar a formar parte del staff de investigadores del Instituto Cubano de Investigaciones Culturales "Juan Marinello". A este centro debo gran parte de mi formación profesional, y entre muchas otras experiencias, la posibilidad de pasar varios años en España realizando esta tesis. Por ello, quiero agradecer en particular el apoyo de su directora Elena Socarras, también de Rodrigo Espina, María Victoria (Vicky), Ana Vera, Rafael Acosta, Rosario Alfonso y Yeisa Sarduy. Por otro lado, los cafés de Deysi y Yolanda, siempre generosas conmigo, motivaron muchas de las jornadas de trabajo en archivos y bibliotecas de La Habana. También quiero agradecer a los 
funcionarios de la Biblioteca Nacional y el Archivo Nacional de Cuba, sobre todo a Julito, Martha Casals y María Teresa Puentes, que atendieron con gran amabilidad cada una de mis peticiones.

Por la complicidad compartida durante tantos años, a mis amigos Ramsés Tola, Karel Rodríguez, Betty Rodríguez, Grether Domenech, Greyser Coto, David Domínguez, Fabio Fernández y María Elena Meneses les pertenece esta investigación. Si este ejercicio sirve para seguir cultivando la pasión por la historia que nos reunió en las aulas -y cafés próximos- de la Facultad de Historia de la Universidad de La Habana, quedaré satisfecho.

Finalmente, quiero agradecer el apoyo incondicional de mi familia y personas más cercanas. El camino que conduce a esta tesis comenzó hace muchos años con los desvelos de una madre que quiso para mí la educación que no pudo tener y con el espíritu equilibrado de un padre que me cultivó en el amor por los libros y el valor transcendente de las palabras. A mis hermanos menores, que han vigilado mis pasos con dedicación. Esta tesis también es un ejercicio de afecto y gratitud a Claudia y su familia, que la hicieron posible de mil y una manera, pero sobre todo con mucho amor. Nada de lo que aquí aparece escrito es ajeno al esfuerzo que compartimos durante muchos años. A Mireia, que ha estado junto a mí en la etapa más difícil de este trabajo y me ha devuelto la confianza necesaria para terminarlo y creer que ha valido la pena. 
IMAGEN 1: CROQUIS DE UNA PLANTACIÓN EN EL QUE SE INDICA LA ENFERMERÍA, UN CEMENTERIO Y VARIAS SEPULTURAS, 1861.

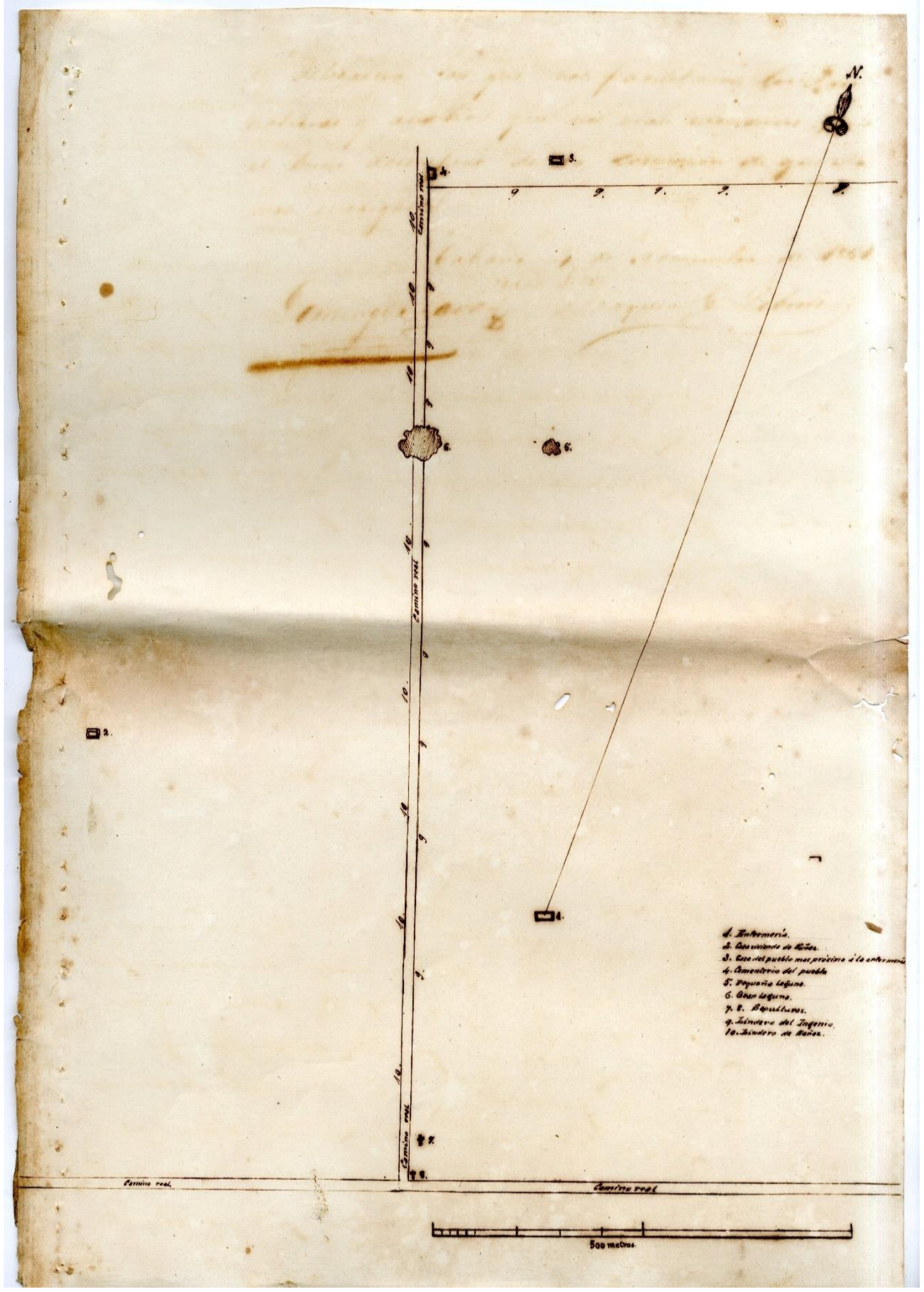

Fuente: "Varios vecinos del pueblo de Corral Falso sobre el hospital de virulentos establecido en el ingenio Sta. Catalina”, ANC, Gobierno Superior Civil, Leg. 944, exp. 80797, 1861. 


\section{CAPÍTULO I: EL BINOMIO ESCLAVITUD-SALUD EN LA HISTORIOGRAFÍA CONTEMPORÁNEA: DEBATES Y CONSENSOS}

La esclavitud atlántica hizo posible el desarrollo de grandes sistemas económicos en el Nuevo Mundo. Indicadores diferenciales de morbilidad y mortalidad revelan la forma en la que ese fenómeno alteró la relación entre los componentes biológicos y psicosociales de la población sometida. Metodológicamente, podemos indicar en la historiografía contemporánea dos corrientes generales de análisis relacionadas entre sí: la epidemiología histórica vinculada a la trata y el análisis de las dinámicas demográficas de las esclavitudes americanas. Un balance de la producción académica existente deja ver su disparidad, siendo más copiosa para los Estados Unidos y las posesiones coloniales británicas, y un tanto más discreto el estudio de los territorios que conformaron el imperio colonial español.

\section{LA CONEXIÓN ATLÁNTICA}

Las tensiones en torno a la salud de la población cautiva se extienden a través de las dos orillas del Atlántico, involucrando a diversos patógenos, millones de personas y una producción constante de conocimiento científico y dispositivos disciplinarios para mantener la sujeción de generaciones de personas, cuya barrera entre la vida y la muerte se tornó, de repente, especialmente quebradiza.

El debate contemporáneo sobre el volumen de africanos importados en América y su distribución regional fue abierto en la década de 1960 por Philip Curtin. ${ }^{1}$ Los cálculos realizados por diferentes especialistas oscilan entre los 9.5 millones estimados por Curtin y los 15 millones que sugiere el historiador Joseph E. Inikori. ${ }^{2}$ La fuente más usada en la actualidad es la base de datos coordinada en sus inicios por David Eltis y Martin Halbert, docentes en Emory University. Como es sabido, la ola del comercio

\footnotetext{
${ }^{1}$ Philip D. Curtin, The Atlantic Slave Trade: A Census, The University of Wisconsin Press, Madison, 1969.

${ }^{2}$ Joseph E. Inikori, Africans and the Industrial Revolution in England: A Study in International Trade and Economic Development, Cambridge University Press, Cambridge, 2002.
} 
atlántico de esclavos coincide cronológicamente con la Revolución Industrial. De acuerdo con los registros de Voyages, solo en el siglo XVIII fueron desembarcados en el Nuevo Mundo más de la mitad de los casi 10 millones de africanos traídos bajo esa condición. Otros 3 millones aproximadamente llegaron con igual finalidad entre 1800 y la década de 1860. El pico anual se alcanzó en 1829, con 105.930 esclavos desembarcados. ${ }^{3}$

En el Caribe insular, donde la colonización temprana redujo significativamente la población autóctona, el aporte demográfico de la inmigración forzada fue mayor. El historiador Nobel David Cook sugiere que entre el 80 y el 95\% de la población indígena fue diezmada en los primeros 100-150 años después de 1492. ${ }^{4}$ Los factores que pudieron determinar ese fenómeno son diversos, pero la mayoría de los investigadores contemporáneos han puesto el énfasis en los efectos combinados de la explotación laboral y el entorno de enfermedades. De acuerdo con la demógrafa inglesa Linda A. Newson, aunque existe consenso sobre la importancia de los factores epidemiológicos en la despoblación autóctona del continente, son significativas las variaciones regionales del fenómeno. Diversos aspectos pudieron condicionar la virulencia y propagación de enfermedades en una u otra zona. ${ }^{5}$

En 1968, Philip D. Curtin publicó un innovador artículo en el que combinó con éxito argumentos biológicos en la explicación de procesos históricos. Desde un enfoque moderno, su trabajo adelantó interesantes reflexiones sobre los vínculos entre los flujos migratorios de personas y enfermedades, los procesos de colonización y el avance de la medicina en el Mundo Atlántico. En este primer trabajo, que tuvo continuidad en estudios posteriores, destacó la importancia que los factores epidemiológicos tuvieron para el comercio transatlántico de esclavos. ${ }^{6}$ Años más tarde, Alfred W. Crosby, uno de

\footnotetext{
3 Voyages. The Trans-Atlantic Slave Trade Database, consultada en https://www.slavevoyages.org/, 1 de abril de 2019. Hablamos de un proyecto desarrollado durante las últimas dos décadas y que comprende información de unas 36.000 expediciones esclavistas realizadas entre 1514 y 1866. Aunque no está exenta de errores, es la base de datos de su tipo más completa y en torno a la cual existe consenso académico. Ver también: David Eltis y David Richardson, Atlas of the Transatlantic Slave Trade, Yale University Press, New Haven y Londres, 2010.

${ }^{4}$ Las valoraciones al respecto divergen en correspondencia con las estimaciones de la población precolombina existente. Noble David Cook, Born to Die: Disease and New World Conquest 1492-1650, Cambridge University Press, Cambridge, 1998.

${ }^{5}$ Linda A. Newson, El costo de la conquista, Editorial Guaymuras, Tegucigalpa, 2000.

${ }^{6}$ Philip D. Curtin, "Epidemiology and the Slave Trade", Political Science Quarterly, vol. 83, No. 2, junio, 1968, pp. 190-216. Los vínculos entre colonización europea y enfermedades tropicales fueron abordados de forma detallada en una obra posterior: Philip D. Curtin, Death by
} 
los pioneros de la historia ambiental, enfatizó, en un texto hoy paradigmático, la importancia de los factores biológicos en el éxito del imperialismo europeo. ${ }^{7}$ El llamado "comercio triangular", que hace referencia a la circulación intercontinental de capitales, mercancías y personas a través del atlántico, también funcionó como canal transmisor de diversas enfermedades. De acuerdo con Crosby, "el azúcar fue el catalizador del cambio social y ecológico", y la trata de esclavos una pieza central del intercambio epidemiológico. Sobre esta idea volvería John R. McNeill años más tarde. Este profesor norteamericano estudió en profundidad el impacto ecológico de la transformación azucarera en los trópicos americanos y su importancia para el desarrollo en esta área de enfermedades como la fiebre amarilla y la malaria. ${ }^{9}$ Sobre esas y otras enfermedades existe una amplia literatura producida en el siglo XIX.

Las condiciones en las que funcionó el comercio atlántico de esclavos y sus efectos sobre la salud de la población involucrada han sido estudiadas en profundidad. De acuerdo con las estimaciones disponibles en Voyages. The Trans-Atlantic Slave Trade Database, existe una diferencia de unos dos millones entre el total de esclavos embarcados en África y el número de estos que llegaron con vida a destinos del Nuevo Mundo. El porcentaje mayor de esa diferencia estuvo determinado por la mortalidad durante el pasaje medio. Desde el siglo XVIII, las opiniones al respecto se han dividido en dos líneas fundamentales. Unos, considerando las mayores tasas de mortalidad durante los primeros días de la travesía, se han enfocado en el análisis de los procesos de pre-embarcación: captura, desplazamiento y alojamiento en las costas africanas. El comercio atlántico de esclavos involucró fundamentalmente a diversas zonas ubicadas a lo largo de la costa occidental subsahariana, pero también a distintos puntos ubicados al este del continente. La procedencia de los esclavos y la distancia a recorrer incidieron

migration. Europe's encounter whit the tropical world in the nineteenth century, Cambridge University Press, Cambridge, 1989.

${ }^{7}$ A. Crosby, Imperialismo Ecológico. La expansión biológica de Europa 900-1900, Crítica, Barcelona, 1998.

${ }^{8}$ Ibídem, p. 113.

${ }^{9}$ John R. McNeill, "El vómito negro y la geopolítica. El medio ambiente, las epidemias y las batallas por el imperio en los trópicos americanos", en: Reinaldo Funes (ed.), Naturaleza en declive. Miradas a la historia ambiental de América Latina y el Caribe, Fundación Instituto de Historia Social, Valencia, 2008. John McNeill, Mosquito Empires: Ecology and War in the Greater Caribbean 1620-1914, Cambridge University Press, Cambridge, 2010. Un estudio en esta línea para Cuba fue realizado por la investigadora Mariola Espinosa, Epidemic Invasions. Yellow Fever and the limits of Cuban Independence 1878-1930, The University of Chicago Press, Chicago, 2009. 
más que otros factores en la mortalidad durante la travesía, registrándose las tasas más elevadas para algunos trayectos iniciados en Mozambique. ${ }^{10}$

Otra corriente ha destacado las pésimas condiciones higiénicas en la que se trasladaban los esclavos y la mala alimentación a bordo. Entre los padecimientos habituales identificados en los diarios de navegación están la disentería, la viruela, "las fiebres", la neumonía, la gangrena, el cólera, la malaria, la deshidratación y la desnutrición. La ingesta durante períodos prolongados de una dieta deficiente en nutrientes esenciales podía provocar enfermedades carenciales, como el escorbuto, o debilitar la resistencia a enfermedades infecciosas. El hacinamiento en estas embarcaciones facilitó la propagación de los agentes patógenos a través de secreciones contaminadas. Lo normal era que durante un trayecto siempre difícil empeorara la ya menguada salud de la población embarcada. ${ }^{11}$

David L. Chandler, en un estudio pionero para las colonias españolas, destacó la "monstruosa mortalidad" asociada a la esclavitud. Este autor sugiere que durante los dos primeros siglos de trata los índices de mortalidad en el pasaje medio oscilaron entre un 25 y un $30 \%$, declinando en el siglo XIX hasta un mínimo del 5\%. ${ }^{12}$ Un estudio posterior de Linda A. Newson y Susie Minchin fija una cifra más moderada para la travesía atlántica desde la alta Guinea hasta Cartagena: entre un 10 y $15 \%$ a principios del siglo XVII. ${ }^{13}$ Para el conjunto de la trata española se ha estimado en un $19 \%$ la tasa de mortalidad de la tripulación esclava durante la travesía atlántica desde el siglo XVIII, cifra entre un 4 y un $7 \%$ superior a la acreditada entonces para las embarcaciones con destino a las colonias británicas y francesas del Caribe. ${ }^{14}$

A partir de 1811, casi la totalidad de los esclavos desembarcados en Hispanoamérica lo hicieron en Cuba. El 23 de septiembre de 1817 los gobiernos de España e Inglaterra firmaron en Madrid un tratado bilateral que prohibía el comercio de esclavos a partir de 1820. De acuerdo con lo estipulado, se constituyeron en 1819 los

\footnotetext{
${ }^{10}$ Herbert S. Klein, "El comercio atlántico de esclavos en el siglo XIX y el suministro de mano de obra a Cuba y Brasil", en: José A. Piqueras (comp.), Azúcar y esclavitud en el final del trabajo forzado, Fondo de Cultura Económica, Madrid, 2002, pp. 37-49.

${ }^{11}$ Herbert S. Klein, Stanley L. Engerman, Robin Haines y Ralph Shlomowitz, "Transoceanic Mortality: The Slave trade in Comparative Perspective", The William and Mary Quarterly, vol. LVIII, $N^{\circ}$. 1, enero, 2001, pp. 93-118.

${ }^{12}$ David L. Chandler, Health and Slavery in Colonial Colombia, Arno Press, Nueva York, 1981.

${ }^{13}$ Linda A. Newson y Susie Minchin, From Capture to Sale: The Portuguese Slave Trade to Spanish South America in the early seventeenth century, Brill Academic Publishers, Leiden y Boston, 2007.

${ }^{14}$ José A. Piqueras, La esclavitud en las Españas. Un lazo transatlántico, Libros de la Catarata, Madrid, 2011, p. 129.
} 
tribunales mixtos anglo-español en Sierra Leona y La Habana. En 1835 se firmó otro convenio entre España e Inglaterra para hacer más efectiva la lucha contra el tráfico ilegal de esclavos, aunque tampoco se pudo contener significativamente esa práctica. ${ }^{15}$ Los estudios que advierten un ligero incremento en la mortalidad promedio durante la fase ilegal de la trata destacan, junto a las defunciones por enfermedades frecuentes, las pérdidas determinadas por las presiones de los buques británicos, que se hizo más activa a partir de la década de 1840. En el momento de realizarse las operaciones de inspección a los buques apresados, varios de estos se encontraban sin tripulación africana, aunque presentaban signos efectivos de estar dedicados a la trata. Si el acuerdo de 1817 estableció que la condena solo podía realizarse a los barcos capturados con esclavos a bordo, el de 1835 dispuso que ese procedimiento pudiera llevarse a cabo si se encontraban evidencias que sugirieran el ejercicio del comercio ilícito. ${ }^{16}$

Aunque el número de barcos capturados por la marina británica durante la trata ilegal fue escaso en relación al volumen de esclavos efectivamente transportados, la información que ofrecen los registros documentales de los juicios realizados por las comisiones mixtas es muy valiosa. La base de datos The Liberated Africans Proyect, que contiene información de la red de tribunales internacionales, ofrece información correspondiente a unas 44 embarcaciones enjuiciadas entre 1824 y 1841 por la comisión mixta establecida en La Habana. De acuerdo con esa fuente, la tasa global de mortalidad de la tripulación esclava, registrada entre la fecha de salida de la embarcación en África Occidental y la fecha de sentencia por ese organismo, promedio un 14\%. En algunas embarcaciones la mortandad superó ampliamente esa cifra, siendo los casos más dramáticos los de los navíos nombrados "Midas", "Intrépido", "Diligencia" y "Marte", que reportaron una sobremortalidad del 63, 61, 55 y 46\% de la tripulación embarcada, respectivamente. Las causas más comunes de fallecimiento incluyen la disentería, la viruela, el cólera, la deshidratación, la desnutrición y la malaria. ${ }^{17}$

Los capitanes de las embarcaciones tuvieron en cuenta diversos aspectos para disminuir las pérdidas regulares durante la travesía, aumentando así sus ganancias en el lucrativo comercio. Siempre que lo permitiese el mercado humano en las costas

15 Arturo Arnalte Barrera, "El tribunal mixto anglo-español de Sierra Leona: 1819-1865", Cuadernos de Historia Moderna y Contemporánea, vol. 6, 1985, pp. 197-215.

${ }^{16}$ Ibídem, p. 204.

17 Henry B. Lovejoy y otros, The Liberated Africans Proyect, consultado en http://www.liberatedafricans.org/hstc/hstc.html, 15 de mayo de 2019. Este es un recurso web en desarrollo, que espera ampliar la información ya disponible sobre Cuba con los registros existentes para un período posterior. 
africanas, seleccionaron aquellos cuerpos que consideraban más aptos para soportar los rigores del viaje, con preferencia hombres jóvenes entre 15 y 35 años. Con el tiempo, la mayor experiencia adquirida por los tratantes, las trasformaciones en el diseño de las embarcaciones, la reducción de los tiempos de viaje, el mejor aprovisionamiento y la atención médica a bordo incidieron positivamente en la tasa de supervivencia de la población transportada. ${ }^{18}$

No obstante, si atendemos la documentación relativa a los barcos conductores de colonos asiáticos hacia las plantaciones cubanas, un tráfico que se produjo bien entrado el siglo XIX, la mortalidad a bordo mantuvo niveles alarmantes. Entre 1872 y 1874 la Junta Subalterna de Sanidad del Mariel pasó varios expedientes a la Superior de Sanidad relativos a la excesiva mortalidad a bordo de varias embarcaciones españolas y francesas encargadas de transportar colonos asiáticos desde Macao hacia la isla. En algunos casos, la tasa de mortalidad durante estas travesías superó el 6\% de la tripulación, lo que violaba lo dispuesto en el artículo 16 del Reglamento del 6 de julio de 1860 sobre la introducción y régimen de colonos asiáticos. Por ejemplo, en el vapor español Juan fallecieron 53 colonos asiáticos durante la travesía desde Macao y el 6\% de los transportados en la fragata francesa Veloce durante similar trayecto. En la mayoría de los casos registrados, las inspecciones sanitarias eximieron de responsabilidad a los gobernantes de las embarcaciones, alegando que se habían cumplido las prescripciones reglamentarias y que las defunciones registradas se debían a "causas generales inapreciables". En el caso del vapor Veloce, se dijo que el capitán era responsable en cierta medida por no impedir el abuso del opio. Mientras que, en otro vapor francés, el Alejandro Lavalley, que transportaba 630 colonos asiáticos y presentó una mortalidad superior al $6 \%$, la responsabilidad fue atribuida al gran número de colonos enfermos embarcados en el puerto de origen, y a que médico chino de la embarcación no tenía los conocimientos necesarios para dirigir la enfermería. ${ }^{19}$

Asimismo, otro informe del Presidente de la Diputación del Puerto del Mariel, fechado el 26 de febrero de 1874, puso en conocimiento de las autoridades sanitarias y políticas de la isla la llegada a las cinco de la tarde del 24 de febrero de 1874, del vapor

\footnotetext{
${ }^{18}$ Santiago Garrido y otros, Tráfico marítimo de esclavos: cambios tecnológicos y mortalidad. Un análisis socio-técnico, Primeras Jornadas Nacionales de Historia Social, La Falda-Córdoba, 30,31 de mayo y $1^{\text {ro }}$ de junio de 2007, consultado en http://cehsegreti.org.ar/historia-social1/mesas\%20ponencias/Mesa\%203/Ponencia_Garrido_Lalouf_Thomas.pdf, 15 de junio de 2015. ${ }^{19}$ Documentos relacionados con la excesiva mortalidad a bordo de barcos conductores de colonos asiáticos, Junta Superior de Sanidad, ANC, Leg. 5, Nº. 3, 1872, 1873, 1874.
} 
español Rosita y Nene, procedente de Macao, luego de una travesía que duró diez meses y siete días, pasando por Batavia (actual Yakarta, Indonesia), Reunión, Puerto Natal ( se refiere a la actual ciudad de Durban, Sudáfrica), Bahía de Algoa (cerca del Puerto Elizabeth , también en Sudáfrica), Bahía de todos los Santos, Río de Janeiro y Puerto Rico. Tenía un médico europeo, dos chinos y tres intérpretes chinos. Transportaba 275 colonos asiáticos, de los cuales fallecieron 125durante la travesía. Uno de ellos de viruela, 10 de tisis tuberculosa, 11 de fiebre perniciosa, 14 de disentería, 8 de "afecciones cerebrales", 5 de "ulceras de mal carácter", 14 de anasarca, 5 de reumatismo, 57 de parálisis "sin más antecedente que la demacración consiguiente a la falta de movimientos". De los 53 tripulantes, fallecieron uno de viruelas, 3 de tisis pulmonar, 2 de fiebre perniciosa -incluyendo uno de los intérpretes. Al arribo de la embarcación a la isla existían varios enfermos: 1 de tisis, 2 de ascitis, otro con fractura humoral derecha, 2 ciegos, 5 con ulceras simples, y otros 15 con herpes. Siendo los más graves los casos de tisis y ascitis. Una vez desembarcados los colonos en la isla se procedió a la fumigación, ventilación y aseo de la embarcación según lo prescrito en el reglamento. ${ }^{20}$

El barco de esclavos, más allá de los riesgos inherentes a la navegación en los siglos que duró ese comercio humano, presentó dinámicas y tensiones particulares que incidieron negativamente en las tasas de supervivencia. En altamar, los marineros europeos daban continuidad al proceso iniciado en las costas africanas: transformar vidas humanas en mercancías para el mercado internacional de trabajo, un proceso necesariamente atravesado por lógicas de represión y terror. Como refieren los estudios icónicos de Marcus Rediker ${ }^{21}$ y Eric Robert Taylor ${ }^{22}$, las revueltas de esclavos eran una amenaza constante durante la travesía. Para mantener la disciplina de la tripulación a bordo, los traficantes se aprovisionaban de un importante arsenal de armas. Taylor llega incluso a sugerir que los costos de protección y seguros contra las revueltas de esclavos y las pérdidas de vida durante la travesía fueron factores determinantes de la abolición de ese comercio, hipótesis que cuestiona el historiador Michael Craton. ${ }^{23}$

\footnotetext{
${ }^{20}$ Ídem. Arribaron además en esta embarcación dos pasajeros europeos.

${ }^{21}$ Markus Rediker, El barco de esclavos. Una historia humana, Imagen Contemporánea, La Habana, 2014.

${ }^{22}$ Eric Robert Taylor, If We Must Die: Shipboard Insurrections in the Era of the Atlantic Slave Trade, Louisiana State University Press, Baton Rouge, 2006.

${ }^{23}$ Michael Craton, The American Historical Review, vol. 113, No. 3, junio, 2008, pp. 789-791.
} 
Ya en las Indias Occidentales, los cautivos debieron superar una compleja primera etapa que en la historiografía sobre la esclavitud se conoce como "seasoning", condimento. Por lo general, los que sobrevivían al trayecto marítimo arribaban a los puertos americanos en deplorable estado de salud. Las estimaciones sobre el período de aclimatación y los índices de mortalidad entre los recién llegados difieren de una región a otra. Como promedio, en el Caribe, una cuarta parte de ellos podía morir en los tres primeros años. ${ }^{24}$ En las plantaciones del Nuevo Mundo proseguía la tragedia iniciada en las factorías africanas. Un destino que exigió de la población sometida el despliegue de las más diversas estrategias posibles para preservar su existencia.

\section{ALIMENTACIÓN Y SALUD EN LA PLANTACIÓN}

En el contexto de la Segunda Guerra Mundial se produjo un gran interés por el hambre y la malnutrición como fenómenos sociales. Desde entonces, médicos, demógrafos, agrónomos, nutricionistas e historiadores, entre otros especialistas, han estudiado con rigor los problemas de la alimentación humana, y los congresos nacionales, regionales e internacionales sobre el tema se han sucedido unos tras otros. ${ }^{25}$ Algunas de las directrices fundamentales de la investigación científica y la agencia de los gobiernos en este campo han estado marcadas por la sinergias entre alimentación y salud, con sus implicaciones demográficas, políticas y socioculturales. En el desarrollo de esa conciencia ha sido fundamental la experiencia de un pasado marcado por ciclos de hambrunas y profundas desigualdades en el acceso a los recursos de subsistencia.

\footnotetext{
${ }^{24}$ Uno de los estudios más completos sobre la salud de los esclavos en el Caribe en: Kenneth F. Kiple, The Caribbean Slave. A Biological History, Cambridge University Press, Nueva York, 1984, pp. 59-60.

${ }^{25}$ La preocupación académica por estos problemas ha estado acompañada de un proceso de institucionalización. El 18 de mayo de 1943 se inauguró en Hot Spring (Virginia), la Conferencia de Naciones Unidas sobre Agricultura y Alimentación, evento que sentó las bases para la fundación de la FAO en Quebec el 16 de octubre de 1945. Luego surgieron nuevas corporaciones internacionales especializadas como el Programa Mundial de Alimentos (PMA) en 1961 y el Fondo Internacional de Desarrollo Agrícola (FIDA) en 1977. Motivada por la Conferencia de Hot Spring, y atendiendo a la crisis alimentaria que atravesaba entonces el país, la Federación Médica Cubana convocó y realizó en La Habana en septiembre de 1943 el Primer Congreso Nacional de Alimentación, en el cual se reunieron representantes de los diferentes sectores implicados en la producción, conservación y distribución de alimentos en el país. Ver: Primer Congreso Nacional de Alimentación, Colegio Médico Nacional, La Habana, 1945.
} 
De forma particular se analizaron enfermedades como la pelagra, el escorbuto, el beriberi o la xeroftalmia, demostrándose que las mismas estaban asociadas a deficiencias nutritivas. Con escasas excepciones, los estudios publicados en la primera mitad del siglo XX no fueron producidos por historiadores, ni abordaban la dimensión histórica del problema en cuestión. ${ }^{26}$ Un trabajo pionero en la historia de la alimentación fue publicado en 1949 por el botánico británico Redcliffe Nathan Salaman. Su estudio analiza diversos aspectos de la historia social de la patata, con un enfoque particular en Irlanda, donde este cultivo ha tenido una gran influencia en la alimentación popular. ${ }^{27}$

A pesar de algunos trabajos pioneros, hasta la década de 1970 la investigación histórica sobre alimentación y salud fue marginal dentro de la producción historiográfica. Desde entonces, su desarrollo ha sido progresivo, aunque geográficamente desigual. Un balance al conjunto de las publicaciones de las últimas décadas en este campo revelaría no solo un incremento cuantitativo, sino además la madurez metodológica y pluralidad temática de la producción existente. ${ }^{28}$ Entre la historia económica y los enfoques más culturales, la experiencia de comer o no comer, con sus determinantes y consecuencias, ha ocupado el tiempo de no pocos estudiosos. Interesa destacar los trabajos que han revindicado la larga duración como categoría de análisis, produciendo un conocimiento funcional al debate contemporáneo sobre el tema.

Aunque existían algunos antecedentes, fueron los debates suscitados alrededor de la publicación de Time on the Cross (1974) los que dinamizaron la investigación sobre las condiciones de vida de los esclavos en las plantaciones americanas. Robert W. Fogel y Stanley L. Engerman discutieron a través de una metodología novedosa, la cliometría, la creencia generalizada en la pésima alimentación y salud de esa población.

\footnotetext{
${ }^{26}$ Ver, por ejemplo, Frederick G. Hopkins, "Feeding Experiments Illustrating the Importance of Accessory Factors in Normal, Dietaries", The Journal of Physiology, vol. 44, No. 5-6, 1912, pp. 425-460. Alfred C. Reed, "Vitamins and Food Deficiency Diseases", The Scientific Monthly, vol. 13, No. 1, julio, 1921, pp. 67-80. Benjamin Harrow, Vitamines; Essential Food Factor, E. P. Dutton \& Company, Nueva York, 1921.

${ }^{27}$ Este clásico del tema, elogiado por el historiador Eric Hobsbawm, ha sido reimpreso y editado en varias ocasiones. Redcliffe Nathan Salaman, The History and Social Influence of the Potato, Cambridge University Press, Cambridge, 1949.

${ }^{28}$ Para un balance historiográfico sobre el tema ver: Jorge Uría, "Una nueva historia de la alimentación", Historia Contemporánea, Nº. 48, 2014, pp. 33-69. Este número de la revista incluye un dossier titulado Comensalidad y alimentación en la época contemporánea, coordinado por Jorge Uría y Luis Benito García. También la revista española Historia Social dedicó en su N ${ }^{\circ}$. 80, del 2014, un monográfico al tema con el título, Ciudades, alimentación y salud en España en los siglos XIX y XX.
} 
Asumiendo que muchos de los productos cultivados en las plantaciones eran consumidos por los cautivos, la dieta de estos, compuesta regularmente de maíz y carne de cerdo, pudo enriquecerse con leche, nabos, batatas, guisantes, naranjas, manzanas, tocino, cordero, pollo y carne de vaca, entre otros alimentos. Régimen alimenticio que superaba al de los trabajadores libres, y que estaba por encima también de los parámetros dietéticos de la época. La revisión de Robert W. Fogel y Stanley L. Engerman de este y otros indicadores, implicaba una reevaluación del alcance de la explotación en las plantaciones del sur americano y sobre la eficiencia del sistema esclavista. $^{29}$

La investigación de estos autores sobre la esclavitud en los Estados Unidos confluía con preocupaciones más generales sobre la relación entre nutrición, salud y esperanza de vida en las economías modernas, campo en el que Robert W. Fogel realizó varios estudios notables. Con varios de sus discípulos impulsó la historia antropométrica, destacando la importancia que indicadores como la altura y el Índice de Masa Muscular (IMC) podían tener en la historia de la salud. Junto a la economista y biodemógrafa Dora Costa, Robert W. Fogel estableció el concepto de "evolución tecnofisio" para definir el proceso, acontecido en los últimos 300 años, mediante el cual el ser humano ha adquirido un control sin precedentes sobre su entorno, lo que le ha permitido incrementar su tamaño corporal medio en más del 50\% y su longevidad media en más del 100\%, en comparación con los estándares de 1800. El ser humano actual, más robusto y longevo que sus antepasados, es el resultado de las sinergias entre las mejoras introducidas en las tecnologías productivas y la fisiología humana durante las tres últimas centurias. ${ }^{30}$

Las polémicas afirmaciones de Robert W. Fogel y Stanley L. Engerman en Tiempo en la cruz, motivaron una reacción inmediata de la comunidad académica. El economista Richard Sutch fue de los primeros en discutir las tesis de estos autores, cuestionando algunas evidencias en las que se apoyaban sus conclusiones. Aquellos

\footnotetext{
${ }^{29}$ Robert W. Fogel y Stanley L. Engerman, Tiempo en la cruz. La economía esclavista en los Estados Unidos, Siglo XXI, Madrid, 1981.

${ }^{30}$ Aunque Robert W. Fogel examina algunas evidencias de países en desarrollo, su hipótesis se sustenta fundamentalmente en datos correspondientes a Europa y los Estados Unidos. Asimismo, destacó el hecho de que una parte importante de la ganancia en salud se produjo en el transcurso del siglo XX. Ver, por ejemplo: Robert W. Fogel, Escapar del hambre y la muerte prematura. Europa, América y el Tercer Mundo 1700-2100, Alianza Editorial, Madrid, 2009. En esta dirección, una obra colectiva más reciente fue editada por Roderick Floud, Robert W. Fogel, Bernard Harris y Sok Chul Hong, The Changing Body. Health, Nutrition, and Human Development in the Western World since 1700, Cambridge University Press, Cambridge, 2011.
} 
habían utilizado como muestra solo el $10 \%$ de las granjas comprendidas en el Censo Agrícola de 1860, subestimaron además el consumo de la población blanca en la finca y no evaluaron correctamente el potencial nutricional de la alimentación regular del esclavo. Para Sutch, más de las 2/3 partes de la dieta suministrada se componía de maíz y carne de cerdo, por lo que el aporte calórico de estos alimentos representó más del $80 \%$ del total ingerido diariamente por los esclavos, y no el $62 \%$ que estimaron Fogel y Engerman. ${ }^{31}$

En los años ochenta, Robert A. Margo y Richard H. Steckel llevaron la discusión sobre la dieta de los esclavos a indicadores antropométricos, evaluando el impacto de la alimentación en su desarrollo físico, particularmente en su altura. La investigación realizada por estos autores arrojó que los esclavos alcanzaron la estatura adulta a edades más tempranas, y eran más altos que los adultos de muchas poblaciones europeas del siglo XIX. Aunque consideraron que en ese fenómeno podían influir factores genéticos y sociales, señalaron que tales evidencias podían provenir de una mejor alimentación de los esclavos americanos respecto a las poblaciones blancas de la época. ${ }^{32}$

Otra contribución antropométrica fue realizada por David Eltis. A través de una muestra de datos físicos sobre esclavos recapturados que proporcionan las actas de los tribunales de Sierra Leona depositados en el Public Record Office, Eltis sugirió el impacto de las diferencias intrarregionales en el entorno nutricional y de salud en las tendencias de estaturas de los esclavos. A pesar de que la altura media entre los africanos que entraron al Nuevo Mundo varió solo ligeramente entre las principales regiones importadoras, los descendientes de africanos en los Estados Unidos eran significativamente más altos que sus homólogos del Caribe británico y Cuba. Asimismo, todas las poblaciones afrodescendientes en las Américas para las que existen datos de altura modernos, son sustancialmente más altos que los africanos que viven en las regiones de sus progenitores. ${ }^{33}$ En esta misma línea, el historiador cubano Manuel Moreno Fraginals indicó para la década de 1860 las diferencias en la estatura promedio de los esclavos en varios ingenios cubanos. Entre los criollos, nacidos y crecidos en la isla, y sus homólogos africanos, había una diferencia de 3 centímetros a favor de los

\footnotetext{
${ }^{31}$ Richard Sutch, "The treatment received by American slaves: A critical review of the evidence presented in Time on the Cross", Explorations in Economic History, vol. 12, N ${ }^{\circ}$. 4, octubre, 1975, pp. 335-438.

${ }^{32}$ Robert A. Margo y Richard H. Steckel, "The heights of American slaves. New evidence on slave nutrition and health", Social Science History, vol. 6, No. 4, 1982, pp. 516-538.

${ }^{33}$ David Eltis, "Nutritional trends in Africa and the Americas: Heights of Africans, 1819-1839", The Journal of Interdisciplinary History, vol. 12, Nº. 3, 1982, pp. 453-475.
} 
primeros en el caso de los varones, y de 4 centímetros para la muestra de mujeres. Si bien Moreno reconoce que tal diferencia no puede explicarse solo desde el factor alimentario, valida la transición nutricional experimentada por los esclavos en su traslado de África a las Américas. ${ }^{34}$

Ahora bien, aunque en las últimas décadas la antropometría histórica tuvo un desarrollo importante en varios países, y existe cierto consenso sobre las ventajas en términos calóricos de la dieta en las plantaciones americanas respecto a los pueblos africanos, se ha discutido también la fidelidad de los indicadores de altura y talla como expresiones de los cambios producidos en la nutrición, salud y calidad de vida de las poblaciones analizadas. Por ejemplo, el historiador Michel Tadman, que no apoya la visión optimista de algunos autores sobre el impacto de la dieta en el crecimiento natural de la población esclava en los Estados Unidos, discute las evidencias antropométricas de Robert W. Fogel, Richard H. Steckel y John Komlos, por considerar atípicas las muestras sobre las que se sostienen, ya que son grupos físicamente seleccionados. ${ }^{35}$

Otra línea de análisis se ha centrado en la calidad de la nutrición de los esclavos y su impacto en la morbimortalidad. Aunque existen posiciones discrepantes, muchos autores coinciden en que la dieta de este grupo era por lo general bastante monótona, sobre todo en las regiones dominadas por monocultivos comerciales. Es cierto que la malnutrición no afectó por igual a todos los sistemas esclavistas del continente, ni al conjunto de la población esclava. Los estudios realizados prueban que, en términos generales, los esclavos del sur de los Estados Unidos estaban mejor alimentados que los de la región del Caribe y algunas regiones del Brasil, y que la desnutrición fue más crónica en las mujeres embarazadas y niños.

El impacto de la malnutrición en los elevados índices de mortalidad infantil ha sido evaluado en profundidad por Kenneth F. Kiple y Richard H. Steckel. ${ }^{36}$ Este último advirtió un cambio en los patrones de alimentación bajo el régimen esclavista que deja ver la lógica económica de los plantadores. Sugiere que la pobre dieta suministrada a los

\footnotetext{
${ }^{34}$ Manuel Moreno Fraginals, El Ingenio. Complejo económico-social cubano del azúcar, Editorial de Ciencias Sociales, La Habana, 2014, p. 60.

${ }^{35}$ Michael Tadman, "The Demographic Cost of Sugar: Debates on Slave Societies and Natural Increase in the Americas", The American Historical Review, vol. 105, N ${ }^{\circ} .5$, diciembre, 2000, pp. 1534-1575.

${ }^{36}$ Richard H. Steckel, "A dreadful childhood: the excess mortality of American slaves", Social Science History, vol. 10, No. 4, 1986, pp. 427-465; "A Peculiar Population. The nutrition, health, and mortality of American slave from childhood to maturity", The Journal of Economic History, vol. 46, No. 3, septiembre, 1986, pp. 721-741.
} 
esclavos durante su infancia fue compensada con una alimentación mejorada durante la adolescencia, cuando se incorporaban a las tareas productivas.

Asimismo, el antropólogo Jerome C. Rose, a través del análisis de una muestra de esqueletos de afroamericanos extraídos del cementerio Cedar Grove, Arkansas, y que vivieron en el período posterior a la emancipación de los esclavos en ese país, pudo confirmar la desigual distribución de los recursos nutricionales por sexo y edad. Su investigación arrojó nuevas evidencias sobre la mala calidad de la dieta de los neonatos, lo que los hacia muy vulnerables a las enfermedades infecciosas. Los datos histológicos de la muestra de Cedar Grove revelaron, según Jerome Rose, la existencia de una población bajo severo estrés nutricional y de enfermedades, y confirman, al menos para esta comunidad, la limitada disponibilidad de nutrientes durante el período posterior a la emancipación. ${ }^{37}$ Por otra parte, los análisis de Philip R. P. Coehlo y Robert A. McGuire ponen el énfasis en las interacciones entre población esclava y entorno epidemiológico. Para ellos, la explicación más acertada de las altas tasas de mortalidad infantil debe considerar el impacto en las embarazadas y niños esclavos de enfermedades parasitarias debilitantes, como la malaria y la anquilostomiasis. ${ }^{38}$

Como es sabido, en los Estados Unidos, la población esclava alcanzó una tasa de crecimiento natural superior a la de otras sociedades esclavistas, fenómeno que Herbert Klein y Stanley L. Engerman han analizado desde las distintas tradiciones culturales de los esclavos importados, específicamente desde las diferencias en las prácticas de lactancia de las mujeres esclavas en los Estados Unidos y sus homólogas del Caribe británico. ${ }^{39}$ Frente a esa postura, Michael Tadman ha argumentado que fue el predominio del cultivo del azúcar, con las exigencias que el mismo requirió, el factor esencialmente determinante del contraste demográfico de la esclavitud en los Estados Unidos respecto al Caribe y Brasil. De acuerdo con Tadman, aunque el azúcar no era el único cultivo asociado a pobres resultados demográficos, ninguna otra actividad económica tenía el potencial de producir una disminución natural de las fuerzas productivas en la escala que el azúcar lo hizo, fenómeno que analizó desde el negativo

${ }^{37}$ Jerome C. Rose, "Biological consequences of segregation and economic deprivation: A postslavery population from Southwest Arkansas", The Journal of Economic History, vol. 49, N. 2, junio, 1989, pp. 351-360.

38 Philip R. P. Coelho y Robert A. McGuire, "Biology, diseases, and economics: And epidemiological history of slavery in the American South", Journal of Bionomics, N ${ }^{\circ} .1,1999$, pp. 151-190.

${ }^{39}$ Herbert S. Klein y Stanley L. Engerman, "Fertility differentials between slaves in the United States and the British West Indies: A note on lactation practices and their possible implications", The William and Mary Quarterly, vol. 35, No. 2, abril, 1978, pp. 357-374. 
balance demográfico en las parroquias de azúcar en Louisiana. ${ }^{40}$ De la mano de este y otros originales autores contemporáneos como Richard Follet ${ }^{41}$, las meras referencias decimonónicas a la mortalidad azucarera han ganado en profundidad científica. Sus trabajos proponen interesantes hipótesis para repensar los riesgos epidemiológicos y las condiciones demográficas asociados a ese particular entorno laboral de la esclavitud atlántica.

En un artículo reciente, Ramiro Alberto Flores realiza una aproximación a las principales posturas que han discutido los problemas relativos a la alimentación de la población cautiva en las grandes sociedades esclavistas de América. El balance realizado por Flores refleja la disparidad cuantitativa en el estudio de este tema, siendo más prolífera la discusión para los Estados Unidos y las posesiones británicas, donde también la documentación conservada para el análisis de la alimentación es más precisa. A su vez, señala las dificultades metodológicas existentes para valorar el potencial nutricional de la dieta de los esclavos en las distintas sociedades estudiadas. ${ }^{42}$ En este punto, es importante contrapuntear los estudios específicos sobre la población cautiva en América con la prolífera producción académica existente sobre la historia de la alimentación. ${ }^{43}$

Particular interés ha cobrado los análisis sobre revoluciones alimentarias y ciclos demográficos, en el cual se discuten las relaciones múltiples entre nutrición y mortalidad. En investigaciones publicadas entre la década de 1950 y 1980, el historiador británico Thomas McKeown argumentó que el crecimiento demográfico después de 1700 en naciones industrializadas como el Reino Unido se debió fundamentalmente a

\footnotetext{
${ }^{40}$ Michael Tadman, "The demographic cost of sugar: Debates on slaves societies and natural increase in the Americas", The American Historical Review, vol. 105, N ${ }^{\circ} .5$, diciembre, 2000, pp. 1534-1575

${ }^{41}$ Richard Follett, "Heat, sex, and sugar: pregnancy and childbearing in the slave quarters", Journal of Family History, vol. 28, No . 4, 2003, pp. 510-539; "Lives of living death: The reproductive lives of slave women in the cane world of Louisiana", Slavery \& Abolition, vol. 26, No. 2, 2005, pp. 289-304.

${ }^{42}$ Ramiro Alberto Flores Guzman, "The feeding of slave population in the United States, the Caribbean, and Brazil; some remarks in the state of the art", América Latina en la Historia Económica, Año. 20, No. 2, mayo-agosto, 2013, pp. 5-35.

${ }^{43}$ Ver, por ejemplo, las excelentes obras en este campo de: Robert I. Rotberg y Theodore K. Rabb (eds.), Hunger and History. The Impact of Changing Food Production and Consumption Patterns on Society, Cambridge University Press, Cambridge, 1985. Jean-Louis Flandrin y Massimo Montanari (eds.), Historia de la alimentación, Ediciones Trea, S.L., Gijón, 2004. La edición original en francés es de 1996. Kenneth F. Kiple y Kriemhild Coneé Ornealas (eds.), The Cambridge World History of Food, vol. I y II, Cambridge University Press, Cambridge, 2000. Jordi Salas-Salvadó y otros (eds.), La alimentación y la nutrición a través de la historia, Editorial Glosa, Barcelona, 2005.
} 
las mejoras de las condiciones económicas y no tanto a la intervención de la medicina o las mejoras en la sanidad pública. Entre 1700 y 1900 la población europea pasó de 125 a 422 millones de habitantes, un crecimiento casi seis veces superior al experimentado en el medio milenio precedente. La influyente y controvertida "tesis de McKeown" ponderaba el papel de la alimentación en el boom demográfico, considerando que la mayor disponibilidad de reservas alimentarias, que se tradujo en una dieta más regular, fue un factor decisivo en la reducción de los índices de mortalidad en Europa en los últimos tres siglos. Las mejoras en el estado de nutrición, con el uso generalizado de los cereales (sobre todo el maíz) y la patata desde mediados del siglo XVIII, habrían contenido positivamente las defunciones producidas por enfermedades infecciosas, principales causas de muerte en el pasado. En consecuencia, el progreso médico y las políticas higienistas del siglo XIX reforzaron la tendencia positiva en la reducción de la mortalidad que ya se estaba experimentando. ${ }^{44}$ Aunque los trabajos de McKeown se han discutido desde su formulación, su hipótesis avivó el debate sobre la oferta de alimentos, el desarrollo económico y el crecimiento demográfico, problemática cuyas raíces modernas podemos remontar a los trabajos pioneros de Thomas Malthus. ${ }^{45}$

El demógrafo e historiador italiano Massimo Livi discute algunos puntos de la “tesis de McKeown”, pero no deja de reconocer una vinculación directa entre niveles de nutrición, enfermedades infecciosas y riesgo de muerte. Este autor suscribe que antes del descubrimiento de la penicilina, el primer antibiótico empleado ampliamente en medicina, los niveles nutricionales tuvieron un impacto "muy definido" sobre enfermedades como el cólera, la diarrea, el herpes, la lepra, las enfermedades respiratorias, el sarampión, los parásitos intestinales, la tos ferina y la tuberculosis, mientras tal influencia puede ser más variable o inexistente en otros padecimientos. Si bien el organismo humano tiene mecanismos compensatorios, la deficiencia de nutrientes puede causar una perturbación general del metabolismo, o predisponerlo a factores secundarios responsables directos de la enfermedad y la muerte. ${ }^{46}$

\footnotetext{
${ }^{44}$ Thomas McKeown, The Modern Rise of Population, Edward Arnold, Londres, 1976; "Food, Infection and Population", Journal of Interdisciplinary History, vol. XIV, N ${ }^{\circ} .2$, 1983, pp. $227-$ 247. Sobre las hambrunas en Europa en el siglo XVIII y el desarrollo de las "comidas de relleno" que comenzaron a formar parte de la dieta de las capas populares en esa centuria y la siguiente, véase: Massimo Montanari, El hambre y la abundancia. Historia y cultura de la alimentación en Europa, Crítica, Barcelona, 1993.

${ }^{45}$ James Colgrove, "La Tesis McKeown: una controversia histórica y su influencia duradera", American Journal of Public Health, vol. 92, No. 5, mayo, 2002, pp. 725-729.

46 Massimo Livi-Bacci, Ensayo sobre la historia demográfica europea. Población y alimentación en Europa, Ariel, Barcelona, 1988.
} 
En 1978 Todd L. Savitt publicó uno de los estudios mejor valorados sobre la salud de la población esclava y el pensamiento médico en el sur de Estados Unidos antes de la guerra civil. ${ }^{47}$ En el mismo, analizó diversos aspectos relacionados con la dieta, las enfermedades y las condiciones de vida y de trabajo de los afroamericanos tanto en zonas urbanas como en las plantaciones. Su propósito, expresado con claridad al principio de la obra, no era un simple análisis de los tipos de enfermedades que padecieron, sino una historia relacional entre la salud negra y la sociedad blanca en el Viejo Sur. Años más tarde, Savitt coordinó junto a Ronald L. Numbers otra obra fundamental sobre el conocimiento médico y científico en el sur de Estados Unidos. ${ }^{48}$ Se trata de una colección de catorce ensayos con énfasis en el período de 1830 a 1860. La segunda sección, que trata sobre la experiencia médica, deja ver como esa profesión estuvo condicionada por las relaciones esclavistas de producción. En tal sentido, son reveladores los trabajos de K. David Patterson y James H. Cassed sobre como la trata o las políticas de manejo de la tierra condicionaron un ambiente de enfermedad particular. Finalmente, en Race and Medicine, Savitt compiló una serie de artículos ya publicados. ${ }^{49}$ Nos interesa destacar aquí el trabajo dedicado al análisis de la elefantiasis -un padecimiento también habitual entre la población esclava de Cuba- en el que interpela el contexto histórico para explicar por qué los afroamericanos desarrollaron esa enfermedad en Lowcountry y no en otras partes del país. Otros artículos analizan el funcionamiento de los seguros de vida para esclavos y de las escuelas de medicina para los afroamericanos, entre otros temas.

Un texto de Niklas T. Jensen sobre la salud de los esclavos en las Indias Occidentales danesas ha cubierto un vacío historiográfico existente en este campo. Su publicación, resultado de su investigación doctoral, analiza las interacciones entre los sistemas de salud y las relaciones de poder en esa región. Centrado en la población esclava de Saint Croix -una pequeña isla del mar Caribe bajo dominio danés entre 1733 y 1917, cuando fue vendida a los Estados Unidos- su estudio advierte la sincronía entre el auge económico y el desarrollo de la medicina occidental en ese territorio. Jensen

\footnotetext{
${ }^{47}$ Edición consultada: Todd L. Savitt, Medicine and Slavery. The Diseases and Health Care of Blacks in Antebellum Virginia, University of Illinois, Illinois, 2002. Un studio más reciente en esta línea en: Katherine K. Bankole, Slavery and Medicine: Enslavement and Medical Practices in Antebellum Louisiana, Garland Publishing Inc., Nueva York y Londres, 1998.

${ }^{48}$ Todd L. Savitt y Ronald L. Numbers, Science and Medicine in the Old South, Louisiana State University Press, Baton Rouge y Londres, 1989.

${ }^{49}$ Todd L. Savitt, Race and Medicine in Nineteenth- and Early-Twentieth-Century America, Kent State University Press, Ohio, 2007.
} 
concluye que entre 1803 y 1848, una etapa caracterizada por el esplendor de la industria azucarera, los esclavos padecieron un espectro amplio de enfermedades, predominando cinco categorías fundamentales: "fiebres", "dolores y lesiones", "enfermedades gastrointestinales" "llagas y enfermedades de la piel" y "enfermedades respiratorias y neumonía". Males asociados a la sobreexplotación, el clima, los problemas en la alimentación, la falta de vivienda y una indumentaria inadecuada. Jensen enfatiza en los esfuerzos realizados por los plantadores y la administración colonial para mejorar la salud de sus dotaciones y reducir los elevados índices de mortalidad, así como en los conflictos culturales y científicos generados en torno a la asistencia médica en la plantación. ${ }^{50}$

En el caso de Brasil, la investigación sobre la salud de la población esclava ha cobrado gran interés en la historiografía de los últimos años. Nuevas tesis y publicaciones profundizan en aspectos que autores clásicos como Gilberto Freyre ${ }^{51} \mathrm{o}$ más contemporáneos como Stuart B. Schwartz ${ }^{52}$ y Mary C. Karasch ${ }^{53}$ habían abordado de manera tangencial.

El proyecto "Sistema de salud del esclavo en el Brasil del siglo XIX: instituciones, enfermedades y prácticas terapéuticas", iniciado en 2006 por la Casa de Oswaldo Cruz, ha desarrollado un conjunto de actividades con el objetivo de dar mayor visibilidad al tema de la salud en la historia de la esclavitud. Particular atención se ha prestado al análisis de la producción científica de instituciones médicas de Río de Janeiro y Bahía. El historiador Jorge Prata de Souza ha destacado el valor de la documentación sobre óbitos de esclavos existente en los archivos de las Santa Casa de Misericordia ubicadas en de Río de Janeiro y Bahía para el análisis de la salud y las causas de muerte de esa población. Esas instituciones ofrecieron asistencia hospitalaria

\footnotetext{
${ }^{50}$ Niklas T. Jensen, "For the benefit of the planters and the benefit of Mankind: The Struggle to Control Midwives and Obstetrics on St. Croix, Danish West Indies, 1800-1848", en: Juanita de Barros, Steven Palmer y David Wright (eds.), Health and Medicine in the circum-Caribbean, 1800-1968, Roudledge, Nueva York, 2009, pp. 19-39; Fort the Health of the Enslaved: Slave, Medicine, and Power in the Danish West Indies 1803-1848, Museum Tusculanum Press, Copenhagen, 2012.

${ }^{51}$ Gilberto Freyre, Casa-Grande y Senzala, Marcial Pons, Madrid, 2010.

${ }^{52}$ Stuart B. Schwartz, Sugar Plantations in the Formation of Brazilian Society: Bahia, 15501835.

${ }^{53}$ Mary C. Karasch, Slave Life in Rio de Janeiro, 1808-1850, Princeton University Press, Princeton, 1987.
} 
a los esclavos hasta la primera mitad del siglo XIX y fueron responsables de la sepultura de los fallecidos. ${ }^{54}$

Los estudios recientes para el Brasil han advertido además la conexión entre el auge de la esclavitud y el desarrollo de la medicina en ese país, un patrón recurrente en otras áreas. La revista História, Ciências, Saúde-Manguinhos -que edita la Casa de Oswaldo Cruz- concentra varios de los trabajos publicados en los últimos años sobre la salud de la población esclava en Brasil. Entre ellos destacamos las contribuciones de Carlos A. M. Lima, ${ }^{55}$ Beatriz A. Loner, ${ }^{56}$ Flávio Gomes, ${ }^{57}$ Kaori Kodama, ${ }^{58}$ Márcia Amantino, ${ }^{59}$ Ángela Porto ${ }^{60}$ y Luiz Antonio Teixeira. ${ }^{61}$

En conjunto, los trabajos publicados en las últimas décadas han propuesto interesantes líneas de análisis en un campo de investigación de gran importancia para valorar las dinámicas de la esclavitud atlántica, y la forma en la que se inserta en las relaciones más generales entre trabajo y salud en la economía-mundo capitalista.

\section{ESCLAVITUD Y SALUD EN LA HISTORIOGRAFÍA SOBRE CUBA}

Aunque los estudios sobre el binomio azúcar-esclavitud eslabonan una de las tendencias más consolidadas de la historiografía reciente sobre Cuba, son escasas las investigaciones que han abordado la salud de la población cautiva como una categoría

\footnotetext{
${ }^{54}$ Ángela Porto, "Fontes e debates em torno da saúde do escravo no Brasil do século XIX", Revista Latinoamericana de Psicopatologia Fundamental, vol. 11, N ${ }^{\circ} .4$, diciembre, 2008, pp. 726-734.

${ }^{55}$ Carlos A. M. Lima, "Fronteira, cana e tráfico: escravidão, doenças e mortes em Capivari, SP, 1821-1869”, História, Ciências, Saúde-Manguinhos, vol. 22, N. 3, julio-septiembre, 2015, pp. 899-919.

${ }^{56}$ Beatriz Ana Loner, Lorena Almeida Gill y Micaele Irene Scheer, "Enfermidade e morte: os escravos na cidade de Pelotas, 1870-1880", História, Ciências, Saúde-Manguinhos, vol. 19, suppl. 1, diciembre, 2012, pp. 133-152.

${ }^{57}$ Flávio Gomes, "The Atlantic demographics of Africans in Rio de Janeiro in the seventeenth, eighteenth, and nineteenth centuries: some patterns based on parish registers", História, Ciências, Saúde-Manguinhos, vol. 19, suppl. 1, diciembre, 2012, pp. 81-106.

${ }^{58}$ Kaori Kodama y otros, "Slave mortality during the cholera epidemic in Rio de Janeiro (18551856): a preliminary analysis", História, Ciências, Saúde-Manguinhos, vol. 19, suppl. 1, diciembre, 2012, pp. 59-79.

${ }^{59}$ Márcia Amantino, "The physical and health status of runaway slaves announced in Jornal do Commercio (RJ) in 1850", História, Ciências, Saúde-Manguinhos, vol. 14, No. 4, octubrediciembre, 2007, pp. pp.1377-1399.

${ }^{60}$ Ángela Porto, "O sistema de saúde do escravo no Brasil do século XIX: doenças, instituições e práticas terapéuticas", História, Ciências, Saúde-Manguinhos, vol. 13, N. 4, diciembre, 2006, pp. 1019-1027.

${ }^{61}$ Luiz Antonio Teixeira, "Da raça à doença em Casagrande e Senzala", História, Ciências, Saúde-Manguinhos, vol. IV, No . 2, julio-octubre, 1997, pp. 231-243.
} 
medular. Durante mucho tiempo, los estudios al respecto se orientaron hacia los componentes estructurales de la industria azucarera y el sistema esclavista, siendo marginal el análisis del factor humano, que interesó, fundamentalmente, como cantidad de trabajo importado. ${ }^{62}$ Déficit llamativo si tenemos en cuenta que desde fines del siglo XVIII existe una literatura valiosa para el estudio de la salud de los cautivos, y lo que el análisis contemporáneo de dicha problemática podría aportar a la compresión del desempeño de la economía esclavista en la isla y las condiciones de reproducción de su fuerza laboral.

Desde el siglo XVI se utilizó en Cuba brazos africanos en diversas tareas, pero debieron pasar tres centurias para que esta colonia se transformara en una de las principales sociedades de plantación esclavista del continente. En las últimas décadas del siglo XVIII, con el desarrollo de la agricultura comercial, el peso de la esclavitud en la estructura demográfica creció de forma exponencial, llegando a su clímax en 1841 cuando representó el $43 \%$ de la población censada. El aporte fundamental a ese crecimiento estuvo determinado por la importación masiva de africanos. ${ }^{63}$

En esa coyuntura, la esclavitud se transformó en tema de reflexión habitual en los círculos económicos y políticos de la isla. La trata ilegal, los problemas sociales determinados por la existencia de una creciente población africana y los fundamentos ideológicos y económicos del abolicionismo, fueron algunos de los tópicos más recurrentes. No menos importante fue el debate sobre la intensidad de la explotación a la que estuvo sometida esa población y las condiciones de su reposición. Tema que se tornó más problemático en las décadas centrales del siglo XIX, cuando la oferta cubana del dulce cubría cuotas elevadas del mercado mundial, superando la producción del Caribe francés y británico, ${ }^{64}$ y se intensificó la presión internacional contra el suministro ilegal de brazos africanos.

\footnotetext{
${ }^{62}$ Un balance historiográfico sobre las fuentes disponibles para el estudio de la industria azucarera y el sistema esclavista en Cuba, y las limitaciones al respecto, en: José A. Piqueras, "El azúcar en Cuba y las fuentes para su estudio", América Latina en la Historia Económica, vol. 6, $\mathrm{N}^{\circ}$. 11, enero-junio, 1999, pp. 35-47; "Esclavitud histórica y capitalismo en la historiografía cubana", en: José A. Piqueras (coord.), Esclavitud y capitalismo histórico en el siglo XIX, Brasil, Cuba y Estados Unidos, Editorial del Caribe, Santiago de Cuba, 2016, pp. 163-254.

${ }^{63}$ Se estima que unos 800.000 africanos fueron vendidos en Cuba como esclavos entre 1800 y la década de 1860. Juan Pérez de la Riva "El monto de la inmigración forzada en Cuba" en: Juan Pérez de la Riva, Para la historia de la gente sin historia, Ariel, Barcelona, 1976, pp. 95-140.

${ }^{64}$ Antonio Santamaría García, "Las islas españolas del azúcar (1760-1898). Grandes debates en perspectiva comparada y caribeña", América Latina en la Historia Económica, $\mathrm{N}^{\circ} .35$, enerojunio, 2011, pp. 149-176.
} 
En estrecha relación con el progreso demográfico y socio-económico de la isla, se produjo entonces un desarrollo importante de las ciencias médicas y las políticas sanitarias. Aumentó el número de profesionales, surgieron las primeras revistas especializadas y se expandió el sector farmacéutico. Una encomiable pesquisa contemporánea comprobó que durante el siglo XIX se publicaron en Cuba un total de 65 títulos de revistas médicas, aunque de ellas no se conservan un número importante. ${ }^{65}$ En 1826 se fundó la Junta Superior de Sanidad y en 1842 se declaró obligatorio reportar la causa de defunción. De acuerdo con el articulado de la legislación promulgada, se prohibió a los curas párrocos extender permiso de enterramiento sin el certificado médico correspondiente. ${ }^{66}$ Las normativas existentes para velar por la sanidad pública se orientaban en dos direcciones fundamentales: las medidas necesarias para prevenir enfermedades y las acciones a desarrollar en caso de epidemia. En este contexto se fundaron las bases para un conocimiento más preciso de los problemas que afectaban la salud de la población de la isla. Años más tarde, José Ángel Cowley, entonces Secretario de la Junta Superior de Sanidad, publicó un detallado estudio sobre la mortalidad en La Habana. El trabajo de Cowley, que recoge la información de registros de defunciones de varias parroquias de La Habana y establece algunas comparaciones entre esta y otras poblaciones, tenía entre sus propósitos dar a conocer a las autoridades nacionales y extranjeras el estado sanitario de una ciudad clave dentro del circuito comercial atlántico desarrollado con la Revolución Industrial. ${ }^{67}$

De aquella época datan los primeros estudios dedicados específicamente a las enfermedades de los esclavos. El primero de los más conocidos es un manuscrito del médico español Francisco Barrera y Domingo redactado en 1798, aunque permaneció inédito hasta su publicación en $1953 .{ }^{68}$ La obra más divulgada de la primera mitad del siglo XIX fue El vademécum de los hacendados cubanos, publicado originalmente en 1831 por el médico francés Bernard de Chateausalins y con rediciones en 1848, 1854 y

\footnotetext{
${ }^{65}$ José Antonio López Espinosa, "La bibliografía médica cubana de la época colonial al alcance del médico en el siglo XXI", Acimed, vol. 12, N . 4, julio-agosto, 2004.

${ }^{66}$ Norma E. Ríos Massabot y otros, "Los registros médicos en Cuba", Revista Cubana de Salud Pública, vol. 31, No. 4, 2005, pp. 345-352.

${ }^{67}$ José Ángel Cowley, Ensayo estadístico-médico de la mortalidad en la diócesis de La Habana durante el año de 1843, Imprenta del Gobierno, La Habana, 1845.

${ }^{68}$ Francisco Barrera y Domingo, Reflexiones histórico físico naturales médico quirúrgicas. Prácticos y especulativos entretenimientos acerca de la vida, usos, costumbre, alimentos, bestidos (sic), color y enfermedades a que propenden los negros de África, venidos a las Américas, Ediciones C. R., La Habana, 1953.
} 
1874. ${ }^{69}$ Posteriormente aparecieron otras dos valiosas obras del también médico francés Henri Dumont ${ }^{70}$ y una memoria sobre el tema del doctor José A. Reynés. ${ }^{71}$ En su conjunto, esas publicaciones se distinguen por ser los primeros estudios de antropología médica realizados en el país, a partir de las observaciones de los autores en las plantaciones en las que ejercieron como médicos.

A esos estudios pueden agregarse reglamentos, topografías, manuales, manuscritos, censos y artículos científicos útiles para evaluar el panorama sanitario y la morbimortalidad de la población residente en el país. En el Archivo Nacional de Cuba, el fondo Junta Superior de Sanidad contiene una abundante y útil documentación sobre los más diversos aspectos relacionados con la salud de la población colonial, pendiente aún de análisis escrupulosos por la historiografía sobre Cuba. También es posible analizar el movimiento vital de la población esclava mediante los registros de bautismos y enterramientos, y de ingresos y egresos en los hospitales. ${ }^{72}$

La primera gran epidemia de cólera, iniciada en 1833, que terminó con la vida de miles de esclavos, léase una parte importante del capital invertido en la industria, marcó un punto de inflexión en la reflexión sobre las debilidades del sistema sanitario existente en la isla y la asistencia médica en las plantaciones cubanas. Aunque "el

${ }^{69}$ Honorato Bernard de Chateausalins, El vademécum de los hacendados cubanos o guía práctica para curar la mayor parte de las enfermedades, Imprenta de Manuel Soler, La Habana, 1854.

${ }^{70}$ Henri Dumont, Investigaciones generales sobre las enfermedades de las razas que no padecen la fiebre amarilla y estudio particular sobre la enfermedad de los ingenios de azúcar o hinchazón de los negros y chinos, Imprenta del Boletín Mercantil, Cárdenas, 1865 (Durante el curso de esta investigación, hemos localizado en el Archivo Nacional de Cuba un manuscrito de esta obra); Antropología y patología comparadas de los negros esclavos, Colección Cubana de Libros y Documentos Inéditos, La Habana, 1922. Este último trabajo es de 1876, premiado por la Real Academia de Ciencias Médicas, Físicas y Naturales de La Habana.

${ }^{71}$ José A. Reynés, "Algunas consideraciones generales sobre la raza negra, su patología y terapéutica", Anales de la Real Academia de Ciencias Médicas, Físicas y Naturales de La Habana, vol. V, 1868, pp. 139-148 y 180-186. Un trabajo de este autor sobre el paludismo en: José Antonio Reynés, De las manifestaciones del paludismo: sus semejanzas y diferencias con otras enfermedades, Imprenta y Librería "El Iris", La Habana, 1870.

${ }^{72}$ Las topografías médicas se desarrollan en España desde mediados del siglo XVIII. Juan Carlos Cossío, "Las topografías médicas: revisión y cronología", Asclepio, vol. LIII, N ${ }^{\circ}$ 1, 2001, pp. 213-244. En Cuba se realizaron algunas en el siglo XIX, ver: Ramón Piña y Peñuela, Topografía médica de la Isla de Cuba, Impr. y Encuadernación del Tiempo, La Habana, 1855. Marcial Dupierris, Memorias sobre la topografía médica de La Habana y sus alrededores, y sobre el estudio físico y moral de los colonos asiáticos, Imprenta La Habanera, La Habana, 1857. Algunos de los más importantes trabajos médicos y sanitarios producidos en la segunda mitad del siglo XIX fueron publicados en los Anales de la Real Academia de Ciencias Médicas, Físicas y Naturales de La Habana, que aparecieron regularmente desde 1868, y en otras revistas especializadas de la época como Crónica Médico Quirúrgica de La Habana o Gaceta Médica de La Habana. 
viajero de Ganges" se presentó de forma epidémica en dos períodos posteriores, los estudios existentes sobre el impacto de esta enfermedad en la isla, la que más interés ha despertado hasta la fecha junto con la fiebre amarilla, se limitan fundamentalmente al primer azote. Al respecto, se produjo en el siglo XIX una amplia literatura, dentro de la cual destacan, por sus connotaciones políticas, los escritos de José Antonio Saco y Ramón de la Sagra. ${ }^{73}$ Desde una perspectiva contemporánea, la enfermedad ha sido abordada por diferentes autores. ${ }^{74}$

Al margen del cólera morbo, los picos de mortalidad registrados en el siglo XIX se produjeron por brotes epidémicos de fiebre amarilla, viruela, disentería, paludismo y fiebre tifoidea. La incidencia de estas enfermedades fue más virulenta en el decenio bélico de 1870, cuando se produjeron solo en la capital vértices de mortalidad superiores al 50 por mil en los años 1870,1877 y $1878 .^{75}$

Una fuente particularmente reveladora de los problemas de salud durante el período de disolución de la esclavitud en Cuba es un ensayo estadístico demográfico publicado en 1881 por la Dirección General de Hacienda. Aunque la mayor parte de la información contenida en ese informe, confeccionado con información de las 177 parroquias existentes en Cuba en esa fecha, corresponde al año 1879, consideramos que

\footnotetext{
${ }^{73}$ José Antonio Saco, Carta sobre el cólera morbo asiático, Imprenta del Gobierno, La Habana, 1833. Ramón de la Sagra, Tablas necrológicas del Cólera-Morbus en la ciudad de La Habana y sus arrabales, Imprenta del Gobierno, La Habana, 1833.

${ }^{74}$ La epidemia de cólera de 1833 es la mejor estudiada por la historiografía sobre Cuba. Cito solo algunos de los trabajos más importantes: Kenneth F. Kiple, "Cholera and Race in the Caribbean", Journal of Latin American Studies, vol. 17, No. 1, mayo, 1985, pp. 157-177. Ver el epígrafe titulado "La epidemia de cólera morbo de La Habana (año de 1833) y su incidencia socio-étnica" en: María Dolores Pérez Murillo, Aspectos demográficos y sociales de la Isla de Cuba en la primera mitad del Siglo XIX, Tesis doctoral, Universidad de Sevilla, Sevilla, 1986, pp. 343-375. Gregorio García Delgado, "El cólera morbo asiático en Cuba. Apuntes históricos y bibliográficos", Cuadernos de Historia de la Salud Pública, No. 78, 1993, pp. 17-35. Julio Ramos, "A citizen body: cholera in Havana (1833)", Dispositio, vol. 19, No. 46, 1994, pp. 179195. Sobre la polémica entre José Antonio Saco y Ramón de la Sagra en torno a la gestión colonial de la epidemia, ver: Adrián López Denis, Saco, Sagra y el cólera morbo, Ediciones Vitral, Pinar del Río, 2002. También sobre esta epidemia, ver: Adrián López Denis, "Higiene pública contra higiene privada: cólera, limpieza y poder en La Habana colonial", Estudios Interdisciplinarios de América Latina y el Caribe, vol. 14, $\mathrm{N}^{\circ}$. 1, enero-junio, 2003, consultado en http://eial.tau.ac.il/index.php/eial/article/view/928/964, 14 de junio de 2016. Manuel Salvador Vázquez, "Morbimortalidad colérica en Cuba: la epidemia de 1833 y la permanencia de la enfermedad en la isla (1834-1835)", en: José Jesús Hernández Palomo (coord.), Enfermedad y muerte en América y Andalucía (Siglos XVI-XX), CSIC, Madrid, 2004, pp. 283302. Enrique Beldarraín Chaple y Luz María Espinosa Cortés, "El cólera en La Habana en 1833. $\mathrm{Su}$ impacto demográfico", Diálogos, vol. 15, $\mathrm{N}^{\circ} .1$, consultado en http://revistas.ucr.ac.cr/index.php/dialogos/article/view/8372/13644, 25 de noviembre de 2016. ${ }^{75}$ Jorge Le Roy Cassá, Estudios sobre la mortalidad de La Habana durante el siglo XIX y los comienzos del actual, Imprenta Lloredo y Ca., La Habana, 1913.
} 
el cuadro general que el mismo ofrece es valioso. Pocos estudios publicados en el siglo XIX ofrecen una información tan detallada para toda la isla sobre morbilidad y mortalidad, y, curiosamente, ha sido una fuente prácticamente inexplorada por quienes de algún modo se han aproximado a la salud de la población cubana, esclava y libre, de la época. No obstante, hay que decir que, aunque para esa fecha se había avanzado en cuanto a estadística demográfica y en el diagnóstico diferencial de enfermedades, persisten imprecisiones, fundamentalmente en cuanto a explicitar las causas de un porciento considerable de la mortalidad registrada. No siempre los párrocos precisaban los detalles exigidos en los formularios que se les encargaba. Limitaciones que fueron reconocidas por Antonio López Prieto, entonces Jefe de la Sección de Estadística Preparatoria, en su nota introductoria al estudio en cuestión. No detallamos aquí la información y trascendencia de esta fuente, por ser aprovechada y citada de forma recurrente a lo largo de nuestra investigación. ${ }^{76}$

Con la abolición definitiva de la esclavitud en 1886, la temática propiamente esclavista cedió al estudio de los conflictos socio-raciales en la sociedad cubana. Los estereotipos construidos en la colonia marcaron una línea de pensamiento dominante hasta bien entrado el siglo XX. La supuesta inferioridad del "negro" y el atavismo de sus costumbres fueron algunos de los tópicos recurrentes en una matriz discursiva seudocientífica que valoró negativamente la herencia africana. De la primera mitad del siglo XX el autor más importante es Fernando Ortiz, pionero en el estudio cultural y antropológico de las comunidades africanas en América. A nuestro objetivo, interesa comentar en particular su trabajo Los negros esclavos (1916), en el que reúne información sobre el desarrollo y características de la esclavitud en Cuba. ${ }^{77} \mathrm{La}$ obra de Ortiz invirtió de algún modo el enfoque dominante en el siglo XIX, en el que la esclavitud importó, sobre todo, en relación a la industria azucarera. En su estudio, el esclavo adquiere valor como unidad de análisis en sí mismo, incursionando en asuntos que hasta entonces eran de poco interés o en gran medida desconocidos. Sin embargo, hay que decir que los capítulos dedicados por el sabio cubano a la alimentación, enfermedades y castigos de los esclavos rurales adolecen de un marcado carácter

\footnotetext{
76 Dirección General de Hacienda, Población. Estudios estadístico-demográficos correspondientes a 1879, La Propaganda Literaria, La Habana, 1881.

${ }^{77}$ Fernando Ortiz, Los negros esclavos, Editorial de Ciencias Sociales, La Habana, 1975.
} 
descriptivo, y reproducen extensos pasajes de autores previos, como el citado médico Bernard de Chateausalins o el escritor costumbrista Anselmo Suárez y Romero. ${ }^{78}$

Como es sabido, la obra escrita de Fernando Ortiz y su intensa gestión institucional sentaron las bases para el desarrollo de los estudios africanistas en Cuba. En 1924 fundó la revista Archivos del Folklor Cubano (1924-1930). En los volúmenes de esa publicación aparecen algunos artículos que dan cuenta del acervo médicopopular y el curanderismo extendidos en los campos cubanos. Esta publicación tuvo continuidad con la aparición de Estudios Afrocubanos (1937-1940, 1945-1946), órgano de una sociedad homónima que nucleó a destacadas figuras de la intelectualidad de la época como Emilio Roig de Leuchsenring, Lydia Cabrera ${ }^{79}$, Ramón Guirao, Nicolás Guillen, Rómulo Lachatañeré, Argeliers León, Juan Marinello y José Luciano Franco, por citar solo algunos de los nombres más relevantes.

No fue hasta la década de 1960 que la investigación histórica en Cuba adquiere un carácter profesional. La escuela de Historia de la Universidad de La Habana se fundó en 1962, en el contexto de la Reforma Universitaria implantada ese año. Una destacada generación de intelectuales impulsó los estudios sobre el binomio azúcar-esclavitud, legando una obra historiográfica trascendente: José Luciano Franco, Pedro Deschamps Chapeaux, Juan Pérez de la Riva y Manuel Moreno Fraginals son algunos de los más importantes.

La obra más referenciada dentro de la producción historiográfica de esa etapa es El Ingenio de Moreno Fraginals. ${ }^{80}$ El volumen dedicado al binomio trabajo-sociedad constituye uno de los análisis más originales sobre la esclavitud cubana. Desde una concepción moderna, Moreno Fraginals incursionó en el análisis de un conjunto de problemáticas obviadas por los estudios realizados hasta entonces. Comprendió la importancia de la salud de los esclavos como variable económica en el sistema de producción azucarera y en tal sentido evaluó los cambios habidos en la alimentación, la atención médica y en el tratamiento de las dotaciones.

\footnotetext{
${ }^{78}$ Anselmo Suárez y Romero, Francisco. El ingenio o las delicias del campo, Editorial Arte y Literatura, La Habana, 1974. Esta novela fue escrita en 1838 aunque no se publicó hasta 1880 en Nueva York.

${ }^{79}$ Sobre el folklor médico en la isla y su influencia africana, ver: Lydia Cabrera, La medicina popular de Cuba: médicos de antaño, curanderos, santeros y paleros de hogaño, Ediciones Universal, 1984.

${ }^{80}$ El primer volumen de esta obra fue publicado en 1964 por la Comisión Nacional Cubana de la Unesco. Posteriormente, el original fue corregido y ampliado, publicándose una segunda edición en tres volúmenes por la Editorial de Ciencias Sociales en 1978. La última reimpresión realizada de esta obre es la que ya hemos citado.
} 
Luego del capítulo dedicado por Moreno Fraginals a la salud de los esclavos, no encontramos otra publicación directamente relacionada con el tema hasta 1986. El texto de Manuel Salvador Vázquez y Carmen Menéndez de León destaca por la utilización de algunas fuentes novedosas del Archivo de Indias, Sevilla. Sin embargo, no ofrece un enfoque diferente respecto a lo que ya se sabía sobre el tema. Sus observaciones se insertan en la misma tradición de pensamiento que deposita en mano de los plantadores toda la suerte tocante a la salud de los esclavos. Enfoque que lleva a estos autores a considerar, como antes lo hizo Moreno Fraginals, que hacia el final del sistema "las condiciones de trabajo se suavizan”, producto del arraigo entre los plantadores cubanos de una "nueva mentalidad" determinada por "criterios puramente mercantiles". ${ }^{81}$ Reducir el problema a esa cuestión supone dejar fuera otros aspectos que también condicionaron las dinámicas de vida y muerte en la plantación.

Un artículo más original, aunque para un período previo, fue publicado en 1991 por Alejandro de la Fuente García en la revista Asclepio. Basado en la información comprendida en los Protocolos Notariales, este historiador pudo analizar la morbilidad en una muestra de 4.446 esclavos de La Habana. Más importante que el examen de algunas de las enfermedades que afectaron a ese grupo, son los indicadores diferenciales determinados por el grado de inserción de los cautivos en la sociedad y la economía cubana. Al agrupar los datos en tres categorías -bozales, ladinos y azucareros-, se observan cambios importantes en el estado de salud de la población analizada. El índice de morbilidad correspondiente a cada categoría es el siguiente: bozales (3,5\%), ladinos $(12,6)$, azucareros $(16,4)$. Las deficiencias nutricionales y digestivas eran la causa principal de la morbilidad entre los bozales, fenómeno asociado a las pésimas condiciones de los depósitos de esclavos en las costas africanas y al rigor de la travesía. Sorprende el elevado índice de alcoholismo y trastornos mentales entre los ladinos, lo que nos lleva a considerar la dimensión de los traumas psicosociales que produjo la esclavitud. Por otro lado, el aumento de la morbilidad general entre los azucareros se debe a una mayor incidencia de enfermedades de los sistemas respiratorio, musculoesquelético y circulatorio, así como a trastornos visuales y afecciones de la piel. Otro aspecto relevante a tener en cuenta en el artículo de Alejandro de la Fuente es la forma en la que salud del esclavo constituye una variable de interés en el proceso de compraventa en el mercado habanero, pudiendo modificar el valor del mismo entre un

\footnotetext{
${ }^{81}$ Manuel Salvador Vázquez y Carmen Menéndez de León, "Higiene y enfermedad del esclavo en Cuba, Anuario de Estudios Americanos, №. 43, 1986, pp. 419-445.
} 
49.4 y $60.5 \%$ según la edad. La depreciación del esclavo dependió de la medida en que la enfermedad contraída afectara su capacidad productiva. ${ }^{82} \mathrm{El}$ hecho de que el interés del vendedor le llevase a declarar solo aquellas afecciones cuya sintomatología eran difíciles de encubrir y que el desconocimiento existente sobre la etiología de muchas enfermedades condicionara una gran morbilidad oculta, propició no pocos pleitos judiciales, amparado el comprador en el derecho legal que le permitía reclamar el dinero invertido en la adquisición de un esclavo con vicios o defectos no declarados.

Para un período posterior, esta cuestión también fue abordada por Beatriz Joda Esteve. La joven historiadora española destacó en su tesis doctoral la importancia de la salud en los procesos de compraventa en el mercado de esclavas de La Habana en el período 1790-1844. En la información que obtuvo de 130 expedientes sobre redhibitorias de mujeres, de los cuales 120 indican el motivo de las reclamaciones, se observa un predominio de "tachas" asociados a comportamientos que tornan conflictiva la relación amo-esclava -como "respondona", "borracha" o "soberbia"- que la autora agrupa bajo el término "cimarrona". Al margen de esos comportamientos, se observa una fuerte incidencia de enfermedades como la tisis, las bubas, tumores, epilepsia, mutilaciones, enfermedades mentales e infecciosas, que disminuyen la utilidad de la esclava o producen su muerte. ${ }^{83}$ Aunque el estudio de Joda comprende solo información sobre mujeres, y es representativo de la esclavitud urbana, revela, como el de Alejandro de la Fuente para un período anterior, la gran morbilidad asociada a la economía esclavista y los conflictos que en torno a ese fenómeno podían generarse.

Sobre la dinámica demográfica de la colonia cubana y su vínculo con la expansión de la industria azucarera destacan los estudios de Ramiro Guerra, Juan Pérez de la Riva, Andrzej Dembicz y Laird W. Bergard, este último con una excelente investigación sobre el monocultivo azucarero y la esclavitud en Matanzas. Menos innovador es el libro del demógrafo Eduardo R. San Marful sobre esa misma región.

\footnotetext{
${ }^{82}$ Los bozales eran los africanos recién introducidos en Cuba, ladinos los esclavos que habían permanecido un período de tiempo en el país y entre ellos se incluían algunos criollos, mientras que los azucareros, como lo sugiere el término, fueron agrupados atendiendo a la ocupación que desempeñaban. Alejandro de la Fuente García, "Índices de morbilidad e incidencia de enfermedades entre los esclavos en La Habana, 1580-1699”, Asclepio, vol. 43, N. 2, 1991, pp. 7-22. Sobre el estado de salud de los esclavos cubanos en este período, ver también: Alejandro de la Fuente, "El mercado esclavista habanero 1580-1699: las armazones de esclavos", Revista de Indias, vol. L, No. 189, 1990, pp. 371-396.

${ }^{83}$ Beatriz Joda Esteve, Mujer y esclavitud doméstica: La Habana (1790-1844), Tesis Doctoral, Universitat Jaume I, Castellón de la Plana, 2014; "Esclavas de Alma en boca: las leyes redhibitorias en La Habana (1790-1840)", en: José A. Piqueras (ed.), Orden político y gobierno de esclavos, Fundación Instituto de Historia Social, Valencia, 2016, pp. 151-175.
} 
Sobre la estadística de la población esclava en los censos coloniales interesan los estudios de Kenneth F. Kiple y José A. Piqueras. ${ }^{84}$

Casi al final de este balance, importa destacar las contribuciones de Adrián López Denis y Steven Palmer. Además de los estudios de López Denis sobre la primera epidemia de cólera, este autor ha publicado otros textos en los que analiza las sinergias entre medicina y sociedad colonial. ${ }^{85}$ Con López Denis, el tema adquiere una dimensión atlántica, no por simple modismo historiográfico, sino por la importancia que las redes internacionales de producción científica tuvieron en el desarrollo de la comunidad médica cubana y en la elaboración de los discursos sobre la enfermedad, la inmunidad y la raza en el contexto de desarrollo de la esclavitud moderna.

Por otra parte, el historiador canadiense Steven Palmer, uno de los principales especialistas en la historia de la salud en Latinoamérica, también ha señalado como La Habana se transformó desde fines del siglo XVIII en un enclave de convergencia médica en las Américas, producto de la riqueza basada en la expansión de la economía esclavista. ${ }^{86} \mathrm{Y}$ es que la práctica médica en la sociedad colonial cubana no puede comprenderse al margen del complejo sistema de transferencias ultramarinas articulado en el siglo XIX, del cual la esclavitud atlántica es un conducto estratégico. En efecto, Cuba, debido al desarrollo más tardío de su economía y a una posición geográfica privilegiada, se benefició de la experiencia médica acumulada no solo por profesionales residentes en su entorno, sino además en latitudes tan lejanas como las colonias del Pacífico. A su vez, la isla operó en el siglo XIX como laboratorio para la investigación científica de problemas de salud muy extendidos en áreas tropicales.

En un texto que marcó un hito en la renovación de la historiografía cubana, la historiadora Gloria García destacó la complejidad de las relaciones establecidas en la

${ }^{84}$ Kenneth F. Kiple, Blacks in colonial Cuba, 1774-1899, University Presses of Florida, Gainesville, 1976. José A. Piqueras, "Censos lato sensu. La abolición de la esclavitud y el número de esclavos en Cuba", Revista de Indias, vol. LXXI, Nº. 251, 2011, pp. 193-230.

${ }^{85}$ Adrián López Denis, "Melancholia, Slavery and Racial Pathology in Eighteenth Century Cuba", Science in Context, vol. 18, N ${ }^{\circ}$. 2, 2005, pp. 179-200; Disease and Society in Colonial Cuba, 1790-1840, Tesis Doctoral, University of California, Los Angeles, 2007. Quiero aprovechar esta nota para agradecer a Adrián López Denis las referencias bibliográficas facilitadas para esta investigación.

${ }^{86}$ Steven Palmer, "From the Plantation to the Academy: Slavery and the Production of Cuban Medicine in the Nineteenth Century", en: Juanita de Barros, Steven Palmer y David Wright, Health and Medicine in circum-Caribbean, 1800-1968, pp. 53-75. Marcos Cueto y Steven Palmer, Medicine and Public Health in Latin America, Cambridge University Press, Nueva York, 2015. Gilberto Hochman, María Silvia Di Liscia y Steven Palmer (coords.), Patologías de la patria. Enfermedades, enfermos y nación en América Latina, Lugar Editorial, Buenos Aires, 2012. 
plantación. Frente al dominio estructuralista, su texto sugirió nuevas líneas que ponderaban el papel activo de los esclavos para obtener ventajas en sus condiciones de vida y trabajo. ${ }^{87}$ En tal sentido, en los últimos años se ha desarrollado una historiografía más heterodoxa sobre la esclavitud en Cuba y se ha profundizado en la investigación de disímiles aspectos como los mecanismos de transición a la libertad, la familia esclava y su descendencia, el cimarronaje y las rebeliones, las prácticas religiosas, etc. Las metodologías utilizadas también son diversas, incorporando el rico arsenal de herramientas desarrolladas en las últimas décadas. ${ }^{88}$ Sin embargo, dentro de los nuevas corrientes, la preocupación por la salud y mortalidad de la población esclava no ha dejado de ser marginal y las fuentes para su análisis menos exploradas. Por lo general, nos hemos movido en consideraciones limitadas a cifras globales de mortalidad, sin profundizar en sus causas y en los factores socioeconómicos subyacentes.

Un monográfico sobre la historiografía cubana contemporánea ${ }^{89}$ evidencia nuestro atraso en la investigación de una problemática tan importante como la salud de la población. Déficit que, un cuarto de siglo antes, fue advertido por el historiador Oscar Zanetti. ${ }^{90}$ El balance realizado por Nicolás Garófalo refleja la pervivencia de enfoques superados y desconoce los aportes que a la historia de la ciencia en Cuba han realizado autores como Armando Rangel Rivero, Miguel Ángel Puig-Samper, Armando García, Consuelo Naranjo, Pedro Pruna y Raquel Álvarez, entre otros. ${ }^{91}$ Tampoco la síntesis de

${ }^{87}$ Gloria García, La esclavitud desde la esclavitud. La visión de los siervos, Centro de Investigación Científica "Ing. Jorge L. Tamayo", México, 1996.

${ }^{88}$ Ver, por ejemplo: María del Carmen Barcia, La otra familia. Parientes, redes y descendencia de los esclavos en Cuba, Editorial Oriente, Santiago de Cuba, 2009. Aisnara Perera Díaz y María de los Ángeles Meriño Fuentes, Un café para la microhistoria. Estructura de posesión de esclavos y ciclo de vida en la llanura habanera (1800-1886), Editorial de Ciencias Sociales, La Habana, 2007. Marial Iglesias Utset, "Los Despaigne en Saint-Domingue y Cuba: narrativa microhistórica de una experiencia atlántica", Revista de Indias, vol. LXXI, No. 251, 2011, pp. 77-107. Oilda Hevia Lanier, Prácticas Religiosas de los Negros en la Colonia, Ediciones Rizo, Instituto de Historia de Cuba, La Habana, 2010. Manuel Barcia, The Great African Slave Revolt of 1825: Cuba and the Fight for Freedom in Matanzas, Louisiana State University Press, Baton Rouge, 2012. Claudia Varela Fernández, Esclavos a sueldo. La coartación cubana en el siglo XIX, Tesis Doctoral, Universitat Jaume I, Castellón de la Plana, 2010.

${ }^{89}$ Instituto de Historia de Cuba, La historiografía en la Revolución cubana. Reflexiones a 50 años, Editora Historia, La Habana, 2010.

${ }^{90}$ Oscar Zanetti, "La historiografía de temática social (1959-1984)", Revista de la Biblioteca Nacional José Martí, No. 1, enero-abril, 1985, pp. 5-17.

${ }^{91}$ La producción de estos autores es extensa. Citaré solo aquellos trabajos que considero más relevantes para el tema en cuestión: ver el monográfico sobre Ciencia y Sociedad en Cuba, publicado en: Asclepio, vol. 43, N ${ }^{\circ}$. 2, 1991. Armando García y Consuelo Naranjo, Racismo e inmigración en Cuba en el siglo XIX, Doce Calles, Aranjuez, 1996. Consuelo Naranjo y Armando García, "Antropología, "raza" y población en Cuba en el último cuarto del siglo XIX", Anuario de Estudios Americanos, vol. 55, №. 1, 1998, pp. 267-289. Armando García y Raquel 
Garófalo hace justicia al esfuerzo de investigadores como Gregorio G. Delgado, José López Sánchez, Cesar Rodríguez Expósito y Enrique Beldarraín Chaple. ${ }^{92}$ A propósito, vale subrayar un trabajo de este último en el que presenta las obras clásicas del siglo XIX sobre enfermedades de los esclavos en un contexto más general del desarrollo de la antropología médica en Cuba. ${ }^{93}$

En suma, el balance realizado podría nutrirse con referencias de otras publicaciones que de modo tangencial abordan la problemática en cuestión, o con los aportes de disciplinas útiles para el estudio de la enfermedad y la salud en las sociedades modernas, pero ello escapa a los límites de este texto. En el caso cubano, vigorizar la investigación sobre la salud de los esclavos y sus descendientes es una urgencia historiográfica, no tanto para reducir la brecha existente en relación a lo realizado en otros países, sino por su importancia para comprender la historia de las relaciones raciales en nuestro país. En definitiva, la salud de toda población es condición sine qua non para el despliegue de su potencial económico y sociocultural.

Álvarez, En busca de la raza perfecta: eugenesia e higiene en Cuba (1898-1958), CSIC, Madrid, 1999. Armando García, El estigma del color: saberes y prejuicios sobre las razas en la ciencia hispano cubana del siglo XIX, 2 vols, Ediciones Idea, Tenerife, 2008. Consuelo Naranjo, "La cuestión racial durante la transición al trabajo libre en Cuba (1860-1890)", en: José A. Piqueras (coord.), Azúcar y esclavitud en el final del trabajo forzado, Fondo de Cultura Económica, Madrid, 2002, pp. 308-330. Armando Rangel Rivero, Antropología en Cuba: Orígenes y desarrollo, Fundación Fernando Ortiz, La Habana, 2012. Consuelo Naranjo, "La aclimatación a los trópicos y el trabajo esclavo en Cuba" en: Justo Cuño Bonito (ed.), Palabras para el intendente: un libro-homenaje al historiador Juan Andreo García, Editorial Renacimiento, Sevilla, 2014, pp. 160-181.

${ }^{92}$ Los trabajos de estos autores pueden leerse en los Cuadernos de Historia de la Salud Pública y otras publicaciones especializadas.

${ }_{93}$ Enrique Beldarraín Chaple, "Medicina y esclavitud", Catauro, Año. 4, No. 7, enero-junio, 2003, pp. 53-78. Una versión revisada de este artículo fue publicada como primer capítulo en: Enrique B. Chaple, Los médicos y los inicios de la antropología en Cuba, Fundación Fernando Ortiz, La Habana, 2006. 


\section{CAPÍTULO II: EL CICLO DEMOGRÁFICO DEL AZÚCAR}

A fines del siglo XVIII, la colonia cubana emprendió un proceso de transformación económica sin precedentes. Fenómeno caracterizado por la liquidación progresiva de las formas tradicionales de organización y explotación del suelo. La nueva estructura agraria se orientó en función de una mayor participación en el mercado mundial de productos tropicales. El colapso económico de Haití tras la Revolución (1791-1804), y las favorables condiciones internacionales fueron aprovechados por la élite criolla para impulsar el salto definitivo hacia la revolución azucarera. Proyecto que fue respaldado por la administración colonial en el marco de las reformas borbónicas.

La aprobación el 12 de octubre de 1778 del Reglamento y Aranceles Reales para el Comercio Libre flexibilizó las relaciones mercantiles entre España y sus posesiones ultramarinas. Una década más tarde (1789) se autorizó el libre comercio de esclavos africanos para el fomento de la agricultura en la isla. Los números relativos a las importaciones y exportaciones de la mayor de las Antillas en este nuevo contexto, revelan los profundos cambios operados en su actividad económica respecto a los primeros siglos coloniales. De acuerdo con Jacobo de la Pezuela, hacia 1790 se inicia una "segunda época" en la dinámica mercantil de la isla, que se consolidó con la aprobación del Real Decreto del 10 de octubre de 1818, que habilitó los puertos cubanos para el comercio con extranjeros. ${ }^{1}$

El despegue económico de la isla la situó en la vanguardia del imperio ultramarino de España, que se redujo significativamente en espacio y población luego de los procesos independentistas en la América continental. Entonces, quedaron bajo el dominio de la corona hispana, además de Cuba, Puerto Rico, Filipinas, las posesiones en el golfo de Guinea y los presidios de África. Solo Filipinas superaba a la mayor de las Antillas en población, aunque no en importancia económica. De hecho, el dulce cubano reportaba a la metrópoli contribuciones superiores a la suma del resto de sus territorios coloniales. Asimismo, a fines de la década de 1830, la isla desplazó al caribe

\footnotetext{
${ }^{1}$ Jacobo de la Pezuela, Diccionario geográfico, estadístico, histórico de la isla de Cuba, t. II, Imprenta del Establecimiento de Mellado, Madrid, 1863, pp. 26-131.
} 
francés y británico en la oferta mundial de ese producto, alcanzando cuotas históricas de producción. ${ }^{2}$ De ahí su creciente importancia geopolítica en el contexto histórico que venimos analizando.

Los cambios en esta etapa se verifican en la actividad de los puertos de Matanzas y Cárdenas. Por ejemplo, este último fue habilitado en 1844 con operaciones mercantiles equivalentes a 449.518 pesos. Tres lustros más tarde, transformada la región en uno de los principales enclaves de la economía azucarera, el valor de sus operaciones se había elevado a casi 5 millones de pesos. El volumen de las exportaciones de azúcar por este muelle pasó de 47.385 arrobas en 1844 a 3.509.040 en 1861. Desde allí se ejecutaban intercambios directos con Estados Unidos e Inglaterra, además de la metrópoli. Si en el primer lustro de la década de 1820 el azúcar representaba cerca del $35 \%$ de las exportaciones cubanas a Estados Unidos, convertido en el principal destino de esta mercancía, cuatro décadas más tarde el mismo renglón engulló otro 35\% del comercio cubano-estadounidense, reduciéndose significativamente las exportaciones de café, el segundo producto mercantil en importancia. ${ }^{3}$

\section{ESCLAVITUD Y MORTALIDAD DIFERENCIAL}

La consolidación de un modelo agroexportador centrado, cada vez más, en la manufactura azucarera, produjo cambios importantes en la estructura demográfica de la isla. El siguiente gráfico refleja la estrecha relación existente entre la dinámica demográfica y el desempeño económico de la isla en el contexto de la "segunda esclavitud". Aunque todos los principales grupos de población aumentaron, ninguno lo hizo en mayor proporción que la esclava. Crecimiento que estuvo motivado por un fuerte componente externo. De este modo, la masiva afluencia de esclavos desde las factorías africanas disminuyó progresivamente la superioridad numérica de la población blanca en la isla. De acuerdo con el primer censo oficial (1776), ordenado durante el gobierno del Márquez de la Torre, la relación entre la población blanca, libre "de color" y esclava era de $56 \%, 18 \%$ y $26 \%$, respectivamente. ${ }^{4}$ En los catorce años transcurridos

\footnotetext{
2 Antonio Santamaría, "Las islas españolas del azúcar (1760-1898). Grandes debates en perspectiva comparada y caribeña", pp. 149-176.

${ }^{3}$ Jacobo de la Pezuela, Diccionario, t. II, pp. 26-131.

${ }^{4}$ Sobre la importancia que las estadísticas demográficas adquieren a fines del siglo XVIII en Cuba y su utilidad política, véase: Karim Ghorbal, "Medir y utilizar la heterogeneidad. Censos,
} 
entre el censo de 1827 y el de 1841, la población blanca aumentó en razón de un 34,5\%, mientras la libre "de color" lo hizo en un $43,5 \%$ y la esclava en un $52,1 \%$. $^{5}$

GRÁFICO 1: CUBA. CORRELACIÓN ENTRE AZÚCAR Y POBLACIÓN, 1792-1887.

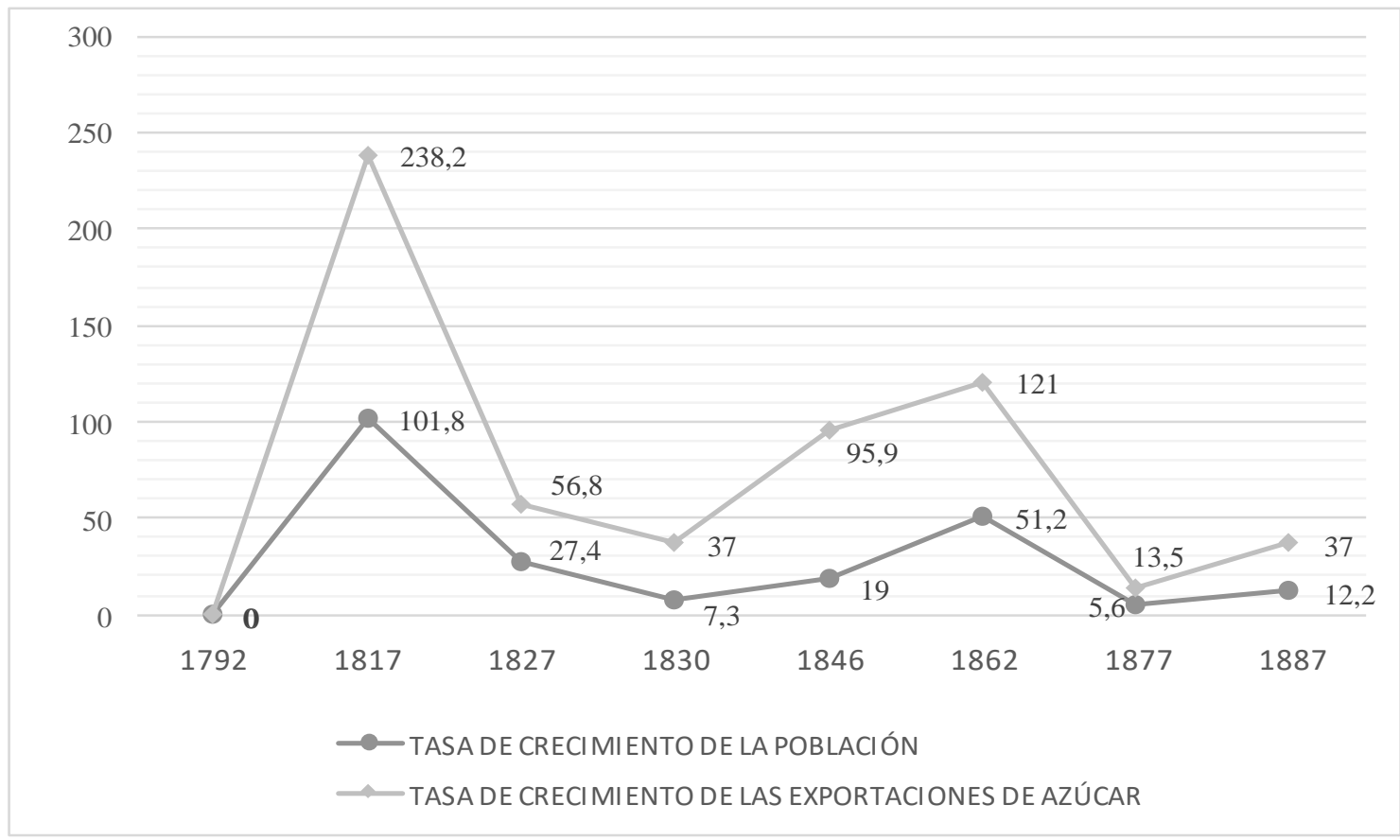

Elaboración propia a partir de la información disponible en: ONEI, El color de la piel según el censo de población y viviendas, Centro de Estudios de Población y Desarrollo, La Habana, 2016, p. 17. Kenneth F. Kiple, Blacks in colonial Cuba, 1774-1899, pp. 4-8. Manuel Moreno Fraginals, El Ingenio, t. 3, pp. 4851.

El carácter agrario de los cambios demográficos asociados a la "segunda esclavitud" se confirma en el siguiente dato: en la década de 1770, La Habana concentraba casi el 45\% de la población censada, magnitud que hacia 1860 se redujo al 15\%. En algunas zonas, la composición étnica se alteró significativamente en favor del elemento africano. En 1827, existían en Matanzas, abarcando la ciudad y pueblos contiguos, 16.671 habitantes blancos, 2.602 pardos y morenos libres y 25.522 esclavos. El incremento de los nativos africanos entre ese año y el previo censo de 1817 fue de $181 \%$, o sea unos 17.075 esclavos más. ${ }^{6}$ En su estudio sobre el monocultivo azucarero en esa región, Laird W. Bergard destacó como su tendencia demográfica estuvo

esclavitud y relación colonial en Cuba", en: José A. Piqueras (ed.), Orden político y gobierno de esclavos, Fundación Instituto de Historia Social, Valencia, 2016, pp. 53-77.

${ }^{5}$ En esa etapa, el aumento fue particularmente significativo en el Departamento Occidental, un $54 \%$ entre una y otra fecha, superior al promedio de la isla. Resumen del censo de población de la isla de Cuba a fin del año de 1841, Imprenta del Gobierno, La Habana, 1842, p. 19.

${ }^{6}$ Cuadro estadístico de la siempre fiel isla de Cuba, correspondiente al año de 1827, Oficina de las viudas de Arazoza y Soler, La Habana, 1829. 
condicionada por la trata atlántica. Entre 1846 y 1862, Matanzas experimentó un rápido crecimiento poblacional, que se desaceleró entre 1862 y 1877, cuando pasó de un 2,7\% a 1,1\% anual. Como sugiere este autor, ese "dramático decline" después de 1862 estuvo esencialmente determinado por los cambios en el comercio de esclavos que sostuvo el incremento demográfico de la primera etapa. ${ }^{7}$

Las siguientes gráficas reflejan la evolución de los dos componentes fundamentales de la población cubana en el siglo XIX. Como se observa, desde fines del siglo XVIII la población blanca creció de manera sostenida en números absolutos y, a mediados del siglo XIX, con un aporte migratorio significativamente menor al africano, superó porcentualmente a la población “de color". Este último grupo aumentó progresivamente hasta la década de 1840, y, al margen de los posibles ocultamientos en los últimos años del sistema esclavista, es notorio su estancamiento demográfico. La diferencia para llegar al 100\% de la población entre 1861 y 1887 corresponde fundamentalmente al elemento asiático, que en el conjunto de la isla no rebasó el 3\% y estuvo muy concentrado en la región Habana-Matanzas, donde sí alcanzó cuotas demográficas superiores a la indicada. ${ }^{8}$ La población “de color" representó en 1841 el $58,5 \%$ de los habitantes censados, con una mayoría esclava estimada en 436.495 personas. Desde esa fecha se inicia un progresivo decrecimiento de la población afrodescendiente -y esclava en particular- que pasó a solo el 32,2\% de la población censada en 1877, proporción que apenas varió en el último cuarto del siglo.

\footnotetext{
${ }^{7}$ Aunque no está estrictamente contabilizado, el impacto demográfico de la Guerra de los Diez Años (1868-1878) en Matanzas no fue considerable. Laird W. Bergard, Cuban Rural Society in the Nineteenth Century. The Social and Economic History of Monoculture in Matanzas, Princeton University Press, Princeton, 1990, pp. 89-106.

${ }^{8}$ Entre fines de la década de 1840 y principios de la de 1870 se agrega una importante corriente migratoria de colonos asiáticos. Ver: Juan Pérez de la Riva, "Demografía de los culíes chinos en Cuba", en: Juan Pérez de la Riva, El barracón y otros ensayos, Editorial de Ciencias Sociales, La Habana, 1975, pp. 469-507.
} 
GRÁFICOS 2 Y 3: CUBA. EVOLUCIÓN EN NÚMEROS ABSOLUTOS Y PORCENTUAL DE LOS PRINCIPALES COMPONENTES RACIALES DE LA POBLACIÓN, 1792-1887.
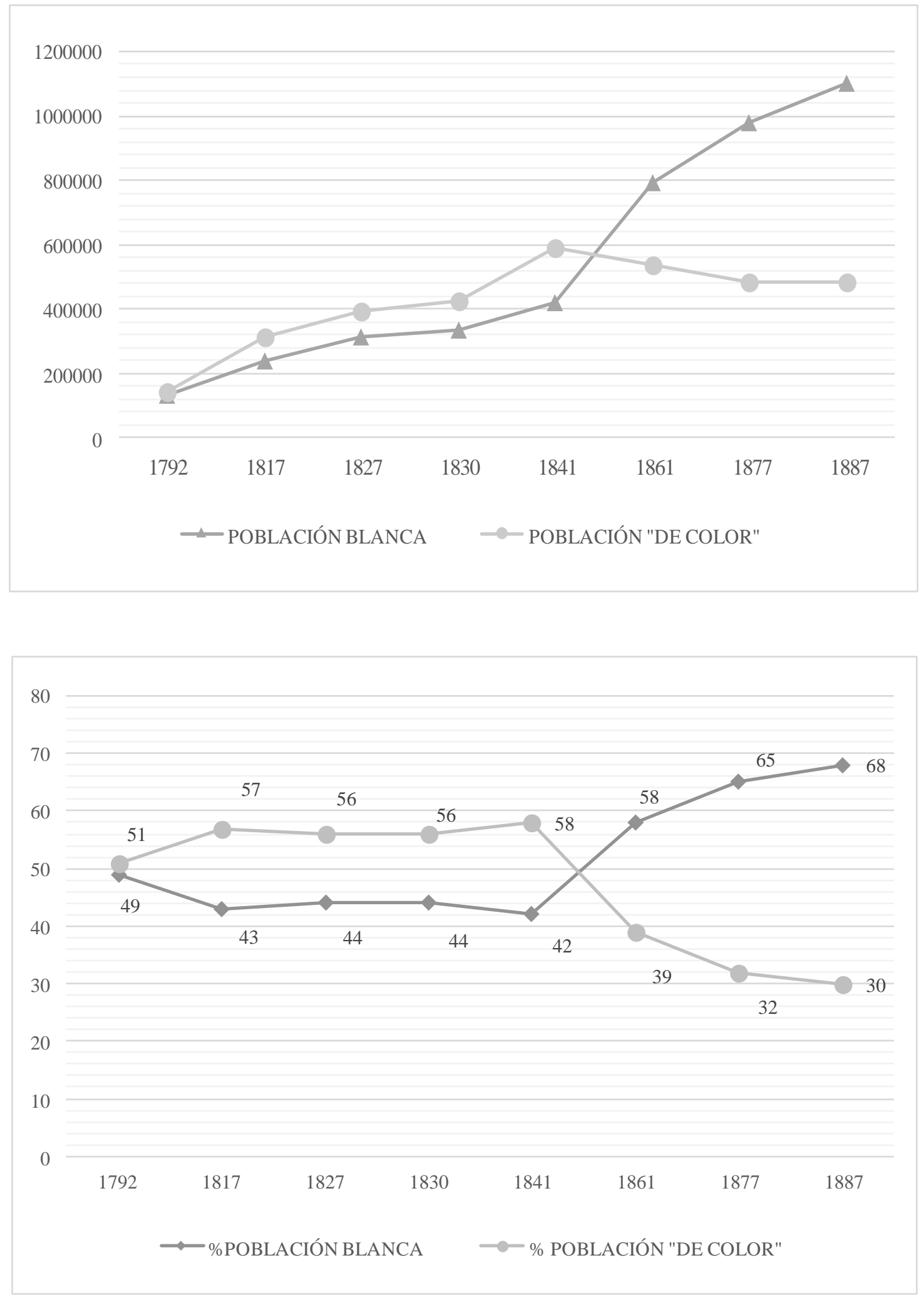

Elaboración propia a partir de la información disponible en: ONEI, El color de la piel según el censo de población y viviendas, p. 17. Kenneth F. Kiple, Blacks in colonial Cuba, 1774-1899, pp. 4-8. 
Diversos factores influyeron en la estabilidad de la población esclava en la isla, que entre 1841 y 1861 se redujo en 65.942 efectivos. Como en otros dominios del Caribe, el crecimiento sostenido de este grupo fue posible a través del comercio atlántico de africanos. Asimismo, consideramos que las desigualdades en salud, expresadas en diferenciales de mortalidad, constituyen un factor de valor para comprender la brecha demográfica abierta entre la década de 1840 y el fin de la esclavitud. Un análisis al respecto debe considerar que el giro indicado coincide con la etapa de expansión de la economía azucarera, que alcanzó entonces las cuotas más elevadas de exportación de todo el siglo XIX, e implicó un fortalecimiento notable en el régimen de explotación del trabajo cautivo.

Cuando en 1867 Carlos Marx publicó El Capital, incorporó en su análisis observaciones del economista irlandés John E. Cairnes ${ }^{9}$ sobre el carácter depredador de la economía cubana. Bajo la transformación agrícola acontecida entonces en la isla, que reportaba rentas millonarias a los plantadores y grandes beneficios a la metrópoli, la población cautiva estaba sometida "a la alimentación más rudimentaria y a los trabajados más agotadores e incesantes", destruyéndose todos los años una buena parte de la misma, "víctimas de esa lenta tortura del exceso de trabajo y de la falta de descanso y de sueño". ${ }^{10}$ La apropiación de Marx no es gratuita. Téngase en cuenta que las plantaciones azucareras cubanas de mediados del siglo XIX figuraban entre los espacios laborales más dinámicos de la moderna economía atlántica.

En efecto, la plantación cubana que tipifica la "segunda esclavitud" constituyó una unidad productiva con una dinámica particular. Como norma, concentró una magnitud espacial y un número de trabajadores superior al de otras fincas de importancia, como las destinadas al cultivo del café o frutos menores. Al mediar el decenio de 1840, el número de ingenios y trapiches activos en toda la isla ascendía a 1.442. ${ }^{11} \mathrm{Al}$ margen de los procesos tecnológicos desarrollados en esta época, o, para ser más precisos, en relación con ellos, el factor humano siguió siendo fundamental en el rendimiento económico de estas empresas. Los ingenios más productivos mantenían el control de amplias dotaciones compuestas de esclavos, colonos asiáticos y trabajadores libres. De acuerdo con los datos publicados por la Dirección General de Hacienda en 1877, existe una fuerte correlación entre la población trabajadora en los ingenios y el

\footnotetext{
${ }^{9}$ John Elliott Cairnes, The Slave Power, Parker, Son, \& Co., Londres, 1862.

${ }^{10}$ Carlos Marx, El Capital. Crítica de la economía política, t. I, Fondo de Cultura Económica, 2001, p. 209.

${ }^{11}$ Jacobo de la Pezuela, Diccionario, t. I, p. 56.
} 
beneficio financiero de su actividad. Los ingenios con un producto líquido superior a los 70.000 pesos operaban con dotaciones de más de 450 trabajadores, entre ellas las propiedades llamadas San Claudio, Esperanza, Tinguaro, Santa Rita, España, San Miguel, Cristina, La Luisa, S. Joaquín y Purísima Concepción, registrados como patrimonios de Juan S. Aguirre, José Baró, la Condesa Armildez de Toledo, Julián Zulueta, Salvador Baró, Francisco F. Ibáñez y los herederos del Conde S. Fernando de Peñalver. El producto líquido está deducido luego de sustraer al producto bruto los gastos correspondientes de refacción. ${ }^{12}$

En 1861, el 94\% de la producción azucarera se concentró en el Departamento Occidental, donde radicaban el $86 \%$ de los 1.365 ingenios contabilizados en toda la isla. Las 7 jurisdicciones indicadas en la tabla 1 concentraban entonces el $46 \%$ de la población esclava, el 56\% de los ingenios y el 73\% de la producción azucarera.

\section{TABLA 1: CUBA. RELACIÓN ENTRE PRODUCCIÓN AZUCARERA Y CONCENTRACIÓN DE ESCLAVOS POR JURISDICCIONES, 1861.}

\begin{tabular}{|l|r|r|r|}
\hline \multicolumn{1}{|c|}{ Jurisdicciones } & $\mathrm{N}^{\circ}$. de esclavos & $\mathrm{N}^{\circ}$. de ingenios & $\begin{array}{r}\text { Producción azucarera } \\
(\mathrm{lb})\end{array}$ \\
\hline Guanajay & 17.708 & 61 & 55.462 .925 \\
\hline Güines & 24.817 & 89 & 99.923 .325 \\
\hline Matanzas & 32.181 & 129 & 119.387 .850 \\
\hline Cárdenas & 27.418 & 147 & 150.988 .200 \\
\hline Colón & 33.699 & 126 & 202.594 .900 \\
\hline Cienfuegos & 16.985 & 119 & 102.351 .325 \\
\hline Sagua & 19.150 & 94 & 95.131 .500 \\
\hline
\end{tabular}

Fuentes: Ramón de la Sagra, Cuba en 1860, Imprenta de Simón Raçon y Ca., París, 1863, p. 12. Jacobo de la Pezuela, Diccionario, t. I, p. 38.

Como norma, el control de la población en esas áreas quedó al margen de cualquier cuestionamiento oficial de rigor. Las evidencias disponibles sugieren que, en la práctica, las pocas normativas de la administración colonial en este sentido tuvieron efectos muy limitados. Muchas cosas del entorno del ingenio quedaron dentro de sus límites, como la violencia directa ejercida sobre la dotación y no pocas de las defunciones que en ella ocurrían. Es sintomático que, en una serie bastante completa del registro de la enfermería de las dotaciones de Julián Zulueta para la década de 1870, con

\footnotetext{
${ }^{12}$ Exceptuando el ingenio Tinguaro, que operaba con una mayoría de trabajadores alquilados y libres, en el resto de las plantaciones citadas las dotaciones estaban compuestas en mayor número por esclavos. Dirección General de Hacienda, Noticia de los ingenios o fincas azucareras que en estado de producción existen actualmente en toda la isla. Imprenta del Gobierno, La Habana, 1877.
} 
picos mensuales de ingresos superiores a las 80 personas, apenas se registren fallecidos. ${ }^{13}$ En caso de epidemias notables, como los tres brotes de cólera, la administración colonial ejerció sobre los plantadores mayor presión para que revelaran los detalles de la forma en que estaba siendo afectada la salud de los sujetos bajo su jurisdicción, sobre todo por los perjuicios que las negligencias pudieran ocasionar a la salud pública, pero incluso en estos casos la información al respecto pocas veces trascendió con trasparencia. No obstante, la mortalidad en esos espacios es fundamental para comprender la subordinación de la dinámica demográfica de la isla a la estructura agraria dominante.

En 1854, Luis José Sartorius y Tapia, Conde de San Luis, firmó un informe dirigido a la Reina en el que abordó la manida cuestión de la escasez de trabajadores agrícolas en la isla y las posibles medidas a tener en cuenta como solución. El entonces Presidente del Consejo de Ministros consideró que la población esclava existente, a pesar de la sensible disminución durante la última epidemia de cólera, bastaría para cubrir las necesidades de su agricultura si no estuviese una gran parte de ella destinada al servicio doméstico y otras tareas en las principales poblaciones, que bien podían ser realizadas por trabajadores libres. Una década antes, la Real Orden del 29 de julio de 1844 había establecido un derecho de capitación sobre los esclavos empleados en el servicio doméstico que apenas surtió el efecto deseado. En tal sentido, el Conde de San Luis sugirió que el impuesto de capitación debía extenderse "a todos los esclavos que no estén dedicados habitualmente a los servicios de la agricultura", "y aumentar dicho impuesto gradualmente en proporción a la riqueza de cada propietario". También recomendó eximir del derecho de alcabala por concepto de venta, consistente en el $6 \%$ del valor estipulado, a los esclavos vendidos o enajenados con destino a trabajar en establecimientos agrícolas. En cambio, podía duplicarse esa tasa para los esclavos involucrados en transacciones con el fin inverso. Otra cuestión fundamental considerada por el Consejo de Ministros fue la reproducción natural de esa población. Con ese fin, recomendó estimular a los propietarios que fomentaran los matrimonios de esclavos en sus fincas y alcanzaran un mayor número de hijos legítimos, así como aquellos que demostraran "esmero y éxito" en la preservación de la salud de su dotación. Junto a estas medidas, consideró conveniente desarrollar una política inmigratoria de

\footnotetext{
${ }^{13}$ Libro de refacción de los ingenios Vizcaya, Habana, España, Alaba y otros ubicados en la provincia de Matanzas, propiedad de Julián Zulueta, correspondiente a los años 1874-1876, ANC, Donativos y Remisiones, Leg. 140, Nº. 1.
} 
trabajadores libres, preferiblemente colonos españoles o extranjeros blancos, para remplazar a los esclavos que desarrollaban diversas actividades en las ciudades. ${ }^{14}$

Atendiendo a estas y otras consideraciones, ese año se aprobó un Real Decreto que, entre otras medidas, contempló una modificación en el impuesto de capitación, gravando más a los propietarios de esclavos que no estuviesen destinados al campo, eximiéndose a las esclavas y sus hijos menores de 12 años. La nueva regulación también favoreció a los esclavos casados mientras vivieran en compañía de sus mujeres, quienes pagarían solo 2 pesos anuales. Si llegase a 4 el número de hijos, el padre esclavo quedaría exento de toda capitación, incluso en caso de quedar viudo, siempre y cuando aquellos llegasen a cumplir 12 años. Siempre que se acreditara la celebración del matrimonio, los esclavos enajenados por este concepto quedaban exentos de dicha contribución y lo mismo se dispuso para los hijos de esclavos, legítimos o legitimados, nacidos después de la publicación del decreto en cuestión, cuando por primera vez salieran del dominio de los dueños en cuyo poder nacieron. Asimismo, se dispuso la creación de tres premios, dotados con los fondos obtenidos por el derecho de capitación, orientados a estimular a los propietarios de más de 50 esclavos que, proporcionalmente, acreditaran anualmente mayor número de hijos legítimos o legitimados, otro al que haya tenido, proporcionalmente, la menor tasa de mortalidad en el mismo período, y, finalmente, un tercer premio para el propietario que acreditase la mejor proporción de hombres y mujeres en su dotación. Los mismos serían adjudicados el día 19 de noviembre de cada año por una junta presidida por el Capitán General de la isla. Este, a través de los funcionarios correspondientes, debía mantener un control estricto sobre la población esclava que, por las normativas estipuladas, quedaba exenta de pagar el derecho de capitación, sancionando, por los mecanismos civiles y penales al uso, a los propietarios que cometiesen cualquier tipo de fraude. ${ }^{15}$

Las políticas de poblamiento estuvieron estrechamente vinculadas con las ideas dominantes sobre la aclimatación de las razas. ${ }^{16}$ En el caso cubano, ese debate se agudizó a partir de la década de 1840, incorporando un arsenal de argumentos no solo sociopolíticos, sino además fisiológicos y demográficos. La manida tesis de que solo mediante una provisión sostenida de brazos africanos era posible mantener la riqueza agrícola de la isla, rebatida tempranamente por importantes personalidades de la

\footnotetext{
${ }^{14}$ Gaceta de Madrid, No $.468,13$ de abril de 1854, pp. 1-2.

15 Ídem.

${ }^{16}$ Ver, por ejemplo, los trabajos previamente citados de Armando García y Consuelo Naranjo sobre racismo e inmigración.
} 
intelectualidad criolla como José Antonio $\operatorname{Saco}^{17}$ o el Conde de Pozos Dulces ${ }^{18}$, fue uno de los principales puntos en cuestión. En sus respectivos análisis, ellos cuestionaron los efectos debilitantes del clima sobre la constitución del trabajador blanco. En esta dirección también apunta la observación del reconocido médico Antonio de Gordon y de Acosta:

\begin{abstract}
"En las empresas industriales, entre las cuales debemos colocar hoy la mayoría de nuestros ingenios por lo que tributan en ese sentido, los blancos resisten igualmente más en estos climas, pues la morbilidad y mortalidad de ellos, es menor que en las razas inferiores como sostiene el referido Dr. Nicolás, las que, por otra parte, están menos familiarizadas con los grandes aparatos modernos y por eso también, en virtud del traumatismo y sus consecuencias, valen menos para dichas empresas." 19
\end{abstract}

Años más tarde, Carlos J. Finlay sostuvo que, al margen del riesgo que representa el tétanos infantil para los blancos recién nacidos y la fiebre amarilla para los inmigrantes blancos recién llegados - "ambos peligros susceptibles de conjurarse por medio de la higiene"-, la aclimatación de los europeos en Cuba y sus descendientes era un hecho demostrable por su aumento progresivo y las bajas tasas de mortalidad que por lo general presentaban en toda la isla. En cambio, la gente "de color" difícilmente se reproducía bajo las mismas condiciones. ${ }^{20}$ En su polémica con Finlay, el médico español Juan Manuel Espada y Montanos consideró insuficientes los datos demográficos presentados por aquel autor, y sostuvo que no era la fiebre amarilla el mayor peligro que enfrentaban los europeos a su llegada, puesto que el paludismo, la tisis y la anemia, producían una mortalidad superior. Como respuesta, Finlay sostuvo que otros datos estadísticos disponibles para La Habana confirmaban la superior mortalidad de la raza “de color" en años sucesivos y que en los guarismos de 1861-1862 tal desventaja era evidente en 26 de las 32 jurisdicciones de la isla. Ello otorgaba el

\footnotetext{
${ }^{17}$ José Antonio Saco, La supresión del tráfico de esclavos africanos en la isla de Cuba examinada en relación a su agricultura y a su seguridad, Imprenta de Panckoucke, París, 1845, pp. 12-27.

${ }^{18}$ Conde de Pozos Dulces, La cuestión del trabajo agrícola y de la población en la isla de Cuba, Imprenta Tipográfica de Jorge Nugelmann, París, 1860, p. v.

${ }^{19}$ Este argumento biológico era reforzado con una supuesta mejor actitud para el trabajo de la raza caucásica frente a la disposición de africanos y asiáticos. Antonio de Górdon y de Acosta, Higiene colonial en Cuba, Sarachaga y H. Miyares, La Habana, 1895. p. 20.

${ }^{20}$ Carlos J. Finlay, "Apología del clima de Cuba II", Gaceta Médica de La Habana, Año. 5, No. $1,1^{\text {ro }}$ de marzo de 1879, pp. 68-72. Juan M. Espada, "De la no aclimatación de los europeos en los climas cálidos", El Eco de Galicia, La Habana, No 32, 1878. Esta publicación, vinculada a la inmigración gallega en la isla, fue editada en La Habana entre 1878 y 1902.
} 
mismo valor que pudiera atribuírsele a una serie de varios años para una misma localidad. No obstante, al valorar la dificultad que ha encontrado la raza negra para propagarse bajo lo que Finlay denominó "las circunstancias actuales y las que han existido desde el principio de siglo", sostuvo que no fue efecto del trabajo forzoso, puesto que la mortandad se acentúa en la clase libre. Finlay no refiere la fuente de sus cálculos, aunque el resultado es muy similar al que se obtiene con los guarismos de las Noticias estadísticas publicadas por el Conde Armildez de Toledo, correspondientes a 1862. Hemos contrastado los guarismos de ambas fuentes y la diferencia más notable se obtiene en la tasa de mortalidad de la población blanca de San Antonio, como queda indicado en la tabla 2.

TABLA 2: CUBA. MORTALIDAD Y NATALIDAD COMPARADA POR JURISDICCIONES Y RAZA, 1862.

\begin{tabular}{|l|r|r|r|r|r|r|r|}
\hline \multicolumn{1}{|c|}{ Jurisdicciones } & \multicolumn{3}{|c|}{ Mortalidad \% } & \multicolumn{3}{|c|}{ Natalidad \% } \\
\hline Bahía Honda & & C & E & B & C & E \\
\hline Bejucal & 18,6 & 22,8 & 19,7 & 45,9 & 14,5 & 13,3 \\
\hline Cárdenas & 26,6 & 29,2 & 32,6 & 50,1 & 32,9 & 33,6 \\
\hline Cienfuegos & 15 & 18,5 & 18 & 27,8 & 22,2 & 20,8 \\
\hline Colón & 22,1 & 20 & 14,7 & 45,9 & 33 & 19 \\
\hline Guanabacoa & 15,1 & 22,9 & 25,3 & 33,6 & 35,6 & 34,5 \\
\hline Guanajay & 34,6 & 35,8 & 26 & 36,4 & 30,5 & 27 \\
\hline Güines & 22,1 & 22,1 & 22,7 & 35,6 & 23,6 & 23 \\
\hline Habana & 24,2 & 28,3 & 29,3 & 38,2 & 31 & 30,8 \\
\hline Isla de Pinos & 32,2 & 39,9 & 34,7 & 21,3 & 29,6 & 33,9 \\
\hline Jaruco & 38 & 32,8 & 35,5 & 32,2 & 21,3 & 23,7 \\
\hline Matanzas & 18 & 23,4 & 24,6 & 66 & 45,6 & 42,4 \\
\hline Pinar del Río & 20,4 & 23,1 & 22 & 32,2 & 23,3 & 21,6 \\
\hline Sagua la Grande & 12,6 & 20 & 21,2 & 39,6 & 21,8 & 17,6 \\
\hline Santiago & 17,6 & 25,1 & 25,6 & 51,2 & 27,9 & 27 \\
\hline San Antonio & 41,6 & 41 & 38,4 & 45,9 & 35,7 & 33,8 \\
\hline San Cristóbal & $44,3 / 47,6$ & 37,7 & 35,6 & 52,5 & 32,5 & 32 \\
\hline San Juan de los Remedios & 18,8 & 21,3 & 24,2 & 36,3 & 21,4 & 17,5 \\
\hline Santa María del Rosario & 16 & 25,2 & 25,6 & 41,9 & 30,2 & 28,4 \\
\hline Sancti-Spíritus & 23,4 & 18,8 & 21,7 & 39,6 & 31,3 & 34 \\
\hline Trinidad & 20 & 22,9 & 19,8 & 43,3 & 25,3 & 19 \\
\hline Villa Clara & 22,2 & 20,2 & 19,8 & 36,5 & 36,1 & 21,5 \\
\hline Departamento Occidental & 14,4 & 18,4 & 18,6 & 32,7 & 30,7 & 27 \\
\hline & 24,7 & 26,4 & 24,8 & 34,8 & 27,6 & 23 \\
\hline Bayamo & & & & & & \\
\hline Baracoa & 19,5 & 24,7 & 26,4 & 42,4 & 42,3 & 31,5 \\
\hline Cuba & 19,1 & 20,8 & 20,8 & 34,2 & 36,3 & 28,3 \\
\hline Guantánamo & 25,4 & 22 & 19,7 & 25 & 29,9 & 22,8 \\
\hline & 6,5 & 19 & 19,3 & 18,9 & 17,7 & 10,5 \\
\hline
\end{tabular}




\begin{tabular}{|l|r|r|r|r|r|r|}
\hline Holguín & 7,3 & 8,9 & 7,7 & 24,9 & 26,4 & 22,7 \\
\hline Jiguaní & 15,8 & 21 & 25,8 & 43,7 & 47,4 & 32,3 \\
\hline Manzanillo & 35,2 & 47 & 94 & 45,7 & 42,7 & 35 \\
\hline Mayarí & 33 & 40 & 126,4 & 59,6 & 58 & 97,5 \\
\hline Puerto Príncipe & 14,8 & 18,6 & 17,8 & 37 & 25 & 26 \\
\hline Tunas & 21 & 35 & 64,4 & 103,7 & 100,5 & 75 \\
\hline Departamento Oriental & 17,3 & 22,9 & 20,9 & 35,6 & 25,8 & 23,4 \\
\hline
\end{tabular}

B) blancos, (C) total "de color", E) esclavos *El Conde Armildez de Toledo advierte que, "no habiéndose recibido a tiempo los datos correspondientes a esta Jurisdicción se ha calculado su movimiento de población por métodos indirectos". Fuentes: Conde Armildez de Toledo, Noticias estadísticas de la isla de Cuba, Imprenta del Gobierno, La Habana, 1864, pp. 27-28. Carlos J. Finlay, "Apología del clima de Cuba II", p. 71.

De acuerdo con la advertencia de Finlay, las cifras muy elevadas de Manzanillo, Mayarí y las Tunas, y las muy bajas de Guantánamo y Holguín se deben a las alteraciones que por entonces se produjeron en la división territorial de esas jurisdicciones. No obstante, del cálculo global de las tasas de mortalidad y natalidad en esos territorios del departamento Oriental se obtienen resultados similares a los de otras demarcaciones. Las variaciones en las tasas de mortalidad y natalidad del cuadro anterior sugieren que las mismas deben ser tomadas con prudencia. De acuerdo con los guarismos de bautismos y entierros que presenta en su informe el Conde Armildez de Toledo, en 1862 la población esclava experimentó una diferencia adversa de 1.266 personas, hecho determinado en su totalidad por una disminución de los varones. En igual fecha, la población blanca experimentó un incremento natural en 3.816 varones y 6.382 hembras, mientras el aumento en la gente "de color" libre fue de 869 varones y 888 hembras. Ahora bien, el entonces Intendente de Hacienda contabilizó como nacimientos la totalidad de los bautismos, aunque, fundamentalmente en la población esclava, este número esta alterado por el número de bozales bautizados en los primeros años de arribo a la isla. Sobre este aspecto volveremos más adelante. Asimismo, hay que tener en cuenta que la mortalidad de la población blanca contempla las defunciones de colonos asiáticos, por lo general superior a la tasa de la población blanca nativa. De la tabla 2 no es correcto sugerir, como refiere Finlay, que la mortalidad fuera como norma superior en la gente "de color" libre que en la esclava. Hay que considerar que la tasa de estos últimos está afectada a la baja por un considerable número de muertes no registradas por las autoridades. 
TABLA 3: RAZA Y MORTALIDAD COMPARADA EN VARIOS TERRITORIOS CUBANOS. (AÑOS SELECCIONADOS)

\begin{tabular}{|l|r|r|r|}
\hline Ciudad o villa & Años & Blancos (\%o) & "De color" (\%) \\
\hline Bahía Honda & 1879 & 46,41 & 170,29 \\
\hline Baracoa & $1877-1878$ & 36,6 & 53,7 \\
\hline Caibarién & 1878 & 28,5 & 34,5 \\
\hline Bejucal & 1878 & 23,5 & 33,7 \\
\hline Cárdenas & $1861-1863$ & 51,12 & 73,38 \\
& $1876-1878$ & 36,52 & 52,11 \\
\hline Cienfuegos & $1861-1863$ & 52,57 & 61,07 \\
& $1876-1878$ & 75,06 & 52 \\
& 1879 & 35,03 & 39,71 \\
\hline Guanabacoa & $1874-1879$ & 35,5 & 49 \\
\hline Manzanillo & $1876-1878$ & 34,9 & 47,14 \\
\hline Matanzas & $1861-1863$ & 44,61 & 45,67 \\
& $1876-1878$ & 40,91 & 56,68 \\
\hline Morón & 1878 & 30,91 & 47,94 \\
\hline Regla & 1878 & 46,52 & 65,91 \\
& 1879 & 37,73 & 61,03 \\
\hline Sagua & $1861-1863$ & 25,54 & 26,06 \\
& $1876-1878$ & 53,06 & 42 \\
\hline Sancti Espíritus & $1876-1878$ & 35,33 & 42,20 \\
\hline San José de las Lajas & $1877-1878$ & 27,30 & 40,70 \\
\hline Trinidad & $1876-1878$ & 28,74 & 35,52 \\
\hline
\end{tabular}

Fuente: Frederic L. Hoffman, "The Negro in the West Indies", Publications of American Statistical Association, vol. 4, №. 30, junio, 1895, p. 192.

Los datos de la tabla 3, compilados a partir de los informes de la Comisión de Fiebre Amarilla de los Estados Unidos, sirven a Frederic L. Hoffman para sostener una primera conclusión: la desigual capacidad de reproducción de estos dos grupos demográficos en la isla. En casi todos los territorios para los años compilados las tasas de mortalidad de la población de ascendencia africana son significativamente más altas que para la población blanca. ${ }^{21}$

\section{TABLA 4: RAZA Y MORTALIDAD COMPARADA EN VARIAS CIUDADES-PUERTOS} DE CUBA, 1876-1878.

\begin{tabular}{|l|r|r|r|r|r|r|r|}
\hline Ciudad & Años & \multicolumn{2}{|c|}{$\begin{array}{c}\text { Población civil } \\
\text { censo de } 1877\end{array}$} & \multicolumn{2}{c|}{$\begin{array}{c}\text { No. de } \\
\text { fallecimientos }\end{array}$} & \multicolumn{2}{c|}{$\begin{array}{c}\text { Tasa de mortalidad } \\
\text { (\%o) }\end{array}$} \\
\cline { 3 - 8 } & & blancos & "de color" & blancos & "de color" & blancos & "de color" \\
\hline La Habana & 1876 & & & 5.290 & 2.148 & 35,79 & 45,10 \\
& 1877 & 147.798 & 47.639 & 4.986 & 2.153 & 33,74 & 45,19 \\
& 1878 & & & 5.996 & 2.598 & 40,57 & 54,54 \\
\hline
\end{tabular}

\footnotetext{
${ }^{21}$ Frederic L. Hoffman, “The Negro in the West Indies", p. 194.
} 


\begin{tabular}{|l|l|l|r|r|r|r|r|}
\hline Matanzas & 1876 & \multirow{3}{*}{27.643} & \multirow{4}{*}{9.504} & 1.182 & 624 & 42,76 & 65,66 \\
& 1877 & & 1.066 & 467 & 38,56 & 49,14 \\
& 1878 & & & 1.145 & 478 & 41,42 & 50,29 \\
\hline Cárdenas & 1876 & \multirow{3}{*}{13.294} & \multirow{4}{*}{4.490} & 736 & 322 & 55,36 & 71,71 \\
& 1877 & & 384 & 192 & 28,89 & 42,76 \\
& 1878 & & & 282 & 189 & 21,21 & 42,09 \\
\hline Cienfuegos & 1876 & & & 1.374 & 322 & 99,57 & 50,16 \\
& 1877 & \multirow{2}{*}{13.799} & \multirow{2}{*}{6.419} & 963 & 476 & 69,79 & 74,15 \\
& 1878 & & & 661 & 273 & 47,9 & 42,53 \\
\hline
\end{tabular}

Elaboración propia a partir de la información disponible en: "Informe preliminar de la Comisión de la Fiebre amarilla de la Junta Nacional de Sanidad", Gaceta Médica de La Habana, Año. 2, №. 5, marzo, 1879, p. 79.

A partir de 1819 la navegación a vapor facilitó las comunicaciones entre los principales puertos de la isla. El flujo de personas y mercancías se fortaleció con la llegada del ferrocarril en la década de 1830. Entre 1836 y 1863 se construyeron aproximadamente mil millas de vía férrea. A través de esta infraestructura, los ciclos epidémicos antes constreñidos a La Habana pudieron expandirse con rapidez a otras áreas costeras y hacia el interior del país. En 1876 se registró en La Habana el mayor número de muertes por fiebre amarilla de la década más beligerante del siglo XIX cubano. Ese mismo año, la población blanca de Matanzas, Cárdenas y Cienfuegos sufrió elevadísimas tasas de mortalidad, susceptibles de ser explicadas a partir de la insidiosa presencia del "vomito negro". Desde las entrañas de la isla, el ciclo enrarecido del azúcar transformó páramos seculares en florecientes e infectas ciudades, en las que sus habitantes, la mayoría de ellos vinculados directa o indirectamente a la dinámica comercial de la "segunda esclavitud", mejor o peor aclimatados al ecosistema de ultramar, aguardaban con entusiasmo y recelo la llegada del próximo buque. Con todo lo que la fiebre amarilla azotó a la población blanca de estas áreas, la gente "de color" estuvo expuesta a tasas más elevadas de mortalidad. Esto fue así en cada uno de los años y territorio indicados, con la excepción de Cienfuegos en 1876. Podemos comprender los factores que contribuyeron a la mortalidad diferencial en estos espacios analizando los datos disponibles para La Habana. La tabla 5 recoge la mortalidad por causas en la capital entre 1872 y 1881. Con diferencia, la tuberculosis fue la enfermedad más letal del período, seguida de la fiebre amarilla, la diarrea y enteritis, la viruela, el tétano infantil y el paludismo. 
TABLA 5: RESUMEN DE LA MORTALIDAD CIVIL POR ENFERMEDADES EN LA HABANA, 1872-1881.

\begin{tabular}{|c|c|c|c|}
\hline Causa registrada & $1872-1876$ & $1877-1881$ & $1872-1881$ \\
\hline Ántrax & - & 13 & 13 \\
\hline Beriberi & 12 & 8 & 20 \\
\hline Cólera esporádico & 13 & 12 & 25 \\
\hline Cólera infantil & 570 & 803 & 1.373 \\
\hline Diarrea y enteritis & 1.542 & 4.274 & 5.816 \\
\hline Difteria y crup & 183 & 269 & 452 \\
\hline Disentería & 701 & 759 & 1.460 \\
\hline Eclampsia infantil & 256 & 245 & 501 \\
\hline Escarlatina & 16 & 17 & 33 \\
\hline Fiebre amarilla & 5.864 & 5.787 & 11.651 \\
\hline Fiebre biliosa & 179 & 216 & 395 \\
\hline Fiebre palúdica & 1.372 & 1.637 & 3.009 \\
\hline Fiebre tifoidea & 782 & 997 & 1.779 \\
\hline $\begin{array}{l}\text { Enfermedades del } \\
\text { hígado }\end{array}$ & - & 1.229 & 1.229 \\
\hline Meningitis & 1.445 & 1.532 & 2.977 \\
\hline Muermo o farcino & 26 & 60 & 86 \\
\hline Muerte repentina & 264 & 308 & 572 \\
\hline $\begin{array}{ll}\text { Neumonía } & \text { y } \\
\text { bronquitis }\end{array}$ & 1.338 & 1.510 & 2.848 \\
\hline Parto y accidentes & 139 & 102 & 241 \\
\hline Rabia & 8 & 6 & 14 \\
\hline Sarampión & 64 & 45 & 109 \\
\hline Tétano en adultos & 227 & 229 & 456 \\
\hline Tétano infantil & 1.941 & 1.882 & 3.823 \\
\hline Tisis & 7.401 & 8.504 & 15.905 \\
\hline Viruelas & 1.864 & 2.997 & 4.861 \\
\hline Tos ferina & 28 & 51 & 79 \\
\hline Pénfigo & - & 11 & 11 \\
\hline Muerte por el rayo & 3 & - & 3 \\
\hline Longevidad & 69 & 118 & 187 \\
\hline Otras causas & 15.594 & 12.864 & 28.458 \\
\hline Sumas & 41.901 & 46.485 & 88.386 \\
\hline
\end{tabular}

Elaboración propia a partir de la información disponible en: Ambrosio González del Valle, Tablas obituarias, Establecimiento Tipográfico de la Viuda de Soler, La Habana, 1882.

La tesis de que la raza blanca no se aclimataba en suelo cubano se sustentó fundamentalmente en consideraciones que tomaban en cuenta la mortalidad ocurrida entre españoles peninsulares, inmigrantes europeos recién llegados, la tropa y marinería, y una gran población flotante en las principales ciudades. Entre 1870 y 1899, la proporción de defunciones causadas por la fiebre amarilla en La Habana fue de 4\%o, en tanto que, durante ese mismo período, la mortalidad general fue de 42\%o. Esta 
enfermedad atacó de forma casi exclusiva a los extranjeros y particularmente a los militares, cuya presencia en la isla se incrementó notablemente a partir de la década de $1830 .^{22}$ El mayor número de muertes por esta causa se produjo entre los meses de junio y septiembre, aproximadamente el $70 \%$ de todas las registradas durante el último tercio del siglo XIX en La Habana. ${ }^{23}$

En medio de la Guerra de los Diez Años (1868 y 1878) la fiebre amarilla determinó una sobremortalidad considerable en la población masculina blanca. Realidad que explica la importancia que el estudio de esta afección alcanzó en la segunda mitad del siglo. Las temperaturas más elevadas en la época estival también aumentaron notablemente la morbilidad por otras enfermedades como el paludismo y las afecciones gastrointestinales. Para reducir la mortalidad en sus tropas, los ingleses, con posesiones coloniales en gran parte del globo, las hacían pasar sucesiva y gradualmente de Inglaterra a sus territorios en el Mediterráneo, después a la isla de Francia - Mauricio, posesión de Francia hasta 1810 cuando pasó a ser dominio británico -, y posteriormente a las Indias. ${ }^{24}$ Una estrategia similar fue defendida por Ramón Hernández Poggio, socio corresponsal de las Academias de Ciencias Médicas de Madrid y La Habana, en una publicación de $1874 .^{25}$

El efecto negativo del clima sobre la salud de la población de la isla no era la base explicativa de la organización de la agricultura tropical con fines comerciales, entiéndase el desarrollo de grandes plantaciones destinadas a la producción para el mercado mundial, sino más bien un efecto de esta. Si el colono europeo blanco no convenía para el trabajo en las plantaciones, no era por su incapacidad fisiológica para el trabajo, sino por el tipo de transformación económica operada en el campo cubano. En efecto, la relación entre naturaleza y sociedad es fundamental para el análisis en cuestión, ya que los factores ambientales no operan en abstracto, sino en condiciones socioeconómicas específicas. Existen marcadas diferencias entre las exigencias del trabajo en los sitios de labor o cultivos menores y el trabajo en las grandes plantaciones

\footnotetext{
${ }^{22}$ Cesar R. Yañez Gallardo, "La última invasión armada. Los contingentes militares españoles a las guerras de Cuba, siglo XIX", Revista de Indias, vol. LII, N. 194, 1992, pp. 107-127.

${ }^{23}$ Censo de la República de Cuba 1907, Oficina del Censo, Washington, 1908, pp. 165-166. Ver también: Carlos M. Trelles, Estadística de mortalidad por fiebre amarilla en la isla de Cuba en la segunda mitad del siglo XIX, Montalvo, Cárdenas \& Co., La Habana, 1922.

24 "Aclimatación", en: Francisco de P. Mellado, Enciclopedia Moderna, Establecimiento Tipográfico de Mellado, Madrid, 1851, t. I, p. 340.

${ }^{25}$ Ramón Hernández Poggio, Aclimatación e higiene de los europeos en Cuba, Imprenta de la Revista Médica, Cádiz, 1874. Ver también: Diego Tamayo, Inmunidad Morbosa. Tesis para el doctorado, Imprenta y Encuadernación de F. Xiqués, La Habana, 1899.
} 
azucareras de mediados del siglo XIX. En el citado trabajo del Conde de Pozos Dulces, este argumentó que no eran brazos lo que necesitaba la agricultura cubana, beneficiada ya con "ochocientos mil trabajadores "de color" que nuestra ambición y nuestra codicia han aclimatado en Cuba", sino reformas. ${ }^{26}$ La organización del trabajo en el ingenio ofrecía pocos estímulos al colono europeo. En cuanto podían, muchos de ellos abandonaron las exigencias de la principal industria rural y derivaron hacia ocupaciones más lucrativas en la ciudad. Esta forma de entender la articulación entre economía y población en la isla, explica una frase concluyente de Moreno Fraginals: "Azúcar y negros crecen paralelo en la isla". ${ }^{27}$ En territorios dominados por el monocultivo azucarero, las posibilidades de encontrar ocupación en tareas menos perjudiciales a la salud eran menores. Asimismo, el dominio azucarero limitó entre las dotaciones de esclavos de los ingenios la capacidad de desarrollar habilidades específicas que le permitieran transitar a ocupaciones más ventajosas.

En un artículo publicado en 1860, Álvaro Reynoso sostuvo que "la familia es una condición en extremo poderosa para aumentar el producto que podemos sacar de la fuerza del esclavo." 28 Contrario a la tesis de una línea de pensamiento dominante, el científico cubano consideró que la existencia de mujeres en la fincas reportaba numerosas ventajas. Según observó, en las dotaciones donde existía un marcado desequilibrio de sexos, las riñas entre los trabajadores eran frecuentes, los negros se fugaban y entre las madres esclavas era notorio el desinterés en la crianza de sus hijos. En cambio, el desarrollo de uniones conyugales en las fincas estimulaba la productividad, mejoraba la disciplina y las prácticas de aseo y alimentación de la dotación. Aunque reconoció que las mujeres estaban expuestas a riesgo de muerte durante la gestación y que las probabilidades de muerte entre los esclavos recién nacidos eran altas, esto podía ser mitigado con una atención más refinada a las esclavas y sus hijos. En algunas fincas, según observó, las esclavas que tenía cierto número de hijos eran dispensadas de todo trabajo. La posibilidad de formar familias cautivas con éxito -entiéndase de su razonamiento, rentables para industria-, dependía de la capacidad de los hacendados o administradores de las fincas para ilustrar a una población "ignorante por naturaleza" sobre los beneficios "de uno de los primeros requisitos del orden social". Al respecto, Reynoso consideró positivo estimular a los

${ }^{26}$ Conde de Pozos Dulces, La cuestión del trabajo agrícola y de la población en la isla de Cuba, p. 10.

${ }^{27}$ Manuel Moreno Fraginals, El ingenio, t. I, p. 46.

${ }^{28}$ Diario de la Marina, Año. 17, Nº. 12, 14 de enero de 1860, p. 2. 
esclavos que habían procreado con la misma mujer determinado número de hijos, entre otras medidas tendentes a favorecer la formación de familias estables entre los esclavos. Reynoso también discutió la "improductividad" de las esclavas embarazadas y recién paridas considerando la posibilidad de aplicarlas en diferentes tareas menos exigentes, pero igual de necesarias en la rutina de las plantaciones. ${ }^{29}$

La idea de racionalizar el sistema de trabajo esclavo en las plantaciones no es del todo nueva, aunque adquiere particularidades propias en un contexto marcado por la incertidumbre sobre el futuro de la trata y una desaceleración en la entrada de brazos africanos a la isla. Esa preocupación había alentado algunas reformas en los dominios españoles cuando se hizo notorio el colapso de la población nativa, fenómeno que sucedió tempranamente en las Antillas. Entonces, la voluntad metropolitana de optimizar el sistema laboral mediante un trato más patriarcal, tampoco se tradujo en un balance demográfico positivo para la población explotada. La posibilidad de reproducir biológicamente a las dotaciones de esclavos pasaba en primer lugar por la existencia de mujeres. ${ }^{30}$ Una parte importante de los plantadores cubanos consideraron más rentable comprar varones robustos que rendían inmediatamente mayores beneficios en las faenas del azúcar, ${ }^{31}$ ello a pesar de que conocían la experiencia demográfica de las Antillas británicas y francesas. Desde la óptica de los plantadores y la administración colonial, el cese de la trata planteó un problema esencialmente laboral, no en otro sentido importó para ellos la reproducción de la población africana en la isla. Ahora bien, para el sujeto sometido y sus descendientes, lo primario no era la rentabilidad de la industria o la reproducción de las relaciones sociales que coartaban sus vidas. En tal sentido, la mortalidad esclava posee una dimensión sociocultural marginada de la mayoría de los análisis historiográficos realizados hasta el momento.

\section{FAMILIA ESCLAVA Y MORTALIDAD}

Un estudio de la reproducción social de la estructura agraria en el contexto estudiado no debe prescindir de algunas reflexiones sobre la familia esclava. Entre uno y otro aspecto existe una relación dinámica. Siendo la familia la unidad básica de la

\footnotetext{
${ }^{29}$ Ídem.

${ }^{30}$ Expediente General de Esclavitud. Proyecto de aumentar la mano de obra por medio de la reproducción natural, AHN, Ultramar, Leg. 3549, N . 4, 1855.

${ }^{31}$ Magnus Mörner, ""Comprar o Criar": Fuentes alternativas de suministro de esclavos en las sociedades plantacionistas del Nuevo Mundo", Revista de Historia de América, N. 91, enerojunio, 1981, pp. 37-81.
} 
organización social, su funcionamiento es fundamental para comprender la forma en la que interactúa con los componentes macro estructurales.

Desde las publicaciones pioneras de W. E. Burghardt Du Bois y E. Franklin Frazier, ${ }^{32}$ el debate sobre como la esclavitud afectó la estructura familiar de la población negra en Estados Unidos ha sido prolífero. Las posiciones al respecto han sido divergentes. En 1965, el sociólogo Daniel Patrick Moynihan publicó un influyente estudio en el que resumió los argumentos de Du Bois y Frazier sobre el impacto negativo de la esclavitud en la familia afroamericana. Moynihan argumentó que "en el corazón del deterioro del tejido de la sociedad negra está el deterioro de la familia negra", fenómeno históricamente arraigado en la esclavitud. Entre otras cosas, la esclavitud estropeó la organización familiar madre-padre, sustituyéndola por la familia madre-hijo. Un patrón que se prolongó a lo largo del siglo XX. ${ }^{33}$

Los argumentos en esta línea fueron rebatidos por nuevos estudios revisionistas sobre la esclavitud y la familia negra en norteamericana, como el polémico trabajo de Robert W. Fogel y Stanley L. Engerman o el más enjundioso de Herbert G. Gutman. Gutman argumentó, en contra de la hipótesis sostenida por Moynihan, que la esclavitud no había afectado la estructura familiar negra. ${ }^{34}$ En esta línea, Robert L. Griswold argumentó, en un trabajo sobre la paternidad en Estados Unidos, que durante la esclavitud "los matrimonios eran notablemente estables" y "la gran mayoría de las familias esclavas estaban encabezadas por dos padres". ${ }^{35}$ De acuerdo con Robert. W. Fogel y Stanley L. Engerman, en la economía esclavista norteamericana el desarrollo de unidades familiares estables fue un factor fundamental en la distribución de recursos, el mantenimiento de la disciplina y en la reproducción natural de esa población. Por tanto, los plantadores estimularon el matrimonio y sancionaron aquellas actitudes como el adulterio o el divorcio contrarias a la estabilidad de una institución que consideraron parte integral del sistema. ${ }^{36}$

32 W. E. Burghardt Du Bois, The Negro American Family, The Atlanta University Press, Atlanta, 1908. E. Franklin Frazier, The Negro Family in the United States, The University of Chicago Press, Chicago, 1940.

${ }^{33}$ Daniel Patrick Moynihan, The Negro Family: The Case for National Action, Office of Policy Planning and Research, U.S. Department of Labor, Washington, DC, 1965.

${ }^{34}$ Herbert G. Gutman, The Black Family in Slavery and Freedom, 1750-1925, Pantheon Books, Nueva York, 1976. En los años posteriores a esta publicación, aparecieron numerosas reseñas críticas en revistas como The American Historical Review, The History Teacher, Political Science Quarterly y otras.

${ }^{35}$ Robert L. Griswold, Fatherhood in America: A History, Basic Book, Nueva York, 1993.

${ }^{36}$ Robert. W. Fogel y Stanley L. Engerman, Tiempo en la cruz, pp. 109-123. 
Tales argumentos fueron puestos en discusión por nuevas investigaciones. Basado en un cuidadoso análisis de los datos censales, el historiador Steven Ruggles sugiere que "la interpretación revisionista necesita ser revisada". Este autor llegó a la conclusión de que la paternidad soltera era dos o tres veces más común entre los afroamericanos que entre los blancos en 1880. Los niños afroamericanos que vivían en zonas rurales eran aproximadamente dos veces más propensos que los niños blancos vecinos a ser criados por una madre soltera. Además, este autor señaló la complejidad de definir el concepto familia bajo las condiciones de esclavitud. El hecho de que un hombre, una mujer y un niño vivan juntos en el momento de ser censados, no significa que constituyan una familia en el sentido socialmente asignado. ${ }^{37}$

Asimismo, James Q. Wilson, que considera sorprendente el hecho de que algunos autores nieguen los efectos negativos de tan brutal sistema de explotación sobre la estructura familiar de la comunidad afroamericana, discute las evidencias de Gutman para cuestionar la importancia otorgada al hombre en su rol de figura paterna y marido. Las posibilidades de que los hombres pudieran desplegar positivamente esas funciones estaban coaptadas por una institución que les sometió a diversos procesos de fractura. Por ejemplo, el padre no tenía ningún derecho de impedir que una venta de esclavos terminara con su unión o les arrancara a sus hijos. Wilson sostiene que, incluso las estadísticas de Gutman revelan que entre el 21 y $28 \%$ de todos los hogares negros que contenían niños estaban encabezados por una madre soltera. En el contexto postesclavista, los datos del censo de 1880 muestran que, en áreas urbanas como Mobile y Richmond, alrededor de un cuarto de todas las familias afroamericanas estaban encabezadas por mujeres. Tanto para Estados Unidos como para Brasil, apunta Wilson, se ha encontrado que en las grandes plantaciones la posibilidad de articular una familia nuclear era mayor que en las más pequeñas. En muchas pequeñas fincas, donde residía una parte considerable de la población esclava, las familias de esta condición estaban encabezadas fundamentalmente por mujeres sin maridos. ${ }^{38}$ De acuerdo con este autor,

\footnotetext{
37 Ver: Steven Ruggles, "The Origins of African-American Family Structure", American Sociological Review, vol. 59, 1994, pp. 136-151; "The Transformation of American Family Structure", American Historical Review, vol. 99, 1994, pp. 103-128; "Marriage, family systems, and economic opportunity in the USA since 1850", en: Susan. M. McHale y otros (eds.), Gender and Couple Relationships, Springer, Heidelberg, 2016, pp. 3-41.

${ }^{38}$ James Q. Wilson, "Slavery and the black family", The Public Interest, $\mathrm{N}^{\circ} .147$, primavera, 2002, pp. 3-23. Este artículo forma parte de un estudio más completo sobre el tema: James Q. Wilson, The Marriage Problem: How Our Culture Has Weakened Families, Harper Collins, Nueva York, 2002.
} 
en varias sociedades americanas con un fuerte legado esclavista, la probabilidad de que los niños negros crecieran en una familia monoparental era alta. ${ }^{39}$

Tales preocupaciones fueron incorporadas tardíamente por la historiografía cubana. Fue en las últimas dos décadas que el estudio de la familia esclava en las plantaciones cubanas ha captado el interés de algunos historiadores, que han valorado la capacidad de los cautivos para, en condiciones difíciles, establecer vínculos familiares y de parentesco. ${ }^{40}$ Algunos indicadores sugieren que en el contexto de la "segunda esclavitud" el esfuerzo de la población cautiva para desarrollar vínculos familiares estables fue mayor que en la época preplantacionista.

En las zonas azucareras, los matrimonios entre esclavos fueron menos frecuentes que en las ciudades, donde un mejor balance entre hombres y mujeres facilitó las relaciones sexuales y la posibilidad de establecer unidades familiares. El trabajo de las mujeres en la ciudad estuvo mejor valorado que en el campo. Por otro lado, las mujeres destinadas a los trabajos en las plantaciones azucareras, por lo general no tenían de las ventajas al alcance en el mundo urbano. De acuerdo con los datos del censo de 1846, en las poblaciones de los tres departamentos en los que estaba divida la isla, la proporción entre mujeres y hombres en edad productiva estaba en favor de las primeras. ${ }^{41}$ En esa fecha, se registraron unos 11.069 esclavos y 29.290 esclavas empleados en servicios domésticos. Considerando el crecido número de mujeres en edad productiva existente en las ciudades, las autoridades coloniales promovieron una política de reorganización de la fuerza laboral disponible, incentivando el flujo de mujeres cautivas hacia la producción agrícola. De este modo se intentó además regular demográficamente esos espacios, disminuyendo una tasa de masculinidad en las zonas azucareras que consideraron una amenaza para el sistema esclavista. ${ }^{42}$

\footnotetext{
${ }^{39}$ James Q. Wilson, "Slavery and the black family", pp. 3-23.

${ }^{40}$ Sobre la familia esclava en Cuba, ver: Verena Stolcke, "La influencia de la esclavitud en la estructura doméstica y la familia en Jamaica, Cuba y Brasil", Desacatos, N ${ }^{\circ}$. 13, invierno, 2003, pp. 134-151. María del Carmen Barcia, La otra familia. Parientes, redes y descendencia de los esclavos en Cuba. Aisnara Perera Díaz y María de los Ángeles Meriño, Esclavitud, familia y parroquia en Cuba: Otra mirada desde la microhistoria, Editorial Oriente, Santiago de Cuba, 2006.

${ }^{41}$ Las edades comprendidas en este registro estadístico son de 14 a 60 años para las hembras y de 16 a 60 años para los varones. Cuadro estadístico de la siempre fiel isla de Cuba correspondiente al año de 1846, Imprenta del Gobierno, La Habana, 1847, p. 28.

${ }^{42} \mathrm{La}$ importancia que la familia podía tener en la disciplina, productividad y reproducción de los esclavos de plantación fue advertida por varios contemporáneos, entre ellos Álvaro Reynoso, como pudimos leer en el artículo suyo previamente citado.
} 
Según las categorías censales de la época, en 1846 solo el 10,7\% de los morenos y el $6,6 \%$ de los pardos esclavos estaban casados. Los de igual estado civil entre los morenos libres representaban el 14,3\% y entre los pardos de igual condición el 13,4\%. La proporción de casados era significativamente superior entre los blancos, 23,2\%. Para los morenos esclavos, el Departamento Occidental presentó el mejor índice de matrimonios, mientras que para los pardos de igual condición el casamiento era más viable en el Departamento Oriental. No obstante, en ninguna otra época de la "segunda esclavitud" la unión conyugal entre la población cautiva de la isla alcanzó mejor coeficiente. De acuerdo con María del Carmen Barcia, tal fenómeno pudo estar determinado por los acontecimientos que entonces influyeron en las observaciones de los hacendados y las autoridades coloniales sobre el manejo y control de las negradas, como las persistente presión de Inglaterra contra la trata ilegal, las revueltas de esclavos en la isla y la creciente expectativa en la reproducción natural de la fuerza de trabajo. ${ }^{43}$

Hacia 1860, la proporción de esclavos desposados acusó un deterioro de un 2,3\%. No ocurrió lo mismo entre los blancos y los libre "de color", que aumentó en $3,4 \%$ y $6,3 \%$ respectivamente. Entre 1861 y 1869 la proporción de casados en la población cubana aumentó ligeramente del $16,5 \%$ al $18 \% .{ }^{44}$

La exigua proporción de matrimonios entre los cautivos fue unos de los factores considerados por Ramón de la Sagra como determinantes de la escasa multiplicación de esta clase. Tal observación entronca con los planteamientos del demógrafo italiano Massimo Livi Bacci, cuando sugiere que, en los regímenes de alta fecundidad y mortalidad, como lo era la sociedad cubana en cuestión, la velocidad de la disolución del matrimonio por muerte de uno de los conyugues puede conllevar consecuencias demográficas importantes, debido a que ese hecho se produce en gran proporción durante la vida fecunda. El trabajo de este autor pone en valor la importancia que la nupcialidad ha tenido históricamente en los procesos de formación y disolución de la familia y como factor regulador de la natalidad. ${ }^{45}$

La evolución descendente de la tasa de matrimonios entre los esclavos en este contexto no puede explicarse por una marcada desproporción de sexos. Si en 1846 el índice de masculinidad en la población blanca entre 16 y 40 años era 149\%o y en los

\footnotetext{
${ }^{43}$ María del Carmen Barcia, La otra familia. Parientes, redes y descendencia de los esclavos en Cuba, pp. 83-84.

${ }^{44}$ Cálculo realizado con los datos disponibles en: Expediente general de esclavitud, AHN, Ultramar, Leg. 4883, Nº. 2, 1876.

${ }^{45}$ Massimo Livi Bacci, Introducción a la demografía, Ariel, Barcelona, 1993, pp. 193-225.
} 
esclavos $173 \%$, tres lustros más tarde la estructura por edad de la población de la isla refleja un mejor balance de varones y hembras de entre 15 y 50 años en los esclavos que entre los blancos. Ello fue el resultado de una mayor presencia de mujeres africanas en las cargazones de bozales que arribaron a la isla en este período, y, por otra parte, del aumento de una población blanca peninsular compuesta en mayor número por varones adultos. Como se observa en la tabla 6, en 1869 la tasa bruta de nupcialidad entre la población blanca fue muy superior a la del resto de la población. El número de uniones legales entre los esclavos es significativamente bajo, apenas 39\% habitantes de esa condición.

TABLA 6: CUBA. ESTADO CIVIL DE LA POBLACIÓN, 1869.

\begin{tabular}{|c|c|c|c|c|c|}
\hline & Censados & Solteros & Casados & Viudos & $\mathrm{V} / \mathrm{C}$ \\
\hline Blancos & 763.176 & $710 \%$ & $250 \%$ & $39 \%$ & $157 \%$ \\
\hline Libres "de color" & 238.927 & $789 \%$ & $169 \%$ & $42 \%$ & $248 \%$ \\
\hline Esclavos & 363.288 & $943 \%$ & $39 \%$ & $19 \%$ & $456 \%$ \\
\hline Total & 1.365 .391 & $786 \%$ & $180 \%$ & $34 \%$ & $189 \%$ \\
\hline
\end{tabular}

(V/C) Proporción de viudos sobre casados. No contemplamos la existencia de 34.420 asiáticos. Elaboración propia a partir de la información disponible en: Expediente general de esclavitud, AHN, Ultramar, Leg. 4883, No. 2, 1876.

En la población de ascendencia africana el desarrollo de vínculos familiares y redes de parentesco fue fundamental para la supervivencia. Por ejemplo, el cuidado de menores, el apoyo recíproco y la transferencia de recursos, fueron aspectos más habituales entre esclavos unidos por vínculos familiares o de parentesco. ${ }^{46}$ En nuestro estudio, ponemos el énfasis en los posibles efectos de la mortalidad esclava en la estabilidad de las redes familiares que pudieron articular. Ello implica no solo preocupaciones estrictamente demográficas, sino además una reflexión sobre las consecuencias afectivas y sociales derivadas de los procesos de enfermedad y muerte que la población esclava debió enfrentar con regularidad. Con este fin, hemos utilizado la proporción de viudos sobre casados como indicador de la desventaja de la población esclava para mantener, digamos con vida, su matrimonio. En efecto, el matrimonio tiene una duración que, en la sociedad cubana decimonónica estuvo determinado fundamentalmente por la muerte de uno de los conyugues. Las implicaciones de ese hecho fueron importantes para la estabilidad familiar.

\footnotetext{
${ }^{46}$ Ver: Nancy Boyd-Franklin, "Black Family Life-Styles: A Lesson in Survival", en: Amy Swerdlow y Hanna Lessinger (eds.), Class, Race, and Sex: The Dynamics of Control, Barnard College Women's Center, Boston, 1983, pp. 198-199.
} 
Mientras en la población blanca la proporción de viudos entre 1846 y 1860 descendió en un 2,2\%, entre la población "de color" libre aumentó en $0,9 \%$ y entre los esclavos descendió discretamente en $0,1 \% .{ }^{47}$ Como se observa en la tabla 6, en 1869 la proporción de viudos sobre casados en la población esclava casi duplicó a la de la población "de color" libre y triplicó a la de la blanca. Aunque este cálculo es aproximativo de la magnitud en la que la mortalidad impacto la unión conyugal y la familia, ya que no contempla la existencia de un importante número de uniones consensuales, no deja de ser indicativo de la menor capacidad de supervivencia de la población esclava. Asimismo, algunas evidencias sugieren que la disolución del matrimonio entre esclavos por muerte de unos de los conyugues fue más probable en las plantaciones azucareras que en las ciudades.

La existencia de una mayor proporción de viudas que viudas se puede explicar por el hecho de que, por lo general, el marido es de mayor edad que la mujer y, por tanto, mueren un mayor número de ellos al año. También por el hecho de que para los viudos la posibilidad de volver a contraer matrimonios es mayor $\mathrm{y}$, al hacerlo, eligen con preferencia a una mujer soltera que a una viuda. Tal fenómeno refleja el dominio de una mentalidad colectiva en la que el segundo matrimonio de un hombre estaba mejor visto que el de una mujer. De ahí también que, como norma, la proporción de viudas entre las defunciones sean mayores en los años analizados.

El indicador que hemos estado utilizando podría distorsionar nuestra hipótesis si muchos de los matrimonios fueran de tipo interracial. La Pragmática Sanción para evitar el abuso de contraer matrimonios desiguales, aprobada por Carlos III en 1776, y que como se indica en su título, estuvo encaminada a regular y restringir la libertad de matrimonio, sometiendo, en principio, a consentimiento paterno la elección conyugal de los sujetos blancos menores de veinticinco años. Esta normativa se hizo extensiva a los dominios de ultramar en 1778 y fue modificada varias veces en los próximos años, hasta derivar en la Real Cédula sobre matrimonios de hijos de familias de 1803, que amplió el control matrimonial sobre la gente "de color".

La posición de las autoridades coloniales en este asunto quedó plasmada también en el artículo 44 del Reglamento de Pedáneos, expedido por el Capitán General de la Isla Gerónimo Valdés en 1842. No fue hasta principios de 1881 que el Ministerio de

\footnotetext{
${ }^{47}$ Ramón de la Sagra, Cuba en 1860, p. 19.
} 
Ultramar promulgó una cédula que otorgó libertad de matrimonio entre razas. ${ }^{48}$ Lo que a nuestro análisis conviene, es que en la práctica el tipo de enlace más habitual fue isogámico, o sea, entre personas de igual condición, con el objetivo de reproducir las jerarquías propias del orden social dominante. De modo que, cuando hablamos de viudos o viudas afrodescendientes, asumimos que esa condición es, por lo general, resultado de la muerte de personas pertenecientes al mismo marcador racial.

TABLA 7: CUBA. MORTALIDAD POR RAZA Y ESTADO CIVIL, 1879.

\begin{tabular}{|l|r|r|r|r|r|r|}
\hline & \multicolumn{3}{|c|}{ Blancos } & \multicolumn{3}{|c|}{ "De color" } \\
\hline & Solteros & Casados & Viudos & Solteros & \multicolumn{1}{c|}{ Casados } & \multicolumn{1}{l|}{ Viudos } \\
\hline 20 a 30 & 2.905 & 496 & 47 & 1.255 & 54 & 10 \\
\hline 30 a 40 & 1.912 & 858 & 166 & 1.447 & 57 & 60 \\
\hline 40 a 50 & 1.045 & 778 & 255 & 1.201 & 73 & 41 \\
\hline 50 a 60 & 583 & 559 & 319 & 1.179 & 87 & 41 \\
\hline 60 a 70 & 413 & 415 & 414 & 892 & 54 & 73 \\
\hline 70 a 80 & 221 & 196 & 331 & 547 & 53 & 74 \\
\hline 80 a 90 & 92 & 71 & 174 & 388 & 28 & 37 \\
\hline 90 a 100 & 28 & 25 & 58 & 166 & 10 & 8 \\
\hline Más de 100 & 12 & 4 & 17 & 57 & 2 & 5 \\
\hline & 7.211 & 3.402 & 1.781 & 7.132 & 418 & 349 \\
\hline
\end{tabular}

Elaboración propia a partir de la información disponible en: Dirección General de Hacienda, Población. Estudios estadístico-demográficos correspondientes a 1879.

Como se observa, la tasa de mortalidad de viudos sobre casados en la población afrodescendiente es superior a la blanca en la etapa comprendida entre los 20 y los 50 años. En 1879, para la población mayor de 20 años, la tasa de mortalidad de viudos sobre casados entre los blancos fue de 524\%, mientras que para la gente "de color" fue de 834\%o. Por cada mil defunciones de esclavos registradas en 1879, 988 correspondieron a solteros, 9 a casados y 3 a viudos. Entre los libres "de color" esa proporción fue de 948, 34 y 26; mientras que para la población blanca fue de 782, 144 y 74. Téngase en cuenta que entre los solteros se incluye a la población infantil, que aportó un número considerable de defunciones. ${ }^{49}$

\footnotetext{
${ }^{48}$ Sobre el tema, ver: Verena Stolcke, Racismo y sexualidad en la Cuba colonial, Alianza Editorial, Madrid, 1992. Leidy Abreu García, "Matrimonio interracial. Legislación, familia y disenso en La Habana colonial (1776- 1881)", Perfiles de la Cultura Cubana, enero-abril, 2008, consultado en http://www.perfiles.cult.cu/article.php?article $\mathrm{id}=257,15$ de agosto de 2017.

${ }^{49}$ Ese año fueron enterrados 35 esclavos casados y 11 viudos de la misma condición, diez de estos últimos eran mujeres. De acuerdo a lo estipulado en la Ley Moret de 1870, no se contabilizan como esclavos los mayores de 60 años. Dirección General de Hacienda, Población. Estudios estadístico-demográficos correspondientes a 1879.
} 


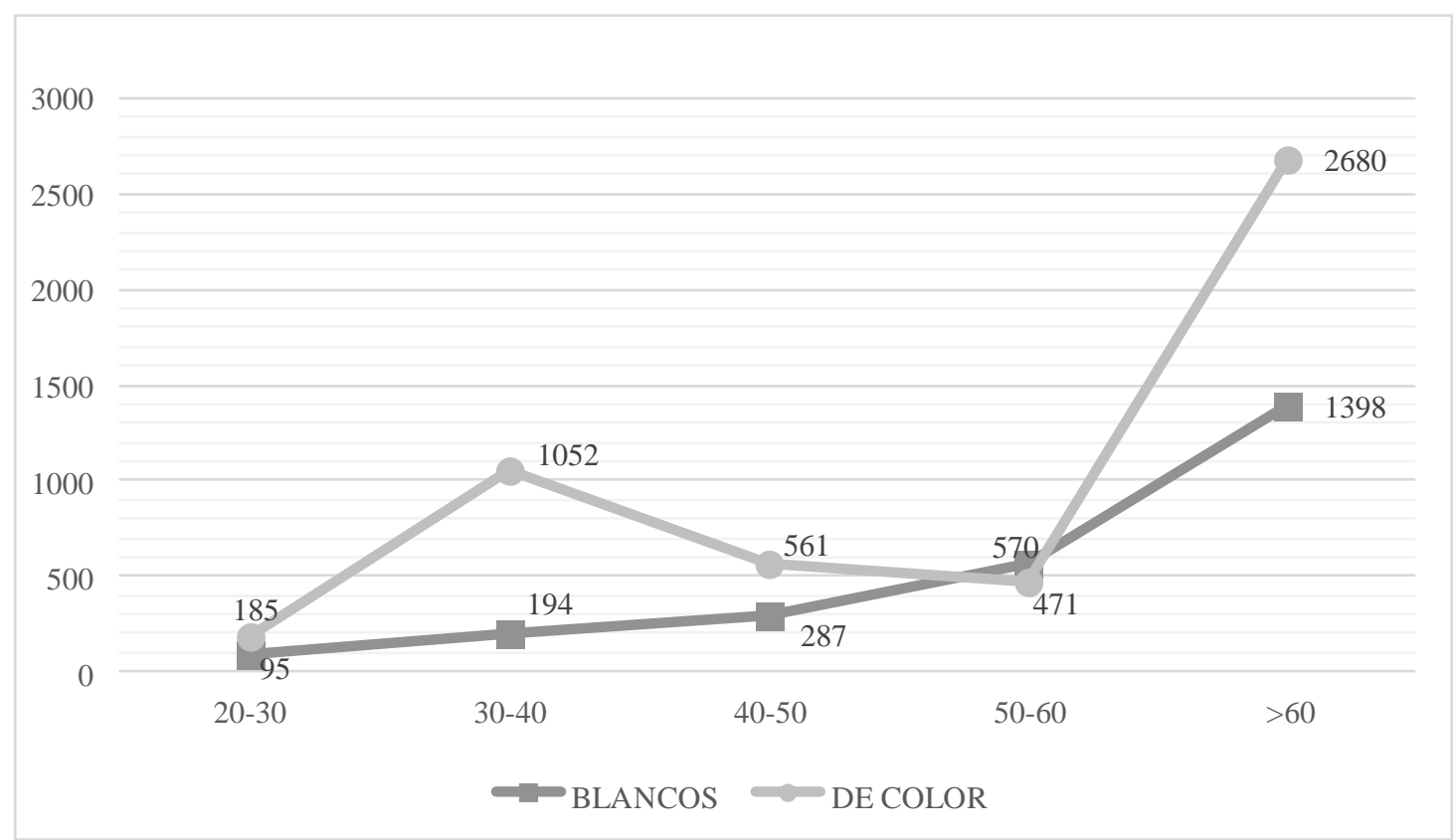

Elaboración propia a partir de la información disponible en: Dirección General de Hacienda, Población. Estudios estadístico-demográficos correspondientes a 1879.

Varios estudios epidemiológicos han destacado la importancia de los vínculos sociales y familiares para la salud de las personas. ${ }^{50}$ La muerte de un miembro de la familia -ya sea conyugue, hijo, padre o hermano- puede afectar la salud física y mental y aumentar el riesgo de muerte en el familiar -o familiares- superviviente. ${ }^{51}$ La alta proporción de viudas y viudos existentes entre la gente "de color", y específicamente entre los esclavos, confirma que, durante el curso de la vida matrimonial, la probabilidad de que uno de sus miembros falleciera era significativamente mayor que entre los blancos, con los efectos negativos que tal fenómeno podía acarrear para las redes familiares y de parentesco conformadas por este grupo.

Como ejemplo de la corta duración de algunos matrimonios en la gente "de color", tenemos el caso de los pardos libres Lucas José de los Dolores Menocal y Prudencia Rosenda de los Ángeles. Ambos contrayentes solteros, fueron desposados el

${ }^{50}$ James S. House, Karl R. Landis y Debra Umberson, "Social Relationships and Health", Science, vol. 241, N $.4865,1988$, pp. 540-545. Peter Franks y otros, "Social relationships and health: The relative roles of family functioning and social support, Social Science and Medicine, vol. 34, No. 7, abril, 1992, pp. 779-788. Bonnie Burman y Gayla Margolin, "Analysis of the association between marital relationships and health problems: An interactional perspective", Psychological Bulletin, vol. 112, No. 1, julio, 1992, pp. 39-63.

${ }^{51}$ Ver: Debra Umberson y otros, "Death of family members as an overlooked source of racial disadvantage in the United States", PNAS, vol. 114, No. 5, 2017, pp. 915-920, consultado en http://www.pnas.org/content/114/5/915.full, 30 de junio de 2017. 
22 de diciembre de 1865 en San Carlos de Matanzas, previa presentación de la competente licencia de conformidad de acuerdo a los dispuesto en el Real decreto del 10 de abril de 1803. El primero, moreno ingenuo natural de San Juan Bautista de Pueblo Nuevo, hijo de María Brígida Menocal y padre no conocido, falleció a principio de junio de 1868, a los 38 años de edad. Prudencia, desde entonces viuda, era hija legítima de los pardos libres José y María del Rosario Martínez. ${ }^{52}$

Otro ejemplo es el de los morenos lucumíes Juan José Balbona y Andrea Alfonso. Ambos de condición libre, contrajeron matrimonio el 23 de diciembre de 1860 en la misma iglesia parroquial, siendo padrinos Jacobo Morales y Florencia Roque. Andrea, en el momento de formalizar su unión con el soltero Balbona, ya era viuda de Pedro Pujadas, natural de África al igual que ella, con el que contrajo matrimonio en la misma parroquia el 7 de diciembre de $1856 .{ }^{53}$ El 21 de agosto de 1868 fue enterrado Juan J. Balbona, a los 60 años, siendo entonces viudo de Andrea Alfonso. No hemos podido identificar el registro de enterramiento de Pedro Pujadas y Andrea Alfonso, que podría ilustrarnos sobre la duración de los vínculos conyugales contraídos. El caso de Andrea Alfonso es también representativo de como la vida de las mujeres de este grupo pudo estar marcada por ciclos alternos de matrimonio y viudez.

Pero algunas no llegaron a vivir los suficiente como para contraer segundas nupcias en una sociedad negada a ese tipo de vínculos entre la gente "de color". La morena Micaela Gómez, procedente de África, vivió lo bastante como para obtener su libertad, pero al ser enterrada del $1^{\text {ro }}$ de mayo de 1868 , a los 40 años, era ya viuda de Antonio Gómez. Situación similar atravesó la criolla esclava Anastasia Cañizares, hija de Genaro y Agustina, ambos de nación carabalí, que fue enterrada el 26 de febrero de 1868, siendo entonces viuda del criollo Martín. A principios de enero del mismo año, falleció en estado de viudez, a los 42 años, la morena Idelfonsa Hernández, esclava de

\footnotetext{
${ }^{52}$ En la partida de matrimonio se refieren a ambos como pardos, pero en la de entierro de Lucas José se registra como moreno ingenuo. Matrimonios de pardos y morenos en la Iglesia Parroquial de San Carlos de Matanzas, libro 5, 1843-1886, en: SSDA, consultado en https://www.slavesocieties.org/. Entierros de pardos y morenos en la Iglesia Parroquial de San Carlos de Matanzas, libro 15, 1867-1875, en: SSDA, consultado en https://www.slavesocieties.org/.

${ }^{53}$ Fueron padrinos de este primer matrimonio, Manuel Piloto y María Alfonso. Tenemos la referencia del entierro de un tal Manuel Piloto, a los 26 años de edad, el 14 de enero de 1867, pero no estamos seguro de que se traté de la misma persona, puesto que hubiese sido padrino de la referida boda con tan solo 15 años. No se indican otras señales de esta persona, solo que era hijo legítimo de Pedro y Paula Campuzano.
} 
Petrona Milian, ${ }^{54}$ propietaria del ingenio San Narciso o Babiney, ubicado en el partido Sabanilla, y de parte del cuerpo de edificios unidos conocido con el nombre de Manzana o Cuadra de Oro, ubicado en la calle del Río, en la ciudad de Matanzas. ${ }^{55}$ Una edificación simbólica del esplendor económico de una urbe desarrollada sobre el quebrantamiento de miles de vidas esclavizadas.

El fenómeno inverso, aunque proporcionalmente menos frecuente, también se observa en los registros parroquiales consultados. La muerte en marzo de 1868 de la morena libre Josefa Pinson, con tan solo 19 años, frustró el que previsiblemente fue un matrimonio de corta duración con el moreno de igual condición Nicolás. Asimismo, ese año se frustró, por muerte de la esposa, el matrimonio contraído por el moreno Felipe Domínguez con la morena conga Ascensión Alvelo, de 50 años. El deceso a los 38 años de María Demetria Núñez, hija de José León y Victoria Manzano, dejó viudo al moreno criollo Francisco Arasan. Algo similar ocurrió con la muerte de Facunda Días a los 40 años, hija de Manuel Días y Cayetana Gama, que unos pocos años antes había contraído matrimonio con Gervasio Roque.

\section{MUERTE NEGRA Y SEPULTURA}

Hasta bien entrado el siglo XIX, los registros parroquiales constituyen una fuente fundamental para la demografía histórica de la isla. Esta documentación contiene información valiosa que no siempre procesaron las publicaciones oficiales. En Cuba, la Iglesia Católica tuvo a su cargo estos registros hasta $1885 .{ }^{56}$ Una parte de esa documentación se ha digitalizado y puesto al servicio de la investigación gracias al proyecto Slave Societies Digital Archive, desarrollado por un equipo dirigido por Jane Landers, historiadora docente en Vanderbilt University. La documentación digitalizada

\footnotetext{
${ }^{54}$ Entierros de pardos y morenos en la Iglesia Parroquial de San Carlos de Matanzas, libro 15, 1867-1875, en: SSDA, consultado en https://www.slavesocieties.org/.

${ }_{55}$ Jacobo de la Pezuela, Diccionario, t. IV, 1866, p. 32. También era propietaria del ingenio Petrona, ubicado en el partido Guamacaro, jurisdicción de Matanzas. Ver: Carlos Rebello, Estados relativos a la producción azucarera de la isla de Cuba, La Habana, 1860, p. 43. El 26 de junio de 1867 Petrona Milian perdió a la esclava Flora, criolla, parda, soltera, de 26 años. Ver anexo.

${ }^{56}$ En enero de 1885 comenzó a regir en Cuba y Puerto Rico la Ley de Registro Civil vigente en la metrópoli desde 1870. La misma dispuso que los registros de nacimientos, matrimonios y defunciones pasaban a ser competencia de los jueces municipales. El Reglamento para su ejecución fue promulgado un año antes. "Reglamento para la ejecución de la Ley del Registro Civil en las Islas de Cuba y Puerto Rico", Gaceta de Madrid, №. 322, 17 de noviembre de 1884, pp. 401-405.
} 
para Cuba incluye registros de bautismos, matrimonios y entierros de pardos morenos correspondientes a parroquias de La Habana y Matanzas, áreas fundamentales de la sociedad esclavista en la mayor de las Antillas. ${ }^{57}$

Hemos trabajado fundamentalmente con los libros de enterramientos correspondientes a la parroquia San Carlos de Matanzas para la década de 1860. Entonces, esa ciudad era, después de La Habana, la segunda más importante de la isla por su riqueza, actividad comercial y población. Con la prudencia pertinente, el examen de esta documentación es fértil para el análisis de la mortalidad esclava. En la mayoría de los casos, las partidas de entierros indican la fecha en la que se realizó, el nombre, la naturalidad, el color de la piel, la condición jurídica, el estado civil y la edad de la persona. El nombre de la madre y el padre es más habitual en el caso de los párvulos. Para los esclavos se indica también el nombre del propietario. Pocas veces revelan la causa de la muerte. En todo caso, respetamos la información de los registros procesados, por lo que la clasificación racial y otras variables fueron contabilizadas solo cuando estas se especifican. Antes de adentramos en el análisis de esa documentación, importa realizar unos comentarios sobre las normativas existentes en el funcionamiento de los cementerios.

Hacia la década de 1840, la urbanización en Matanzas forzó la clausura de un antiguo cementerio construido en los arrabales al occidente de la ciudad -cerca de la plaza llamada de "La Horca", por ser el sitio donde ejecutaban a los reos condenados a muerte-, y se dispuso su traslado a otra parcela más alejada del casco de la población. Francisco J. Ponte informa que, durante la represión desatada por la Conspiración de la Escalera, muchos cuerpos de implicados fueron trasladados en carreta hasta el "Hospital Provisional de los presos enfermos de la conspiración de la Gente de Color", desde donde luego salían cadáveres hacia el cementerio de Matanzas para darles sepultura con la inscripción de "fallecidos de diarrea" ${ }^{58}$ En septiembre de 1872 quedó oficialmente inaugurada la nueva necrópolis de la ciudad, concebida teniendo en cuenta los avances higiénico-sanitarios propios de la época. El nuevo camposanto vino a solucionar el problema de Matanzas con los cementerios desde su fundación, pues esta era la localidad de la isla con mayor número de lugares destinados a ese propósito. Conforme

\footnotetext{
${ }^{57}$ SSDA, consultado en http://www.vanderbilt.edu/esss/.

${ }^{58}$ Francisco J. Ponte y Domínguez, Matanzas. Biografía de una provincia, Imprenta "El siglo XX”, La Habana, 1959, p. 127.
} 
a la reglamentación vigente, se dispuso un apartado para el enterramiento de los que morían fuera de la Comunión Católica. ${ }^{59}$

De acuerdo con las ordenanzas municipales de la ciudad, en vigor desde enero de 1857, los facultativos que asistieren en caso de enfermedad o accidente que resultara en muerte, debían remitir inmediatamente la certificación correspondiente para que se pudiera despachar la papeleta de enterramiento. Cuando se produjese la muerte de una persona sin ser visitada o reconocida por un facultativo, para poder obtener el permiso de enterramiento debía el celador del barrio pasar aviso al médico de semana para que este practicara inmediatamente el debido reconocimiento. Los cadáveres no podían permanecer insepultos por tiempo superior a las 24 horas, exceptuando los casos en los que los facultativos considerasen necesario retardar el entierro. Esto podía suceder en casos de muerte que dieran motivo a investigaciones judiciales. ${ }^{60}$

Sin la licencia del párroco o la orden debidamente visada, no eran admitidos los cadáveres para sepultura. En su defecto, el cuerpo era retenido en la sala mortuoria y se comunicaba el hecho a la autoridad gubernativa. Estas también podían ser avisadas en caso de observar el médico inspector del establecimiento signos en el cuerpo de muerte violenta o de enfermedad especial. El capellán, jefe local del cementerio, era el encargado de recibir los cadáveres y llevar registro de los mismos. Por otra parte, el administrador del cementerio tenía entre sus funciones elaborar la estadística mortuoria y remitirla, acorde al modelo exigido, a la Junta de Sanidad. El médico inspector, en caso de notar un aumento extraordinario de la mortandad por razas, sexos o edades, sospechando de alguna enfermedad contagiosa, debía participarlo inmediatamente a la Junta de Sanidad. La fosa de enterramiento para los epidemiados era un metro más profundo que la dimensión establecida. ${ }^{61}$

Como se observa en la tabla 8, para los 9 años completos entre 1860 y 1868 el promedio anual de bautismos fue de 379, mientras que para los 12 años contabilizados de entierros el promedio fue de 413. O sea, de acuerdo con esta sola fuente, se

\footnotetext{
${ }^{59}$ Ver: Ercilio Vento Canosa, La última morada. Historia de los cementerios de Matanzas, Ediciones Matanzas, Matanzas, 2002.

${ }^{60}$ Disposiciones similares regían en otras ciudades de la isla. Las sanciones establecidas por infracciones al respecto oscilaban entre 3 y 10 pesos. "Ordenanzas municipales de la ciudad de Matanzas, aprobadas el 29 de octubre de 1856 por el gobierno superior civil y puestas en observancia desde el $1^{\text {ro }}$ de enero de 1857", en: Félix Erénchun, Anales de la isla de Cuba, Imprenta "La Antilla", La Habana, 1861, p. 2184.

61 "Reglamento del nuevo cementerio de Matanzas aprobado en 1873", en: Ambrosio González del Valle, Legislación sobre cementerios, Imprenta "La Especial", La Habana, 1894, pp. 105117.
} 
produjeron cada año un promedio de 34 defunciones más que bautismos. Téngase en cuenta que no todos los bautizados fueron nacidos. Como ya hemos indicado, muchos bozales recibieron este rito sacramental a su llegada a Cuba. Asimismo, los entierros de la fuente consultada se refieren solo a los pardos y morenos previamente bautizados. En libro aparte se registraron los entierros de la gente "de color" y los asiáticos que no habían recibido ese acto germinal de relación con Dios.

TABLA 8: BAUTISMOS Y ENTIERROS DE PARDOS Y MORENOS EN LOS REGISTROS DE LA IGLESIA PARROQUIAL DE SAN CARLOS DE MATANZAS, 1860-1870.

\begin{tabular}{|l|r|r|}
\hline & Bautismos & Entierros \\
\hline 1860 & 396 & 355 \\
\hline 1861 & 435 & 602 \\
\hline 1862 & 379 & 305 \\
\hline 1863 & 410 & 293 \\
\hline 1864 & 425 & 353 \\
\hline 1865 & 401 & 295 \\
\hline 1866 & 335 & 456 \\
\hline 1867 & 324 & 412 \\
\hline 1868 & 308 & 503 \\
\hline 1869 & $* 188$ & 314 \\
\hline 1870 & & 656 \\
\hline
\end{tabular}

(*) Contabilizado hasta el 16 de agosto, donde se interrumpe el libro. Elaboración propia a partir de la información disponible en: SSDA, consultado en https://www.slavesocieties.org/.

Sobre esta fuente y fondos del Archivo Histórico Provincial de Matanzas, hemos desagregado la información correspondiente a 2.373 enterramientos registrados en varios lugares de Matanzas entre los años 1850 y 1869. La mayor parte de estos se verificaron en la Iglesia Parroquial de San Carlos de Matanzas, pero también se incluyen otras localidades como Sabanilla, Corral Nuevo, Limonar, Guamacaro, Alacranes, Madruga, Canasí, Cabezas, Bolondrón y Santa Ana.

De los 2.373 enterramientos procesados, 1.258 correspondieron al sexo masculino y 1.115 al femenino. Atendiendo al color de la piel, 702 fueron reconocidos como morenos, 558 como morenas, 178 como pardos, 183 como pardas, 24 chinos, 2 “achinadas", y en 726 casos no se especifica. Esto último sucedió en su gran mayoría en enterramientos de menores de 1 año. De la muestra total, se especifica que 601 eran esclavos, 403 esclavas, 561 libres, 24 chinos contratados y en los restantes 784 casos no se apunta esa condición. También aquí, el déficit de la información es mayor en los 
casos de mortalidad infantil. ${ }^{62}$ Téngase en cuenta además que es posible que no pocos de los que murieron en libertad pudieron haber sido esclavos, hecho incuestionable en los casos de procedencia africana. De acuerdo con la naturalidad declarada, de los 2.373 casos, 509 eran criollos, 598 criollas, 159 congos, 155 gangas, 105 lucumíes, 57 carabalíes, 35 mandingas, 16 minas, 14 macuas, 11 araras, 64 de África sin especificar la etnia, 24 de China, 4 de Puerto Rico, 3 de Florida, 2 de Caracas, 1 Curasao, 1 de Portugal, 1 de Charleston, 1 de Nueva Orleans y 613 casos no se especifica la naturalidad. Atendiendo al estado civil, 477 fueron reconocidos como solteros, 412 solteras, 37 casados, 34 casadas, 15 viudos, 41 viudas, 1.027 personas menores de $15 \mathrm{y}$ en consecuencia solteros -puesto que rara vez se contraía matrimonio antes de esa edad-, y en 330 casos de 15 años o más no se especifica el estado civil. La baja proporción de casados entre los fallecidos se corresponde con la baja tasa de matrimonios en esta población.

\section{GRÁFICO 5: ESTRUCTURA POR GRUPOS DE EDADES DE LOS 2.206 ENTERRAMIENTOS “DE COLOR” PROCESADOS, 1850-1869.}

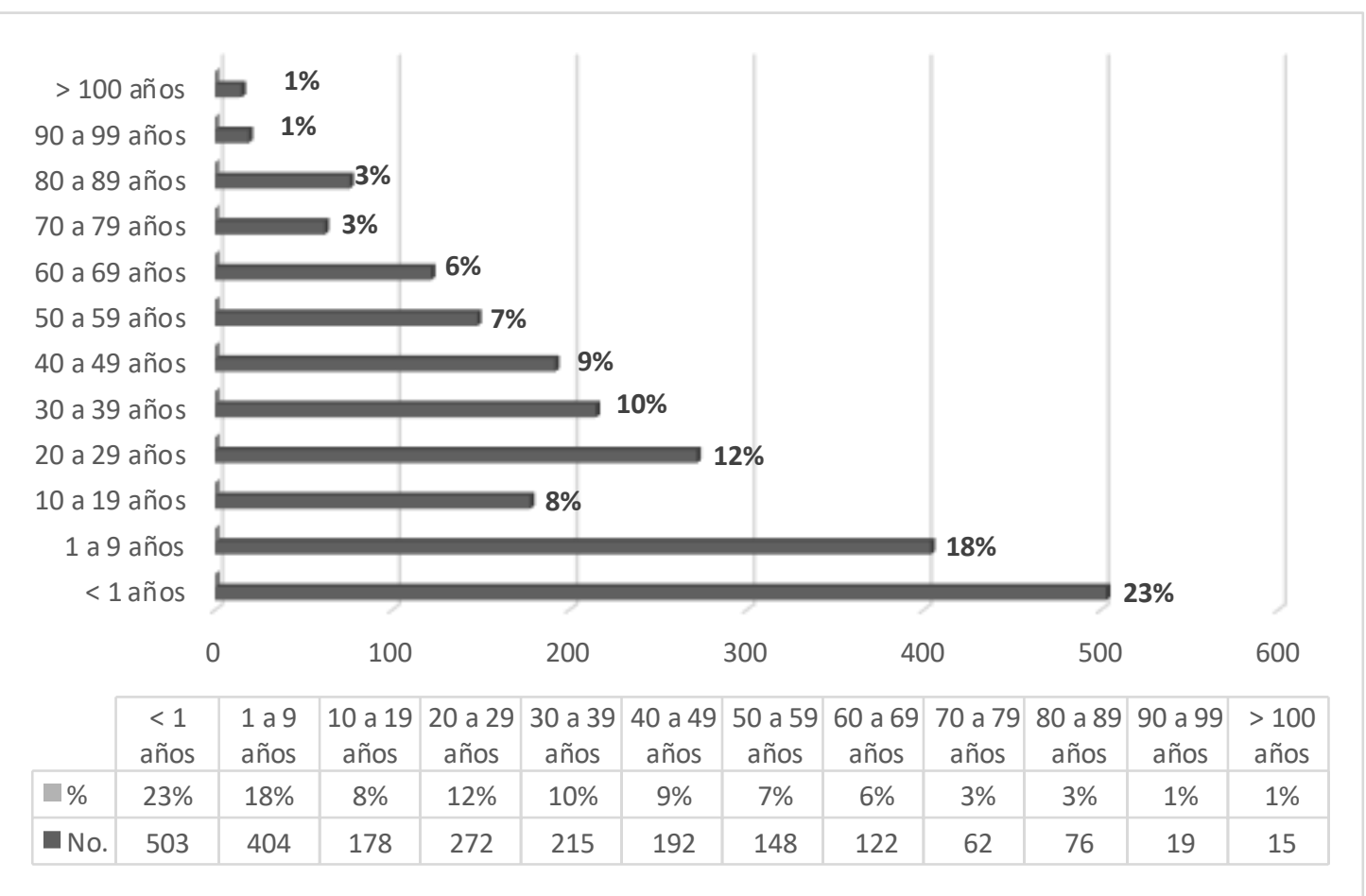

Elaboración propia a partir de la información disponible en: SSDA y Defunciones, Fondo Gobierno Provincial, AHPM.

\footnotetext{
${ }^{62}$ De estos 784 registros, 351 no llegaron al año de vida y 636 eran menores de 14 años. Aunque en no pocos casos se refiere que sus padres, o al menos uno de ellos, eran esclavos, hemos respetado la información directa y explícita sobre la condición del menor que ofrecen las fuentes consultadas.
} 
En el 94\% de los enterramientos procesados, 2.206 casos, se especifica la edad aproximada del fallecido, en 51 casos se advierte que eran párvulos, otros 74 se reconocen como adultos y no se especifica en 42 . Sobre esta base, la edad promedio de los 2.206 enterramientos se sitúa en 25 años. Una tasa tan baja de supervivencia se debió fundamentalmente a la gran mortalidad infantil. El 22,8\% de los enterramientos correspondieron a personas que no sobrevivieron al primer año de vida y poco más del 45\% no cumplió más de 15 años. El hecho es representativo de los patrones de supervivencia de la época, en el que la mortalidad infantil tuvo un peso decisivo. La mortalidad también fue significativa en la población entre los 16 y 59 años, el 42\%. En consecuencia, solo el 13\% de los casos registrados vivieron más de 60 años, siendo los casos más longevos el de Pastor Vidal, moreno de etnia gangá, esclavo, que fue enterrado el 24 de junio de 1864 a los 115 años de edad, y el de Manuela Gómez, parda libre, enterrada el 9 de marzo de 1869 también con 115 años.

Como se observa en los gráficos 6 y 7, la estructura de la mortalidad cambia sensiblemente atendiendo a la condición social. Considerando los 925 casos de esclavos en los que se especifica la edad, la duración promedio se sitúa en torno a los 34 años. Tal aumento respecto a la muestra general se explica fundamentalmente por el hecho de que a través de la trata se introdujo en la isla con preferencia población joven adulta, eliminando así los riesgos de la mortalidad infantil entre la población procedente de África. Por otro lado, y como hemos indicado antes, en un porciento considerable de la mortalidad en menores de un año no se precisó la condición jurídica, y, por tanto, queda excluida de la muestra que ahora analizamos. No obstante, la quinta parte de los esclavos que comprende esta muestra no sobrevivieron a los 15 años y la mortalidad se acentúa considerablemente en la etapa comprendida entre los 20 y los 29 años. Para las esclavas nacidas en la isla, la edad media de los enterramientos registrados se sitúa en los 22,8 años, mientras que para los esclavos de igual naturalidad fue ligeramente superior, 23,6 años. La edad promedio de mortalidad que resulta del análisis de los enterramientos de la población libre "de color" se sitúa en los 32,6 años, poco más de 1 año menos que para toda la población cautiva. Esto se explica esencialmente por un mayor impacto de la mortalidad infantil en este grupo. La tercera parte de los entierros registrados para la población reconocida como libre correspondió a menores de 15 años. Para los asiáticos registrados, la edad media de los enterramientos fue 29 años. 


\section{GRÁFICO 6: ESTRUCTURA POR GRUPOS DE EDADES DE LOS 925 ENTERRAMIENTOS DE ESCLAVOS PROCESADOS, 1850-1869.}

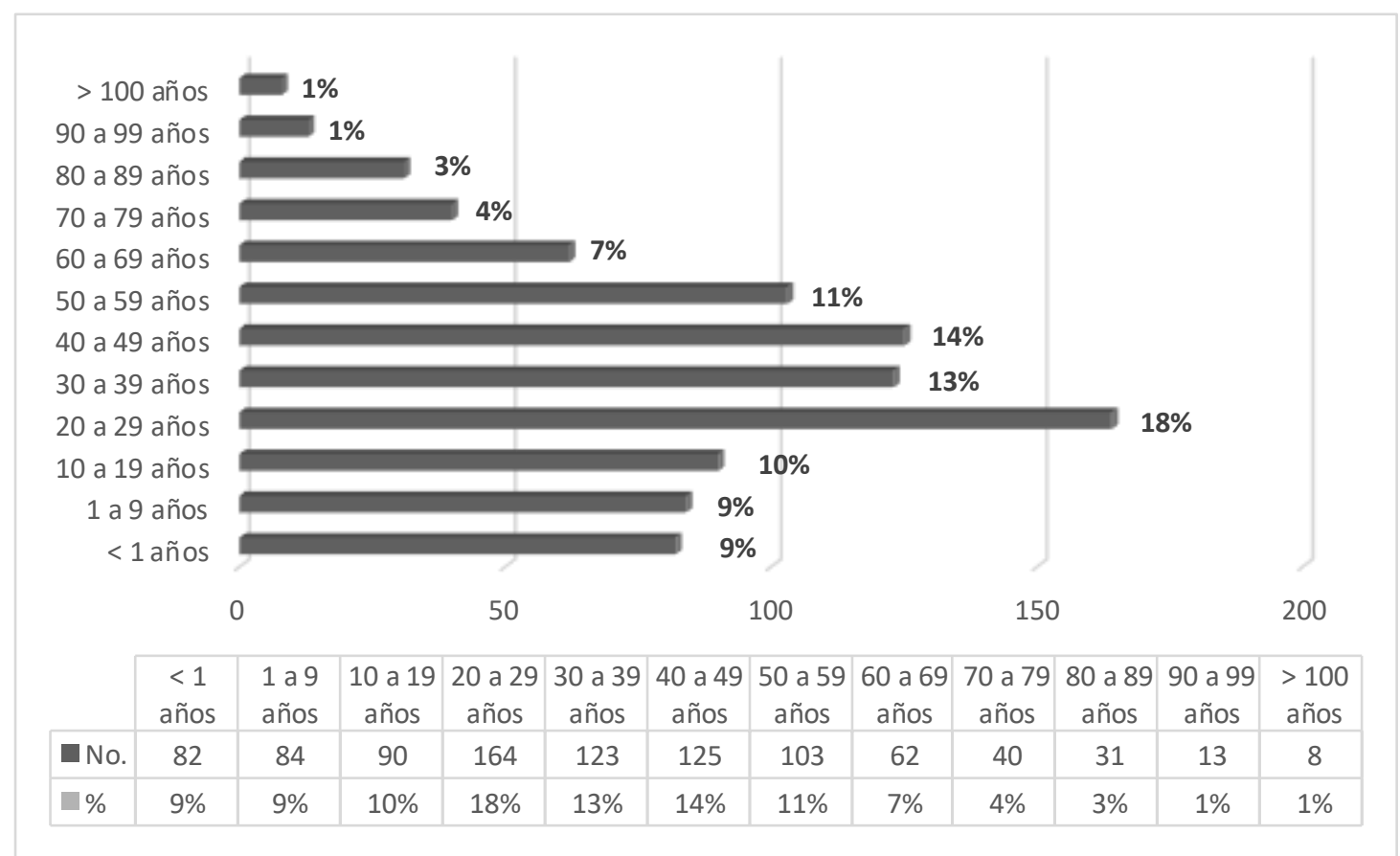

Elaboración propia a partir de la información disponible en: SSDA y Defunciones, Fondo Gobierno Provincial, AHPM.

\section{GRÁFICO 7: ESTRUCTURA COMPARADA DE LOS ENTERRAMIENTOS PROCESADOS ATENDIENDO A LA EDAD Y CONDICIÓN SOCIAL, 1850-1869.}

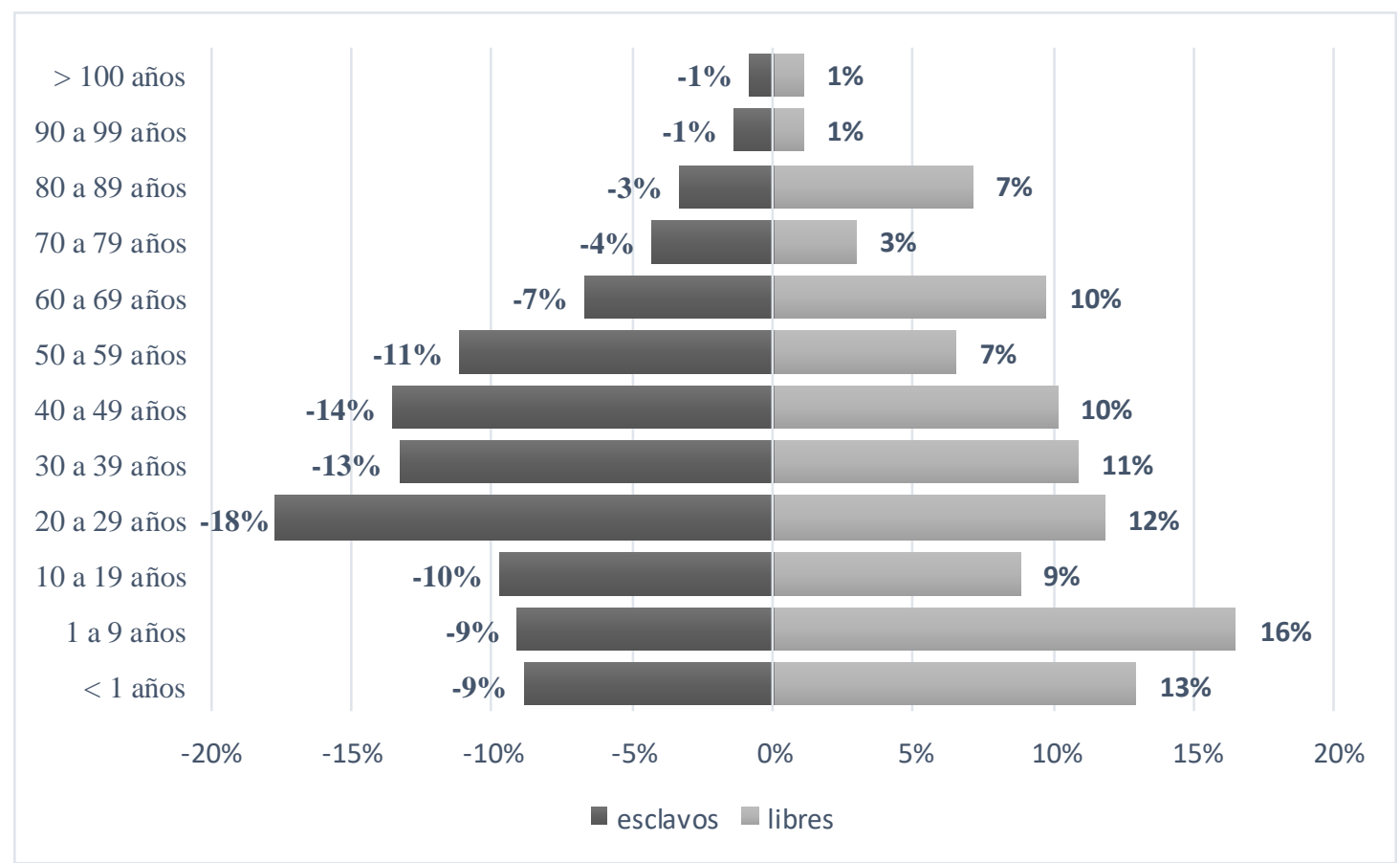

Elaboración propia a partir de la información disponible en: SSDA y Defunciones, Fondo Gobierno Provincial, AHPM. 
De esos esclavos menores de 15 años, solo uno, el moreno Ángel Sampedro, esclavo de Bartolomé R. Sampedro, era procedente de África, tenía entonces 14 años. La baja proporción de enterramiento de niños esclavos, comparado con la de pardos y morenos libres, guarda relación con la tendencia importadora de bozales de los años previos. De acuerdo con las fuentes consultadas, para los esclavos la mortalidad se acentúa en la edad comprendida entre los 20 y los 29 años.

La tabla 9 detalla los registros de mortalidad procesados atendiendo a la clasificación étnica. La mayor proporción de enterramientos de congos, gangás y lucumis en esta parroquia, coincide con la relación de fallecidos en territorios contiguos marcados igualmente por el ciclo demográfico del azúcar. Al respecto, un artículo basado en los registros parroquiales de Cárdenas, refiere que esas fueron las etnias africanas que más muertes tuvieron en el período $1787-1881 .^{63}$

\section{TABLA 9: DISTRIBUCIÓN ÉTNICA DE LOS ENTERRAMIENTOS DE POBLACIÓN DE ORIGEN AFRICANO, 1850-1869.}

\begin{tabular}{|c|c|c|c|c|c|c|}
\hline \multirow[t]{2}{*}{ Etnia } & \multirow[t]{2}{*}{$\mathrm{N}^{\mathrm{o}}$. } & \multicolumn{2}{|c|}{ Sexo } & \multirow{2}{*}{$\begin{array}{l}\text { Edad media } \\
\quad \text { (años) }\end{array}$} & \multicolumn{2}{|c|}{ Condición social** } \\
\hline & & $\mathrm{m}$ & $\mathrm{f}$ & & esclavos & libres \\
\hline Congo & 159 & 109 & 50 & 41 & 145 & 11 \\
\hline Gangá & 155 & 96 & 59 & 54 & 124 & 28 \\
\hline Lucumí & 105 & 69 & 36 & 54 & 70 & 29 \\
\hline Carabalí & 57 & 31 & 26 & 61 & 37 & 17 \\
\hline Mandinga & 35 & 23 & 12 & 60 & 33 & 12 \\
\hline Mina & 16 & 10 & 6 & 61 & 10 & 5 \\
\hline Macua & 14 & 10 & 4 & 45 & 13 & 1 \\
\hline Arará & 11 & 5 & 6 & 48 & 3 & 1 \\
\hline África* & 64 & 35 & 29 & 53 & 23 & 37 \\
\hline Suma & 616 & 388 & 228 & 51 & 458 & 141 \\
\hline
\end{tabular}

(*) No se especifica la etnia, ni zona de procedencia. (**) Condición social en el momento del deceso, ya que, presumiblemente, todos fueron en principio esclavos. En 17 casos no se especifica esta variable. Elaboración propia a partir de la información disponible en: SSDA y Defunciones, Fondo Gobierno Provincial, AHPM.

De los 616 casos en los que especifica que son de naturalidad africana, 388 eran varones y 228 hembras. Tal proporción está en correspondencia con la tendencia importadora mediante la trata atlántica. La edad media de los enterramientos de esta

63 Mabel E. Valdés, Comportamiento sociocultural de los esclavos africanos y sus descendientes en la región de Cárdenas (1800 - 1880), CD de Monografías, Universidad de Matanzas, 2011 , consultado en http://monografias.umcc.cu/monos/2011/FUM\%20CARDENAS/mo11sc27.pdf. Se extraña en este artículo un mayor rigor metodológico, que hubiese hecho más provechosa la información de la que se vale. 
muestra es de 51 años. Solo el $23 \%$ de esta población de origen africano alcanzó la libertad antes de morir. Los congos presentaron la edad media de enterramiento más baja y los carabalí la más alta. Entre uno y otro grupo la diferencia es de 20 años en favor de los de la costa de Calabar. La explicación a tan significativa diferencia requiere un conocimiento más profundo de la estructura demográfica del mercado de brazos en las costas africanas. Pese a los significativos avances de las últimas décadas en el estudio de la trata transatlántica, es deficiente la información sobre las edades de los esclavos importados atendiendo a su origen étnico. De modo que, no podemos precisar si esta desventaja fue resultado neto del funcionamiento de la esclavitud en la isla.

Además, la edad de los bozales muchas veces era asignada a su arribo a los mercados americanos luego de un examen físico, con alguna seguridad ajustado a los intereses del propio mercado. En los registros parroquiales, cuando se procede al bautismo de africanos adultos, la edad estimada se expresa de forma recurrente a través de la fórmula gramatical como de $x$ años. Los ejemplos de bautismos de africanos adultos fueron frecuentes en los libros parroquiales consultados. Tal fue el caso de los morenos de nación lucumí Emeterio, Teodoro, Fernando, Venancio, Eduardo, Eusebio, Demetrio, Nemecio, Julio y Evaristo, todos adultos propiedad de Francisco Bon, que fueron bautizados el viernes 6 de mayo de 1830. Asimismo, los morenos arará Ricardo y Pedro, como de 30 y 16 años respectivamente, ambos propiedad de Tomás F. Fales, quien legó a aquellos su apellido como era costumbre, fueron bautizados el domingo 2 de febrero de 1845, siendo en ambos casos el padrino Luis criollo. A la misma ceremonia fue presentada la párvula de cuatro años de edad Rosario Fales, esclava del mismo propietario y de padres no conocidos, siendo su madrina Rosalía gangá. Un mes después, fue bautizado por el mismo propietario otro moreno de nación gangá, llamado Ricardo Fales, como de 30 años de edad, siendo su padrino Bernardo Fales. Otro ejemplo fue el de los morenos adultos procedentes de África, Cristóbal, León y Rafael, esclavos de Manuel Arias. En estos casos solo se dice la edad de Cristóbal, como de 22 años, y no se indica la región de África de la que proceden.

Es frecuente que los registros de bautismos de personas pertenecientes al mismo propietario sean consecutivos, lo que indica que estos aprovecharan un mismo día para efectuar el correspondiente sacramento. La frecuencia con la que se realizaban ceremonias conjuntas para personas adultas o párvulos nacidos en otros años, hace en extremo complicado analizar el movimiento natural de esta población en un año natural. De acuerdo los datos que ofrece un artículo ya citado, que analiza los registros 
parroquiales de Cárdenas, el 58,5\% de 1.633 bautismos contabilizados en esa región entre 1788 y 1868 , correspondieron a sujetos con más de diez años. ${ }^{64}$ Alguno incluso accedió a este sacramento que autorizaba un entierro digno, tan tarde como después de los 65 años, cuando la muerte era, con alguna probabilidad, un suceso inminente.

A través de los registros parroquiales consultados podemos tener una idea de la mortalidad asociada, presumiblemente, a la epidemia de cólera de la década de 1850. Particularmente sensible fueron las perdidas ocurridas en la dotación propiedad de la influyente matancera Guadalupe del Junco Gener. La tabla 10 recoge información de los enterramientos de esclavos realizados en el cementerio provisional de su ingenio y que fueron reportados a la parroquia de la ciudad. El registro de Silverio Junco precisa el nombre del ingenio La Guadalupe. Sobre el mismo no hemos encontrado información. En el informe de Carlos Rebello de 1860, Guadalupe del Junco Gener aparece como propietaria del ingenio San Francisco de Lima, ubicado en el partido Cabezas. ${ }^{65}$ Ignoramos si se trata de la misma propiedad.

TABLA 10: ESCLAVOS FALLECIDOS EN UN INGENIO PROPIEDAD DE GUADALUPE DEL JUNCO GENER EN 1850 Y REGISTRADOS EN LA IGLESIA PARROQUIAL DE SAN CARLOS DE MATANZAS.

\begin{tabular}{|l|l|l|r|r|}
\hline \multicolumn{1}{|c|}{ Nombre } & \multicolumn{1}{|c|}{ Nación } & \multicolumn{1}{|c|}{ Estado civil } & Edad & Fecha de entierro \\
\hline Fausto Junco & mandinga & casado con Andrea carabalí & 50 & $17 / 5 / 1850$ \\
\hline Tania Junco & criolla & - & párvula & $14 / 6 / 1850$ \\
\hline Dolores Junco & gangá & casada con Vidal lucumí & 26 & $15 / 6 / 1850$ \\
\hline Nicolás Junco & lucumí & soltero & 29 & $17 / 6 / 1850$ \\
\hline Adolfo Junco & gangá & soltero & 30 & $18 / 6 / 1850$ \\
\hline Fermín Junco & lucumí & soltero & 35 & $20 / 6 / 1850$ \\
\hline Ramón Junco & gangá & soltero & 30 & $20 / 6 / 1850$ \\
\hline Roque Junco & lucumí & soltero & 34 & $21 / 6 / 1850$ \\
\hline Estanislao Junco & carabalí & soltero & 60 & $21 / 6 / 1850$ \\
\hline Perfecto Junco & gangá & casado con Rosalía carabalí & 50 & $21 / 6 / 1850$ \\
\hline Anselmo Junco & criollo & soltero & - & $21 / 6 / 1850$ \\
\hline Rosario Junco & gangá & - & 35 & $21 / 6 / 1850$ \\
\hline Francisco Junco & lucumí & soltero & 25 & $22 / 6 / 1850$ \\
\hline Martín Junco & gangá & soltero & $22 / 6 / 1850$ \\
\hline Casimira Junco & carabalí & soltera & 25 & 50 \\
\hline
\end{tabular}

${ }^{64}$ Los libros parroquiales de matrimonios de pardos y morenos en Cárdenas abarcan el período 1716 a 1887. Su información revela la multiplicidad de naciones africanas que fueron transportadas allí y el carácter interétnico de no pocos de los matrimonios contraídos. Mabel E. Valdés, Comportamiento sociocultural de los esclavos africanos y sus descendientes en la región de Cárdenas (1800 - 1880).

${ }^{65}$ Carlos Rebello, Estados relativos a la producción azucarera de la isla de Cuba, p. 41. 


\begin{tabular}{|c|c|c|c|c|}
\hline Plácido Junco & lucumí & soltero & 28 & $25 / 6 / 1850$ \\
\hline Ricardo Junco & lucumí & soltero & 35 & $25 / 6 / 1850$ \\
\hline Rita Junco & conga & soltera & 28 & $25 / 6 / 1850$ \\
\hline Leonardo Junco & mandinga & soltero & 26 & $26 / 6 / 1850$ \\
\hline Anastasia Junco & criolla & - & párvula & $26 / 6 / 1850$ \\
\hline José Alfonso* & criollo & - & párvulo & $26 / 6 / 1850$ \\
\hline Simona Alfonso* & criolla & - & párvula & $26 / 6 / 1850$ \\
\hline Carlos Junco & criollo & - & párvulo & $30 / 6 / 1850$ \\
\hline Pedro Junco & congo & soltero & 27 & $30 / 6 / 1850$ \\
\hline Francisco Alfonso* & lucumí & soltero & 35 & $2 / 7 / 1850$ \\
\hline Manuela Alfonso* & & soltera & 40 & $2 / 7 / 1850$ \\
\hline Silverio Junco & gangá & - & - & - \\
\hline Andrés Junco & gangá & casado & 46 & - \\
\hline
\end{tabular}

Los esclavos de apellido Alfonso, aunque fueron enterrados en el cementerio provisional de Guadalupe del Junco, eran propiedad de José Agustín Alfonso. En el caso de Silverio Junco, no se indica la fecha de su enterramiento, pero esta fue reportada el 4 de enero de 1851, casi un mes después que para el resto. Entre el 29 de junio y el 16 de julio de 1850, fueron enterrados en el cementerio provisional del ingenio San Diego, propiedad de los herederos de Manuel del Junco, los esclavos de nación gangá José Dolores, Nepomuceno, German, Carlos y Encarnación, y también la criolla Isabel. No se informó sobre la edad de los mismos.

La mortalidad ocurrida en la referida dotación de Guadalupe del Junco, tuvo consecuencias importantes en las relaciones familiares articuladas por sus esclavos. La muerte de Perfecto gangá puso fin al matrimonio que había contraído con Rosalía carabalí. Estos eran los padres de Cecilia Junco, criolla, que el 10 de abril de 1843 contrajo matrimonio con el moreno Andrés gangá, fallecido a principio de enero de 1851, cuando tenía 46 años. Ruperto y Rosalía fueron los padrinos de bautismo de Josefa del Junco, nacida el 22 de enero de 1845 e hija de Encarnación gangá. En la misma ceremonia de Josefa, fueron bautizados Magdalena, Jacinto y Ana, todos nacidos ese año, hijos de Rosario, Serafina y Mónica, las tres de nación gangá. En ningún caso se registra la identidad de los padres. Mariano congo y Francisca mandinga, Julián carabalí y Francisca mandinga, Víctor gangá y Rosario gangá, fueron los padrinos respectivos en cada caso. Está ultima también falleció en 1850. Las redes familiares de esclavos articuladas en torno a la posesión de Guadalupe del Junco Gener es realmente extensa. Destaca la voluntad de formalizar los vínculos contraídos por sus siervos, así como la existencia de no pocos matrimonios interétnicos. Los datos son representativos 
también de la elevada mortalidad y las cuantiosas pérdidas sufridas por los hacendados cubanos cuando enfrentaron eventos epidémicos. La referida propietaria también perdió en 1868 a Juan criollo, soltero, de 50 años, y a Matías Junco, de 4 años y condición libre.

De acuerdo con los libros de entierros consultados, en solo dos años varios propietarios tuvieron que enfrentar la muerte de varios esclavos. El caso más notable fue el de Pedro Sala, que perdió 8. Francisco Aballí perdió 6 esclavos, José Sala y Félix Soloni 4 cada uno y, Salvador Alcina, la Marquesa de Castell Florit y Pelegrin Fialo, tres cada uno, para no seguir con pérdidas de menor cuantía. En los anexos ofrecemos una lista detallada de los enterramientos de esclavos ocurridos en la Iglesia Parroquial san Carlos de Matanzas en 1867 y 1868. Téngase en cuenta que están registrados solo los 332 casos en los que se precisa tal condición. 


\section{CAPÍTULO III: ESCLAVITUD Y MALNUTRICIÓN ${ }^{1}$}

En este capítulo analizamos las sinergias entre nutrición y salud en las plantaciones azucareras cubanas en el contexto de la "segunda esclavitud". En el último epígrafe nos centramos en el beriberi, una enfermedad carencial con particular incidencia entre la población esclava y afrodescendiente de la isla. Si bien las explicaciones médicas en el siglo XIX se apoyaron fundamentalmente en factores raciales, biológicos y culturales, nos proponemos demostrar que la notable incidencia diferencial del beriberi en Cuba en aquella época no puede explicarse al margen de su correlato socioeconómico: el desarrollo de un régimen agrícola asentado en la especialización azucarera y la explotación del trabajo cautivo. En consecuencia, el argumento central que desarrollamos en nuestro análisis es que la transición demográfica en el siglo XIX, con el desarrollo de la agricultura comercial y la consolidación de las relaciones esclavistas de producción, generaron diferencias notables en los patrones alimentarios de la población residente en la isla. Para reducir la brecha que el reinado del dulce creó entre crecimiento demográfico y disponibilidad de alimentos, las importaciones de subsistencias baratas y duraderas fue la alternativa implementada. De ello resultó la estandarización de una dieta básica, compuesta de unos cuantos víveres económicos y fáciles de conservar, pero monótona y pobre por su calidad nutritiva, fenómeno que tuvo implicaciones directas en la salud de la población empleada en varias plantaciones azucareras del occidente cubano.

Para los historiadores, el análisis de los patrones de alimentación en el pasado y su relación con la salud supone un gran desafío por diversas razones. En primer lugar, la investigación en un campo de conocimiento atravesado por discursos provenientes de la biología, medicina, demografía, y también de la política, la economía y la cultura, requiere un ejercicio de "deconstrucción" del conocimiento histórico tal y como tradicionalmente se ha concebido, abriendo el trabajo a las más diversas fuentes

\footnotetext{
${ }^{1}$ Parte de este capítulo fue publicado en: Reinier Borrego Moreno, "La temible trinidad. Esclavitud, malnutrición y beriberi en Cuba", en: José Antonio Piqueras (ed.), Orden político y gobierno de esclavos, Fundación Instituto de Historia Social, Valencia, 2016, pp. 177-204.
} 
posibles. Por lo general, existen muchas imprecisiones en las fuentes históricas que de manera directa ofrecen información sobre nutrición y enfermedades, y tanto los mecanismos utilizados para evaluar la calidad de la alimentación, como los diagnósticos de la segunda cuestión, han cambiado a través del tiempo.

Más complejo resulta establecer con exactitud, para colectividades humanas del pasado, el potencial nutricional de la dieta regularmente consumida y su incidencia, digamos neta, en la salud. Existe hoy un consenso generalizado sobre la sinergia entre alimentación y mortalidad, pero se han desestimado las explicaciones monocausales, reconociendo que en esa relación influyen diversos factores, ya sea directa o indirectamente. Por otra parte, la documentación conservada es fundamentalmente la producida por los sectores dominantes, y la disponibilidad de fuentes con información directa elaborada por los grupos subalternos de la sociedad es más limitada. De ahí que, a través de los registros oficiales no siempre nos sea posible conocer los usos alimentarios de las capas populares, las redes informales articuladas para intercambiar alimentos, sus actitudes ante la enfermedad, entre otras experiencias de valor para el análisis que proponemos. De igual modo, es menos sistemática la información disponible para los pequeños núcleos de poblaciones aislados de los centros de poder, y en sociedades rurales como la que analizamos, en el conjunto de esos nichos radica una parte importante de la población.

La historiografía contemporánea que de alguna manera se ha interesado por la alimentación de los esclavos en Cuba no profundiza en los efectos que la misma tuvo sobre la morbilidad y mortalidad de ese grupo. Fue Manuel Moreno Fraginals el primero en analizar, desde una concepción moderna, la alimentación de los cautivos como variable de importancia en el complejo azucarero del siglo XIX. Aunque reconoce una primera etapa entre finales del siglo XVIII y la década de 1820 de gran crisis de abastecimiento, sostiene también, que desde esta última fecha se normalizó la alimentación de los esclavos y que los sacarócratas, conscientes de la relación entre nutrición y productividad, garantizaron a su dotación "una comida que cumplía los requerimientos dietéticos, administrativos y aun psicológicos". ${ }^{2}$ También las investigadoras Natalia Bolívar Aróstegui y Carmen González Díaz -sin distinguir etapas en el desarrollo de la economía colonial, ni diferencias en cuanto a los patrones alimentarios de los diferentes estamentos que integraban la sociedad- alegaron que "la

\footnotetext{
${ }^{2}$ Manuel Moreno Fraginals, El Ingenio, t. 2, p. 57.
} 
abundancia y variedad de alimentos disponibles haría que la población de la Isla, sin excluir a la esclava y a la marginal, no padeciera de privaciones". ${ }^{3}$ Afirmaciones discutibles incluso dentro de los parámetros de la época.

En sus trabajos sobre la cultura material en Cuba en la primera mitad del siglo XIX, Ismael Sarmiento Ramírez ha puesto el énfasis en los cambios que el desarrollo de la agricultura comercial imprimió en las prácticas y gustos alimentarios de los diferentes sectores del país. Su enfoque, más cultural que económico, tiene raíces en las investigaciones pioneras de Fernando Ortiz sobre la cocina cubana y en los últimos años también ha sido cultivado por las antropólogas Niurka Núñez y Estrella González. ${ }^{4}$ Un artículo de Javier Laviña analiza los usos alimentarios de los cimarrones cubanos. De acuerdo con los datos que ofrece este autor, el tipo de alimentos consumidos por los cimarrones en la región de Vuelta Abajo fueron básicamente los mismos que se daban a los esclavos en las plantaciones. De hecho, este autor sugiere que la dependencia de los cimarrones cubanos a los suministros de las plantaciones era mayor que en otros países del área, como Surinam; y que en la colonia española existían menos posibilidades para el establecimiento de comunidades campesinas de cimarrones. ${ }^{5}$

Algunas ideas establecidas sobre la disponibilidad de subsistencia en los ingenios cubanos y la alimentación de sus trabajadores adolecen de cierta uniformización, tanto por derivar de indicadores macroeconómicos un consumo hipotético para la totalidad de las plantaciones, como por extrapolar la realidad de una finca determinada al resto del paisaje azucarero cubano. Podemos realizar estimaciones aproximadas con las cifras globales de producción e importaciones, pero sabido es que ellas no reflejan con fidelidad el consumo real per cápita de la población, ya que habría que considerar, entre otras cosas, el volumen neto destinado al consumo humano y efectivamente aprovechado, así como las mediaciones que atraviesan ese consumo.

\footnotetext{
3 Natalia Bolívar Aróstegui y Carmen González Díaz, Mitos y leyendas de la comida afrocubana, Editorial Plaza Mayor, San Juan, 2000, p. 12.

${ }^{4}$ Fernando Ortiz, "La cocina afrocubana", Revista Bimestre Cubana, La Habana, vol. 18, 1923, pp. 409-420. Ismael Sarmiento Ramírez, Cuba: entre la opulencia y la pobreza, S. L. Agualarga Editores, Madrid, 2004. Niurka Núñez González, "Diferencias regionales en las comidas tradicionales de la población rural de Cuba", Revista Cubana de Alimentación y Nutrición, vol. 2, 1995, pp. 79-93. Niurka Núñez González y Estrella González Noriega, "Antecedentes etnohistóricos de la alimentación tradicional de Cuba, Revista Cubana de Alimentación y Nutrición, vol. 13, Nº 2, 1999, pp. 145-150. Niurka Núñez González y Estrella González Noriega, "Algunas transformaciones en las comidas tradicionales de la población rural cubana", Revista Cubana de Alimentación y Nutrición, vol. 15, №. 2, 2001, pp. 139-145.

5 Javier Laviña, "Alimentación y cimarronaje en Vuelta Abajo. Notas sobre el diario del rancheador", Boletín americanista, No .37 , 1987, pp. 203-214.
} 
Por las balanzas comerciales, libros de contabilidad de los ingenios, reglamentos de esclavos $\mathrm{u}$ otras fuentes, conocemos el tipo de alimentos suministrado a los trabajadores, pero un poco más incierta es la cantidad y calidad de los mismos. También se ha dado un crédito exagerado a lo que disponen los reglamentos de esclavos respecto a la alimentación. Téngase en cuenta que la economía esclavista azucarera del siglo XIX llegó a estar formada por más de un millar de unidades agrícolas productivas. En el conjunto de esas plantaciones residía un porciento elevado de la población cubana, pero su dinámica interna, distante y en cierta medida autónoma, no siempre se documentó con la precisión que los poderes de la época demandaron y los historiadores futuros hubiésemos agradecido. Por otro lado, el aprovechamiento historiográfico de las investigaciones realizadas en el transcurso del pasado siglo en el campo de la fisiología y la dietética nos han permitido evaluar con mayor rigor las carencias nutricionales y enfermedades que aquejaron a las poblaciones que vivieron en el pasado.

\section{EL REINO DEL DULCE Y DEL FUNCHE}

El rasgo más destacado de la historia económica de Cuba ha sido el desarrollo de un modelo agroexportador centrado fundamentalmente en la producción azucarera. Introducida en el Nuevo Mundo con las primeras expediciones colombinas, la caña de azúcar impuso en el Caribe insular un modelo económico y demográfico dominante en su etapa colonial. Sobre el suelo cubano su cultivo se intensificó en las primeras décadas del siglo XIX, y con el boom de la agricultura comercial el panorama de la alimentación en la isla sufrió cambios significativos. La ofensiva del azúcar, sobre todo en el occidente del país, se produjo a costa de otros cultivos y la ganadería, transformación que tuvo un impacto negativo a largo plazo en la producción y consumo de frutas, hortalizas, viandas, carne fresca, leche y derivados. En 1860 el azúcar representaba el 68,1\% del valor global de la producción agropecuaria en la región occidental. $^{6}$

\footnotetext{
${ }^{6}$ Instituto de Historia de Cuba, Historia de Cuba: la Colonia, evolución socioeconómica y formación nacional, Editora Política, La Habana, 1998, p. 486. Para un análisis del impacto del despegue azucarero sobre las haciendas ganaderas en Cuba ver: Reinaldo Funes Monzote, "Especialización azucarera y crisis de la ganadería en Cuba, 1790-1868", Historia Agraria, vol. 57, agosto, 2012, pp. 105-134.
} 
La expansión azucarera no solo se tradujo en un dominio extensivo sobre la superficie cubana, sino además en una progresiva concentración de las fuerzas productivas en una actividad económica con un valor superior en el mercado mundial. El historiador Levi Marrero destacó el hecho de que dedicar a los esclavos a la producción de abastecimientos fue considerado "antieconómico" en una coyuntura de intercambio comercial favorable para los hacendados cubanos por el alto precio del azúcar y el café. ${ }^{7}$ Con los beneficios de esas industrias se adquirían gran parte de los víveres destinados al consumo nacional.

Ya en su Ensayo político, Alejandro de Humbolt destacó la gran dependencia de la alimentación insular del mercado externo. ${ }^{8}$ También Ramón de la Sagra señaló hacia finales de la década de 1820 el peso que determinados comestibles como la harina de maíz, el arroz y las carnes habían adquirido en el volumen de las importaciones cubanas, artículos que a su consideración, podían en un futuro figurar más bien en los estados de exportación o, al menos, cubrir en su totalidad el consumo interno mediante el fomento de esas industrias. ${ }^{9}$ Los Estados Unidos figuraban entonces como el principal socio comercial extranjero, y las compras de granos y harinas representaban, con cerca de 3 millones de pesos, el mayor gasto desembolsado por la totalidad de los renglones importados. El valor de las importaciones procedentes de la nación vecina en 1827 superó los 7 millones de pesos, cifra muy por encima de las compras realizadas ese año a Francia e Inglaterra, sus más cercanos competidores extranjeros. ${ }^{10}$ Con el tiempo, las compras cubanas se concentraron aún más en los Estados Unidos, a su vez el principal mercado del dulce cubano. En la década de 1860 las importaciones de alimentos provenientes de ese país superaron el comercio del mismo tipo que la isla mantenía con España.

Como otros aspectos de las relaciones sociales en la plantación, la alimentación estuvo determinada por las desigualdades intrínsecas al régimen esclavista de producción. Para los plantadores, las consideraciones al respecto estaban subordinadas a un elemental principio económico: la reposición a bajo costo de la energía que los esclavos invertían en el trabajo. En contraste con la variedad que pudo caracterizar la

\footnotetext{
${ }^{7}$ Levi Marrero, Cuba: Economía y Sociedad, t. 12, Editorial Playor, Madrid, 1985, p. 151.

${ }^{8}$ Alejandro de Humbolt, Ensayo político sobre la Isla de Cuba, París, 1827.

9 "Balance general del comercio marítimo de la isla de Cuba, y producto de las rentas en el año de 1827", en: Ramón de la Sagra, Anales de Ciencias, Agricultura, Comercio y Artes, febrero, 1829 , p. 219.

10 Ídem.
} 
mesa de los hacendados, la dieta regular de los trabajadores fue estandarizada, y como norma se componía de unos cuantos productos básicos. El tasajo, el arroz o la harina, y las legumbres de importación, más algunas viandas producidas en el país, fijaron en este grupo un patrón alimentario monótono y deficiente en nutrientes esenciales. El consumo de leche y derivados, frutas y verduras, caldos, carnes o pescados frescos, huevos, u otros víveres fue inusual en la alimentación de los esclavos.

En 1838, a raíz de las denuncias realizadas a las autoridades sobre el escaso alimento" que recibía la dotación del ingenio La Lima, jurisdicción de Matanzas, se procedió a una inspección de la finca en el horario de almuerzo, a las doce del día, y se verificó que la alimentación de los esclavos consistía en una ración de carne salada y harina, "en proporción insignificante para satisfacer las necesidades de esas personas". El inspector pregunto si esas mismas raciones eran las que siempre les suministraban o sí sucedía desde un tiempo hasta la fecha, a lo que respondieron que se les daba regularmente dos pequeñas raciones como las vistas por el inspector, una a la hora de almuerzo y otra en las oraciones. De acuerdo con el informe consultado, la subalimentación a la que estaba sometida la dotación se notaba en su aspecto físico. Al ser interrogado el mayoral de la finca sobre el particular, este alegó que, por problemas de abastecimiento de carne, se les estaba suministrando esas pequeñas raciones. ${ }^{11}$

Una década más tarde, la precariedad de alimentación de la negrada del ingenio Santa trinidad o Mariel, motivó otra investigación. Se informó al Alcalde Mayor de Mariel, Martín Galiano, del "lamentable estado" en el que se encontraba la alimentación y necesidades de la mencionada finca. Entonces se advirtió al encargado del ingenio sobre el cumplimiento de lo establecido en los artículos 6 y 7 del Reglamento de Esclavos de 1842 respecto a la alimentación de la dotación, y se dispuso mantener la finca bajo estricta vigilancia de las autoridades con el objetivo de garantizar el cumplimiento de lo dispuesto. Las autoridades manifestaron su temor de que por la falta de alimentos la tranquilidad de la finca se viera afectada, y que tal situación no se ajustaba a "los sentimientos de humanidad y aun de caridad cristiana conque nuestras sabias Leyes recomienda se trate a los esclavos". ${ }^{12}$

\footnotetext{
${ }^{11}$ Sobre desnudez y escaso alimento que se da a la negrada del ingenio "La Lima" jurisdicción de Matanzas, ANC, Leg. 938, Nº. 33105, 1938.

${ }^{12}$ Expediente participando al Alcalde Mayor D. Martín Galiano, el abandono en que se encuentra el ingenio "Santa Trinidad" o "El Mariel" con respecto al alimento de la negrada, ANC, Leg: 946, No. 33342, agosto-octubre, 1848.
} 
La calidad de la alimentación estuvo en el centro de no pocas estrategias articuladas por los esclavos para llamar la atención de las autoridades ante posibles arbitrariedades de sus amos. A principios de enero de 1850, el pedáneo de Guanajay informó al Teniente Gobernador del Mariel que se le presentó la dotación del cafetal Las Mercedes quejándose de falta de alimento y mal trato. Este ordenó al juez pedáneo que, con la escolta necesaria, condujera la negrada a su finca y esperase allí su llegada. Una vez en la finca, el Teniente Gobernador mandó formar la dotación y al momento descubrió al cabecilla y otros dos líderes de la insubordinación. Considerando la autoridad que el trato y la alimentación que recibían los esclavos era bueno, impuso al primero un ligero castigo y prisiones a los tres, haciéndoles responsables de cualquier reincidencia y perturbación de la tranquilidad de la negrada. Parte de la dotación confesó que en realidad se había alzado porque "no se les permitió tocar el tambor los días de pascuas". Reconvenidos por su actuación y recordándoles sus deberes para con su amo, el Teniente Gobernador los despidió al trabajo "arrepentidos ya de su mal comportamiento". ${ }^{13}$

Las diferencias en el régimen de alimentación de los esclavos no solo respondieron a distinciones socioclasistas, cuestión más divulgada, sino también a variables como la edad de la población consumidora, la estación del año, la dinámica comercial a escala local o regional, la actitud de las personas encargas de proveer de alimentos a la plantación, así como por las jerarquías y prácticas establecidas por los distintos grupos consumidores. Si la comida fue el detonante de no pocas revueltas llevadas a cabo por esclavos de ingenios, también estuvo en el centro de estrategias y conflictos entre los propios trabajadores, de lo cual resultó cierto aprovechamiento desigual tanto de las subsistencias regularmente administradas a la dotación, como de aquellas disponibles en el entorno de la plantación.

Al estar sujeto a un doble proceso de subordinación -al mercado internacional, con los determinantes de costo y durabilidad de los productos a importar, pero también a la decisión de los hacendados- el suministro regular de alimento a las dotaciones no se comportó de manera uniforme en el territorio insular, y varió también en dependencia de la coyuntura histórica. En las plantaciones más conectadas al mercado externo, la alimentación de la dotación, aunque más regular, pudo ser más monótona. Mientras una dieta más ajustada a las condiciones del agro cubano pudo ser la norma en aquellas

${ }^{13}$ Expediente sobre la presentación al capitán de Guanajay de la dotación del cafetal "La Mercedes" quejándose de falta de alimento, ANC, Leg. 946, Nº. 33375, enero, 1850. 
fincas más dependientes del mercado interno, aunque también más expuestas a ciclos de escasez si la producción local era, por alguna razón, afectada. Este puede ser, grosso modo, el contraste entre la región occidental y centro-oriental.

IMAGEN 2: CUBA. ESCLAVOS A LA ESPERA DE SU RACIÓN DE ALIMENTOS, 1866.

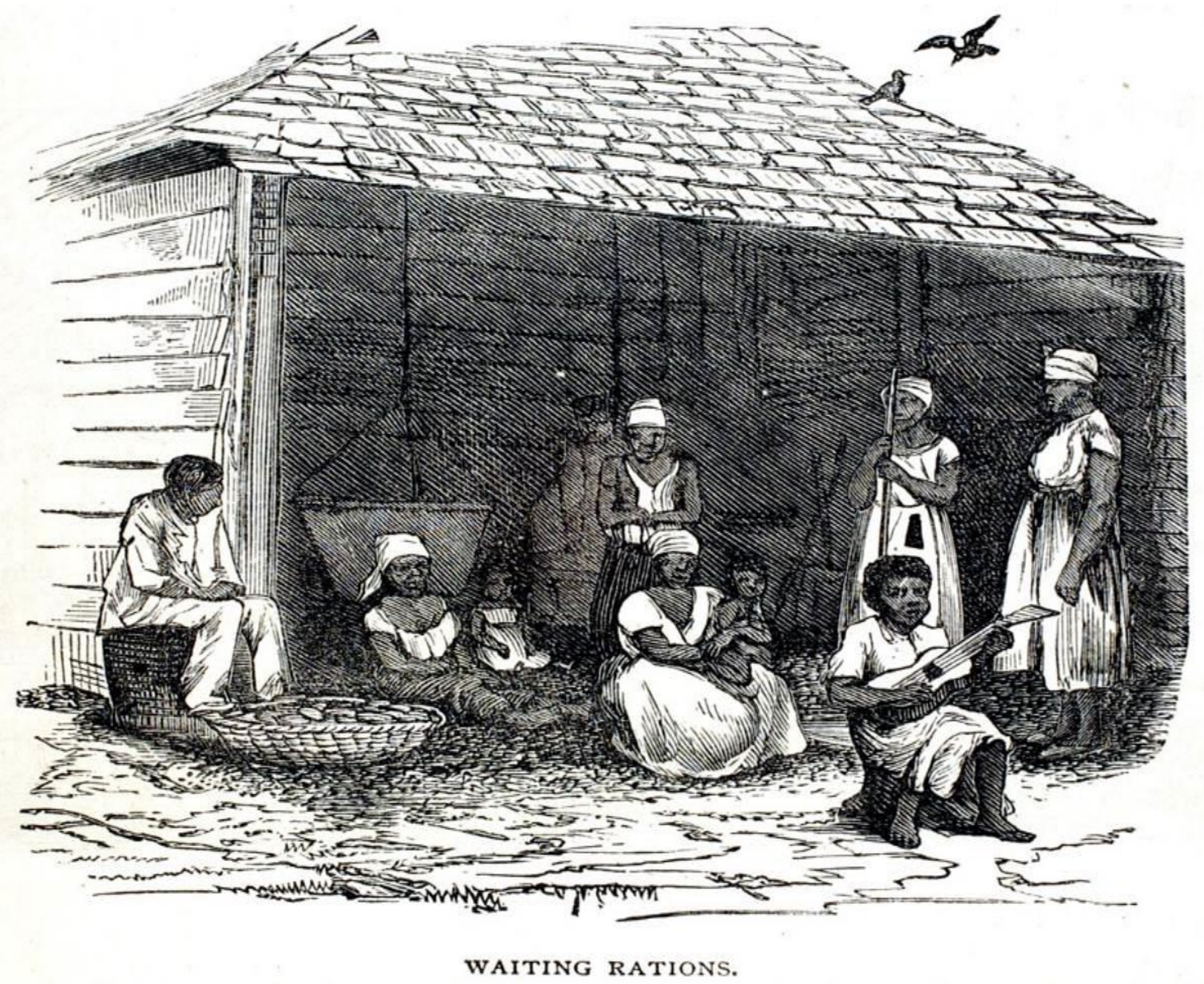

Fuente: Jerome S. Handler y Michael L. Tuite Jr, The Atlantic Slave Trade and Slave Life in the Americas. A Visual Record, Virginia Foundation for the Humanities and University of Virginia, disponible en http://www.slaveryimages.org/.

Los plantadores occidentales, con una posición geográfica privilegiada por su cercanía al principal puerto comercial de la isla y contando con una mejor red de comunicación, tuvieron un control más directo sobre los productos de importación necesarios para abastecer de alimentos a sus numerosas dotaciones. Mientras, hacia el este de la isla, con un desarrollo menor de la agroindustria azucarera, la producción de subsistencia tenía un peso importante en los sitios de labor y estancias, aunque también fue la región más afectada por fenómenos climatológicos (sequías, ciclones, etc.), o por eventos militares de envergadura como la guerra de los Diez Años (1868-1878). Debido a la escasez periódica de frutos y viandas en la zona occidental del país, fue regular la 
transferencia de estos desde la región oriental. No obstante, las limitaciones del transporte interno, con un sistema ferroviario diseñando fundamentalmente para conectar el puerto habanero con el hinterland, constreñían la circulación de determinados géneros por el territorio insular y encarecía el coste de los mismos. De ahí que no solo existieran desigualdades en el consumo que las capas más bajas y más altas de la población hacían de determinados alimentos, sino además marcadas diferencias regionales.

Apenas se han estudiado los efectos de eventos naturales como ciclones o sequías sobre la economía cubana del siglo XIX, y de forma específica sus secuelas a corto plazo en la disponibilidad de alimentos. De la primera mitad del siglo XIX se recuerdan los grandes estragos causados por los ciclones de 1844 y 1846 . El primero de estos, que impactó en la isla en el mes de octubre, y una sequía extraordinaria fueron factores domésticos determinantes de la significativa caída que experimentó la producción azucarera en 1845. Ese año disminuyó a 7.604,580 arrobas, menos de la mitad de la producción de 1844 que fue de 16.153,052 arrobas; hecho que tuvo repercusión directa en el volumen de las importaciones cubanas, sobre todo en la compra de alimentos como el arroz, el tasajo y las carnes de vaca y cerdo, que disminuyeron significativamente respecto al año anterior. ${ }^{14}$ A principios de octubre de 1870 llegó a la isla el huracán de San Marcos. Con una duración de varios días, afectó gran parte del país, quedando numerosas poblaciones completamente arruinadas. Se estima que solo en la región de Matanzas fallecieron cerca de 1.000 habitantes por ese fenómeno meteorológico. En los próximos días, 19 y 20 de octubre, otro huracán también afectó el occidente cubano. ${ }^{15}$ Meses después se desató en varias fincas de esta región una importante epidemia de beriberi, de la cual hablaremos más adelante.

Interesa destacar el dominio que la harina de maíz y el arroz adquieren en la alimentación cubana del siglo XIX. Ello estuvo vinculado al desarrollo de la agricultura comercial y la imposición de la "opción cerealística" como la alternativa alimentaria por excelencia de amplios sectores de una población que pasó de unos 171620 habitantes censados en 1774 a 1509291 en $1877 .{ }^{16}$ Esos cereales dominaron en Cuba la dieta de la población esclava y pobre, constituyendo la más regular y principal fuente de calorías. Aunque, frente al proteccionismo que caracterizó el comercio de la harina, el

\footnotetext{
${ }^{14}$ Jacobo de la Pezuela, Diccionario, t. I, p. 56.

15 "Huracanes de la Isla de Cuba", Anales de la Real Academia de Ciencias Médicas, Físicas y Naturales de La Habana, vol. VIII, 1871, p. 552.

${ }^{16}$ ONEI, El color de la piel según el censo de población y viviendas, p. 17.
} 
arroz gozó de mayor libertad y se transformó en un alimento más accesible. En el siglo XIX Cuba se convirtió en un gran importador de ese grano, y ha sido históricamente uno de los países fuera de Asia con mayor consumo per cápita.

En 1827 el consumo de arroz en la isla doblaba la cifra de una producción doméstica estimada en 520.897 arrobas. Entre las limitaciones de la cosecha de este cereal estaba la falta de máquinas para descascarar el grano, operación que por lo general se hacía manualmente. ${ }^{17}$ El Cuadro Estadístico de 1846 también reconoce que, debido a la falta de maquinarias para descascarar el grano, la producción de arroz seguía siendo insuficiente para cubrir el consumo general de la población. ${ }^{18} \mathrm{Al}$ comenzar la década de 1860, cerca del $60 \%$ de las importaciones cubanas de arroz provenían del sudeste asiático (Indias Orientales) y otras dos cuotas, alrededor del 20\%, de la región valenciana en España y las Carolinas en Estados Unidos. Como promedio, se importó entre 1855 y 1864 unos 14.312 .699 kilogramos de este producto. ${ }^{19}$ Como refleja el gráfico 8, existió cierta correspondencia, para nada accidental, entre dominio azucarero, crecimiento demográfico y consumo de arroz en la isla.

${ }^{17}$ Cuadro estadístico de la siempre fiel isla de Cuba correspondiente al año de 1827, Imprenta del Gobierno, La Habana, 1829, p. 32.

${ }^{18}$ Cuadro estadístico de la siempre fiel isla de Cuba correspondiente al año de 1846, Imprenta del Gobierno y Capitanía General, La Habana, 1847, p. 21.

${ }^{19}$ A partir de 1861 se interrumpieron las importaciones desde Estados Unidos debido a la Guerra de Secesión (1861-1865). Levi Marrero, Cuba: Economía y sociedad, t. 12, p. 164. 


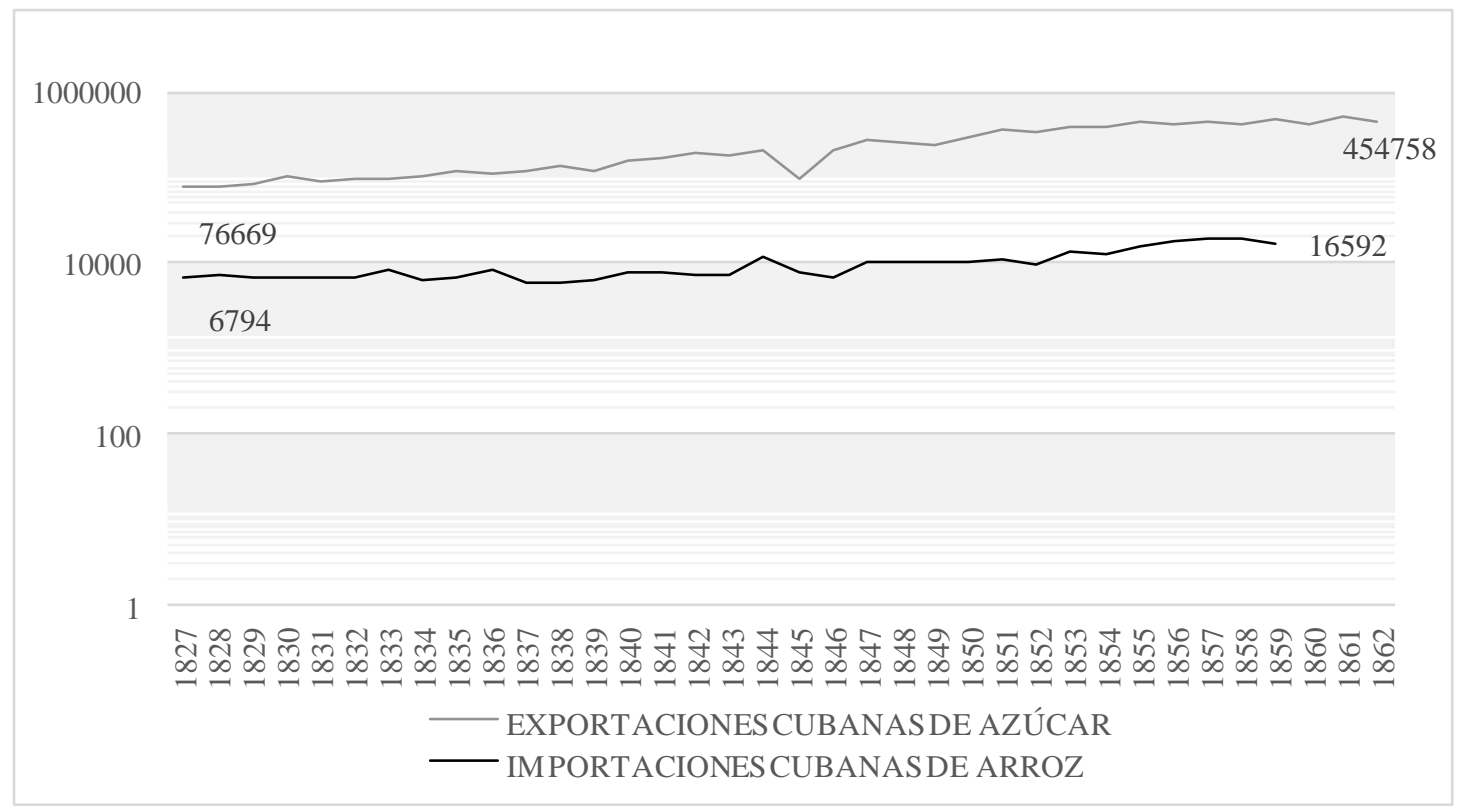

Elaboración propia a partir de la información disponible en: Instituto de Historia de Cuba, Historia de Cuba: la Colonia, evolución socioeconómica y formación nacional, pp. 493-494.

El incremento de las importaciones cubanas de arroz hacia mediados del siglo XIX refleja la centralidad que adquiere ese producto en el sistema alimentario de la pujante economía de plantación azucarera. La historia de la conquista occidental de este cereal, producido a gran escala en Oriente y consumido en el Caribe fundamentalmente por los trabajadores cautivos, se inserta en la misma geografía colonial que refleja la transformación del azúcar que se elabora en esta región en un alimento cada vez más consumido por la población europea. Un artículo reciente analiza precisamente las interdependencias coloniales que se establecieron a través del comercio del arroz, y como la ruta de este cereal a través de los océanos Índico y Atlántico constituye un trazado más en la dinámica globalizante del capitalismo moderno. ${ }^{20}$

Otro alimento básico en la dieta regular de las dotaciones era el tasajo. Cuba y Brasil fueron en la primera mitad del siglo XIX los principales compradores del tasajo de Buenos Aires, que en esa etapa se transformó en una de las principales regiones productoras del continente. Después de la Revolución de mayo de 1810 que produjo el desmembramiento del Virreinato del Río de la Plata y la Declaración de Independencia en 1816, las exportaciones de tasajo desde Buenos Aires aumentaron

20 Katheen D. Morrison y Mark W. Hauser, "Risky business: rice and inter-colonial dependencies in the Indian and Atlantic Oceans", Atlantic Studies, vol. 12, No. 3, pp. 371-392. 
considerablemente, una vez abolidas las restricciones comerciales impuestas por la corona española. Las exportaciones pasaron de unos cientos de toneladas métricas por año en la década de 1810 a miles durante el período de 1820 a 1840, una evolución paralela también al desarrollo del sistema esclavista en Cuba. La dependencia de esta isla al tasajo bonaerense llegó a ser de más de la mitad de todas sus importaciones de esa mercancía. De modo que, a través de ella se establecieron fuertes relaciones comerciales entre estos países, conectadas a su vez a la dinámica de la economía atlántica en el siglo XIX. Empero -y por esa misma dependencia-, el comercio de este renglón, principal fuente de proteína animal para los esclavos y las capas populares del país, estuvo afectado en reiteradas ocasiones, generando períodos de escasez y carestía. No solo el proceso independentista interrumpió las importaciones de tasajo que la isla realizaba desde Argentina, esta ruta también estuvo afectada por la guerra entre Argentina y Brasil de 1825 a 1828, el bloqueo francés a Buenos Aires de 1838 a 1840 y el bloqueo británico-francés a la misma ciudad entre 1845 y $1848 .{ }^{21}$ Tales situaciones obligaron a las autoridades cubanas a tomar medidas de emergencia para garantizar el suministro de un alimento que se había transformado en parte integral del complejo azucarero cubano.

En septiembre de 1844, una Junta de Autoridades encabezada por el Capitán General Leopoldo O’Donnell y el Conde de Villanueva, Superintendente de Hacienda, adoptó como medida provisional admitir la entrada en los puertos de la isla a los buques mercantes venezolanos con cargamentos de tasajo $\mathrm{u}$ otros productos de absoluta necesidad, para aliviar la escasez producida a raíz de la guerra civil que acontecía en Buenos Aires. La medida se tornó más urgente cuando en los primeros días de octubre la isla fue impactada por el ya mencionado huracán de 1844 que ocasionó cuantiosos daños. La iniciativa tomada por el gobierno colonial fue ratificada por Real Orden del 4 de diciembre, a fin de que el tasajo pudiera expenderse en el mercado interno a precios cómodos y accesibles para las clases menesterosas y otros grupos sociales que hacían uso frecuente de ese alimento. ${ }^{22}$ Con la estabilidad política en el Río de la Plata, en la segunda mitad del siglo XIX fue posible un incremento de las importaciones de tasajo desde esa región, un alimento cada vez más solicitado en Cuba para satisfacer la creciente demanda de su población trabajadora.

\footnotetext{
${ }^{21}$ Andrew Sluyter, "The Hispanic Atlantic's Tasajo Trail”, Latin American Research Review, vol. $45, \mathrm{~N}^{\circ} .1,2010$, pp. 99-100.

${ }^{22}$ Admisión de buques venezolanos con cargamento de tasajo, AHN, Ultramar, Leg. 16, №. 26, septiembre de 1844-febrero de 1845.
} 
Sin embargo, parte de la historiografía contemporánea sostiene la idea de que la dieta de los esclavos se componía regularmente de unos 200 gramos de tasajo, norma estipulada por las autoridades coloniales y que los plantadores dijeron asegurar. ${ }^{23}$ Tal consumo supone que los esclavos de las plantaciones cubanas, como promedio, comían más carne que sus homólogos en Estados Unidos, que el cálculo optimista de Robert W. Fogel establece en 170 gramos de carne por día. La creencia de que nuestra población trabajadora del pasado consumía "abundante" carne se sustenta sobre cifras globales que resultan engañosas. Bastan algunos cálculos sencillos para sospechar de un consumo que ha pasado prácticamente incólume entre excelentes investigaciones.

En 1848, pleno apogeo del sistema esclavista, se importaron 31.768,000 libras de tasajo, lo que representa un consumo per cápita de 35,3 libras respecto a la población de 1846, como efectivamente calculó Levi Marrero. Supongamos que todo ese volumen fue destinado y efectivamente consumido solo por la población esclava existente en la isla $(323,759)$, excluyendo de tal consumo tanto a la población blanca como a la libre "de color". Si así fuera, el tasajo importado daría para un per cápita de 98,2 libras que, divido entre 300 días, daría un consumo diario per cápita de 0,32 libras, equivalente a 145 gramos. Tal cifra, resultante de un cálculo en el que marginamos al 64\% de la población y descontamos la ingesta de tasajo de 65 días, supone un consumo inferior al estipulado en el Reglamento de Esclavos de 1842. Es poco probable que los plantadores pudieran completar con la producción interna o el contrabando la norma establecida en ocho onzas (unos 230 gramos), incluso aunque fuera solo para la población cautiva adulta. Recordemos que la población esclava de la isla en esa fecha estaba compuesta por una mayoría de hombres en edad productiva.

Veamos otro cálculo al respecto. La suma de las medias anuales de importación de tasajo, tocino y bacalao en el período 1856-1859 es de 48.725,000 libras. Si generosamente destinamos todo ese volumen solo al consumo de la población esclava estimada en 1862, unos 370.553 esclavos, arroja un per cápita de 131 libras, equivalente a 195 gramos si la distribuimos en 300 días. El resultado es más próximo a la dieta estipulada, aunque sigue siendo ligeramente inferior. ¿Pero es estadísticamente correcto e históricamente aceptable marginal a los sectores más dinámicos de la sociedad del consumo de esos productos? Creemos que no. Si aceptamos que los plantadores tuvieron plena conciencia de la importancia de asegurar la proteína animal de sus

\footnotetext{
${ }^{23}$ Robert W. Fogel y Stanley L. Engerman, Tiempo en la cruz, p. 96.
} 
dotaciones y estuvieron dispuestos a ello, debemos también admitir una constante y desigual competencia entre ellos por un bien que, en el mejor de los casos, nunca sobró en Cuba. Siempre que algunas dotaciones tuvieran garantizadas una regular y suficiente ingesta de proteína animal, al mismo tiempo, para otros esclavos y una parte nada despreciable del total de la población trabajadora, el consumo de carnes fue, cuando menos, deficiente. Qué realidad subyace en la mentalidad de un grupo social que produjo las siguientes expresiones: "El perro con hambre no defiende a su amo" o "En la mesa del pobre, boniatico frucío no eta de má". ${ }^{24}$

Recordemos que fue habitual el robo de subsistencias entre plantaciones -muy a menudo de ganado-, muchas veces realizado por los esclavos con el consentimiento del mayoral de la finca. En su discurso de apertura de la Real Audiencia Pretorial, pronunciado el 2 de enero de 1857, el Regente reconoció que uno de los delitos más frecuentes en la isla era el hurto de reses y caballerías, hecho facilitado entre otras cosas por la inseguridad de muchas fincas y el libre tráfico de personas entre ellas. ${ }^{25}$

Sobre el consumo de tubérculos, Moreno Fraginals ha señalado que a excepción del plátano o el boniato, las viandas tropicales no eran rentables por su escasa durabilidad, y por lo tanto los esclavos las comían poco. ${ }^{26}$ Vale señalar que hacia la década de 1870 el gorgojo del boniato estaba extendido por toda la isla, ocasionando significativas pérdidas en su cultivo. La Academia de Ciencias subrayó entonces la importancia de ese particular, convocando a un premio para el estudio que propusiera el remedio más efectivo contra esa plaga. Años antes, el naturalista Felipe Poey había aconsejado para hacer desaparecer del suelo cubano el cylas formicarius, nombre científico de la plaga, la destrucción de todos los buniatales existentes, y no volver a sembrarlos hasta pasados dos años, medida que, por supuesto, no fue adoptada de forma generalizada. ${ }^{27}$ Los agricultores cubanos utilizaban entonces, con desigual efectividad, diversos abonos insecticidas, entre ellos, la cal en polvo o en lechada, el azufre, la ceniza, y el excremento de cerdo, entre otros. De ahí que, toda consideración sobre la alimentación de los trabajadores debe tener en cuenta las posibles pérdidas ocasionadas

\footnotetext{
${ }^{24}$ Lydia Cabrera, Refranes de negros viejos, Ediciones Colección del Chichereku, La Habana, 1955.

25 "Discurso pronunciado en la apertura de la Real Audiencia Pretorial, el día 2 de enero de 1857, por Illmo. Sr. Regente", Revista de Jurisprudencia, Administración y Comercio, Año. II, $\mathrm{N}^{\mathrm{o}}$. I, Imprenta del Tiempo, La Habana, 1857, pp. 28-53.

${ }^{26}$ Manuel Moreno Fraginals, El Ingenio, t. 2, p. 59.

${ }^{27}$ José Fernández de Castro, "El gorgojo del boniato", Anales de la Real Academia de Ciencias Médicas, Físicas y Naturales de La Habana, vol. VIII, 1871, p. 489.
} 
por plagas u otras afectaciones, por lo que la superficie cultivada no siempre constituye un fiel indicador del consumo que en realidad se hace de determinado producto.

Algunos autores han sobrevalorado la contribución del conuco a la alimentación del esclavo. Téngase en cuenta que la concesión de estas parcelas no fue extensiva a todas las plantaciones, y no pocos esclavos debieron rechazar el hecho de tener que dedicar en ellas su exiguo tiempo libre. Por otro lado, los frutos obtenidos podían ser objetos de tensiones entre esclavos y propietarios. Cuestión que en la fraseología popular quedó plasmada en refranes como este: "Cochino gordo que yo criá, señor misuamo me lo quitá". ${ }^{28}$ Jacobo de la Pezuela ha señalado el carácter de "usufructuario condicional" de los beneficiarios de estas parcelas, en las que además, según sus observaciones, raras veces se criaba algún ganado. ${ }^{29}$ Aunque en los primeros siglos coloniales el sistema de conucos pudo significar un complemento seguro en la alimentación de los trabajadores, es menos probable que lo fuera bajo las condiciones agrícolas del siglo XIX. En todo caso, faltan estudios capaces de determinar con mayor exactitud la extensión de estas áreas de cultivo, su productividad e incidencia directa en la alimentación de los esclavos.

Aunque existieron esfuerzos previos, no fue hasta finales del siglo XIX y principios del XX que, de la mano de una moderna generación de "reformadores agrícolas", se realiza una obra de divulgación científica sobre la importancia de fomentar en la isla el cultivo de frutas, hortalizas y viandas. Como ha indicado la historiadora Leida Fernández, es significativo que regiones históricamente dominadas por la agroindustria azucarera, como Matanzas y el valle de Güines, fueran el centro de varios de los experimentos realizados en esa etapa. ${ }^{30}$ Los nuevos esfuerzos por diversificar la agricultura cubana prestaron particular interés al análisis del potencial nutritivo de varios alimentos. Los valores de la tabla 11 corresponden al cálculo realizado a principios del pasado siglo por el doctor Leonel Plasencia con productos del suelo cubano, la primera estimación de este tipo realizada en Cuba que hemos encontrado. Hasta la fecha, solo se tenía conocimiento de un estudio sobre la yuca hecho por la Estación Experimental del Estado de la Florida, Estados Unidos, y un análisis del boniato del doctor C. W. Wehmer. Aunque los valores expuestos son

\footnotetext{
${ }^{28}$ También se conoce "El cochino gordo que crió el esclavo, ese fue el que el amo se quiso comer". Lydia Cabrera, Refranes de negros viejos, p. 15.

${ }^{29}$ Jacobo de la Pezuela, Diccionario, t. I, p. 214.

${ }^{30}$ Leida Fernández Prieto, Cuba agrícola: mito y tradición, 1878-1920, CSIC, Madrid, 2005, p. 267.
} 
aproximados, eran válidos para fijar la hipótesis que entonces se quería argumentar: que las viandas cubanas tienen más alto valor nutricional del que generalmente se les atribuye, y que varias de ellas son más alimenticias que la papa, considerada casi universalmente como el tipo de los tubérculos alimenticios. ${ }^{31}$

\title{
TABLA 11: CUADRO COMPARATIVO DEL VALOR NUTRITIVO DE VARIOS ALIMENTOS CUBANOS. \\ (calculado para 100 gramos)
}

\begin{tabular}{|l|r|r|r|r|}
\hline \multicolumn{1}{|c|}{ Productos } & Proteínas & Carbohidratos & Grasas & Producción de \\
\hline Papa & 2.00 & 21.08 & - & 98 \\
\hline Boniato & 2.93 & 19.02 & 3.11 & 126.25 \\
\hline Malanga amarilla & 1.76 & 23.78 & 1.27 & 114.26 \\
\hline Plátano macho maduro & 2.30 & 34.46 & - & 150.72 \\
\hline Name & 1.70 & 24.77 & 3.65 & 139.68 \\
\hline Malanga blanca & 0.96 & 8.63 & 0.22 & 41.39 \\
\hline Yuca & 1.48 & 20.31 & 0.70 & 95.80 \\
\hline Plátano verde & 1.10 & 13.26 & - & 65.07 \\
\hline
\end{tabular}

Fuente: José A. Taboadela, “La alimentación del hombre”, pp. 398-399.

En el umbral del siglo XX, el efervescente proceso nacional-revisionista de la experiencia colonial, también tuvo un punto de apoyo en el análisis de los patrones alimentarios establecidos en una población llamada ahora a forjar una república vigorosa y saludable. Incluso dentro de las posiciones historiográficas más conservadoras como la de Francisco Figueras, la crítica en este sentido tocaba la epidermis de un sistema comercial hecho muy al gusto de los sujetos económicos y políticos dominantes.

\begin{abstract}
"Los artículos que la importación suministra á la subsistencia, elaborados expresamente para Cuba, no para responder á las exigencias racionales del mercado, sino para que su ínfima calidad, reduciendo su precio de fabricación, consienta mayor utilidad a los expendios al detalle. Así el tasajo, la manteca, el tocino, el vino, el café, y otros géneros se han fabricado ó escogido expresamente para explotar á los cubanos, aún a riesgo de envenenarlos." 32
\end{abstract}

Diatriba de la cual Francisco Figueras, acto seguido, deriva otra acusación más letal:

\footnotetext{
31 José A. Taboadela, "La alimentación del hombre", Sanidad y Beneficencia, La Habana, noviembre, 1918, pp. 398-399.

${ }^{32}$ Francisco Figueras, Cuba y su evolución colonial, Imprenta Avisador Comercial, La Habana, 1907, p. 346.
} 
"De esa manera se ha vivido y se vive aún en Cuba. Ahora corresponde apuntar como se muere. No había que esperarse, que un Gobierno, que mantiene con criminal incuria la mortalidad de Madrid al tipo de treinta seis por mil, el más alto de todas las capitales europeas, se preocupara, lo más mínimo, de llevar la cuenta y razón de las víctimas prematuramente cosechadas por la muerte entre unos colonos lejanos y no bien queridos. ${ }^{33}$

Pero la manifiesta exaltación antiespañola de Figueras convergía en este punto con las revelaciones de la fisiología y dietética moderna a principios del siglo XX. Entonces comenzaron a publicarse en Cuba algunas investigaciones científicas sobre la calidad de la alimentación de los trabajadores cubanos. Si hasta ese momento las preocupaciones médicas giraban fundamentalmente entorno a las prácticas de lactancia, la higiene de los alimentos o la calidad de productos específicos como la leche, la harina o el azúcar, la cuestión ahora era establecer análisis más precisos entre nutrición y producción, o intentar explicar el impacto de una alimentación deficiente en las tasas de mortalidad nacional. Tales observaciones indicaron las desigualdades sociales que atravesaban la alimentación en Cuba, y la inferioridad de la dieta del trabajador cubano en comparación con la de obreros de áreas geográficas similares.

\section{TABLA 12: RACIÓN ALIMENTICIA DE OBREROS DE TRABAJOS FUERTES EN VARIOS PAÍSES DE CLIMA TROPICAL.}

\begin{tabular}{|l|r|r|}
\hline \multicolumn{1}{|c|}{ Obreros y regiones } & \multicolumn{1}{|c|}{ Temperatura } & \multicolumn{1}{|c|}{$\begin{array}{c}\text { Alimentos } \\
\text { (Calorías) }\end{array}$} \\
\hline $\begin{array}{l}\text { Labradores y trabajadores fuertes de Nagasaki y } \\
\text { Kagosima, Japón }\end{array}$ & $25^{\circ} \mathrm{C}$ & 4.090 \\
\hline $\begin{array}{l}\text { Agricultores rudos de las provincias de Nápoles y } \\
\text { Sicilia, Italia }\end{array}$ & $23.9^{\circ} \mathrm{C}$ & 3.470 \\
\hline $\begin{array}{l}\text { Labradores y trabajadores fuertes a lo largo de la costa } \\
\text { de China entre los ríos Yang-tse-kiang y Si-kiang }\end{array}$ & $26.4^{\circ} \mathrm{C}$ & 3.410 \\
\hline Obreros de trabajo fuerte de Formosa, Japón & $26.0^{\circ} \mathrm{C}$ & 3.100 \\
\hline Labradores nativos del Sudan Anglo-Egipcio & $24.8^{\circ} \mathrm{C}$ & 2.825 \\
\hline Obreros de trabajo fuerte de Cuba & $25.1^{\circ} \mathrm{C}$ & 2.588 \\
\hline
\end{tabular}

Fuente: Rafael J. Fosalba, "La mortinatalidad y la mortalidad infantil en la República de Cuba", Sanidad y Beneficencia, junio, 1914, p. 676.

De uno de los más acuciosos investigadores sobre la dimensión biológica de la esclavitud en las Américas es la tabla 13. En ella se valora el potencial nutricional de la alimentación de los esclavos en las plantaciones del Caribe.

\footnotetext{
33 Ídem.
} 
TABLA 13: UNA ESTIMACIÓN DEL ESTADO NUTRICIONAL DE LOS ESCLAVOS DEL CARIBE SIGUIENDO EL ANÁLISIS DE DOS TIPOS DE DIETAS “IDEALES” DE ESCLAVOS.

\begin{tabular}{|l|l|l|}
\hline \multicolumn{1}{|c|}{ Nutrientes } & \multicolumn{1}{c|}{ Carne/ Maíz } & \multicolumn{1}{c|}{ Pescado/ Arroz } \\
\hline Proteína & Apenas lo adecuado & Apenas lo adecuado \\
\hline Grasa & Muy bajo & Peligrosamente bajo \\
\hline Calcio & Bajo & Bajo \\
\hline Fósforo & Alto & Alto \\
\hline $\begin{array}{l}\text { Hierro } \\
\text { - Hombres }\end{array}$ & - Adecuado & - Adecuado \\
Vitamina A & - Menor a lo adecuado & - Menor a lo adecuado \\
\hline Tiamina & Muy bajo & Peligrosamente bajo \\
\hline Riboflavina & Bajo & Peligrosamente bajo \\
\hline Niacina & Muy bajo & Muy bajo \\
\hline Vitamina C & Peligrosamente bajo & Bajo \\
\hline
\end{tabular}

Fuente: Kenneth F. Kiple, The Caribbean Slave, p. 88.

Según la estimación de Kenneth F. Kiple, más del 80\% de las calorías ingeridas diariamente por los esclavos en esta región tenían como fuente la harina de maíz, el arroz, y la carne o pescado salado, en dependencia de las prácticas establecidas en cada plantación. El consumo de esos productos fijó un patrón alimentario deficiente que se ha mantenido en varios países del área. ${ }^{34}$ La tesis de Kiple queda patente en la frecuencia con que se daban determinados alimentos en la dotación de Julián Zulueta. Un examen del libro de refacción de los ingenios Vizcaya, España, Habana y Álava, de su propiedad, arroja la distribución que representamos en la gráfica siguiente.

\footnotetext{
${ }^{34}$ Kenneth F. Kiple, The Caribbean Slave, pp. 96-103.
} 


\section{GRÁFICO 9: FRECUENCIA CON LA QUE SE DABAN VARIOS ALIMENTOS A LA DOTACIÓN EN INGENIOS DE JULIÁN ZULUETA.}

(contabilizados un total de 450 días entre diciembre de 1874 y noviembre de 1876)

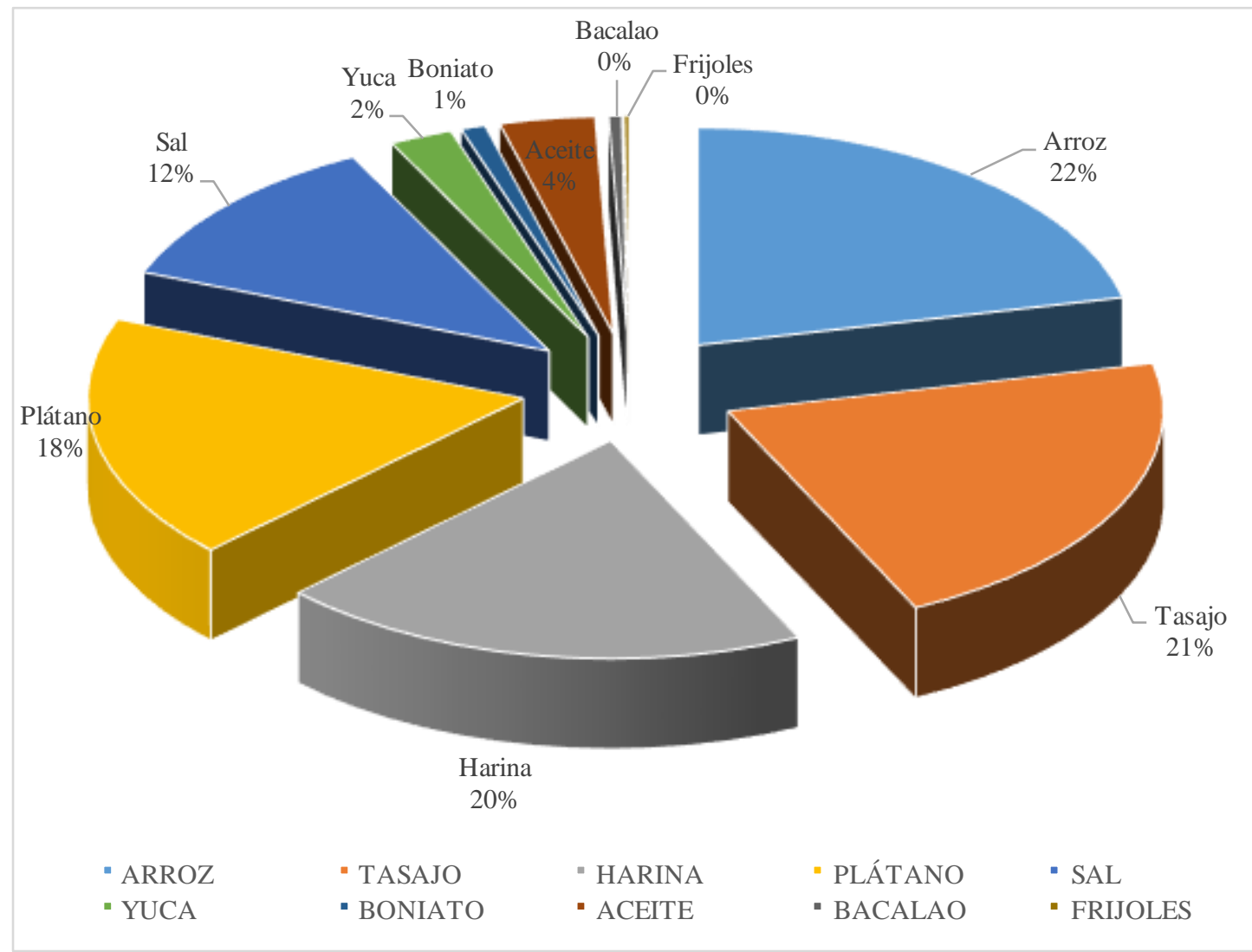

Elaboración propia a partir de la información disponible en: Libro de refacción de los ingenios Vizcaya, Habana, España, Álaba (sic) y otros ubicados en la provincia de Matanzas, propiedad de Julián de Zulueta correspondiente a los años 1874-1876, ANC, Donativos y Remisiones, Leg. 140, №. 1.

De las principales enfermedades nutricionales que resultaron de esa realidad, el beriberi ocupa un lugar destacado por ser la única capaz de producir una mortalidad elevada entre los más jóvenes.

\section{BERIBERI EN OCCIDENTE}

Corría el 10 de julio de 1871 cuando en la enfermería del ingenio Antonia, ubicado en Limonar, entonces jurisdicción de Matanzas, fue ingresado el moreno criollo Agustín, quejándose de fuertes dolores articulares y gran molestia en todo el cuerpo. Tenía los pies un poco hinchados, y a los dos días de estar en la enfermería la hinchazón había invadido todas las extremidades inferiores y parte del vientre. En poco tiempo la hinchazón se apoderó de todo el cuerpo sin poder el médico hacer nada para impedirlo. En medio de las mayores angustias falleció Agustín el día 24 del mismo mes. 
Con gran hinchazón de las extremidades inferiores y dolores agudos en las principales articulaciones fueron ingresados en los próximos días los negros Cándido, Ramón, Esteban y Luciano, alquilados, y Marcial, criollo de la dotación de la finca. En el mes de agosto se presentaron nuevos casos acusando un malestar general, dolores articulares, dificultad para moverse, tristeza y malas digestiones. Entre ellos, los esclavos de la finca Aniceto y Antonio, criollos, Rosalía, ganga, y también el alquilado Eusebio. Al mes siguiente, también entraron en la enfermería con los síntomas manifiestos los morenos Donato, Cristóbal, Eusebio, Simón y Juan, todos de la finca, los cuales llegaron a ofrecer una hinchazón monstruosa. De estos casos graves dos terminaron en muerte, uno el ya relacionado Agustín y el otro Esteban, que murió el día 9 de octubre. Según las observaciones realizadas por el facultativo que los examinó, otros trabajadores entraron en la enfermería con síntomas que también indicaban la invasión del beriberi, una enfermedad asociada a una alimentación deficiente. ${ }^{35}$

Grosso modo, la malnutrición es el estado que aparece como resultado de una dieta desequilibrada, en la cual hay nutrientes que faltan, o de los cuales hay un exceso, o cuya ingesta se da en la proporción errónea. Sin ser conscientes de ello, hasta bien entrado el siglo $\mathrm{XX}$ muchas poblaciones vivieron en un estado permanente de malnutrición por carencia de nutrientes esenciales. No fue hasta principios del siglo XX que se descubrieron varios de ellos como las vitaminas, sustancias indispensables para los diferentes procesos metabólicos de los organismos vivos. Tales hallazgos en el campo de la fisiología y la dietética moderna marcaron una revolución científica, cuestionando el tradicional mapa de la nutrición humana.

\section{TABLA 14: TIPOS Y FUENTES PRINCIPALES DE NUTRIENTES.}

\begin{tabular}{|l|l|l|}
\hline \multicolumn{1}{|c|}{ Nutrientes } & \multicolumn{1}{c|}{ Fuentes vegetales } & \multicolumn{1}{c|}{ Fuentes animales } \\
\hline $\begin{array}{l}\text { Hidratos de carbono } \\
\text { (azúcares y almidón) }\end{array}$ & $\begin{array}{l}\text { Frutas, cereales, tubérculos, } \\
\text { leguminosas }\end{array}$ & Miel, leche \\
\hline Grasas & $\begin{array}{l}\text { Semillas oleaginosas, frutos } \\
\text { secos, y legumbres }\end{array}$ & $\begin{array}{l}\text { Carne, aves, mantequilla, } \\
\text { ghee, pescado }\end{array}$ \\
\hline Proteínas & $\begin{array}{l}\text { Leguminosas, frutos secos y } \\
\text { cereales }\end{array}$ & $\begin{array}{l}\text { Carne, pescado, productos } \\
\text { lácteos }\end{array}$ \\
\hline
\end{tabular}

\footnotetext{
${ }^{35}$ Francisco P. Grima declaró haber observado muchos casos también en el ingenio Concepción. "Beriberi", Anales de la Real Academia de Ciencias Médicas, Físicas y Naturales de La Habana, vol. VIII, 1871, pp. 367-370.
} 


\begin{tabular}{|l|l|l|}
\hline Vitaminas & $\begin{array}{l}\text { Carotenos: zanahorias, } \\
\text { mangos, papaya } \\
\text { Vitamina C: frutas yitamina A: hígado, huevos, } \\
\text { hortalizas } \\
\text { Complejo de Vitaminas B: }\end{array}$ & $\begin{array}{l}\text { leche } \\
\text { Complejo de Vitaminas B: } \\
\text { carne, aves, productos lácteos }\end{array}$ \\
\hline Minerales & $\begin{array}{l}\text { Calcio: guisantes, judías } \\
\text { Hierro: hortalizas de hoja } \\
\text { verde oscura y frutos secos }\end{array}$ & $\begin{array}{l}\text { Calcio: leche, carne, queso } \\
\text { Hierro: carne, pescado, } \\
\text { marisco }\end{array}$ \\
\hline
\end{tabular}

Fuente: Organización Internacional del Trabajo, Enciclopedia de salud y seguridad en el trabajo, tabla 64.1.

Entre las enfermedades que aquejaron a las poblaciones del pasado con hiponutrición y avitaminosis están el escorbuto, la pelagra, el raquitismo, la xeroftalmia y el beriberi. El nombre de esta última deriva probablemente del término cingalés "beri”, que significa debilidad o impotencia. Su causa es un déficit de vitamina $\mathrm{B}_{1}$ o tiamina, sustancia hidrosoluble que los seres humanos debemos obtener a través de los alimentos ya que el organismo no la produce. En el ser humano la tiamina es imprescindible para el metabolismo de los azúcares que nos dan energía, y para el funcionamiento de los músculos y los nervios. La enfermedad afecta el aparato cardiovascular (beriberi húmedo) o el sistema nervioso (beriberi seco), y puede ser mortal si no se aporta la vitamina al organismo, ya sea en la alimentación o como suplemento farmacológico. La tiamina está presente en algunas carnes frescas, legumbres y cereales integrales. Las mujeres embarazadas y los hombres expuestos a trabajos físicos rigurosos pueden ser particularmente vulnerables a la enfermedad. ${ }^{36}$

A lo largo del siglo XIX, varios autores argumentaron sobre la presencia generalizada del beriberi en grandes poblaciones del sudeste asiático, donde el arroz constituía la base alimentaria de millones de campesinos. Entonces, era un mal endémico en la costa oeste de la Bahía de Bengala, en Borneo, Java y Sumatra.

En Japón el beriberi llegó a ser conocida como “enfermedad nacional”. En la década de 1880, el médico naval Takaki Kanehiro, mientras ejercía en la Armada

\footnotetext{
${ }^{36}$ Las primeras observaciones científicas modernas del beriberi fueron publicadas en el siglo XVII por los médicos holandeses Jacobus Bontius (1592-1631) y Nicolás P. Tulp (1593-1674), considerados pioneros de la medicina tropical. Ejercieron como médicos de la Compañía Neerlandesa de las Indias Orientales (VOC) fundada en 1602, y sus observaciones sobre el beriberi fueron realizadas en Java, Indonesia. Nicolás P. Tulp, Observationum medicarum libri tres, Lud. Elzevirum, Amsterdam, 1641. Jacobus Bontius, Medicina Indorum, Lugduni Batav, 1642. Para el desarrollo del conocimiento científico sobre el beriberi ver: Robert R. Williams, Toward the Conquest of Beriberi, Harvard University Press, Cambridge, 1961. Kenneth F. Kiple (ed.), The Cambridge Historical Dictionary of Disease, Cambridge University Press, Nueva York, 2003. Jordi Salas-Salvadó y otros (eds.), La alimentación y la nutrición a través de la historia, p. 374.
} 
Imperial Japonesa, observó que el beriberi era endémico entre la tripulación de bajo rango, que por lo general se alimentaba solo con arroz, y que la enfermedad no se presentaba entre los oficiales que tenían una dieta más variada. Sus experimentos en la marina de guerra japonesa arrojaron que en una alimentación exuberante en arroz y poco variada estaba la causa del beriberi. ${ }^{37}$ Años después, Christiaan Eijkman, médico holandés con experiencia profesional en Indonesia, comprobó el vínculo directo entre el beriberi y el arroz pulido. Este alimento carecía de un componente que sí se encontraba en el arroz integral, y que Eijkman llamó “el factor antiberiberi”. La relación entre el beriberi y el arroz también fue investigada en profundidad por Evart van Dieren, otro destacado médico holandés, aunque a diferencia del enfoque más acertado de Eijkman, este atribuyó el origen de la enfermedad a "comer arroz venenoso". 38

Con el desarrollo de la industria molinera se extendió la práctica del descascarillado del grano, y con el procesamiento industrial se empobreció la calidad nutritiva de este cereal, ya que casi toda la tiamina está en el salvado. De modo que las poblaciones dependientes del arroz blanco, sin saberlo, comenzaron a sustentarse con una dieta deficiente en esta vitamina. Cuando no era satisfecha con la ingesta de otros alimentos, el beriberi se presentó como un importante problema de salud pública.

La metrópoli española, nada ajena a los debates sobre la sanidad imperial en oriente, también se interesó por la cuestión, y en 1897 concedió una comisión gratuita a Tomás del Valle y Ortega, Médico Mayor de la Real Armada destinado en el Hospital de Cañacao, en Filipinas, para que realizara estudios sobre la enfermedad. Interesa subrayar la importancia que la ciencia occidental dio al estudio etiológico del beriberi, cuya prevención, junto a la de la viruela, la fiebre amarilla, la disentería y la malaria, se consideró de gran importancia para la vitalidad de los proyectos coloniales. ${ }^{39}$

${ }^{37}$ Kenneth John Carpenter, Beriberi, White Rice, and Vitamin B: A Disease, a Cause, and a Cure, University of California Press, California, 2000. Alexander R. Bay, Beriberi in Modern Japan. The Makin of a National Disease, University of Rochester Press, Nueva York, 2012.

${ }^{38}$ Por sus contribuciones al descubrimiento de la vitamina antineurítica, Christiaan Eijkman (1858-1930) ganó en 1929 el Premio Nobel de Medicina juntó al bioquímico inglés Frederick G. Hopkins (1861-1947). Klaas Van Berkel, Albert Van Helden y Lodewijk Palm (eds.), A History of Science in the Netherlands, Brill, Leiden-Boston-Köln, 1999.

${ }^{39}$ Creado en septiembre de 1876 al noroeste de Cavite, el Hospital de Marina de Nuestra Señora de los Dolores de Cañacao funcionó como centro sanitario de referencia de la Real Armada Española en Filipinas. Al producirse la Batalla Naval de Cavite (1898) en el contexto de la guerra hispano-estadounidense, Tomas del Valle ejercía como director del hospital. Comisión para estudiar el beriberi al médico Tomás del Valle Ortega, AHN, Ultramar, Leg. 547, $\mathrm{N}^{\circ} .8$, 1897. Sobre la incidencia del beriberi en Filipinas véase: Ken De Bevoise, Agents of Apocalypse: Epidemic Disease in the Colonial Philippines, Princenton University Press, Princenton, 1995. 
Pero la frontera geográfica del beriberi estaba extendida más allá del mundo oriental. Durante el siglo XIX la enfermedad tuvo apariciones frecuentes en las llamadas Indias Occidentales, siendo habitual en plantaciones azucareras del Caribe y Brasil. Una pesquisa realizada en publicaciones médicas cubanas de ese período facilita la referencia de unos 18 trabajos que abordan directamente la etiología e incidencia del beriberi en la mayor de las Antillas. ${ }^{40}$ En nuestra investigación, hemos encontrado otras publicaciones sobre esa enfermedad no referenciadas en la citada pesquisa. Las primeras referencias se remontan a finales del siglo XVIII y hasta bien entrado el XX siguió siendo objeto de debate entre los científicos cubanos, aunque durante esa etapa no todos los casos de beriberi fueron diagnosticados como tal. No fue hasta la segunda mitad del siglo XIX que el beriberi estuvo mejor prescrito en los informes médicos de la época, y aparece con ese nombre en estadísticas de mortalidad. La frecuencia con la que fue investigada y discutida por diversos especialistas revela la importancia que tuvo en la época, llegando en ocasiones a figurar entre las principales causas de mortalidad.

\footnotetext{
${ }^{40}$ Moisés Hernández Fernández, José Antonio López Espinosa y Gregorio Delgado García, "Bibliografía cubana sobre alimentación y nutrición humanas durante los siglos XVIII al XX. Índice de autores y materias", Revista Cubana de Alimentación y Nutrición, vol. 19, №. 1, 2009, pp. 164-172. José Antonio López y otros, "El tema nutrición y alimentación en la bibliografía médica cubana del período colonial", Acimed, vol. 14, No . 5, 2006, pp. 1-14.
} 
IMAGEN 3. MAPA PUBLICADO A FINES DEL SIGLO XIX EN EL QUE SE OBSERVA LA DISTRIBUCIÓN GEOGRÁFICA DEL BERIBERI Y SU INCIDENCIA EN CUBA.

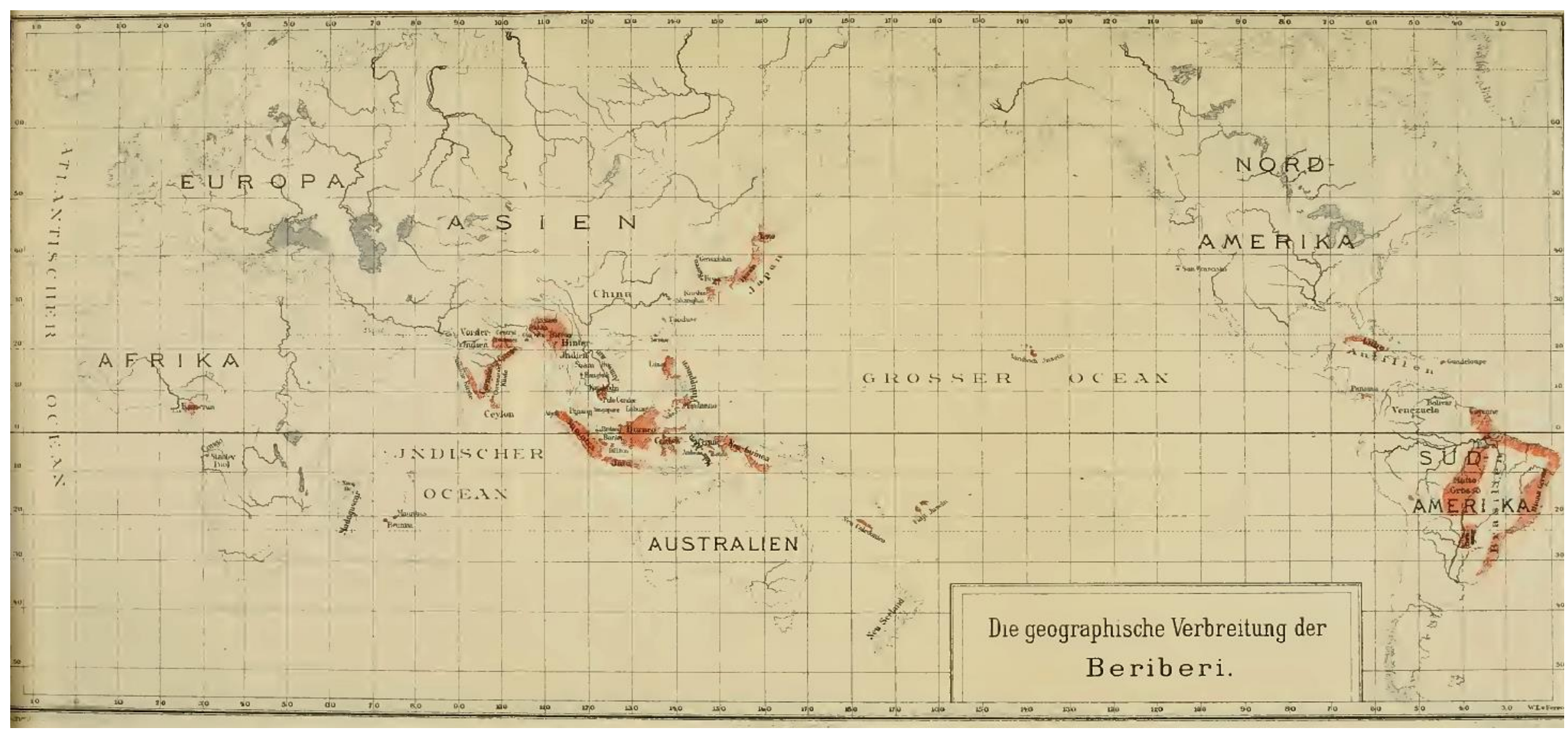

Fuente: B. Scheube, Die Beriberi - Krankheit. Eine geographisch-medicinische Studie, Editor de Gustav Fischer, Jena, 1894. La traducción al castellano de esta publicación alemana es La enfermedad del beriberi. Un estudio geográfico-médico. 
La incidencia del beriberi en Cuba en el siglo XIX estuvo asociada al desarrollo de la agricultura comercial y la imposición de la opción cerealística como dieta básica de una creciente población trabajadora. La transformación que el azúcar operó sobre la economía cubana creó las condiciones sociales propicias para el desarrollo de la enfermedad en cuestión. Si todavía es discutible el aporte calórico neto de la dieta regular proporcionada a los esclavos, son más claras sus deficiencias nutricionales. A una alimentación monótona y deficiente en tiamina, se une el hecho de que en la "isla del dulce" muchos esclavos acudieron frecuentemente a la ingesta de azúcar para palear sus necesidades nutricionales. Moreno Fraginals refiere como los plantadores, en sus reglamentos de gobierno de ingenios, hablaron in extenso del hábito de comer caña de azúcar y la ingesta de guarapo, melado y raspadura desarrollada por lo esclavos, llegando en algunos casos a ocasionar "pérdidas significativas" según las observaciones de algunos técnicos de la época. ${ }^{41}$ De ese modo agotaban las pocas reservas de tiamina en su organismo e incrementaban la deficiencia.

La epidemia de beriberi ocurrida en el ingenio Antonia en el verano de 1871 no fue un caso aislado. Un mes antes de que se desatara allí la enfermedad, se produjo en la Academia de Ciencias Médicas, Físicas y Naturales de La Habana un intercambio a raíz de un informe remitido por el Ayuntamiento en el que manifestaba su preocupación por la explosión de la enfermedad en varias plantaciones, muriendo trabajadores "incluso en fincas en que se preciaban sus dueños de suministrar a las dotaciones los mejores alimentos", como en una de Alquízar, propiedad del Sr. Marqueti, donde habían fallecido 16 asiáticos. ${ }^{42}$ El doctor José A. Reynés que tomó parte en la discusión habida en la Academia, recordó que la aparición de esa enfermedad era frecuente en los años secos cuando faltaban las viandas, y los buenos resultados obtenidos por un antiguo profesor suyo -exmiembro de la Academia- al suministrar a su dotación vegetales frescos. Mencionó también que en la India se había disminuido la ración de arroz en la alimentación de las tropas inglesas por atribuirse a su exceso una influencia marcada en la producción de la enfermedad. El doctor José Ignacio Torralbas también refirió casos de beriberi ocurridos en los polvorines de la Marina durante ese año, faltando las viandas y siendo la comida exuberante en arroz y compuesta sobre todo de tasajo y

\footnotetext{
${ }^{41}$ Manuel Moreno Fraginals, El Ingenio, t. 2, pp. 108-109.

42 "Beriberi", Anales de la Real Academia de Ciencias Médicas, Físicas y Naturales de La Habana, vol. VIII, 1871, p. 161.
} 
bacalao. ${ }^{43}$ Un parte sanitario correspondiente al mes de agosto de 1871 advirtió el aumento en la isla de los casos de disentería y diarreas respecto al mes anterior, y registró tres muertes por cólera y otras tres por beriberi, estas últimas ocurridas "en negros de tribus africanas”. El parte indicaba que el aumento en esa calurosa temporada del año de las enfermedades gastrointestinales estaba asociado a la ingesta de comidas en descomposición. ${ }^{44}$

Tampoco fue la epidemia de 1871 un caso único en el siglo XIX. En la sesión del 13 de agosto de 1865 Juan G. Havá presentó en la Academia de Ciencias de La Habana la primera comunicación recibida en esa institución en la que se caracteriza el beriberi como enfermedad existente en las plantaciones de la isla. Otros facultativos residentes en el campo cubano habían informado y estudiado antes casos semejantes a los que había referido Havá, pero nadie antes que él sugirió que la especie patológica observada en Cuba pudiera ser la misma enfermedad que con el nombre de beriberi o beriberia reinaba en las Indias Orientales. También en la década de 1860 el médico brasileño José Francisco de Lima Silva, pionero en la introducción de la medicina tropical en Brasil, publicó en la Gaceta Médica de Bahía un informe en el que certificaba la existencia del beriberi entre las dotaciones de esclavos de esa región. Como se observa en el mapa anterior, y diversos informes de la época advirtieron, el beriberi se extendió gradualmente por toda la zona costera de Brasil y también hacia el interior, especialmente en las provincias de Pará, Minas-Gerais y Mato Grosso. ${ }^{45}$

En uno y otro lugar los trabajos presentados fueron objeto de discusión, existiendo detractores y partidarios de las hipótesis sostenidas por esos médicos El antropólogo francés Henri Dumont publicó en 1865 sus investigaciones sobre la "hinchazón de los negros y chinos o enfermedad de los ingenios". Las observaciones fueron realizadas en varias plantaciones de Matanzas, y aunque insistió en distinguir entre "hinchazón” y "beriberia”, que a su consideración eran erróneamente asimiladas, las diferencias que alegó entre una y otra en realidad no lo son tanto. Gran parte de la literatura médica posterior sostiene que se trataba de la misma enfermedad, y las evidencias sobran a favor de esta conclusión. Como gran parte de los médicos franceses,

\footnotetext{
${ }^{43}$ Ídem.

44 "Aspecto atmosférico y sanitario de agosto", Anales de la Real Academia de Ciencias Médicas, Físicas y Naturales de La Habana, vol. VIII, 1871, p. 216.

${ }^{45}$ Juan Havá, "Comunicación dirigida a la Academia sobre una epidemia de beriberi", Anales de la Real Academia de Ciencias Médicas, Físicas y Naturales de La Habana, vol. II, 1865, pp. 158-161. Los artículos de Lima Silva fueron compilados en un libro: José Francisco de Lima Silva, Ensaio sobre o beriberi no Brazil, J. B. Martin, Bahia, 1872.
} 
ingleses y brasileños de la época, Henri Dumont puso, equivocadamente, el énfasis en las condiciones climatológicas, particularmente en la incidencia del calor. ${ }^{46}$ En ese año particularmente significativo en el desarrollo del beriberi en la isla, el tabaquero asturiano Saturnino Martínez, a través del primer periódico de los trabajadores en Cuba, daba cuenta de la escasez de alimentos en los siguientes términos:

\begin{abstract}
"Estamos atravesando una época terrible para los trabajadores. La escasez de frutos del país está tocando en lo sumo: un par de tomates cuesta diez centavos, un par de huevos, veinte; una libra de manteca, cuarenta; y muy en breve los plátanos, ese rico producto cubano que muchas veces sustituye al pan, estará colocado á la altura de los precios á que se espenden (sic) los efectos extranjeros. $" 47$
\end{abstract}

TABLA 15: CUADRO DE LA EPIDEMIA DE “HINCHAZÓN” ESTUDIADA POR HENRI DUMONT EN VARIAS FINCAS DE MATANZAS, 1865.

\begin{tabular}{|l|l|r|r|r|}
\hline \multicolumn{1}{|c|}{ Ingenio } & \multicolumn{1}{|c|}{ Partido } & Dotación & \multicolumn{1}{c|}{$\begin{array}{c}\text { Fallecidos } \\
\text { (hasta el 15 de } \\
\text { agosto) }\end{array}$} & \multicolumn{2}{c|}{$\begin{array}{c}\text { Convalecientes } \\
\text { (hasta el 15 de } \\
\text { agosto) }\end{array}$} \\
\hline La Granja & Cimarrones & 300 & 24 & 12 \\
\hline Conteo & Cimarrones & 200 & 2 & 13 \\
\hline Los Atrevidos & Colón & 500 & 21 & 5 \\
\hline La Rudeé & Coliseo & 150 & 14 & - \\
\hline La Paz & Coliseo & - & 6 & - \\
\hline
\end{tabular}

Elaboración propia a partir de la información disponible en: Henri Dumont, Investigaciones generales sobre las enfermedades de las razas que no padecen la fiebre amarilla, pp. 43-44.

La gran mayoría de los casos de beriberi de los cuales tenemos conocimiento directo se produjeron en la región Habana-Matanzas, lo cual revela las diferencias regionales y vulnerabilidades en materia de alimentación que surgieron con el desarrollo de la economía esclavista azucarera en el siglo XIX. En esta región, el patrón dominante en la dieta de los esclavos fue una fécula preparada con arroz pulido y carnes secas, cuyo contenido de tiamina era inferior a los requeridos por el organismo humano. También en Brasil la incidencia del beriberi en el siglo XIX tuvo marcadas diferencias regionales. La década de 1870, coincidiendo con el desarrollo de la Guerra de los Diez Años, fueron particularmente duros en muchas plantaciones en cuanto a la provisión de alimentos. Tenemos testimonios de una terrible epidemia de beriberi ocurrida en 1873

\footnotetext{
${ }^{46}$ Henri Dumont, Investigaciones generales sobre las enfermedades de las razas que no padecen la fiebre amarilla y estudio particular sobre la enfermedad de los ingenios de azúcar o hinchazón de los negros y chinos.

47 "Escaseces", La Aurora, La Habana, 17 de diciembre de 1865, pp. 6-7.
} 
entre las dotaciones de dos fincas próximas a Palmira, Cienfuegos, que causó una mortalidad del $75 \%$ en una y del $60 \%$ en la otra. ${ }^{48}$

Como refleja el gráfico 10, en 1879 se produjeron en Matanzas 182 de las 220 defunciones registradas ese año por beriberi, mientras ningún caso fue reportado en Camagüey, región reconocida por su tradición ganadera y en la cual el acceso a carne fresca era más probable. El gráfico siguiente refleja la mortalidad registrada por beriberi en 1879 en relación al número de ingenios existentes en cada provincia en 1877. La gran mortalidad en la zona azucarera más productiva significa que en esa fecha el beriberi fue la sexta causa de muerte identificada entre su población, superando a la viruela (179) y solo por detrás de la tisis (627), la fiebre tifoidea (329), la disentería (291), la fiebre palúdica (249) y el tétanos infantil (246). Conviene decir que la mortalidad de estas y otras enfermedades determinaron un decrecimiento vegetativo de la población “de color" en Matanzas en los siguientes términos: 4.164 muertes registradas por solo 2.655 nacimientos en $1879 .{ }^{49}$

\section{GRÁFICO 10: CUBA. CORRELACIÓN ENTRE NÚMERO DE INGENIOS Y MORTALIDAD POR BERIBERI, 1879.}

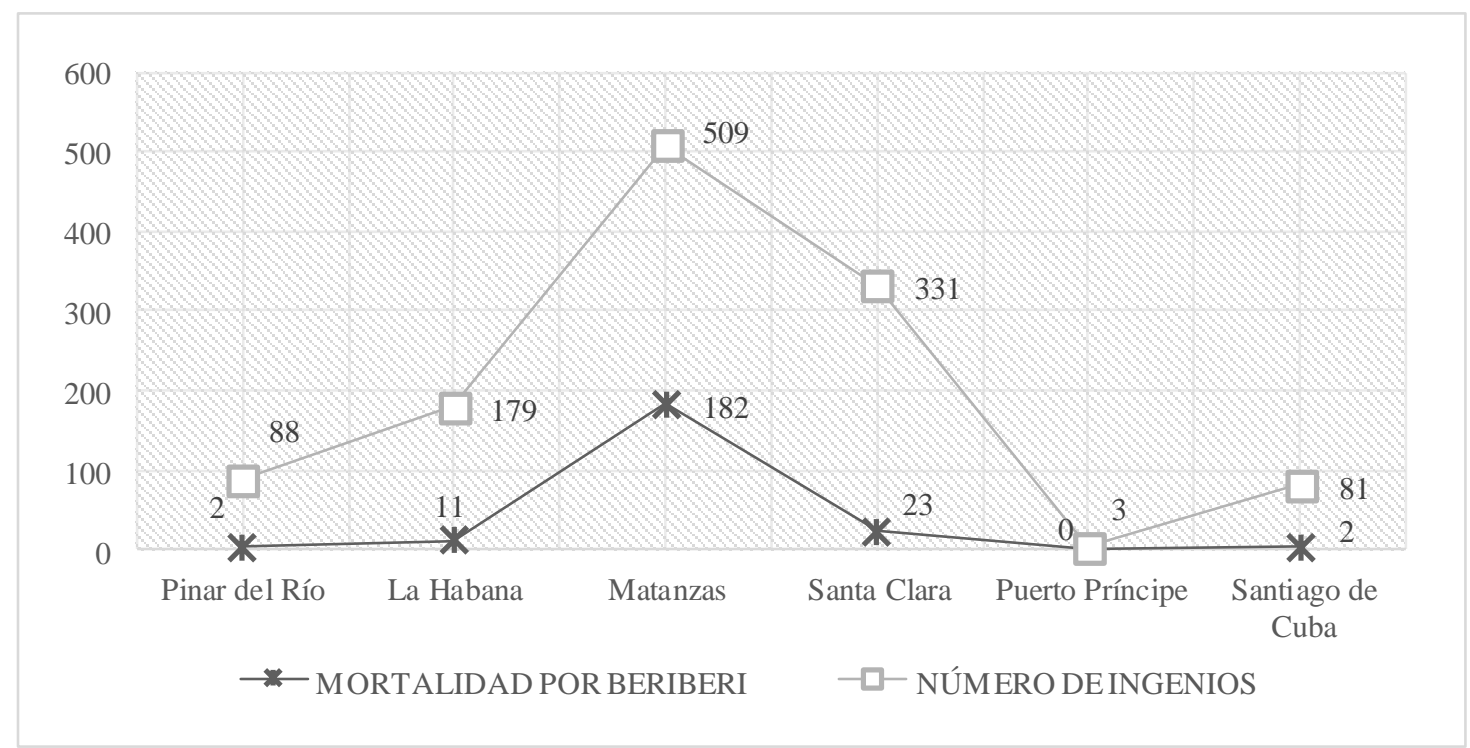

Elaboración propia a partir de la información disponible en: Población, estudios estadístico-demográficos correspondientes a 1879, p. 27.

\footnotetext{
48 "Correspondance Médicale. Lettre sur le Béribéri”, Gazette Médicale de Paris, 3 de enero de 1874, p. 35.

${ }^{49}$ También en La Habana la población "de color" tuvo más muertes que nacimientos ese año, mientras que la población blanca tuvo más nacimientos que defunciones en todas las provincias. Población, estudios estadístico-demográficos correspondientes a 1879.
} 
Asimismo, la morbilidad y mortalidad del beriberi fue diferencial por causas sociales y no biológicas. En Cuba, los principales grupos en riesgo fueron las dotaciones de esclavos y trabajadores contratados en las plantaciones azucareras, que tuvieron un control limitado sobre su dieta y estuvieron sometidos a una explotación más intensiva. El 74,0\% de las defunciones registradas por beriberi en la citada estadística de 1879 fueron esclavos, un 16,3\% libres "de color" y un 9,5\% blancos. Es posible que dentro de estos últimos estuvieran contabilizados algunos trabajadores asiáticos de los contratados en las plantaciones azucareras del occidente cubano. En la provincia de Matanzas, centro de la epidemia, había en 1877 unos 20.000 asiáticos. La mortalidad por sexo fue de $88,6 \%$ varones y $11,4 \%$ mujeres. La fuente consultada no registra la edad de los fallecidos por esta enfermedad, pero podemos presumir que la mayoría de ellos eran adultos jóvenes. Ya el médico Juan G. Havá en el verano de 1865 había dado cuenta de la particular vulnerabilidad de ese grupo. A partir de sus observaciones en el ingenio $L a$ Palma -ubicado en el partido de la Cidra, jurisdicción de Matanzas- informó a la Academia de Ciencias que la mayor parte de los atacados de la enfermedad que entonces diagnóstico de beriberi eran jóvenes de 25 a 30 años de edad, el menor de ellos tenía 16 años y murió a los tres días de enfermedad, y el mayor de los atacados pasaba de 50 años. Havá confrontó su experiencia en la finca "La Palma" con la de los doctores D. Marcos Díaz y D. J. Casabueno, médicos de aquel partido, y estos le confirmaron que también habían visto en algunos ingenios de la región la misma epidemia, "y de que en todos habían observado los mismos síntomas seguidos de un numero considerables de muertes, principalmente en el ingenio Santo Domingo, propiedad de D. Miguel Aldama." $" 50$

${ }^{50}$ Juan G. Havá, "Comunicación dirigida a la Academia sobre una epidemia de beriberi”, p. 160. 


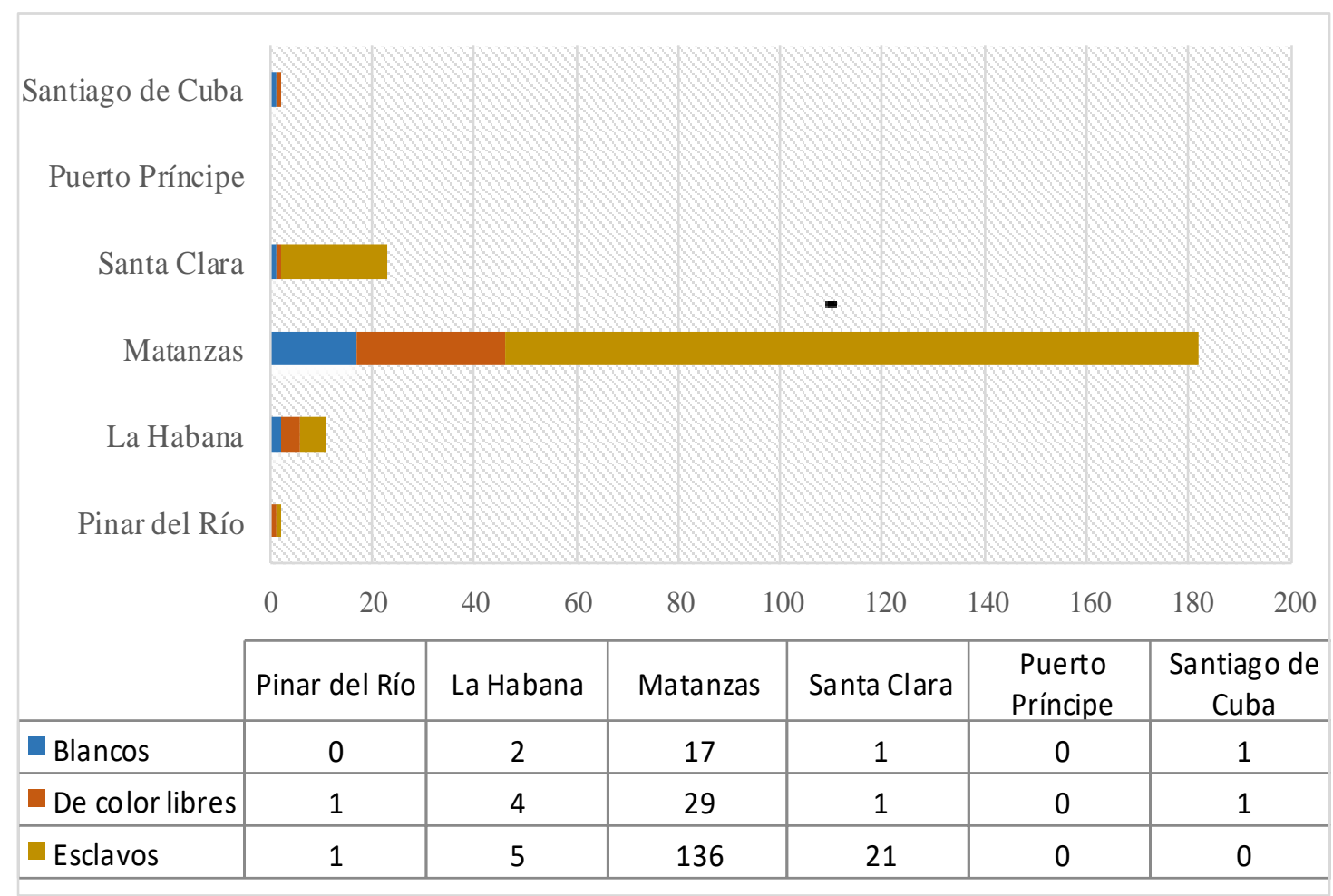

Elaboración propia a partir de la información disponible en: Población, estudios estadístico-demográficos correspondientes a 1879, p. 27.

\section{HINCHAZON O BERIBERI Ouracia con la Fisana Diarética do Artis.}

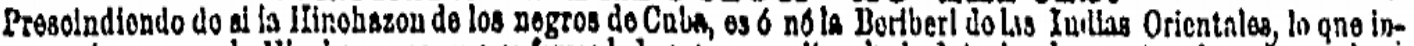

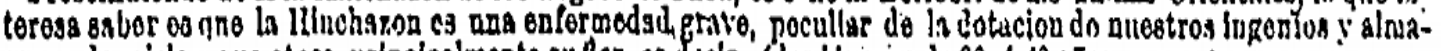

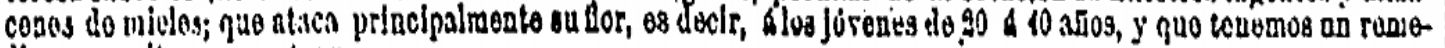
dio para eritar gus estragca.

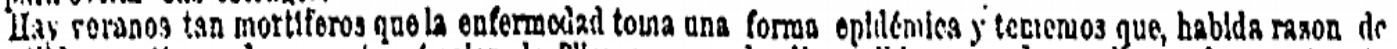

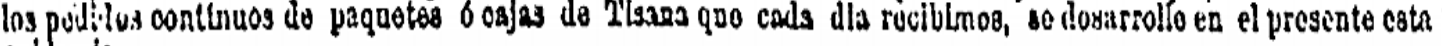
opldemis.

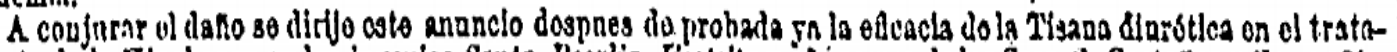

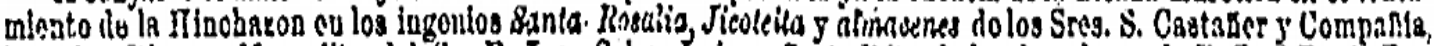

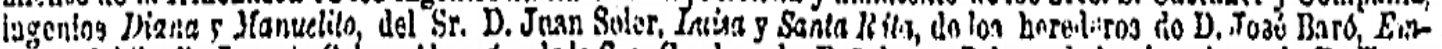

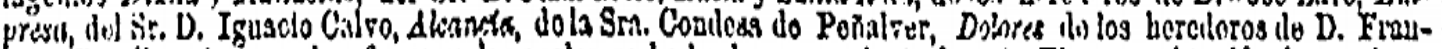

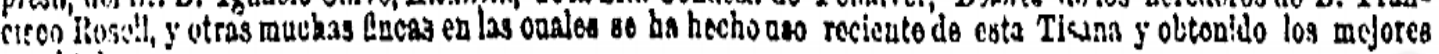
rosilltillos.

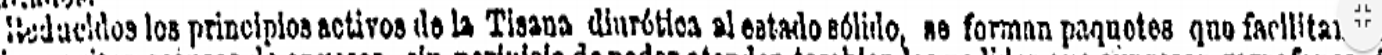

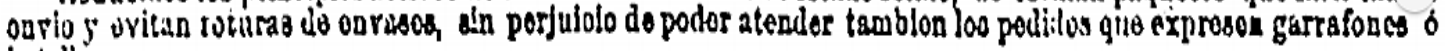
boteillis.

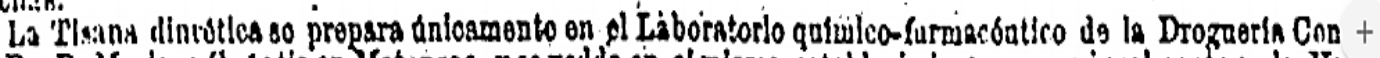

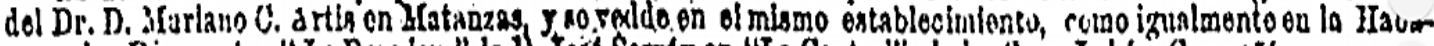

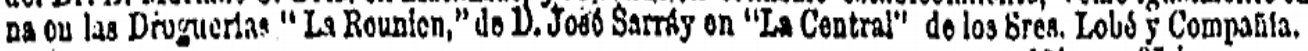

Fuente: Diario de la Marina, 9 de agosto de 1879.

lot $97 \mathrm{Jl}$ 
No solo en el Caribe y Brasil fue diferencial la morbilidad y mortalidad del beriberi, también fue evidente en las Indias Orientales, donde mató a más población nativa que europea, por lo que no existía una predisposición biológica del africano a la enfermedad, como creyó una parte de la comunidad médica cubana del siglo XIX. En la segunda mitad de ese siglo, las posesiones holandesas del Pacífico eran uno de los principales focos de beriberi del planeta. Según un informe del servicio de Sanidad de las Indias Holandesas, en 1894 esta enfermedad atacó, entre la tropas, 816 veces a los europeos y 4.177 a los asiáticos, por lo que fue cinco veces más frecuente en estos últimos y la principal causa de mortalidad entre ellos, con una proporción de 468,61 por mil, cifra superior a las defunciones habidas ese año por fiebre palúdica, infecciones intestinales y tisis pulmonar, e incluso mayor a las producidas por armas de fuego. ${ }^{51}$

En la sesión del 20 de octubre de 1880 el médico brasileño J. Francisco Roldan y Cruz presentó ante la Comisión de Patología Médica de la Academia de Ciencias de La Habana su memoria titulada "De la Hipoemia Intertropical", con la cual pretendía dar a conocer entre los científicos cubanos sus observaciones sobre esa misteriosa enfermedad. ${ }^{52}$ Roldan afirmaba que la "hipoemia", reconocida desde finales del siglo XVIII en las Indias Occidentales con diferentes denominaciones, estaba extendida por los países intertropicales, siendo bastante frecuente en Brasil donde atacaba casi exclusivamente a la "clase de color". Si bien la enfermedad había sido descrita con precisión en sus manifestaciones clínicas, las posiciones sobre sus causas eran divergentes. Unos atribuían su origen a las influencias climatéricas, otros a la ingestión de sustancias tóxicas como medio de suicidio, mientras una tercera posición, a tono con los descubrimientos de los médicos alemanes Wilhelm Greiseinger en Egipto y Otto Wucherer en Brasil, ${ }^{53}$ atribuían su causa a la existencia de vermes en el duodeno, aceptando como factor concomitante las malas condiciones higiénicas en las que vivían

\footnotetext{
${ }^{51}$ Los médicos militares de la época que observaron la incidencia de esta enfermedad en las tropas, advirtieron que existía mayor predisposición a la enfermedad cuando permanecían durante varios meses en un mismo asentamiento, lo que podía favorecer un régimen alimentario monótono. "Estadística Médica de las Indias Neerlandesas en 1894", Revista de Sanidad Militar, Madrid, Año. 10, N. 217, $1^{\text {ro }}$ de julio de 1896, pp. 300-301.

${ }^{52}$ J. Francisco Roldan y Cruz, "De la Hipoemia Intertropical", Anales de la Real Academia de Ciencias Médicas, Físicas y Naturales de La Habana, vol. XVII, 1880, pp. 341-370.

${ }^{53}$ Wilhelm Greiseinger (1815-1877) fue un médico alemán que trabajó en la década de 1850 como director de la escuela médica de El Cairo, Egipto. Otto Eduard Heinrich Wucherer (18201873) fue un médico alemán cuya familia tenía negocios en Brasil, donde ejerció la profesión. La experiencia y trabajos de estos doctores fueron fundamentales para el desarrollo de la medicina tropical y el conocimiento de las enfermedades parasitarias entre la población de las regiones donde ejercieron.
} 
las personas atacadas. La hipótesis parasitaria era defendida por Roldan, aunque también dio gran importancia a la alimentación en la etiología de la llamada "hipoemia". Veamos lo que dijo al respecto:

\begin{abstract}
"Alimentándose la clase pobre, y más particularmente los negros esclavos en el Brasil, de farináceos y de sustancias hidrocarbonadas que fatigan al estómago con un trabajo de que obtiene poca nutrición, se produce una atonía del órgano ó dispepsia continua, que como consecuencia empobrece la sangre, haciendo caer al individuo en una anemia por inanición. A igual resultado conduce la insuficiencia de la alimentación por cantidad..."54
\end{abstract}

A lo que agregaba según sus observaciones en terreno:

"La demostración de este hecho se halla en la frecuencia con que se encuentran los hipoémicos en las fincas que alimentan con escasas raciones á sus esclavos, ó los tienen privados de la carne; en la rareza ó ausencia de esta enfermedad en los que son tratados más humanamente [...] Sabido es que la carne, por su composición, es el alimento exclusivamente reparador; que los feculentos, si por algún tiempo sostienen la vida, no es por cierto muy largo, y su consecuencia, aun conservando el individuo sus formas, es la falta de fuerzas y languidez para el desempeño de sus quehaceres." 55

Roldan indicó además que el abuso de las bebidas alcohólicas era un factor de alguna importancia en la producción de esa enfermedad, aunque el hecho de que atacara también a los niños podía ser una evidencia en contra. No obstante, apuntó que, si la influencia del alcohol "no juega el principal papel, contribuye al menos al empobrecimiento de la sangre por las alteraciones á que todos sabemos dan lugar en la nutrición estas sustancias." Tal intuición estaba en el camino de la veracidad científica. Hoy sabemos que una dieta extraordinariamente baja en grasa incrementa los requerimientos de tiamina en el cuerpo, y que el consumo de alcohol predispone a la enfermedad, ya que el etanol es uno de los principales inhibidores de la tiamina. En el siglo XIX, el alcoholismo fue indicado como causa frecuente de mortalidad entre las capas populares, y es sabido que la ingesta de alcohol fue una práctica habitual entre muchos esclavos. ${ }^{56}$

\footnotetext{
${ }^{54}$ J. Francisco Roldan y Cruz, "De la Hipoemia Intertropical”, p. 346.

${ }^{55}$ Ibídem, p. 347.

${ }^{56}$ En 1880 el alcoholismo fue indicado como causa directa de unas 52 muertes en La Habana, 26 entre la población blanca, y otras tantas defunciones para la "de color". Ambrosio González del Valle, "Resumen de la mortalidad de La Habana en 1880", Anales de la Real Academia de Ciencias Médicas, Físicas y Naturales de La Habana, vol. XVII, 1880, p. 371.
} 
La evaluación realizada por la Academia habanera sobre la memoria presentada por el Dr. Roldan fue leída por el médico Félix Giralt, y se puede resumir a los siguientes puntos:

1. Para sorpresa del médico brasileño, en la Academia cubana sí se conocía, y bien, la enfermedad que él denominó "hipoemia intertropical".

2. Que la erróneamente llamada "hipoemia intertropical" no constituye una nueva entidad morbosa, y presenta las mismas causas, síntomas y lesiones anatómicas que el beriberi.

3. Que el verme llamado Anquilóstomo no es la casusa del mal en cuestión, ya que puede ser consecutivo a la enfermedad. El parásito penetra en el organismo debilitado donde encuentra condiciones propicias para desarrollarse, crecer y multiplicarse. Si así no fuera ¿por qué prefiere al negro?” -preguntan.

4. Que en la memoria del Sr. Roldan nada hay de original -ni una autopsia, ni el más ligero examen de la sangre, ni observaciones clínicas, nada en una palabra que demuestre la acción propia del observador y sí la del compilador- pero sugiere que en el beriberi o "hipoemia", como él le llama, pueden existir parásitos intestinales llamados Anquilóstomos, cuya acción sobre la economía no está aún demostrada. ${ }^{57}$

Nos hemos detenido en la discusión de la memoria del Dr. Roldan porque es representativa de dos aspectos que consideramos significativos. El primero tiene que ver con la importancia que la malnutrición seguía teniendo en la década de 1880 en la producción de enfermedades específicas en la población esclava, cuestión que los plantadores no lograron resolver en las dos únicas sociedades americanas donde todavía no se había abolido la economía esclavista. Evidencia contraria a la idea de una actitud más paternalista de los hacendados hacia el final del sistema. Un segundo aspecto tiene que ver con la producción y circulación de conocimiento científico sobre el beriberi. En torno a esa enfermedad se establecieron colaboraciones y redes entre especialistas que ejercieron en diferentes dominios coloniales, tanto del hemisferio oriental como occidental, al sur y al norte, y ello fue de gran importancia para la administración de

\footnotetext{
${ }^{57}$ Félix Giralt, "Informe acerca de una memoria relativa a la Hipoemia Intertropical", Anales de la Real Academia de Ciencias Médicas, Físicas y Naturales de La Habana, vol. XVII, 1880, pp. 373-383.
} 
territorios bio-económicamente transformados por la esclavitud y el desarrollo de la agricultura comercial.

Aunque la literatura producida entre 1700 y 1900 contribuyó mucho al establecimiento de la sintomatología del beriberi y a su fijación como entidad clínica, no tuvo éxito en lo relativo a su etiología, creando gran confusión al respecto. Muchas de las observaciones médicas realizadas en el siglo XIX registraron la calidad de la alimentación como agente del beriberi, pero no fue hasta la década de 1920 que se estableció con precisión científica que su causa era una deficiencia nutritiva.

En el mes de noviembre de 1897 se desató en la cárcel de Matanzas una epidemia de beriberi con caracteres alarmantes ya que mató al 50\% de los enfermos. Una "enfermedad esporádica" -informa la prensa- que "ataca con frecuencia a la gente de color" y que es conocida también con los nombres de "Hinchazón de los negros y de los chinos y enfermedad de los ingenios". Pero que, según la nota que divulga el hecho, algunos médicos consideraban se trataba de una "fiebre infecciosa". ${ }^{58}$

La epidemia en la cárcel de Matanzas sugiere otra línea de análisis, imposible de abordar aquí, relacionada con la calidad de la alimentación y la incidencia de esta enfermedad en determinadas instituciones: prisiones, asilos, hospitales, escuelas, centros laborales, entre otros. A finales del siglo XIX y principios del XX se produjeron brotes esporádicos en Jamaica y varios lugares del sur de Estados Unidos. Aunque no parece haber sido en este último país una enfermedad igual de preocupante que en el Caribe y Brasil, en 1895-1896 se informó de una epidemia de esta enfermedad entre los pacientes del asilo estatal para enfermos mentales de Tuscaloosa, Alabama y en igual institución de Arkansas. En 1907 otra importante epidemia se desarrolló en el manicomio de Texas, atacando a unas 200 personas de las que murieron 20. Dos años después la junta estatal de salud de California publicó en su boletín mensual una lista de 25 defunciones por esa enfermedad entre 1907-1909: 22 japoneses, dos chinos y un alemán. En esta misma época se reportaron varios casos entre la población convicta de Charleston, Carolina del Sur. También se registró en esa época un número importante de muertes por beriberi en el asilo San Juan de Dios para enfermos mentales, ubicado en Bahía, Brasil, fenómeno que intrigó sobremanera al destacado médico legista Nina

\footnotetext{
${ }^{58}$ También divulgó la noticia el periódico vespertino La Correspondencia de España. A la cárcel de Matanzas fueron enviados desde La Habana dos médicos especialistas para asistir a los atacados y se tomaron otras medidas para evitar que la epidemia progresara. "El beriberi", $L a$ Época, Madrid, Año XLIX, Nº. 17.051, 23 de noviembre de 1897, p. 1.
} 
Rodríguez. ${ }^{59}$ Curiosa relación existe entre la distribución geográfica de la enfermedad y las grandes economías de plantación-esclavista desarrolladas en el continente. En cualquier caso, el debate en torno a la etiología del beriberi estaba muy vivo a principios del pasado siglo. Todavía en 1916 el reconocido epidemiólogo cubano Mario GarcíaLebredo, que señaló la endemia de esa enfermedad en las plantaciones de azúcar, y la indiscutible incidencia en ella de la mala alimentación a la que se sometían los esclavos, no del todo satisfecho con la explicación etiológica existente, consideraba que había un "elemento activo" que la producía, actitud comprensible dentro de la fascinación bacteriológica que vivían entonces las ciencias médicas. ${ }^{60}$

A pesar de la relativa baja mortalidad producida por el beriberi respecto a otras enfermedades de la época, tuvo un alcance significativo sobre la productividad y la demografía del sistema esclavista en Cuba. El impacto de la malnutrición y las enfermedades carenciales sobre el crecimiento económico y el bienestar social no solo debe evaluarse atendiendo a las defunciones que produce, sino además por ser fuente de baja productividad y afectar la capacidad de reproducción de la población atacada. Varias enfermedades crónicas presentan baja mortalidad respecto a otros padecimientos, y sin embargo constituyen verdaderos flagelos sociales. Coincidimos con Kenneth F. Kiple cuando dice que la mortalidad esporádica o epidémica por beriberi en la población esclava adulta revela la punta de un iceberg, ya que un amplio sector de esa población podría haber padecido la enfermedad a niveles subclínicos. ${ }^{61}$

Aunque menos documentado, más importante fue seguramente el impacto del beriberi sobre la mortalidad infantil, considerando que las malnutridas madres esclavas, a través de una lactancia deficiente en tiamina, transmitieron la enfermedad a sus hijos, provocando en estos la muerte prematura. Aunque la madre puede presentar la enfermedad sin mostrar signos clínicos, y convivir con cierta deficiencia de tiamina, el déficit de esa vitamina en la leche materna puede resultar mortal para los neonatos en el período de lactancia. El beriberi infantil por lo general se presenta entre los dos y los seis meses de edad. En Cuba, como en gran parte del Caribe y Brasil, la mortalidad

59 "Beriberi in the United States", Public Health Reports, vol. XXV, N ${ }^{\circ} .26,1^{\text {ro }}$ de julio de 1910 , pp. 921-923. Ronaldo Ribeiro Jacobina y Fernando Martins Carvalho, "Nina Rodrigues, epidemiologista: estudo histórico de surtos de beribéri em um asilo para doentes mentais na Bahia, 1897-1904, História, Ciências, Saúde-Manguinhos, vol. VIII, No . 1, marzo-junio, 2001, pp. 113-132.

${ }^{60}$ Mario G. Lebredo, "Beri-Beri”, Sanidad y Beneficencia, t. XV, No $.1,2$ y 3, enero-febreromarzo, La Habana, 1916, pp. 79-92.

${ }^{61}$ Kenneth F. Kiple, "The nutritional link with slave infant and child mortality in Brazil", The Hispanic American Historical Review, vol. 69, №. 4, noviembre, 1989, pp. 677-690. 
infantil fue uno de los factores condicionantes del fracaso demográfico experimentado por la población esclava, y las consecuencias de ello no fueron solo económicas, sino además socioculturales. ${ }^{62}$

\section{IMAGEN 5: DISTINTOS ASPECTOS DE LESIONES CUTÁNEAS EN DOS MENORES ENFERMOS GRAVES DE AVITAMINOSIS B.}

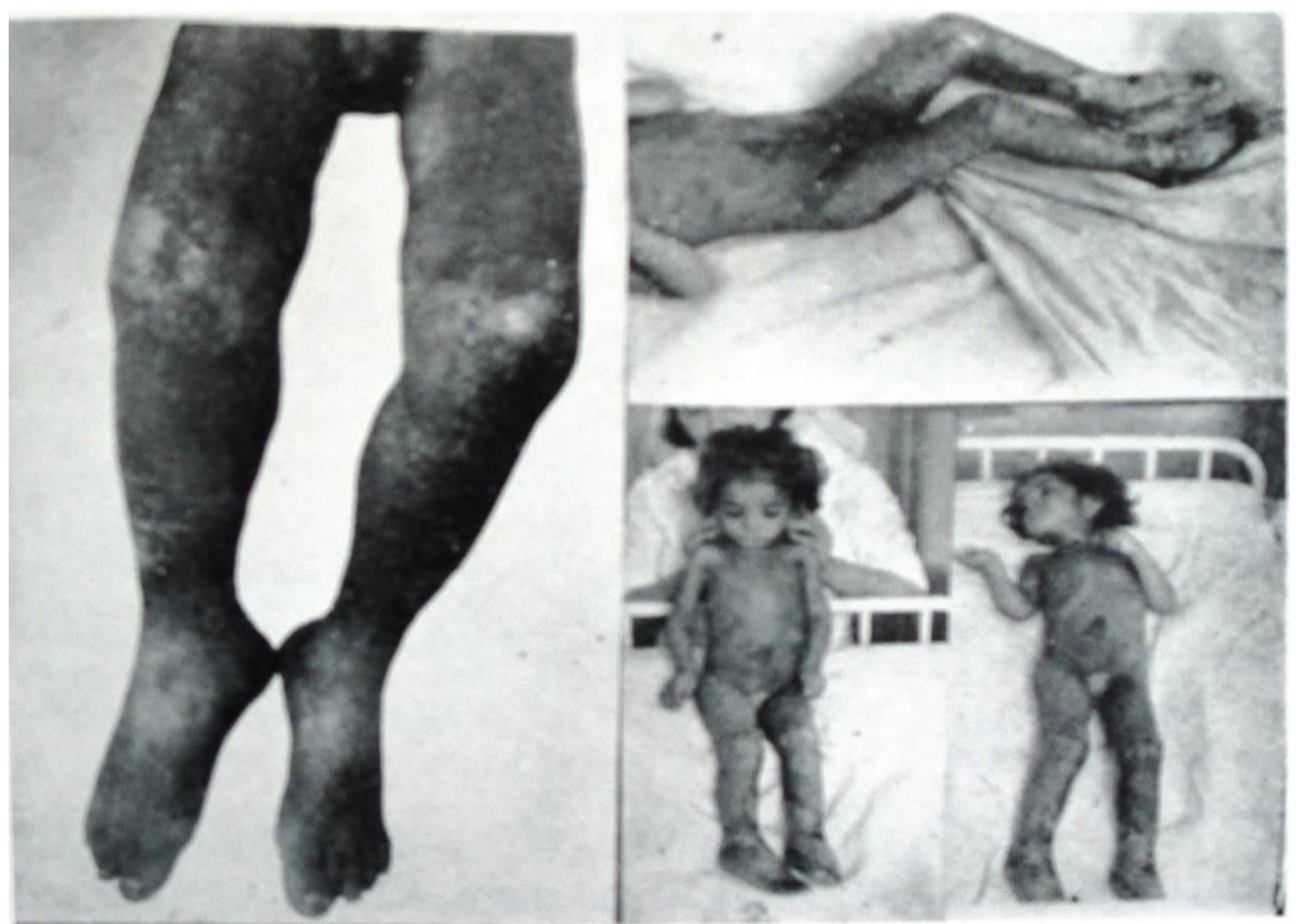

Fuente: Boletín de la Sociedad Cubana de Pediatría, vol. XI, No. 10, octubre, 1939, p. 453.

Hasta bien entrado el siglo XX las enfermedades carenciales correspondientes al déficit del complejo vitamínico B eran las más frecuentes en Cuba. En la dieta diaria de amplios sectores de la población rural y urbana dominaba todavía una fécula excesiva en alimentos hidrocarbonados. ${ }^{63}$ La prevalencia del beriberi en la isla era evidente en la población adulta, pero se revelaba ahora particularmente grave en la población infantil. ${ }^{64}$ Como herencia de la esclavitud, la incidencia de la enfermedad en el siglo XX seguía presentando un marcado carácter diferencial. La falta de recursos económicos y

\footnotetext{
${ }^{62}$ Ídem.

${ }^{63}$ Primer Congreso Nacional de Alimentación, Colegio Médico Nacional, La Habana, 1945, p. 74.

${ }^{64}$ Arturo J. Aballí y Fernando Sala Panicello, "La avitaminosis B del niño en Cuba", Boletín de la Sociedad Cubana de Pediatría, vol. XI, Nº. 10, octubre, 1939, pp. 443-485.
} 
las prácticas impuestas durante décadas -que terminaron forjando hábitos alimentarios muy arraigados- eran los factores determinantes del régimen nutricional deficiente comprobado en gran parte de la población de ascendencia africana. En no pocos casos la enfermedad se presentaba asociada a la deficiencia de otras fracciones del complejo B y el estado de desnutrición de la población enferma favorecía el desarrollo de procesos infecciosos secundarios y más letales, como la tuberculosis.

Como antaño hacían sus abuelos cautivos, los "ciudadanos negros" de la modernidad cubana intentaban suplir las carencias de su alimentación con el consumo de abundante azúcar, hábito adquirido entre la maleza de un sistema económico agitado por el "vendaval en los cañaverales". Una peculiar y nociva práctica desarrollada hasta nuestros días, aunque hace mucho tiempo una destacada nutricionista cubana intentó conjurarla valiéndose de un recurso tan popular como la décima: ${ }^{65}$

\footnotetext{
La Tiamina, es un factor nutritivo, poderoso, del simpático nervioso, del sensitivo y motor; actúa, como un soplador, que el metabolismo, acrece. Cuando de ella se carece, hay reuma, o falta apetito; engorda un caramelito, no se nace o no se crece.

No extrañen, que con Tiamina, seamos tan insistentes; en sus raciones, carentes, van las dietas, en cocina. En Cuba, cáscara fina del arroz, no se aprovecha, y hasta al puerco se le hecha, así su riqueza es alta.

A veces, frijol nos falta, y el trigo, no se cosecha. Ten cuidado campesina con ese caramelito, al niño, quita apetito, porque consume Tiamina, que es $\mathrm{B}_{1}$, vitamina, que está en el grano integral,
}

${ }^{65}$ Gertrudis Aguilera y Céspedes de Ferrer, Alimentos y nutrición en gráficas y cantos populares: asistencia social de puericultura y atención a la manigua, Editorial Lex, La Habana, 1944, p. 231. 
en el frijol, te da igual,

y mucha en puerco o jamón.

Piña, naranja, y limón

$y$ hortaliza en general. 


\section{CAPÍTULO IV: ESCLAVITUD Y EPIDEMIOLOGÍA HISTÓRICA}

Refiriéndose a la década de 1830, José de Armas y Céspedes habló de un exceso de defunciones sobre nacimientos entre los esclavos que arroja como término medio el $8,5 \%$ anual, teniendo en cuenta que si en los cafetales tal exceso sube solo al 5\%, en los ingenios se eleva al 10\%. ${ }^{1}$ Un contraste determinado por la mayor intensidad de la explotación a la que estaban sometidos los cautivos en las plantaciones azucareras. De acuerdo con los datos estadísticos del Conde Armildez, en 1862 se registraron en toda la isla 8.739 bautismos por 9.089 entierros, para un balance negativo de 350 vidas. El centro de tal decrecimiento fue el Departamento Occidental, donde se registraron 7.164 bautismos y 7.686 entierros, para una diferencia adversa de 522 existencias. Mientras que el balance fue positivo para el Departamento Oriental con 1.575 bautismos y 1.403 entierros. ${ }^{2}$ No es necesario que nos extendamos ahora en referencias de autores clásicos que sugieren una estrecha relación entre las tasas de mortalidad y la actividad productiva de la población cubana en el siglo XIX.

La tasa bruta de mortalidad que proporciona Moreno Fraginals en El Ingenio apenas varió en el intervalo 1835-1841 y 1856-1860: 63 y 61 por mil respectivamente, cifras equivalentes a una destrucción anual de la población activa superior al 5\%. Índice elevado, como él mismo señala, si tenemos en cuenta que eran personas físicamente seleccionadas por los negreros. ${ }^{3}$ El demógrafo Juan Pérez de la Riva habla de una sobremortalidad azucarera que calculó en un $7 \%$ anual para la década de $1870 .{ }^{4}$ En esta línea de análisis, el historiador español José A. Piqueras destacó, junto a la imprecisión de los registros oficiales para analizar la dinámica demográfica del sistema esclavista en sus últimos años, el hecho de que hasta el final del mismo los propietarios explotaron de manera intensa el trabajo en las plantaciones. Una fuente de la época, oficial y reservada, citada por él, reconoce una mortalidad esclava mínima del 6,2\% para principios de la década de 1870. Un cálculo realizado para el período 1871-1877,

\footnotetext{
${ }^{1}$ José de Armas Céspedes, El trabajo Libre, La Propaganda Literaria, La Habana, 1880, p. 22.

${ }^{2}$ Conde Armildez de Toledo, Noticias estadísticas de la Isla de Cuba en 1862.

${ }^{3}$ Manuel Moreno Fraginals, El Ingenio, t. 2, p. 88.

${ }^{4}$ Juan Pérez de la Riva, Para la historia de la gente sin historia, p. 110.
} 
basado en una estadística oficial de este último año, y dando por fallecida una diferencia de 29.550 esclavos entre una y otra fecha -de los cuales nada dice la fuente consultada-, arroja una mortalidad anual del 4,2\%, más aproximada a la realidad que ocultan los informes estatales publicados. José A. Piqueras nos recuerda que ese digito, a raíz de lo dispuesto en la Ley Moret, no contabiliza como esclavos los nacidos en ese período y los mayores de 60 años, grupos particularmente vulnerables, máxime, cuando muchos permanecen atados a la rutina del ingenio. De este modo, Piqueras concluye que "la vía más frecuente por la que después de 1880 alguien dejaba de ser esclavo era la muerte". 5

La historiadora Imilcy Balboa refiere un hecho que refleja la naturaleza destructora del ingenio en el período que abordamos. Como alternativa al trabajo esclavo, entre 1868 y 1887 se implementó en algunas plantaciones la contrata de penados. En ese período fallecieron un total de 1.732 presos, para un promedio anual de 91 muertes, cifra equivalente al 7,5\% de la población carcelaria existente de forma regular en el presidio de La Habana. Por tal razón, los ingenios fueron conocidos entonces como "el matadero del presidio". 6

De acuerdo con los guarismos del ensayo estadístico demográfico publicado por la Dirección General de Hacienda en 1879, se produjo entonces un crecimiento vegetativo moderado para la población blanca y el balance fue negativo para la "de color”. La población blanca, que representaba en 1879 el 67\% del total del país, aportó el $61 \%$ de la mortalidad ocurrida ese año. En contraste, la población "de color" que representaba el 33\% de la población del país aportó el 39\% de la mortalidad general. Solo en las provincias de Santa Clara y Pinar del Río el crecimiento fue positivo para ambos grupos demográficos, aunque en la primera se produjo muy por debajo del $1 \%$. El negativo balance entre nacimientos y defunciones registrados para la población negra y mestiza fue más acusado en las provincias de Matanzas y La Habana. La concentración racial y la geografía laboral fueron los principales factores determinantes de las desigualdades en salud. La fuente consultada revela la estrecha relación existente entre azúcar y mortalidad, siendo la Cuba A, para decirlo con el concepto de Pérez de la Riva, la región del país con mayores probabilidades para morir. Matanzas, con el 17\% de la población censada en 1877 aportó en 1879 el 22\% de la mortalidad. La tisis, la fiebre tifoidea, la disentería, el paludismo, el tétanos infantil, el beriberi, la viruela, la

\footnotetext{
${ }^{5}$ José A. Piqueras, "Censos lato sensu. La abolición de la esclavitud y el número de esclavos en Cuba”, p. 226.

${ }^{6}$ Imilcy Balboa Navarro, Los brazos necesarios. Inmigración, colonización y trabajo libre en Cuba (1878-1898), Fundación Instituto de Historia Social, Valencia, 2000, p. 194.
} 
enteritis, la hidropesía y las enfermedades del corazón, por ese orden de importancia, cobraron en vidas a la Atenas de Cuba su gran contribución a la economía insular. Otro tanto hicieron los colosos azucareros de la llanura habanera. La Habana concentró en 1879 el 31,6\% de la mortalidad de la población negra y mestiza, una cifra superior a su proporción $(26,23 \%$ en 1877$)$ en el conjunto de la provincia. ${ }^{7}$

\section{GRÁFICO 12: CUBA. RELACIÓN (\%) ENTRE POBLACIÓN “DE COLOR”, INGENIOS Y MORTALIDAD, 1879.}

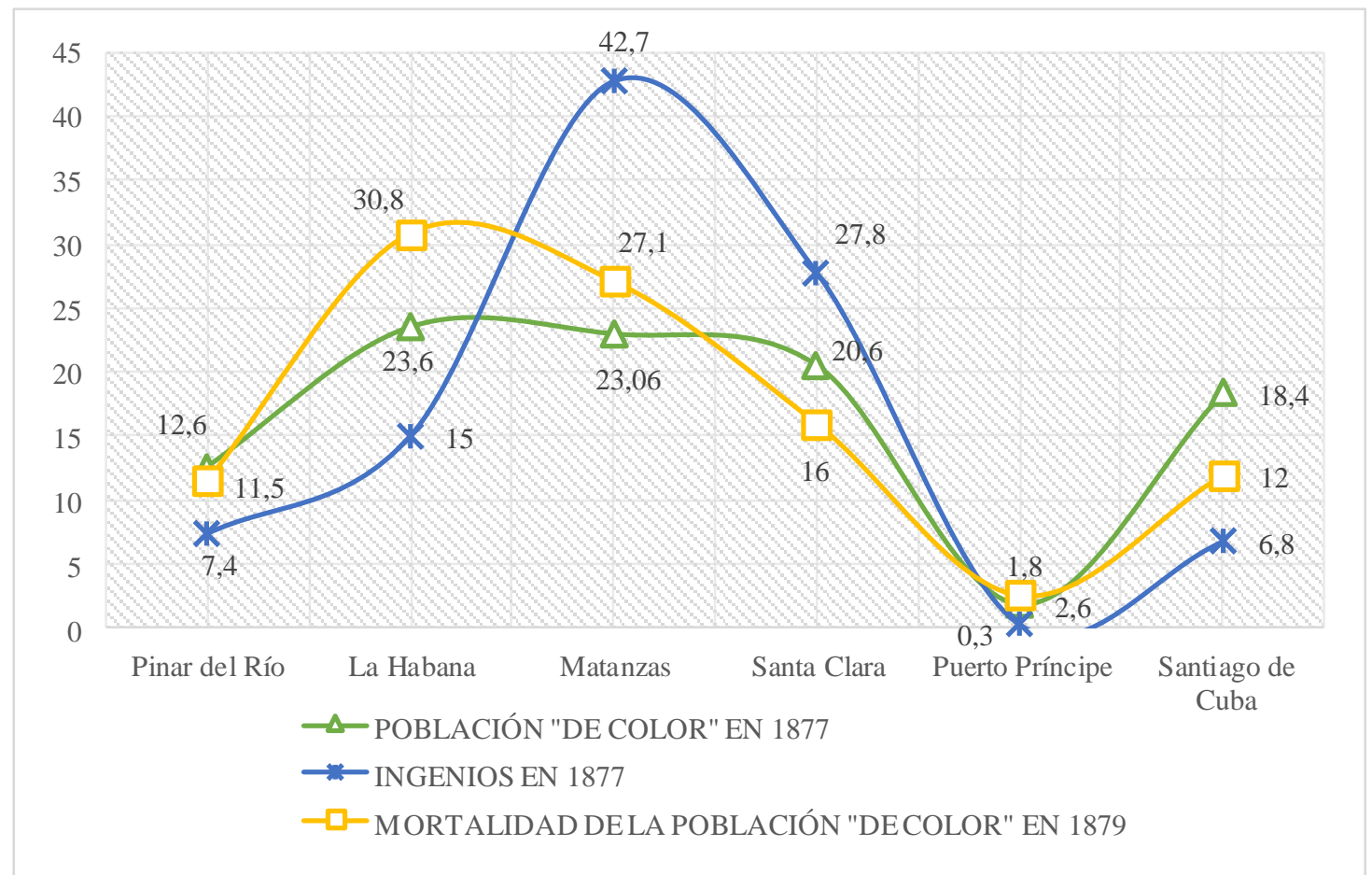

Elaboración propia a partir de la información disponible en: Dirección General de Hacienda, Población. Estudios estadístico- demográficos correspondientes a 1879.

Con las notables excepciones de la fiebre amarilla y el beriberi, cuya incidencia estuvo muy concentrada en La Habana y Matanzas, respectivamente, existe homogeneidad en cuanto a las principales causas de defunciones. Además de las excepciones antes señaladas, que son las más importantes, otras enfermedades tuvieron a nivel regional un impacto mayor que algunas de las enfermedades registradas como principales causas de mortalidad para la isla en 1879. Por ejemplo, el tétanos de adultos,

\footnotetext{
${ }^{7}$ Calculamos la mortalidad registrada en 1879 en razón de la población censada en 1877, tal y como se realiza en la fuente consultada, por no disponer de datos generales de población para el primer año. No obstante, no se produjo en ese corto plazo una variación significativa de los porcentajes indicados. Dirección General de Hacienda, Población. Estudios estadísticodemográficos correspondientes a 1879.
} 
una enfermedad con un impacto moderado a escala nacional, causó en Matanzas, en el año indicado, más muertes que la neumonía, un tanto más letal para el conjunto de la población cubana. Es importante subrayar que las enfermedades que afectaron a la población "de color" -y esclava en particular- también afligieron a la blanca. No es la raza, sino el entorno socio-ambiental en el que cada grupo demográfico desarrolló su existencia la base explicativa de las desigualdades en salud registradas.

Las enfermedades infecciosas fueron las principales responsables de la mortalidad global, un patrón epidemiológico que se mantuvo hasta bien entrado el siglo XX. Atendiendo a la estacionalidad de la mortalidad, tiende a aumentar en los meses de mayo a septiembre, coincidiendo con la época de lluvias y el estío, cuando la virulencia de algunas enfermedades contagiosas fue más notable. Si bien el porciento de casos en los que no se indica el motivo de las defunciones es elevado -aparecen agrupadas con el término "otros males"- si están precisadas las enfermedades más importantes de la época. Dado el desarrollo médico y la experiencia alcanzada para la fecha de esta publicación, existe mayor precisión en el diagnóstico diferencial de las afecciones registradas, aunque se desconoce la etiología de muchas de ellas. El progreso es evidente en el diagnóstico de las llamadas fiebres o calenturas, teniendo en cuenta la distinción que se establece frente a la tradicional clasificación bajo una misma nomenclatura.

Atendiendo a la condición social, existe un impacto diferencial considerable. Los esclavos, que en 1879 eran el 12\% de la población total del país, aportaron el 10\% de la mortalidad general ese año. El hecho de que la mortalidad global de la población esclava sea inferior a su proporción en el conjunto nacional se explica si tenemos en cuenta que a raíz de la promulgación de la Ley Moret, los mayores de 60 años y los nacidos desde esa fecha fueron declarados libres, pasando al régimen de patronato estipulado. Una parte considerable de la mortalidad registrada en 1879 correspondió a personas de entre 0 y 10 años y a mayores de 60 años. Por lo cual, la desventaja en cuanto a supervivencia de la gente "de color" jurídicamente libre es notoria si tenemos en cuenta que representando en esa fecha el $21 \%$ de la población total del país, aportó el $29 \%$ de las defunciones. ${ }^{8}$

Diversos testimonios médicos dieron cuenta de la mayor morbilidad y mortalidad de la población africana en la isla. Por ejemplo, el doctor José A. Reynés

\footnotetext{
8 Ídem.
} 
aclaró que a pesar del notable desarrollo del sistema muscular que se observaba a simple vista en los negros de muchas fincas, producto del trabajo sostenido que realizaban, ellos no oponían a muchas enfermedades la resistencia que la raza blanca, que en la población esclava las epidemias causaban más estragos y que la proporción de mortalidad en toda clase de afecciones es superior en ese grupo. ${ }^{9}$ Como aproximación a esta idea, examinemos algunas causas de muerte registradas en la provincia de Matanzas en 1879. Ciñéndonos exclusivamente a la población esclava, la mortalidad en números de este grupo supera a la blanca -y a la jurídicamente libre- no solo en el caso realmente extraordinario del beriberi, sino además por otras causas como el cólera esporádico, los accidentes del parto, la hepatitis, las enfermedades del hígado, la fiebre puerperal, la hidrofobia, hemorragias, la hidropesía, el tétano de adultos, la neumonía, las enfermedades del corazón, el pénfigo y la tos ferina. Datos que reflejan la descomunal vulnerabilidad epidemiológica de la población cautiva en esta región. Si a ella sumamos las defunciones de la población "de color" jurídicamente libre, la sobremortalidad respecto a la blanca es patente en prácticamente todas las causas indicadas, destacando los casos de disentería, paludismo, tétano infantil, cólera infantil, diarrea de los países cálidos, accidentes de la dentición, apoplejía, escarlatina, erisipela, eclampsia infantil, entre otras. La única enfermedad registrada para la que la población "de color" poseía una inmunidad comparativamente notable en esta región era para la fiebre amarilla. ${ }^{10}$

Téngase en cuenta que la variable racial no refleja toda la complejidad de las desigualdades en salud resultantes de la dinámica de la economía colonial. Más exacta que la distinción general que establecemos entre razas es, por ejemplo, la contraposición entre plantadores y esclavos, aunque es también más difícil de estimar.

Una parte considerable de la población blanca, entre ellos colonos asiáticos y yucatecos introducidos desde la década de 1840, vivían en condiciones similares a la de muchos negros y mulatos, y su mortalidad también era superior a la de la media de la población blanca criolla o peninsular. En 1879 se registraron 972 defunciones de asiáticos, el $46 \%$ de ellas en la provincia de Matanzas y otro $31 \%$ en La Habana. ${ }^{11}$ Otros

\footnotetext{
9 José A. Reynés, "Algunas consideraciones generales sobre la raza negra, su patología y terapéutica", Anales de la Real Academia de Ciencias Médicas, Físicas y Naturales de La Habana, vol. V, 1868, pp. 147-148.

10 Dirección General de Hacienda, Población. Estudios estadístico-demográficos correspondientes a 1879.

${ }^{11}$ Ídem.
} 
indicadores también deben estudiarse con mayor profundidad. Por ejemplo, la mortalidad diferencial en relación al lugar específico de residencia, entre los hospitales civiles y los militares, entre pardos y morenos, criollos y bozales, y también en relación al estado civil de la población. Sobre este último punto, es evidente que la formación de unidades familiares fue un elemento potenciador de salud. Por lo general, una familia de esclavos era el resultado de un desempeño relativamente ventajoso dentro del sistema. Podían contar con determinados beneficios otorgados por el dueño de la finca e incrementaba las aspiraciones personales de cara al futuro. El impacto positivo de este hecho se puede apreciar en las menores tasas de mortalidad entre la población casada que entre los solteros. También en los diferenciales de mortalidad entre los hijos legítimos e ilegítimos, por lo general en favor de los primeros.

Una última acotación es necesaria. Las estadísticas oficiales no reflejan la magnitud del impacto de muchas enfermedades, teniendo en cuenta que regularmente se conformaron con los partes mensuales remitidos por las Juntas Subalternas de Sanidad a la Superior de la isla, documentación que no comprende un número considerable de enfermos no asistidos por los facultativos encargados de realizar los antedichos informes. En la década de 1850, Ramón Piña estimó que cerca de una tercera parte de la población enferma de la isla se curaban por sí solos, con remedios caseros o con los criterios de "los innumerables curanderos que hormiguean por toda la Isla."12 Las omisiones, incluso en tiempos de epidemias, fueron corrientes en las áreas rurales y de manera particular en los ingenios.

\footnotetext{
${ }^{12}$ Ramón Piña, Topografía médica de la isla de Cuba, Imprenta y Encuadernación del Tiempo, La Habana, 1855, p. 72.
} 
TABLA 16: CUBA. CRECIMIENTO VEGETATIVO, POR RAZA Y PROVINCIA, 1879.

\begin{tabular}{|c|c|c|c|c|c|c|}
\hline \multicolumn{2}{|c|}{ Población blanca } & \multicolumn{2}{|c|}{ Cifra absoluta } & \multicolumn{2}{|c|}{ x 100 habitantes } & \multirow[b]{2}{*}{ Diferencia porcentual de N/D } \\
\hline Provincias & Población en 1877 & Nacimientos & Defunciones & Nacimientos & Defunciones & \\
\hline Pinar del Río & 129.724 & 5.327 & 2.665 & 4,11 & 2,05 & 2,06 \\
\hline La Habana & 312.447 & 9.534 & 10.224 & 3,05 & 3,27 & $-0,22$ \\
\hline Matanzas & 141.978 & 4.368 & 4.409 & 3,08 & 3,11 & $-0,03$ \\
\hline Santa Clara & 215.433 & 6.099 & 4.164 & 2,83 & 1,93 & 0,9 \\
\hline Puerto Príncipe & 46.987 & 1.444 & 900 & 3,07 & 1,92 & 1,15 \\
\hline Santiago de Cuba & 116.606 & 4.339 & 1.868 & 3,72 & 1,6 & 2,12 \\
\hline Cuba & 963.175 & 31.111 & 24.230 & & & \\
\hline \multicolumn{2}{|c|}{ Población "de color" } & \multicolumn{2}{|c|}{ Cifra absoluta } & \multicolumn{2}{|c|}{ x 100 habitantes } & \\
\hline Provincias & Población en 1877 & Nacimientos & Defunciones & Nacimientos & Defunciones & Diferencia porcentual de N/D \\
\hline Pinar del Río & 59.496 & 2.437 & 1.762 & 4,1 & 2,96 & 1,14 \\
\hline La Habana & 111.096 & 3.249 & 4.722 & 2,92 & 4,25 & $-1,33$ \\
\hline Matanzas & 108.750 & 2.655 & 4.164 & 2,44 & 3,83 & $-1,93$ \\
\hline Santa Clara & 96.959 & 2.654 & 2.450 & 2,74 & 2,53 & 0,21 \\
\hline Puerto Príncipe & 8.472 & 348 & 399 & 4,11 & 4,71 & $-0,6$ \\
\hline Santiago de Cuba & 86.799 & 3.327 & 1.839 & 3,83 & 5 & $-1,17$ \\
\hline Cuba & 471.572 & 14.670 & 15.336 & & & \\
\hline
\end{tabular}

Elaboración propia a partir de la información disponible en: Dirección General de Hacienda, Población. Estudios estadístico-demográficos correspondientes a 1879. 


\section{GRÁFICO 13: CUBA. PARTICIPACIÓN (\%) DE CADA PROVINCIA EN LAS PRINCIPALES CAUSAS DE MORTALIDAD, 1879.}

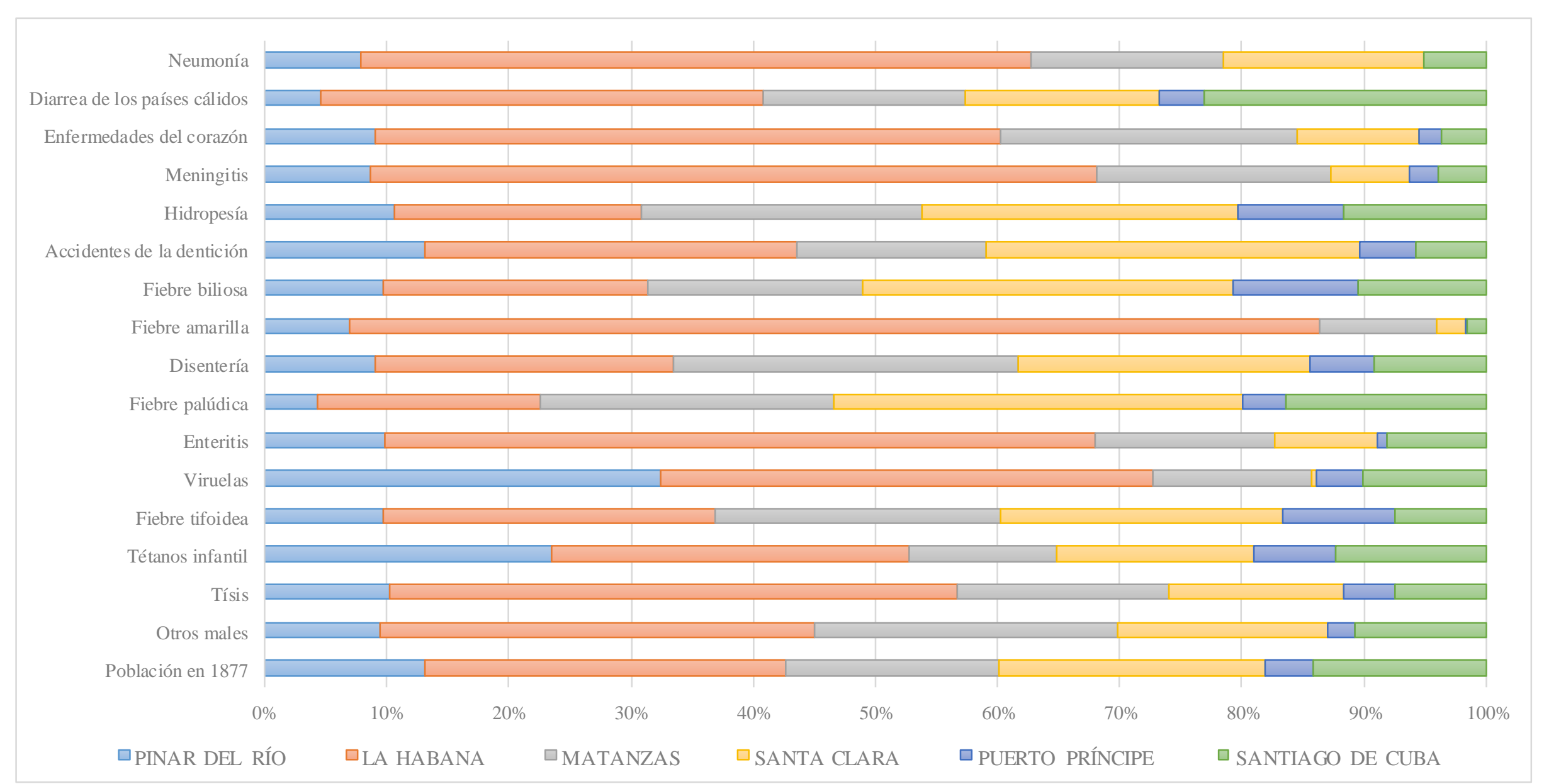

Elaboración propia a partir de la información disponible en: Dirección General de Hacienda, Población. Estudios estadístico-demográficos correspondientes a 1879. 
GRÁFICOS 14 Y 15: CUBA. NACIMIENTOS Y DEFUNCIONES DE CADA RAZA, 1793-1879.

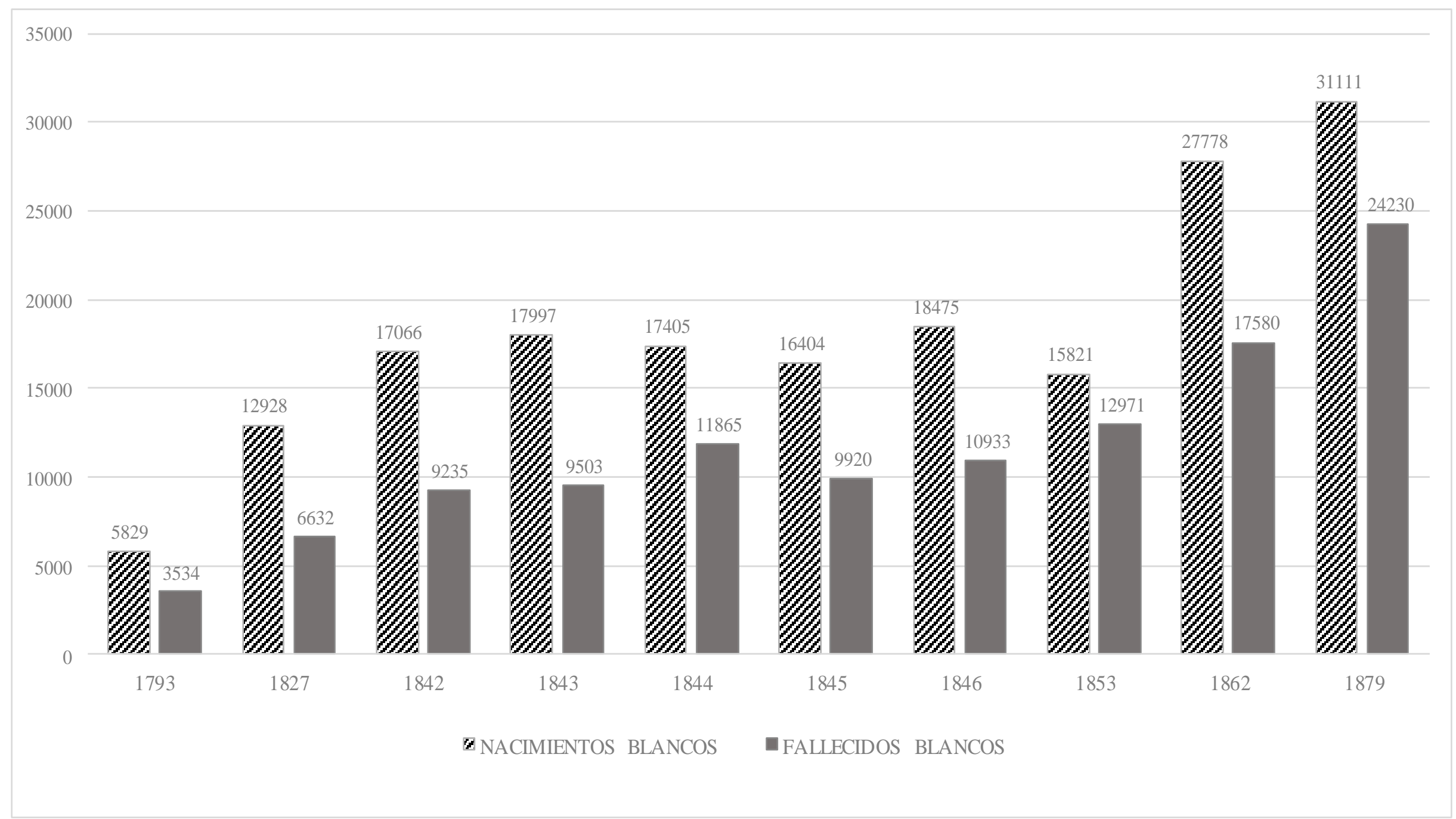




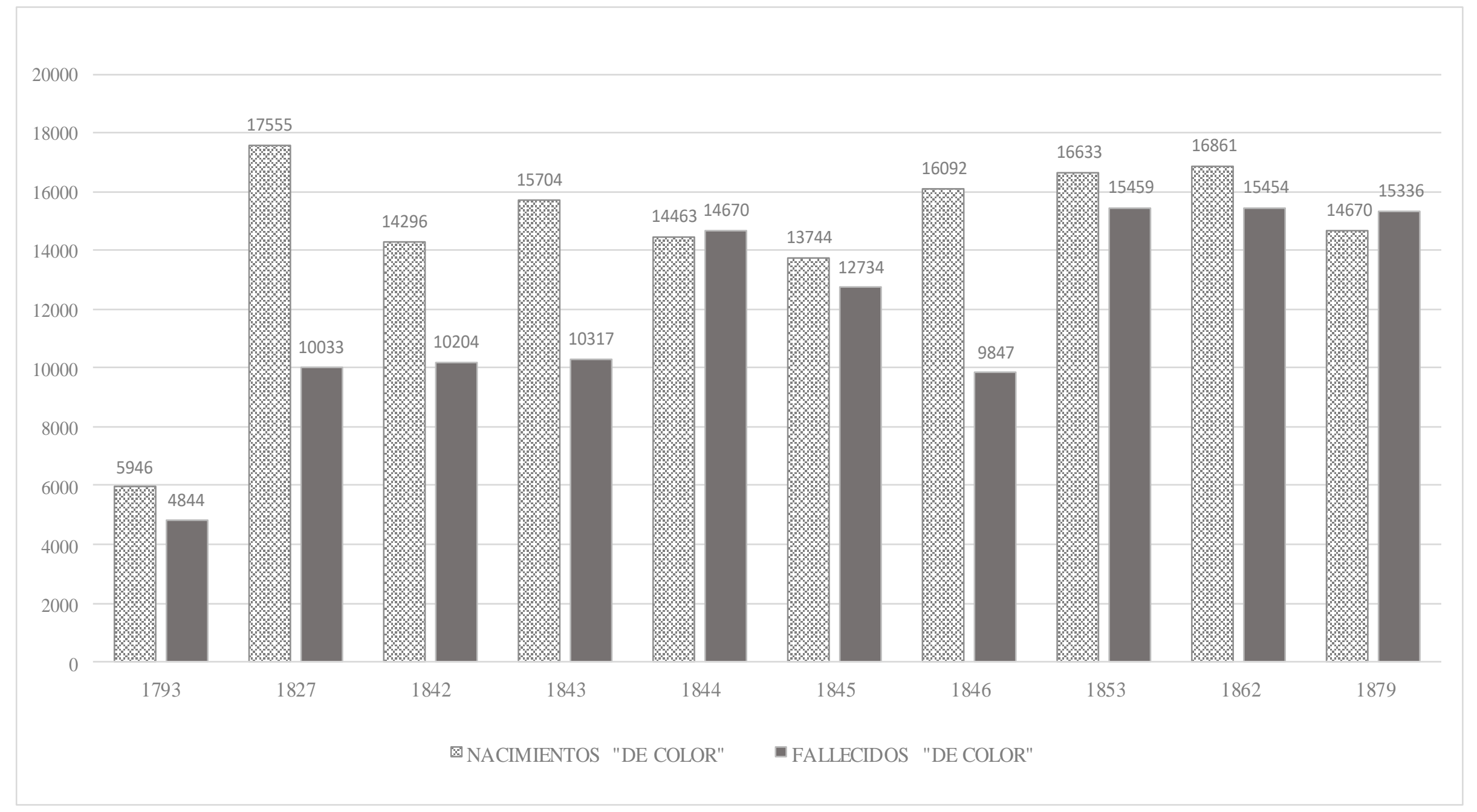

Elaboración propia a partir de la información disponible en: Dirección General de Hacienda, Población. Estudios estadístico-demográficos correspondientes a 1879. 


\section{GRÁFICO 16: CUBA. MORTALIDAD POR RAZA Y GRUPO ETARIO, 1879.}

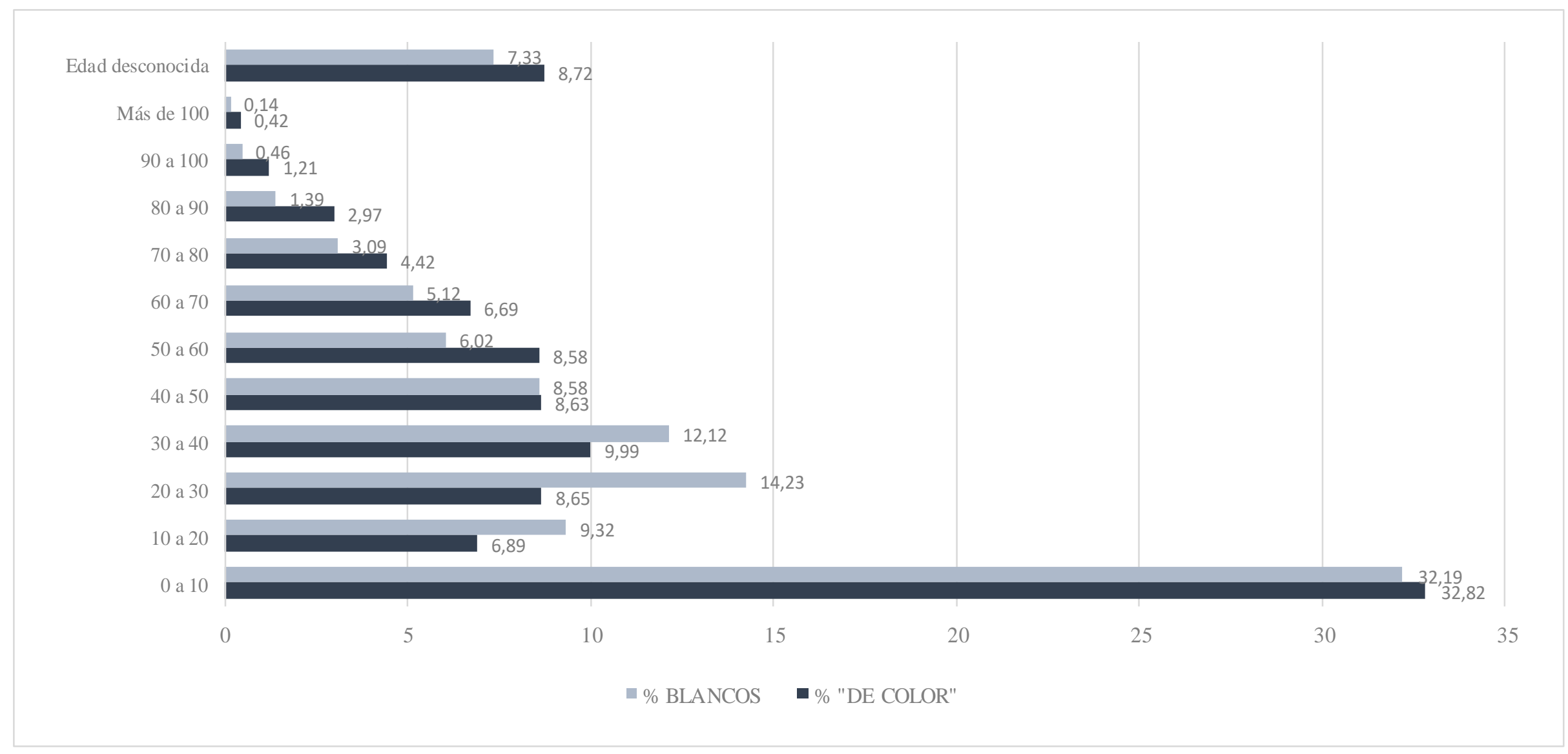

Elaboración propia a partir de la información disponible en: Dirección General de Hacienda, Población. Estudios estadístico-demográficos correspondientes a 1879. 


\section{GESTACIÓN EN CAUTIVERIO Y MUERTE PREMATURA}

Moreno Fraginals sugiere que en las últimas décadas del sistema esclavista hubo un notable rejuvenecimiento de la población esclava, resultado de una "política consciente de procreación", del "deliberado esfuerzo de los amos por mejorar el nivel de vida de los esclavos para conservar el capital invertido" y de la "dramática disminución de la mortalidad infantil". Para él, un aumento de la fecundidad y una reducción de la mortalidad bruta redundaron en una disminución "sensible" de la población activa, lo cual implicó una disminución de la productividad per caput - "si se mantiene constantemente la tecnología"- y un aumento de los gastos del "personal improductivo". Factores que terminaron haciendo "irrentable el sistema". ${ }^{13}$

Para encuadrar su concepción un tanto idealizada de la lógica capitalista del sistema, Moreno Fraginals distorsiona la evolución demográfica del paisaje azucarero cubano. Cuando menos, proyecta para el conjunto de la población esclava una realidad verificada solo en algunas fincas. En cambio, consideramos que no se produjo en esta etapa un proceso generalizado de crecimiento vegetativo en el sistema esclavista cubano, debido a un cambio significativo hacia un régimen productivo y de vida más apacible. Tampoco la enunciada crisis bajo esos fundamentos.

En 1841 la población esclava entre uno y quince años representaba el 22,68\% del total. ${ }^{14}$ De acuerdo con un empadronamiento de 1855 , la población esclava menor de doce años representó el $21,84 \%$ del total. La proporción de este grupo era ligeramente superior entre los esclavos urbanos $(22,11 \%)$ que entre los rurales $(21,78 \%)$. Hacia 1860 esa relación descendió ligeramente en el campo (20,99\%) y aumentó en las poblaciones $(23,56 \%)$. En ese año, los esclavos menores de doce años constituían el $21,44 \%$ del total contabilizado en la isla. ${ }^{15}$ Este dato global tuvo, por ejemplo, un reflejo casi exacto en la estructura por edades de las dotaciones de los

\footnotetext{
${ }^{13}$ Moreno Fraginals omite las referencias de las fuentes que avalan esta parte de su investigación. Manuel Moreno Fraginals, El ingenio, t. 2, p. 85. Esta hipótesis también ha sido apoyada por: Jorge Ibarra Cuesta, Marx y los historiadores ante la hacienda y la plantación esclavistas, pp. 181-198. Una crítica temprana a estos argumentos fue realizada en uno de los estudios más importantes realizados hasta la fecha sobre las últimas décadas del sistema esclavista en Cuba: Rebecca J. Scott, La emancipación de los esclavos en Cuba: la transición al trabajo libre, 1860-1899, Fondo de Cultura Económica, México D. F., 1989.

${ }^{14}$ Resumen del censo de población de la isla de Cuba a fin del año de 1841, Imprenta del Gobierno, La Habana, 1842.

${ }^{15}$ Ramón de la Sagra, Cuba en 1860, p. 14.
} 
ingenios del partido Pepe Antonio, jurisdicción de Guanabacoa: el 21,64\% eran por esa fecha esclavos menores de doce años. ${ }^{16}$ Según fuentes oficiales, a principios de 1871 la población esclava entre cuatro y diez años era el 14,84\% del total. Si a esta agregamos los esclavos entre esta última edad y los quince años, la proporción de la población esclava "infantil" se eleva al 25\% del total. ${ }^{17}$ Téngase en cuenta que no están contabilizados los menores de cuatro años, ya que por el artículo segundo de la Ley Moret, los nacidos después del 17 de septiembre de 1868 fueron adquiridos por el Estado mediante el pago a sus dueños de ciento veinticinco pesetas y en consecuencia con el artículo quinto de la misma ley declarados libres, aunque permanecerían bajo el patronato de los dueños de la madre. Por lo cual, la población menor de doce años residente en las plantaciones debió ser un tanto mayor a la indicada en el conteo de 1871, pero ese margen -desconocemos su número- de algún modo queda compensado en nuestro cálculo agregando el subgrupo ascendente a los quince años.

Sobre tales registros, no hay razón para sugerir un crecimiento extraordinario de la población esclava infantil en los ingenios en las últimas décadas del sistema esclavista, determinado básicamente por un tratamiento más humano de los propietarios. Téngase en cuenta además que durante los últimos años de la trata el porcentaje de recién nacidos y niños bozales introducidos en la isla aumentó significativamente. ${ }^{18}$ Este factor exógeno es importante si tenemos en cuenta que una parte considerable de la población esclava menor de doce años contada en el decenio de 1870 pudo haber sido introducida en la década anterior.

Si bien las cifras macro-demográficas no reflejan la composición específica de la fuerza de trabajo de cada ingenio, menos apropiado es realizar un razonamiento a la inversa. Un palo no hace monte, así como la dinámica interna de un ingenio no representa a la totalidad del sistema esclavista. No solo son limitados los registros existentes sobre las dotaciones cubanas, sino además deficiente la información respecto a la edad de los esclavos. Teniendo en cuenta los diversos mecanismos desarrollados para la transición al trabajo libre desde la Ley Moret, que beneficiaron en mayor número a la población infantil y anciana, los plantadores debieron alterar las

\footnotetext{
${ }^{16}$ Jacobo de la Pezuela, Diccionario, t. IV, pp. 194-195.

${ }^{17}$ Esclavitud. Datos estadísticos oficiales, AHN, Ultramar, Leg. 4883, №. 2, 1882-1883.

${ }^{18}$ Herbert S. Klein, "El comercio atlántico de esclavos y el suministro de mano de obra a Cuba y Brasil", pp. 37-49. Un estudio de un caso significativo de importación de niños esclavizados en: Arturo Arnalte, Los últimos esclavos de Cuba: los niños cautivos de la goleta Batans, Alianza Editorial, Madrid, 2001.
} 
edades de sus negradas para retenerlas legalmente en su beneficio, sorteando los contratiempos que podía ocasionar un sujeto jurídicamente libre. A mediados de la década de 1870, la Sociedad Abolicionista Española difundió en su órgano oficial una correspondencia recibida de la isla en la que denunciaba algunos abusos cometidos en la jurisdicción de Matanzas, consistentes en no cursar las instancias de los esclavos que habiendo cumplido los sesenta años debían ser declarados libres conforme al artículo cuatro de la mencionada ley, así como que no se estaban bautizando como libres a recién nacidos hasta que no lo ordenara expresamente el Obispo de La Habana. ${ }^{19}$

De acuerdo con el estudio de Laird W. Bergard, Matanzas concentraba en 1862 el $27,8 \%$ de toda la población esclava de la isla y la estructura por edad de la misma revela el predominio de esclavos en la edad más productiva: más del 50\% tenía entre 16 y 40 años, mientras que otro $21 \%$ superaba esa edad. Lo estudios de casos analizados por este autor confirman que muchos ingenios, como el San Juan y Nuestra Señora de la Paz, funcionaban entonces con una proporción muy elevada de esclavos entre 30 y 60 años, fenómeno más acentuado en el conjunto de los nacidos en África, que era además el grupo predominante en esas dotaciones. Aunque la pirámide de edad es más equilibrada para la población esclava criolla, esta se revela insuficiente para reproducir de forma natural la fuerza de trabajo cautiva. ${ }^{20}$

Asimismo, la historiadora Rebecca J. Scott, luego de analizar una información disponible para Santa Isabel de las Lajas, un área azucarera importante a mediados de la década de 1870, demuestra que en esa localidad no existía entonces una proporción elevada de niños esclavos. La estructura por edades de la población de la muestra de fincas de Santa Isabel de las Lajas varía en dependencia de diversos factores, pero los esclavos entre 16 y 40 años eran predominantes, oscilando entre el $47 \%$ en el ingenio California y el $89 \%$ en el San Isidro. Esta autora arribó a la siguiente conclusión: “El buen trato, si lo había en Las Lajas, no había tenido tiempo para crear una población esclava que reprodujera sus números, ni una población llena de jóvenes y viejos."21

\footnotetext{
19 "Los negros recién nacidos y los sexagenarios de Matanzas", El Abolicionista, Redacción y Administración, Madrid, Año VI., Nº. 4, 1875, p. 60.

${ }^{20}$ Laird W. Bergard, Cuban rural society in the nineteenth century. The social and economic history of monoculture in Matanzas, pp. 193-197.

${ }^{21}$ El concepto buen trato aparece entre comillas en el texto original, lo ponemos en cursiva para no repetir este recurso. Rebecca J. Scott, La emancipación de los esclavos en Cuba: la transición al trabajo libre, 1860-1899, pp. 125-128.
} 
La gráfica 17 revela como la natalidad de la población "de color" en la isla disminuye de forma drástica hacia la década de 1830. En el decenio siguiente se mantuvo muy por debajo de la tasa de nacimientos de la población blanca. A partir de 1850 , un mejor equilibrio por sexos en la población "de color" y la masiva entrada de colonos asiáticos, que apenas aportaron a los nacimientos de la población blanca, hacen que las líneas representativas de los nacimientos de uno y otro grupo tiendan a confluir, aunque sigue siendo superior entre los blancos.

Si aceptamos los valores absolutos de nacimientos de la fuente consultada, en la población “de color" se mantienen desde la década de 1840 relativamente estables, promediando unos 15.300 en los 8 años indicados. Mientras que en igual etapa la población blanca promedió unos 5.000 nacimientos más, debido fundamentalmente a un aumento significativo a partir de la década de 1860. Tal fenómeno confirma la estrecha dependencia del crecimiento de la población "de color" en esta etapa de las importaciones de esclavos. En 1879 el número de nacimientos registrados en la población "de color" fue inferior al de los fallecidos. ${ }^{22}$

Por las condiciones socio-demográficas de los ingenios, las tendencias generales fueron más agudas en esos espacios, sobre todo en fincas que se mantuvieron funcionando con dotaciones caracterizadas por altos índices de masculinidad y de esclavos nacidos en África. Como regla, los niños esclavos permanecieron en esta etapa en torno a un quinto del total de la gente de su clase. Los factores internos que explican tales fenómenos son la fecundidad y la mortalidad infantil, que no debieron variar de forma drástica.

22 Dirección General de Hacienda, Población. Estudios estadístico-demográficos correspondientes a 1879 . 


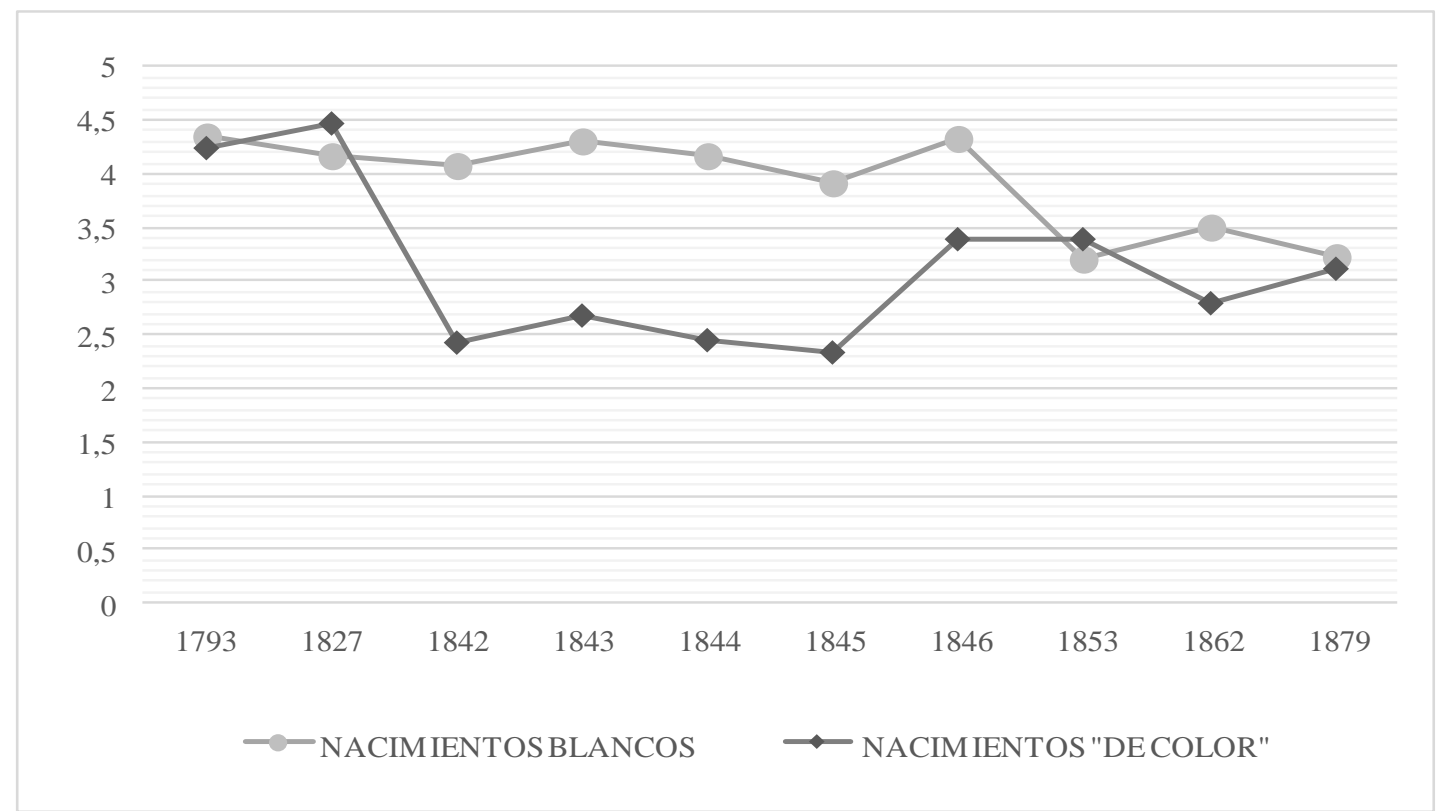

Elaboración propia a partir de la información disponible en: Dirección General de Hacienda, Población. Estudios estadístico-demográficos correspondientes a 1879.

Retomando el estudio modélico de Moreno Fraginals, encontramos que como parte de la evolución demográfica de la población esclava de ingenios azucareros en la zona occidental, la tasa global de fecundidad, o sea, el número de nacimientos por cada mil esclavas en edad fértil en un año, aumentó de 87 por mil en 1835-1841 a 132 por mil en 1856-1860. ${ }^{23}$ Algunas evidencias nos llevan a sospechar de la generalización de ese registro. Si calculamos la tasa de fecundidad general (TFG) para la jurisdicción de Matanzas en 1862, tomando por fieles los 701 bautismos de esclavos de ese año y las 7.434 esclavas entre 13 y 40 años, el resultado obtenido es una TFG=94 por mil. Si para compensar el número de nacidos pero no bautizados tomamos los 720 esclavos entre 0 y 1 año, el resultado se eleva a 130 por mil, más próximo al que ofrece Moreno Fraginals pero sigue siendo inferior. ${ }^{24}$ Es cierto que no está contabilizada la mortalidad infantil, pero también lo es que no todos los bautizados eran nacidos. Este cálculo aproximativo que, como veremos, arroja un resultado similar al que da un bien informado hombre de la época, puede darnos una referencia de los nacimientos "logrados" por cada mil esclavas, que son al final los que

\footnotetext{
${ }^{23}$ Manuel Moreno Fraginals, El ingenio, t. 2, p. 88.

${ }^{24}$ Jacobo de la Pezuela, Diccionario, t. IV, p. 25.
} 
interesan para evaluar la capacidad reproductiva de esta población en un área esencialmente azucarera como Matanzas.

Durante la Junta de Información celebrada en 1866, en la sección Negros Esclavos se discutió un informe sobre las causas naturales y sociales que determinaban el decrecimiento de esta población en Cuba, a saber: exceso de mortandad sobre nacimientos; desproporción de los sexos, a favor del masculino; menor fecundidad de las esclavas; escasez relativa de los matrimonios; manumisiones parciales y totales; y juego de lotería. Entre las primeras cuatro causas existía una fuerte correlación determinada por la dinámica del sistema esclavista en la isla. El informe refiere que, de acuerdo con estadísticas oficiales de la época, el número de mujeres en edad de procrear, entre 15 y 50 años, era de 162.489 blancas, 60.525 libres y emancipadas y 87.782 esclavas. Tomando entonces los 27.778 nacimientos blancos, los 8.122 libres "de color" y los 8.739 esclavos, la tasa de fecundidad por cada mil mujeres de cada grupo es 171,134 y 100 , respectivamente. ${ }^{25}$

Téngase en cuenta que el cálculo anterior considera un rango de edad prolongado y desconoce las profundas diferencias demográficas del paisaje azucarero cubano, por lo general más agresivas en el occidente cubano. Como norma, un argumento de peso marginó de estas funciones a las esclavas más adultas. La fertilidad de las mujeres disminuye naturalmente con el paso de los años, siendo en la época que analizamos menos probable que ocurriera -o muy riesgoso- después de los 40 años. Asimismo, la salud reproductiva de estas mujeres, viviendo en poblaciones esclavistas con un alto índice de masculinidad, pudo afectarse considerablemente a través de continuados procesos de embarazo en su período más fértil, sobre todo si eran inducidos como parte de la estrategia pro-natalista tan azuzada desde la década de 1840. Por lo general, se ha pensado este fenómeno desde una concepción ideal: promover un equilibrio de género y más matrimonios en las dotaciones, cuando la norma fue, un elevado índice de masculinidad y pocos matrimonios en los ingenios, motivando el rédito esperado en nacimientos por la vía, más rentable para el plantador y más traumática para la esclava, de poner a unas cuantas cautivas en función permanente de procreación.

\footnotetext{
${ }^{25}$ La desventaja de las mujeres cautivas para concebir fue contrastada también en otros territorios de la región como Martinica, Guadalupe, Guyana y Borbón. Ramón de la Sagra, "Decrecimiento de la raza esclava en nuestras Antillas", El Abolicionista, Redacción y Administración, Madrid, Año VI, Nº. 18, 1875, p. 279.
} 
Tales evidencias confirman lo que venimos negando en cuanto a un hipotético salto en la capacidad reproductiva de la población esclava hacia la década de 1860 . Asimismo, la desventaja de este grupo se reduce significativamente bajo la condición de libertad. Por tanto, cualquier consideración al respecto debe ponderar los factores sociales que lo determinaron. Como ha demostrado Richard Follet para entornos azucareros de Estados Unidos, es posible que la capacidad biológica de las esclavas para concebir en Cuba, sometidas a condiciones de explotación y climáticas tan o más severas que las soportadas por sus convecinas norteñas, estuviera profundamente afectada por la naturaleza del empleo. Múltiples factores se combinaron en el ingenio del siglo XIX para estropear materialmente el cuerpo de las esclavas. Analizando una muestra de 1.233 nacimientos de las parroquias de azúcar de Louisiana, Follet sugiere, combinando fuentes clásicas con argumentos fisiológicos modernos, como el calor estresante, una nutrición deficiente, el esfuerzo físico realizado y el trasfondo de enfermedades tropicales, determinó una "disfunción ovárica" y una disminución relativa de la fecundidad en las esclavas, contrastada en una estacionalidad de las concepciones regida por la dinámica laboral en las plantaciones. "El poder invasor del azúcar definió la vida reproductiva de los esclavos y reclamó a sus víctimas no nacidas a través de embarazos fallidos y de mortinatos", concluye Follet. ${ }^{26}$

Un aumento de la fecundidad no necesariamente conlleva una disminución de los índices de mortalidad infantil. Moreno Fraginals refiere que la tasa de mortalidad infantil en ingenios de la zona occidental experimentó una reducción vertical hacia mediados del siglo XIX: de 575 por mil en el período 1835-1841 a 283 por mil entre 1856-1860. Sorprende que sugiera un verdadero milagro demográfico -una reducción del $51 \%$ en apenas dos décadas decimonónicas- sin profundizar en los factores que lo hicieron posible, ni aportar la referencia de las fincas donde se produjo. ${ }^{27}$ En cualquier caso, el hecho también dista de ser representativo del paisaje azucarero cubano. Hasta bien entrado el siglo XIX la mortalidad infantil en Cuba, como en otras sociedades del circuito atlántico, se mantuvo elevada. Tampoco debemos asumir con demasiado

\footnotetext{
${ }^{26}$ En principio, no es erróneo trasladar a la realidad cubana los argumentos generales de la hipótesis de Follet, pero queda pendiente profundizar en la estacionalidad de los nacimientos de la población esclava en los ingenios cubanos y en los factores que pudieron determinarla. Richard Follett, "Lives of living death: The reproductive lives of slave women in the cane world of Louisiana", p. 299; "Heat, sex, and sugar: Pregnancy and childbearing in the slave quarters", pp. 510-539.

${ }^{27}$ Manuel Moreno Fraginals, El ingenio, t. 2, p. 88.
} 
entusiasmo una mejora relativa si esta se verifica en un contexto de acentuadas desigualdades en salud.

De acuerdo con el estudio demográfico de 1879, de las 39.566 defunciones registradas ese año, 12.802 correspondieron a menores de 10 años, o sea, el 32,4\%. La población “de color", con 5.002 defunciones entre 0 y 10 años, aportó el 39,1\% de la mortalidad de ese grupo, una cifra superior a su proporción en el conjunto de la población cubana. Aunque la fuente no lo refiere, es de suponer que una parte importante de esa mortalidad se produjese durante el primer año de vida. Entre los años 1888 y 1892 la tasa promedio para La Habana de defunciones para menores de un año fue de 300 por mil. ${ }^{28}$ El marcado carácter socio-racial del fenómeno puede comprobarse al examinar el mayor tributo de la población afrodescendiente. ${ }^{29}$ Por ejemplo, esta representaba en 1880 poco menos de un cuarto de la población de La Habana pero, de acuerdo con una tabla de mortalidad civil de ese año, aportó el 49,4\% del total de fetos nacidos y extraídos muertos. ${ }^{30}$ La mortinatalidad solo expresa un parte del problema en cuestión, ya que muchos de los nacidos no superaban el primer año de vida, e incluso, también era significativa la mortalidad de la población entre uno y cinco años.

Las estadísticas disponibles para la población rural son más escasas que para la capital, pero no hay razón para confiar en una mejora significativa de las condiciones de supervivencia en el campo. De acuerdo a la tendencia observada, por lo general el crecimiento de la población infantil fue superior en las principales ciudades que en las áreas agrícolas. El hecho de que muchos de los esclavos nacidos en las décadas centrales del siglo XIX no sobrevivieron a su condición, es un fuerte argumento contra la hipotética política de "buen trato". Una parte considerable de los neonatos cautivos no sobrevivieron al primer año de vida y para ellos el filtro demográfico fue particularmente agresivo durante la primera infancia.

El historiador británico E. P. Thompson, citando un informe médico del Hospital General de Sheffield, destacó que de las 11.944 defunciones habidas allí entre 1837 y 1842, 2.893 ocurrieron antes del año de vida y un total de 6.038

\footnotetext{
${ }^{28}$ Juan Guiteras, "Sobre mortalidad infantil", Sanidad y Beneficencia, La Habana, octubre, 1913, pp. 429-435.

${ }^{29}$ Rafael J. Fosalba, "La mortinatalidad y la mortalidad infantil en Cuba", Sanidad y Beneficencia, La Habana, junio-octubre, 1914.

${ }^{30}$ Ambrosio González del Valle, "Resumen de la mortalidad de La Habana", Anales de la Real Academia de Ciencias Médicas, Físicas y Naturales de La Habana, vol. XVII, 1880, pp. 371 372.
} 
correspondieron a menores de cinco años, cifras equivalentes a tasas de 250 por mil y 506 por mil, respectivamente. Ese registro, representativo de la mortalidad infantil en otros distritos ingleses, revela que el período crítico de la infancia no concluía con el primer año de vida. ${ }^{31}$ Para el otro lado del atlántico, en uno de los mejores trabajos sobre la mortalidad infantil de la población esclava en los Estados Unidos, Richard H. Steckel no solo comprobó la gran desventaja de este grupo respecto a los blancos, sino además el hecho de que en la etapa previa a la Guerra de Secesión (1861-1865), el $46 \%$ de los esclavos nacidos murieron antes de llegar a los quince años. ${ }^{32}$ Esto en la sociedad esclavista del continente que mejor éxito tuvo en la reproducción natural.

Con atino del fenómeno en cuestión, el historiador norteamericano Kenneth F. Kiple sostuvo que la imposibilidad del crecimiento vegetativo de la población esclava en el Caribe, incluyendo a Cuba, no estuvo determinado tanto por una baja fertilidad, sino que fue la consecuencia de una mezcla de factores genéticos, culturales, inmunológicos y especialmente nutricionales, que "rápidamente transformaron las estadísticas de nacimientos en estadísticas de muerte". 33

En efecto, la alimentación fue uno de los aspectos más discutidos por su impacto en la mortalidad infantil del siglo XIX. El Reglamento de esclavos de 1842 normó que en el caso de los recién nacidos la alimentación en la finca, si sus madres estaban trabajando, debía ser "muy ligeras", como sopas, atoles o leche, hasta que terminaran el período de lactancia y dentición. Este documento también estipuló la creación de un espacio para el cuidado de los menores no aptos para el trabajo, que debían quedar bajo el cuidado de una o más esclavas en dependencia con las necesidades de cada finca. El médico francés Chateausalins recomendó a los hacendados prevenir las indigestiones antes de verse en la necesidad de curarlas, asegurándose personalmente del tipo y las cualidades de los alimentos que le suministraban a los párvulos. ${ }^{34}$ En cualquier caso, durante la fase "pro-natalista" de la esclavitud en la isla, la calidad de la nutrición siguió determinando elevadas tasas de

\footnotetext{
${ }^{31}$ E. P. Thompson, La formación de la clase obrera en Inglaterra, t. I, Crítica, Barcelona, 1989, pp. 361-362.

${ }^{32}$ Richard H. Steckel, "A dreadful childhood: The excess mortality of American slaves”, pp. 427-465.

${ }^{33}$ Kenneth F. Kiple, The Caribbean Slave, p. 120.

${ }^{34}$ Honorato Bernard de Chateausalins, El vademécum de los hacendados cubanos, p. 100.
} 
mortalidad infantil. A propósito, es revelador el debate sobre lactancia materna v/s alimentación artificial. ${ }^{35}$

El alquiler de "madres de leche" o nodrizas en la crianza no era una práctica ajena a la tradición hispana previa al desarrollo de la servidumbre africana en el Nuevo Mundo. Tampoco lo era el mestizaje racial que operó en esa actividad. Por lo cual, no debe sorprender que se desarrollara en las colonias americanas desde los primeros siglos post-colombinos. En 1824 apareció la primera obra sobre obstetricia impresa en Cuba. ${ }^{36}$ El 7 de junio de 1828 se inauguró en el hospital San Francisco de Paula, en La Habana, una academia para la formación de parteras que funcionó hasta 1833, cuando el local se puso en función de una clase para enfermeras destinadas a ese servicio durante la epidemia de cólera de 1833, aunque Rosaín continuó un tiempo más dando las clases en su casa. Este mismo año, se fundó en el hospital Nuestra Señora del Carmen, en Camagüey, una clase del "arte de partear".37

A mediados del siglo XIX circuló en la capital un polémico anuncio que rezaba: "No más crianderas. No más indigestiones. Sana y segura lactancia para los niños. Productos químicos por Ramón María de Hita." El descubrimiento que este médico procuraba era la transfiguración de la leche de vaca en leche de mujer mediante el uso de un elemento químico. Su fórmula, según aseguró, servía para la alimentación de los recién nacidos desde el alumbramiento hasta el tercer año y evitaba las indigestiones que tantas muertes provocaba, "ya fuera por la calidad natural de las leches de vaca, ya por las malas condiciones de las crianderas". La propuesta de

\footnotetext{
35 "Reglamento de esclavos, agregado y publicado con el bando de buen gobierno de la Isla de Cuba, que fue expedido en 14 de noviembre de 1842", en: José María Zamora y Coronado, Biblioteca de la legislación ultramarina en forma de diccionario, t. III, Imprenta de J. Martín Alegría, Madrid, 1845, p. 136.

${ }^{36}$ Domingo Rosaín, Examen y cartilla de parteras, teórico-práctica, Oficina de Don José Boloña, La Habana, 1824.

${ }^{37}$ Sobre el desarrollo de la obstetricia en Cuba véase el discurso de recepción de Jorge Le Roy Cassá como académico de número en la Academia cubana: Jorge Le-Roy Cassá, "Apuntes para la historia de la obstetricia en Cuba", Anales de la Academia de Ciencias Médicas, Físicas y Naturales de La Habana, vol. XXXVIII, 1903, pp. 336- 374. Ver también: José A. López Espinosa, "Contribución al estudio de la bibliografía cubana sobre Obstetricia", Acimed, vol. 14, $\mathrm{N}^{\circ}$. 6, 2006, consultado en http://bvs.sld.cu/revistas/aci/vol14 6 06/aci11606.htm , 23 de noviembre de 2016. Sobre el desempeño de la mujer "de color" en el oficio de partera en la isla pueden consultarse los estudios de: Pedro Deschamps Chapeaux, El negro en la economía habanera del siglo XIX, UNEAC, La Habana, 1971. Beatriz Joda Esteve, Mujer y esclavitud doméstica: La Habana (1790-1844). María del Carmen Barcia, Oficios de mujer: parteras, nodrizas y "amigas": servicios públicos en espacios privados (siglo XVII-siglo XIX), Editorial Oriente, Santiago de Cuba, 2015.
} 
Hita provocó un fuerte rechazo en la Academia y avivó el debate sobre los perjuicios de la lactancia artificial. En sesión de gobierno efectuada el 27 de agosto de 1871 se acordó hacer pública la siguiente declaración: "La Academia ha visto con mucho desagrado la conducta profesional de dos de sus miembros, que valiéndose de la prensa diaria y de otros medios abusan de la credibilidad pública con sus ruidosos anuncios, convirtiendo la más sagrada de las profesiones en el más vulgar de los comercios". ${ }^{38}$ Como en este caso, entorno a la lactancia infantil se desarrollaron intensos debates médico-sociales, con las más diversas opiniones, extendidos hasta bien entrado el siglo XX.

En el contexto de auge de la esclavitud en la isla, era habitual que los recién nacidos se entregaran al cuidado de una nodriza negra, fuese libre o esclava. De acuerdo con un testimonio médico de la época, era una actividad regularmente ejercida por mujeres nacidas en África, “cuya constitución, naturaleza, costumbres y carácter difieren en tanto grado de los nuestros y cuya abyección y dependencia la tienen continuamente en un estado de disgusto interior difícil de ocultar." 39 Razones que fueron consideradas nocivas para la salud y el conveniente desarrollo de los neonatos. Ramón Piña consideró que "los malos humores" de las que crían los niños en la isla, "los virus sifilítico, escrofuloso, herpético, psórico, de que ocultamente están contaminadas" pasaban con la leche al menor, determinando su muerte prematura o una existencia enfermiza. ${ }^{40}$ Tal razonamiento sugiere que existía una fuerte creencia en que las mujeres “de color" -más aún las esclavas- con una mayor exposición al contagio, podían transmitir a los recién nacidos las afecciones de las que eran portadora. De ahí el rigor con el que algunas familias seleccionaron a sus nodrizas. Aunque hoy sabemos que muchas enfermedades no se trasmiten a través de la lactancia, la buena salud de la nodriza es un factor potenciador de la supervivencia del menor. Máxime en una época en la que no existía un desarrollo positivo de instituciones encargadas de la atención pre y posnatal en caso de enfermedad o convalecencia de la madre.

Las publicaciones referentes al oficio de parteras y nodrizas combinaron un conjunto de requisitos morales, habilidades personales y conocimientos tendentes a regular una actividad que calaba en lo más íntimo de la estructura social. Como

\footnotetext{
38 "Reflexiones sobre la lactancia", Anales de la Real Academia de Ciencias Médicas, Físicas y Naturales de La Habana, vol. VIII, 1871, pp. 181-194.

${ }^{39}$ Ramón Piña, Topografía médica de la isla de Cuba, p. 108.

${ }^{40}$ Ibídem, p. 109.
} 
sucedió con otras actividades relacionadas con la medicina, su carácter científico cuajó progresivamente en las ciudades. En el campo, la asistencia a las embarazadas y los neonatos conservó su naturaleza tradicional durante más tiempo, determinado por una circulación limitada de los avances médicos y un tenaz rechazo a los mismos.

Además de una lactancia deficiente y perniciosa, múltiples enfermedades amenazaban la vida de los recién nacidos. Una de las más letales fue el tétano infantil. Esta enfermedad infecciosa, conocida en la época como el "mal de los siete días" por el período en el que generalmente atacaba a los recién nacidos, fue reconocida por Ramón de la Sagra, para el segundo quinquenio de la década de 1820 en La Habana, como el principal motivo conocido de la enorme mortalidad que se producía en la semana posterior al alumbramiento. ${ }^{41}$ En su novela cumbre, Cirilo Villaverde refiere en varios pasajes la incidencia de esta enfermedad en la mortalidad infantil de la población esclava. ${ }^{42}$ Bernard de Chateausalins la consideró un gran azote en las plantaciones cubanas, que por lo general se presentaba en los meses de diciembre, enero y febrero, y podía destruir a la tercera parte de la población esclava. Asimismo, este experimentado médico francés aseguró que la enfermedad era "rarísima entre los blancos". 43

La superior mortandad en los primeros días de vida de la gente "de color" se explica por las condiciones predisponentes al contagio con la bacteria Clostridium tetanis y una asistencia sanitaria deficiente, entre otros factores. Este microrganismo no se trasmite de persona a persona. En zonas agrícolas como el ingenio, la infección era frecuente a través de heridas mal atendidas o por las heces contaminadas de animales habituales en esos espacios como perros, gatos, ratas, ganado, caballos, pollos, etc. En 1879 el tétano infantil se registró como la causa de unas 2.028 muertes, distribuidas por provincias del modo siguiente: La Habana (595), Pinar del Río (476), Matanzas (245), Santa Clara (325), Puerto Príncipe (138) y Santiago de Cuba (249). El $40 \%$ de la mortalidad por esta causa correspondió a la población "de color" y fue muy determinante en la mortalidad de la población agrupada entre 0 y 10 años. ${ }^{44}$

\footnotetext{
${ }^{41}$ Ramón de la Sagra, Historia económico- política y estadística de la isla de Cuba, Imprenta de las viudas de Arazoza y Soler, La Habana, 1831, p. 56.

${ }^{42}$ Cirilo Villaverde, Cecilia Valdés o La Loma del Ángel, Editorial Verbum, Madrid, 2014.

${ }^{43}$ Honorato Bernard de Chateausalins, El vademécum de los hacendados cubanos, p. 87.

44 Dirección General de Hacienda, Población. Estudios estadístico-demográficos correspondientes a 1879.
} 
El espectro morboso que afectaba a los niños lo completaban las aftas o sapillo, oftalmías, cólicos, diarreas, vómitos, constipación, enfermedades eruptivas, afecciones nerviosas, lombrices, anginas, croup, encefalitis, coqueluche o tos ferina, escrófulas, tumores, raquitismo y accidente de la dentición, entre otras. ${ }^{45}$ Aunque un número importante de textos sobre las enfermedades más comunes en la niñez circularon en La Habana a lo largo del siglo XIX, el salto institucional en este sentido no se produjo hasta la creación de la Catedra de Enfermedades de la Infancia, en $1887 .{ }^{46}$

Por otra parte, los "partos difíciles" fueron una causa habitual de mortalidad infantil y materna entre la población esclava. Si el embarazo no es saludable, el riesgo a que el parto se produzca antes de término es mayor. Fenómeno que bien pudo ser la norma en esclavas sometidas a trabajos físicos agobiantes y a una alimentación deficiente durante la etapa de gestación. En el reino del azúcar, el embarazo implicó un gran sacrifico. Antes referimos la superior tasa de mortinatalidad entre la gente "de color" y advertimos que en 1879 las defunciones en Matanzas por causas asociadas con el parto ocurrieron en mayor proporción entre la población esclava que en la población libre "de color" y blanca. Por ejemplo, como accidentes del parto se registraron en esa provincia 24 muertes, de las cuales correspondieron doce a morenas esclavas, una parda esclava, otras cuatro morenas libres y las restantes siete a mujeres blancas. También es de destacar la superior mortalidad en esta región de las esclavas por otras dos causas vinculadas a un embarazo y posparto poco saludables, como la fiebre puerperal y la cistitis. ${ }^{47} \mathrm{El}$ riesgo de contraer esta última, generalmente producida por la infección con la bacteria Escherichia coli, así como otras infecciones urinarias, se multiplica durante el embarazo. De acuerdo con tales indicios, que bien pueden tomarse como representativos del panorama de la época en cuanto a mortalidad materna e infantil, no hay razones para sostener un significativo desarrollo de los servicios de maternidad, la obstetricia y ginecología en el campo cubano y particularmente en las zonas azucareras. De hecho, las observaciones microscópicas que permitieron reconocer el origen de muchas infecciones genitales y los procedimientos quirúrgicos necesarios para extirpar tumores o quistes malignos en el

\footnotetext{
${ }^{45}$ Ramón Piña, Topografía médica de la isla de Cuba, p. 109. Muchas de las enfermedades registradas por Piña también fueron indicadas por Honorato Bernard de Chateausalins en su conocido manual sobre enfermedades de esclavos.

${ }^{46}$ Jorge Le-Roy Cassá, "Apuntes para la historia de la obstetricia en Cuba”, p. 370.

47 Dirección General de Hacienda, Población. Estudios estadístico-demográficos correspondientes a 1879 .
} 
útero, las trompas u ovarios antes de que llegasen a producir la muerte, no se desarrollaron hasta fines del siglo XIX. La primera ovariotomía realizada en Cuba la practicó en 1878 el doctor Manuel Sánchez de Bustamante, muriendo a los 12 días su paciente, producto del tétanos. ${ }^{48}$

Es difícil precisar para la época que nos ocupa el número de mujeres fallecidas durante el proceso de gestación, parto y posparto. Una estimación muy aproximativa del fenómeno podemos realizarla cotejando los registros de nacimientos con las defunciones por accidentes del parto en 1879. Aunque esta no es la única causa involucrada con la mortalidad materna en la época -ya que la fiebre puerperal, las convulsiones y las hemorragias, entre otras enfermedades, también fueron responsables directas de una maternidad fracasada-, nos permite establecer una relación mucho más precisa. Hecho esto, se obtiene que, como promedio, tres mujeres por cada mil nacimientos en Cuba fallecieron por esta sola causa. El riesgo de perder la vida durante el parto era muy superior para la población "de color" en las provincias de La Habana y Matanzas. De hecho, estas fueron entonces las únicas provincias en las que la tasa de este indicador fue superior en ese grupo. La notable desigualdad que se observa en la capacidad de supervivencia entre las mujeres embarazadas de una y otra raza en las provincias azucareras, sobre todo en Matanzas, sugiere que, por diversas razones, algo decisivo conspiró contra las concepciones exitosas de las mujeres de ascendencia africana. Si estos indicadores revelan la pauta, constituyen otra prueba del fracaso de la política "pro-natalista" de los plantadores en el occidente cubano. Recordemos que en Matanzas la mitad de las muertes por la causa analizada correspondieron a esclavas. Un tanto superior a las cifras registradas debió ser entonces la mortalidad materna en Cuba por la combinación de diferentes causas. ${ }^{49}$

Un estudio para Inglaterra y Gales estimó para el período 1800 y 1850, a partir de los registros de trece parroquias, una mortalidad materna promedio en torno a 5 defunciones por cada mil nacimientos. ${ }^{50}$ En el caso de Suecia, la mortalidad materna

\footnotetext{
${ }^{48}$ La primera operación exitosa de este tipo realizada en la isla se produjo en diciembre de 1882. Ver: Jorge Le-Roy Cassá, “Apuntes para la historia de la obstetricia en Cuba”, pp. 366368.

${ }^{49}$ Como referencia téngase en cuenta que la ratio de mortalidad materna en Cuba en el período 1950-1959 fue de 137,8 por 100.000 nacidos vivos. Evelio Cabezas Cruz, "Evolución de la mortalidad materna en Cuba", Revista Cubana de Salud Pública, vol. 32, No. 1, enero-marzo, 2006, consultado en http://scielo.sld.cu/scielo.php?pid=S0864$34662006000100005 \&$ script=sci_arttext\&tlng=pt, 15 de noviembre de 2016.

${ }^{50}$ Geoffrey Chamberlain, "British maternal mortality in the 19th and early 20th centuries", Journal of the Royal Society of Medicine, vol. 99, noviembre, 2006, pp. 559-563.
} 
descendió significativamente entre 1861 y 1900, de 567 a 227 defunciones por 100.000 nacidos vivos, debido a mejoras socio-sanitarias, regulaciones en el ejercicio de las parteras, introducción de las técnicas antisépticas y un desarrollo apreciable de la atención prenatal y obstétrica, entre otros factores que, en el caso de Cuba, comenzarían a dar resultados mucho más tarde. ${ }^{51}$

GRÁFICO 18: CUBA. MORTALIDAD COMPARADA POR ACCIDENTES DEL PARTO EN CADA RAZA Y PROVINCIA EN RELACIÓN (\%) AL NÚMERO DE NACIMIENTOS REGISTRADOS, 1879.

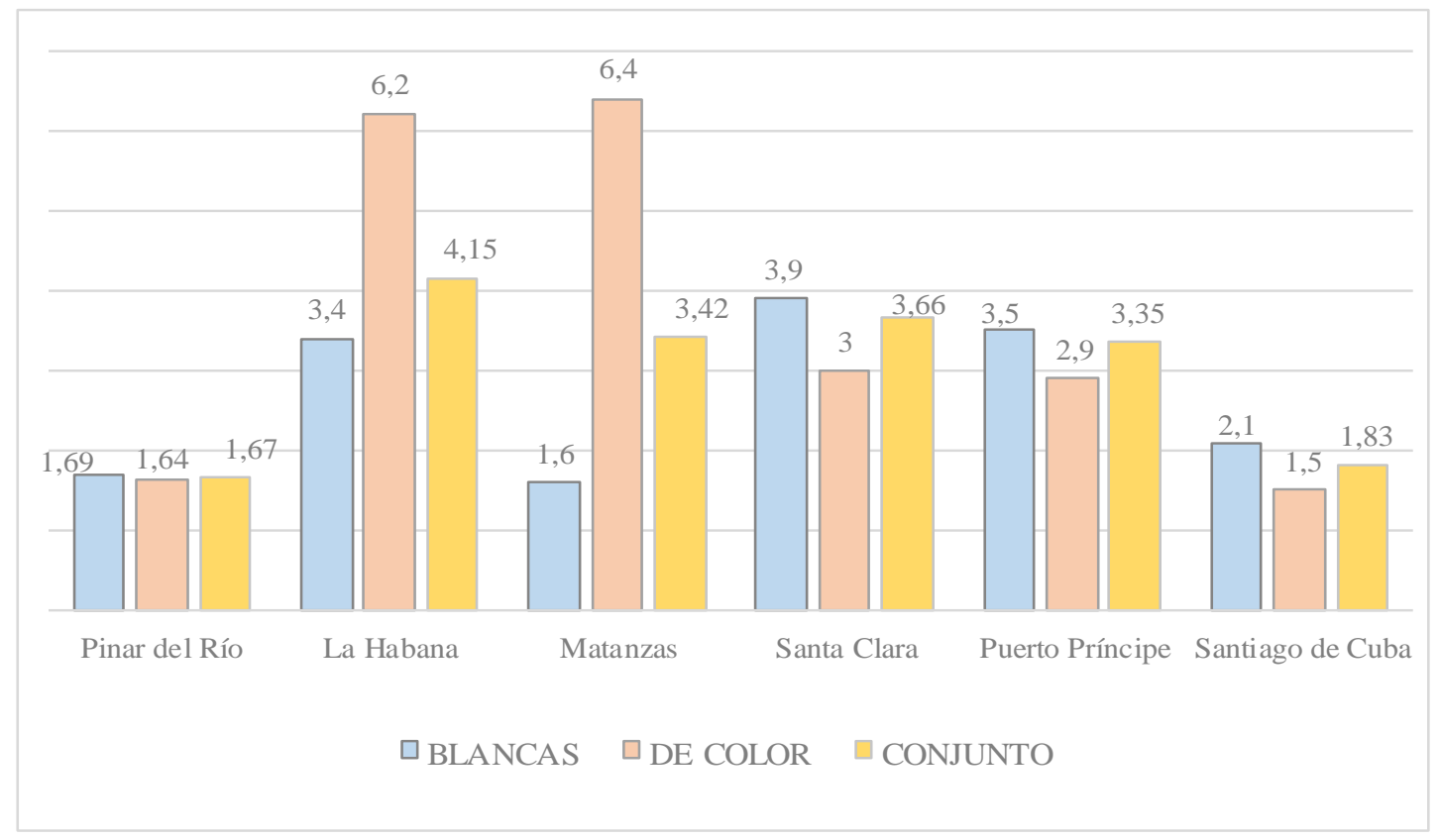

Elaboración propia a partir de la información disponible en: Dirección General de Hacienda, Población. Estudios estadístico-demográficos correspondientes a 1879.

Para contrarrestar las amenazas señaladas a la mortalidad infantil, más importante que un hipotético giro en la mentalidad de los plantadores, inducido por las circunstancias que amenazaban el remplazo de los esclavos mediante la trata, fue la evolución de los recursos médicos y las experiencias adquiridas en favor de la supervivencia infantil y de la madre. A fin de cuentas, los hacendados cubanos estaban convencidos de que la política inmigratoria -fuera de brazos libres o cautivos, de africanos, europeos o asiáticos- les resultaba mucho más rentable para el trabajo

\footnotetext{
${ }^{51}$ U. Högberg, S. Wall y G. Broström, "The impact of early medical technology on maternal mortality in late 19th century Sweden", International Journal of Gynecology and Obstetrics, vol. 24, No. 4, agosto, 1986, pp. 251-261. Uno de los estudios médico-sociales más importantes sobre este interesante problema en: Irvine Loudon, Death in Childbirth: An International Study of Maternal Care and Maternal Mortality 1800-1950, Clarendon Press, Oxford, 1992.
} 
requerido en las plantaciones que la azarosa y demorada provisión de brazos biológicamente logrados. En consecuencia, es importante relativizar la vocación "paternalista" que presumieron en las décadas centrales del siglo XIX y los hipotéticos efectos de la misma.

En el más condescendiente de los análisis, hay que pensar que no solo hubo entonces cierta necesidad políticamente creada, sino también una posibilidad científica, toda vez que los conocimientos al uso verificaban un impacto positivo en la reducción de la mortalidad infantil. De modo que, preferimos leer El vademécum y otros trabajos similares como esfuerzos de "concientización" dirigido a los plantadores por parte de la comunidad médica en desarrollo. Un profesional experimentado como Chateusalins sabía que en el mundo atlántico la discusión sobre la mortalidad prematura era un tema troncal de la economía política y la ciencia médica, cuestión que, ajustada a la realidad cubana, derivó en un debate científico y no solo político, sobre las garantías para la reproducción natural de la población esclava. Otra cosa eran las implicaciones sociales de una estrategia que interesaba en términos esencialmente económicos.

\section{EL INGENIO EN LOS TIEMPOS DEL CÓLERA}

El cólera es una infección intestinal aguda causada por la bacteria vibrio cholerae. El contagio se produce fundamentalmente por la ingestión de alimentos o agua contaminados. El período de incubación de esta enfermedad es breve y puede causar con rapidez una deshidratación grave y la muerte. En caso de epidemia, las heces de las personas infectadas son generalmente la fuente de contaminación. ${ }^{52}$ Antes del siglo XIX el término cólera se utilizó en referencia a enfermedades similares, pero en la primera mitad de esa centuria se estableció un diagnóstico firme. El vómito que por lo general padecen las personas atacadas de cólera morbo y la mayor gravedad fueron algunos de los fundamentos clínicos que sirvieron entonces para distinguirla de otras afecciones como el llamado cólera esporádico o la diarrea habitual. ${ }^{53}$

\footnotetext{
52 OMS, "Cólera", consultado en http://www.who.int/mediacentre/factsheets/fs107/es/, 25 de octubre de 2016.

${ }^{53}$ Ver, por ejemplo: Honorato Bernard de Chateausalins, El vademécum de los hacendados cubanos, pp. 234-235. Ramón Piña, Topografía médica de la isla de Cuba, pp. 37-44. En la actualidad, existe consenso sobre que todo el cólera en Occidente antes de las epidemias del siglo XIX era endémico o esporádico y no causado por el vibrio cholerae. Ver: Reinhard S.
} 
A lo largo del siglo XIX se publicaron múltiples estudios sobre esta enfermedad. Las pruebas realizadas en 1854 por el médico inglés John Snow sobre la transmisión del cólera por agua contaminada y por el italiano Filippo Pacini sobre la presencia del bacilo en el intestino de fallecidos de cólera, fueron determinantes para su conocimiento científico, quebrando los juicios de los partidarios de la teoría miasmática o anticontagionista, dominante en la época. Décadas más tarde, las investigaciones del médico alemán Robert Koch sentaron definitivamente la causa bacteriana del cólera. ${ }^{54}$

Este microorganismo fue uno de los que mejor aprovechó el desarrollo de las rutas comerciales y el boom demográfico del siglo XIX. La pandemia de la década de 1830 demostró, por vez primera a las economías del circuito atlántico, el potenciar devastador de una enfermedad hasta entonces relegada al delta del Ganges en la India. En el segundo semestre de 1832 el cólera se expandió por varios territorios del sur de los Estados Unidos y se temía su entrada en Cuba. Meses antes de que se presentara el cólera morbo en la isla, Juan Bernardo O-Gavan, en una circular que ordenó en todas las iglesias del dominio español rogaciones públicas para pedir protección al "Todo Poderoso", se refirió a la trayectoria de la epidemia en los siguientes términos:

\begin{abstract}
"Un nuevo azote de la ira celestial ha descargado sobre los pecados de los hombres. Una peste destructora, como un diluvio de gérmenes venenosos, ha ido recorriendo sucesivamente la tierra y destruyendo una gran parte de la raza humana. Los síntomas que la acompañan, las agonías y dolores que causa á las victimas de su voracidad, son más terribles que la muerte misma. Ese principio exterminador, conocido con el nombre de Cólera-morbo, se ha difundido prodigiosamente en países y climas muy diversos, sin perdonar a ninguna clase de sus habitantes [...] Los recursos de la medicina, los cordones sanitarios, las medidas más sabias y prudentes, que han dictado los soberanos ilustrados y filantrópicos de la Europa, han sido burladas por el torrente de esa enfermedad desconocida y espantosa." 55
\end{abstract}

Speck, "Cholera", en: Kenneth F. Kiple (ed.), The Cambridge Historical Dictionary of Disease, pp. 74-78.

${ }^{54}$ La literatura histórica contemporánea sobre las epidemias de cólera en el siglo XIX es extensa. Ver, entre otros: Asa Brigs, "Cholera and society in the nineteenth century", Past and Present, vol. 19, N ${ }^{\circ} .1$, 1961, pp. 76-96. Charles E. Rosenberg, The Cholera Years, The United States in 1832, 1849, and 1866, The University of Chicago Press, Chicago, 1987. La publicación original es de 1962. François Delaporte, Disease and Civilization. The Cholera in Paris, 1832, MIT Press, Cambridge, 1985. Leonard de J. Mata Jiménez, El cólera: historia, prevención y control, EUNED-EUCR, San José, 1992.

${ }^{55}$ Juan Bernardo O-Gavan, Carta circular, Oficina de D. José Boloña, La Habana, 1832, pp.

2-3. Hemos abreviado el título del original por ser demasiado extenso. 
A pesar de las plegarias elevadas por importantes figuras del aparato eclesiástico y las medidas sanitarias tomadas por la administración colonial, el vibrión colérico entró en La Habana en febrero de $1833 .{ }^{56}$ Entre esa fecha y la abolición de la esclavitud, el "viajero del Ganges" puso a prueba en tres ocasiones la capacidad de la colonia cubana para enfrentarlo. La primera epidemia se extendió hasta mediados de la década de 1830. Las cifras de mortandad en La Habana que ofrecen José Antonio Saco y Ramón de la Sagra, hasta el 20 de abril, fecha del "Te Deum” que simbolizó el fin de la fase crítica de la epidemia, son similares: 8.315 y 8.253, respectivamente. El vibrio cholerae se extendió rápidamente por la Isla, ocasionado muchas muertes entre las dotaciones de ingenios y cafetales. Aproximadamente, dos tercios de la población fallecida entonces era “de color", entre libre y esclava. Si bien la debacle producida por este azote reveló a los hacendados el potencial devastador de las epidemias, estos no resolvieron con éxito los problemas sanitarios de sus dotaciones. Algunos de los más importantes hacendados de occidente contrataron los servicios de profesionales con experiencia, pero proporcionar una atención médica de calidad a los esclavos no estuvo a la mano de la mayoría. Por lo general, en los llamados "hospitales de ingenio" las condiciones eran precarias y la asistencia sanitaria la realizaban personas de baja especialización o curanderos. En cualquier caso, poco se pudo hacer para prevenir una enfermedad cuya etiología era entonces parcial o totalmente desconocida.

La segunda epidemia se desarrolló a principios del decenio de 1850. Entre ese año y 1854 la enfermedad llevó al sepulcro a unos 17.144 cuerpos, más de la mitad de los casos registrados. Como en 1833, la epidemia fue importada desde los Estados Unidos, y en una y otra fecha se generó un polémico debate sobre las implicaciones comerciales de las medidas cuarentenarias establecidas. En octubre de 1867, por tercera ocasión de forma epidémica, se presentó en la Isla "el viajero del Ganges", causando estragos considerables entre la población esclava, aunque fue menos letal que las precedentes. Nos centraremos en los ciclos epidémicos de las décadas de 1850 y 1860, menos estudiados por la historiografía, aunque existe al respecto abundante información en los archivos cubanos. Al haberse desarrollado en un contexto de clímax productivo, sus efectos fueron particularmente notables en la dinámica de la esclavitud.

\footnotetext{
${ }^{56}$ El 2 de febrero de 1833 la administración colonial levantó las cuarentenas que se aplicaban a los barcos procedentes de Estados Unidos, invadiendo el cólera la isla días después. José Antonio Saco, Carta sobre el cólera morbo-asiático, Imprenta del Gobierno, La Habana, 1833, p. 14.
} 
Si bien en su periplo global esta enfermedad no discriminó entre sus víctimas, la mortalidad que dejó a su paso es uno de los testimonios más elocuentes de las profundas desigualdades sociales de la época. ${ }^{57} \mathrm{La}$ isla de Cuba no fue la excepción. Aquí, la población “de color” y particularmente la esclava sufrió con mayor rigor el azote del cólera. Los brotes epidémicos del siglo XIX acentuaron las desigualdades en salud de la población cubana, en desventaja de la gente "de color". De acuerdo con Kiple, en el caso de Cuba un mayor equilibrio racial en la estructura de la población permite un análisis más escrupuloso del impacto diferencial de esta enfermedad en el Caribe. Se estima que durante la primera epidemia de cólera fallecieron en Cuba casi 23.000 personas, cerca del $80 \%$ de ellos eran negros y mestizos. ${ }^{58} \mathrm{La}$ inferior mortandad de la población blanca en esta región no se explica, como creyeron varios observadores, entre ellos José Antonio Saco, “por un principio predisponente para el cólera" ${ }^{59}$ en los negros, sino por factores socio-ambientales. Si en Europa el impacto diferencial estuvo asociado a la posición social, siendo los sectores pobres los más vulnerables, en Cuba el color de la piel reveló la desigual capacidad de la población para sobrevivir a la epidemia. Un hecho significativo, la relación entre atacados y fallecidos, al que los estudios realizados han prestado poco interés, revela que no solo la exposición al contagio fue superior en la población de ascendencia africana, sino que además fue menor la probabilidad de recuperarse una vez contraída la enfermedad.

El impacto mortífero de la segunda epidemia se agravó en 1852 al combinarse con una de viruela. En carta fechada el 14 de agosto de 1852, dirigida al presidente del Consejo de Ministros, se comunicó que, aunque el cólera seguía causando víctimas en La Habana, no se estaba desarrollado generalmente entre la población. En la capital, los estragos fueron mayores en el ejército, la armada y el presidio. Se dispuso entonces la creación de tres hospitales para los atacados, entre otras medidas sanitarias que la experiencia aconsejaba en estos casos. ${ }^{60}$ Pero el orden establecido en la capital contrastaba con la experiencia en el campo, donde la epidemia volvió a provocar cuantiosas pérdidas. Kiple estimó que, esta epidemia cobró a la isla la vida de por lo

${ }^{57}$ Para una visión global véase el capítulo dedicado a las desigualdades sociales ante la enfermedad y la muerte en: Hartmut Kaelble, Desigualdad y movilidad social en los siglos XIX y XX, Ministerio de Trabajo y Seguridad Social, Madrid, 1994, pp. 153-177.

${ }^{58}$ Kenneth F. Kiple, "Cholera and Race in the Caribbean", Journal of Latin American Studies, vol. $17, \mathrm{~N}^{\circ} .1$, mayo, 1985 , pp. 157-177.

59 José Antonio Saco, Carta sobre el cólera morbo asiático, Imprenta del Gobierno, La Habana, 1833.

${ }^{60}$ Parte de tranquilidad de la isla de Cuba remitido por el gobernador Capitán General al presidente del Consejo de Ministros, AHN, Ultramar, Leg. 4637, N $.54,1852$. 
menos 26.000 a 30.000 esclavos. Algunas fuentes elevaron la mortalidad de la población cautiva en toda la isla a mucho más que lo sugerido por este autor. ${ }^{61}$

La relación entre atacados y fallecidos por esta enfermedad que ofrece Ramón Piña para el quinquenio 1850-1854 es la siguiente:

TABLA 17: CUBA. REGISTRO SOBRE LA EPIDEMIA DE CÓLERA, 1850-1854.

\begin{tabular}{|l|r|r|r|r|r|r|}
\hline \multirow{2}{*}{ Años } & \multicolumn{3}{|c|}{ Solo en la capital } & \multicolumn{3}{|c|}{ En toda la isla } \\
\cline { 2 - 7 } & Casos & \multicolumn{1}{|c|}{ Muertos } & $\begin{array}{l}\text { Relación de } \\
\text { mortalidad }\end{array}$ & Casos & Muertos & $\begin{array}{c}\text { Relación de } \\
\text { mortalidad }\end{array}$ \\
\hline 1850 & 4.623 & 2.858 & $62 \%$ & 11.423 & 6.033 & $53 \%$ \\
\hline 1851 & 1.408 & 1.098 & $78 \%$ & 3.451 & 2.473 & $72 \%$ \\
\hline 1852 & 2.246 & 1.401 & $62 \%$ & 7.030 & 3.341 & $48 \%$ \\
\hline 1853 & 1.046 & 810 & $77 \%$ & 8.834 & 4.420 & $50 \%$ \\
\hline 1854 & 24 & 13 & $54 \%$ & 1.346 & 877 & $65 \%$ \\
\hline Total & 9.348 & 6.180 & $66 \%$ & 32.048 & 17.144 & $53 \%$ \\
\hline
\end{tabular}

Fuente: Ramón Piña, Topografía médica de la isla de Cuba, p. 44.

La enfermedad no desapareció de forma súbita luego de esta etapa, la más crítica, por lo que habría que añadir no pocas muertes sobrevenidas por esta causa en años posteriores a los indicados. Es cierto que muchos de los fallecidos en este período, si no se presentaba muy clara la verdadera causa, pudieron atribuirse al cólera, pero también lo es que muchos casos no fueron reportados, sobre todo los ocurridos en partidos rurales. Como veremos, fueron frecuentes los conflictos suscitados entre las autoridades sanitarias y los propietarios de algunas fincas por omisión de numerosos casos de atacados y fallecidos por la enfermedad en cuestión.

Un documento de la Junta Subalterna de Sanidad de Matanzas, fechado el 21 de julio de 1853 informó que, de acuerdo con los partes dados por los facultativos de esa ciudad y los partidos de su jurisdicción, entre el 15 de junio y el 15 de julio de ese año ocurrieron 6 casos de fiebre amarilla, 57 de viruelas -de los que fallecieron 7-, 64 de colerina -de los cuales12 ocurrieron en la ciudad- y 10 de cólera -de los que habían fallecido 8. Mientras que, en varias fincas de esa región, en igual período, se reportaron 499 casos de cólera, de los que fallecieron 210. Otros 8 casos de cólera

\footnotetext{
${ }^{61}$ Kenneth F. Kiple, "Cholera and Race in the Caribbean", p. 164.
} 
epidémico se registraron en la ciudad después del día 15, de los cuales habían fallecido 2 hasta la fecha de notificación del parte. ${ }^{62}$

Otra fuente, firmada dos días después, dio a conocer que en la refinería de los señores Balchar \& Brothers, situada en la orilla sur del río San Juan, en Pueblo Nuevo, se había desarrollado una epidemia de cólera entre los chinos que componían la dotación, sin que el facultativo encargado de su asistencia informara de ello a la autoridad competente. Teniendo en cuenta que tal omisión violaba las normativas sanitarias, se dispuso averiguar quién era dicho facultativo para sancionarlo con una multa de \$25.00, “por haber faltado a su deber". Si de tal indagación resultaba que algunos de los coléricos habían sido visitados por "curanderos o intrusos", se pidió aplicar las penas que señala el artículo 15, capítulo segundo, del Reglamento de Medicina y Cirugía regente. ${ }^{63}$ A saber, que los que sin título legal ejercieran la ciencia de curar o se excedieran en las facultades que el mismo le concede, se les impondrá una multa de 100 pesos o un mes de prisión para la primera infracción, 200 pesos o dos meses en la segunda y 300 pesos o tres meses en la tercera, esto sin perjuicio de la causa judicial que pudiera instruirse por algún resultado funesto. ${ }^{64}$

A fines de julio de 1853, el médico de Sanidad del puerto de Matanzas y Vocal Secretario de la Junta de este ramo se quejó de que los facultativos no estaban declarando al momento los atacados en las áreas bajo su responsabilidad, "sin comprender el motivo que los impele á sus graves faltas". Omisiones que podían acarrear "gravísimas consecuencias" para la salud pública. ${ }^{65}$ Es posible que este comportamiento resultara del contubernio establecido entre algunos hacendados y médicos para evadir cualquier motivo que pudiera implicar una mayor vigilancia sobre sus dotaciones en una coyuntura marcada por la represión a la trata ilegal.

Como se desprende de la tabla 18, entre el 5 y el 29 de julio de 1853, resultaron de los partes médicos 82 atacados y 25 defunciones por la enfermedad en cuestión. Sin embargo, la diferencia entre los enterramientos realizados en el cementerio general en ese período y los de igual etapa en 1852 sugiere que un número importante de casos de

${ }^{62}$ En otra fuente se ubican las principales fincas atacadas en los partidos de Alacranes, Sabanilla y Canímar. Policía Sanitaria Terrestre, ANC, Junta Superior de Sanidad, Leg. 25, $\mathrm{N}^{\mathrm{o}}$. 3, parte 1, folios 58 y 59, 1832-1868.

${ }^{63}$ Policía Sanitaria Terrestre, ANC, Junta Superior de Sanidad, Leg. 25, No. 3, parte 1, folio 59, 1832-1868.

${ }^{64}$ Reglamento de medicina y cirugía formado por la Inspección de Estudio de las islas de Cuba y Puerto Rico, Imprenta del Gobierno, La Habana, 1844, p. 8.

${ }^{65}$ Policía Sanitaria Terrestre, ANC, Junta Superior de Sanidad, Leg. 25, No . 3, parte 1, folio 59, 1832-1868. 
cólera en 1853 no fueron notificados. La diferencia entre uno y otro año en esos días de julio es de 97 muertes, sin que pueda explicarse por causas ajenas a la epidemia.

TABLA 18: REGISTRO SOBRE LA EPIDEMIA DE CÓLERA EN MATANZAS, 1853.

\begin{tabular}{|c|c|c|c|c|}
\hline $\begin{array}{c}\text { Días de julio de } \\
1853\end{array}$ & $\begin{array}{l}\text { Atacados de } \\
\text { cólera, según } \\
\text { los partes de los } \\
\text { médicos que lo } \\
\text { han dado }\end{array}$ & $\begin{array}{l}\text { Muertos de } \\
\text { cólera, según } \\
\text { los partes de los } \\
\text { médicos que lo } \\
\text { han dado }\end{array}$ & $\begin{array}{l}\text { Entierros en el } \\
\text { cementerio } \\
\text { general }\end{array}$ & $\begin{array}{l}\text { Entierros en el } \\
\text { cementerio } \\
\text { general (1852) }\end{array}$ \\
\hline 5 & 1 & 1 & 2 & 6 \\
\hline 6 & - & - & 2 & 2 \\
\hline 7 & 1 & - & 5 & 2 \\
\hline 8 & 1 & - & 2 & - \\
\hline 9 & - & - & 3 & 1 \\
\hline 10 & 1 & - & 3 & 3 \\
\hline 11 & - & - & 7 & 2 \\
\hline 12 & 2 & - & 3 & 3 \\
\hline 13 & 1 & 1 & 7 & 3 \\
\hline 14 & 2 & - & 1 & 2 \\
\hline 15 & 1 & 1 & 3 & 3 \\
\hline 16 & 3 & 1 & 7 & 7 \\
\hline 17 & - & - & 6 & 4 \\
\hline 18 & 1 & - & 7 & 1 \\
\hline 19 & 3 & - & 6 & 5 \\
\hline 20 & 1 & - & 6 & 2 \\
\hline 21 & 3 & 1 & 7 & 1 \\
\hline 22 & 2 & 2 & 8 & 3 \\
\hline 23 & - & - & 6 & 3 \\
\hline 24 & 2 & - & 6 & 1 \\
\hline 25 & 4 & 3 & 9 & 4 \\
\hline 26 & 21 & 8 & 18 & 3 \\
\hline 27 & 14 & 4 & 14 & 3 \\
\hline 28 & 8 & 2 & 12 & 5 \\
\hline 29 & 10 & 1 & 18 & 2 \\
\hline Suma & 82 & 25 & 168 & 71 \\
\hline
\end{tabular}

Fuente: Policía Sanitaria Terrestre, ANC, Junta Superior de Sanidad, Leg. 25, №. 3, parte 1, folio 60, 1832-1868.

Por el artículo 24 del Reglamento de Medicina y Cirugía, los médicos y cirujanos debían dar cuenta a la Junta de Sanidad y al Subdelegado de su partido de todos los casos de enfermedad epidémica o contagiosa que se les presentase. ${ }^{66}$ Los informes debían ser diarios y con la mayor exactitud posible, para de este modo tener

${ }^{66}$ Reglamento de medicina y cirugía formado por la Inspección de Estudio de las islas de Cuba y Puerto Rico, p. 10. 
una idea clara sobre su progreso o disminución y poder establecer las medidas convenientes en cada caso. Entre otras cuestiones, de esos informes dependía la actualización de las patentes de sanidad que se despachaban a los buques.

Propietarios de varios ingenios de Matanzas estuvieron implicados en litigios por la violación de tales procedimientos. Por vox poluli las autoridades sanitarias del partido Ceiba Mocha se enteraron que en el ingenio Desvío, propiedad entonces de los herederos de Francisco Carriera, habían fallecido muchos esclavos de la epidemia de cólera, por lo que pidieron al facultativo que allí trabajaba, profesor Domingo Valdez Marzal, que "a la mayor brevedad" les comunicara si efectivamente era así, "para con la certeza del hecho, dar parte a quien corresponda, y también prevenir las medidas ordenadas en semejantes casos". Pasaron los días sin que recibieran información alguna, por lo que decidieron iniciar un expediente sancionador contra Marzal. Previamente, este médico fue multado por no incluir en un parte mensual de salud los casos de coléricos que asistió y por ocultar enterramientos al párroco de la localidad. Las autoridades temían que por esas negligencias se produjeran "grandes calamidades" en el partido y castigaron a Marzal con una multa de 100 pesos. ${ }^{67}$

Otro caso fue el suscitado con los propietarios del ingenio San Luis en Macurijes, en el verano de 1852. La Junta de Caridad de ese partido tuvo conocimiento de que esa propiedad, de los señores José Padró y Pedro Blay, carecía de un médico para asistir a los enfermos de cólera después del fallecimiento del licenciado Alejandro Lagarde, quien tenía a su cargo la enfermería del ingenio. Por tal motivo, y de acuerdo a lo reglamentado en esos casos, se encargó al subdelegado de medicina y cirugía procurar un médico del partido con el objetivo de asistir a los enfermos de aquella finca, actividad que debía realizar mientras durara la epidemia. La gratificación por este trabajo, que debían cubrir los dueños, era de 34 pesos diarios si el facultativo permanecía de asiento en la finca, y de 17 pesos si realizaba sus servicios por visita, en cuyo caso debía ser "detenida y escrupulosa". Con tal misión se trasladó allí el médico Antonio Ruiz, quien a fines de septiembre de ese año reportó con el estado de la enfermería del ingenio, la existencia de dos "convalecientes coléricos", los morenos Pedro lucumí y Rafael mandinga. ${ }^{68}$ El rechazo de José Padró y Pedro

\footnotetext{
${ }^{67}$ Policía Sanitaria Terrestre, ANC, Junta Superior de Sanidad, Leg. 25, No .3 , parte 3, folio $18,1832-1868$.

${ }^{68}$ El facultativo comunicó además la situación de mejoría del blanco Francisco Benítez y el estado regular del moreno Fernando criollo, ambos enfermos de fiebre biliosa, y que los
} 
Blay a la decisión tomada por la Junta fue tajante. Exigieron que el médico Antonio Ruiz fuera retirado del ingenio. Con tal fin, argumentaron que mientras duraron los desastres de la epidemia que afligía al ingenio, perdiendo "la séptima parte de sus esclavos", no merecieron de la Junta "la menor señal de su atención, ni una visita, ni un consuelo, ni una palabra, nada", que "no hubo entonces facultativo que quisiera ir allí, a pesar de haberlo buscado" y que, "cuando por misericordia divina va cesando el azote", cuando "habían pasado tres días sin ningún caso nuevo", se anuncia la Junta, "pero no para favorecer sino para proteger a un ahijado con el cuantioso sueldo de dos onzas diarias (es decir, la renta de un obispo) y obligar a los dueños a que la paguen." Costo que los hacendados consideraron lastimoso para sus intereses e "impropio de un país civilizado". Comunicaron que después de la muerte de Lagarde ajustaron un contrato con el médico Pedro Hernández Velazco, pero que este no llegó a cumplir. Aunque los propietarios no se negaban a tener un facultativo en la finca, querían que este fuera de su confianza, ajustando ellos el contrato de acuerdo con "los términos racionales y de costumbre", "no con el estupendo sueldo asignado por la Junta", que les parecía "una extravagancia sin ejemplo". ${ }^{9}$

morenos José criollo y Clara lucumí, enfermos "del pecho", "siguen bien”. Policía Sanitaria Terrestre ANC, Junta Superior de Sanidad, Leg. 25, N . 3, parte 3, folios 14 al 17, 1832-1868. ${ }^{69}$ Ídem. 
IMAGEN 6: NOTA EN LA QUE SE CERTIFICA EL FALLECIMIENTO DE COLETA CONGA, DE 46 AÑOS, A CONSECUENCIA DE LA EPIDEMIA DE CÓLERA MORBO.

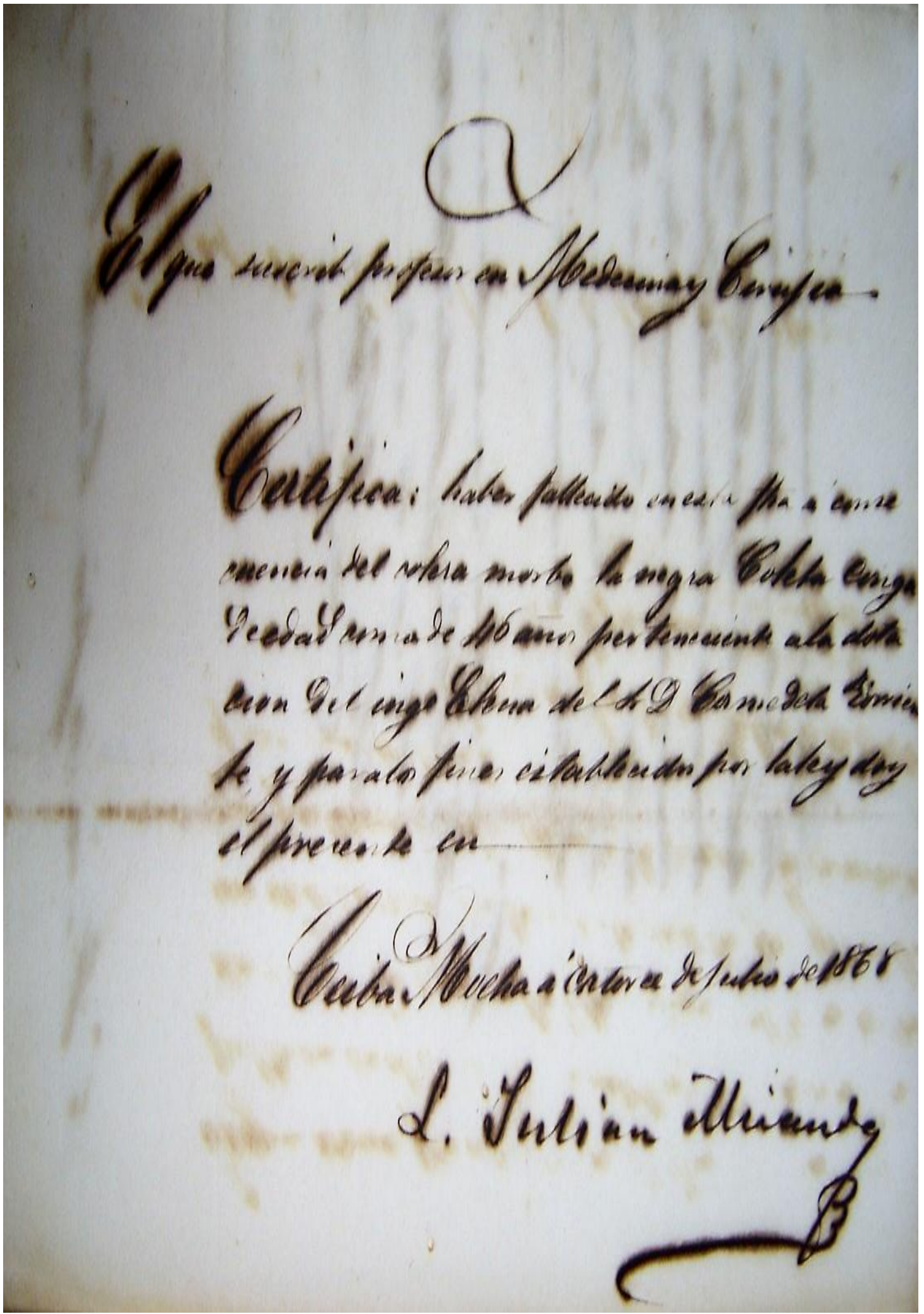

Coleta pertenecía a la dotación del ingenio Elena, propiedad de Cosme de la Torriente. Fuente: Defunciones, Fondo Gobierno Provincial, AHPM. 


\section{PATOLOGÍAS DE LA PLANTACIÓN}

La enfermería de los ingenios fue un reservorio de diversas afecciones, entre las cuales la tuberculosis, la disentería y el paludismo conformaron una triada de infecciones letales. Gran parte de la morbimortalidad de los esclavos en las plantaciones cubanas estuvo determinado directamente por estas causas. En la provincia de Matanzas, el 14\% de las defunciones registradas en 1879 se debió a estas enfermedades, siendo particularmente notable su incidencia entre los esclavos. De acuerdo con las observaciones de José A. Reynés, era raro que en las dotaciones de las fincas no se desarrollaran epidemias de diarreas, disenterías o fiebres catarrales cada vez que una fuerte lluvia sorprendía a los trabajadores en medio de sus faenas. ${ }^{70}$ Asimismo, la agobiante actividad laboral en las plantaciones bajo un clima muy cálido como el de la isla en gran parte del año, produjo en los trabajadores estrés térmico, fatigas, insolaciones y no pocos casos de enfermedades de los riñones.

Autores contemporáneos han destacado como la trasformación ecológica asociada al desarrollo de la agricultura comercial y en particular el cultivo de azúcar facilitó la expansión de múltiples enfermedades infecciosas como la fiebre amarilla y la malaria, trasmitidas por mosquitos. Este hecho fue analizado con prolijidad por J. R. Mc. Neill en su clásico Mosquito Empires. En el caso de Cuba, Reinaldo Funes, el principal historiador medioambiental cubano, analizó en profundidad el proceso de deforestación en la isla asociado al desarrollo de la plantación esclavista, aunque interrogó menos los efectos que tal proceso tuvo en la salud de la población residente en los espacios transformados. ${ }^{71}$ En efecto, el auge del paludismo en las décadas centrales del siglo XIX no puede explicarse al margen de la transformación ecológica asociada la expansión del cultivo de azúcar en la isla. La degradación del hábitat se reflejó en procesos de deforestación, seguías y en el desarrollo de otras condiciones propicias para la proliferación de los agentes transmisores. ${ }^{72}$

\footnotetext{
${ }^{70}$ José A. Reynés, "Algunas consideraciones generales sobre la raza negra, su patología y terapéutica", p. 144.

${ }^{71}$ Reinaldo Funes Monzote, De los bosques a los cañaverales. Una historia ambiental de Cuba 1492-1926, Editorial de Ciencias Sociales, La Habana, 2010.

${ }^{72}$ Estudios contemporáneos han confirmado que en zonas transformadas por procesos de deforestación la presencia del vector palúdico es relativamente mayor. Amy Yomiko Vittor y otros, "The effect of deforestation on the human-biting rate of anopheles darlingi, the primary vector of falciparum malaria in the peruvian amazon", The American Journal of Tropical Medicine and Hygiene, vol. 74, $\mathrm{N}^{\circ} .1,2006$, pp. 3-11.
} 
La malaria es una enfermedad parasitaria transmitida por las hembras de los mosquitos Anopheles. La existencia de esos insectos varía en dependencia de las condiciones ambientales de cada región. En el caso cubano, la enfermedad ha sido transmitida por mosquitos del tipo Albimanus, abundantes también en otros territorios del Caribe insular y en zonas de la costa este de América central. Los parásitos Plasmodium registrados en América son el Plasmodium falciparum, el Plasmodium vivax y el Plasmodium malariae, siendo los dos primeros los más peligrosos. Además del contagio directo mediante la picadura de estos insectos, es posible que una mujer embarazada lo transmita al feto por vía placentaria. En Cuba, las primeras referencias directas al paludismo se remontan a principios del siglo XIX. Antes, los casos de esta enfermedad se incluían dentro de estadísticas que comprendían diversos tipos de fiebres. Un número considerable de enfermos no recibieron tratamiento y, por tanto, no figuran en los registros médicos conservados. Por otro lado, la documentación disponible a menudo ignora otras complicaciones derivadas de la infección palúdica.

En la segunda mitad del siglo XIX, con la aparición de la prensa médica y el desarrollo de instituciones científicas, se publican numerosos estudios sobre la enfermedad en cuestión. En su tesis doctoral leída el 18 de marzo de 1872 y dedicada al estudio del paludismo, José Antonio Reynés sostuvo que: "En este país donde la vegetación es tan rica y exuberante (sic), donde las lluvias son torrenciales y el sol abrasador, hemos visto desarrollarse constantemente los miasmas palúdeos (sic) en las grandes talas de terrenos vírgenes que tienen lugar para el fomento de los ingenios."73 Los trabajadores ocupados en esas faenas agrícolas, que por lo general se realizaban en época de lluvias, estaban particularmente expuestos al contagio de una enfermedad que Reynés reconoció entre las más extendidas y mortíferas del planeta. Refiriéndose al atacado de esta enfermedad, este médico refiere que "escuálido su cuerpo y abotagado su rostro, su fisonomía triste y apática revela el germen de muerte que circula por sus venas y que le precipita á una vejez prematura". ${ }^{74}$ Sobre los criterios de estudios extranjeros, definió en su memoria los elementos clínicos que permitían establecer un diagnóstico diferencial de la enfermedad, distinguiéndola de otras como la fiebre tifoidea, pero su tesis se mantiene en los marcos de la teoría miasmática, sin realizar aportes originales sobre la etiología del paludismo.

\footnotetext{
${ }^{73}$ José Antonio Reynés, De las manifestaciones del paludismo: sus semejanzas y diferencias con otras enfermedades, pp. 12-14.

${ }^{74}$ Ídem.
} 
Un recurso importante para el tratamiento de la malaria, la fiebre amarilla y otras enfermedades tropicales fue desarrollado por el médico inglés Charles Warburg. $\mathrm{Su}$ medicamento, conocido como "Tintura de Warburg", ganó progresivamente aceptación dentro de la comunidad médica europea y fue considerado por algunos facultativos como más efectivo que la quinina. A mediados del siglo XIX la tintura de Warburg fue adoptada como una medicina oficial por el imperio austríaco. A principio de la década de 1860, el médico alemán Juan Bautista Ullersperger, entonces corresponsal del Instituto Médico Valenciano, recomendó la introducción en España de la fórmula antifebril de Warburg. En el decenio siguiente, en el contexto de la Guerra de los Diez Años, el embajador de España en Londres dirigió una correspondencia al gobierno del Reino en el que informaba sobre la fórmula de Warburg, con el objetivo de que el inspector general de Sanidad Militar en la isla la implementara en la asistencia de las tropas españolas, muy afectadas por el vómito negro y la malaria. ${ }^{75}$

Podemos mejorar nuestro conocimiento del carácter de la morbilidad y mortalidad por paludismo en las plantaciones cubanas de azúcar del siglo XIX al considerar los siguientes datos. Entre septiembre de 1920 y agosto de 1921, N. Nedergaard, médico en el hospital del central Preston, tuvo la oportunidad de estudiar los problemas de salud en una de las mayores plantaciones de azúcar de la isla. Esta propiedad, fundada por la United Fruit Company, ${ }^{76}$ estaba situada en tierras bajas al oeste de la bahía de Nipe, en una región caracterizada por un clima semi-tropical, lluvias frecuentes durante gran parte del año y la existencia de manglares y áreas pantanosas proclives a la reproducción de Anopheles. Entonces, la población residente en esta localidad estaba compuesta en gran parte por inmigrantes y varió

\footnotetext{
${ }^{75}$ Sobre un medicamento del doctor Warburg contra el vómito, AHN, Ultramar, Leg. 4730, $\mathrm{N}^{\mathrm{o}}$. 27, 1875-1877. En 1863 el Instituto Médico Valenciano convocó un premio con el tema "Redacción de una cartilla higiénica para el cultivador de arroz y habitante en tierras pantanosas, que le preserve de las enfermedades palúdicas, acompañada de la Memoria espositiva del fundamento de sus prescripciones comprobadas especialmente por hechos prácticos y esperimentales" (sic), obteniendo el premio Juan Bautista Ullersperger. Juan Bautista Ullersperger, Cartilla higiénica para el cultivador de arroz y habitante en tierras pantanosas, Imprenta de José Matéu Garín, Valencia, 1866. Sobre la relación entre la incidencia del paludismo y el desarrollo de la agricultura comercial valenciana, ver: Enric Mateu, Arroz y paludismo. Riqueza y conflicto en la sociedad valenciana del siglo XVIII, Institució Valenciana d’Estudis i Investigació, Valencia, 1987.

${ }^{76}$ Sobre el funcionamiento de esta empresa, ver: Oscar Zanetti Lecuona, "La United Fruit Company en Cuba.: organización del trabajo y resistencia obrera", Clío América, vol. 2, No .4 , 2008, pp. 238-258.
} 
significativamente en dependencia de la actividad azucarera. Durante los últimos meses de 1920 existían menos de 9.000 habitantes y más de 16.000 durante la primera parte de 1921. De ellos, un $40 \%$ eran braceros haitianos, alrededor del $25 \%$ eran jamaicanos y solo del 5 al 10\% eran cubanos. El resto correspondía a nacionales de otros países. ${ }^{77}$

De acuerdo con N. Nedergaard, la organización del trabajo en esa plantación determinó diferentes niveles de morbilidad por malaria. La mayoría de los haitianos eran ocupados en los campos de caña y vivían en barracones en grupos de veinte a cincuenta. Los jamaicanos eran empleados principalmente en obras de transporte y construcción. Como se observa en los datos de la tabla 19, ambos grupos estaban particularmente expuestos a la picadura de mosquitos infectados que criaban en lugares próximos a su lugar de trabajo y residencia. Menos expuestos estaban los cubanos empleados en esa plantación, que por lo general vivían en las ciudades. Asimismo, el gráfico $\mathrm{N}^{\circ}$. 2 muestra como la estacionalidad del empleo en esta plantación determinó cambios en las tasas de morbilidad por el tipo de malaria más perjudicial entre los trabajadores haitianos y jamaicanos.

TABLA 19: TIPOS DE MALARIA EXAMINADOS EN EL HOSPITAL DEL CENTRAL PRESTON, SEPTIEMBRE DE 1920-AGOSTO DE 1921.

\begin{tabular}{|l|r|r|r|r|}
\hline & \multicolumn{1}{|l|}{ Total } & Haitianos & Jamaicanos & \multicolumn{1}{l|}{ Cubanos } \\
\hline Admisiones & 5453 & 2830 & 1564 & 332 \\
\hline Sangre examinada & 5161 & 2733 & 1564 & 320 \\
\hline Malaria terciana & 296 & 127 & 108 & 7 \\
\hline Malaria cuartana & 25 & 18 & 5 & 0 \\
\hline Malaria estivo-otonal & 2154 & 1120 & 741 & 72 \\
\hline
\end{tabular}

Fuente: N. Nedergaard, "Malaria in Eastern Cuba", p. 387.

${ }^{77}$ N. Nedergaard, "Malaria in Eastern Cuba", The American Journal of Tropical Medicine, Baltimore, MD., vol. 1, No. 6, noviembre, 1921, pp. 381-388. 


\section{GRÁFICO 19: DISTRIBUCIÓN DE LOS CASOS DE MALARIA ESTIVO-OTOÑAL EXAMINADOS EN EL HOSPITAL DEL CENTRAL PRESTON.}

(septiembre de 1920-agosto de 1921)

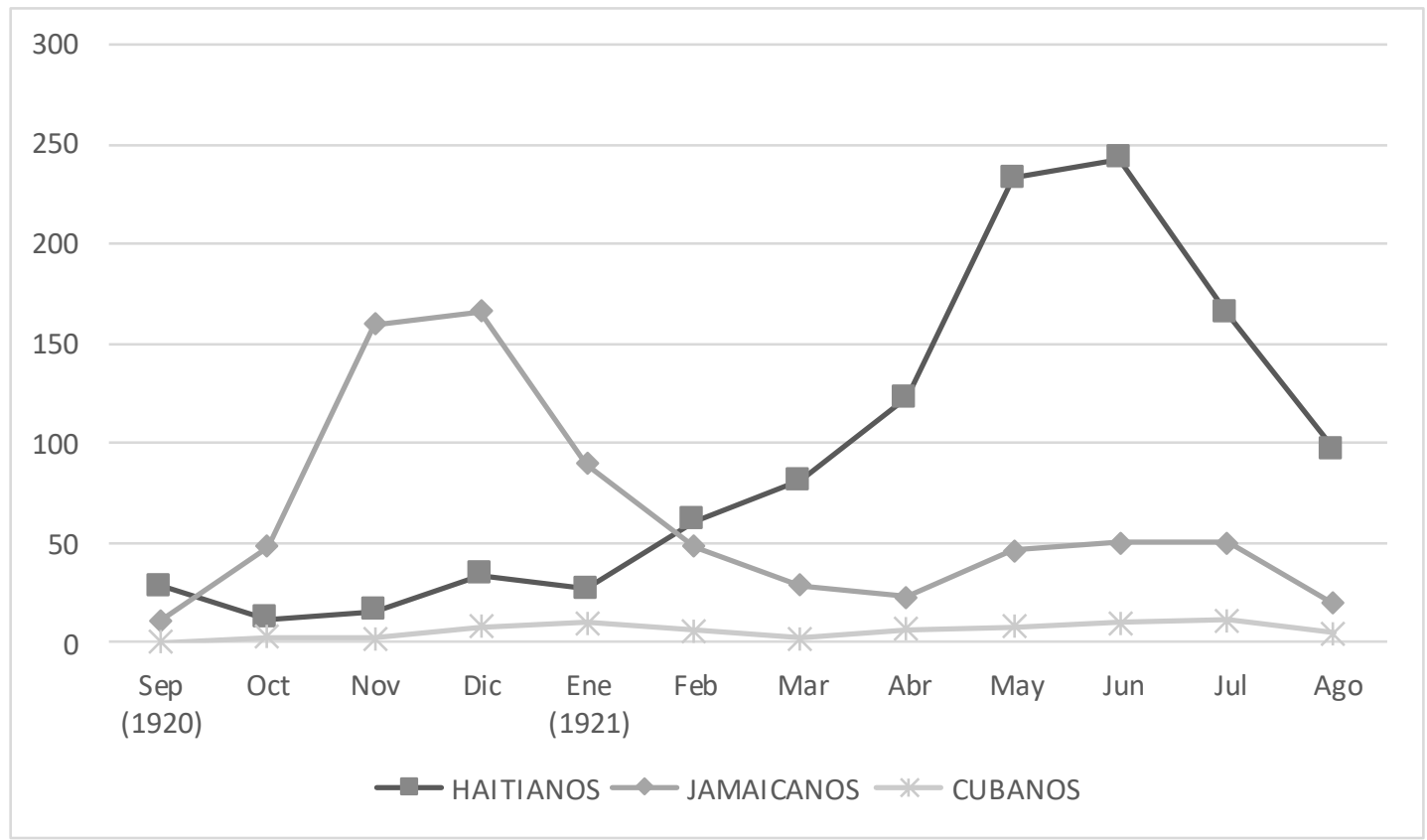

Elaboración propia a partir de la información disponible en: N. Nedergaard, "Malaria in Eastern Cuba", p. 384.

Los meses de noviembre y diciembre fueron particularmente húmedos $\mathrm{y}$ favorecieron la cría de Anopheles en la plantación. En cambio, las temperaturas más bajas entre enero y marzo retardaron su desarrollo. Los tres meses siguientes volvieron a ser particularmente favorables para la cría de estos insectos. N. Nedergaard sugiere que la malaria fue responsable de algo más del $50 \%$ de la morbilidad en la plantación. El hecho de que muchos pacientes hubiesen tomado quinina poco antes de ingresar al hospital con síntomas de malaria, y considerando que el mayor número de casos eran del tipo maligno o estivo-otoñal, que a menudo muestra pocos parásitos o ninguno en la sangre, son factores que pudieron reducir el porcentaje de casos positivos en los análisis de sangre realizados. Muchos de los trabajadores hospitalizados también presentaron infección por anquilostomiasis. De lo anterior, N. Nedergaard concluyó que era imprescindible enfrentar la situación de la malaria en las plantaciones del este de Cuba con medidas proactivas, ya que los costos de las pérdidas regulares debidas a esa enfermedad eran mayores que los necesarios para una prevención eficaz.

La multinacional estadounidense United Fruit Company, que fomentó un significativo foco palúdico en las extensas propiedades agrícolas adquiridas al este de la isla, destinó recursos para que la Escuela de Medicina Tropical de la Universidad 
Tulane, realizara estudios experimentales sobre la malaria, la pelagra, la lepra, el beriberi, la fiebre negra y la filariasis, entre otras enfermedades tropicales que afectaban su imperio agrícola. ${ }^{78}$ Por otro lado, el epidemiólogo norteamericano Kenneth Maxcy destacó la distribución geográfica de la malaria en los Estados Unidos a principios del siglo XX. En las plantaciones de algodón de la costa atlántica sur, los Anopheles encontraron condiciones favorables para su reproducción, determinando altos niveles de mortalidad entre los contingentes de trabajadores negros.

El desarrollo de la malaria en el campo cubano tuvo repercusiones directas en la salud pública de la capital. El flujo de personas y el desarrollo de las comunicaciones -ferrocarriles y caminos entre nuevos asentamientos- facilitó el desplazamiento de la enfermedad a lo largo de país. A pesar de los cambios tecnológicos, la producción de azúcar dependía de la cantidad de brazos disponibles. A su vez, las exigencias del trabajo en las plantaciones de caña determinaron un flujo constante de trabajadores hacia las ciudades en busca de actividades laborales más ventajosas. $^{79} \mathrm{El}$ temor de que una picadura pudiera desencadenar la agobiante enfermedad, consolidó prácticas cotidianas como el uso de mosquiteros en los hogares o la protección de las ventanas con tela metálica a prueba de mosquitos. Desde mediados del siglo XIX un número importante de mosquiteros figuran en las balanzas comerciales de la isla.

Años antes de su disertación doctoral sobre la malaria, Reynés también destacó la fuerte incidencia de la tuberculosis en la población "de color". ${ }^{80}$ Conocida antiguamente como tisis, hablamos de una enfermedad contagiosa que afecta principalmente a los pulmones, aunque también puede comprometer a otros órganos. La bacteria más importante en la etiología de esta enfermedad se denomina Mycobacterium tuberculosis o bacilo de Koch. Los síntomas más notables de la enfermedad son una tos crónica en ocasiones con esputo sanguinolento, fiebre, sudores nocturnos y pérdida de peso. Desde mediados del siglo XIX, con el surgimiento de la prensa médica especializada, se publican los primeros trabajos científicos sobre la tisis, que empezaba a ser común en la isla. En algunas de las más importantes publicaciones de ese tipo, como la Crónica Médico-Quirúrgica de La Habana o los

\footnotetext{
78 "The study of malary", Science, vol. XXXVI. No. 929, 18 de octubre de 1912, pp. 509-510.

${ }^{79}$ J. T. Crawley, El cultivo de la caña de azúcar en Cuba, Imprenta y Papelería de Rambla Bouza y Co., La Habana, 1917, p. 6.

${ }^{80}$ José A. Reynés, "Algunas consideraciones generales sobre la raza negra, su patología y terapéutica”, p. 148.
} 
Anales de la Academia de Ciencias Médicas, Física y Naturales, aparece abundante bibliografía sobre el tema.

En 1854 se registraron un total de 1.475 casos de los cuales fallecieron 765, entre ellos 176 hombres de las tropas. Tanto en entornos rurales como urbanos, la "gente de color" acusó una sobremortalidad en relación a la población blanca. De acuerdo con las consideraciones demográficas publicadas por el doctor $\mathrm{V}$. de la Guardia, la tuberculosis aportó en 1889 cerca del 20\% de todas las defunciones registradas en La Habana. Entonces, la población negra y mestiza aportó el 67,7\% de la mortalidad por esa causa, una cifra más de dos veces superior a su proporción en el conjunto de la población de la ciudad. Téngase en cuenta que la cifra que ofrece V. de la Guardia es inferior a la que da Jorge Le Roy en unas 199 defunciones. ${ }^{81}$

Otras enfermedades del sistema respiratorio pudieron ser frecuentes en el entorno del ingenio. Por ejemplo, estudios contemporáneos reconocen como bagazinosis una enfermedad pulmonar producida por la respiración de polvo de la caña de azúcar o bagazo almacenado, muy común entre los trabajadores de zonas azucareras. $^{82}$

De acuerdo con la información que presentamos en la tabla 20, en 1879 la población esclava de Matanzas aportó el 32\% de la mortalidad por disentería registrada en la provincia, el 43,5\% de la mortalidad por hepatitis, el 30,4\% de la mortalidad por enfermedades del corazón, el $47,1 \%$ de la mortalidad por enfermedades del hígado, el 54,2\% de la mortalidad por accidentes del parto, el 39,8\% de la mortalidad por fiebre palúdica, el $50 \%$ de la mortalidad por fiebre puerperal, el $41 \%$ de la mortalidad por hemorragia, el 48,7\% de la mortalidad por hidropesía, el $60 \%$ de la mortalidad por muermo y farcino, el 50\% de la mortalidad por pénfigo, el 51,4\% de la mortalidad por tétano en adultos, el $40 \%$ de la mortalidad por tos ferina, el $44,4 \%$ de la mortalidad por suicidio y el $32 \%$ de la mortalidad por homicidios.

\footnotetext{
${ }^{81}$ Jorge Le Roy y Cassa, "La sanidad en Cuba. Sus progresos", Sanidad y Beneficencia, julioagosto, 1913, p. 233.

82 Organización Panamericana de la Salud, Clasificación estadística internacional de problemas relacionados con la salud, OPS, Washington, 2003.
} 
IMAGEN 7: NOTA EN LA QUE EL LICENCIADO FRANCISCO DE P. GRIMA COMUNICA AL CAPITAN PEDÁNEO DEL PARTIDO DE SANTA ANA LA DEFUNCIÓN DE AMBROSIO MINA, A CONSECUENCIA DE UNA DISENTERÍA.

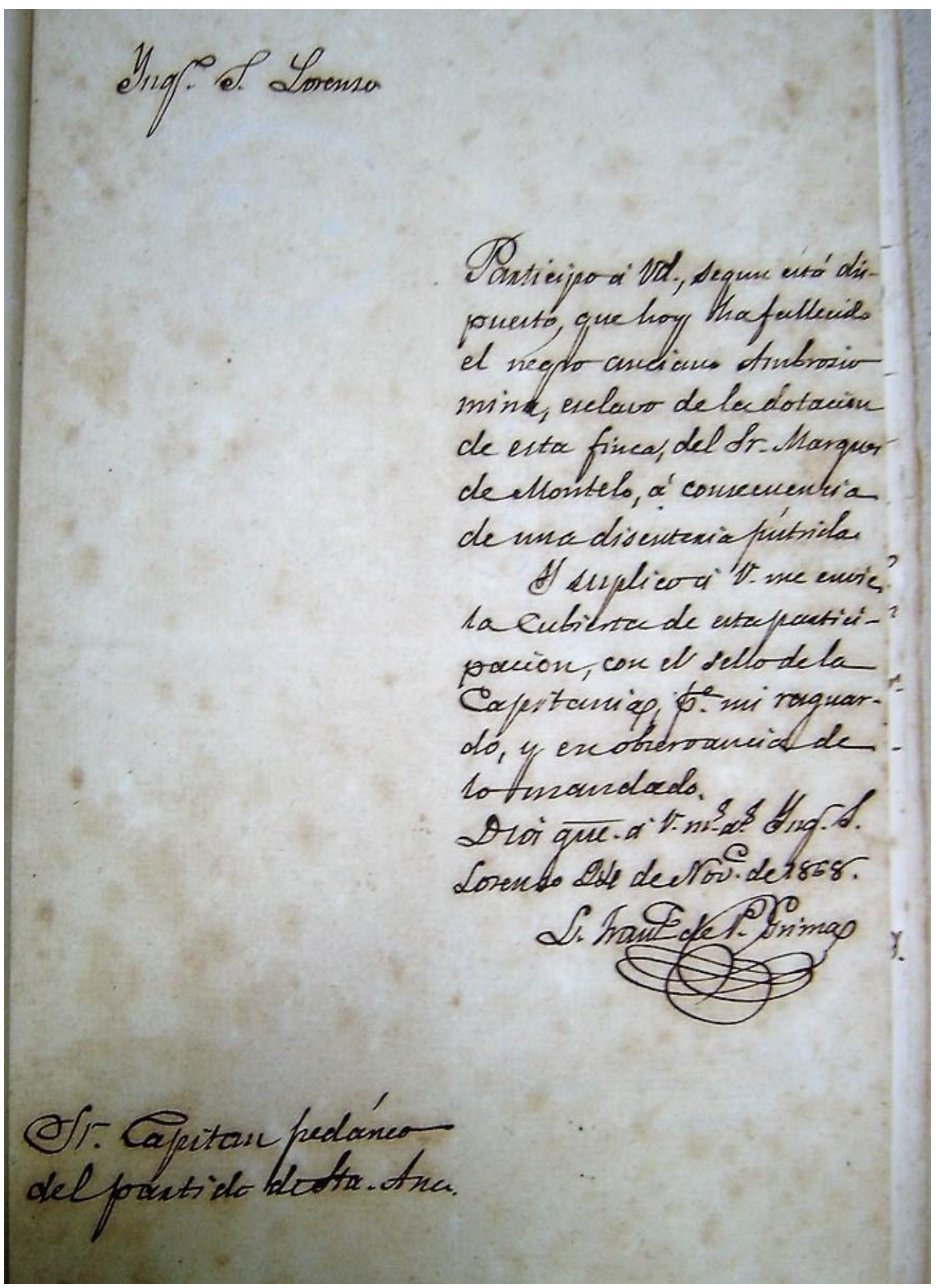

Ambrosio era esclavo de la dotación del ingenio San Lorenzo, propiedad del Marqués de Montelo. Fuente: Defunciones, Fondo Gobierno Provincial, AHPM. 
GRÁFICO 20: ESTACIONALIDAD DE LA MORTALIDAD EN MATANZAS, POR RAZA Y CONDICIÓN SOCIAL, 1879.

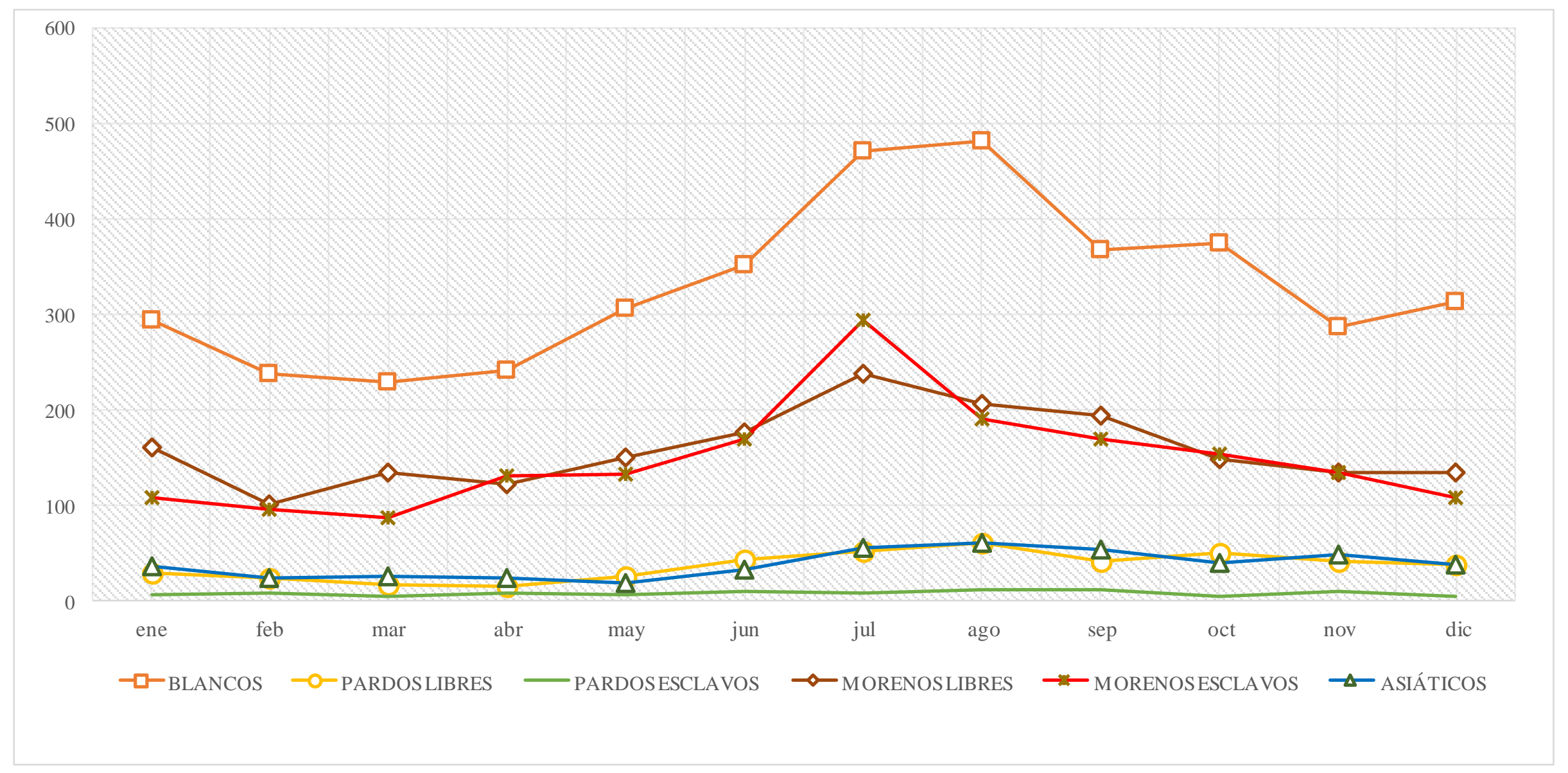

Elaboración propia a partir de la información disponible en: Dirección General de Hacienda, Población. Estudios estadístico-demográficos correspondientes a 1879. 
TABLA 20: MORTALIDAD EN MATANZAS, POR CAUSAS REGISTRADAS, RAZA, SEXO Y CONDICIÓN SOCIAL, 1879.

\begin{tabular}{|c|c|c|c|c|c|c|c|c|c|c|c|}
\hline \multirow[t]{2}{*}{ Enfermedades } & \multicolumn{2}{|c|}{ Blancos } & \multicolumn{2}{|c|}{ Pardos libres } & \multicolumn{2}{|c|}{ Pardos esclavos } & \multicolumn{2}{|c|}{ Morenos libres } & \multicolumn{2}{|c|}{ Morenos esclavos } & \multirow[t]{2}{*}{ Suma } \\
\hline & $\mathrm{V}$ & $\mathrm{H}$ & $\mathrm{V}$ & $\mathrm{H}$ & $\mathrm{V}$ & $\mathrm{H}$ & $\mathrm{V}$ & $\mathrm{H}$ & $\mathrm{V}$ & $\mathrm{H}$ & \\
\hline Alcoholismo & 6 & 0 & 1 & 0 & 0 & 0 & 2 & 0 & 1 & 0 & 10 \\
\hline Ántrax & 2 & 0 & 0 & 0 & 0 & 0 & 0 & 0 & 1 & 0 & 3 \\
\hline Apoplejía & 16 & 10 & 0 & 2 & 2 & 0 & 12 & 4 & 11 & 5 & 62 \\
\hline Asma & 2 & 1 & 1 & 0 & 0 & 0 & 3 & 1 & 2 & 1 & 11 \\
\hline Anginas & 10 & 19 & 2 & 0 & 0 & 0 & 6 & 4 & 1 & 1 & 43 \\
\hline Accidentes de la dentición & 28 & 28 & 6 & 6 & 0 & 0 & 29 & 21 & 1 & 1 & 120 \\
\hline Accidentes del parto & 0 & 7 & 0 & 0 & 0 & 1 & 0 & 4 & 0 & 12 & 24 \\
\hline Beriberi & 17 & 0 & 0 & 0 & 3 & 0 & 24 & 5 & 118 & 15 & 182 \\
\hline Cólera esporádico & 2 & 0 & 0 & 0 & 0 & 0 & 3 & 0 & 3 & 0 & 8 \\
\hline Cólera infantil & 17 & 11 & 3 & 3 & 0 & 0 & 16 & 9 & 1 & 0 & 60 \\
\hline Cistitis & 1 & 3 & 0 & 1 & 0 & 1 & 8 & 2 & 5 & 3 & 24 \\
\hline Diarrea de países cálidos & 16 & 9 & 3 & 2 & 0 & 0 & 17 & 10 & 11 & 5 & 73 \\
\hline Difteria & 7 & 6 & 0 & 0 & 1 & 0 & 6 & 4 & 2 & 2 & 28 \\
\hline Disentería & 78 & 29 & 9 & 0 & 2 & 1 & 51 & 31 & 65 & 25 & 291 \\
\hline Eclampsia infantil & 7 & 6 & 3 & 3 & 0 & 0 & 10 & 5 & 1 & 0 & 35 \\
\hline Escarlatina & 0 & 0 & 0 & 0 & 0 & 0 & 4 & 3 & 4 & 0 & 11 \\
\hline Erisipela & 4 & 1 & 1 & 1 & 0 & 0 & 3 & 4 & 4 & 1 & 19 \\
\hline Enteritis & 52 & 33 & 7 & 4 & 0 & 1 & 22 & 26 & 11 & 5 & 161 \\
\hline Epatitis (sic) & 25 & 8 & 0 & 0 & 1 & 0 & 10 & 9 & 29 & 10 & 92 \\
\hline Enfermedades del corazón & 37 & 14 & 2 & 3 & 6 & 0 & 26 & 15 & 35 & 10 & 148 \\
\hline Enfermedades del hígado & 16 & 6 & 0 & 0 & 0 & 0 & 4 & 1 & 14 & 10 & 51 \\
\hline Fiebre amarilla & 72 & 12 & 1 & 0 & 0 & 0 & 1 & 2 & 2 & 1 & 91 \\
\hline Fiebre biliosa & 57 & 33 & 2 & 1 & 1 & 0 & 12 & 10 & 18 & 6 & 140 \\
\hline Fiebre palúdica & 76 & 35 & 6 & 5 & 2 & 1 & 14 & 14 & 70 & 26 & 249 \\
\hline Fiebre tifoidea & 137 & 62 & 13 & 11 & 2 & 0 & 13 & 19 & 51 & 21 & 329 \\
\hline
\end{tabular}




\begin{tabular}{|c|c|c|c|c|c|c|c|c|c|c|c|}
\hline Fiebre puerperal & 2 & 6 & 2 & 0 & 0 & 0 & 4 & 2 & 8 & 8 & 32 \\
\hline Hidrofobia & 0 & 1 & 0 & 0 & 0 & 0 & 2 & 0 & 2 & 0 & 5 \\
\hline Hemorragia & 7 & 8 & 0 & 0 & 0 & 1 & 5 & 6 & 12 & 5 & 44 \\
\hline Hidropesía & 34 & 8 & 2 & 2 & 2 & 1 & 19 & 16 & 46 & 28 & 158 \\
\hline Meningitis & 45 & 19 & 6 & 4 & 0 & 1 & 14 & 20 & 11 & 7 & 127 \\
\hline Farcino y muermo & 0 & 0 & 0 & 0 & 0 & 0 & 1 & 1 & 2 & 1 & 5 \\
\hline Neumonía & 8 & 15 & 0 & 0 & 1 & 1 & 16 & 2 & 14 & 7 & 64 \\
\hline Pénfigo & 2 & 2 & 0 & 0 & 0 & 0 & 0 & 0 & 4 & 0 & 8 \\
\hline Peritonitis & 8 & 8 & 1 & 1 & 0 & 0 & 1 & 5 & 3 & 7 & 34 \\
\hline Sarampión & 1 & 0 & 0 & 0 & 0 & 0 & 1 & 2 & 1 & 1 & 6 \\
\hline Tétano de adultos & 16 & 6 & 3 & 1 & 0 & 0 & 12 & 9 & 35 & 15 & 97 \\
\hline Tétanos infantil & 78 & 43 & 18 & 15 & 1 & 0 & 33 & 40 & 7 & 10 & 245 \\
\hline Tisis & 293 & 123 & 20 & 10 & 7 & 1 & 51 & 49 & 75 & 43 & 672 \\
\hline Tos ferina & 7 & 0 & 1 & 0 & 0 & 0 & 4 & 6 & 11 & 1 & 30 \\
\hline Viruelas & 50 & 44 & 5 & 6 & 1 & 1 & 19 & 17 & 27 & 9 & 179 \\
\hline Longevidad & 18 & 8 & 2 & 1 & 0 & 0 & 32 & 24 & 13 & 6 & 104 \\
\hline Muerte repentina & 28 & 3 & 0 & 0 & 0 & 0 & 5 & 0 & 17 & 1 & 54 \\
\hline Suicidio & 15 & 0 & 0 & 0 & 0 & 0 & 0 & 0 & 11 & 1 & 27 \\
\hline Homicidio & 13 & 0 & 0 & 0 & 1 & 0 & 4 & 0 & 7 & 0 & 25 \\
\hline Otros males & 1.637 & 835 & 119 & 106 & 21 & 17 & 530 & 440 & 453 & 233 & 4.391 \\
\hline Suma & 2.947 & 1.462 & 239 & 188 & 54 & 28 & 1.049 & 842 & 1.220 & 543 & 8.572 \\
\hline
\end{tabular}

Fuente: Dirección General de Hacienda, Población. Estudios estadístico-demográficos correspondientes a 1879 


\section{GRÁFICO 21: CAUSAS DE MUERTE IDENTIFICADAS EN LOS REGISTROS DE ENTERRAMIENTOS PROCESADOS, 1855-1869.}

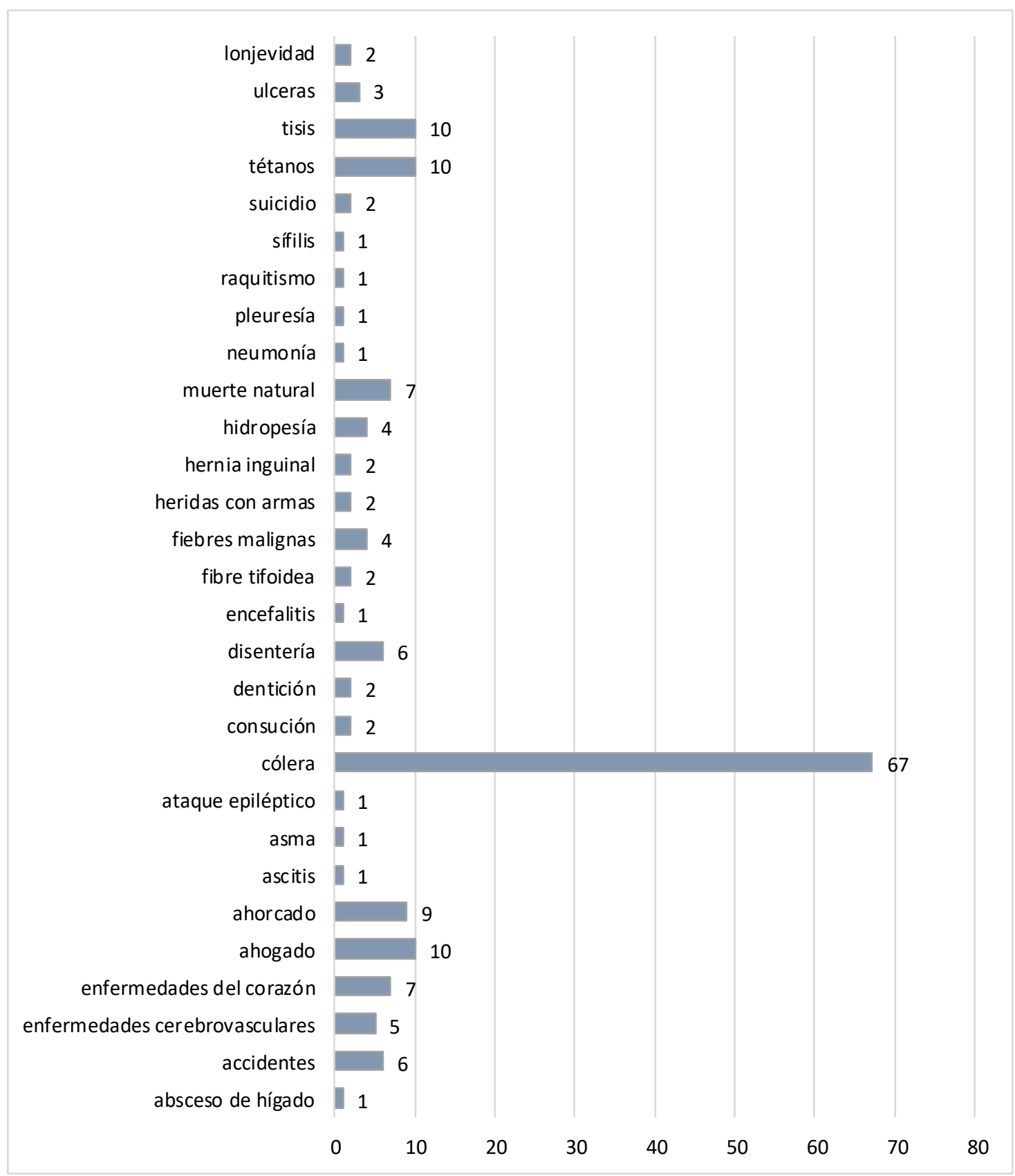

Elaboración propia a partir de la información disponible en: Defunciones, Fondo Gobierno Provincial, AHPM.

El gráfico 21 muestra las 29 causas de muerte que hemos identificado en 171 registros de enterramientos de esclavos ocurridos en varios partidos de Matanzas entre los años 1855 y 1869. Más del $90 \%$ de los enterramientos verificados por cólera se produjeron en el verano de 1868, fundamentalmente en el mes de julio, coincidiendo con la etapa más virulenta de la tercera epidemia. 
El gráfico 22 refleja el estado de la población enferma en ingenios propiedad de Julián Zulueta, uno de los más notables traficantes de esclavos y productores de azúcar de la colonia cubana. La fuente consultada solo específica los casos de esclavas "paridas", y, teniendo en cuenta que el número de estas es muy bajo, podemos asumir que casi la totalidad de los ingresos se deben a enfermedades corrientes. El registro coincide con el período de zafra, por lo que la entrada en la enfermería solo debió admitirse en casos de incapacidad manifiesta para el trabajo. Los datos confirman una elevada morbilidad asociada a la dinámica del régimen laboral, justo en la época de año en la que el hacendado debió poner mejor empeño en la salud de la dotación. De unos 135 días contabilizados, obtuvimos un promedio diario de 51 trabajadores hospitalizados. La tasa promedio para los hombres fue de 24 enfermos por día, para las hembras 21, y para los asiáticos 6. En el período tabulado no se observa una gran diferencia de la morbilidad entre mujeres y hombres. Los picos de morbilidad en el período tabulado se alcanzaron en el mes de febrero, con días con más de 80 enfermos. Aunque la fuente no lo refiere, es probable que los cambios bruscos en la morbilidad estuvieran determinados por algún brote epidémico. En esos casos se observa un rápido aumento de la población enferma y luego una súbita disminución, de lo cual parece más lógico inferir mortalidad que una pronta recuperación. Téngase en cuenta que los meses tabulados no corresponden a la etapa del año más nociva para la salud de la población trabajadora, toda vez que la mortalidad durante el invierno es relativamente baja en comparación con los meses de fin de zafra y el verano. Este registro descubre el impacto neto de la dinámica azucarera sobre la población trabajadora, si consideramos que desde hace varios años finalizó la trata ilegal en la isla y la población hospitalizada ha superado el período crítico de aclimatación. 


\section{GRÁFICO 22: REGISTRO DE LA POBLACIÓN ENFERMA EN INGENIOS DE JULIÁN ZULUETA, 1875-1876.}

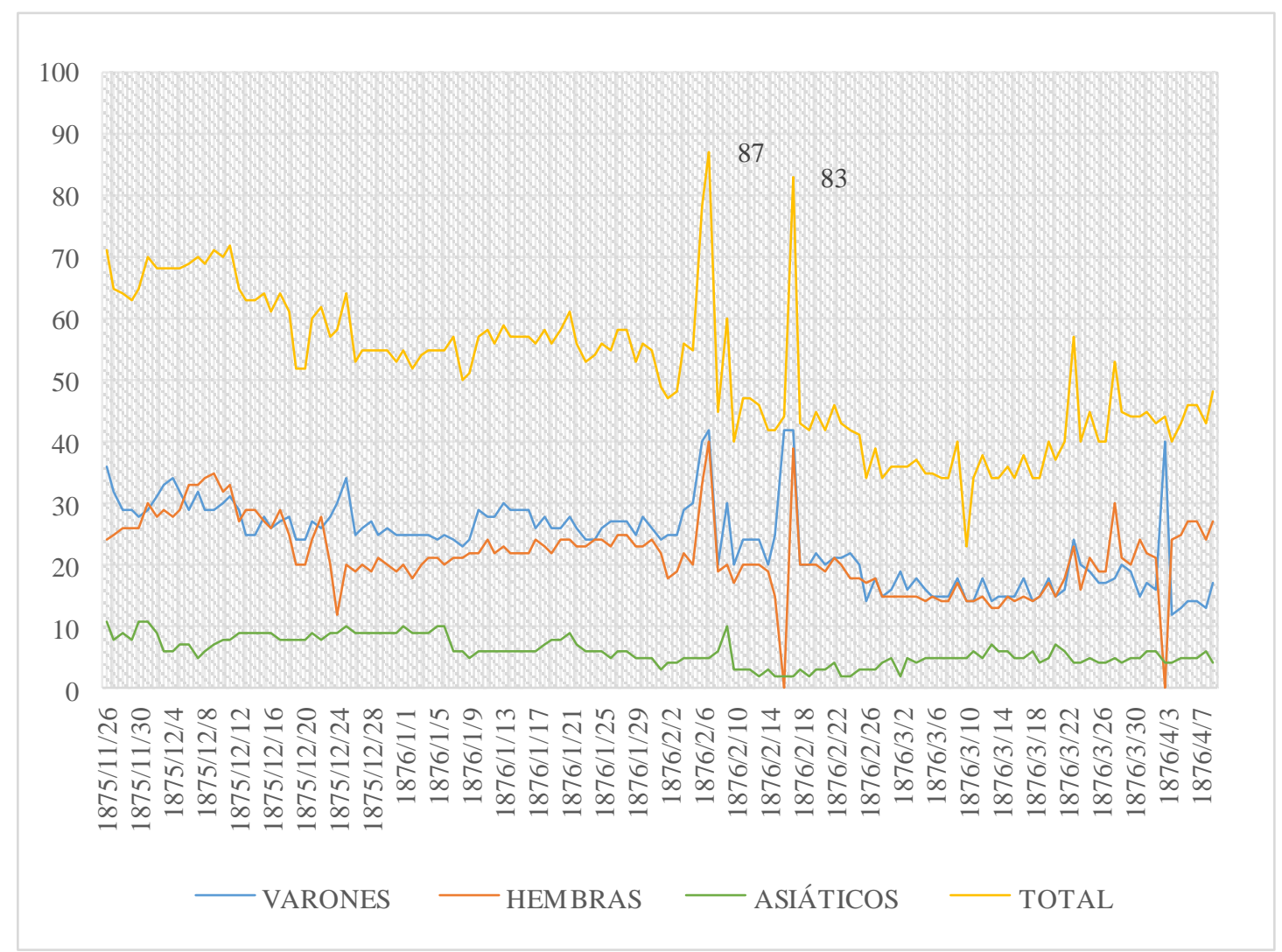

Elaboración propia a partir de la información disponible en: Libro de refacción de los ingenios Vizcaya, Habana, España, Álaba (sic) y otros ubicados en la provincia de Matanzas, propiedad de Julián de Zulueta correspondiente a los años 1874-1876, ANC, Donativos y Remisiones, Leg. 140, №. 1.

Otro elemento a considerar en el estado de salud de la población esclava es la incidencia de la viruela. Adrián López Denis comprobó la fuerte correlación entre las tasas de vacunación y las importaciones de esclavos legales hasta la década de 1820, y, efectivamente, sugiere que esta práctica preservativa de la salud estuvo dirigida principalmente a los esclavos recién importados. ${ }^{83}$ Con la trata ilegal se violaron los controles de policía sanitaria establecidos, pero los hacendados comprendieron la importancia de este mecanismo preventivo y con el tiempo promovieron la vacunación y revacunación en sus dotaciones. Sin embargo, todavía en 1879 la viruela tuvo la capacidad de matar a 1.380 personas en todo el país -un $10 \%$ de ellos esclavos-, siendo

\footnotetext{
${ }^{83}$ Adrián López Denis, Disease and Society in Colonial Cuba, 1790-1840.
} 
particularmente fuerte en las provincias de Pinar del Río y La Habana, donde se concentró el $73 \%$ de las defunciones por esa causa. ${ }^{84}$

Otra enfermedad habitual en las plantaciones cubanas fue el tétanos de adultos. Si en los recién nacidos el manejo antihigiénico del cordón umbilical determinó en no pocos casos el desarrollo de esta enfermedad, entre los esclavos adultos lo fue la naturaleza de los trabajos que realizaban, las heridas producidas por accidentes o acciones violentas. El riesgo de contaminación con la espora tetánica se multiplica si la herida se produce con algún instrumento sucio u oxidado, por la mordedura de un animal, o si entra en contacto con la tierra, factores que confluyeron con regularidad en los ingenios cubanos.

En los años 1845 y 1846 el profesor de cirugía y medicina Diego M. Jiménez de Cisneros atendió muchos casos de tétanos traumático y espontaneo en el ingenio Triunvirato, propiedad de Julián L. Alfonso y en otras fincas de Matanzas. Entre ellos los morenos Longinos y Josefa criollos del citado ingenio y Manuel Rodríguez, mayoral del ingenio La Palma. En el primero de estos casos la enfermedad sobrevino por las mordeduras de un perro y en Josefa por habérsele amputado un brazo. El mayoral contrajo la infección a consecuencia de una herida en una mano. En los tres casos la enfermedad alcanzó su expresión extrema, pero fueron curados por Jiménez con un particular método consistente en el uso medicinal del tabaco. Por sus buenos resultados, el medicó Francisco de P. Grima también adoptó el método de su comprofesor en el tratamiento de un considerable número de tetánicos que asistió en los ingenios San Cayetano, Triunvirato, Antonia, Ácana, Casualidad, La Palma, La Concepción, San Miguel, San Lorenzo y San Antonio, salvando a muchos de los atacados. Fue el caso del moreno criollo Próspero, de nueve años de edad, que en marzo de 1873 entró “con el trismo ya bien marcado" en la enfermería del ingenio San Miguel, propiedad de la señora Merced Alfonso de la Guardia. Próspero no tenía “el menor rasguño”, "ni se había extraído niguas", ni fue expuesto a cambios repentinos de temperaturas, ni comió otra cosa que lo de costumbre, ni presentaba señales de vermes intestinales, o sea, no presentaba indicios de causa conocida por Grima a la que pudiera atribuir el origen del mal. Al mes siguiente ingresó en la misma enfermería con marcados síntomas de tétanos la criolla Elvira, de 25 años, hermana de Próspero. Tampoco en este caso Grima

\footnotetext{
${ }^{84}$ Es de significar que en Pinar del Río fallecieron 69 de los 143 esclavos muertos por esta causa. Dirección General de Hacienda, Población. Estudios estadístico-demográficos correspondientes a 1879.
} 
pudo determinar el origen de la enfermedad. En octubre, también fue atacado de tétano el criollito Marcelo, de un año y nueve meses de edad, hijo de Elvira. Cuando se presentaron los primeros síntomas en Marcelo, este se encontraba acompañando a su madre en la enfermería, que estaba convaleciente de una fiebre catarral. Grima confesó desconocer la explicación de la invasión de la enfermedad en cuestión en estas tres personas de una misma familia, atacadas en el mismo año y en diferentes estaciones. La única conclusión relevante determinada por su experiencia era que existían localidades en las que la enfermedad se desarrollaba con facilidad, aun por heridas leves, mientras que en otras era muy rara, incluso en casos de lesiones graves. Las dudas de Grima revelan el divorcio existente en la época entre la práctica médica y el conocimiento científico en la terapéutica de esta y otras enfermedades. ${ }^{85}$

El uso del tabaco como curativo del tétanos había sido desarrollado por algunos médicos ingleses, sobre todo por Thomas Blizard Curling, que en 1834 obtuvo el premio Jacksonian del Real Colegio de Cirujanos de Londres por un texto sobre esta enfermedad. $^{86}$ Seguramente el profesor cubano Diego M. Jiménez conocía las investigaciones de Blizard Curling e introdujo en la isla un método que el médico inglés consideró como el más efectivo que existía entonces.

No obstante, el índice de mortalidad asociado a esta causa se mantuvo elevado hasta bien entrado el siglo XIX. En diciembre de 1850 se registraron en la isla 33 caos de tétanos de toda clase, de los cuales solo se salvaron 13 personas, para una mortalidad superior al 60\%. ${ }^{87}$ En 1879 el tétanos produjo 349 muertes en Cuba, 247 de las cuales fueron varones, hecho que confirma las observaciones de la época referentes a su mayor incidencia entre los hombres, sobre todo en sujetos jóvenes y muy activos en el trabajo. De los 97 esclavos fallecidos ese año por esta razón, 50 eran de Matanzas. ${ }^{88}$

Teniendo en cuenta que el alcoholismo estaba muy extendido en el siglo XIX entre las capas populares de la isla, decir que la embriaguez fue una práctica regular de los esclavos rurales no es en sí mismo un gran hallazgo. Tampoco lo es revelar que este producto lo obtuvieran mediante una especie de trueque subrepticio con los comercios

\footnotetext{
${ }^{85}$ Francisco de P. Grima, "Tratamiento del tétano por el tabaco", Anales de la Real Academia de Ciencias Médicas, Físicas y Naturales de La Habana, vol. XI, 1874, pp. 42-46.

${ }^{86}$ Thomas Blizard Curling, A Treatise on Tetanus, Impreso por J. G. \& F. Rivington, Londres, 1836. En extenso sobre las diversas posturas de la época referentes a esta enfermedad, en: Tratado completo de patología y terapéutica, general y especial, t. XII, Imprenta de la Viuda de Jordán e Hijos, Madrid, 1846, pp. 420-431.

87 "Crónica sanitaria del mes de diciembre", Gaceta de La Habana, №. 9, 9 de enero de 1851.

88 Dirección General de Hacienda, Población. Estudios estadístico-demográficos correspondientes a 1879.
} 
próximos a la plantación o proveedores ambulantes. Todo lo que el esclavo no recibía de su amo, y eran muchas las cosas que podía necesitar o apetecer, las obtenía mediante es tipo de intercambios. Hoy sabemos que la plantación no era el mundo cerrado que se concibe en algunos relatos. Para nuestra investigación, la importancia del consumo habitual de alcohol estaría dada por sus implicaciones en la salud de los esclavos y en la rutina de la plantación. En el capítulo anterior sugerimos la posible incidencia de un consumo regular de alcohol en el desarrollo del beriberi. Más notable pudo ser su impacto en otras enfermedades. ${ }^{89}$ Por ejemplo, en la morbilidad por hepatología alcohólica. La etapa final de esta enfermedad se conoce como cirrosis, que se produce por un daño en el funcionamiento del hígado relacionado con un consumo excesivo de alcohol.

Ramón Piña informó que, entre la población de edad avanzada de la Jurisdicción de Santa María del Rosario, las "tisis hepáticas" se presentaban con bastante frecuencia, siendo pocas las personas que fallecían de enfermedades crónicas en la vejez, "donde la hepatitis no haya tomado la iniciativa, ó haya sido una de sus principales complicaciones." 90 A mediados de la década de 1850, la población de Santa María del Rosario, perteneciente al Departamento Occidental, estaba compuesta por 11.467 blancos, 2.148 libres "de color" y 5.379 esclavos. ${ }^{91}$ De ser exactos los datos que ofrece Félix Erénchun, en el quinquenio siguiente la población libre "de color" se redujo en 257 habitantes, mientras la esclava y la blanca crecieron en un $1 \%$ y $16,3 \%$ respectivamente. Esto en un territorio en el que solo el 0,7\% de sus 1.015 fincas rurales eran entonces ingenios o trapiches. ${ }^{92}$ Piña también indicó que en esa localidad eran frecuentes los males de las vías urinarias, el reumatismo, la gota, la tisis pulmonar, la sífilis, las calenturas disentéricas y tifoideas, enfermedades que hicieron estragos principalmente en las dotaciones de las fincas.

La accidentalidad en los ingenios fue una causa habitual tanto de mortalidad como de invalidez en la población trabajadora. Con los procesos de mecanización, los accidentes derivados de las tareas industriales aumentaron en gravedad. En 1855, el 0,68\% de la población esclava empadronada se clasificó como "inhábiles", unas 2.363 personas. De ellas, 1.830 , equivalentes al $0,66 \%$, correspondía a la totalidad de la población esclava rural. Este valor aumenta al $0,88 \%$ si consideramos solo a la

\footnotetext{
${ }^{89}$ Fernando Ortiz, Los negros esclavos, p. 249.

${ }^{90}$ Ramón Piña, Topografía médica de la isla de Cuba, pp. 176-178.

${ }^{91}$ José García Arboleya, Manual de la isla de Cuba, p. 113.

${ }^{92}$ Félix Erénchun, Anales de la isla de Cuba, Imprenta "La Antilla”, La Habana, 1861, p. 2390.
} 
población entre 12 y 60 años. Mientras se clasificó como "inutilizados" a 533 brazos en el empadronamiento urbano, dígito equivalente al $0,81 \%$ del total de los de esta clase y al 1,1\% en relación a los de edad productiva. En ambos territorios la proporción de varones inutilizados superó a las mujeres, lo que sugiere que, a pesar de los padecimientos específicos relacionados con el embarazo, los hombres corrían mayor riesgo de quedar inutilizados para el trabajo. Aunque la cifra absoluta de la población esclava rural inhábil era mucho mayor que la de igual condición en las ciudades, esto se explica por un total muy superior de la población esclava rural que urbana: $283.625 \mathrm{y}$ 65.121 respectivamente. ${ }^{93}$ De hecho, fue habitual que muchos esclavos inhábiles para el trabajo rural fueran reubicados en la servidumbre urbana.

En 1836 la Sociedad Económica de Amigos del País publicó un trabajo del consejero francés Louis Becquey sobre las medidas de precaución necesarias en el uso de las máquinas de vapor de alta presión. La corporación académica criolla consideró que era una materia de gran utilidad para los propietarios cubanos que, "siguiendo el impulso que ha impreso el siglo a la maquinaria, se valen de este poderoso agente en sus ingenios de fabricar azúcar." ${ }^{24} \mathrm{El}$ exhaustivo trabajo del consejero francés fijaba algunas de las cuestiones fundamentales a tener en cuenta para el buen funcionamiento de un aparato con un gran potencial destructivo. La máquina debía ser confiada a personas capacitadas en su manejo y el propietario que no mantuviera una vigilancia constante sobre su funcionamiento, en caso de accidente, no solo era víctima de las considerables pérdidas que este podía ocasionar sino también responsable indirecto del hecho. ${ }^{95}$

En la etapa que comprende las décadas de 1820 y 1830 varios hacendados cubanos introdujeron la máquina de vapor en sus ingenios. Entonces, antiguas plantaciones realizaron inversiones importantes en esa y otras mejoras tecnológicas. Asimismo, desde 1837 comenzó a funcionar el ferrocarril en la isla. Unas décadas más tarde, la modernización tecnológica se había operado en gran parte del complejo azucarero cubano. ${ }^{96}$ Estos cambios alteraron la dinámica del proceso productivo,

${ }^{93}$ Esa cifra no contempla otros 17.675 esclavos no clasificados. José García de Arboleya, Manual de la isla de Cuba, pp. 116-117.

94 "Instrucción sobre las medidas de precaución que deben hacerse habituales en el uso de las máquinas de vapor de alta presión", Memorias de la Sociedad Económica de Amigos del País, La Habana, vol. 2, 1836, p. 306.

${ }^{25}$ Ídem.

${ }^{96}$ Sobre la modernización industrial de la producción azucarera cubana en la segunda mitad del siglo XIX destaca el clásico estudio de Fe Iglesias, Del ingenio al central, Editorial de la Universidad de Puerto Rico, San Juan, 1998. Ver también los capítulos dedicados a los cambios tecnológicos en: Manuel Moreno Fraginals, El ingenio, t. 2, pp. 19-23. Antonio Santamaría y 
creando nuevas exigencias a las que debieron adaptarse los trabajadores. Era interés de los propietarios garantizar el correcto funcionamiento de las nuevas tecnologías, entre ellas la potente máquina de vapor, pero no siempre dispusieron de operarios calificados $\mathrm{y}$ los accidentes fueron frecuentes.

En febrero de 1882, cuando la máquina de vapor ya contaba con varias décadas de uso en la isla, se produjo un accidente en el ingenio Confianza, en el territorio de Alacranes, Matanzas, que produjo la muerte de tres individuos "de color", dos morenos y dos asiáticos en estado grave, y lesiones y quemaduras menos graves de otros dos asiáticos y dos blancos, entre otros daños materiales. El ingenio disponía de cinco calderas, reventando solo una de ellas. Se pidió entonces a la Academia cubana que ilustrara a cerca de algunas cuestiones técnicas referidas como motivo de la explosión, para que en base a ello el Juzgado de Primera Instancia de Alfonso XII, que llevaba el caso, pudiera dictaminar. Las versiones de los dos maquinistas del ingenio, evidentemente coordinadas, coincidían casi en su totalidad, destacando que no se encontraban en el emplazamiento de las calderas en el momento de la explosión, que el accidente no pudo resultar del mal estado de la caldera, que la misma estaba funcionando por debajo de la presión habitual, y que la explosión se produjo por alguna columna de aire frío que se introdujo por los registros de la fornalla. Las declaraciones de otros dos maestros mecánicos, en calidad de peritos del Juzgado, no aportaron detalles que dieran mayor claridad al suceso. ${ }^{97}$ La Academia consideró insustanciales estos testimonios y acusó a los maquinistas del ingenio Confianza de carecer de los conocimientos más rudimentarios acerca del funcionamiento de estas calderas de vapor, siendo "estrafalaria" su hipótesis sobre las corrientes de aire en la fornalla.

Al margen de la disquisición científica del caso, interesante para comprender los conflictos de conocimientos en torno a los componentes tecnológicos que sustentaron la transformación del ingenio en central, lo que nos interesa destacar son las consecuencias para el factor humano. Si bien las actuaciones judiciales no dieron a la Academia información detallada del trágico suceso, esta consideró razonable concluir que el

Alejandro García, Economía y colonia: la economía cubana y la relación con España (17651902), CSIC, Madrid, 2004, pp. 168-208. Reinaldo Funes Monzote, De los bosques a los cañaverales. Una historia ambiental de Cuba 1492-1926, pp. 283-339.

${ }^{97}$ Claudio Delgado, "Informe relativo a la explosión de una caldera", Anales de la Real Academia de Ciencias Médicas, Físicas y Naturales de La Habana, vol. XXIII,1886, pp. 292316. 
mismo estuvo determinado por negligencia de los operarios. ${ }^{98}$ La sincrónica ausencia de los mismos de su puesto laboral cobró la vida de varios trabajadores y causó en otros lesiones importantes.

\section{CUERPOS CAUTIVOS Y NEMATODOS LIBRES}

En abril de 1872 ingresó en la enfermería del ingenio Antonia, propiedad de la señora Antonia Madan de Alfonso, el moreno congo Nolasco, de unos cuarenta años y constitución fuerte, quejándose de un dolor intenso en la frente y la nariz, "decía que le andaba una cosa por dentro". Al tercer día de su ingreso, Nolasco empezó a secretar por las fosas nasales "un líquido sanioso, sanguinolento y muy fétido", sospechando el médico que lo examinó, doctor Francisco de P. Grima, de la presencia de gusanos en los senos frontales y partes contiguas del enfermo. Se le aplicó entonces un tratamiento consistente en baños de vapor e inyecciones con agua creosotada dirigidos a la nariz, arrojando el enfermo en los próximos días "multitud de gusanos, como de media pulgada de extensión". A los pocos días Nolasco fue dado de alta. ${ }^{99}$

En abril del año siguiente, Nolasco volvió a ingresar en la enfermería con síntomas que delataban la misma enfermedad. Fue sometido a un tratamiento similar y el enfermero de la finca aseguró haber contado 101 gusanos solo en la primera expulsión. A pesar del carácter más agudo de la afección verminosa en esta ocasión, Nolasco se recuperó otra vez y fue incorporado a los trabajos de la finca. Aunque Grima no desconocía esta enfermedad, le impresionó la regularidad de este caso y el hecho que se produjera en una plantación en la que no era común, “como sucede en la generalidad de los ingenios", la presencia de lombrices intestinales en los criollitos y afecciones verminosas en los trabajadores. Previendo que en 1874 padeciera Nolasco idéntico malestar, lo sometió desde principios de ese año a un tratamiento de sulfato de quinina, método que puso en conocimiento de la Academia por los buenos resultados que comprobó en el tratamiento de esta y otras enfermedades. ${ }^{100}$

En efecto, a lo largo del siglo XIX, la helmintiasis, conjunto de enfermedades parasitarias en las que una parte del cuerpo está infestada por helmintos, estaba muy

\footnotetext{
${ }^{98}$ Ídem.

${ }^{99}$ Francisco de P. Grima, "Vermes en los senos frontales", Anales de la Real Academia de Ciencias Médicas, Físicas y Naturales de La Habana, vol. XI, 1874, pp. 46-48.

100 Ídem.
} 
extendida entre las poblaciones esclavas de las Indias Occidentales. En un texto publicado en 1803, uno de esos manuales con recomendaciones para el manejo y tratamiento médico de los negros en las colonias de azúcar, habituales en tiempos de la "segunda esclavitud", su autor David Collins, que se identificó como un "plantador profesional", refiriéndose a estos gusanos señaló que el cuerpo humano tenía varios reclusos problemáticos de este tipo. ${ }^{101}$

El término helminto designa a dos grupos de organismos metazoos con profundas diferencias biológicas. En común comparten el hecho de ser parásitos de las personas. Sus dimensiones pueden oscilar entre milímetros y metros, según la especie. Entre las principales enfermedades humanas causadas por nematodos patógenos están la ascariasis, la tricuriasis y la anquilostomiasis. La morbilidad por parasitosis depende de la cantidad de gusanos que alberga un organismo. En casos de infestaciones graves pueden producirse trastornos nutricionales, anemia, y un deterioro físico peligroso para la persona. ${ }^{102}$

${ }^{101}$ David Collins, Practical rules for the management and medical treatment of negro slaves, in the sugar colonies, Impreso por J. Barfield, Londres, 1803, p. 388.

102 OMS, "Helmintiasis transmitidas por el suelo", consultado en www.who.int/mediacentre/factsheets/fs366/es/, 18 de octubre de 2016. 


$$
\text { R. } 200.953 \div
$$

\section{TRA TA D O}

\section{$1 A$ \\ EN F E R M E D A D E S 586 \\ QDE}

PRODUCEN LAS LOMBRICES EN EL CUERPO HUMANO

$\mathbf{x}$

So metrodo curatyo.

$O B R A$

INTERESENTE PARA LOS HACENDADOS Y AGRICULTORES

DE LAS

\section{ISLAS DE CUBA Y PUERTO RICO, $\mathbf{x}$}

PARA LOS HABITANTES

DE LA

AMERICA SETENTRIONAL Y MERIDIONAL.

Elustraba coir Potas $\mathfrak{y}$ Zstampas.

$\mathbf{Y}$

Traducida del Orijinal Raliano al Francín, por el Doctor J. BARTOLI, de la Seciedad de Emulacion de Pario-de ente idioma al Inglkn, por el Docton JOHN H. COFFIN, de Baton-y del Inglie al Eoparial,

POR

\section{JOSE QUINTANA WARNES,}

HACENDADO DE LA HABANA.

Aro cum Natura ad solstem conopirane.-Cewo.

I M PRESO

Por Adam Wazdr, Crudad de Pemladelpin, Betado de Prevelakin. Alto de 1831. 
En 1831 el hacendado habanero José Quintana Warners imprimió en Philadelphia, Estado Unidos, el Tratado sobre las enfermedades que producen las lombrices en el cuerpo humano y método curativo, destinado a los propietarios y agricultores de las islas de Cuba y Puerto Rico. ${ }^{103}$ La obra original apareció en italiano y contaba ya con traducciones al francés, alemán e inglés. Otro ejemplo de la activa circulación atlántica de conocimiento médico en el siglo XIX. Warners concibió esta edición porque, de acuerdo con su experiencia de más de veinte años como hacendado en Cuba, "la mayor parte de las enfermedades que padecen los siervos de las fincas rurales, y de las que tantos de ellos son víctimas infelices, son producidas generalmente por la presencia de las Lombrices". También por el gran desconocimiento que la mayoría de los médicos rurales que ejercían en la isla tenían de una enfermedad "tan perjudicial a los intereses individuales y la riqueza pública". ${ }^{104}$ Por tanto, recomendó que existiera un ejemplar de esta obra en cada finca. De acuerdo con este autor, entre las causas que facilitaban el desarrollo de los "gérmenes verminosos" se encontraban la ingesta de alimentos groseros, de mala calidad o mal condimentados y de frutas verdes, las aguas insalubres, el desaseo y habitar en lugares húmedos, el excesivo trabajo y la falta de descanso y la "irregularidad de la intemperie". Factores que, con mayor o menor grado, concurrían en gran parte de las fincas rurales de la isla, contribuyendo a la "desproporcionada mortandad" que se observa entre sus trabajadores. ${ }^{105}$

Causas similares fueron reconocidas por Ramón Piña, quien también advirtió que las lombrices intestinales eran muy comunes en la población infantil y en la generalidad de los negros de la isla. La infestación parasitaria se confirmó en un número importante de cadáveres de personas que fallecieron por enfermedades graves. De acuerdo con las observaciones de este médico, entre los síntomas característicos de las personas invadidas por lombrices destacan el color aplomado de la cara, los ojos apagados, la picazón en la nariz y en el ano, el olor desagradable en la boca, un apetito desordenado, la hinchazón del vientre, vómitos y cólicos, entre otros. No obstante, pudo observar sujetos infestados asintomáticos que expulsaron muchas lombrices. Asimismo, Piña comunicó que entre las especies de helmintos existentes en la isla había uno

\footnotetext{
${ }^{103}$ José Quintana Warners, Tratado sobre las enfermedades que producen las lombrices en el cuerpo humano y método curativo, Impreso por Adam Waldie, Philadelphia, 1831. El texto original corresponde a Valeriano Luis Brera (1772-1840), médico italiano que ejerció como profesor de Medicina Clínica en la Universidad de Padua.

${ }^{104}$ José Quintana Warners, Tratado sobre las enfermedades que producen las lombrices en el cuerpo humano y método curativo, p. iii.

${ }^{105}$ Ídem.
} 
llamado "Filaria, Dracúnculo, Lombriz de Guinea o de Medina, muy común entre los negros y principalmente entre los carabalíes." 106

También en su conocido estudio sobre patología comparada, Henri Dumont registró la enfermedad producida por la llamada "lombriz de Guinea". Su nombre científico es dracunculiasis. El médico francés observó que era más frecuente en los ingenios ubicados en el interior del país y en los meses de verano y otoño. Aunque no era exclusiva de la población "de color", en estos se presentó con mayor frecuencia que entre los blancos. De acuerdo con Henri Dumont, estos últimos contraían "la lombriz de Guinea" cuando vivían en promiscuidad con los negros, como sucedía en el ingenio España, ubicado en la localidad de Perico, Matanzas. Ejemplo de ello fueron los casos de una mujer blanca esposa del mayoral y de un hombre de igual raza de unos 40 años, que trabaja como sereno en la indicada finca. Henri Dumont descartó, acertadamente, la posibilidad que la lombriz penetrase en el organismo a través de la piel, como sucedía con las niguas, pero no acertó al considerar que la presencia del "parasito africano" se debía a un desarrollo espontaneo. ${ }^{107}$

Mientras Dumont realizaba esas observaciones en las plantaciones cubanas, sin poder establecer con precisión la etiología de la enfermedad en cuestión, el médico búlgaro Hristo Tanev Stambolski, durante su exilio en Yemen (1877-1878), estudió esta patología y argumentó que la enfermedad se debía a la ingesta de agua infectada. ${ }^{108} \mathrm{El}$ dracunculus es una de las pocas excepciones de helmintos que se transmiten a través del consumo de agua contaminada con cyclops, organismos habituales en depósitos de agua con escaza o ninguna circulación como charcas, fosas, estanques o zanjas. ${ }^{109}$

\footnotetext{
${ }^{106}$ Ramón Piña, Topografía médica de la isla de Cuba, p. 104. En enero de 1866 el Diario de la Marina publicitó un remedio "eficaz" contra las lombrices del licenciado Sotomayor, que se vendía en una farmacia de la capital. En enero de 1880, el mismo diario publicitó unos polvos "infalibles" anti-helminticos que se vendían en la botica de Santa Ana, una de las más populares de La Habana. La nota publicitaria destacaba la facilidad con la que los niños adquirían lombrices en la isla y el hecho de que este tipo de infestaciones constituyeran una causa importante de mortalidad en los menores.

${ }^{107}$ Henri Dumont, Antropología y patología comparadas de los negros esclavos, p. 74.

${ }^{108}$ Bernard Lory (ed.), Le Yémen en 1877-78 Tel Que l'Ont Vu Deux Médecins Bulgares: H. Stambolski y J. Ljubenov, Isis, Estambul, 2008.

${ }^{109}$ Ver: Ernesto Ruiz-Tiben y Donald R. Hopkins, "Dracunculiasis (Guinea Worm Disease) Eradication", Advances in Parasitology. Control of Human Parasitic Diseases, vol. 61, 2006, pp. 275-309; "Helminthic diseases: dracunculiasis", en: K. Heggenhougen y S. Quah, (eds.) International encyclopedia of public health, Elsevier-Academic Press, Amsterdam, 2008, pp. 294-311.
} 
TABLA 21: FOCO DE DRACUNCULIASIS OBSERVADO EN EL INGENIO ESPAÑA, 1866.

\begin{tabular}{|c|c|c|c|c|c|c|c|}
\hline $\mathrm{N}^{\mathrm{o}}$ & Nombres & Nación & Edad & Entrada & Días & Salida & Observaciones \\
\hline $\begin{array}{l}1 \\
2 \\
3 \\
4 \\
5 \\
6 \\
7 \\
8 \\
9 \\
10 \\
11 \\
12 \\
13\end{array}$ & $\begin{array}{l}\text { Gracia } \\
\text { Matilde } \\
\text { Eufemia } \\
\text { Anatalia } \\
\text { Felipa } \\
\text { Lucía } \\
\text { Gaspar } \\
\text { Augusto } \\
\text { Torcuato } \\
\text { Tomás } \\
\text { Felipe } \\
\text { Mauricio } \\
\text { Dámaso }\end{array}$ & $\begin{array}{l}\text { Lucumí } \\
\text { Mina } \\
\text { Magin } \\
\text { Mina } \\
\text { Magin } \\
\text { Arará } \\
\text { Lucumí } \\
- \\
- \\
\text { Criollo } \\
\text { Lucumí } \\
\quad \ldots \\
\ldots\end{array}$ & $\begin{array}{l}17 \\
18 \\
18 \\
20 \\
18 \\
21 \\
23 \\
23 \\
26 \\
27 \\
22 \\
\ldots \\
\ldots\end{array}$ & $\begin{array}{l}8 \text { de agosto } \\
1 \text { de agosto } \\
7 \text { de agosto } \\
9 \text { de agosto } \\
19 \text { de Julio } \\
29 \text { de Julio } \\
8 \text { de agosto } \\
- \\
28 \text { de Julio } \\
- \\
5 \text { de agosto } \\
21 \text { de agosto } \\
21 \text { de agosto }\end{array}$ & 12 & $\begin{array}{ll}10 & \mathrm{de} \\
\text { agosto } & \end{array}$ & $\begin{array}{l}\text { Parásito de } 50 \mathrm{~cm} \\
\text { de largo }\end{array}$ \\
\hline
\end{tabular}

Datos enviados a Henri Dumont por E. Lebreton, médico interno del ingenio España, propiedad de Julián Zulueta. Fuente: Henri Dumont, Antropología y patología comparadas de los negros esclavos, p. 74.

A luz de los conocimientos contemporáneos, podemos establecer una razonable conexión entre una causa frecuente de mortalidad en el pasado y una infestación con un nematodo que afecta principalmente a las personas en edad laboral en áreas en las que abundan los mosquitos, entre ellos Culex, Anopheles y Aedes, muy activos en el Caribe. Hasta bien entrado el siglo XIX, la hidropesía se registró como una enfermedad específica en diversos documentos. El médico escocés Jorge Buchan -del Colegio de Médicos de Edimburgo y director de la Casa de Niños expósitos de Ackwort- describió esta enfermedad como "una hinchazón preternatural de todo el cuerpo ó de alguna parte de él, causada por una colección ó depósito de humor aquoso" (sic), que se distingue con diferentes nombres según la parte del cuerpo donde se concentra." ${ }^{110}$ La hidropesía fue la causa indicada de la muerte del negro Leandro Alegre, perteneciente a la dotación del Ingenio San Cristóbal de Baracoa, acontecida el 19 de diciembre de 1853. Como se ve en el gráfico $\mathrm{N}^{\circ}$. 2, en 1879 la hidropesía se registró como una de las principales causas de mortalidad en la isla, con unas 688 defunciones, una quinta parte de ellas de

${ }^{110}$ Desde el siglo XVIII la hidropesía es un mal recurrente en varios manuales de medicina. Jorge Buchan, Medicina doméstica ó Tratado completo del método de precaver y curar con el método y medicinas simples, Imprenta de Álvarez, Madrid, 1818, p. 288. Esta edición fue traducida al castellano por el Coronel Antonio Alcedo, Capitán de Reales Guardias Españolas. La primera traducción al castellano de esta obra fue realizada en 1785. El texto de Buchan tuvo en poco tiempo varias reediciones en inglés y traducciones al francés, holandés y alemán. Antes de esta obra Buchan obtuvo reconocimiento por una disertación sobre el modo de criar a los niños en el hospital de Ackwort, Inglaterra. 
esclavos y el $47 \%$ correspondiente a la totalidad de la gente "de color". Su incidencia fue notoria en las provincias de Matanzas y Santa Clara, donde produjo 158 y 178 muertes respectivamente. ${ }^{111}$ Hoy sabemos que la hidropesía o edema no constituye una enfermedad independiente, sino un signo clínico que acompaña a diversas enfermedades. Se manifiesta principalmente en las extremidades inferiores, aunque también puede afectar otras partes del cuerpo. Es posible que el impreciso y recurrente diagnóstico de esta enfermedad en Cuba en el siglo XIX encubriera muchos casos de filariasis linfática.

La filariasis linfática o elefantiasis se produce en los seres humanos por la infección del parásito Wuchereria bancrofti. El parásito puede vivir años dentro del organismo humano sin manifestarse la enfermedad. Cuando prospera en el sistema linfático la hinchazón que produce puede llegar a ser bastante grande. Se cree que la filariasis llegó al Nuevo Mundo a través de la trata de esclavos. Con el desarrollo de la agricultura comercial y el crecimiento demográfico en Cuba se crearon las condiciones propicias para el desarrollo de esta enfermedad. De hecho, un primer paso en la comprensión de la elefantiasis ocurrió en 1863 cuando un médico francés, Jean-Nicolás Demarquay, describió microfilarias que observó en fluidos extraídos de un paciente cubano. Estudios posteriores de Otto Wucherer en Brasil, Timothy Lewis en la India, de T. Spencer Cobbold en China, considerado el principal helmintólogo británico de su época, de Patrick Manson y de Joseph Bancroft en Queensland, sentaron el conocimiento científico de la filariasis. ${ }^{112}$

José A. Reynés apuntó que el linfatismo característico de la raza negra se podía deducir de la frecuencia con que se presentaba en ellos la elefantiasis. Una afección caracterizada por la obstrucción de los canales linfáticos que erróneamente atribuyó a los repentinos cambios atmosféricos a los que los africanos estaban expuestos en la isla. ${ }^{113}$ Las siguientes imágenes ilustran dos casos de filariasis linfática con hinchazón del escroto o hidrocele. La primera corresponde al negro congo Domingo Fernández, realizada en La Habana a fines del siglo XVIII, aunque entonces no se diagnosticó

${ }^{111}$ En el mismo expediente se comunican las defunciones de los morenos Polonio Rebollo y Rafael Cajigal, también de la dotación del ingenio San Cristóbal, aunque no se especifica la causa. ANC, Misceláneas de Expedientes, Leg. 1705, Ac, 1854.

112 "Un legado de la trata de esclavos en los Estados Unidos fue el establecimiento de un foco de filariasis bancroftiana en Charleston, Carolina del Sur y su entorno "Low Country", que sobrevivió hasta principios del siglo XX". Todd L. Savitt, "Filariasis", en: Kenneth F. Kiple (ed.), The Cambridge Historical Dictionary of Disease, pp. 125- 128.

113 José A. Reynés, "Algunas consideraciones generales sobre la raza negra, su patología y terapéutica”, p. 146. 
como tal la enfermedad en cuestión. La segunda es una fotografía tomada por el reconocido fotógrafo alemán Walther Dobbertin en Tanzania a principios del siglo XX. En tal grado de desarrollo, la persona enferma no solo sufría una discapacidad permanente -con gran riesgo para su vida- sino además el estigma social, con las consecuencias que ambos problemas acarreaban. 


\section{IMAGEN 9: DOMINGO FERNÁNDEZ, CONGO, 32 AÑOS, ENFERMO DE "HERNIA DISFORME".}

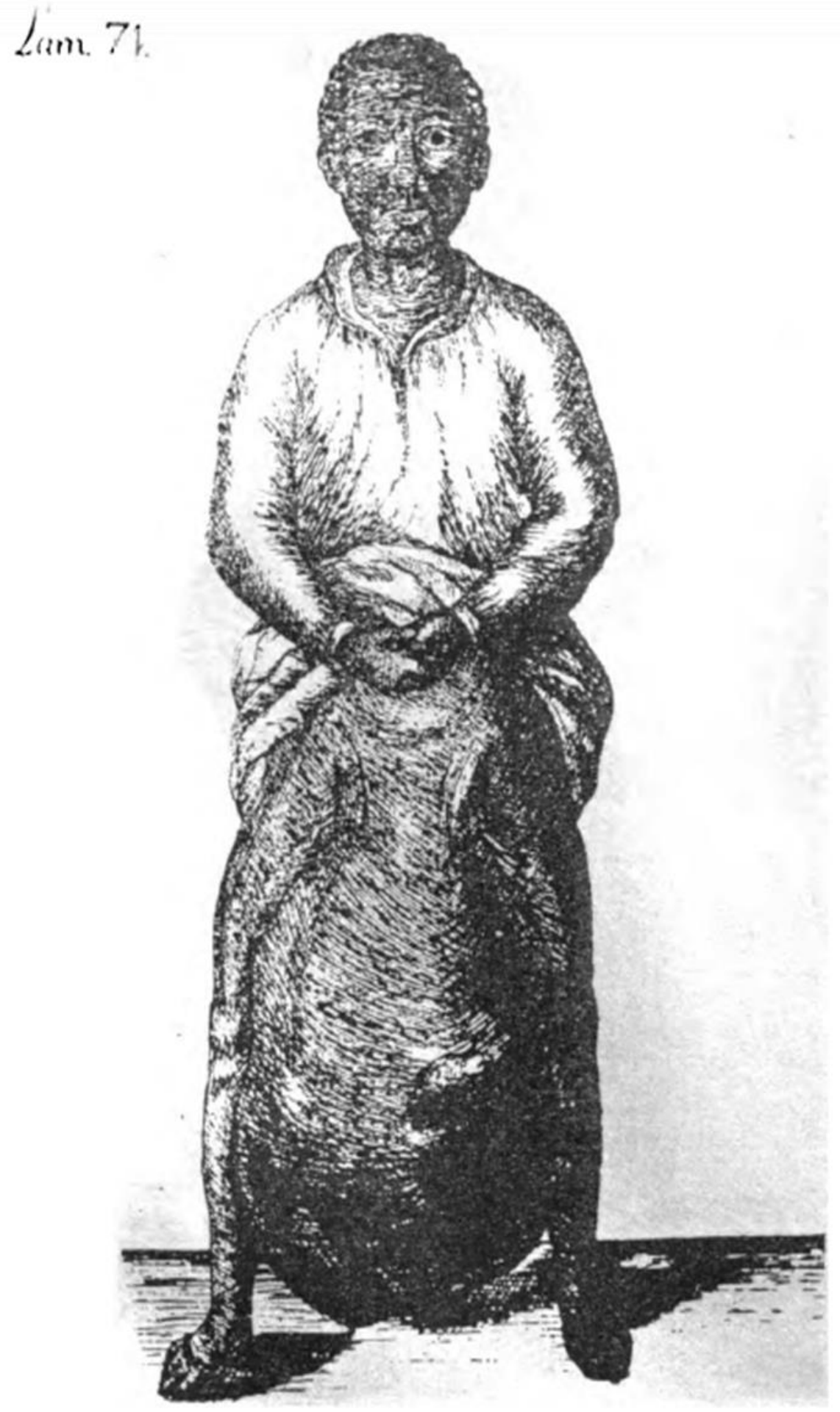

Domingo Fernández trabajaba en La Habana a fines del siglo XVIII de calesero y cochero cuando enfermó de la causa sugerida. Fuente: Antonio Parra, Descripción de diferentes piezas de historia natural, Imprenta de la Capitanía General, La Habana, 1787. 
IMAGEN 10: HOMBRE CON ELEFANTIASIS DEL ESCROTO. ÁFRICA ORIENTAL ALEMANA (TANZANIA), 1906-1914.

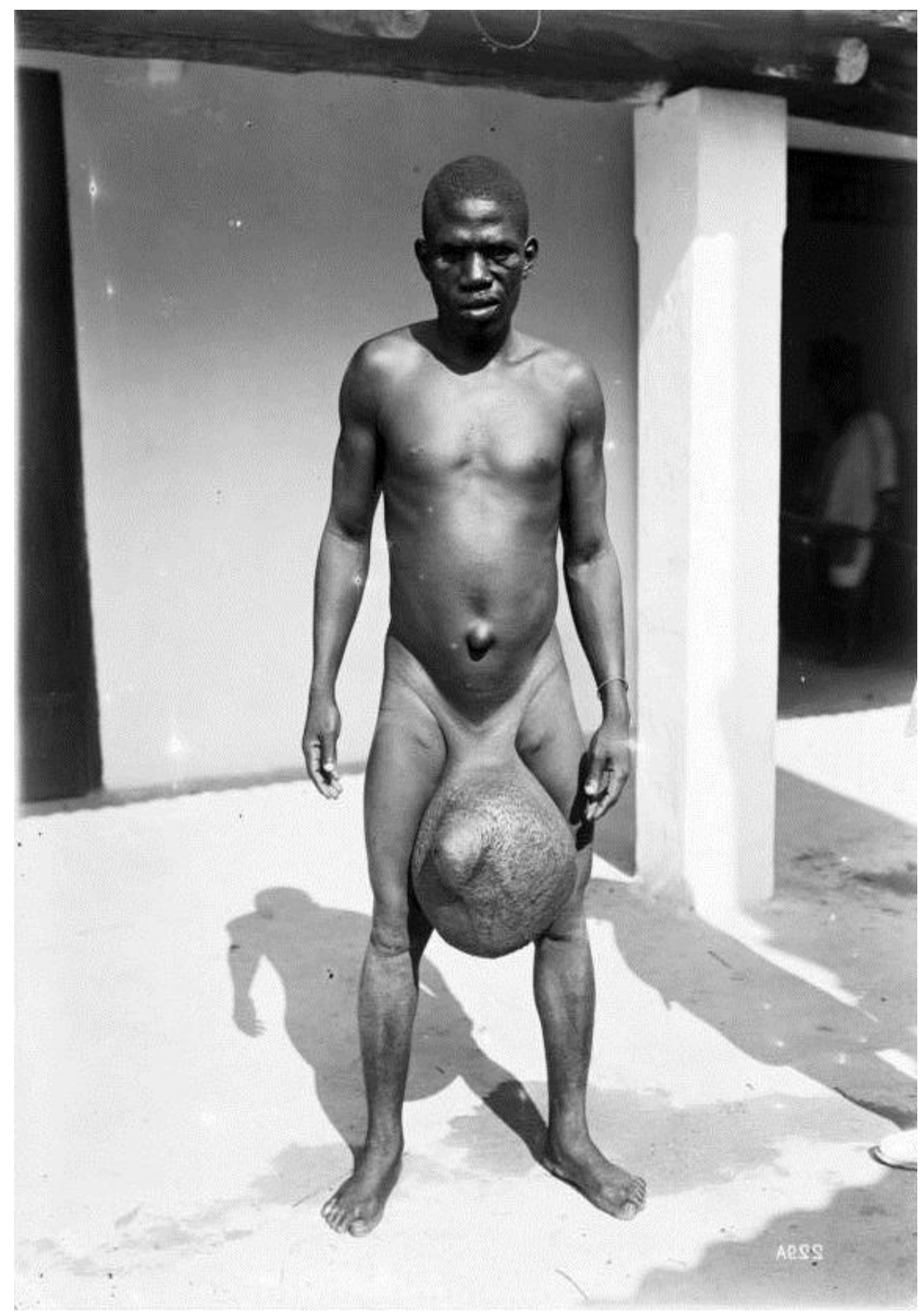

Fuente: Walther Dobbertin, "Neger mit Elefantiasis", Archivo Federal de Alemania, consultado en https://www.bild.bundesarchiv.de/cross-search/search/_1484595358/, 30 de septiembre de 2016. 


\section{CAPÍTULO V: VIOLENCIA Y MORTALIDAD}

En la mañana del 28 de agosto de 1863 , constituido el Juzgado de $1^{\text {ra }}$ instancia de Cárdenas en la causa criminal seguida por homicidio, procedieron dos facultativos nombrados al efecto a practicar la exhumación y autopsia del cadáver perteneciente a un individuo de la raza negra, de unos 40 a 45 años, de estatura baja y constitución robusta. El reconocimiento del cuerpo en cuestión tenía como objetivo averiguar cuál fue la causa de la muerte de Luis, que así se llamaba. Extraído el cadáver, la cara tenía una expresión desfigurada y monstruosa, los ojos fuera de la órbita y marchitos, la lengua pálida, los labios y orejas reblandecidos. En cada muñeca presentaba el occiso una ligadura circular hecha con cordón de algodón y en el pecho grandes equimosis de figura irregular debidas a fuertes contusiones sufridas en vida, poco tiempo antes del fallecimiento. Abierta la cavidad, se hallaron los pulmones de un color negruzco, flácidos y corrugados. Del examen dedujeron los facultativos que el fallecimiento podía datar de seis a ocho días, y, que en efecto, resultó de una violencia exterior. ${ }^{1}$

Por conducto del Gobernador Superior Civil, el Alcalde mayor de Cárdenas solicitó a la Academia de Ciencias su parecer respecto a dos cuestiones que consideró fundamental en la instrucción del caso. En primer lugar, considerando la naturaleza e intensidad de las lesiones pulmonares descritas en la autopsia, ¿si pudo el paciente sobrevivir a ellas siete días, y en la afirmativa, qué síntomas debieron presentarse? A lo que la Comisión contestó que unas veces la marcha de la enfermedad es rápida y la muerte sobreviene en muy breve tiempo, y otras, las más frecuentes, lo es mucho menos, habiendo podido el paciente sobrevivir siete días y aún más, en cuyo caso el dolor de pecho, la tos, los esputos de sangre, la fiebre, la opresión y dificultad para respirar son algunos de los síntomas que suelen presentarse. La segunda cuestión consultada fue, ¿si el negro Luis pudo tener libres ambos brazos y ejercitarse durante tres días en llenar cajones de tierra con un azadón? Considerando la Comisión que era

\footnotetext{
1 "Informe con el objeto de averiguar cual fuese la causa de la muerte del negro Luis", en: Trabajos de la Comisión de Medicina Legal e Higiene Pública de la Real Academia de Ciencias Médicas, Físicas y Naturales de La Habana, t. I, Imprenta "La Antilla", La Habana, 1872, pp. 110-115.
} 
muy difícil que, en tales circunstancias, se dedicase el enfermo a dicho trabajo, "pero si después de las violencias de que se considera víctima, la afección interna tardó algo en llegar a su mayor incremento, no es imposible que se le viese trabajando con interrupciones en los tres primeros días que sucedieron al de los golpes, dado el caso probable de que se le forzara a hacerlo. ${ }^{2}$

El informe que acabamos de extractar nos sirve para introducir el problema que examinamos en este capítulo: La fuerte relación existente entre violencia y mortalidad en el contexto de la "segunda esclavitud" en la isla. Aunque es un fenómeno de larga data, ha sido en las últimas décadas cuando se han estructurado investigaciones más complejas y profundas al respecto. ${ }^{3}$ Durante mucho tiempo, la violencia fue un dominio casi exclusivo de las ciencias penales. En 1996, la Asamblea Mundial de Salud aprobó una resolución por la cual se declaró a la violencia como uno de los principales problemas de salud pública en todo el mundo. ${ }^{4}$ A los efectos del problema que analizamos, nos acogemos a la definición que ofrecen Daniel La Parra y José María Tortosa sobre violencia estructural:

"El término violencia estructural es aplicable en aquellas situaciones en las que se produce un daño en la satisfacción de las necesidades humanas básicas (supervivencia, bienestar, identidad o libertad) como resultado de los procesos de estratificación social, es decir, sin necesidad de formas de violencia directa. El término violencia estructural remite a la existencia de un conflicto entre dos o más grupos de una sociedad (normalmente caracterizados en términos de género, etnia, clase nacionalidad, edad u otros) en el que el reparto, acceso o posibilidad de uso de los recursos es resuelto sistemáticamente a favor de alguna de las partes y en perjuicio de las demás, debido a los mecanismos de estratificación social. La utilidad del término violencia estructural radica en el reconocimiento de la existencia de conflicto en el uso de los recursos materiales y sociales y como tal, es útil para entender y relacionarlo con manifestaciones de violencia directa (cuando alguno de los grupos quiere cambiar o reforzar su posición en la situación conflictiva por la vía de la fuerza) o de violencia

\footnotetext{
2 "Informe con el objeto de averiguar cual fuese la causa de la muerte del negro Luis", pp. 110115 .

${ }^{3}$ Ver, por ejemplo: Gilles Vandal, Rethinking Southern Violence: Homicides in Post-Civil War Louisiana, 1866-1884, Ohio State University Press, Columbus, 2000. Jeff Forret, Slave against slave. Plantation Violence in the Old South. Andrew T. Fede, Homicide Justified: The Legality of Killing Slaves in the United States and the Atlantic World, The University of Georgia Press, Athens, 2017.

${ }^{4}$ Durante mucho tiempo, la violencia fue un dominio casi exclusivo de las ciencias penales. En 1996, la Asamblea Mundial de Salud aprobó una resolución por la cual se declaró a la violencia como uno de los principales problemas de salud pública en todo el mundo. Sobre el tema, ver: Informe mundial sobre la violencia y la salud, Organización Panamericana de la Salud, Washington, D.C, 2002.
} 
cultural (legitimizaciones de las otras dos formas de violencia, como, por ejemplo, el racismo, sexismo, clasismo o eurocentrismo)."

En el contexto histórico que analizamos, la violencia fue un componente fundamental de múltiples procesos de enfermedad y muerte de la población esclava. Las manifestaciones más importantes para nuestra investigación comprenden casos de homicidios, sevicias, suicidios, heridas, violaciones y riñas, entre otros eventos inscritos en la estadística criminal como delitos contra las personas. No obstante, hay que decir que en la práctica las fronteras entre estas expresiones de violencia son bastante sutiles y se tornan en extremo problemáticas a la investigación contemporánea. La documentación conservada al respecto es abundante -ocupaban a menudo la sección de noticias de la prensa- pero hay que tener en cuenta que numerosos eventos de violencia no dejaron rastro en el tiempo. Por otro lado, multiplicidad de problemas físicos, sexuales, reproductivos y mentales derivados directamente de agresiones tampoco fueron registrados. Es por ello que, la magnitud real de la violencia estructural que caracterizó la dinámica esclavista en la isla supera, con mucho, los análisis que podemos estructurar a partir de la documentación conservada.

\section{LA ISLA DEL “DULCE TRATO”: REGLAMENTACIÓN Y SLAVE AGENCY}

Moreno Fraginals, seducido por las cuestiones que hicieron posible la rentabilidad del ingenio como empresa capitalista, sugiere que "los amos mostraron siempre gran preocupación por la salud de sus siervos, pues ello equivalía a la eutaxia de sus caudales. Y este cuidado estuvo en relación directa con el valor de los negros en el mercado". 6

\footnotetext{
${ }^{5}$ Daniel La Parra y José María Tortosa, "Violencia estructural: una ilustración del concepto", Documentación Social, N ${ }^{\mathrm{o}}$ 131, 2003, pp. 57-72.

${ }^{6}$ En el texto aparece eutaxia, término que no encontramos en el diccionario de la RAE. Es posible que la palabra correcta sea eutanasia. Manuel Moreno Fraginals, El ingenio, t. 2, p. 74. Los testimonios sobre la "menor severidad" de la esclavitud hispana respecto a la anglosajona se remontan a los tiempos coloniales. De igual época datan testimonios contrarios a esa hipótesis. La crítica en tal sentido es consustancial al abolicionismo que se desarrolla desde la década de 1830. Ver, por ejemplo: J. G. Alexander, Observaciones sobre la esclavitud y comercio de esclavos, Imprenta de A. Bergnes y Cía., Barcelona, 1841. David Turnbull, Travels in the West, Cuba; with notices of Porto Rico and the slave trade, Imprenta Longman, Londres, 1840. Richard R. Madden, La isla de Cuba, sus recursos, progresos y perspectivas, Consejo Nacional de Cultura, La Habana, 1964. La obra original de R. R. Madden fue publicada en Londres en 1849. El debate contemporáneo sobre el tema se avivó con una publicación del historiador
} 
En efecto, hacia la década de 1840 la trata ilegal disminuye y en la siguiente el valor de los esclavos aumenta notablemente. ${ }^{7}$ Ello supone considerar un consumo más "racional" de la fuerza de trabajo, asunto que está en el centro de varios escritos y debates de la época. Ahora bien, de acuerdo con los datos que Laird W. Bergad, Fe Iglesias y María del Carmen Barcia aportan en su estudio sobre el mercado de esclavos en la isla, entre 1821 y 1835 aumentan considerablemente las ventas de la cohorte generacional entre uno y catorce años de edad. En ninguna otra etapa de la "segunda esclavitud" en la isla se produjo un comercio igual de intenso de brazos jóvenes. ${ }^{8}$ Asimismo, en estos años se promovió un aumento de las importaciones de mujeres. La nueva estructura por edad y sexo sugiere, efectivamente, un cambio en las expectativas sobre la posibilidad de mantener la esclavitud mediante la reproducción natural. De modo que, en las décadas centrales del siglo XIX el despegue de la agroindustria azucarera en la isla se realizó sobre un contingente de población esclava en mejores condiciones biológicas para la reproducción, pero no se produjo el rendimiento demográfico que los plantadores podían desear.

Que el principio de ningún empresario moderno es eliminar ex professo a su fuerza de trabajo, menos en condiciones difíciles de reposición, es una obviedad. Aunque no siempre tal voluntad es manifiesta. En el contexto de la "segunda esclavitud" en Cuba, los plantadores tuvieron razones suficientes para prolongar el tiempo productivo de sus trabajadores. Una valoración en profundidad de la manida cuestión del "buen trato", debe considerar en qué medida las inversiones directas en

norteamericano Frank Tannenbaum, y desde entonces ha permeado buena parte de los estudios comparados sobre la esclavitud en América. Frank Tannenbaum, Slave and Citizen: The Negro in America, Knopf, Nueva York, 1946. Ver también: Herbert S. Klein, Slavery in the Americas: A Comparative Study of Virginia and Cuba, University of Chicago Press, Chicago, 1967. Una reseña muy crítica con el estudio de Klein en: Marvin Harris "Reviewed Work(s): Slavery in the Americas: A Comparative Study of Virginia and Cuba", Political Science Quarterly, vol. 85, $\mathrm{N}^{\mathrm{o}}$. 1, marzo, 1970, pp. 146-149. En el caso cubano, el "giro" en la mentalidad explotadora de los plantadores también es analizado en: Karim Ghorbal, "La política llamada del «buen tratamiento»: reformismo criollo y reacción esclavista en Cuba (1789-1845)", Nuevo Mundo Mundos Nuevos, consultado en https://journals.openedition.org/nuevomundo/57872, 10 de mayo de 2016.

${ }^{7}$ Sobre la tendencia en el precio de los esclavos en Cuba, ver: Manuel Moreno Fraginals, Herbert S. Klein y Stanley L. Engerman, "El nivel y estructura de los precios de los esclavos en las plantaciones cubanas a mediados del siglo XIX: algunas perspectivas comparativas", Revista de Historia Económica, Año. 1, Nº 1,1983, pp. 97-120. Laird W. Bergad, Fe Iglesias y María del Carmen Barcia, The Cuban Slaves Market 1790-1880, Cambridge University Press, Cambridge, 1995, p. 48.

${ }^{8}$ Laird W. Bergad, Fe Iglesias y María del Carmen Barcia, The Cuban Slaves Market 17901880, p. 43. 
salud realizadas por los plantadores cubanos estuvo en equilibrio con la intensidad de la explotación que aplicaron a sus trabajadores. Si bien la oferta de brazos es una variable fundamental en la proyección que el propietario hace sobre el consumo de la fuerza de trabajo que posee, pudiendo modificar su mentalidad explotadora, el ciclo de vida y muerte en la plantación es un fenómeno que trasciende su mera voluntad. Durante mucho tiempo, las valoraciones en este punto fueron muy obedientes con los relatos dominantes en la época y la balbuceante legislación colonial.

Por otro lado, recordemos que, a pesar de los no pocos casos de suicidios, la muerte no es algo que los esclavos acepten sin más. Contra ese final desplegaron los recursos a su disposición y tejieron, en condiciones difíciles, redes de ayuda para preservar su existencia. Esto último es importante, porque se ha argumentado mucho sobre los que pudieron hacer los plantadores para preservar su capital humano, desconociendo lo que probablemente resultó ser una inversión mayor de los propios esclavos para sobrevivir dentro del sistema. Con esta afirmación no solo consideramos posibles gastos en alimentación y servicios médicos, sino además la incidencia de múltiples factores, no mesurables, a lo largo de sus vidas. Atendiendo a la noción de agencia o capacidad creativa de los esclavos, que la historiadora Rebecca J. Scott sentó en el estudio de la esclavitud en Cuba y otras como Gloria García desarrollaron, es posible advertir la complejidad de las estrategias que los esclavos desarrollaron para enfrentar los conflictos cotidianos que amenazaban su existencia.

En la práctica, la esclavitud se sostuvo siempre sobre un precario equilibrio de fuerzas. Reglamentar las relaciones entre amos y esclavos, así como el límite de la violencia justificada dentro del sistema, fue una vieja preocupación recogida ya en la Siete Partidas redactadas durante el reinado de Alfonso X (El Sabio). ${ }^{9}$ Las normativas de ese código referentes a la esclavitud personal, que regía desde el siglo XIII en Castilla y León, fueron introducidas posteriormente en las colonias hispanas del Nuevo Mundo. Entonces estaba reconocido el derecho de los amos a castigar a su esclavos, pero se establecieron restricciones al respecto y sanciones para los propietarios que cometieran excesos, incluso la inhabilitación de por vida para poseer esclavos. ${ }^{10}$ Las

\footnotetext{
${ }^{9}$ José Luis Cortés López, La esclavitud negra en la España peninsular del siglo XVI, Ediciones Universidad de Salamanca, Salamanca, 1989, p. 117.

${ }^{10}$ Manuel Lobo Cabrera, "Las partidas y la esclavitud: aplicación en el sistema esclavista canario", Vegueta, N ${ }^{\circ}$. 1, octubre, 1993, pp. 75-83. Manuel Lucena Samoral sostiene incluso que las Partidas contienen "el primer código de buen tratamiento de los siervos", reconociendo
} 
preocupaciones del poder colonial en cuanto a la crueldad con la que muchos propietarios trataban a sus esclavos en la isla están implícitas también en las Ordenanzas de Cáceres, que entrarían en vigor en 1641. Un trato inhumano era la causa de muchas muertes de esclavos, pero también de fugas y diversas formas de resistencia al orden establecido. ${ }^{11}$ Con algunas modificaciones, las Ordenanzas de Cáceres estuvieron vigentes hasta mediados del siglo XIX. Con la agudeza peculiar de Tomás Gutiérrez Alea, el filme La última cena (1976) refleja la tensión entre obediencia y violencia intrínseca a la economía esclavista en expansión. ${ }^{12}$

Entre fines del siglo XVIII y la abolición de la esclavitud en Cuba, varios documentos oficiales, entre ellos el Reglamento de Esclavos de 1842, normaron el tratamiento que se debía dar a los esclavos. ${ }^{13}$ La cuestión de los castigos corporales fue ampliamente discutida, sin que pudieran llegar a un consenso, como sucedió en la Junta de Información de $1866,{ }^{14}$ sobre los límites de una práctica que los plantadores revindicaron continuamente como forzosas para garantizar la disciplina laboral sobre la que se sostenía el reino antillano del azúcar.

En efecto, al margen de las normativas jurídicas, diversos testimonios dieron cuenta de la situación real de los esclavos en las plantaciones cubanas. En pleno apogeo del sistema esclavista, Alejandro de Humboldt distinguió la escala de privaciones según el trabajo al que se dedica el esclavo y reservó al ingenio el lugar de explotación por excelencia. En la soledad de las plantaciones azucareras el esclavo soportó con más rigor las fracturas de una legislación colonial de por si precaria en la regulación de los deberes del amo. Allí el trabajo fue más rudo y los excesos mayores. ${ }^{15}$ En esta misma

el derecho a la vida y a la integridad de la persona. Manuel Lucena Samoral, "La esclavitud americana y las Partidas de Alfonso X", Revista de Historia y Arte, Nº 1, 1995, pp. 33-44.

${ }^{11}$ Este documento fue redactado en el siglo XVI por Alonso de Cáceres, entonces oidor de la Real Audiencia de Santo Domingo. El segmento de las Ordenanzas referente a los esclavos puede consultarse en: Fernando Ortiz, Los negros esclavos, pp. 404-408.

12 Tomás Gutiérrez Alea, La última cena, (cinta cinematográfica), ICAIC, La Habana, 1976. Esta emblemática producción cinematográfica sobre la esclavitud en Cuba contó con la asesoría de Manuel Moreno Fraginals. Ver el análisis que la historiadora Natalie Zemon Davis presenta en su libro sobre cine y esclavitud histórica. Natalie Zemon Davis, Esclavos en la pantalla, Ediciones ICAIC, La Habana, 2012.

${ }^{13}$ Sobre la legislación española referida a la esclavitud, ver: Manuel Lucena Samoral, Los códigos negros de la América Española, Ediciones Unesco, Universidad de Alcalá, 1996; Regulación de la esclavitud negra en las colonias de América Española (1503-1886): documentos para su estudio, Universidad de Alcalá-Universidad de Murcia, Madrid-Murcia, 2005.

${ }^{14}$ Ver: María Dolores Domingo Acebrón, "La Junta de Información en Madrid para las reformas en las Antillas, 1866", Hispania, vol. LXII/1, N. 210, 2002, pp. 141-166.

${ }^{15}$ Alejandro de Humboldt, Ensayo político sobre la Isla de Cuba, París, 1827. 
línea, el médico francés Bernard de Chateausalins, que ejerció la profesión en importantes fincas de la isla, escribió lo siguiente:

\begin{abstract}
"la suerte de los negros esclavos tocante á su salud, que tanto importa conservar, es despreciada en sumo grado. Regularmente entregada al arbitrio de hombres que con las facultades de mayoral ó contra-mayoral, no les permiten siquiera quejarse aunque tengan el cuerpo adolorido, desprecian sus lamentos, exigen de ellos en este principio de enfermedad, trabajos recios, y así es que en muchos casos esos infelices llegan á la enfermería solo para exalar (sic) el alma." 16
\end{abstract}

El 19 de julio de 1835 el Consejo de Gobierno del reino de España remitió a S. M. una exposición de Tomás Pérez Villada en la que refiere los horrores de la esclavitud en Cuba, los duros trabajos a los que estaban sujetos los esclavos de ambos sexos desde antes de salir el sol hasta después de anochecido, así como el escaso alimento y mal trato que recibían de los capataces. Pérez Villada expone también que a pesar de "la justicia y sabiduría de las leyes existentes", estas "se perdieron en aquellos dominios por culpa de los encargados de aplicarla”, y que a pesar de la abolición del comercio de negros "se sigue practicando ese infame tráfico bajo el pabellón español porque las autoridades de la isla de Cuba lo protegen para enriquecerse con la sangre de los mismos negros". Concluye la misiva suplicando a S. M. se digne dictar las medidas que estime convenientes "para aliviar la suerte de aquellos infelices", encargando su ejecución "a personas fieles y virtuosas que la sostengan con firmeza y energía."17

Años más tarde, el abolicionista inglés Richard R. Madden, que ejerció en Cuba a fines de la década de 1830 el cargo de Superintendente de Emancipados y Árbitro Interino de la Comisión Mixta en La Habana, denunció la situación de los esclavos en la isla en los siguientes términos:

"Con respecto a mi experiencia, creo que no es por un particular ejemplo de crueldad $\mathrm{u}$ opresión que debe establecerse el hecho de que la esclavitud en Cuba es más destructiva para la vida humana, perniciosa para la sociedad, degradante para el esclavo, envilecedora para el amo, y fatal para la salud y felicidad, que ningún otro país esclavista en la fase habitable del globo. Ejemplos suficientes de crueldad, han llegado a mi conocimiento, de la muerte de negros perpetuadas con impunidad, de hombres literalmente azotados hasta morir, de mujeres arrancadas a sus hijos y separadas de

\footnotetext{
${ }^{16}$ Honorato Bernard de Chateausalins, El vademécum de los hacendados cubanos, p. vii.

${ }^{17}$ Expediente de solicitud de medidas para alivio de los esclavos de Cuba, AHN, Ultramar, Leg. 4603, $\mathrm{N}^{\circ}$. 70, 1834-1836. Recordemos que casi un mes antes, el 28 de junio de 1835, se firmó en Madrid un nuevo tratado entre España y Gran Bretaña para la abolición de la trata ilegal de esclavos.
} 
ellos, de haciendas donde no puede verse ni un negro anciano y donde las hembras no forman una tercera parte de la población esclava; más aún, de haciendas donde no hay una sola hembra; de ingenios en que durante la época del corte de caña y la molienda la jornada de trabajo dura veinte horas seguidas y eso, frecuentemente, por espacio de más de seis meses al año, y raras veces o nunca durante menos de cinco meses, pues la opinión que prevalece a este respecto y que es generalmente practicada por los amos, es de que cuatro horas de sueño son suficientes para un esclavo."18

Estos y otros testimonios son representativos de un contexto particularmente sensible en la historia del imperio español. Hacia la década de 1820 cristalizó en la América continental hispana la oleada independentista que, entre otras reformas, quebrantó aún más los pilares políticos de la esclavitud africana en el Nuevo Mundo, ya conmovidos por la Revolución de Haití (1791-1804). En el decenio siguiente estalló en la península la primera Guerra Carlista, un conflicto por la sucesión del poder monárquico que mantendrá bien ocupada a la metrópoli. El desarrollo sin precedentes de la economía esclavista en la principal colonia hispana del hemisferio occidental sobreviene además bajo el constante asedio de la diplomacia británica, erigida en árbitro de la política y el comercio atlántico. ${ }^{19}$ No es casual que, en esta época, con los temores sociales habidos por la existencia de una creciente población "de color", se genere una abundante documentación sobre el conveniente "buen trato" a los esclavos en la isla. De este modo se pretende desmarcar la servidumbre hispana de sistemas homólogos en América, evocando un legado jurídico del que no disponían otras metrópolis.

A mediados del siglo XIX, las exigencias del dilema de brazos llevaron a las autoridades española a razonamientos más realistas sobre lo que era la esclavitud en sus colonias. La Sección de Ultramar reconoció, siempre en comunicaciones reservadas, que a pesar de lo estipulado en la legislación colonial, "no en todos los ingenios y fincas de la Isla se daba un tratamiento humano a los esclavos, y los propietarios cometían abusos sobreexplotándolos, a fin de sacar en el menor tiempo posible el máximo de ganancia". ${ }^{20}$ Para promover un cambio de actitud en este sentido, la Sección de Ultramar planteó no dejar el asunto a la voluntad de los propietarios y elaborar un nuevo

\footnotetext{
${ }^{18}$ Richard R. Madden, La isla de Cuba, sus recursos, progresos y perspectivas. Citado a través de: Carmen Almodóvar, Antología crítica de la historiografía cubana, (época colonial), Editorial Félix Varela, La Habana, 2010, p. 299.

${ }^{19}$ Sobre el abolicionismo inglés y la presión británica a España, véase: David Murray, Odious commerce. Britain, Spain and the abolition of the cuban slave trade, Cambridge University Press, Cambridge, 1980. Rodolfo Sarracino, Inglaterra: sus dos caras en la lucha cubana por la abolición, Editorial Letras Cubanas, La Habana, 1988.

${ }^{20}$ Informe de la Sección de Ultramar del Consejo Real, AHN, Ultramar, Leg. 3548, No 1 1, 1846.
} 
reglamento de esclavos en el que se reunieran todas las disposiciones vigentes que se hallen en los anteriormente publicados, añadiéndose las que por experiencia puedan ser convenientes al fin que se persigue. Entre las medidas consideradas estaban reformar el derecho de capitación para reconducir a las plantaciones la población esclava estacionada en las ciudades; promover la instrucción religiosa de los esclavos para frenar lo que consideraron una tendencia suicida; reducir el número de horas de trabajos en los ingenios de azúcar a un término "racional", de modo que pudiera conservarse por más tiempo "la salud, robustez y vida de los infelices esclavos"; y estimular a los propietarios que presentasen tasas más altas de natalidad y más bajas de mortalidad. El nuevo reglamento, sujeto a la aprobación del Supremo Gobierno, debía considerase esencialmente reservado, ordenando a las autoridades competentes que lo comunicasen directamente a los dueños de fincas. De modo que los cambios que pudieran experimentar los esclavos fuesen vistos como el resultado de la propia voluntad de sus amos y no de la mano del Gobierno. ${ }^{21}$

No habiéndose promulgado un Reglamento de Esclavos posterior al de 1842, fue este el soporte legal de la fase que se ha dado en llamar de "buen tratamiento". ${ }^{22}$ Ese documento reguló, en teoría, la alimentación, descanso, atención médica, entre otras cuestiones relativas a la vida de esa población. Normativas que, como indicamos, las propias autoridades coloniales consideraron deficientes para fomentar el cambio de mentalidad que los nuevos tiempos demandaban. En realidad, de gran parte de la documentación disponible sobre el asunto se infiere una razonable desconfianza en la reproducción biológica del sistema. En esta lógica, ponderamos el razonamiento del historiador británico Hugh Thomas, quien consideró que el origen de un mejor trato “cabe buscarlo más en el subdesarrollo económico que en la magnanimidad de los blancos". ${ }^{23}$ En las condiciones económicas de la "segunda esclavitud" en Cuba, el "buen trato" fue el artilugio discursivo que articuló los intereses de la corona española y la clase dominante en la isla para legitimar la prolongación de una institución con pilares muy debilitados en el mundo atlántico. Tal estrategia como fase generalizada dentro del sistema esclavista cubano adolece de fundamentos. Al margen de algunos resultados

\footnotetext{
${ }^{21}$ Ídem.

${ }^{22}$ Las normativas posteriores no introducen modificaciones sustanciales en el régimen de vida de los esclavos y patrocinados en las plantaciones cubanas. Un estudio detallado del Reglamento de Esclavos de 1842 en: Jean-Pierre Tardieu, "Morir o dominar": en torno al reglamento de esclavos de Cuba (1841-1866), Vervuert-Iberoamericana, Madrid, 2003.

${ }^{23}$ Hugh Thomas, Cuba. La lucha por la libertad, Debate, Barcelona, 2004, p. 53.
} 
puntuales, no se resolvió el progresivo declive de la población empleada en el sector, fundamentalmente esclava y libre "de color".

Por el contrario, en sus últimas décadas, la dinámica del sistema esclavista requirió mecanismos coercitivos y una explotación intensa del trabajo que lastraron considerablemente la salud de la población cautiva. Al margen de las consideraciones sobre la actitud más o menos indulgente del amo, la violencia fue siempre un factor intrínseco en la coordinación del trabajo en las plantaciones azucarera. El fundamento económico del ingenio se imponía sobre la legislación vigente en materia de esclavos, y la administración colonial siempre cuidó de no quebrar con sus disposiciones la autoridad del hacendado sobre su propiedad. El Reglamento de marzo para la aplicación de la Ley de febrero de 1880, que declaró abolida la esclavitud en Cuba, autorizó mecanismos represivos para garantizar el trabajo de los patrocinados, entre ellos el cepo y el grillete, aplicables hasta por 24 días si la falta era considerada grave. En torno al trabajo gravitaban casi todas las faltas posibles que podían cometer el patrocinado. La sacarocracia cubana defendió hasta el último momento los castigos corporales. Consultados en cierta ocasión sobre la conveniencia de abolir las penas de cepo y grillete, los propietarios sostuvieron que "tales castigos no podían considerase penas aflictivas ni infamantes, sino meras correcciones indispensables para conservar el orden y la subordinación en los ingenios". ${ }^{24}$ Aunque las autoridades metropolitanas, presionadas por la intensa campaña abolicionista y la opinión pública, desestimaron tal juicio, y, por Real Orden publicada en la Gaceta con fecha de 28 de noviembre de 1883 se ordenó legalmente la supresión de esos castigos, ello no puso fin a la administración del terror en los ingenios.

El patronato implicó un reforzamiento de la vigilancia en las plantaciones en un contexto de coexistencia de brazos coactivos y libres en el trabajo, entre estos últimos, antiguos esclavos que participaron en la insurrección de 1868. En comunicación oficial de la Sociedad Abolicionista Española dirigida al Ministro de Ultramar, esta denunció las violaciones cometidas por la Juntas Protectoras, ya que algunas no realizaban las reuniones ordinarias establecidas y desestimaban las peticiones de los patrocinados. Propietarios y mayorales utilizaron los más diversos mecanismos para impedir la libertad de sus patrocinados. La experiencia de la Sociedad confirmaba que muchos de los esclavos que permanecían bajo el régimen de patronato en los ingenios no

\footnotetext{
${ }^{24}$ Telegramas dirigidos a Ultramar sobre supresión del cepo y grillete y sustitución por otros
} castigos, AHN, Ultramar, Leg. 4814, Nº. 1, 1883-1886. 
aceptaban, de forma "resignada y tranquila", el "excesivo trabajo" a que estaban dedicados, mientras veían disfrutando de la completa libertad a los que estuvieron en la insurrección. De acuerdo con esta fuente, la libertad a largo plazo producía en los patrocinados "la impaciencia precursora de la desobediencia" y "la desobediencia precursora de las rebeliones" y que, en caso de producirse una sublevación de doscientos mil esclavos, de nada servirían los consejos de guerra. ${ }^{25}$

Desde la publicación del estudio pionero de Rebecca J. Scott, varios autores han enfatizado en el papel decisivo de la agencia de los esclavos en la transición al trabajo libre, para lo cual la documentación es más expedita. En cambio, se ha discutido menos el hecho de que ese factor debió crear tensiones al interno de la dotación que no siempre tuvieron una salida favorable para los trabajadores. Bajo el título de "Salvajismo", el diario La Lucha denunció en junio de 1886 el asesinato del patrocinado Ambrosio Gattorno a manos de su mayoral en un ingenio cerca de San Juan de los Yeras, antigua provincia Santa Clara, "quien no contento con vapulearlo a su gusto, le descerrajó un tiro". ${ }^{26}$ Como veremos, este es uno de los no pocos casos que demuestran los abusos cometidos contra los patrocinados, hasta los últimos días del sistema, hábilmente ocultados por los plantadores y las autoridades coloniales. Está claro que muchos de los testimonios que pueden dar fe de ello fueron intencionadamente descuidados por las Juntas Protectoras, no pocas integradas por reconocidos esclavistas.

En el epílogo de la reglamentación esclavista en la isla, el artículo cuatro de la Ley de abolición de la esclavitud, del 13 de febrero de 1880, estableció entre las obligaciones del patrono respecto a sus patrocinados mantenerlos, vestirlos, asistirlos en sus enfermedades y retribuir su trabajo conforme a lo estipulado en dicha ley. El artículo quinto fijó las tres primeras obligaciones respecto a los hijos de los patrocinados "que se hallen en la infancia y la pubertad", nacidos antes o después del patronato. En cambio, el patrón aprovecharía el trabajo de estos. El incumplimiento de lo estipulado en el artículo cuarto podía extinguir el patronato. O sea, acelerar el proceso de transición a la libertad programado por la citada ley para aquellos patrocinados que pudieran demostrar la infracción.

De la tabla 22 podemos extraer dos primeras conclusiones convenientes a nuestra investigación. Primero, con todo y lo enmarañado de los pleitos establecidos en

${ }^{25}$ Carta de la Sociedad Abolicionista Española dirigida al Ministro de Ultramar, AHN, Ultramar, Leg. 4814, $\mathrm{N}^{\mathrm{o}}$. 1, 1883-1886.

26 "Salvajismo", La Lucha, La Habana, 25 de junio de 1886, p. 3. 
caso de reclamaciones por mal trato del patrón al patrocinado, estas constituyeron un mecanismo troncal del proceso de extinción del patronato. Los patrocinados y sus representantes legales, a través de las cartas de libertad obtenidas por este motivo, nos dejan un testimonio nada apacible de lo que fueron las relaciones esclavistas en su fase final de descomposición. Es posible que otros mecanismos de libertad escondieran no pocos casos de los comprendidos en el artículo cuatro. Por otro lado, obtener la libertad por faltar los patronos a los deberes establecidos en esta Ley era más viable en La Habana. En zonas azucareras como Matanzas o Santa Clara, más alejadas de la administración colonial, el desarrollo de este recurso legal fue menos frecuente y en múltiples casos se frustró. ${ }^{27}$

El procedimiento legalmente establecido en la capital para los casos en los que el esclavo se presentaré ante el síndico en condición de estar herido, lastimado o enfermo, necesitando de asistencia médica, era su pronto traslado al hospital de Caridad, participando el hecho al juez correspondiente, comunicándolo al dueño al mismo tiempo que lo invita a la conferencia. El mismo reglamento establecía que si la reclamación del esclavo no procede de sevicia o el síndico desestimaba esa posibilidad, debía ser entregado a su dueño, tomando las precauciones que estimase convenientes, mientras se resolvía la reclamación ya fuese en actos judiciales o extrajudiciales. ${ }^{28}$

TABLA 22: NÚMERO DE PATROCINADOS QUE POR LOS CONCEPTOS QUE SE EXPRESAN ADQUIRIERON LA LIBERTAD DURANTE EL TERCER AÑO DE ABOLIDA LA ESCLAVITUD.

(Comprende del 8 de mayo de 1882 al 7 de mayo de 1883)

\begin{tabular}{|l|r|r|r|r|r|r|}
\hline \multicolumn{1}{|c|}{ Provincia } & \multicolumn{1}{|c|}{$\begin{array}{c}\text { Por } \\
\text { acuerdo } \\
\text { mutuo de } \\
\text { patrono y } \\
\text { patrocinad } \\
\text { o }\end{array}$} & $\begin{array}{c}\text { Por } \\
\text { renuncia } \\
\text { de } \\
\text { patronato }\end{array}$ & $\begin{array}{c}\text { Por } \\
\text { indemniza } \\
\text { ción de } \\
\text { servicios }\end{array}$ & $\begin{array}{c}\text { Por faltar } \\
\text { el patrono } \\
\text { a los } \\
\text { deberes } \\
\text { que } \\
\text { expone el } \\
\text { artículo 4 } \\
\text { de la ley }\end{array}$ & $\begin{array}{c}\text { Por otras } \\
\text { causas }\end{array}$ & Total \\
\hline $\begin{array}{l}\text { Pinar del } \\
\text { Río }\end{array}$ & 579 & 387 & 461 & 71 & 165 & 1.663 \\
\hline La Habana & 819 & 1.492 & 609 & 1.126 & 280 & 4.326 \\
\hline Matanzas & 2.583 & 489 & 871 & 162 & 842 & 4.947 \\
\hline
\end{tabular}

${ }^{27}$ El estudio citado de Rebecca J. Scott confirma este hecho para todos los años del proceso de transición del patronato al trabajo libre.

28 "Reglamento que debe observarse por los Síndicos de la capital en su calidad de defensores de esclavos", Revista de Jurisprudencia, Administración y Comercio, Imprenta "La Antilla", Año VIII, t. I, La Habana, 1863, pp. 261-263. 


\begin{tabular}{|l|r|r|r|r|r|r|}
\hline Santa Clara & 2.291 & 729 & 949 & 150 & 367 & 4.486 \\
\hline $\begin{array}{l}\text { Puerto } \\
\text { Príncipe }\end{array}$ & 4 & 50 & 3 & 10 & 10 & 77 \\
\hline $\begin{array}{l}\text { Santiago de } \\
\text { Cuba }\end{array}$ & 678 & 567 & 448 & 77 & 149 & 1.919 \\
\hline Suma & 6.954 & 3.714 & 3.341 & 1.596 & 1.813 & 17.418 \\
\hline
\end{tabular}

Fuente: Expediente General de Esclavitud. Tercera parte. Legislación sobre pago de jornales a los declarados libres y empadronamiento de esclavos, supresión de castigos corporales, AHN, Ultramar, Leg. $4814, \mathrm{~N}^{\circ} .1,1883-1886$.

La Sociedad Abolicionista Española denunció en reiterados informes los abusos que se cometían en el cumplimiento de los mecanismos reglamentados para la obtención de la libertad y los innumerables obstáculos impuestos a los patrocinados por los patronos y las Juntas. Fue el caso, por ejemplo, de las patrocinadas Dolores Pizarro y Gregoria Ferrán. La primera se presentó en octubre de 1881 en la Junta Central de Patronato de La Habana en demanda de su libertad por haber faltado su patrono, Juan de Dios Lima, vecino de Aguacate, a las obligaciones que la ley le imponía. La patrocinada, con una hija de pecho, fue internada en el Asilo de San José. Desde la presentación de la solicitud de Dolores Pizarro pasaron catorce meses sin respuesta alguna de la Junta, infringiéndose de este modo los procedimientos y plazos fijados en los artículos doce y trece del reglamento de marzo para la aplicación de la ley de febrero de $1880 .{ }^{29}$ Desestimada fue también la reclamación de la negra Gregoria Ferrán, patrocinada del Secretario de la Audiencia de Puerto Príncipe. En este caso, acudió a la Junta de Patronato reclamando su libertad por no haberle satisfecho su patrono el estipendio al que estaba obligado por el inciso cuarto del artículo cuarto de la ley de abolición. Al día siguiente de ser registrada su reclamación se presentó ante la Junta su patrono y el solo testimonio de este bastón para que se rechazara la formación del expediente oportuno en tales casos. ${ }^{30}$

Un ejemplo notable de infracción de la ley fue el del patrocinado José Dolores Pérez. En el mes de marzo de 1882 este se presentó en la Junta de Patronato de Santiago de las Vegas reclamando su libertad por haber faltado José Díaz Suarez, su patrón, a la obligación que le señala el artículo cuatro de la ley de 1880. Nueve meses duró el expediente y al cabo de ellos se desestimó la instancia. José Dolores Pérez no se atrevió a intentar una nueva reclamación, entre otras cosas, por haberse negado su amo a

\footnotetext{
${ }^{29}$ Expediente general de esclavitud. Tercera parte: Legislación sobre pago de jornales a los declarados libres, empadronamiento de esclavos, supresión de castigos corporales, AHN, Ultramar, Leg. 4814, $\mathrm{N}^{\mathrm{o}} .1$, 1883-1886.

${ }^{30}$ Ídem.
} 
prestarle la asistencia médica a que por ley estaba obligado. Precisamente en los momentos en que la Junta de Patronato incoaba el expediente, José Dolores fue trasladado enfermo al Hospital de Caridad, a despecho del inciso tercero del artículo cuarto de la ley, que estipulaba entre las obligaciones del patrono asistir al patrocinado en sus enfermedades. El patrocinado pidió entonces que se le tasará para obtener su libertad por indemnización de servicios. Reunidos por suscripción popular los ciento diez pesos cincuenta centavos oro en que José Dolores Pérez fue tasado, se hizo el oportuno depósito en la Junta de Patronato de Santiago de las Vegas por la esposa del aquel, la morena Nicasia Martínez, a quien se le entregó resguardo con fecha quince de noviembre de 1882. La ley estipulaba que el patrocinado que depositase en la Junta la cantidad legal para el cese del patronato no podía ser obligado a volver al dominio del patrono, autorizándole la Junta para trabajar por su cuenta mientras se resolvía definitivamente el litigio. Pero también entonces se barrenó la ley. José Antonio Guzmán, representante de los herederos de Díaz Suarez, extrajo sigilosamente del Hospital de Caridad a José Dolores, tan pronto como tuvo conocimiento de lo ocurrido, y le trasladó al depósito de cimarrones. Al poco tiempo José Dolores fue vendido al propietario de un ingenio en la jurisdicción de Remedios. Esto, a pesar tener depositada la cantidad necesaria para libertarse y ser ese hecho contrario a la letra del artículo segundo de la ley que prohibía separar a los individuos que constituían familia, ya que José Dolores era casado y tenía tres hijos en Santiago de las Vegas. La Junta de esta localidad toleró la venta. A fines de 1883, José Dolores Pérez continuaba sometido a la condición de patrocinado, a pesar de haber sido elevado el caso a la Junta Provincial de Patronato de La Habana, de la cual no se tuvo respuesta a la reclamación que por los hechos comentados se le presentó. ${ }^{31}$ Por esa misma fecha, fueron vendidos en pública subasta cuarenta patrocinados del ingenio Conchita, de la propiedad de Juan Lavín, separándose en ese acto a personas que constituían familia -padres, hijos, esposas y hermanos-, a pesar de estar prohibido por la ley. Suceso del cual se desentendió la Junta de Corral Falso, Matanzas, lugar al que pertenecía el nombrado ingenio. ${ }^{32}$ Sirvan estos ejemplos para ilustrar el enmarañado proceso de transición a la libertad en la isla y los ingentes esfuerzos desarrollados por los patrocinados para apropiarse de un cuerpo jurídico en la práctica demasiado escurridizo.

\footnotetext{
${ }^{31}$ Ídem.

32 Ídem.
} 
Si bien es cierto que la esclavitud hispana desarrolló un cuerpo jurídico peculiar para transformar esclavos en libertos, es abundante la documentación sobre los límites que en la práctica tenían los instrumentos legales al uso para que los primero pudieran enfrentar o cambiar condición. ${ }^{33}$ En 1847 se inició un expediente judicial con el objetivo de investigar el maltrato que recibía la dotación del ingenio Buena Madre. De acuerdo con los testimonios consultados, frecuentemente se presentaban al capitán del partido Alacranes, esclavos de ese ingenio para denunciar el trato que recibían de Félix Soloni, entonces propietario de la finca. La excitación al que en cierto punto llegó la dotación hizo temer a las autoridades locales de una posible revuelta, por lo que se ordenó además de la correspondiente investigación judicial una estricta vigilancia sobre la finca. Años antes, esta había sido una de las haciendas involucradas en la conspiración de la gente "de color". La negra Isabel, criolla perteneciente a la dotación, denunció haber sido cruelmente castigada por la esposa de Soloni. Para investigar estos hechos, se nombró síndico al licenciado Martín de Nueces, que asumió la representación de Isabel. Oídas las partes y comprobado el maltrato, de acuerdo a lo dispuesto en el Reglamento de Esclavos de 1842, tocaba a Soloni “dar papel” para que Isabel buscará otro dueño. Sin embargo, Soloni argumentó que, estando la finca en venta, se suspendiese la cesión de Isabel, a lo que se accedió por plazo de dos meses. Durante el proceso, el síndico Marín de Nueces puso al descubierto el carácter agresivo del que tenía fama Félix Soloni. Sin embargo, su actuación en el caso se torció en febrero de 1849 cuando, por "el lenguaje violento de sus escritos", Soloni presentó quejas contra él. En consecuencia, el alcalde mayor Martín Galiano expresó que era conveniente dejar sin efecto el nombramiento realizado a Martín de Nueces, sustituyéndolo por otro que reuniese "las cualidades convenientes" para seguir representando los intereses de la esclava Isabel. Días después, el teniente Gobernador de Alacranes contestó a la anterior resolución y dejó sin efecto el nombramiento de síndico a Martín de Nueces, sustituyéndolo por José Valladares. ${ }^{34}$

${ }^{33}$ En 1881, se reconocía "que es indudable que entre los que sirven de agentes a los patrocinados habrá quienes abusen de la ignorancia de estos". "Carta dirigida al presidente de la Junta Provincial de Patronato de Matanzas que trata sobre la defensa de los derechos de los patrocinados, 17 de septiembre de 1881", Junta Provincial de Patronato de Matanzas Records, CHC5298, Cuban Heritage Collection, Universidad de Miami, consultado en http://merrick.library.miami.edu/cdm/compoundobject/collection/chc5298J/id/87/rec/36, 16 de mayo de 2018.

${ }^{34}$ Sobre maltrato que recibe la dotación del ingenio "Buena Madre", en jurisdicción de Alacranes, de la propiedad de D. Félix Soloni, ANC, Gobierno Superior Civil, Leg. 946, exp. 33360, 1849. 
En el Archivo Nacional de Cuba, se conservan múltiples expedientes de entre la década de 1830 y 1886, sobre esclavos que denunciaron el maltrato que recibían. No pocos de ellos, en uso de las disposiciones vigentes, solicitaron cambiar de amo. Fueron los casos, por ejemplo, de Mateo, José de los Ángeles, Francisco Reyes, María del Carmen Valdés y Pío Montoto, quienes revelaron los abusos cometidos por sus poseedores José Hernández, Enrique Sual, José García, María Calonge y José Lincheta, respectivamente. ${ }^{35}$ Como venimos argumentando, este tipo de reclamaciones fueron habituales hasta los últimos años del sistema esclavista. En diciembre de 1880 se presentó a la Junta Provincial de Patronato de Matanzas el moreno Martín quejándose de que su amo, Francisco Gómez, vecino de Cárdenas y propietario del ingenio Oriente, lo tenía "siempre en prisiones y no le pagaba más que tres pesos en billete". ${ }^{36}$ Meses después se presentó ante la Junta Local de Guamutas el moreno Lucas para denunciar los frecuentes golpes que recibía de su patrono Francisco Pedroso, propietario del ingenio San Cayetano, ubicado en el mismo término municipal. ${ }^{37}$

Algunos expedientes se refieren a casos de maltratos colectivos, como el formado en 1848 para averiguar el tratamiento que recibían los esclavos del ingenio Manaca, propiedad de los herederos de Juan Martín Hidalgo ${ }^{38}$ o el formado en 1854 por

\footnotetext{
${ }^{35}$ Expediente sobre haberse presentado el negro Mateo quejándose de excesivo castigo que le infirió su amo D. José Hernández Romero, ANC, Gobierno Superior Civil, Leg. 938, exp. 33100, 1837. Expediente en que José de los Ángeles moreno esclavo se queja del abandono en que lo tiene su amo Pbro. D. Enrique Sual, ANC, Gobierno Superior Civil, Leg. 941, exp. 33212, 1843. Expediente en el que el negro Francisco Reyes se queja del mal trato que le da su amo D. José García, ANC, Gobierno Superior Civil, Leg. 947, exp. 33454, 1852. Expediente en que la negra María del Carmen Valdés se queja de mal trato que le da su ama Dña. María Calonge, ANC, Gobierno Superior Civil, Leg. 949, exp. 33548, 1854. Expediente promovido por Pío Montoto criollo esclavo de D. José Lincheta quejándose de maltrato y solicitando autorización para buscar otro dueño, ANC, Gobierno Superior Civil, Leg. 1056, exp. 37610, 1864.

36 "Carta sobre una querella presentada por el patrocinado Martín a la Junta Provincial de Patronato de Matanzas, 30 de diciembre de 1880", Junta Provincial de Patronato de Matanzas Records, CHC5298, Cuban Heritage Collection, Universidad de Miami, consultado en http://merrick.library.miami.edu/cdm/compoundobject/collection/chc5298J/id/303/rec/65, 16 de mayo de 2018.

37 "Carta o reporte sobre una queja de abuso hecha por el patrocinado Lucas acerca de su patrono Francisco Pedroso, 24 de febrero de 1881", Junta Provincial de Patronato de Matanzas Records, CHC5298, Cuban Heritage Collection, Universidad de Miami, consultado en http://merrick.library.miami.edu/cdm/compoundobject/collection/chc5298J/id/454/rec/52, $16 \mathrm{de}$ mayo de 2018.

${ }^{38}$ Testimonio del expediente gubernativo formado sobre el mal trato que se da a los negros esclavos del ingenio "Manaca" de la propiedad de los herederos de D. Juan Martín Hidalgo, ANC, Gobierno Superior Civil, Leg. 945, exp. 33336, 1848.
} 
el maltrato que denunció recibir la dotación del ingenio San Miguel, de Miguel Azopardo. ${ }^{39}$

En la práctica el ingenio funcionó como espacio disciplinar por excelencia de la sociedad esclavista cubana. Los testimonios sobre la plantación azucarera como lugar punitivo, sobre la degradación al trabajo rural -por el sacrifico y el aislamiento que suponía- son recurrentes desde el siglo XIX y es un tema destacado en la historiografía cubana contemporánea. ${ }^{40}$

Apropiándonos de la definición conceptual de La Parra y Tortosa que citamos al principio de este capítulo, las tensiones entre la reglamentación colonial y la agencia de los esclavos que venimos comentando forman parte de, y se desenvuelven en, un entorno en extremo violento. La infracción es el punto de encuentro de voluntades enfrentadas. Y esas voluntades definen realidades en permanente conflicto por recursos materiales y simbólicos. La existencia de unos y otros está marcada por cotidianas agresiones, que desafían los fundamentos de las jerarquías sociales establecidas. En el día a día, la agencia de los esclavos desbordó la reglamentación al uso, y con ello, estaba constantemente expuesto al ejercicio violento del poder. En el sentido opuesto, la reglamentación sobre la vida de los esclavos nunca comprendió la complejidad del sistema, ni el hecho de que, en determinadas circunstancias, la legislación misma era más problemática que la realidad. La violencia intrínseca de las relaciones sociales bajo la esclavitud dio muestras de lo anterior en todo momento.

Varios autores han analizado episodios de violencia en la plantación, específicamente suicidios y homicidios, como parte de las estrategias de resistencia que adoptó la población esclava. ${ }^{41}$ Pero esta resistencia no es un componente marginal del sistema, sino su naturaleza misma. En nuestro estudio, esos y otros eventos importan no

\footnotetext{
${ }^{39}$ Sobre haberse presentado al Capitán de Macuriges, ocho negros del ingenio "San Miguel" de la propiedad de Miguel Azopardo, quejándose de mal trato, ANC, Gobierno Superior Civil, Leg. 944, exp. 33303, 1854.

${ }^{40}$ Ver, entre otros: Yolanda Díaz Martínez, "De marginados a trabajadores. Usos y destinos de la población penal en La Habana", Millars, vol. XXV, 2012, pp. 129-149. Imilcy Balboa, "Presidiarios por esclavos. Mano de obra cautiva en la transición al trabajo libre", en: José A. Piqueras (ed.), Trabajo libre y coactivo en sociedades de plantación, Siglo XXI, Madrid, 2009, pp. 253-279. Tal experiencia es narrada en Francisco, una de las más conocidas novelas cubanas del siglo XIX.

${ }^{41}$ Ver: Gloria García, La esclavitud desde la esclavitud. La visión de los siervos, Centro de Investigación Científica "Ing. Jorge L. Tamayo", México, 1996. Javier Laviña y José Luis RuizPeinado, Resistencias esclavas en las Américas, Doce Calles, Madrid, 2006. Javier Laviña, Cuba. Plantación y adoctrinamiento, Ediciones Idea, Santa Cruz de Tenerife, 2007. Manuel Barcia, Seeds of Insurrection. Domination and Resistance on Western Cuban Plantations, 1808-1848, Louisiana State University Press, Baton Rouge, 2008.
} 
como episodios espectaculares, como casos esporádicos o singulares, dignos de metodologías de microhistorias, sino por la regularidad con la que impregnaron de sangre el sistema. La integridad física y moral de la población trabajadora, fundamentalmente en esos recintos de brutalidad que eran las plantaciones esclavistas, se jugó cotidianamente en situaciones que desencadenaron procesos de enfermedad y muerte. Hablamos de una población que vivió al límite cada jornada. La vida del esclavo importó en la medida en la que era productivo y la productividad comenzaba por aceptar el sometimiento. En esta condición se justificó su existencia. Si respiraba, era para que ese movimiento de elemental vitalidad insuflara de vida el complejo económico y social de la "segunda esclavitud".

\section{VIOLENCIA EXTERNA Y PERICIA JUDICIAL}

En el partido de Cimarrones, Matanzas, a los 12 días de junio de 1872, Joaquín de Palomino, Juez local, en compañía de los testigos Gonzalo Jurado y Leonardo García Menocal, del mismo vecindario, se trasladaron al ingenio Ceres con el objetivo de atender un parte escrito remitido por Carlos Delmonte, propietario de la finca. Constituidos en la enfermería del mismo, situada de Este a Oeste y entrando por la puerta principal que es al Sur, en un cuarto a la izquierda, vieron el cuerpo de una mujer negra al parecer muerta, tendida sobre un catre, con la cabeza hacia el Oeste y los pies al Este, como de 36 años de edad, estatura regular, de buena constitución al parecer, vestida con túnico de muselina de algodón blanco, un pañuelo blanco atado en la cabeza. El cuerpo estaba alumbrado con cuatro velas al parecer de esperma, colocadas en cuatro botellas que hacían de candeleros. En su custodia se encontraban dos individuos también negros que dijeron llamarse Aparicio Congo y Fermín de la misma nación. Interrogados para que dijesen quién era aquel cadáver, ambos contestaron diciendo que era su compañera Polonia Conga, que había fallecido en la madrugada, después de una enfermedad de muchos días. ${ }^{42}$ Experiencias similares desembocaron en enmarañados procesos judiciales para determinar las condiciones en la que se produjo la muerte de no pocos esclavos y trabajadores de plantaciones cubanas.

\footnotetext{
${ }^{42}$ Expediente formado con motivo de haber fallecido en el ingenio "Ceres" la emancipada liverta (sic) Polonia Conga, recontratada con Don Carlos Delmonte, ANC, Gobierno Superior Civil, Leg. 1570, exp. 81301, 1872.
} 
Una fuente poco explorada para el análisis de la violencia resultante de la dinámica esclavista en la isla es la documentación generada por la Comisión de Medicina Legal de la Academia cubana. Entre la fundación de esta institución en 1861 y la abolición de la esclavitud se discutieron múltiples casos de homicidios, sevicias, heridas, infanticidios, etc., que sugieren lo regular de estos fenómenos en este período, y como en torno a los procesos judiciales instruidos los propietarios articularon las más diversas estrategias para evadir su responsabilidad.

En abril de 1864, las autoridades judiciales del partido de Bauta solicitaron a la Academia de Ciencias un informe con el objetivo de determinar si los reconocimientos realizados por los facultativos, en causa criminal formada por los supuestos excesos cometidos por los empleados del ingenio Mascatá ${ }^{43}$ contra algunos trabajadores de su dotación, "estaban arreglados a la ciencia en sus formas y conclusiones". Entre los documentos remitidos figura un testimonio del reconocimiento judicial practicado por el pedáneo del partido en la enfermería de varones del referido ingenio, en el cual se encontró el cadáver de un asiático llamado Nicolás. Igualmente, se notificó la existencia de otros cuatro asiáticos y varios negros enfermos, presentando seis de ellos lastimaduras y escoriaciones en las nalgas unos y otros en los brazos. Los médicos que practicaron la autopsia de Nicolás encontraron en la cavidad del cráneo un derrame sanguíneo en la membrana aracnoides, heridas en los huesos fémures -que pudieron ser producidas por un cuerpo dislacerante, tal como colmillo de perro- y hematomas en la cara posterior del tronco. Certificaron que la causa ocasional de la muerte del expresado asiático al parecer no había sido otra que una apoplejía cerebral, que atribuyeron a un "padecimiento moral". ${ }^{4}$

En otro atestado, suscrito por los mismos profesores que signaron la autopsia, se expresa que, en tres asiáticos, un negro y una negra, todos trabajadores del ingenio, encontraron heridas y contusiones leves en distintas partes del cuerpo. Uno de los firmantes de la autopsia, que había ejercido como médico de la dotación, al ser interrogado por la muerte de Clara, mandinga, contestó que sí la conoció, que era de

\footnotetext{
${ }^{43}$ En el inventario que ofrece Carlos Rebello sobre la producción azucarera en 1860 no figura este ingenio. En 1877, dicha plantación figura como propiedad de Sebastián Peñalver, con una dotación compuesta por 97 esclavos, 40 alquilados y libres y 27 colonos asiáticos. Dirección General de Hacienda, Noticia de los ingenios o fincas azucareras que en estado de producción existen actualmente en toda la isla.

44 "Consulta sobre los reconocimientos hechos por varios facultativos en un caso de sevicia", en: Trabajos de la Comisión de Medicina Legal e Higiene Pública de la Real Academia de Ciencias Médicas, Físicas y Naturales de La Habana, t. I, pp. 118-122.
} 
mucha edad y padecía "tisis por consunción”, que nunca se le quejó de recibir golpes, y que murió de "enfermedad natural". También declaró que ignoraba si los empleados de la finca maltrataban a los esclavos, y aseguró no haber conocido a la negra Dorotea e ignora si abortó. Similar declaración ofreció otro facultativo que estuvo asistiendo a Clara hasta tres días antes de su muerte, pronosticando este evento por consunción. Que no supo ni por ella, ni por otra persona, que hubiese sido golpeada, y que en el reconocimiento que le practicó no le observó señal alguna de castigo. Respecto a Dorotea, respondió no haberla asistido de enfermedad alguna, pero que sí recuerda haberle dicho que estaba abortando, que entonces la reconoció y encontró manchas de sangre en sus vestidos, pero sin otra evidencia que confirmara lo que le había confesado, por lo que juzgó que el supuesto aborto no era sino un "flujo de sangre resultante de una exageración de su menstruación”. Sí afirmó el hecho de que a Dorotea se le habían dado algunos azotes. Como se ve, las referencias sobre la posibilidad de que la dotación del ingenio Mascatá sufriera maltratos sistemáticos eran contradictorias. Otro de los médicos consultados en el caso, que había prestado servicios a la dotación del ingenio, afirmó que jamás había asistido a ningún trabajador por efecto de sevicia. En cambio, en la certificación emitida por otros dos facultativos, con el reconocimiento practicado en varios individuos de la dotación, se expone que Antonio y Pánfilo, criollos, y Juliana, conga, tenían cicatrices en sus nalgas resultantes de castigos que les fueron inferidos, que en Ramón, lucumí, y José Hermenegildo, encontraron largas cicatrices en sus espaldas que también parecen efecto de correctivos, y que el negro Crispin, lucumí, padece un tumor huesoso en la región lumbar, debido, según asegura el paciente, a los excesivos castigos a los que ha estado sometido. ${ }^{45}$

La atención de la Comisión se fijó fundamentalmente en el certificado de la autopsia, por considerarlo el único a fin con las cuestiones médicos legales que le competen. Aunque consideró ese documento ajustado en su forma y conclusiones a los preceptos de la ciencia, lo encontró defectuoso en su fondo, poco meditado, conjetural y contradictorio al afirmar que la causa ocasional de la muerte del asiático Nicolás fue un "padecimiento moral". A la cuestión de si después de un mes de finada, la exhumación podría permitir encontrar señales de castigo, los facultativos respondieron que, como la

\footnotetext{
45 "Consulta sobre los reconocimientos hechos por varios facultativos en un caso de sevicia", pp. 118-122.
} 
putrefacción se adelantaba mucho en el clima cubano, nada podría conseguirse como no fuera para buscar fracturas o venenos. ${ }^{46}$

En efecto, la posibilidad de obtener indicios que comprueben un presunto delito en casos de muertes sospechosas, dependía de la rapidez con la que se produjera la exhumación del cadáver. Reclamaciones al respecto encontramos en decenas de los casos consultados. En 1856, la negativa de un párroco a que las autoridades procedieran a la exhumación de un cuerpo sin previa autorización del ordinario diocesano, motivó una reclamación de la Real Audiencia a las máximas autoridades eclesiásticas de la isla para que estas comunicaran a los vicarios y párrocos de sus respectivas diócesis la importancia de facilitar el trabajo de las personas encargadas de administrar justicia, permitiendo no solo la exhumación de un cadáver sino además declarando en caso de ser su testimonio requerido por un juez, aunque por la urgencia del caso no se hubiese conseguido previamente el impartimiento de auxilio eclesiástico. ${ }^{47}$ Por otro lado, la baja disponibilidad de facultativos con los conocimientos necesarios para desempeñar los servicios médico-forenses, sobre todo en las zonas rurales, atentó contra este tipo de diligencias. Con frecuencia, los informes remitidos a los juzgados carecían de los requisitos indispensables para la correcta administración de la justicia.

Otra cuestión importante para comprender la excepcionalidad de los procedimientos médicos legales relativos a causas en los que la muerte de un esclavo o trabajador de una plantación se produce bajo circunstancias sospechosas son los costos relativos a los trabajos de reconocimiento, autopsia y exhumación del cadáver. A raíz de la muerte del asiático Remigio, colono del ingenio Encarnación, se produjo en febrero de 1869 una consulta a la Academia de Ciencias, a petición del Alcalde Mayor de Güines, para que informara acerca de "la justa regulación" de los honorarios asignados a los facultativos que actuaron en la causa instruida para aclarar las circunstancias en la que se produjo el suceso. La costumbre en los casos comunes de un reconocimiento practicado en la misma localidad en que reside el médico, era pagar a cada perito la suma de 17 escudos. Cifra que la clase médica consideraba exigua. Si el reconocimiento conllevaba un desplazamiento de varias horas, como fue el caso, la cantidad a pagar podía incrementarse considerablemente. Luego una autopsia común en La Habana estaba valorada en 200 escudos para cada perito. Diversas circunstancias también

\footnotetext{
46 Ídem.

47 "Discurso pronunciado en la apertura de la Real Audiencia Pretorial, el día 2 de enero de 1857, por Illmo. Sr. Regente", Revista de Jurisprudencia, Administración y Comercio, Imprenta del Tiempo, Año. II, t. II, La Habana, 1857, p. 39.
} 
podían encarecer el valor de esta diligencia. Asimismo, en circunstancias normales, el tipo de las exhumaciones ascendía a 200 escudos para cada perito. "Más si se atiende a que la del asiático Remigio se practicó a seis leguas de distancia, por mal camino, en tiempo de lluvias, en el campo y al sol; si se tiene presente que se trata de un caso grave, en el cual hubo intervención facultativa anterior, lo que aumentaba el grado de responsabilidad de los segundos peritos, se puede, siendo económico, alzar esta cantidad hasta el triple". Finalmente, la Comisión informó que "los honorarios de 8.000 escudos asignados a los profesores en las diligencias de exhumación y autopsia del asiático Remigio, aunque en otras circunstancias no son exagerados, deben reducirse a 2.608 escudos, si es cierta la posición financiera que el condenado al pago de las costas afecta en su escrito de foj. 154; más no debe mermarse en caso contrario." ${ }^{48}$ Por lo expuesto, es lógico pensar que, ante casos similares, por demás frecuentes, los propietarios eludieran en la medida de lo posible los procesos judiciales.

Si las sevicias figuran con tan pocos casos en los records criminales de la colonia cubana, se debe en gran medida a la baja capacidad de intervención policial. Sistemáticos atropellos a esclavos y a trabajadores formalmente libres como los colonos chinos quedaron impunes. Cuando el suceso trascendía a las autoridades, los hacendados con regularidad podían comprar el testimonio de los facultativos involucrados. Cuando se les requería, las declaraciones de los médicos contratados para asistir a las dotaciones y trabajadores de ingenios eran oscuras, contradictorias, descaradamente manipuladas. Nunca sabremos cuantas de las notas y certificaciones de defunción de esta gente, emitidas a lo largo y ancho de la isla, que refieren como causa enfermedades habituales o indican con vaguedad "muerte natural", en realidad esconden historias de extremo sadismo. E impresiona, por obsceno, el tecnicismo del que algunas veces se valieron para enmascarar la violencia.

El negro Francisco, esclavo criollo del ingenio San José de Oviedo, murió el 1ro de julio de 1868 a consecuencia de una gangrena de la extremidad inferior derecha, tiempo después de ser severamente castigado de varios modos. Dicha enfermedad atravesó -entre el 16 de mayo, cuando entró en la enfermería por "dolores generales", luego de haber sido azotado, y la fecha de su muerte- diversas fases hasta el desprendimiento no solo de las partes blandas sino de la totalidad de la pierna. Esto

\footnotetext{
48 "Consulta sobre regulación de honorarios", en: Trabajos de la Comisión de Medicina Legal e Higiene Pública de la Real Academia de Ciencias Médicas, Físicas y Naturales de La Habana, t. I, pp. 514-520.
} 
último ocurrió ocho días antes de su deceso. En la enfermería, en vez de un descanso adecuado a su situación, fue puesto en el cepo por ambos pies, cargado de prisiones. Un enfermero, sin más formación que la de haber ejercido como tal en la campaña de Santo Domingo, le atendió los primeros veinte días de su ingreso, con un desordenado plan que combinó vomitivos, purgantes, quinina, cáusticos, unturas excitantes, aplicaciones detersivas, etc. No fue hasta la visita de un facultativo el 2 de junio que se le retiró el cepo, viendo este que presentaba una tumefacción edematosa de ambos pies. En este caso, la Academia reconoció el hecho de que a Francisco le faltará "una asistencia médica inteligente y bien dirigida en los primeros momentos del padecimiento" y, por igual motivo, concluyó que la muerte sobrevino como consecuencia del castigo; "pero no fatal, no necesaria, porque hubiera podido evitarse quizás, si reconocido el accidente inflamatorio desde los primeros momentos de su manifestación, se hubiesen alejado las causas que la producían y que debieron ser el roce de los grillos y el magullamiento que el cepo ocasionaba necesariamente en los pies, y también la dificultad de circulación dela sangre en las extremidades inferiores, colocadas como estaban en un plano más alto que el general del cuerpo, que comprimía y magullaba las extremidades". ${ }^{49}$ Visto así, en esta historia lo menos justificable era el descuido del enfermero. Elocuente expresión de la racionalidad que informaba la gobernanza de la plantación esclavista.

En septiembre de 1871 se analizaron en la Academia dos casos, uno de homicidio y el otro de sevicia. El primero se produjo a raíz de la muerte del asiático Florentino. El proceso llevado a cabo por el Juzgado de Remedios era contra Cecilio Martínez, de quien se sospechaba era el responsable del crimen. La Academia debía dictaminar si la muerte de Florentino se produjo por las mordeduras de un perro o debido a vómitos y diarreas crónicas. Luego de examinar el cadáver y los documentos periciales del caso, concluyó que no fueron las diarreas, como se quería insinuar, sino la hemorragia ocasionada por las mordeduras, la causa de la muerte. Una de ellas alcanzó la arteria y venas braquiales de Florentino y el desangramiento se produjo sin la asistencia oportuna para salvarle la vida. ${ }^{50} \mathrm{El}$ otro caso fue la causa seguida contra Isabel Feliú por sevicia en el negrito Anacleto. El Alcalde Mayor de Guanajay inquirió a la Academia sobre los signos de violencia exterior existentes en el cuerpo del menor.

\footnotetext{
49"“Consulta para determinar si la muerte del negro Francisco fue ocasionada por los castigos que recibió", en: Trabajos de la Comisión de Medicina Legal e Higiene Pública de la Real Academia de Ciencias Médicas, Físicas y Naturales de La Habana, t. I, pp. 435-442.

50 "Medicina legal. Informe sobre heridas", Anales de la Real Academia de Ciencias Médicas, Físicas y Naturales de La Habana, vol. VIII, 1871, pp. 158.
} 
A juzgar por la descripción del caso, Isabel Feliú golpeó brutalmente a Anacleto con un látigo u otro instrumento lacerante provocando su muerte, ${ }^{51}$ vulnerando con su comportamiento el artículo 21 de la Ley Moret que prohibió los castigos corporales.

De 1876 es el expediente formado para investigar la muerte de Jacoba, conga, esclava de la dotación del ingenio Caridad, de Ramón Flores de Apodaca. Ella fue sometida por dos empleados de la finca a un triple castigo de golpes, cepo y amenazas, que pudieron acelerar la marcha de una lesión cerebral prexistente. Antes, había perdido la vista por completo debido a una afección de los ojos. Ese mismo año, se pidió a la Academia de Ciencias que informara su parecer en el homicidio de la negra Liboria; la sevicia en el negro Manuel, del ingenio Agüica; el maltrato a los negros Hermenegildo y Manuel criollo; la sevicia a la dotación del ingenio Columbia; la verdadera causa de la muerte del asiático Patricio; la muerte del asiático Casimiro, cuyo cadáver fue encontrado en una cantera del potrero Audacia; etc. La mayoría de estos instruidos en el Juzgado de primera instancia de Colón. ${ }^{52}$

De acuerdo con los testimonios del caso de Liboria, era "continuamente azotada" y "poco o nada alimentada", fue colgada desnuda y de sus pies con una cuerda, así acostumbraban castigarla, "uno de sus pechos fue herido y quemado con una plancha caliente", mientras “dos negritos mordían sus orejas y ayudaban a flagelarla". A los pocos días falleció Liboria sin una afección crónica conocida, "rodeados de misterio la hora y día del suceso" y sin asistencia médica. No obstante, el facultativo que emitió el correspondiente certificado de defunción, que "solo le miró el rostro", diagnosticó que había fallecido por una "fiebre perniciosa", fundándose solamente en que unos 15 o 20 días antes la había visto con una fiebre terciana. ${ }^{53}$

Los casos analizados resultan de procesos en los que se estaba dirimiendo alguna responsabilidad penal. Pero es posible que agresiones mortales con suicidio del autor, ocurrieran sin trascender a las autoridades. Podríamos imaginar esto en casos de parricidio o infanticidio, aunque ciertamente son raros dentro de la documentación consultada.

\footnotetext{
51 "Cuestión de sevicia", Anales de la Real Academia de Ciencias Médicas, Físicas y Naturales de La Habana, vol. VIII, 1871, p. 159. Ver también: Miguel Riva, "Consulta para averiguar si está arreglado a la ciencia el dictamen facultativo en causa por sevicia", Trabajos de la Comisión de Medicina Legal e Higiene Pública de la Real Academia de Ciencias Médicas, Físicas y Naturales de La Habana, t. II, Imprenta "La Antilla", La Habana, 1873, pp. 97-99.

${ }^{52}$ Ver: Anales de la Real Academia de Ciencias Médicas, Físicas y Naturales de La Habana, vols. XIII-XIV, 1876-1877.

53 "Medicina legal. Cuestión de sevicia", Anales de la Real Academia de Ciencias Médicas, Físicas y Naturales de La Habana, vol. XIII, 1876, pp. 410, y 427-428.
} 


\section{VIOLENCIA INTRARRACIAL}

En una publicación reciente, el historiador Jeff Forret analiza a través de cientos de casos de violencia intrarracial referidos al sur de Estados Unidos, como los esclavos estuvieron involucrados en disímiles comportamientos agresivos, no pocos de los cuales terminaron en muerte. De acuerdo con este autor, aunque la participación de la población esclava en eventos espectaculares como revueltas y sublevaciones contra las autoridades ha sido objeto de interés por la historiografía contemporánea, los múltiples episodios de violencia que marcaron el día a día en la plantación ha sido menos estudiados. Estos episodios fueron el resultado de conflictos y rivalidades entre los diferentes grupos raciales que convivían en la plantación. Los múltiples documentos en los que esclavos, colonos chinos y sujetos libres “de color" aparecen como responsables de actos violentos en el complejo azucarero cubano, confirman una idea potenciada por Forret en su estudio: nos referimos a sujetos con una participación activa en su realidad, que para nada encajan en la tipología creada por la historiografía tradicional que los reducía a una personalidad uniforme y pasiva. ${ }^{54}$

Los conflictos que la dinámica de la plantación generó entre los propios trabajadores conforman un universo de casos extremadamente útiles y pertinentes para el análisis de los procesos de enfermedad y muerte en la plantación. El artículo quinto del Reglamento de Esclavos de 1842 establece que correspondía al dueño de la fínca no solo hacer comprender a sus esclavos "la obediencia que deben á las autoridades constituidas", sino además la importancia de "vivir en armonía con sus compañeros". 55 Los motivos que podían desencadenar peleas en la dotación eran diversos y la incorporación de colonos chinos potenció las diferencias internas. Como veremos, varios expedientes descubren procesos judiciales abiertos por agresiones mortales cometidas en ingenios que operaban con fuerza de trabajo heterogénea. Antes, importa hacer algunas observaciones sobre los guarismos relativos a la violencia que informaba las relaciones sociales bajo la "segunda esclavitud" en la isla.

Algunos documentos oficiales de mediados del siglo XIX revelan el temor existente por el hecho de que los hombres "de color" frecuentemente infringían la legislación sobre portación de armas prohibidas y la posibilidad de reagravar las penas

\footnotetext{
${ }^{54}$ Jeff Forret, Slave against slave. Plantation Violence in the Old South.

55 "Reglamento de esclavos, agregado y publicado con el bando de buen gobierno de la Isla de Cuba, que fue expedido en 14 de noviembre de 1842", p. 135.
} 
por ese delito. ${ }^{56}$ Asimismo, en un trabajo publicado años más tarde, el doctor L. Montané reconoció que "pocos países, excepto en época de guerras, ofrecen mayor oportunidad que este para observar las heridas penetrantes del pecho."57

De acuerdo con la estadística criminal correspondiente a 1862, los delitos contra las personas (1.449) agruparon el mayor número de sanciones, solo superados por los delitos contra la propiedad (2.267). O sea, el 27,5\% de las infracciones registradas en toda la isla en 1862 se produjeron contra las personas. Los delitos de este tipo en el Departamento Occidental (993) más que duplicaron a los cometidos en el Departamento Oriental (408). El extraordinario índice de violencia de la administración occidental puede explicarse no tanto por el mayor numeró de los delitos registrados, ya que esta concentraba en 1862 el $81 \%$ de la población total de la isla, sino por el hecho de que los delitos contra las personas representaron en esta región el 30\% de las infracciones y sucesos registrados en la estadística criminal, mientras que en la administración este del país la proporción fue solo del $23 \%{ }^{58}$

Al valorar esta información, José Antonio Saco destacó que el 35\% de los delincuentes permanecían en absoluto desconocimiento para las autoridades, lo cual probaba el hecho de que en la isla no se perseguía la delincuencia con la firmeza que en otros territorios. ${ }^{59}$ El patricio bayamés advierte sobre "la deplorable condición moral" que presentan los campos de la isla, donde se registraron el $43 \%$ de los hechos delictivos, y en los cuales "la vida, el honor y la propiedad del hombre, están expuestos a grandes peligros". Nótese que, los 592 labradores comprendidos entre los reos conocidos en 1862, hacían de este oficio, con gran diferencia, el más representado en la estadística criminal. Sobre el notable aumento y la gravedad de los homicidios procedentes de violencia ajena, José Antonio Saco cita las palabras del Regente de la

\footnotetext{
56 "Discurso pronunciado en la apertura de la Real Audiencia Pretorial, el día 2 de enero de 1857, por Illmo. Sr. Regente", Revista de Jurisprudencia, Administración y Comercio, Imprenta del Tiempo, Año II, t. II, La Habana, 1857, p. 36.

${ }^{57}$ L. Montané, "Tratamiento de las hemorragias en las heridas penetrantes del pecho", Gaceta Médica de La Habana, Año 1, No. 11, septiembre, 1879, pp. 167-169.

${ }^{58}$ Conde Armildez de Toledo, Noticias estadísticas de la isla de Cuba, en 1862. La fuente no indica las páginas.

${ }^{59}$ A propósito, conviene recordar que el 15 de mayo de 1862, el entonces Capitán General Francisco Serrano y Domínguez, firmó una circular en la que pedía a los funcionarios del Ministerio público y a las autoridades administrativas absoluta colaboración y diligencia en sus acciones para investigar y castigar los graves atentados contra la propiedad y la seguridad individual que frecuentemente se suceden en la isla. "Circular de la Audiencia y el Gobierno sobre persecución de malhechores y criminales", Revista de Jurisprudencia, Administración y Comercio, Imprenta “La Antilla”, año VII, t. II, La Habana, 1862, pp. 263-264.
} 
Audiencia de La Habana, quien destacó el hecho de que dentro de ese grupo de delitos eran "pocas las muertes peleadas y muchos los homicidios alevosos y premeditados". 60

Al considerar la baja proporción de delitos sancionados entre la población esclava, José Antonio Saco tuvo en cuenta dos factores. Primero, el hecho de que la mayoría de los esclavos residieran en las plantaciones, donde los amos ejercían su particular justicia, evitó que muchas infracciones en las que aquellos estaban involucrados trascendieran a la jurisdicción de los tribunales. Segundo, al ser el propietario el responsable de las costas resultantes de las causas criminales en las que estuvieran involucrados sus esclavos, evitaron en lo posible la intromisión de la justicia ordinaria en las infracciones de sus trabajadores. Sin embargo, la responsabilidad criminal de la población esclava atendiendo a cada sexo, indica que mientras que en los varones se registró una menor proporción de actos delictivos respecto a los hombres blancos y libres "de color", lo contrario sucede en las mujeres. José Antonio Saco sugiere que ese fenómeno puede tener por causa el elevado número de infanticidios que cometen las esclavas. ${ }^{61}$

Podemos comprender la magnitud de la violencia existente en Cuba comparando las tasas de homicidios, suicidios y lesiones sancionados en 1862 con las de Puerto Rico en igual fecha. Mientras en la mayor de la Antillas la tasa de homicidios fue de 12,5 por 100.000 habitantes, en Puerto Rico fue tan solo 1,3. Solo 7,8 de cada 100.000 habitantes de Puerto Rico cometieron suicidio ese año, mientras en Cuba esa tasa se elevó a 25,3. Asimismo, la tasa de lesiones penadas en Cuba fue 49,3 por 100.000 habitantes, mientras en la colonia vecina fue solo 19,1. La diferencia es también notable si se comparan los delitos contra la propiedad. En su discurso de apertura de la Audiencia Pretorial de La Habana, el jurista liberal Joaquín Calbetón y Legarra, regente de la misma, sugirió que "cuestión tan grave y tan complexa (sic)" podía tener como causas el pronto cese de la trata en Puerto Rico y la disminución progresiva de su población cautiva, también el hecho de que aquella isla no necesitara "trabajadores extraños" -en clara referencia a los colonos chinos que tanto aportaron la criminalidad cubana- para el fomento de una agricultura que, por otro lado, está dominada por el café, un cultivo menos violento que el azúcar, y desarrollado fundamentalmente por pequeños

\footnotetext{
${ }^{60}$ José Antonio Saco, "La estadística criminal de Cuba en 1862", en: José Antonio Saco, Colección póstuma de papeles científicos, históricos, políticos y otros ramos sobre la isla de Cuba, Editor Miguel de Villa, La Habana, 1881, pp. 141-150. El texto fue publicado originalmente en la revista española La América, el 12 de enero de 1864.

${ }^{61}$ José Antonio Saco, "La estadística criminal de Cuba en 1862", p. 147.
} 
propietarios. Por último, el hecho de que en Puerto Rico los artículos de primera necesidad fueran más baratos también pudo contener determinados actos criminales. ${ }^{62}$

La conexión que este magistrado establece no es gratuita. Sin duda, el peso específico de la esclavitud y el carácter de la agricultura en cada territorio marcó el tipo relaciones establecidas por su población. En 1860 solo el 7,2\% de la población de Puerto Rico era esclava y otro 41,3\% libre "de color". ${ }^{63}$ Aunque el peso demográfico de la población no blanca en Cuba en 1862 es similar a la de Puerto Rico, la proporción de esclavos es significativamente mayor.

Los delitos contra las personas repuntaron en el segundo lustro de la década de 1860. En 1867, con 2.033 casos, llegaron a representar la proporción más elevada dentro de la estadística criminal para los años que hemos podido registrar entre 1857 y 1875. Hay que tener en cuenta que durante la Guerra de los Diez Años (1868-1878), muchos delitos quedaron impunes debido al estado excepcional en el que se encontraba la isla. A través de la prensa y otras fuentes, podemos ver como una parte considerable de estos delitos se refieren a conflictos entre esclavos, colonos chinos, y población libre "de color".

TABLA 23: CUBA. DELITOS CONTRA LAS PERSONAS REGISTRADOS, 1857 A 1875.

\begin{tabular}{|r|r|r|r|}
\hline Años & Número de delitos contra las personas & \% sobre el total de causas criminales \\
\hline 1857 & 1.121 & 20,3 \\
\hline 1858 & 1.083 & 23,7 \\
\hline 1859 & 1.313 & 26,7 \\
\hline 1860 & 1.373 & 27,1 \\
\hline 1861 & 1.428 & 25,3 \\
\hline 1862 & 1.449 & 27,5 \\
\hline 1863 & 1.407 & 25,1 \\
\hline 1864 & 1.527 & 24,5 \\
\hline 1866 & 1.685 & 34,4 \\
\hline 1867 & 2.033 & 36,9 \\
\hline 1872 & 1.226 & 24,4 \\
\hline 1875 & 1.595 & 24,3 \\
\hline Elaboración propia a partir de diversas fuentes. & & & \\
\hline
\end{tabular}

\footnotetext{
${ }^{62}$ Joaquín Calbetón, Discurso de apertura de la Audiencia Pretorial de La Habana, Imprenta del Gobierno, La Habana, 1870, pp. 8-9.

${ }^{63}$ D. J. Jimeno Agius, Población y comercio de la isla de Puerto Rico, Establecimiento Tipográfico de "El Correo", Madrid, 1885, p. 12.
} 


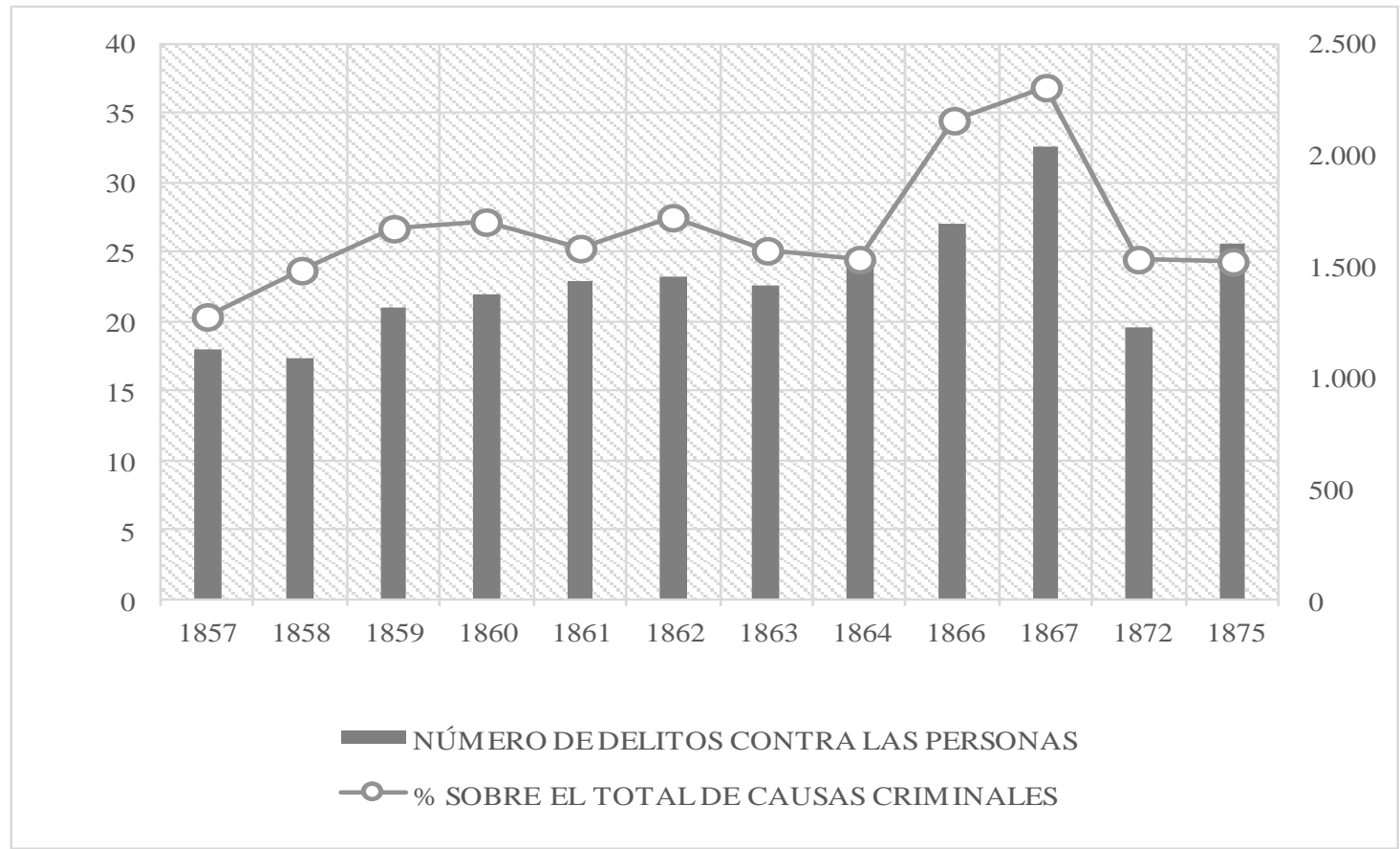

Elaboración propia a partir de diversas fuentes.

TABLA 24: ESTADÍSTICA CRIMINAL SELECCIONADA, CON INDICACIÓN DE LOS CASOS DE SEVICIA A ESCLAVOS EN LAS PRINCIPALES JURISDICCIONES ESCLAVISTAS, 1861/1862.

\begin{tabular}{|l|r|r|r|r|}
\hline \multicolumn{1}{|c|}{ Jurisdicciones } & $\begin{array}{c}\text { Población } \\
\text { esclava (1861) }\end{array}$ & $\begin{array}{l}\text { Sevicia a } \\
\text { esclavos }\end{array}$ & \multicolumn{2}{c|}{$\begin{array}{c}\text { Delitos contra las personas } \\
\text { Jacobo de la } \\
\text { Pezuela }\end{array}$} \\
\hline Bejucal & & & $\begin{array}{c}\text { Conde Armildez } \\
\text { de Toledo }\end{array}$ \\
\hline Cárdenas & 7.052 & - & 68 & 80 \\
\hline Colón & 27.418 & 0 & 75 & 86 \\
\hline Cienfuegos & 33.699 & 0 & 59 & 38 \\
\hline Cuba & 16.985 & 0 & - & 53 \\
\hline Güines & 32.255 & - & - & 62 \\
\hline La Habana & 24.817 & - & 389 & 359 \\
\hline Matanzas & 29.013 & 1 & - & 116 \\
\hline Pinar del Río & 32.181 & - & - & 53 \\
\hline Sagua la Grande & 14.590 & - & 66 & 66 \\
\hline Villa Clara & 19.150 & 2 & 38 & 38 \\
\hline
\end{tabular}

(-) Sin referencia al hecho. Fuente: Jacobo de la Pezuela, Diccionario, tomos I, II, III y IV. Conde Armildez de Toledo, Noticias estadísticas de la isla de Cuba, en 1862.

De acuerdo con estas fuentes, en Cárdenas y Colón, las principales jurisdicciones azucareras, no se sancionó -o no ocurrió- ni un solo caso de sevicia. En cambio, registraron 31 y 34 casos de suicidios, respectivamente. Aunque la fuente no lo específica, es posible que un número importante de ellos correspondieran a esclavos y 
colonos asiáticos. Otros 22, 28 y 66 casos de suicidios fueron registrados en las jurisdicciones de Cienfuegos, Sagua la Grande y La Habana. ${ }^{64}$ Sorprende el número de "muertes casuales" o el hallazgo de restos humanos, fenómenos registrados dentro de los hechos que no constituyen delitos. De las primeras se contabilizaron en 1862, en los juzgados ordinarios, 283 casos, destacando por su número las jurisdicciones de Cárdenas (21), Colón (19), Matanzas (23) y Sagua La Grande (19), todas con una concentración importante de esclavos. ${ }^{65}$

De 1868 es el expediente criminal abierto al asiático Matías, colono del ingenio Surinam, en Güines, por el homicidio del negro Teodoro Ganga, del mismo ingenio. ${ }^{66}$ De igual fecha data otro expediente criminal contra el asiático Ignacio Azoy, por las heridas que infirió al trabajador de igual procedencia nombrado Cosme, ocasionándole la muerte. ${ }^{67}$ El 8 de agosto del mismo año fue fusilado en Sagua la Grande el moreno libre Agustín congo, por haber asesinado a un chino y a un negro en el depósito de cimarrones. Al mes siguiente, fueron ejecutados en el ingenio Ignacia, en presencia de la dotación, los colonos chinos Juan y Ricardo Marcos, por el homicidio perpetrado en un negro. El 27 de abril de 1870, corrieron idéntica suerte en Cárdenas los asiáticos Norberto, Francisco y Benigno. El primero de ellos por el homicidio perpetrado en la persona del negro Tranquilino. Los otros dos por la misma causa en la persona de Pío, también chino. Asimismo, en la mañana del 30 de octubre, en el ingenio Jicarita, partido de Bolondrón, en presencia de toda de la dotación, se fusilaron dos asiáticos condenado por el asesinato de un compañero suyo perpetrado meses atrás. La lista de colonos chinos ejecutados por decreto en 1870 continua con Rodrigo, el 9 de noviembre, por el homicidio que cometió en la persona de su paisano Diómenes, ambos pertenecientes a la dotación del ingenio San Antonio, en Cárdenas. ${ }^{68}$

A menudo, los conflictos involucraron a hombres y mujeres de la misma condición. Por ejemplo, en 1876 se instruyó en el Juzgado de primera instancia de Sagua, una causa contra el moreno Luis mandinga por las lesiones mortales que

\footnotetext{
${ }^{64}$ En Colón se registró ese año un caso de "sevicia a su esposa".

${ }^{65}$ Conde Armildez de Toledo, Noticias estadísticas de la isla de Cuba, en 1862. La fuente no indica las páginas.

${ }^{66}$ ANC, Misceláneas de Expedientes, Leg. 255, Ab, 1868.

${ }^{67}$ ANC, Misceláneas de Expedientes, Leg. 270, F, 1868.

${ }^{68}$ Manuel B. López, El garrote en Cuba, Imprenta "América Arias", La Habana, 1927, pp. 4849. Ibídem, pp. 49-51.
} 
ocasionó a la de su clase Martina lucumí. ${ }^{69}$ En esta línea de análisis, el siguiente pasaje sirve para reflexionar sobre problemas apenas abordados por la historiografía sobre el sistema esclavista y las relaciones raciales en Cuba: el machismo "de color" como expresión de la violencia intrarracial y la autoridad de la figura materna en las familias formadas por la población de ascendencia africana.

A fines de septiembre de 1863, las autoridades políticas del partido de Sabanilla, Matanzas, procedieron a investigar la muerte del negro Gonzalo criollo, esclavo de D. Gonzalo Alfonso. De las diligencias instruidas resulta que: la parda nombrada Domitila, querida de Gonzalo, marchó al río a lavar la ropa de este tardando en regresar al bohío más que lo que de costumbre tenía, por lo que Gonzalo se molestó con Domitila, arrojándole al suelo la ropa que traía lavada y pisoteándole esta, a cuya circunstancia llegó la madre de Gonzalo y le reprendió por este hecho, manifestándole al propio tiempo Domitila que al siguiente día iría a lavar la ropa que había pisoteado y tardaría en volver aún más que el anterior: a la represión de la madre y contestación de Domitila, Gonzalo sacó un cuchillo que tenía a la cintura y se infirió dos heridas en el pecho, atravesándoles una de ella el corazón, por lo que se desprende que Gonzalo sin duda alguna se privó de su existencia por celos con la relacionada Domitila.

De acuerdo con Jeff Forret, el reconocimiento de experiencias como esta no significa negar cualquier sentido de solidaridad entre la población esclava. De lo que se trata es de explorar los límites de esa cohesión y entender las formas en la que el sistema esclavista engendró situaciones de violencia extrema entre compañeros y familiares que compartían la misma condición. Por otro lado, un enfoque sistémico de estos comportamientos permite superar los juicios tradicionales sustentados en la supuesta violencia "innata" y "patológica" de la raza negra. Las fuentes consultadas no siempre contribuyen a esclarecer las motivaciones de los actos violentos registrados y menudo privilegian lo sensacional sobre lo mundano. También son parciales a la violencia perpetrada por esclavos en lugar de por esclavas. Por lo general, la violencia podía resultar con frecuencia por desacuerdos durante el trabajo y el juego, la propiedad, la familia y el honor. ${ }^{70}$

\footnotetext{
69 "Correspondencia”, Anales de la Real Academia de Ciencias Médicas, Físicas y Naturales de La Habana, vol. XIII, 1876, pp. 145.

${ }^{70}$ Jeff Forret, Slave against slave. Plantation Violence in the Old South, pp. 8-11.
} 
TABLA 25: CUBA. CASOS REGISTRADOS COMO SUICIDIOS, HOMICIDIOS Y MUERTES VIOLENTAS, 1879.

\begin{tabular}{|l|r|r|r|}
\hline \multicolumn{1}{|c|}{ Provincias } & \multicolumn{2}{|c|}{$\begin{array}{c}\text { No. de casos } \\
\text { registrados }\end{array}$} & \multicolumn{2}{c|}{$\begin{array}{c}\text { Tasa x } 100.000 \\
\text { habitantes }\end{array}$} & $\begin{array}{c}\text { \% sobre el total de } \\
\text { muertes registradas }\end{array}$ \\
\hline Pinar del Río & 40 & 21.5 & 0.9 \\
\hline La Habana & 132 & 31.2 & 0.9 \\
\hline Matanzas & 52 & 20.7 & 0.6 \\
\hline Santa Clara & 93 & 29.8 & 0.8 \\
\hline Puerto Príncipe & 3 & 5.4 & 0.2 \\
\hline Santiago de Cuba & 20 & 9.8 & 0.5 \\
\hline Cuba & 299 & 20.8 & 0.8 \\
\hline
\end{tabular}

Fuente: Dirección General de Hacienda, Población. Estudios estadístico- demográficos correspondientes a 1879.

La proporción de estas tres causas en la mortalidad general registrada en Matanzas es la tercera más baja de la isla, pero sube hasta $1.1 \%$ si consideramos solo la mortalidad esclava. El peso específico de la esclavitud matancera en la mortalidad por causas violentas es notable. Las 20 defunciones de esclavos registradas como suicidios u homicidios, representan el $38.5 \%$ del total de muertes por esas causas en la provincia, unos tres puntos porcentuales por encima de la proporción de la esclavitud en la estructura demográfica de la región. Asimismo, esas 20 muertes representan el $61 \%$ de las 33 defunciones por esas causas registrada entre toda la población cautiva de la isla, cuando la esclavitud matancera representaba entorno al 35\% del total. Desde una perspectiva de género, el $94 \%$ de las defunciones ocurridas en 1879 por el grupo de causas indicadas correspondió a varones. La fuente consultada no distingue si el entorno en el que se produjeron estas muertes era urbano o rural.

Por su posible relación con la violencia habría que considerar también otras dos causas de muerte registradas en 1879: las hemorragias y enfermedades del corazón. En Matanzas se registraron entonces 44 defunciones por la primera de esas causas, de las cuales 18 ocurrieron en esclavos, o sea, el 41\%. Mientras de las enfermedades del corazón se contabilizaron en toda la provincia 148 defunciones, 51 de ellas en esclavos, el 35\%. La proporción de la mortalidad por esta causa en la región considerada se eleva al 66\% si incluimos a la población libre "de color". Recordemos que este último grupo, dada la Ley Moret y los efectos de otras dinámicas de transición a la libertad, debe comprender un número no despreciable de antiguos esclavos.

La sobremortalidad de la población negra y mestiza es notable si tenemos en cuenta que ese $66 \%$ supera en unos 23 puntos porcentuales la proporción de esa 
población en la estructura demográfica de la provincia de acuerdo al censo de 1877. Asimismo, las 51 muertes de esclavos por enfermedades del corazón ocurridas en Matanzas corresponden al 47\% de las 109 registradas para ese grupo en toda la isla, mientras esta región concentraba en 1877, como mucho, el 35\% de toda la población esclava de la isla. Esto sugiere que las condiciones para que los esclavos desarrollaran alguna enfermedad del corazón era muy superior en Matanzas que en el resto del país.

\section{TABLA 26: CUBA. MORTALIDAD REGISTRADA POR ENFERMEDADES DEL CORAZÓN, 1879.}

\begin{tabular}{|l|r|r|r|}
\hline & $N^{\circ}$. de muertes & $\begin{array}{c}\mathrm{N}^{\mathrm{o}} \text {. de muertes en } \\
\text { negros y mestizos* }\end{array}$ & $\begin{array}{c}\mathrm{N}^{\mathrm{o}} \text {. de muertes en } \\
\text { esclavos. }\end{array}$ \\
\hline Pinar del Río & 55 & 23 & 9 \\
\hline La Habana & 311 & 148 & 35 \\
\hline Matanzas & 148 & 97 & 51 \\
\hline Santa Clara & 61 & 31 & 13 \\
\hline Puerto Príncipe & 11 & 4 & 0 \\
\hline Santiago de Cuba & 22 & 11 & 109 \\
\hline Cuba & 608 & 314 & 1 \\
\hline
\end{tabular}

(*) Incluye las defunciones de esclavos. Elaboración propia a partir de la información disponible en: Dirección General de Hacienda, Población. Estudios estadístico- demográficos correspondientes a 1879.

Cerca del 52\% de las defunciones registradas por enfermedades del corazón en 1879 correspondieron a personas "de color". Un tercio de estás fueron esclavos. Dicho de otra manera, el $18 \%$ de la población cubana que en el año indicado perdió la vida por alguna enfermedad del corazón eran esclavos. Esto, cuando el monto de la población cautiva de la isla ascendía solo al 13\% del total. Podemos comprender las condiciones que pudieron determinar tal diferencial si comparamos dos provincias con estructuras demográficas muy parecidas, pero realidades socioeconómicas muy diferentes: Matanzas y Santiago de Cuba. Al finalizar la década de 1870, en ambas regiones la población negra y mestiza sumaban el $43 \%$ del total. ${ }^{71}$ Pero, mientras en Matanzas la proporción de la mortalidad negra y mestiza por enfermedades del corazón sobre el total de defunciones registradas por esta causa se elevó al 66\% -muy superior a la media nacional y unos 23 puntos porcentuales por encima de la proporción de esa población en la estructura demográfica de la provincia- en Santiago de Cuba la mitad de las muertes registradas por esta causa fueron en personas “de color", para una sobremortalidad de 7 puntos porcentuales respecto al peso de este grupo en la población de la provincia. De

\footnotetext{
${ }^{71}$ La población total censada de Matanzas en 1877 superó a la de Santiago de Cuba en 47.323
} habitantes. 
modo que, para la población no blanca, la probabilidad de morir por una enfermedad del corazón fue muy superior en Matanzas. Que la dinámica de la esclavitud condicionó esta desventaja, puede advertirse si consideramos que, en Matanzas, como lo muestra el gráfico 24 , la proporción de la mortalidad esclava por enfermedades del corazón es muy superior a la de Santiago de Cuba.

Entre los principales factores de riesgo que pudieron condicionar la sobremortalidad de la población esclava por enfermedades del corazón se encuentra la hipertensión arterial, el colesterol elevado o el consumo de alcohol. Estos dos últimos se explican por el hecho de que, como hemos visto, la dieta regular de los esclavos marginó alimentos saludables para el corazón como verduras y frutas, y sí incluyó otros perjudiciales por su alto contenido de grasas, sodio y colesterol, además del consumo regular de alcohol que hacía esta población. Por otro lado, investigaciones contemporáneas han profundizado en el impacto de los factores psicosociales en las enfermedades cardiovasculares. La exposición cotidiana a situaciones de estrés agudo puede aumentar la frecuencia cardíaca y la presión arterial, también la formación de coágulos en sangre, factores que pueden precipitar enfermedades cardiovasculares como el infarto agudo de miocardio o la muerte súbita. 
GRÁFICO 24: CUBA. CORRELACIÓN PORCENTUAL ENTRE ESCLAVITUD Y MORTALIDAD POR ENFERMEDADES DEL CORAZÓN, 1879.

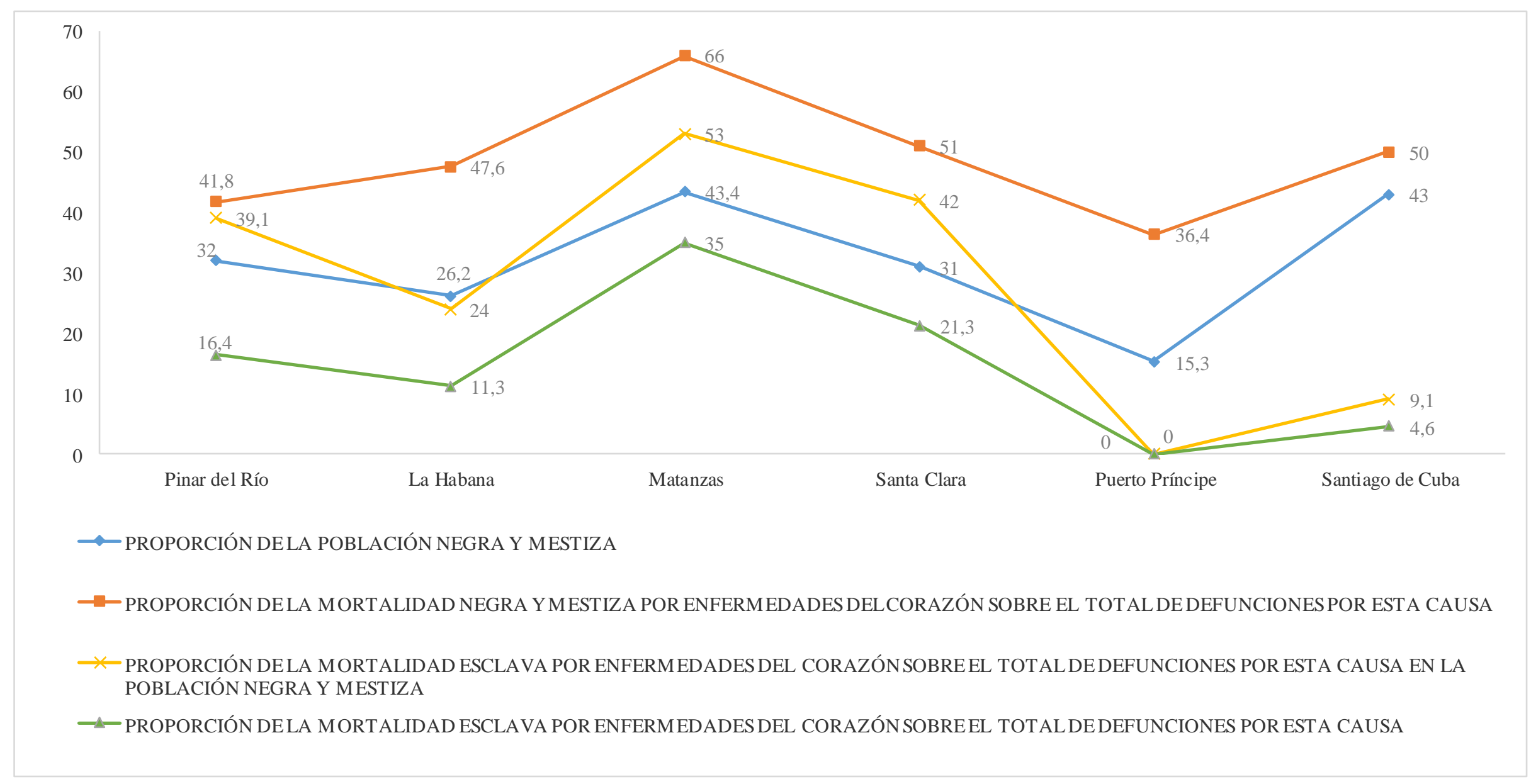

Elaboración propia a partir de la información disponible en: Dirección General de Hacienda, Población. Estudios estadístico- demográficos correspondientes a 1879. 


\section{MORIR, A PESAR DE NOSOTROS Y CONTRA ELLOS}

Una de las expresiones más comunes de la violencia que caracterizó a la esclavitud atlántica, y en particular al régimen desarrollado en Cuba, fue el suicidio. ${ }^{72}$ Numerosos testimonios refieren que a lo largo del siglo XIX era común encontrase negros ahorcados o ahogados en distintos lugares de la isla. Una de estas traumáticas experiencias marcó al joven José Martí, que la plasmó en su poema El rayo surca, sangriento:

\footnotetext{
El rayo surca, sangriento,

El lóbrego nubarrón:

Echa el barco, ciento a ciento,

Los negros por el portón.

El viento, fiero, quebraba

Los almácigos copudos;

Andaba la hilera, andaba,

De los esclavos desnudos.

El temporal sacudía

Los barracones henchidos:

Una madre con su cría

Pasaba, dando alaridos.

Rojo, como en el desierto,

Salió el sol al horizonte:

Y alumbró a un esclavo muerto,
}

\footnotetext{
${ }^{72}$ Este ha sido un tema recurrente en la historiografía cubana. Ver, por ejemplo: Fernando Ortiz, "Il suicidio tra i negri", Archivio de Psichiatria, Medicina Legale ed Antropologia Criminale, vol. XXVII, fasc. III. 1906. Artículo que amplió en Los negros esclavos (1916). El análisis más completo en: Louis A. Pérez Jr., To Die in Cuba: Suicide and Society, The University of North Carolina Press, Chapel Hill, 2005. Otras aproximaciones en: María Poumier Taquechel, "El suicidio esclavo en Cuba en los años 1840", Anuario de Estudios Americanos, vol. 43, 1986, pp. 69-86. Manuel Barcia, Seeds of Insurrection. Domination and Resistance on Western Cuban Plantations, 1808-1848; "Going back home': slave suicide in nineteenth century Cuba", Millars, vol. 42, Nº 1, 2017, pp. 49-73. Un examen más global en: Miguel Ángel Puig-Samper, "El suicidio esclavo en el Mundo Atlántico", en: Consuelo Naranjo (ed.), Esclavitud y diferencia racial en el Caribe hispano, Ediciones Doce Calles, Madrid, 2016, pp. 71-88. Un abordaje diferente del fenómeno en: Pedro Marqués de Armas, Ciencia y poder en Cuba. Racismo, homofobia, nación (1790-1970), Editorial Verbum, Madrid, 2014. Pedro Marqués de Armas, "Exclusiones post mortem. Esclavitud, suicidio y derecho de sepultura", Revista Tunecina de Estudios Hispánicos, $\mathrm{N}^{\circ}$. 2, 2015, pp. 49-63. Un estudio con referencias a Cuba, en: Elsa Malvido, "El suicidio entre los esclavos negros en el Caribe en general y en el francés en particular. Una manera de evasión considerada enfermedad, siglos XVII y XVIII", Trace, $\mathrm{N}^{\circ}$. 58, 2010, pp. 113-124.
} 
Colgado a un seibo del monte.

Un niño lo vio: tembló

De pasión por los que gimen:

¡Y, al pie del muerto, juró

lavar con su vida el crimen! ${ }^{73}$

En los registros de entierros revisados para esta investigación encontramos con frecuencia esclavos ahogados. Por ejemplo, tenemos el caso de Josefa Gangá, cuyo cadáver hallaron en un pozo de un sitio de Juan de Dios Rodríguez, su propietario. ${ }^{74}$ Fue también el caso del moreno Gregorio Días, de 28 años, esclavo de José Coll, que apareció ahogado en la margen del barrio del teatro del rio Yumurí en septiembre de 1868. El mes anterior, fue encontrado ahogado en el río San Juan el pardo Alfredo Aguirre, de 12 años. ${ }^{75}$ Asimismo, en 1876, el Juzgado de primera instancia de Pinar del Río asumió una investigación para averiguar las circunstancias en la que se produjo la muerte de la morena Isabel Lucumí, cuyo cadáver fue hallado en el río San Sebastián, partido de San Juan y Martínez. Vale decir que, dada la dificultad para precisar los pormenores de este tipo de muerte cuando fue registrada, pudo estar asociada no solo con suicidios sino además con accidentes y muertes violentas.

De acuerdo con un informe de la Audiencia Pretorial de La Habana, entre 1839 y 1845 "se mataron a sí mismos" 103 blancos, 54 libres "de color" y 1.076 esclavos, dudándose si se suicidaron también otros 58 de los primeros, 23 de los segundos y 238 de los últimos. Números sorprendentes a pesar de que "nadie ignora que procuran ocultarse esos hechos para evitar las indagaciones de las autoridad y la responsabilidad consiguiente á los dueños ó dependientes de las fincas á cuya dotación pertenecen". ${ }^{76} \mathrm{La}$ proporción en cada grupo, calculada en relación a la población del Departamento Occidental, que es a la que corresponde este informe, es de 5 suicidios por cada diez mil habitantes blancos, 9 en los "de color" libres y 36 en los esclavos. La tendencia suicida entre los esclavos estaba además en ascenso, teniendo en cuenta que aumentó en razón de un 50\% si se compara el bienio 1844-1845 con el de 1840-1841. Por lo cual, el fiscal

\footnotetext{
73 "El rayo surca, sangriento" en: José Martí, Obras completas, vol. 16, Editorial de Ciencias Sociales, La Habana, 1991, pp. 106-107.

${ }^{74}$ Diligencias sumarias sobre haberse encontrada ahogada dentro del pozo del sitio de D. Juan de Dios Rodríguez la negra Josefa Gangá su esclava, ANC, Gobierno Superior Civil, Leg. 938, exp. 33110, 1838.

${ }^{75}$ SSDA, consultado en https://www.slavesocieties.org/.

${ }^{76}$ Expediente general de esclavitud: Sobre las causas que influyen en los frecuentes suicidios de esclavos, AHN, Ultramar, Leg. 3548, Nº. 3, 1847-1852.
} 
dedujo que el suicido no era una propensión inherente a la raza "de color" y que sus causas debían averiguarse en el régimen de servidumbre al que estaban sometidos. No obstante, reconoció que la esclavitud era una institución necesaria para el desarrollo de la isla y que por tanto era necesario desarrollar los medios posibles para atenuar los suicidios entre los trabajadores sin alterar el orden social existente. Con tal fin, algunos plantadores propusieron la combustión del cadáver en presencia de sus compañeros. Oficialmente, el gobierno acordó medidas menos dramáticas, como reforzar la educación religiosa de los esclavos en las fincas y un mayor control del trato que recibían. ${ }^{77}$ Con el arribo de los colonos chinos proliferaron las conductas autodestructivas en la población cubana.

Si bien el suicidio esclavo, sobre todo la oleada que se registró en la década de 1840, despertó en las autoridades coloniales gran preocupación, no es posible deducir que la mortalidad por esta causa llegara a representar un problema igual de preocupante para los propietarios. Manuel Barcia sostiene que "los suicidios eran a menudo una forma de resistencia que afectaba tanto la imagen paternalista del sistema católico español y la prosperidad económica de propietarios de plantaciones". ${ }^{78}$ Podemos convenir en lo primero, pero lo segundo amerita un estudio en mayor profundidad que los realizados hasta la fecha. Difícilmente, la mortalidad por esta causa entre la población esclava pudo poner en jaque un sistema surtido hasta la década de 1860 con miles de nuevos brazos todos los años. En las dos últimas décadas del sistema, aunque las tasas seguían siendo particularmente elevadas, no alcanzaron los niveles de mediados del siglo XIX. En cualquier caso, existen pocas evidencias de que el suicidio fuera una preocupación económica fundamental para los plantadores.

Siendo demasiado arriesgado reconocer que la "vocación" suicida de los trabajadores se debía a la dinámica interna de la esclavitud, observadores contemporáneos focalizaron su valoración en factores culturales. Ramón Piña apuntó que los frecuentes casos de suicidios entre los esclavos de las fincas rurales emanaban de una firme creencia en que estrangulándose resucitarían en su país natal. ${ }^{79}$ Tal

\footnotetext{
${ }^{77}$ Ídem.

78 Manuel Barcia, Seeds of Insurrection. Domination and Resistance on Western Cuban Plantations, 1808-1848.

${ }^{79}$ De acuerdo con los datos presentados por la Audiencia Pretorial de La Habana en la Gaceta Oficial del 3 de enero de 1854, en 1853 ocurrieron 162 suicidios en esa jurisdicción y otras 14 inmolaciones en la tropa. Piña sostiene que no pudo encontrar información sobre el suicidio en la isla con la facilidad que hubiera deseado. Ramón Piña, Topografía médica de la isla de Cuba, p. 107.
} 
percepción ha marcado gran parte de los estudios realizados sobre el suicidio en la colonia cubana. Fernando Ortiz destacó el hecho de que los esclavos y chinos utilizaran el suicidio como un "medio de emanciparse del amo", una particular forma de resistencia de la población trabajadora al sistema, determinada igualmente por la creencia de que a través de la muerte podían retornar a su lugar de origen. ${ }^{80}$ Sin desconocer la importancia que los factores culturales tuvieron en las "muertes voluntarias" de esclavos africanos y colonos chinos, es posible que muchos de los casos así registrados en realidad fueran el resultado directo de agresiones externas.

El político español liberal Rafael María de Labra, ironizando sobre el ridículo número de casos de sevicias denunciados y el absoluto desconocimiento que de este fenómeno se tenía en el Congreso español, apuntó que, "para la estadística oficial apenas si ocurre en Cuba alguno que otro atropello de la desconocida persona del negro", y que en 1862 solo se registraron 26 casos de sevicias mientras los de suicidios subieron a $346 .{ }^{81}$ Vistas las cosas, no pocos de los últimos pudieron ser en realidad de los primeros. Entre los delitos contra las personas sancionados en 1862 en la jurisdicción de Matanzas estaban solo 2 casos de sevicias y 30 de suicidios, mientras que otras 23 muertes fueron consideradas causales y por tanto fuera de cualquier responsabilidad penal. ${ }^{82}$ Siempre que las condiciones del hecho conspiraran en favor del sujeto homicida, está claro que este optó por ocultar a las autoridades el verdadero motivo de un cuerpo menos bajo su dominio. El subregistro de los suicidios en las estadísticas oficiales pudo estar determinado además por la confusión con accidentes u otras causas aparentes de muerte. No siempre el deseo personal de acometer el hecho era manifiesto. Ante el rechazo social que el fenómeno generaba, es posible que muchos cuidaran de no dejar evidencias de su trágica decisión.

De los 346 suicidios registrados en 1862, el 50\% correspondieron a colonos chinos, el 37,3\% a esclavos y solo el 12,7\% a personas blancas. Aunque no se indica en las fuentes consultadas, la mayor parte de los suicidios registrados se produjeron en zonas rurales. Para José Antonio Saco, el elevado índice de suicidios entre los chinos revela la condición moral de una población que consideró "corrompida" y "perversa" y

\footnotetext{
${ }^{80}$ Para un resumen de las ideas que sostuvo el destacado etnólogo cubano sobre el suicidio en Cuba y otras visiones de estudiosos cubanos sobre el tema, ver el dossier compilado por: Pedro Marqués de Armas, "Suicidio ¿tradición nacional?", Encuentro de la Cultura Cubana, No. 4445, verano-otoño, 2007, pp. 120-177.

${ }^{81}$ Rafael María de Labra, La abolición de la esclavitud en el orden económico, Imprenta de J. Noguera, Madrid, 1873, pp. 18-19.

${ }^{82}$ Jacobo de la Pezuela, Diccionario, t. IV, pp. 30-31.
} 
"una de las plagas más terribles que sobre Cuba han caído". Criterio igual de racista emite respecto a la población de ascendencia africana que, por su elevada tasa de criminalidad, calificó como una influencia "contagiosa y maléfica". ${ }^{3}$ Tales observaciones le sirven para reafirmar su proyecto de colonización blanca como premisa para la conservación del dominio español. ${ }^{84}$

En 1879 se reportaron 101 muertes por suicidios en toda la isla, para una tasa aproximada de 7 x 100.000 habitantes. De ellas, 91 correspondieron a hombres y solo 10 a mujeres. El 19\% de la mortalidad registrada por esta causa en 1879 correspondió a esclavos. En Matanzas, esa relación se eleva hasta el $44 \%$. La tasa de suicidios de esclavos registradas en la isla en 1879 es de 11 x 100.000, mientras que en Matanzas asciende a 17 x 100.000. El hecho de que los esclavos sigan representando en esta fecha un porciento elevado de los suicidios registrados, pone en cuestión la idea de la propensión de los esclavos recién importados a cometer suicidio, toda vez que desde fines de la década anterior se suprimió la trata en la isla. Esto sugiere que más que en los factores culturales importados, el énfasis del análisis debe situarse en la naturaleza del sistema esclavista. Al parecer, la transición a la libertad obró como un poderoso factor de contención de las prácticas autodestructivas en este grupo. Entre los suicidios de la población blanca se incluyen los cometidos por colonos chinos, que debieron representar el mayor número de estos.

TABLA 27: CUBA. MUERTES REGISTRADAS POR SUICIDIOS, 1879.

\begin{tabular}{|l|r|r|r|r|r|r|}
\hline & $\begin{array}{c}\text { Pinar del } \\
\text { Río }\end{array}$ & La Habana & Matanzas & $\begin{array}{c}\text { Santa } \\
\text { Clara }\end{array}$ & \multicolumn{1}{c|}{$\begin{array}{c}\text { Puerto } \\
\text { Príncipe }\end{array}$} & $\begin{array}{c}\text { Santiago de } \\
\text { Cuba }\end{array}$ \\
\hline Varones & 8 & 41 & 26 & 10 & 2 & 4 \\
\hline Hembras & 2 & 5 & 1 & 2 & 0 & 0 \\
\hline Total & 10 & 46 & 27 & 12 & 2 & 4 \\
\hline Esclavos & 5 & 2 & 12 & 0 & 0 & 0 \\
\hline $\begin{array}{l}\text { Libres “de } \\
\text { color" }\end{array}$ & 0 & 4 & 0 & 11 & 1 & 2 \\
\hline Blancos & 5 & 40 & 15 & 1 & 1 & 2 \\
\hline
\end{tabular}

Fuente: Dirección General de Hacienda, Población. Estudios estadístico- demográficos correspondientes a 1879.

Un artículo publicado en 2007 por Saulo Veiga y Ana María Galdini, analiza el suicidio esclavo en Sao Paulo entre 1870 y 1888, a partir de la información existente en

\footnotetext{
${ }^{83}$ José Antonio Saco, "La estadística criminal de Cuba en 1862", p. 143.

${ }^{84}$ José Antonio Saco, "La estadística criminal de Cuba en 1862", p. 147.
} 
la Gazeta de Campinas. El balance historiográfico que acompaña su estudio, reconoce los aportes que al tema en cuestión han realizado para Brasil Roger Bastide, José Alípio Goulart, Clóvis Moura, Renato Pinto Venancio, Mary Karasch y Jackson Ferreira, entre otros. ${ }^{85}$ Los enfoques de estos autores son similares a los desarrollados por la historiografía sobre Cuba. Bastide, Goulart y Moura enfatizaron en el suicidio esclavo como expresión de protesta contra el sistema y nostalgia hacia la tierra natal. Banzo fue el terminó que definió en el caso de la colonia portuguesa, la melancolía de los esclavos y su creencia en el retorno espiritual a África. En su libro Da Fuga ao Suicídio, Goulart consideró esa práctica como "la más trágica de las reacciones a la violencia del cautiverio". Para la población cautiva, los suicidios, homicidios y fugas conforman una triada de reacciones habituales ante la impotencia de modificar su condición." 86

Renato Pinto Venancio, en un artículo de 1990 sobre el suicidio de esclavos en la ciudad Rio de Janeiro en las últimas décadas del sistema esclavita, correlaciona el fin del régimen con el número global de suicidios registrados. Este autor usa los datos compilados por el jurista Francisco Viveiros de Castro en 1894, un trabajo que también utilizó Bastide en 1943. Este autor sugiere que el porcentaje de suicidios de los esclavos pudo doblar el de la población libre, siendo la mayoría de los motivos ignorados. Veiga y Galdini destacan el aporte de Mary Karasch por su originalidad. Esta investigadora identificó como métodos más comunes para los suicidios el ahogamiento, ahorcamiento o estrangulamiento y el uso de armas de fuego o blancas. La rebeldía contra el sistema y la respuesta inmediata al maltrato, fueron las principales motivaciones para el suicidio. También pudieron influir en esta decisión trastornos mentales y el banzo. Sobre este último aspecto, la autora de Slave life in Rio de Janeiro, 1808-1850, sugiere conexiones entre las creencias religiosas de las etnias más presentes entonces en esa región, como los congos, y el uso de métodos de suicidio como el ahorcamiento o el ahogamiento que facilitarían la pretendida metempsícosis de regreso a África. Esta conclusión coincide con los resultados de la pesquisa que realizaron Veiga y Galdini. ${ }^{87}$ La manera en la que esclavos y libres se suicidaban difiere fundamentalmente en el uso de armas de fuegos,

\footnotetext{
${ }^{85}$ Saulo Veiga Oliveira y Ana María Galdini Raimundo Oda, "O suicídio de escravos em São Paulo nas últimas duas décadas da escravidão", História, Ciências, Saúde - Manguinhos, vol. 15, No. 2, abril-junio, 2008, pp. 371-388.

${ }^{86}$ José Alípio Goulart, Da Fuga ao Suicídio: aspectos de rebeldia do escravo no Brasil, Conquista, Río de Janeiro, 1972.

${ }^{87}$ Saulo Veiga Oliveira y Ana María Galdini Raimundo Oda, "O suicídio de escravos em São Paulo nas últimas duas décadas da escravidão", pp. 371-388. Mary Karasch, Slave life in Rio de Janeiro, 1808-1850, Princeton University Press, Princeton, 1987.
} 
un método preferido por los segundos y menos al alcance de los primeros. Esto también fue así para la población cubana cautiva, sobre todo en áreas rurales. Además, el estrangulamiento y ahogamiento podían encubrirse con más facilidad.

En este punto, Jackson Ferreira, en un excelente artículo, ${ }^{88}$ pone en cuestión el fundamento religioso del problema, que ha marcado una línea dominante en los estudios sobre el suicidio esclavo en Brasil, y también en Cuba, sugiriendo la frecuencia con la que pudieron enmascarar homicidios o sevicias. El suicidio se explicó con regularidad a partir del carácter moralmente viciado de la población cautiva, y frente a la rotundidad de este juicio en la mentalidad de la época, pocas dudas cabían.

A la pregunta de si en la provincia de Sao Paulo los esclavos se mataban más que la población libre, Veiga y Galdini responden afirmativamente. El 66\% de esclavos que aparecen en las noticias de suicidios examinadas entre 1871 y 1879 supera ampliamente la proporción de este grupo en la población estimada en el censo de 1872, aproximadamente el 19\%. En la década siguiente, el porcentaje de esclavos suicidas dentro del total de casos noticiados se redujo significativamente, aunque todavía supera a la proporción de este grupo en la estructura demográfica de la provincia. Considerando los casos consumados que aparecen en la Gazeta, las tasas medias anuales de suicidio entre 1870 y 1879 serían 3,2 por cien mil entre los esclavos y 0,3 por cien mil entre los libres, mientras que entre 1880 y 1887 fue de 2,8 por cien mil entre los primeros y 0,8 entre los segundos. De acuerdo con las estadísticas oficiales, en el primer período las tasas serían de 6 suicidios por cien mil esclavos y 1,6 por cien mil libres, mientras que para la segunda etapa se registraron 4,6 suicidios por cien mil esclavos y 0,3 por cien mil personas libres. ${ }^{89}$ Para ambos grupos el suicidio fue un fenómeno fundamentalmente masculino. Diverso factores, como la progresiva reducción de la población cautiva, la radicalización del movimiento abolicionista y la perspectiva real de obtener la libertad, pudieron determinar la disminución en el sentido que apunta la documentación oficial revisada por Veiga y Galdini, verificada en otras regiones de Brasil como Bahía, aunque los autores no descartan, como antes lo hicieron Roger Bastide y Kátia Mattoso, un subregistro importante del fenómeno en los años previos a la abolición de la esclavitud..$^{90}$ Con todo, los números de Sao Paulo están muy

\footnotetext{
${ }^{88}$ Jackson Ferreira, "Por hoje se acaba a lida": suicídio escravo na Bahía (1850-1888)", AfroÁsia, vol. 31, 2004, pp. 197-234.

${ }^{89}$ Saulo Veiga Oliveira y Ana María Galdini Raimundo Oda, "O suicídio de escravos em São Paulo nas últimas duas décadas da escravidão", pp. 379-385.

${ }^{90}$ Ídem.
} 
lejos de la tasa que hemos estimado para Matanzas en 1879. Los 12 suicidios registrados para la provincia cubana representan, considerando los 70.390 esclavos censados allí en 1877, una alarmante tasa de 17,1 suicidios por cien mil.

También en Cuba, diversos factores pudieron distorsionar la veracidad de la información oficial. Debido a los costos de la investigación y sus implicaciones para la dinámica interna de la plantación, es probable que los propietarios no solo tuvieran interés en ocultar aquellos delitos de trágico final de los que fueran responsables directos, sino también algunos sucesos ocurridos entre miembros de su dotación. Que el sujeto suicida fuera considerado un pecador sin derecho a un entierro en suelo sagrado, ${ }^{91}$ también pudo determinar que muchos casos no trascendieran. Además, concordamos con Saulo Veiga y Ana María Galdini en que el uso de estos sucesos como argumento abolicionista pudo influir en la distorsión de la información oficial. Con seguridad, el subregistro fue más agudo en los conatos de suicidios.

Al margen de los estudios realizados para Cuba, muchos aspectos sobre el suicidio en la colonia cubana merecen ser revisados. Por ejemplo, importa profundizar en el conocimiento de su distribución según sexo, medios usados y etnias implicadas. Sabemos que, entre los africanos, los lucumíes eran muy propensos a cometer suicidio, pero es algo que la historiografía no ha explicado con precisión. Interesante sería establecer conexiones entre el suicidio y los procesos de fractura de familias esclavas.

Desde mediados del siglo XIX, varios estudios establecen una fuerte relación entre el suicidio y la frustración asociada a estados "patológicos" crónicos, físicos y espirituales. Comportamientos muy frecuentes bajo un régimen de servidumbre como el desarrollado en la isla. Desde este punto de vista, el suicidio es la acción elegida para quebrar una angustia devenida insoportable. Esto explica el hecho de que el instinto suicida se desarrolle con el curso de los años. Fuel el caso del sexagenario Bernardo gangá, esclavo del ingenio La Luisa, quien decidió estrangularse un día de diciembre de 1865, acto que acometió luego de haberle confesado a varios compañeros estar cansado de una "mala vida" esperando una "libertad que no llega". 92 Demográficamente hablando, la desesperanza de este sujeto no era infundada si consideramos que un $5 \%$ de

\footnotetext{
91 Pedro Marqués de Armas, "Exclusiones post mortem. Esclavitud, suicidio y derecho de sepultura", pp. 49-63

${ }^{92}$ ANC, Misceláneas de Expedientes, Leg. 1697, Ah, 1865.
} 
la población esclava de la jurisdicción de Matanzas en 1862, unas 1.718 personas, tenía más de 60 años, entre ellos 12 esclavos que contaban con un siglo a sus espaldas. ${ }^{93}$

A mediados de la década de 1840, La Luisa y otros ingenios de los partidos de Macurijes y Cimarrones fueron el epicentro de una importante conspiración de la gente “de color” contra el sistema. Un tal Bernardo gangá aparece entre los “instigadores” del conato de sublevación que se verificó en el ingenio San Miguel, propiedad de Miguel Azopardo, también ubicado en Macurijes. ${ }^{94}$ De tratarse de la misma persona, probablemente, algo de la excitante trama tejida entonces por los de su clase y de la fuerte represión desatada por las autoridades permanecía en la memoria del taita Bernardo gangá antes de evadir por asfixia la envejecida servidumbre de la colonia cubana. Es sintomático que se verificara su muerte un día de diciembre, toda vez que para los gangá es el mes de Yebbé, su santo más venerado, dueño de las enfermedades y de la tierra, Babalú Ayé para los yorubas y San Lázaro de acuerdo al sincretismo con la religión católica. ${ }^{95}$ En definitiva, según reza un proverbio yoruba sobre la muerte, "el Mundo es un mercado (que visitamos), el Otro Mundo es el hogar. (Aiyé l’ôjà, ôrùn n`ilé)". 96

\footnotetext{
${ }^{93}$ Jacobo de la Pezuela, Diccionario, t. IV, p. 25.

${ }^{94}$ Un negro esclavo de nombre Bernardo gangá aparece entre los condenados. La sanción que se le impuso como "instigador" fue a diez años de presidio con retención, pero en la isla. Colección de los fallos pronunciados por una sección de la Comisión militar establecida en la ciudad de Matanzas para conocer de la causa de conspiración de la gente de color, Imprenta del Gobierno, Matanzas, 1844.

95 Alessandra Basso Ortiz, Los Gangá en Cuba: la comunidad de Matanzas, Fundación Fernando Ortiz, La Habana, 2005.

${ }^{96}$ Rogelio A. Martínez Furé, El caballo de la palabra. Proverbios y enigmas africanos, Editorial Arte y Literatura, La Habana, 2015, p. 70.
} 
TABLA 28: CUBA. ESTADÍSTICA CRIMINAL SELECCIONADA DE LA POBLACIÓN CHINA, 1859-1875.

\begin{tabular}{|c|c|c|c|c|c|c|c|c|}
\hline Años & $\begin{array}{l}\text { Homicidios y } \\
\text { (conato de } \\
\text { ídem) }\end{array}$ & $\begin{array}{l}\text { Suicidios y } \\
\text { (conato de } \\
\text { ídem) }\end{array}$ & $\begin{array}{l}\text { Lesiones } \\
\text { graves y } \\
\text { (leves) }\end{array}$ & Golpes y riñas & $\begin{array}{l}\text { Portación de } \\
\text { armas } \\
\text { prohibidas }\end{array}$ & Otros & $\begin{array}{c}\mathrm{N}^{\mathrm{o}} \text {. de personas } \\
\text { delincuentes }\end{array}$ & $\begin{array}{c}\text { Tasa de } \\
\text { criminalidad x } \\
1000 \text { hab. }\end{array}$ \\
\hline 1859 & 31 & 212 & & & & & 418 & 12,1 \\
\hline 1860 & $28(1)$ & $142(14)$ & $3(25)$ & 2 & - & 21 & 398 & 10,8 \\
\hline 1861 & $29(1)$ & $158(13)$ & $2(24)$ & 5 & - & 26 & 430 & 10,8 \\
\hline 1862 & $37(1)$ & $167(2)$ & $3(26)$ & 7 & 1 & 52 & 465 & 13,7 \\
\hline 1863 & $43(2)$ & $122(3)$ & $2(51)$ & - & 1 & 61 & 556 & 16,6 \\
\hline 1864 & 24 & $85(7)$ & $3(48)$ & 3 & 1 & 64 & 407 & 11,9 \\
\hline 1866 & & & & & & & 355 & 7,6 \\
\hline 1867 & & & & & & & 467 & 8,2 \\
\hline 1868 & $35(1)$ & $127(10)$ & $1(43)$ & 16 & - & 106 & 515 & 8,7 \\
\hline 1871 & 6 & $35(7)$ & $67 *$ & - & - & 106 & 242 & 4,7 \\
\hline 1872 & $8(1)$ & 52 & $3(40)$ & - & - & 113 & 252 & 4,3 \\
\hline 1875 & $12(9)$ & $20(2)$ & $7(10)$ & - & - & 115 & 214 & 4,4 \\
\hline
\end{tabular}

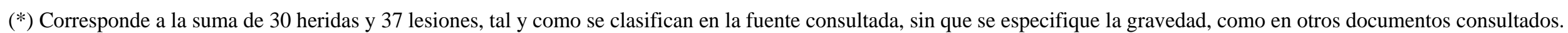
Elaboración propia a partir de diversas fuentes. 
No menos frecuente fueron las expresiones de rebeldía y violencia contra los poderes establecidos en la plantación. A menudo, los trabajadores no aceptaron de forma pasiva su realidad, y ante la posibilidad de ser atropellados, prefirieron tomarse la justicia por su mano, acto que muchos pagaron con la pena capital. ${ }^{97}$

En la mañana del 9 de septiembre de 1858, Diego Nagle, esclavo criollo, salió, junto a parte de la dotación de la vega propiedad de Lorenzo García, a los trabajos de campo a los que estaba dedicado. En medio de la faena, el mayoral de la finca, Julián Martínez, se arrojó sobre él, agarrándole por un brazo con el fin de someterlo a castigo. No pudiendo el mayoral derribar al esclavo, llamó a gritos a cuatro negros de la finca para que le ayudaran. Nagle entonces se defendió, y, tirando de un cuchillo, le ocasionó a Martínez una herida en el cuello. Posteriormente huyó internándose en un platanal cercano. Con el fin de apresarlo, el mayoral montó en un mulo y en el trayecto muere. Estos hechos motivaron una causa criminal contra Nagle por homicidio. ${ }^{98}$

Juan Pérez de la Riva, en su artículo "La situación legal del culí en Cuba", cita varios sucesos en los que trabajadores chinos arremetieron contra el mayoral o contramayoral de la finca en la que estaban contratados, llegando en algunos casos a asesinarlo. Fue el caso, por ejemplo, del asesinato perpetrado el 21 de enero de 1868 por ocho asiáticos pertenecientes al ingenio San Francisco, partido de Bolondrón, Matanzas, en la persona del negro criollo Aniceto, contramayoral de la finca. De la sumaria instruida por este caso, se conoce que los trabajadores chinos denunciaron sistemáticos agravios sufridos en el ingenio, tanto en lo referido a la alimentación como a los castigos corporales que recibían. ${ }^{99}$ Coincidimos con Pérez de la Riva al considerar la "trágica monotonía" con la que hechos como este se repitieron desde la entrada de los primeros colonos chinos. En igual año y en el mismo partido, otro asiático terminó con

\footnotetext{
${ }^{97}$ En medio de este escenario sorprende la publicación de un cubano, que no reveló su nombre, contra la pena capital. La lectura del texto hace pensar que no estaba proyectado desde la realidad cubana, donde ese castigo entraría en auge producto de la necesidad de controlar a una creciente población considerada potencialmente peligrosa. Imbuido del pensamiento utilitarista de Jeremy Bentham y su reforma penitenciaria, el autor anónimo argumentó por qué consideraba la reclusión como "el medio represivo más justo". Ver: Examen del derecho de vida y muerte, egercido (sic) por los gobiernos, Imprenta de Ignacio Estivill, Barcelona, 1838.

98 "Causa criminal contra el negro criollo, esclavo, Diego Nagle, por homicidio al mayoral D. Julián Martínez", Revista de Jurisprudencia, Administración y Comercio, Imprenta del Tiempo, Año IV, t. I, La Habana, 1859, pp. 384-400.

${ }^{99}$ Juan Pérez de la Riva, "La situación legal del culí en Cuba", en: Juan Pérez de la Riva, El barracón y otros ensayos, p. 214.
} 
la vida de un negro que ejercía también como contramayoral del ingenio Feliz, por lo que fue condenado a garrote vil y ejecutado en dicha finca el 8 de agosto. ${ }^{100}$

Manuel Barcia analizó el papel activo de los contramayorales negros y mestizos en el engranaje disciplinario que regía las dinámicas productivas en la plantación. En su artículo comenta casos de homicidios perpetrados en la figura de contramayorales por trabajadores chinos o esclavos. ${ }^{101}$ Aunque la controversial figura del mayoral pudo valerse de disímiles argumentos para coordinar la producción, no rehusó a la violencia física. Numerosos testimonios revelan la tragedia desencadenada por el ejercicio de la fuerza de otrora esclavos, hombres libres "de color", e incluso colonos asiáticos. En un texto, por excepcional varias veces citados en este capítulo, se recogen varios de esos casos. Antes hemos comentado el suceso ocurrido en 1868 en el ingenio Feliz y en 1870 en el ingenio La Julia. Poco tiempo después, esta última finca repitió como escenario de otro homicidio perpetrado en la persona del contramayoral por otro negro, por el que fue condenado a pena capital y ejecutado el 11 de mayo de 1875. A estos podemos sumar el "horroroso asesinato" cometido por los morenos Luis, Mateo, Eduardo, Antonio y Joaquín, el pardo Julián y el asiático Calixto, en la persona de Tranquilino Rodríguez, mayoral del ingenio Cristo, en Bejucal, del cual eran trabajadores, suceso por el cual fueron ejecutados el 23 de enero de $1876 .{ }^{102}$

El año 1870 fue particularmente incisivo en cuanto a penas capitales a colonos chinos. El 9 de febrero se ejecutaron en el ingenio Julia, jurisdicción de Matanzas, seis chinos acusados del asesinato del mayoral de esa finca. El 29 de abril, se llevó acabo en el potrero San Francisco, de la misma jurisdicción, la ejecución del asiático Antolín, condenado por el homicidio de Mariano, trabajador de igual procedencia que fungía como mayoral de la finca. El 23 de noviembre se procedió al fusilamiento de otros diez chinos pertenecientes a la dotación del ingenio Álava, condenados por el homicidio de Federico Carballo, mayoral de la imponente propiedad de Julián Zulueta. ${ }^{103}$ Zulueta, que había sido uno de los más destacados promotores del tráfico ilegal de africanos hacia Cuba, también participó activamente en la "colonización asiática". En 1877, sus cuatro principales ingenios, entre ellos el Álava, contaban con 286 coolies contratados.

\footnotetext{
${ }^{100}$ Manuel B. López, El garrote en Cuba, pp. 48-49.

${ }^{101}$ Manuel Barcia, "Los contramayorales negros y mulatos en la Cuba decimonónica", Gabinete de Arqueología, $\mathrm{N}^{\circ} .2$, Año 2, 2002, pp. 88-93.

${ }_{102}$ Manuel B. López, El garrote en Cuba, p. 56.

${ }^{103}$ Ibídem, pp. 49-51.
} 
La investigación que en 1874 impulsó el Imperio Chino sobre las condiciones de vida y trabajo de sus ciudadanos en la isla, terminó con la suspensión de los acuerdos bilaterales que autorizaban tan degradante colonización. El problema diplomático se solucionaría mediante otro convenio suscrito en 1877. 


\section{CONCLUSIONES}

Durante la discusión del proyecto de Ley de Vientres Libres, Ramón Ortiz de Zárate, diputado a las Cortes españolas por la provincia de Álava, manifestó no ser partidario de la esclavitud, una institución entonces muy reprobada, pero argumentó que al hacerse una ley para su abolición debía examinarse bien "el modo y el tiempo" y que a su juicio era conveniente retomar la propuesta inicial del Ministro de Ultramar Segismundo Moret y Prendergast, que otorgaba la libertad sin indemnización a los esclavos mayores de 65 años y a los que en adelante llegasen a la misma, requisito que la comisión acortó a 60 años y que finalmente fue la aprobada. ${ }^{1}$

El argumento esgrimido por Ortiz de Zárate, que según confesó nunca había estado en los dominios de ultramar, era la mayor longevidad de los esclavos, "un atributo recibido de la Providencia en compensación por su desgraciada suerte". Expresó que cierta persona le dijo "que en Cuba un negro á los 65 años es igual á un blanco de 40", "que era muy común ver negros de 100 y más años" y haber conocido en un ingenio a un negro de "ciento veintitantos años". De modo que consideraba una violación a la propiedad privada declarar libres sin indemnización a los esclavos de 60 a 65 años.

Tales planteamientos derivaron en una extravagante polémica entre este y el también diputado Gallego Díaz sobre esclavitud, longevidad y abolicionismo en la isla de Cuba. Este ultimó acusó a Ortiz de Zárate de haber sido un negrero el que le dio las noticias referentes a la longevidad de los esclavos, de ser él un "amante platónico de la abolición” y que, si a los 60 años los negros esclavos aparentan 40, "si están dotados de larga vida á pesar de sus rudas faenas y males sin cuento", seguramente otorgándoles la libertad les concederían el don de la inmortalidad. ${ }^{2}$

Tarde se sumó al debate el diputado valenciano Rafael Cervera Royo, destacado oftalmólogo, con un discurso nutrido de razonamientos médicos para pedir que se

\footnotetext{
${ }^{1}$ Diario de sesiones de las cortes constituyentes. Dieron principio el día 11 de febrero de 1869, t. XIII, Imprenta J. A. García, Madrid, 1870, pp. 8737 y 8767.

2 Ídem.
} 
rebajase a 50 años la edad de concesión de la libertad, e increpó a los asistentes en los siguientes términos: "preguntaré a la comisión y a la Asamblea qué fundamento tiene esa creencia, tan admitida en esta Cámara, de que la raza negra en la isla de Cuba vive mucho. ¡Vivir mucho el hombre en el estado de esclavitud, sometido a trabajos tan rudos, a un clima como aquel, con una alimentación tan escasa como sabemos que se le da en los ingenios! ¿Qué interés hay en hacer desconocer la verdad? ¿Y a quién se dice esto?". 3

Apenas unos días después del debate en cuestión se aprobó la enunciada ley, sin tener en cuenta unas modificaciones que pudieron acelerar el remiso proceso de transición a la libertad en Cuba. Así las cosas, al otro lado del atlántico, numerosos esclavos envejecidos al ritmo mareante de los ingenios cubanos, reducidos a negros guardieros, matungos, cangrejos, aguardaban, esperanzados y temerosos, la ambigua carta de libertad de sus mezquinos poseedores.

De acuerdo con la definición lexicológica que ofrece Fernando Ortiz, el vocablo taita designa "el tratamiento que suele darse a los negros ancianos". En el plano histórico-social, ese apelativo aludía a un esclavo o antiguo esclavo con cierto capital simbólico adquirido con los años. Calificaba a la persona autorizada para realizar funciones típicas en la plantación o en el espacio urbano donde radicaba. Bautizaba una particular relación de parentesco entre la comunidad afrodescendiente. Pero el taita es también el resultado de un proceso bio-demográfico, es un sujeto con una capacidad acreditada de supervivencia dentro de un sistema social y un escenario epidemiológico particularmente hostil a su previa condición.

En nuestra investigación hemos destacado la centralidad de los procesos de enfermedad y muerte en el desempeño de la economía esclavista en Cuba entre 1840 y 1886. En términos generales, el auge de la plantación implicó un deterioro de las condiciones sociales y severas restricciones demográficas. El alto nivel de productividad obtenido en esa etapa fue resultado de una explotación física intensa más que de la eficiencia en la organización del trabajo esclavo. El estudio de la mortalidad esclava puede ayudar más que otros fenómenos a comprender la naturaleza del sistema económico desarrollado para satisfacer la creciente demanda de azúcar y otras mercancías comerciales.

\footnotetext{
${ }^{3}$ Ibídem, pp. 8813- 8814.
} 
Una primera conclusión importante, a tono con el debate parlamentario que comentábamos antes, es que la vejez fue privilegio de unos pocos esclavos. En 1860, solo el 5,9\% de la población esclava rural tenía más de 60 años. De acuerdo con los datos vitales del anexo que presentamos, la edad promedio de los enterramientos registrados fue de 34 años. El 21\% de estas personas no rebasó los 15 años de edad. La mortalidad es acentuada en la etapa comprendida entre los 20 y los 39 años, cuando las condiciones para el desarrollo de familias podían ser mejores. Para las mujeres esclavas de nuestra muestra la edad media de enterramiento fue de 28,8 años y para los hombres de 37,5 años. Sin embargo, al analizar los datos correspondientes solo a la población cautiva nacida en la isla, obtenemos que la media de la mortalidad registrada para las mujeres se reduce a los 22,8 años y para los hombres a 23,6 años. La reducción de la brecha indicada entre sexos atendiendo a la naturalidad sugiere que la trata de esclavos hacia la isla no solo alteró el equilibrio demográfico introduciendo más hombres que mujeres, sino además con una diferencia de edad notable entre unos y otros.

Sabemos que los matrimonios entre esclavos fueron realidades poco frecuentes en comparación con la población libre, pero se ha insistido menos en el carácter extremadamente frágil de estas instituciones. La muerte de uno de los conyugues al poco tiempo de haberse consumado la unión sacramental no fue algo extraño. Un porciento elevado de las uniones conyugales legitimadas no vivió lo suficiente como para desarrollar tipos de familias prototípicas. Frente a esa realidad, la población esclava fortaleció otros vínculos parenterales. La gran mayoría de los hombres africanos que arribaron a la isla como fuerza de trabajo y los esclavos criollos nunca llegaron a experimentar la paternidad efectiva. Relación social sistemáticamente negada por las exigencias del sistema. Una de las consecuencias directas de estas restricciones fue la matrifocalidad en detrimento de unidades familiares representadas por la presencia de madre, padre e hijos. Realidad manifiesta en muchos de los registros parroquiales consultados, donde se desconoce la figura paterna. Es difícil siquiera imaginar el drama emocional de una comunidad sujeta a una vida marcada por la rutina de pérdidas sucesivas de madres, hijos, cónyuges y compañeros de trabajo.

Los elevados niveles de mortalidad infantil hasta el final del sistema ponen en cuestión la capacidad de los plantadores para manipular el comportamiento reproductivo de sus esclavos. La regularidad con la que sobrevino la muerte a los pocos días de nacido, incluso horas, sugiere que las condiciones prenatales y en el momento del parto no fueron óptimas. La mala salud reproductiva de las esclavas también se reflejó en la 
sobremortalidad materna por accidentes y enfermedades relacionadas con el parto. Asimismo, hemos visto que la fragilidad vital de la población esclava fue particularmente grave durante la primera infancia, o sea entre el nacimiento y los 5 años. El 14\% de los 1.000 enterramientos de esclavos que recoge la muestra que anexamos se produjo en esa etapa. La proporción aumenta considerablemente -al 34\%si consideramos la base de datos más general de 2.373 enterramientos de pardos y morenos.

La muerte en la plantación sintetiza un sistema de relaciones e intercambios asociados a la circulación transatlántica de población, capitales, alimentos, plantas, gérmenes, conocimiento, tecnologías, animales, etc., y sus transiciones en el tiempo. Por ejemplo, hemos comprobado los graves problemas derivados de la pobre calidad de la alimentación regular en las plantaciones azucareras, manifiesta en la notable incidencia diferencial del beriberi, enfermedad nutricional debida al déficit crónico de tiamina o vitamina $\mathrm{B} 1$, y hemos sugerido, confrontando argumentos historiográficos establecidos, que ese hecho está estrechamente relacionado con las transformaciones socioeconómicas del siglo XIX. En zonas dominadas por monocultivos comerciales y muy dependientes de las importaciones de alimentos baratos, como fue el caso de Matanzas, núcleo de la economía esclavista azucarera cubana, determinados productos ricos en micronutrientes esenciales no formaban parte de la dieta regular de los esclavos. Una alimentación deficiente también facilitó el desarrollo de procesos de morbilidad más letales y problemas en la productividad de la fuerza de trabajo.

En este sentido, profundizamos en el impacto diferencial de enfermedades habituales en el ecosistema azucarero cubano en el contexto de la "segunda esclavitud", como la malaria, el cólera, la disentería, la tuberculosis pulmonar, las afecciones del corazón y las infestaciones parasitarias, entre otras. Destacamos que la vulnerabilidad epidemiológica de la población esclava se explica no por cierta "predisposición racial" sino por el escenario en el que este grupo demográfico desarrolla su existencia. Por otro lado, la prolongación de la trata de esclavos hacia la isla hasta bien entrado el siglo XIX, alcanzando cuotas importantes en las décadas de 1850 y 1860, determinó el flujo continuo de una población no inmune a los riegos epidemiológicos en el entorno de la plantación. La trata misma, como vimos en el primer capítulo, funcionó como un catalizador transatlántico de enfermedades, que en el caso cubano se acentuó durante su fase ilegal entre 1820 y 1867. En el contexto histórico que analizamos, la salud de la población esclava estuvo afectada también por el hecho de que muchos plantadores no 
estaban dispuestos o no podían permitirse una atención médica de calidad a sus dotaciones. A propósito, los datos que citamos a continuación son concluyentes sobre la naturaleza de la esclavitud en Cuba y en manos de quién estaba la vida de su población. Según el Cuadro Estadístico de 1846, la jurisdicción de Cárdenas tenía registrado un mayoral por cada 109 esclavos y un médico o cirujano por cada 4.254 esclavos. En la jurisdicción de Matanzas la proporción era de un mayoral por cada 99 esclavos y un médico o cirujano por cada 1.099 sujetos de la misma condición. La situación era ligeramente menos asfixiante en los 32 partidos rurales que comprendía la jurisdicción de La Habana, un mayoral por cada 108 esclavos y un médico o cirujano por cada 905 esclavos. De modo que, por lo general, en la gran mayoría de las plantaciones de la isla predominó la atención médica de baja especialización o el curanderismo.

Por otro lado, la mortalidad esclava en el circuito del azúcar no puede comprenderse al margen de la violencia estructural que informó el sistema. Hemos visto que no fueron pocos los casos registrados de sevicias, homicidios, asesinatos, suicidios y lesiones, por más que fueran deliberadamente ocultados por los hacendados y las autoridades coloniales. Cuando la plantación esclavista alcanzó su pleno desarrollo mostró sin cortapisas la naturaleza violenta del sistema. De hecho, la década de 1840 se inició con una alarmante ola de suicidios y revueltas. Al final de este decenio comenzó la importación de coolies chinos, una práctica que agudizó los conflictos entre los miembros de una fuerza laboral más heterogénea. En este escenario, hombres y mujeres libraron al interior de la plantación disputas cotidianas por recursos materiales y simbólicos que no pocas veces tuvieron fatídicos desenlaces.

Ténganse en cuenta que la mortalidad de los trabajadores nos revela solo una parte de la brutal explotación a la que estuvieron sometidos hasta el final de la esclavitud. Los análisis contemporáneos que de algún modo han analizado la salud de la población cautiva en las plantaciones americanas, han indagado menos sobre aquellas enfermedades o situaciones que no acabaron en muerte. Por ello, los datos de mortalidad no restituyen en su totalidad las diferencias sociales ante la enfermedad y la muerte impuestas por las relaciones esclavistas de producción. Muchos de los que sobrevivieron a la esclavitud lo hicieron en deplorables condiciones físicas y mentales. A principios del siglo $\mathrm{XX}$, los asilos cubanos acogían no pocos antiguos esclavos y contratados chinos que, envejecidos, sin familias, y sin poder valerse por sí mismos, acudían a la beneficencia pública para exhalar la vida que les consumió el ingenio. Patrones sociodemográficos consolidados durante el auge de la plantación esclavista 
marcaron el desarrollo posterior de la comunidad cubana afrodescendiente. Entre ellos, persistentes desigualdades en salud, tipificadas en diferentes variables de morbilidad y mortalidad.

En el plano metodológico, destacamos el desarrollo de una base de datos sobre la mortalidad de la población esclava y afrodescendiente en el contexto de la "segunda esclavitud" en la isla. Hasta la fecha, la historiografía cubana ha mostrado mayor preocupación por los registros parroquiales de bautismo y matrimonio, desconociendo la importancia que los registros de enterramientos tienen para la comprensión de la dinámica interna del sistema esclavista. Unos 2.373 registro de enterramientos fueron procesados para el desarrollo de la investigación que presentamos, incluyendo los 1.000 casos de enterramientos de esclavos desglosados en el anexo adjunto. La documentación procesada es particularmente valiosa para extraer conclusiones sobre el carácter de la dominación impuesta, el entorno epidemiológico, la edad, el sexo, las etnias africanas de procedencia, las relaciones familiares articuladas, entre otros factores que determinaron la capacidad de supervivencia en una región vital para el desempeño de la esclavitud y la economía atlántica en el siglo XIX.

La historia demográfica y epidemiológica de la "segunda esclavitud" en Cuba constituye un campo abierto a múltiples análisis. Próximos acercamientos deben profundizar en la información disponible en archivos locales, municipales y provinciales. El desarrollo de un conocimiento más fiable a partir de una base de datos amplia sobre los registros parroquiales, permitirá realizar estudios comparados con entornos socioeconómicos similares. Es nuestro propósito avanzar en esta dirección. Conviene además abrir el análisis a temas ocultos como la gestión de recursos vitales para el desarrollo de la plantación como lo fue el agua, cuyo impacto en la salud de la población residente en esos espacios fue meridiano. La historia del agua en su relación con el desarrollo de la plantación esclavista y la vida en ella está aún por hacer.

Habría que profundizar además en la actividad social y cultural desarrollada por la población esclava en torno a la muerte. Algunos de los problemas más apasionantes y complejos de la esclavitud radican en las estrategias que la población sometida tuvo que articular para preservar su existencia frente a la naturaleza corrosiva del sistema. Tampoco se han desarrollados estudios históricos sistemáticos sobre las desigualdades en salud por color de la piel o condición social.

Asimismo, la documentación conservada es fundamentalmente la producida por los sectores dominantes, y la disponibilidad de fuentes con información elaborada por 
los grupos subalternos de la sociedad es más limitada. De modo que, a través de los registros oficiales, no siempre sea posible conocer comportamientos de las capas populares ante la enfermedad y la muerte, así como las redes informales articuladas para intercambiar ayuda, entre otras experiencias de valor para el análisis que se propone.

En resumen, consideramos que la mortalidad es un factor fundamental para comprender la progresión decreciente de la población empleada en la industria azucarera desde la década de 1840, fundamentalmente esclava y libre "de color". En el contexto estudiado, la expresión popular que Moreno Fraginals consideró una "filosofía del simple perdurar", pero que expresa la más elemental forma de resistencia al sistema esclavista, revela la paradoja de la vida en la plantación: "lo importante aquí es no morirse". 
ANEXOS 
REGISTRO DE ESCLAVOS ENTERRADOS EN VARIOS LUGARES DE MATANZAS, 1850-1869.

\begin{tabular}{|c|c|c|c|c|c|c|c|c|c|}
\hline $\mathrm{N}_{\mathrm{O}}$ & FUENTE & $\begin{array}{c}\text { FECHA } \\
\text { DEL } \\
\text { ENTIERRO }\end{array}$ & NOMBRE & SEXO & NATURALIDAD & $\begin{array}{l}\text { COLOR } \\
\text { DE PIEL }\end{array}$ & PROPIETARIO & $\begin{array}{l}\text { ESTADO } \\
\text { CIVIL }\end{array}$ & EDAD \\
\hline 1. & libro 12 & $04-12-1850$ & Eusebio & $\mathrm{m}$ & gangá & moreno & Santiago R. & soltero & 40 \\
\hline 2. & libro 12 & $04-12-1850$ & Manuel & $\mathrm{m}$ & África & moreno & Mariana Mantilla & soltero & 30 \\
\hline 3. & libro 12 & $04-12-1850$ & Teresa & $\mathrm{f}$ & lucumí & morena & José Carbó & soltera & 30 \\
\hline 4. & libro 12 & $05-12-1850$ & Antonio & $\mathrm{m}$ & gangá & moreno & Juan Sapbla & soltero & 30 \\
\hline 5. & libro 12 & $08-12-1850$ & Valentina & $\mathrm{f}$ & no se dice & morena & Pedro Prats & $\mathrm{m}_{\mathrm{e}}$ & 8 \\
\hline 6. & libro 12 & $09-12-1850$ & Roberto & $\mathrm{m}$ & gangá & moreno & Bruno José Caraballo & no se dice & $\mathrm{a}$ \\
\hline 7. & libro 12 & $10-12-1850$ & Rita & $\mathrm{f}$ & conga & morena & Ramón Gonzalez & soltera & 17 \\
\hline 8. & libro 12 & $10-12-1850$ & Diego & $\mathrm{m}$ & gangá & moreno & Pedro A. & no se dice & 80 \\
\hline 9. & libro 12 & $17-05-1850$ & Fausto Junco & $\mathrm{m}$ & mandinga & moreno & Guadalupe del Junco de Gener & casado & 50 \\
\hline 10. & libro 12 & $14-06-1850$ & Tania Junco & $\mathrm{f}$ & criolla & morena & Guadalupe del Junco de Gener & $\mathrm{m}_{\mathrm{e}}$ & $\mathrm{p}$ \\
\hline 11. & libro 12 & $15-06-1850$ & Dolores Junco & $\mathrm{f}$ & gangá & morena & Guadalupe del Junco de Gener & casada & 26 \\
\hline 12. & libro 12 & $17-06-1850$ & Nicolás Junco & $\mathrm{m}$ & lucumí & moreno & Guadalupe del Junco de Gener & soltero & 29 \\
\hline 13. & libro 12 & $18-06-1850$ & Adolfo Junco & $\mathrm{m}$ & gangá & moreno & Guadalupe del Junco de Gener & soltero & 30 \\
\hline 14. & libro 12 & $20-06-1850$ & Fermín Junco & $\mathrm{m}$ & lucumí & moreno & Guadalupe del Junco de Gener & soltero & 35 \\
\hline 15. & libro 12 & $20-06-1850$ & Ramón Junco & $\mathrm{m}$ & gangá & moreno & Guadalupe del Junco de Gener & soltero & 30 \\
\hline 16. & libro 12 & 21-06-1850 & Roque Junco & $\mathrm{m}$ & lucumí & moreno & Guadalupe del Junco de Gener & soltero & 34 \\
\hline 17. & libro 12 & $21-06-1850$ & Estanislao Junco & $\mathrm{m}$ & carabalí & moreno & Guadalupe del Junco de Gener & soltero & 36 \\
\hline 18. & libro 12 & $21-06-1850$ & Perfecto Junco & $\mathrm{m}$ & gangá & moreno & Guadalupe del Junco de Gener & casado & 60 \\
\hline 19. & libro 12 & $21-06-1850$ & Anselmo Junco & $\mathrm{m}$ & criollo & moreno & Guadalupe del Junco de Gener & soltero & 50 \\
\hline 20. & libro 12 & $22-06-1850$ & Francisco Junco & $\mathrm{m}$ & lucumí & moreno & Guadalupe del Junco de Gener & soltero & 35 \\
\hline 21. & libro 12 & $22-06-1850$ & Martín Junco & $\mathrm{m}$ & gangá & moreno & Guadalupe del Junco de Gener & soltero & 30 \\
\hline 22. & libro 12 & $22-06-1850$ & Casimira Junco & $\mathrm{f}$ & carabalí & morena & Guadalupe del Junco de Gener & soltera & 25 \\
\hline 23. & libro 12 & $25-06-1850$ & Plácido Junco & $\mathrm{m}$ & lucumí & moreno & Guadalupe del Junco de Gener & soltero & 28 \\
\hline 24. & libro 12 & $25-06-1850$ & Ricardo Junco & $\mathrm{m}$ & lucumí & moreno & Guadalupe del Junco de Gener & soltero & 35 \\
\hline
\end{tabular}




\begin{tabular}{|c|c|c|c|c|c|c|c|c|c|c|}
\hline 25. & libro 12 & $25-06-1850$ & Rita Junco & $\mathrm{f}$ & conga & morena & Guadalupe del Junco de Gener & soltera & 28 & \\
\hline 26. & libro 12 & $26-06-1850$ & Leonardo Junco & $\mathrm{m}$ & mandinga & moreno & Guadalupe del Junco de Gener & soltero & 26 & \\
\hline 27. & libro 12 & $26-06-1850$ & Anastasia Junco & $\mathrm{f}$ & criolla & morena & Guadalupe del Junco de Gener & $\mathrm{m}_{\mathrm{e}}$ & $\mathrm{p}$ & \\
\hline 28. & libro 12 & $26-06-1850$ & José Alfonso & $\mathrm{m}$ & criollo & moreno & José Agustín Alfonso & $\mathrm{m}_{\mathrm{e}}$ & $\mathrm{p}$ & \\
\hline 29. & libro 12 & $26-06-1850$ & Simona Alfonso & $\mathrm{f}$ & criolla & morena & José Agustín Alfonso & $\mathrm{m}_{\mathrm{e}}$ & $\mathrm{p}$ & \\
\hline 30. & libro 12 & $30-06-1850$ & Carlos Junco & $\mathrm{m}$ & criollo & moreno & Guadalupe del Junco de Gener & $\mathrm{m}_{\mathrm{e}}$ & $\mathrm{p}$ & \\
\hline 31. & libro 12 & $30-06-1850$ & Pedro Junco & $\mathrm{m}$ & congo & moreno & Guadalupe del Junco de Gener & soltero & 27 & \\
\hline 32. & libro 12 & $02-07-1850$ & Francisco Alfonso & $\mathrm{m}$ & lucumí & moreno & José Agustín Alfonso & soltero & 35 & \\
\hline 33. & libro 12 & $02-07-1850$ & Manuela Alfonso & $\mathrm{f}$ & lucumí & morena & José Agustín Alfonso & soltera & 40 & \\
\hline 34. & libro 12 & 29-06-1850 & José Dolores & $\mathrm{m}$ & ganga & moreno & Herederos de Manuel del Junco & no se dice & no & se \\
\hline 35. & libro 12 & $01-07-1850$ & Nepomuceno & $\mathrm{m}$ & gangá & moreno & Herederos de Manuel del Junco & no se dice & no & se \\
\hline 36. & libro 12 & $01-07-1850$ & Encarnación & $\mathrm{f}$ & gangá & morena & Herederos de Manuel del Junco & no se dice & no & se \\
\hline 37. & libro 12 & $05-07-1850$ & Germán & $\mathrm{m}$ & gangá & moreno & Herederos de Manuel del Junco & no se dice & no & se \\
\hline 38. & libro 12 & $15-07-1850$ & Isabel & $\mathrm{f}$ & criolla & morena & Herederos de Manuel del Junco & no se dice & no & se \\
\hline 39. & libro 12 & $16-07-1850$ & Carlos & $\mathrm{m}$ & gangá & moreno & Herederos de Manuel del Junco & no se dice & no & se \\
\hline 40. & libro 12 & $11-12-1850$ & Juan & $\mathrm{m}$ & mandinga & moreno & $?$ & soltero & 15 & \\
\hline 41. & libro 12 & $19-12-1850$ & Isabel & $\mathrm{f}$ & gangá & morena & Manuel A. & soltera & 25 & \\
\hline 42. & libro 12 & $29-12-1850$ & José López & $\mathrm{m}$ & criollo & moreno & no se dice & soltero & 25 & \\
\hline 43. & libro 12 & $30-12-1850$ & María del Rosario & $\mathrm{f}$ & criolla & morena & María de los Ángeles Estorino & $\mathrm{m}_{\mathrm{e}}$ & 14 & \\
\hline 44. & libro 12 & $02-01-1851$ & Andrés & $\mathrm{m}$ & gangá & moreno & Guadalupe del Junco de Gener & no se dice & 46 & \\
\hline 45. & libro 12 & 04-01-1851 & Silverio Junco & $\mathrm{m}$ & gangá & moreno & Guadalupe del Junco de Gener & no se dice & no & se \\
\hline 46. & libro 12 & $06-01-1851$ & Miguel & $\mathrm{m}$ & gangá & moreno & A. García y Compañía & soltero & 40 & \\
\hline 47. & libro 12 & $07-01-1851$ & Juan de la Cruz & $\mathrm{m}$ & congo & moreno & José María Domínguez & soltero & 50 & \\
\hline 48. & libro 12 & 09-01-1851 & Benigna & $\mathrm{f}$ & criolla & morena & José Delgado & soltera & 20 & \\
\hline 49. & libro 12 & $10-01-1851$ & María de Regla & $\mathrm{f}$ & lucumí & morena & Pablo María García & no se dice & no & se \\
\hline 50. & libro 12 & $12-01-1851$ & Rosario & $\mathrm{m}$ & gangá & moreno & Juana Chirino & soltero & 60 & \\
\hline 51. & libro 12 & $13-01-1851$ & José & $\mathrm{m}$ & gangá & moreno & Pedro Hernández Morejón & soltero & 38 & \\
\hline 52. & libro 12 & $15-01-1851$ & Félix & $\mathrm{m}$ & lucumí & moreno & Juan Ortiz & no se dice & 60 & \\
\hline
\end{tabular}




\begin{tabular}{|c|c|c|c|c|c|c|c|c|c|}
\hline 53. & libro 12 & $16-01-1851$ & $\begin{array}{l}\text { Sisto de las } \\
\text { Mercedes }\end{array}$ & $\mathrm{m}$ & no se dice & moreno & José de la Fuente & no se dice & a \\
\hline 54. & libro 12 & $18-01-1851$ & Pascual & $\mathrm{m}$ & congo & moreno & Herederos de Manuel del Junco & no se dice & 40 \\
\hline 55. & libro 12 & 20-01-1851 & Gervasio Crisan & $\mathrm{m}$ & criollo & moreno & Pelegrin Fialo & soltero & 19 \\
\hline 56. & libro 12 & 26-01-1851 & Juliana & f & lucumí & morena & María Leonarda Alfonso & soltera & 60 \\
\hline 57. & libro 12 & 29-01-1851 & Pablo & $\mathrm{m}$ & gangá & moreno & Juan de Gómez & soltero & 30 \\
\hline 58. & libro 12 & $31-01-1851$ & Francisco & $\mathrm{m}$ & lucumí & moreno & A. García y Compañía & soltero & 28 \\
\hline 59. & libro 12 & $01-02-1851$ & Catalina & $\mathrm{f}$ & gangá & morena & Ignacio Martínez & no se dice & 38 \\
\hline 60. & libro 12 & $01-02-1851$ & Andrea Carbó & $\mathrm{f}$ & criolla & morena & Félix Dávalos & $\mathrm{m}_{\mathrm{e}}$ & 7 \\
\hline 61. & Libro 14 & 03-01-1864 & Inocencia & $\mathrm{f}$ & criolla & morena & Pedro González Arias & soltera & 40 \\
\hline 62. & Libro 14 & $10-01-1864$ & Juan Bergara & $\mathrm{m}$ & no se dice & pardo & Francisco Bergara & $\mathrm{m}_{\mathrm{e}}$ & 11 \\
\hline 63. & Libro 14 & $15-01-1864$ & Fermín Oliva & $\mathrm{m}$ & gangá & moreno & José Oliva & soltero & 50 \\
\hline 64. & Libro 14 & 22-01-1864 & Buenaventura & $\mathrm{f}$ & criolla & morena & Cirilo Espinoza & soltera & 25 \\
\hline 65. & Libro 14 & $01-02-1864$ & Carmen & $\mathrm{f}$ & criolla & no se dice & Irene Menocal Rives & soltera & 23 \\
\hline 66. & Libro 14 & $05-02-1864$ & Rosario & $\mathrm{f}$ & conga & morena & Clara Lossabe & soltera & 65 \\
\hline 67. & Libro 14 & 08-02-1864 & Severo & $\mathrm{m}$ & congo & moreno & Fabián García & soltero & 20 \\
\hline 68. & Libro 14 & $09-02-1864$ & Luciano & $\mathrm{m}$ & criollo & moreno & $?$ & soltero & 36 \\
\hline 69. & Libro 14 & $11-02-1864$ & Ramón Aguirre & $\mathrm{m}$ & no se dice & no se dice & Petrona Aguirre & soltero & 70 \\
\hline 70. & Libro 14 & $13-02-1864$ & Daniel & $\mathrm{m}$ & criollo & no se dice & Antonia Hernán & $\mathrm{m}_{\mathrm{e}}$ & 14 \\
\hline 71. & Libro 14 & $14-02-1864$ & Alejandro & $\mathrm{m}$ & congo & moreno & Manuel Serviá & soltero & 19 \\
\hline 72. & Libro 14 & $16-02-1864$ & José de la Luz & $\mathrm{m}$ & criollo & moreno & Francisca Rojo de García & no se dice & $\mathrm{a}$ \\
\hline 73. & Libro 14 & $19-02-1864$ & Fernando Viciedo & $\mathrm{m}$ & no se dice & moreno & Isabel Viciedo y Cartaya & soltero & 45 \\
\hline 74. & Libro 14 & $20-02-1864$ & Toribia García & $\mathrm{f}$ & criolla & morena & Fabián García & soltera & 30 \\
\hline 75. & Libro 14 & $26-02-1864$ & Manuel & $\mathrm{m}$ & congo & moreno & José Sala & soltero & 15 \\
\hline 76. & Libro 14 & 01-03-1864 & Antonio Gonzalez & $\mathrm{m}$ & congo & moreno & María del Rosario Gonzalez & soltero & 70 \\
\hline 77. & Libro 14 & 01-03-1864 & Josefa Gonzalez & $\mathrm{f}$ & no se dice & morena & Narciso Gonzalez & soltera & 60 \\
\hline 78. & Libro 14 & 11-03-1864 & Mateo Aballí & $\mathrm{m}$ & congo & no se dice & Francisco Aballí & $\mathrm{m}_{\mathrm{e}}$ & 12 \\
\hline 79. & Libro 14 & 19-03-1864 & Victoria & $\mathrm{f}$ & ganga & morena & Francisco del valle & soltera & 31 \\
\hline 80. & Libro 14 & 24-03-1864 & Pedro Miravet & $\mathrm{m}$ & criollo & moreno & Carmen Miravet & soltero & 14 \\
\hline
\end{tabular}




\begin{tabular}{|c|c|c|c|c|c|c|c|c|c|}
\hline 81. & Libro 14 & $26-03-1864$ & Salvador & $\mathrm{m}$ & no se dice & moreno & Carmen de la Vallina & soltero & 90 \\
\hline 82. & Libro 14 & $30-03-1864$ & Paulino & $\mathrm{m}$ & no se dice & no se dice & Caridad Pérez & $\mathrm{m}_{\mathrm{e}}$ & 1 \\
\hline 83. & Libro 14 & 04-04-1864 & Antonio & $\mathrm{m}$ & gangá & no se dice & Antonio Aloma & soltero & 50 \\
\hline 84. & Libro 14 & $05-04-1864$ & Camila & f & no se dice & no se dice & Francisco E. Plá & $\mathrm{m}_{\mathrm{e}}$ & 0 \\
\hline 85. & Libro 14 & 06-04-1864 & $\begin{array}{l}\text { Isabel Dávalos de } \\
\text { Santoyo }\end{array}$ & $\mathrm{f}$ & mandinga & no se dice & Asunción Dávalos de Santoyo & casada & 60 \\
\hline 86. & Libro 14 & $11-04-1864$ & Domingo & $\mathrm{m}$ & criollo & pardo & Sebastián Perdomo & soltero & 46 \\
\hline 87. & Libro 14 & $26-04-1864$ & Anselmo & $\mathrm{m}$ & no se dice & moreno & María Regla Comas & $\mathrm{m}_{\mathrm{e}}$ & 0 \\
\hline 88. & Libro 14 & $01-05-1864$ & María Alejandra & f & no se dice & no se dice & Antonio Armas & $\mathrm{m}_{\mathrm{e}}$ & 0 \\
\hline 89. & Libro 14 & 04-05-1864 & Dolores Puig & $\mathrm{f}$ & gangá & morena & José Puig & soltera & 43 \\
\hline 90. & Libro 14 & $07-05-1864$ & Rafael & $\mathrm{m}$ & criollo & no se dice & José Manuel Trelles & viudo & 65 \\
\hline 91. & Libro 14 & $13-05-1864$ & Santiago Crespo & $\mathrm{m}$ & congo & moreno & León Crespo & soltero & 30 \\
\hline 92. & Libro 14 & $21-05-1864$ & Bonifacia & f & no se dice & no se dice & Joaquín Lorville & $\mathrm{m}_{\mathrm{e}}$ & 0 \\
\hline 93. & Libro 14 & $27-05-1864$ & $\begin{array}{l}\text { Mercedes Alfonso } \\
\text { de Armas }\end{array}$ & f & carabalí & morena & $\begin{array}{l}\text { Herederos de María de Jesús } \\
\text { Alfonso de Armas }\end{array}$ & soltera & 70 \\
\hline 94. & Libro 14 & $31-05-1864$ & Lugarda & $\mathrm{f}$ & criolla & achinada & $\begin{array}{l}\text { Herederos de Félix María } \\
\text { Gonzalez }\end{array}$ & $\mathrm{m}_{\mathrm{e}}$ & 1 \\
\hline 95. & Libro 14 & 03-06-1864 & Gervasio Álvarez & $\mathrm{m}$ & criollo & moreno & Mauricia L. de Aldasabal & soltero & 38 \\
\hline 96. & Libro 14 & 03-06-1864 & Felipe & $\mathrm{m}$ & congo & no se dice & José N. Caro & soltero & 28 \\
\hline 97. & Libro 14 & $12-06-1864$ & Salomé & f & no se dice & morena & Antonia Miravet & $\mathrm{m}_{\mathrm{e}}$ & 11 \\
\hline 98. & Libro 14 & $14-06-1864$ & Ángel & $\mathrm{m}$ & criollo & moreno & José Madan & soltero & 40 \\
\hline 99. & Libro 14 & $24-06-1864$ & Pastor Vidal & $\mathrm{m}$ & gangá & moreno & Bienvenido Caballo & viudo & 115 \\
\hline 100. & Libro 14 & $30-06-1864$ & Ernesto & $\mathrm{m}$ & congo & no se dice & Antonio Armas & soltero & 40 \\
\hline 101. & Libro 14 & 30-06-1864 & Socorro & f & gangá & no se dice & Fernando Sischka & soltera & 40 \\
\hline 102. & Libro 14 & 09-07-1864 & Eusebio & $\mathrm{m}$ & carabalí & moreno & Fernando Anastasio de Zayas & soltero & 70 \\
\hline 103. & Libro 14 & $11-07-1864$ & Emilio de la Torre & $\mathrm{m}$ & no se dice & moreno & Cosme de la Torriente & no se dice & 36 \\
\hline 104. & Libro 14 & $11-07-1864$ & Adolfo Chirino & $\mathrm{m}$ & criollo & no se dice & Juana Chirino & $\mathrm{m}_{\mathrm{e}}$ & $\mathrm{p}$ \\
\hline 105. & Libro 14 & $14-07-1864$ & Cruz & $f$ & no se dice & no se dice & Ramón Rusmiyol & $\mathrm{m}_{\mathrm{e}}$ & 0 \\
\hline 106. & Libro 14 & $16-07-1864$ & Alonso & $\mathrm{m}$ & lucumí & moreno & Francisco Silveira & soltero & 45 \\
\hline
\end{tabular}




\begin{tabular}{|c|c|c|c|c|c|c|c|c|c|}
\hline 107. & Libro 14 & $17-07-1864$ & Catalina & $\mathrm{f}$ & gangá & morena & Ramón Govín & soltera & 45 \\
\hline 108. & Libro 14 & $22-07-1864$ & Andrés & $\mathrm{m}$ & congo & moreno & Juan Manuel Casuso & soltero & 20 \\
\hline 109. & Libro 14 & $05-08-1864$ & Santiago & $\mathrm{m}$ & criollo & no se dice & Antonio Candal & soltero & 22 \\
\hline 110. & Libro 14 & $12-08-1864$ & María de Estrada & $\mathrm{f}$ & lucumí & no se dice & Ildefonso de Estrada & soltera & 80 \\
\hline 111. & Libro 14 & $12-08-1864$ & Lucía & f & conga & no se dice & Inés Valera & soltera & 40 \\
\hline 112. & Libro 14 & $16-08-1864$ & Alberto & $\mathrm{m}$ & criollo & no se dice & Tomas Ortiz & $\mathrm{m}_{\mathrm{e}}$ & 0 \\
\hline 113. & Libro 14 & $19-08-1864$ & Alejandro Gómez & $\mathrm{m}$ & criollo & moreno & Teresa Gómez & soltero & 22 \\
\hline 114. & Libro 14 & $19-08-1864$ & Camilo Hernández & $\mathrm{m}$ & mandinga & moreno & Saturnino Hernández & soltero & 50 \\
\hline 115. & Libro 14 & $20-08-1864$ & Isabel & $\mathrm{f}$ & África & morena & $\begin{array}{l}\text { Herederos del Conde de } \\
\text { Santovenia }\end{array}$ & no se dice & $\mathrm{a}$ \\
\hline 116. & Libro 14 & $20-08-1864$ & Gabriela & f & arará & morena & Lugarda Gonzalez & soltera & 55 \\
\hline 117. & Libro 14 & 24-08-1864 & Isabel Aballí & $f$ & conga & morena & Francisco Aballí & soltera & 22 \\
\hline 118. & Libro 14 & $25-08-1864$ & Pelegrin & $\mathrm{m}$ & lucumí & no se dice & Pedro Sala & soltero & 45 \\
\hline 119. & Libro 14 & $26-08-1864$ & Víctor & $\mathrm{m}$ & macua & moreno & Sres. Amezaga y Arena & soltero & 34 \\
\hline 120. & Libro 14 & 29-08-1864 & Martina Garciarena & $\mathrm{f}$ & criolla & morena & Jacinto Garciarena & soltera & 36 \\
\hline 121. & Libro 14 & $29-08-1864$ & Federico & $\mathrm{m}$ & gangá & no se dice & Joaquín Ferrer & soltero & 35 \\
\hline 122. & Libro 14 & $31-08-1864$ & Rogiero & $\mathrm{m}$ & congo & moreno & Fabián García & soltero & 24 \\
\hline 123. & Libro 14 & 01-09-1864 & Andrés Gómez & $\mathrm{m}$ & lucumí & no se dice & Gerónimo Gómez & soltero & 70 \\
\hline 124. & Libro 14 & 03-09-1864 & Rufino Romero & $\mathrm{m}$ & no se dice & moreno & Luisa Romero & $\mathrm{m}_{\mathrm{e}}$ & 0 \\
\hline 125. & Libro 14 & 19-09-1864 & Dámaso del & $\mathrm{m}$ & China & asiático & Manuel del Portillo & soltero & 24 \\
\hline 126. & Libro 14 & 22-09-1864 & Ramón & $\mathrm{m}$ & no se dice & pardo & José de Jesús Caro & $\mathrm{m}_{\mathrm{e}}$ & 0 \\
\hline 127. & Libro 14 & $13-10-1864$ & Martín & $\mathrm{m}$ & no se dice & pardo & Carlos Polony & soltero & 16 \\
\hline 128. & Libro 14 & 06-11-1864 & Ramona & f & conga & no se dice & José G. Reconco & soltera & 15 \\
\hline 129. & Libro 14 & $17-11-1864$ & Carlos Simpson & $\mathrm{m}$ & no se dice & moreno & Rafael Lucas Sánchez & no se dice & 24 \\
\hline 130. & Libro 14 & $17-11-1864$ & Pilar & $\mathrm{f}$ & no se dice & parda & Regla Cepero & $\mathrm{m}_{\mathrm{e}}$ & 2 \\
\hline 131. & Libro 14 & $18-11-1864$ & María Antonia & $f$ & gangá & morena & María Jesús Simpson & soltera & 70 \\
\hline 132. & Libro 14 & 26-11-1864 & Lucía Jiménez & $f$ & no se dice & parda & Josefa Jiménez & soltera & 30 \\
\hline 133. & Libro 14 & $02-12-1864$ & Manuel & $\mathrm{m}$ & carabalí & no se dice & Francisco Condoni & soltero & 50 \\
\hline 134. & Libro 14 & $03-12-1864$ & Andrés & $\mathrm{m}$ & arará & moreno & Felipe Rivero & soltero & 15 \\
\hline
\end{tabular}




\begin{tabular}{|c|c|c|c|c|c|c|c|c|c|}
\hline 135. & Libro 14 & 04-12-1864 & Brígida Zamora & f & criolla & morena & Ángela Zamora & soltera & 22 \\
\hline 136. & Libro 14 & $06-12-1864$ & Manuel & $\mathrm{m}$ & gangá & moreno & Fran de Fuentes & soltero & 35 \\
\hline 137. & Libro 14 & $07-12-1864$ & José & $\mathrm{m}$ & no se dice & moreno & Manuel del Portillo & $\mathrm{m}_{\mathrm{e}}$ & 1 \\
\hline 138. & Libro 14 & $07-12-1864$ & María & $\mathrm{m}$ & congo & moreno & María Regla Alfonso & soltero & 36 \\
\hline 139. & Libro 14 & $08-12-1864$ & Adriano & $\mathrm{m}$ & lucumí & no se dice & José Coll y D. Brugada & soltero & 60 \\
\hline 140. & Libro 14 & $19-12-1864$ & José Oliva & $\mathrm{m}$ & congo & moreno & Pablo Oliva & soltero & 60 \\
\hline 141. & Libro 14 & $20-12-1864$ & Isabel & $\mathrm{f}$ & criolla & no se dice & María del Pino Peñate & soltera & 21 \\
\hline 142. & Libro 14 & $20-12-1864$ & Crispín & $\mathrm{m}$ & criollo & moreno & Joaquín Andricaín y Campa & soltero & 45 \\
\hline 143. & Libro 14 & $23-12-1864$ & Napoleón & $\mathrm{m}$ & mandinga & moreno & Francisco Iturrondo & soltero & 34 \\
\hline 144. & Libro 14 & $26-12-1864$ & Julia Rodríguez & f & no se dice & no se dice & Antonia Rodríguez & $\mathrm{m}_{\mathrm{e}}$ & 0 \\
\hline 145. & Libro 14 & $29-12-1864$ & Juan María & $\mathrm{m}$ & no se dice & no se dice & Francisco Alonso & $\mathrm{m}_{\mathrm{e}}$ & $\mathrm{p}$ \\
\hline 146. & Libro 14 & $31-12-1864$ & Julio & $\mathrm{m}$ & criollo & no se dice & Joaquín Polledo y Campa & $\mathrm{m}_{\mathrm{e}}$ & 11 \\
\hline 147. & Libro 14 & $05-01-1865$ & Gavino Hernández & $\mathrm{m}$ & no se dice & no se dice & José Loreto Hernández & $\mathrm{m}_{\mathrm{e}}$ & 0 \\
\hline 148. & Libro 14 & $09-01-1865$ & Juan & $\mathrm{m}$ & criollo & no se dice & Juan Lerena & soltero & 80 \\
\hline 149. & Libro 14 & $09-01-1865$ & Salvador & $\mathrm{m}$ & gangá & moreno & Bienvenido Caballol & soltero & 42 \\
\hline 150. & Libro 14 & $11-01-1865$ & José Solís & $\mathrm{m}$ & criollo & moreno & José Pérez & soltero & 50 \\
\hline 151. & Libro 14 & $17-01-1865$ & $\begin{array}{l}\text { Juan de la Cruz } \\
\text { Alfonso }\end{array}$ & $\mathrm{m}$ & no se dice & no se dice & Pedro Antonio Alfonso & soltero & 24 \\
\hline 152. & Libro 14 & $22-01-1865$ & Carlota Crespo & f & África & morena & León Crespo & $\mathrm{m}_{\mathrm{e}}$ & 13 \\
\hline 153. & Libro 14 & $01-02-1865$ & Vicenta & $\mathrm{f}$ & criolla & morena & Ana Hernández de Guerra & soltera & 19 \\
\hline 154. & Libro 14 & $07-02-1865$ & José García & $\mathrm{m}$ & congo & moreno & José García & soltero & 50 \\
\hline 155. & Libro 14 & $12-02-1865$ & Guillermo & $\mathrm{m}$ & congo & moreno & Benito Esteva & soltero & 24 \\
\hline 156. & Libro 14 & $12-02-1865$ & Mariano Rodríguez & $\mathrm{m}$ & no se dice & moreno & Domingo Rodríguez & no se dice & $\mathrm{a}$ \\
\hline 157. & Libro 14 & $13-02-1865$ & Salvador del & $\mathrm{m}$ & lucumí & moreno & Manuel del Portillo & no se dice & 60 \\
\hline 158. & Libro 14 & $16-02-1865$ & Domingo Malet & $\mathrm{m}$ & congo & no se dice & Jacinto Malet & soltero & 60 \\
\hline 159. & Libro 14 & $22-02-1865$ & Antonio & $\mathrm{m}$ & criollo & pardo & Juan Blanchet & no se dice & 48 \\
\hline 160. & Libro 14 & $24-02-1865$ & Florencia & $f$ & no se dice & no se dice & Josefa García & $\mathrm{m}_{\mathrm{e}}$ & 0 \\
\hline 161. & Libro 14 & $25-02-1865$ & Alejandro & $\mathrm{m}$ & no se dice & pardo & Josefa Plana & soltero & 70 \\
\hline 162. & Libro 14 & 04-03-1865 & Eleuterio Rovira & $\mathrm{m}$ & no se dice & no se dice & no se dice & $\mathrm{m}_{\mathrm{e}}$ & 3 \\
\hline
\end{tabular}




\begin{tabular}{|c|c|c|c|c|c|c|c|c|c|}
\hline 163. & Libro 14 & 06-03-1865 & Mauricio Perdomo & $\mathrm{m}$ & no se dice & no se dice & no se dice & $m_{e}$ & 0 \\
\hline 164. & Libro 14 & $06-03-1865$ & Prudencia & f & no se dice & no se dice & no se dice & $\mathrm{m}_{\mathrm{e}}$ & 0 \\
\hline 165. & Libro 14 & $09-03-1865$ & Genoveva & $\mathrm{f}$ & lucumí & morena & Guillermo Benítez & soltera & 66 \\
\hline 166. & Libro 14 & $17-03-1865$ & Pedro Escudero & $\mathrm{m}$ & criollo & moreno & Rosa Escudero & soltero & 40 \\
\hline 167. & Libro 14 & $20-03-1865$ & Pedro Ferrer & $\mathrm{m}$ & congo & moreno & Joaquín Ferrer & soltero & 40 \\
\hline 168. & Libro 14 & $20-03-1865$ & Concepción & $\mathrm{f}$ & criolla & morena & Isabel Madan & casada & 42 \\
\hline 169. & Libro 14 & $27-03-1865$ & Martín & $\mathrm{m}$ & congo & moreno & Pedro Cameron & soltero & 17 \\
\hline 170. & Libro 14 & $31-03-1865$ & Ramón Fernández & $\mathrm{m}$ & no se dice & no se dice & María Manuela Fernández & $\mathrm{m}_{\mathrm{e}}$ & 0 \\
\hline 171. & Libro 14 & $08-04-1865$ & Fernando & $\mathrm{m}$ & criollo & no se dice & Pedro Guibus & soltero & 45 \\
\hline 172. & Libro 14 & $12-04-1865$ & Merced Díaz & $\mathrm{f}$ & carabalí & morena & Teresa Morejón & soltera & 45 \\
\hline 173. & Libro 14 & $12-04-1865$ & Basilio & $\mathrm{m}$ & congo & moreno & Santiago Gasmury & soltero & 65 \\
\hline 174. & Libro 14 & $14-04-1865$ & Juana María & $\mathrm{f}$ & no se dice & no se dice & Saúl Ramírez & $\mathrm{m}_{\mathrm{e}}$ & 11 \\
\hline 175. & Libro 14 & $17-04-1865$ & $\begin{array}{l}\text { Tomasa Hernández } \\
\text { Morejón }\end{array}$ & f & criolla & morena & Juana Hernández Morejón & soltera & 40 \\
\hline 176. & Libro 14 & $06-05-1865$ & Sofía García & $\mathrm{f}$ & criolla & morena & Anselmo García & $\mathrm{m}_{\mathrm{e}}$ & 10 \\
\hline 177. & Libro 14 & $12-05-1865$ & Tomás & $\mathrm{m}$ & África & moreno & Celedonio Holy & soltero & 30 \\
\hline 178. & Libro 14 & $19-05-1865$ & Luisa Izquierdo & f & lucumí & morena & José N. Izquierdo & soltero & 40 \\
\hline 179. & Libro 14 & $21-05-1865$ & María Gonzalez & f & gangá & morena & Epifania Trelles de Gonzalez & no se dice & 70 \\
\hline 180. & Libro 14 & $21-05-1865$ & Encarnación & $\mathrm{f}$ & criolla & no se dice & Lorenzo Ruiz & $\mathrm{m}_{\mathrm{e}}$ & 3 \\
\hline 181. & Libro 14 & $23-05-1865$ & Matías Puñales & $\mathrm{m}$ & mandinga & moreno & Alejo Puñales & soltero & 50 \\
\hline 182. & Libro 14 & 24-05-1865 & Ignacia López & f & no se dice & morena & Manuel López & $\mathrm{m}_{\mathrm{e}}$ & 0 \\
\hline 183. & Libro 14 & $26-05-1865$ & $\begin{array}{l}\text { María } \quad \text { Tomasa } \\
\text { Carrera }\end{array}$ & $\mathrm{f}$ & criolla & morena & Domingo Hernández & soltera & 23 \\
\hline 184. & Libro 14 & 01-06-1865 & Julia Olivera & $\mathrm{f}$ & conga & morena & Segismundo Olivera & soltera & 22 \\
\hline 185. & Libro 14 & $01-06-1865$ & Francisco & $\mathrm{m}$ & lucumí & moreno & Venancio Casalins & no se dice & 113 \\
\hline 186. & Libro 14 & 04-06-1865 & Bruno & $\mathrm{m}$ & gangá & moreno & Guillermo Fenches & no se dice & $\mathrm{a}$ \\
\hline 187. & Libro 14 & $15-06-1865$ & Melchor & $\mathrm{m}$ & no se dice & moreno & Pedro Cameron & soltero & 40 \\
\hline 188. & Libro 14 & $15-06-1865$ & Felicia & $\mathrm{f}$ & criolla & morena & Clotilde Montesquieu & soltera & 36 \\
\hline 189. & Libro 14 & 20-06-1865 & Jacinta & $f$ & no se dice & morena & Mariano de Beltraneva & soltera & 17 \\
\hline
\end{tabular}




\begin{tabular}{|c|c|c|c|c|c|c|c|c|c|}
\hline 190. & Libro 14 & $22-06-1865$ & Belén del Portillo & $\mathrm{f}$ & criolla & morena & María de los Ángeles del Portillo & $\mathrm{m}_{\mathrm{e}}$ & 14 \\
\hline 191. & Libro 14 & $01-07-1865$ & Manuel & $\mathrm{m}$ & congo & moreno & Sres. Busquets & soltero & 20 \\
\hline 192. & Libro 14 & $02-07-1865$ & Juan & $\mathrm{m}$ & no se dice & pardo & no se dice & $\mathrm{m}_{\mathrm{e}}$ & 0 \\
\hline 193. & Libro 14 & $11-07-1865$ & Martina García & $\mathrm{f}$ & criolla & no se dice & Antonio Alfonso & soltera & 30 \\
\hline 194. & Libro 14 & $15-07-1865$ & Joaquín Betancourt & $\mathrm{m}$ & arará & moreno & Francisco Betancourt & soltero & 40 \\
\hline 195. & Libro 14 & $16-07-1865$ & Jacinta & $\mathrm{f}$ & conga & morena & Lucas Francés & soltera & 16 \\
\hline 196. & Libro 14 & $17-07-1865$ & Victoria & $\mathrm{f}$ & criolla & no se dice & Cosme de la Nuez & soltera & 20 \\
\hline 197. & Libro 14 & $20-07-1865$ & Enrique & $\mathrm{m}$ & criollo & no se dice & Mariana Vivens de Davis & $\mathrm{m}_{\mathrm{e}}$ & 0 \\
\hline 198. & Libro 14 & $22-07-1865$ & Zacarías & $\mathrm{m}$ & congo & moreno & José Prats & soltero & 60 \\
\hline 199. & Libro 14 & $26-07-1865$ & Casimiro & $\mathrm{m}$ & criollo & moreno & Ricardo G. Oña & soltero & 28 \\
\hline 200. & Libro 14 & $30-07-1865$ & Carlos Silva & $\mathrm{m}$ & criollo & moreno & Juan Silva & soltero & 18 \\
\hline 201. & Libro 14 & $02-08-1865$ & Serafín Rodríguez & $\mathrm{m}$ & arará & moreno & Cecilio Rodríguez & soltero & 40 \\
\hline 202. & Libro 14 & $05-08-1865$ & Josefa Velasco & $\mathrm{f}$ & criolla & no se dice & Herederos de Francisco Velasco & soltera & 42 \\
\hline 203. & Libro 14 & $08-08-1865$ & Francisca & $\mathrm{f}$ & mandinga & no se dice & Juan Antonio Silva & soltera & 45 \\
\hline 204. & Libro 14 & 09-08-1865 & María de los & $\mathrm{f}$ & no se dice & no se dice & Domingo Oliva & $\mathrm{m}_{\mathrm{e}}$ & 0 \\
\hline 205. & Libro 14 & $13-08-1865$ & Marina & $\mathrm{f}$ & criolla & morena & Luis Valera & $\mathrm{m}_{\mathrm{e}}$ & 6 \\
\hline 206. & Libro 14 & $13-08-1865$ & Sebastián García & $\mathrm{m}$ & lucumí & no se dice & Lorenza García & soltero & 40 \\
\hline 207. & Libro 14 & $15-08-1865$ & Andrés & $\mathrm{m}$ & macua & no se dice & Domingo Madan & soltero & 40 \\
\hline 208. & Libro 14 & $19-08-1865$ & José María & $\mathrm{m}$ & gangá & moreno & Bienvenido Caballol & soltero & 80 \\
\hline 209. & Libro 14 & $03-09-1865$ & José Solano & $\mathrm{m}$ & congo & moreno & Manuel Solano & soltero & 80 \\
\hline 210. & Libro 14 & $08-09-1865$ & Federico & $\mathrm{m}$ & lucumí & moreno & Fernando A. Zayas & soltero & 50 \\
\hline 211. & Libro 14 & $18-09-1865$ & Teresa Jordán & $\mathrm{f}$ & no se dice & morena & Marcos Jordán & soltera & 17 \\
\hline 212. & Libro 14 & $20-09-1865$ & Cerapio Campos & $\mathrm{m}$ & criollo & moreno & Dña. Eusebia Campos & soltero & 19 \\
\hline 213. & Libro 14 & $20-09-1865$ & Lucía Moya & $\mathrm{f}$ & África & morena & Josefa Moya & soltera & 50 \\
\hline 214. & Libro 14 & $25-09-1865$ & Francisco Ferrer & $\mathrm{m}$ & congo & moreno & Francisco Ferrer & soltero & 58 \\
\hline 215. & Libro 14 & $26-09-1865$ & José Abraham & $\mathrm{m}$ & no se dice & no se dice & María de los Ángeles Bermejo & $\mathrm{m}_{\mathrm{e}}$ & 6 \\
\hline 216. & Libro 14 & $03-10-1865$ & Victoriana & $\mathrm{f}$ & no se dice & no se dice & Pedro Beltraneva & $\mathrm{m}_{\mathrm{e}}$ & 0 \\
\hline 217. & Libro 14 & $14-10-1865$ & Federico & $\mathrm{m}$ & lucumí & moreno & Manuel Servía & soltero & 60 \\
\hline 218. & Libro 14 & $16-10-1865$ & Florentino & $\mathrm{m}$ & lucumí & moreno & Herederos del Conde de & soltero & 50 \\
\hline
\end{tabular}




\begin{tabular}{|c|c|c|c|c|c|c|c|c|c|}
\hline 219. & Libro 14 & $18-10-1865$ & Petrona Rufin & $\mathrm{f}$ & criolla & morena & Josefa Rufin & no se dice & 16 \\
\hline 220. & Libro 14 & $23-10-1865$ & Catalina Aballí & $\mathrm{f}$ & conga & morena & Francisco Aballí & soltera & 25 \\
\hline 221. & Libro 14 & $26-10-1865$ & Matilde Aballí & $\mathrm{f}$ & conga & morena & Francisco Aballí & soltera & 20 \\
\hline 222. & Libro 14 & $17-11-1865$ & Simón Junco & $\mathrm{m}$ & no se dice & moreno & María Margarita Junco (parda) & soltero & 20 \\
\hline 223. & Libro 14 & $20-11-1865$ & Micaela Lima & $\mathrm{f}$ & gangá & morena & Rosario Lima & soltera & 60 \\
\hline 224. & Libro 14 & $23-11-1865$ & Dionisio de los & $\mathrm{m}$ & criollo & moreno & José de los Ríos & soltero & 30 \\
\hline 225. & Libro 14 & $27-11-1865$ & Antonia Gonzalez & $\mathrm{f}$ & mina & no se dice & Paula Gonzalez & soltera & 60 \\
\hline 226. & Libro 14 & $30-11-1865$ & Miguel Domínguez & $\mathrm{m}$ & criollo & pardo & Pedro Domínguez & soltero & 60 \\
\hline 227. & Libro 14 & 01-12-1865 & Merced & $\mathrm{f}$ & mina & morena & Antonio Romniguera & soltera & 70 \\
\hline 228. & Libro 14 & $02-12-1865$ & Valentina & $\mathrm{f}$ & criolla & morena & Eduardo Larbe & soltera & 15 \\
\hline 229. & Libro 14 & $03-12-1865$ & Dolores Mestre & $\mathrm{f}$ & África & morena & Pedro Mestre & soltera & 20 \\
\hline 230. & Libro 14 & 04-12-1865 & Manuel Batalla & $\mathrm{m}$ & congo & moreno & Guillermo Batalla & soltero & 70 \\
\hline 231. & Libro 14 & $05-12-1865$ & Aurelia Gómez & $\mathrm{f}$ & no se dice & parda & Dolores Gómez & $\mathrm{m}_{\mathrm{e}}$ & 7 \\
\hline 232. & Libro 14 & $07-12-1865$ & Joaquín Arocha & $\mathrm{m}$ & no se dice & moreno & Felipa Arocha & soltero & 100 \\
\hline 233. & Libro 14 & $08-12-1865$ & Isidro Aballí & $\mathrm{m}$ & criollo & no se dice & Francisco Aballí & $\mathrm{m}_{\mathrm{e}}$ & 6 \\
\hline 234. & Libro 14 & $13-12-1865$ & Tomasa Santana & $\mathrm{f}$ & criolla & morena & Josefa Santana & soltera & 20 \\
\hline 235. & Libro 14 & $16-12-1865$ & Margarita del & $\mathrm{f}$ & gangá & morena & Joaquín de Junco & soltera & 50 \\
\hline 236. & Libro 14 & $22-12-1865$ & Tomasa Jiménez & $\mathrm{f}$ & criolla & parda & Nicolasa Jiménez & $\mathrm{m}_{\mathrm{e}}$ & 13 \\
\hline 237. & Libro 14 & $25-12-1865$ & $\begin{array}{l}\text { José María de la } \mathrm{O} \\
\text { Díaz }\end{array}$ & $\mathrm{m}$ & no se dice & no se dice & Regina Díaz & $\mathrm{m}_{\mathrm{e}}$ & 0 \\
\hline 238. & Libro 14 & 01-01-1866 & $\begin{array}{l}\text { Dolores Rojo de } \\
\text { García }\end{array}$ & $\mathrm{f}$ & criolla & parda & Francisca Rojo de García & $\mathrm{m}_{\mathrm{e}}$ & 10 \\
\hline 239. & Libro 14 & 02-01-1866 & Teresa Roque & $\mathrm{f}$ & gangá & morena & Gregorio Roque & soltera & 48 \\
\hline 240. & Libro 14 & 11-01-1866 & Miguel Sala & $\mathrm{m}$ & congo & moreno & Pedro Sala & soltero & 60 \\
\hline 241. & Libro 14 & 13-01-1866 & Candelaria Deville & $\mathrm{f}$ & criolla & no se dice & Antonio Deville & soltera & 21 \\
\hline 242. & Libro 14 & 14-01-1866 & Rafael María & $\mathrm{m}$ & gangá & moreno & María del Pino Fabelo & casado & 60 \\
\hline 243. & Libro 14 & 16-01-1866 & $\begin{array}{l}\text { Nepomuceno } \\
\text { Hernández }\end{array}$ & $\mathrm{m}$ & gangá & no se dice & Pedro Hernández Morejón & soltero & 40 \\
\hline 244. & Libro 14 & $17-01-1866$ & Leocadia Kobber & $\mathrm{f}$ & no se dice & morena & A. Kobber & soltera & 28 \\
\hline
\end{tabular}




\begin{tabular}{|c|c|c|c|c|c|c|c|c|c|}
\hline 245. & Libro 14 & $18-01-1866$ & Salomé de la & $\mathrm{m}$ & no se dice & no se dice & no se dice & $m_{e}$ & 0 \\
\hline 246. & Libro 14 & $19-01-1866$ & Néstor Rodríguez & $\mathrm{m}$ & criollo & no se dice & Cecilio Rodríguez & $\mathrm{m}_{\mathrm{e}}$ & 11 \\
\hline 247. & Libro 14 & 23-01-1866 & Candelaria Viciedo & $\mathrm{f}$ & no se dice & morena & Rosario Viciedo & soltera & 38 \\
\hline 248. & Libro 14 & $28-01-1866$ & Rafael Velazco & $\mathrm{m}$ & no se dice & no se dice & Francisco Velazco & $\mathrm{m}_{\mathrm{e}}$ & 1 \\
\hline 249. & Libro 14 & $28-01-1866$ & $\begin{array}{l}\text { Francisco de la } \\
\text { Tejera }\end{array}$ & $\mathrm{m}$ & criollo & moreno & Francisco de la Tejera & soltero & 60 \\
\hline 250. & Libro 14 & 04-02-1866 & Enrique & $\mathrm{m}$ & no se dice & no se dice & Narciso Valdés & $m_{e}$ & 6 \\
\hline 251. & Libro 14 & $07-02-1866$ & Ramón Casanovas & $\mathrm{m}$ & no se dice & pardo & Pablo Casanovas & $\mathrm{m}_{\mathrm{e}}$ & 9 \\
\hline 252. & Libro 14 & $07-02-1866$ & María Luisa & $\mathrm{f}$ & no se dice & no se dice & Manuel Amores & $\mathrm{m}_{\mathrm{e}}$ & 0 \\
\hline 253. & Libro 14 & $02-02-1866$ & Timoteo & $\mathrm{m}$ & gangá & moreno & Francisco Aballí & soltero & 28 \\
\hline 254. & Libro 14 & $13-02-1866$ & Francisca Guerra & $\mathrm{f}$ & gangá & no se dice & Cosme Guerra & soltera & 42 \\
\hline 255. & Libro 14 & $15-02-1866$ & Victoria & $\mathrm{f}$ & no se dice & morena & Catalina Fleming & soltera & 18 \\
\hline 256. & Libro 14 & $18-02-1866$ & Desiderio Osorio & $\mathrm{m}$ & no se dice & no se dice & no se dice & $\mathrm{m}_{\mathrm{e}}$ & 0 \\
\hline 257. & Libro 14 & $21-02-1866$ & $\begin{array}{ll}\text { José } & \text { María } \\
\text { Domínguez } & \end{array}$ & $\mathrm{m}$ & no se dice & no se dice & no se dice & $\mathrm{m}_{\mathrm{e}}$ & 0 \\
\hline 258. & Libro 14 & 07-03-1866 & Micaela & f & criolla & morena & Salvador Baró & $\mathrm{m}_{\mathrm{e}}$ & 1 \\
\hline 259. & Libro 14 & 08-03-1866 & Miguel & $\mathrm{m}$ & criollo & no se dice & Julián Hernández Campos & soltero & 30 \\
\hline 260. & Libro 14 & $10-03-1866$ & Pablo & $\mathrm{m}$ & criollo & pardo & no se dice & $\mathrm{m}_{\mathrm{e}}$ & 0 \\
\hline 261. & Libro 14 & $18-03-1866$ & José Matilde Junco & $\mathrm{m}$ & no se dice & no se dice & no se dice & $\mathrm{m}_{\mathrm{e}}$ & 0 \\
\hline 262. & Libro 14 & $19-03-1866$ & Felipe & $\mathrm{m}$ & criollo & no se dice & Ramón Brufan & soltero & 60 \\
\hline 263. & Libro 14 & $20-03-1866$ & Rosario & $\mathrm{f}$ & gangá & morena & Carlos Lamerend & soltera & 60 \\
\hline 264. & Libro 14 & $20-03-1866$ & Rosa Baró & $\mathrm{f}$ & no se dice & no se dice & no se dice & $\mathrm{m}_{\mathrm{e}}$ & 0 \\
\hline 265. & Libro 14 & $21-03-1866$ & Casilda & $\mathrm{f}$ & criolla & parda & Ramón Rodríguez & $\mathrm{m}_{\mathrm{e}}$ & 3 \\
\hline 266. & Libro 14 & $23-03-1866$ & Francisca & $\mathrm{f}$ & no se dice & no se dice & no se dice & $\mathrm{m}_{\mathrm{e}}$ & 0 \\
\hline 267. & Libro 14 & $25-03-1866$ & Valentín Osuna & $\mathrm{m}$ & gangá & moreno & Manuel Osuna & soltero & 70 \\
\hline 268. & Libro 14 & 27-03-1866 & Carlota Jiménez & $\mathrm{f}$ & no se dice & no se dice & no se dice & $\mathrm{m}_{\mathrm{e}}$ & 2 \\
\hline 269. & Libro 14 & $31-03-1866$ & Úrsula Junco & $\mathrm{f}$ & criolla & morena & no se dice & soltera & 18 \\
\hline 270. & Libro 14 & $31-03-1866$ & Pedro Hernández & $\mathrm{m}$ & gangá & moreno & Pablo Hernández Ríos & soltero & 85 \\
\hline 271. & Libro 14 & 03-04-1866 & Coleta Pon & $\mathrm{f}$ & no se dice & no se dice & no se dice & $\mathrm{m}_{\mathrm{e}}$ & 1 \\
\hline
\end{tabular}




\begin{tabular}{|c|c|c|c|c|c|c|c|c|c|}
\hline 272. & Libro 14 & 07-04-1866 & Elvira Hernández & $\mathrm{f}$ & conga & morena & Martin E. Hernández & soltera & 28 \\
\hline 273. & Libro 14 & 13-04-1866 & Susana Días & $\mathrm{f}$ & criolla & parda & Francisco Días & soltera & 24 \\
\hline 274. & Libro 14 & $15-04-1866$ & Candelario Alemán & $\mathrm{m}$ & no se dice & no se dice & no se dice & $\mathrm{m}_{\mathrm{e}}$ & 0 \\
\hline 275. & Libro 14 & 19-04-1866 & Hermenegildo & $\mathrm{m}$ & no se dice & no se dice & no se dice & $\mathrm{m}_{\mathrm{e}}$ & 0 \\
\hline 276. & Libro 14 & $20-04-1866$ & Isabel & $\mathrm{f}$ & carabalí & morena & Francisco Alonso & soltera & 50 \\
\hline 277. & Libro 14 & $27-04-1866$ & Anastasio Dávalos & $\mathrm{m}$ & no se dice & moreno & no se dice & $\mathrm{m}_{\mathrm{e}}$ & 0 \\
\hline 278. & Libro 14 & $04-05-1866$ & Catalina García & $\mathrm{f}$ & no se dice & morena & Fulgencio García y Sáez & $\mathrm{m}_{\mathrm{e}}$ & 0 \\
\hline 279. & Libro 14 & 04-05-1866 & Agustín & $\mathrm{m}$ & gangá & no se dice & Luis Motiño & soltero & 60 \\
\hline 280. & Libro 14 & $06-05-1866$ & Narcisa García & $\mathrm{f}$ & criolla & morena & Fulgencio García & soltera & 30 \\
\hline 281. & Libro 14 & $10-05-1866$ & Pablo & $\mathrm{m}$ & congo & moreno & Pelegrin Fialo & soltero & 93 \\
\hline 282. & Libro 14 & $11-05-1866$ & Matilda Arteaga & $\mathrm{f}$ & criolla & no se dice & Juan Bautista Arteaga & no se dice & $\mathrm{a}$ \\
\hline 283. & Libro 14 & $15-05-1866$ & Pedro Coll & $\mathrm{m}$ & no se dice & no se dice & no se dice & $\mathrm{m}_{\mathrm{e}}$ & 1 \\
\hline 284. & Libro 14 & $17-05-1866$ & Inés Capó & $\mathrm{f}$ & no se dice & no se dice & no se dice & $\mathrm{m}_{\mathrm{e}}$ & 0 \\
\hline 285. & Libro 14 & $23-05-1866$ & María Capó & $\mathrm{f}$ & no se dice & no se dice & no se dice & $\mathrm{m}_{\mathrm{e}}$ & 0 \\
\hline 286. & Libro 14 & $23-05-1866$ & Daniel Espinosa & $\mathrm{m}$ & no se dice & moreno & no se dice & $\mathrm{m}_{\mathrm{e}}$ & 1 \\
\hline 287. & Libro 14 & 24-05-1866 & Pedro Junquera & $\mathrm{m}$ & congo & moreno & Salvador Junquera & soltero & 24 \\
\hline 288. & Libro 14 & $25-05-1866$ & Hilario & $\mathrm{m}$ & no se dice & moreno & Elena Castellini & $\mathrm{m}_{\mathrm{e}}$ & 12 \\
\hline 289. & Libro 14 & 02-06-1866 & Juan Lorenzo & $\mathrm{m}$ & no se dice & moreno & Manuel Esquerra & no se dice & $\mathrm{a}$ \\
\hline 290. & Libro 14 & 03-06-1866 & María Micaela & $\mathrm{f}$ & no se dice & no se dice & no se dice & $\mathrm{m}_{\mathrm{e}}$ & 0 \\
\hline 291. & Libro 14 & $05-06-1866$ & Matías & $\mathrm{m}$ & no se dice & moreno & Sres. Setien y hermano & soltero & 22 \\
\hline 292. & Libro 14 & $06-06-1866$ & María Tápanes & f & criolla & morena & Benito Ávila & soltera & 28 \\
\hline 293. & Libro 14 & 08-06-1866 & Paulino Jiménez & $\mathrm{m}$ & criollo & moreno & Concepción Jiménez & $\mathrm{m}_{\mathrm{e}}$ & 13 \\
\hline 294. & Libro 14 & $14-06-1866$ & Pascual Gómez & $\mathrm{m}$ & congo & moreno & Sres. Gómez y Ortiz & soltero & 30 \\
\hline 295. & Libro 14 & 14-06-1866 & José & $\mathrm{m}$ & África & moreno & Pedro Cameron & soltero & 48 \\
\hline 296. & Libro 14 & $20-06-1866$ & Epifanio Frelles & $\mathrm{m}$ & no se dice & moreno & no se dice & $\mathrm{m}_{\mathrm{e}}$ & 0 \\
\hline 297. & Libro 14 & $25-06-1866$ & Caridad & $\mathrm{f}$ & no se dice & no se dice & no se dice & $\mathrm{m}_{\mathrm{e}}$ & 2 \\
\hline 298. & Libro 14 & 04-07-1866 & Incas Macías & $\mathrm{m}$ & congo & moreno & Gabriel Macías & soltero & 50 \\
\hline 299. & Libro 14 & $06-07-1866$ & José & $\mathrm{m}$ & gangá & moreno & Tomas Laurence & soltero & 80 \\
\hline 300. & Libro 14 & $12-07-1866$ & Ambrosio Gálvez & $\mathrm{m}$ & criollo & no se dice & José María Gálvez & $\mathrm{m}_{\mathrm{e}}$ & 9 \\
\hline
\end{tabular}




\begin{tabular}{|c|c|c|c|c|c|c|c|c|c|}
\hline 301. & Libro 14 & $19-07-1866$ & Cristina Días & $\mathrm{f}$ & criolla & morena & no se dice & $\mathrm{m}_{\mathrm{e}}$ & 0 \\
\hline 302. & Libro 14 & $20-07-1866$ & $\begin{array}{l}\text { Simón de la } \\
\text { Torriente }\end{array}$ & $\mathrm{m}$ & criollo & moreno & Cosme de la Torriente & no se dice & $\mathrm{a}$ \\
\hline 303. & Libro 14 & $23-07-1866$ & Bonifacio Morales & $\mathrm{m}$ & criollo & pardo & Morales y Benet & soltero & 30 \\
\hline 304. & Libro 14 & 23-07-1866 & Enrique & $\mathrm{m}$ & no se dice & pardo & no se dice & $\mathrm{m}_{\mathrm{e}}$ & 0 \\
\hline 305. & Libro 14 & $26-07-1866$ & Justa Ferrer & $f$ & criolla & parda & Úrsula María Ferrer & soltera & 18 \\
\hline 306. & Libro 14 & $28-07-1866$ & Isabel Valiente & f & lucumí & morena & $\begin{array}{l}\text { Faustino P. Liborio y D. Cándido } \\
\text { Valiente }\end{array}$ & soltera & 40 \\
\hline 307. & Libro 14 & $01-08-1866$ & Juana Morales & $\mathrm{f}$ & criolla & morena & Luz de Morales & soltera & 46 \\
\hline 308. & Libro 14 & 03-08-1866 & Aniceto García & $\mathrm{m}$ & congo & moreno & Felipe García & soltero & 30 \\
\hline 309. & Libro 14 & 04-08-1866 & Emilio de & $\mathrm{m}$ & criollo & no se dice & no se dice & $\mathrm{m}_{\mathrm{e}}$ & 1 \\
\hline 310. & Libro 14 & 06-08-1866 & Sixto Jimeno & $\mathrm{m}$ & criollo & no se dice & no se dice & $\mathrm{m}_{\mathrm{e}}$ & 0 \\
\hline 311. & Libro 14 & 06-08-1866 & María Mariana & $\mathrm{f}$ & no se dice & morena & Luisa Domeche & soltera & 15 \\
\hline 312. & Libro 14 & 08-08-1866 & Ángela & $\mathrm{f}$ & criolla & no se dice & no se dice & $\mathrm{m}_{\mathrm{e}}$ & 4 \\
\hline 313. & Libro 14 & $13-08-1866$ & $\begin{array}{l}\text { Pio Escudero de } \\
\text { Andricain }\end{array}$ & $\mathrm{m}$ & África & moreno & Rosa Escudero de Andricain & soltero & 50 \\
\hline 314. & Libro 14 & $20-08-1866$ & José Blanco & $\mathrm{m}$ & no se dice & no se dice & no se dice & $\mathrm{m}_{\mathrm{e}}$ & 0 \\
\hline 315. & Libro 14 & $20-08-1866$ & Sixto del Valle & $\mathrm{m}$ & criollo & moreno & Manuel del Valle & no se dice & $\mathrm{a}$ \\
\hline 316. & Libro 14 & 24-08-1866 & Dolores García & f & no se dice & parda & Fabián García & no se dice & $\mathrm{a}$ \\
\hline 317. & Libro 14 & $25-08-1866$ & Saturnino Alfonso & $\mathrm{m}$ & criollo & no se dice & Vicente Pinas & soltero & 50 \\
\hline 318. & Libro 14 & $28-08-1866$ & Sabina Izquierdo & $\mathrm{f}$ & mandinga & morena & Ignacio Izquierdo & soltera & 58 \\
\hline 319. & Libro 14 & 02-09-1866 & Santiago Acosta & $\mathrm{m}$ & congo & moreno & Ramón Acosta & soltero & 55 \\
\hline 320. & Libro 14 & 03-09-1866 & Dolores Hernández & f & gangá & morena & Pablo Hernández & no se dice & 50 \\
\hline 321. & Libro 14 & $05-09-1866$ & Elena Bonet & f & gangá & morena & Concepción Bonet & soltera & 40 \\
\hline 322. & Libro 14 & 09-09-1866 & Merced & $\mathrm{f}$ & gangá & morena & Agustín Gómez & soltera & 35 \\
\hline 323. & Libro 14 & 09-09-1866 & Zacarías Rodríguez & $\mathrm{m}$ & gangá & moreno & Ulpiano Rodríguez & soltero & 50 \\
\hline 324. & Libro 14 & $11-09-1866$ & Bruno & $\mathrm{m}$ & criollo & moreno & Sres. Setien y hermano & no se dice & $\mathrm{a}$ \\
\hline 325. & Libro 14 & 11-09-1866 & Celestina Baró & $f$ & macua & morena & José Baró & soltera & 20 \\
\hline 326. & Libro 14 & 13-09-1866 & Polonia Rodríguez & f & criolla & morena & Rafael Rodríguez & soltera & 17 \\
\hline
\end{tabular}




\begin{tabular}{|c|c|c|c|c|c|c|c|c|c|}
\hline 327. & Libro 14 & 03-10-1866 & Salustiano & $\mathrm{m}$ & no se dice & no se dice & $\begin{array}{l}\text { Mariana Armenteros y Trinidad } \\
\text { Armenteros }\end{array}$ & $m_{e}$ & 9 \\
\hline 328. & Libro 14 & 06-10-1866 & Manuel & $\mathrm{m}$ & criollo & moreno & Pedro Salas & no se dice & $\mathrm{a}$ \\
\hline 329. & Libro 14 & 09-10-1866 & Andrés Ávalos & $\mathrm{m}$ & criollo & no se dice & Pedro Antonio Ávalos & no se dice & 22 \\
\hline 330. & Libro 14 & $15-10-1866$ & Agustín & $\mathrm{m}$ & gangá & moreno & Miguel Dama & soltero & 60 \\
\hline 331. & Libro 14 & $18-10-1866$ & Luisa Alsina & f & criolla & morena & Salvador Alsina & soltera & 30 \\
\hline 332. & Libro 14 & $20-10-1866$ & Antonio Gonzalez & $\mathrm{m}$ & no se dice & moreno & $\begin{array}{l}\text { Herederos de Bernardo Gonzalez } \\
\text { Lausan }\end{array}$ & no se dice & 80 \\
\hline 333. & Libro 14 & $23-10-1866$ & Filomena & $\mathrm{f}$ & criolla & morena & Fernando Lichka & no se dice & 20 \\
\hline 334. & Libro 14 & 24-10-1866 & José Hernández & $\mathrm{m}$ & congo & moreno & Domingo Hernández & soltero & 90 \\
\hline 335. & Libro 14 & $25-10-1866$ & Rafael Visiedo & $\mathrm{m}$ & gangá & moreno & José Visiedo & soltero & 50 \\
\hline 336. & Libro 14 & $25-10-1866$ & Dionisio Enrique & $\mathrm{m}$ & no se dice & moreno & Pascasio Gómez & soltero & 60 \\
\hline 337. & Libro 14 & 01-11-1866 & $\begin{array}{l}\text { María de Luz } \\
\text { Rodríguez }\end{array}$ & f & arará & morena & $\begin{array}{l}\text { Herederos de José Rodríguez de } \\
\text { Armas }\end{array}$ & soltera & $\mathrm{a}$ \\
\hline 338. & Libro 14 & $08-11-1866$ & Sofía Betancourt & f & conga & morena & Antolín Betancourt & casada & $\mathrm{a}$ \\
\hline 339. & Libro 14 & $09-11-1866$ & José Casuso & $\mathrm{m}$ & criollo & moreno & Juan Manuel Casuso & $\mathrm{m}_{\mathrm{e}}$ & 8 \\
\hline 340. & Libro 14 & $11-11-1866$ & $\begin{array}{l}\text { José Clotilde } \\
\text { Domínguez }\end{array}$ & $\mathrm{m}$ & criollo & pardo & Jacoba Domínguez & soltero & 25 \\
\hline 341. & Libro 14 & 14-11-1866 & Ernesta Gómez & f & criolla & morena & Lucas Gómez & soltera & 24 \\
\hline 342. & Libro 14 & $15-11-1866$ & Dolores Rodríguez & $\mathrm{f}$ & mandinga & no se dice & Manuel Rodríguez & soltera & 70 \\
\hline 343. & Libro 14 & $17-11-1866$ & Vicenta Baes & f & criolla & morena & Bartolomé Casada & $\mathrm{m}_{\mathrm{e}}$ & 8 \\
\hline 344. & Libro 14 & $20-11-1866$ & Domingo López & $\mathrm{m}$ & congo & moreno & Juan López & soltero & 20 \\
\hline 345. & Libro 14 & $20-11-1866$ & Marcelina Ureña & f & Puerto Rico & morena & Dolores Ureña & no se dice & 58 \\
\hline 346. & Libro 14 & $27-11-1866$ & Felicia Almirall & f & criolla & morena & José Almirall & $\mathrm{m}_{\mathrm{e}}$ & 8 \\
\hline 347. & Libro 14 & $28-11-1866$ & Pilar & $\mathrm{f}$ & no se dice & no se dice & José Batlle & $\mathrm{m}_{\mathrm{e}}$ & 0 \\
\hline 348. & Libro 14 & $01-12-1866$ & María Ignacia & $\mathrm{f}$ & criolla & no se dice & José Visiedo & soltera & 25 \\
\hline 349. & Libro 14 & $02-12-1866$ & Agustín Pellet & $\mathrm{m}$ & criollo & no se dice & José Emilio Pellet & no se dice & 17 \\
\hline 350. & Libro 14 & $03-12-1866$ & Antonio Días & $\mathrm{m}$ & congo & moreno & Juan José Días & soltero & 30 \\
\hline 351. & Libro 14 & $03-12-1866$ & Mateo & $\mathrm{m}$ & África & moreno & Pelegrin Fialo & soltero & 25 \\
\hline
\end{tabular}




\begin{tabular}{|c|c|c|c|c|c|c|c|c|c|}
\hline 352. & Libro 14 & $03-12-1866$ & Nieves Rubio & $\mathrm{f}$ & carabalí & morena & Gregorio Rubio & soltera & 40 \\
\hline 353. & Libro 14 & 04-12-1866 & Desiderio Salas & $\mathrm{m}$ & congo & moreno & José Salas & soltero & 33 \\
\hline 354. & Libro 14 & $06-12-1866$ & Delfina & $\mathrm{f}$ & criolla & parda & Dámaso Dulzaides & $\mathrm{m}_{\mathrm{e}}$ & 6 \\
\hline 355. & Libro 14 & $07-12-1866$ & José & $\mathrm{m}$ & carabalí & moreno & Pedro Cano & soltero & 70 \\
\hline 356. & Libro 14 & $10-12-1866$ & Francisco & $\mathrm{m}$ & gangá & moreno & Leopoldo Zarragoitia & no se dice & 40 \\
\hline 357. & Libro 14 & $11-12-1866$ & Andrés Luria & $\mathrm{m}$ & no se dice & moreno & Enrique Lluria & $\mathrm{m}_{\mathrm{e}}$ & 0 \\
\hline 358. & Libro 14 & $12-12-1866$ & Florencia Plaza & $\mathrm{f}$ & gangá & morena & Eugenia Plaza & no se dice & 36 \\
\hline 359. & Libro 14 & $12-12-1866$ & Tránsito & $\mathrm{f}$ & criolla & morena & Martin Esteva & soltera & 45 \\
\hline 360. & Libro 14 & $12-12-1866$ & Juan Visiedo & $\mathrm{m}$ & criollo & no se dice & José Visiedo & casado & 45 \\
\hline 361. & Libro 14 & $13-12-1866$ & Pascual & $\mathrm{m}$ & congo & moreno & Adeodato A. Salón & soltero & 56 \\
\hline 362. & Libro 14 & $13-12-1866$ & Julia Arocha & $\mathrm{f}$ & criolla & morena & Agustín Gómez & soltera & 24 \\
\hline 363. & Libro 14 & $14-12-1866$ & Joaquín & $\mathrm{m}$ & criollo & moreno & Félix Maylin & soltero & 70 \\
\hline 364. & Libro 14 & $15-12-1866$ & María de la & $\mathrm{f}$ & no se dice & no se dice & Diego Jiménez & $\mathrm{m}_{\mathrm{e}}$ & 0 \\
\hline 365 . & Libro 14 & $15-12-1866$ & Sabina Simpson & $\mathrm{f}$ & criolla & morena & Diego y Antonio Simpson & soltera & 25 \\
\hline 366. & Libro 14 & $16-12-1866$ & Pablo Alonso & $\mathrm{m}$ & criollo & moreno & Francisco Alonso & $\mathrm{m}_{\mathrm{e}}$ & 14 \\
\hline 367. & Libro 14 & $16-12-1866$ & María Inés & $\mathrm{f}$ & criolla & no se dice & Diego Jiménez & soltera & 18 \\
\hline 368. & Libro 14 & $17-12-1866$ & Virginia Mendosa & $\mathrm{f}$ & no se dice & parda & no se dice & $\mathrm{m}_{\mathrm{e}}$ & 4 \\
\hline 369. & Libro 14 & $17-12-1866$ & Josefa Fialo & $\mathrm{f}$ & África & morena & Pelegrin Fialo & no se dice & 15 \\
\hline 370. & Libro 14 & $18-12-1866$ & José María Ortis & $\mathrm{m}$ & congo & moreno & Francisco Ortis & soltero & 40 \\
\hline 371. & Libro 14 & $17-12-1866$ & Indalecio Rubio & $\mathrm{m}$ & criollo & pardo & Gaspar Pérez & soltero & 24 \\
\hline 372. & Libro 14 & $18-12-1866$ & José María & $\mathrm{m}$ & congo & moreno & Francisco Ortis & soltero & 40 \\
\hline 373. & Libro 14 & $19-12-1866$ & León López & $\mathrm{m}$ & África & moreno & Demetrio López & soltero & 45 \\
\hline 374. & Libro 14 & $20-12-1866$ & Domingo Visiedo & $\mathrm{m}$ & congo & moreno & José Visiedo & soltero & 65 \\
\hline 375. & Libro 14 & $21-12-1866$ & Pedro & $\mathrm{m}$ & congo & moreno & Ser. Caricaburu y Aróstegui & no se dice & 16 \\
\hline 376. & Libro 14 & $21-12-1866$ & Merced Burgois & $\mathrm{f}$ & conga & morena & Luis Burgois & soltera & 70 \\
\hline 377. & Libro 14 & $22-12-1866$ & María Petrona & $\mathrm{f}$ & no se dice & no se dice & Andrés Calves & $\mathrm{m}_{\mathrm{e}}$ & 2 \\
\hline 378. & Libro 14 & $22-12-1866$ & José Bacallao & $\mathrm{m}$ & gangá & moreno & Nicolás Bacallao & no se dice & 40 \\
\hline 379. & Libro 14 & 23-12-1866 & Teresa Avalos & $\mathrm{f}$ & criolla & parda & José Avalos & soltera & 24 \\
\hline 380. & Libro 14 & 24-12-1866 & José María & $\mathrm{m}$ & criollo & moreno & Teresa Mansanet (morena libre) & soltero & 40 \\
\hline
\end{tabular}




\begin{tabular}{|c|c|c|c|c|c|c|c|c|c|}
\hline 381. & Libro 14 & 24-12-1866 & Margarita & $\mathrm{f}$ & conga & morena & Juan Vivó & soltera & 45 \\
\hline 382. & Libro 14 & 24-12-1866 & María Antonia & $\mathrm{f}$ & criolla & morena & Aniceto García & soltera & 34 \\
\hline 383. & Libro 14 & $27-12-1866$ & Benita Gómez & $\mathrm{f}$ & criolla & parda & Torcuato Gómez & no se dice & 22 \\
\hline 384. & Libro 14 & $28-12-1866$ & Brito García & $\mathrm{m}$ & no se dice & moreno & Francisco García & $\mathrm{m}_{\mathrm{e}}$ & 13 \\
\hline 385. & Libro 14 & $31-12-1866$ & Dolores Fernández & $\mathrm{f}$ & criolla & parda & Antonio Fernández & soltera & 25 \\
\hline 386. & libro 14 & $01-01-1867$ & Gertrudis Ortiz & $\mathrm{f}$ & criolla & morena & Eusebio Ortiz & soltera & 28 \\
\hline 387. & libro 14 & $01-01-1867$ & Antonio Ferrer & $\mathrm{m}$ & congo & moreno & Francisco Ferrer & soltero & 25 \\
\hline 388. & libro 14 & 02-01-1867 & Pastor del Valle & $\mathrm{m}$ & no se dice & moreno & Herederos de Manuel del Valle & no se dice & 26 \\
\hline 389. & libro 14 & 02-01-1867 & Joaquín Rodríguez & $\mathrm{m}$ & carabalí & moreno & Esteban Rodríguez & soltero & 50 \\
\hline 390. & libro 14 & 02-01-1867 & Félix Mendoza & $\mathrm{m}$ & criollo & moreno & Rafael Mendoza & $\mathrm{m}_{\mathrm{e}}$ & 4 \\
\hline 391. & libro 14 & 03-01-1867 & Adolfo Ybarra & $\mathrm{m}$ & congo & moreno & Vicente Ibarra & no se dice & 21 \\
\hline 392. & libro 14 & $05-01-1867$ & Ricardo Jiménez & $\mathrm{m}$ & criollo & moreno & José Jiménez & no se dice & 40 \\
\hline 393. & libro 14 & $06-01-1867$ & Gervasio Mariscal & $\mathrm{m}$ & congo & moreno & Rafael Mariscal & soltero & 45 \\
\hline 394. & libro 14 & 06-01-1867 & Teodoro Sarrasín & $\mathrm{m}$ & criollo & no se dice & J. B. Sarrasín & no se dice & 25 \\
\hline 395. & libro 14 & $07-01-1867$ & Crispina Martínez & $\mathrm{f}$ & criolla & morena & Juan Martínez & soltera & 36 \\
\hline 396. & libro 14 & 07-01-1867 & Gregorio Tejidor & $\mathrm{m}$ & criollo & moreno & José Tejidor & soltero & 22 \\
\hline 397. & libro 14 & $07-01-1867$ & Dámaso Avalos & $\mathrm{m}$ & no se dice & pardo & Pedro Antonio Avalos & $\mathrm{m}_{\mathrm{e}}$ & 3 \\
\hline 398. & libro 14 & $08-01-1867$ & Pablo Rodríguez & $\mathrm{m}$ & gangá & moreno & Josefa Rodríguez & soltero & 45 \\
\hline 399. & libro 14 & 09-01-1867 & $\begin{array}{l}\text { José María de } \\
\text { Estrada }\end{array}$ & $\mathrm{m}$ & lucumí & moreno & Idelfonso de Estrada & soltero & 80 \\
\hline 400. & libro 14 & $09-01-1867$ & Carmen Garceran & $\mathrm{f}$ & África & morena & Jacinto Garceran & soltera & 22 \\
\hline 401. & libro 14 & $09-01-1867$ & José Yumurí & $\mathrm{m}$ & gangá & moreno & Gaspar Pérez & soltero & 50 \\
\hline 402. & libro 14 & $10-01-1867$ & Vicenta Montero & f & criolla & no se dice & Juan Rodríguez & soltera & 26 \\
\hline 403. & libro 14 & $11-01-1867$ & Florencio Puñales & $\mathrm{m}$ & no se dice & moreno & Micaela Puñales & $\mathrm{m}_{\mathrm{e}}$ & 10 \\
\hline 404. & libro 14 & $13-01-1867$ & Manuel Martínez & $\mathrm{m}$ & congo & moreno & Justo Pastor Martínez & no se dice & 50 \\
\hline 405. & libro 14 & $14-01-1867$ & Úrsula Silva & $\mathrm{f}$ & criolla & morena & Francisco Silva & soltera & 29 \\
\hline 406. & libro 14 & $15-01-1867$ & Pastor Sangines & $\mathrm{m}$ & congo & moreno & Sres. Sangines y hermanos & no se dice & $\mathrm{a}$ \\
\hline 407. & libro 14 & $15-01-1867$ & María de la Cruz & $\mathrm{f}$ & criolla & morena & Pablo Hernández Ríos & soltera & 40 \\
\hline 408. & libro 14 & $17-01-1867$ & Andrés Pon & $\mathrm{m}$ & no se dice & moreno & José Pon & $\mathrm{m}_{\mathrm{e}}$ & 4 \\
\hline
\end{tabular}




\begin{tabular}{|c|c|c|c|c|c|c|c|c|c|}
\hline 409. & libro 15 & $18-01-1867$ & Carmen Riverón & $\mathrm{f}$ & criolla & no se dice & Ángela Riverón (morena libre) & soltera & 60 \\
\hline 410. & libro 15 & $18-01-1867$ & José & $\mathrm{m}$ & congo & moreno & Salvador Junquera & no se dice & 24 \\
\hline 411. & libro 15 & 19-01-1867 & Avelina & $\mathrm{f}$ & criolla & no se dice & Manuela Díaz & soltera & 20 \\
\hline 412. & libro 15 & 20-01-1867 & Telesfora & $\mathrm{f}$ & criolla & no se dice & Domingo Pérez & no se dice & 26 \\
\hline 413. & libro 15 & 20-01-1867 & Narciso & $\mathrm{m}$ & criollo & no se dice & $\begin{array}{l}\text { Herederos de María de Regla } \\
\text { Villalobos }\end{array}$ & no se dice & 15 \\
\hline 414. & libro 15 & 21-01-1867 & Leandro & $\mathrm{m}$ & congo & moreno & Rosa Escudero y Compañía & soltero & 40 \\
\hline 415. & libro 15 & 21-01-1867 & Cirilo & $\mathrm{m}$ & criollo & no se dice & Francisco Ferrer & soltero & 30 \\
\hline 416. & libro 15 & 22-01-1867 & Nazario & $\mathrm{m}$ & congo & moreno & María de la E... & soltero & 19 \\
\hline 417. & libro 15 & 23-01-1867 & Luis & $\mathrm{m}$ & Florida & no se dice & Rosa Escudero & no se dice & 50 \\
\hline 418. & libro 15 & 24-01-1867 & Demetrio & $\mathrm{m}$ & criollo & no se dice & Sixto Avalos & soltero & 20 \\
\hline 419. & libro 15 & 26-01-1867 & Irene & $\mathrm{f}$ & criolla & no se dice & Pedro Antonio Avalos & no se dice & 20 \\
\hline 420. & libro 15 & $28-01-1867$ & Victoriano & $\mathrm{m}$ & criollo & pardo & Antonio Gutiérrez & no se dice & 25 \\
\hline 421. & libro 15 & 29-01-1867 & Pascual & $\mathrm{m}$ & criollo & pardo & José María Olaño & soltero & 18 \\
\hline 422. & libro 15 & $30-01-1867$ & Eusebia Rodríguez & $\mathrm{f}$ & criolla & parda & María Fabelo & no se dice & 24 \\
\hline 423. & libro 15 & $31-01-1867$ & Nicolás & $\mathrm{m}$ & congo & moreno & Bienvenido Caballol & no se dice & 26 \\
\hline 424. & libro 15 & $01-02-1867$ & $\begin{array}{l}\text { Guadalupe } \\
\text { Almendro }\end{array}$ & $\mathrm{f}$ & criolla & parda & Antonio Almendro & no se dice & 15 \\
\hline 425. & libro 15 & $01-02-1867$ & Rosalía & f & no se dice & no se dice & Manuel Domínguez & $\mathrm{m}_{\mathrm{e}}$ & $\mathrm{p}$ \\
\hline 426. & libro 15 & $02-02-1867$ & Carlos Espinosa & $\mathrm{m}$ & criollo & no se dice & Celestino Espinosa & $\mathrm{m}_{\mathrm{e}}$ & 7 \\
\hline 427. & libro 15 & $02-02-1867$ & María Andua & $\mathrm{f}$ & conga & morena & José María Andua & no se dice & 36 \\
\hline 428. & libro 15 & $05-02-1867$ & Josefa & $\mathrm{f}$ & conga & morena & Saturnino Basda & soltera & 24 \\
\hline 429. & libro 15 & $05-02-1867$ & Esteban & $\mathrm{m}$ & conga & moreno & José K. y Compañía & no se dice & 38 \\
\hline 430. & libro 15 & $05-02-1867$ & Severo & $\mathrm{m}$ & África & moreno & María de Regla Alfonso & no se dice & 40 \\
\hline 431. & libro 15 & 07-02-1867 & Rosario & f & lucumí & morena & Félix Govín & soltera & 50 \\
\hline 432. & libro 15 & $07-02-1867$ & Gregoria & $\mathrm{f}$ & criolla & no se dice & Luis Arnet & soltera & a \\
\hline 433. & libro 15 & $08-02-1867$ & Petrona & $\mathrm{f}$ & no se dice & no se dice & Manuel Domínguez & $\mathrm{m}_{\mathrm{e}}$ & 3 \\
\hline 434. & libro 15 & $09-02-1867$ & Gumersinda & $\mathrm{f}$ & criolla & no se dice & Antonio María Simpson & soltera & 25 \\
\hline 435. & libro 15 & $12-02-1867$ & Fernanda & f & criolla & morena & Lope Dávalos & no se dice & 40 \\
\hline
\end{tabular}




\begin{tabular}{|c|c|c|c|c|c|c|c|c|c|}
\hline 436. & libro 15 & $13-02-1867$ & Paulino & $\mathrm{m}$ & Portugal & moreno & Roda Esendero & no se dice & 30 \\
\hline 437. & libro 15 & $13-02-1867$ & Teodora & $\mathrm{f}$ & criolla & morena & Fernando Sichka & soltera & 26 \\
\hline 438. & libro 15 & $14-02-1867$ & Seferina & $\mathrm{f}$ & criolla & morena & María Grnaford & no se dice & 16 \\
\hline 439. & libro 15 & $14-02-1867$ & Gaspar & $\mathrm{m}$ & criollo & moreno & Pedro Sala & no se dice & 28 \\
\hline 440. & libro 15 & $15-02-1867$ & Tomás & $\mathrm{m}$ & no se dice & moreno & Manuel Solano & no se dice & 55 \\
\hline 441. & libro 15 & $17-02-1867$ & Fernando & $\mathrm{m}$ & gangá & moreno & Pedro Sala & no se dice & 45 \\
\hline 442. & libro 15 & $17-02-1867$ & Carlota & $\mathrm{f}$ & gangá & morena & Felipe García & no se dice & 50 \\
\hline 443. & libro 15 & $20-02-1867$ & Francisco & $\mathrm{m}$ & gangá & moreno & Pedro Sala & no se dice & 48 \\
\hline 444. & libro 15 & $22-02-1867$ & Bonifacia & $\mathrm{f}$ & no se dice & morena & Cecilio Rodríguez & $\mathrm{m}_{\mathrm{e}}$ & 2 \\
\hline 445. & libro 15 & $27-02-1867$ & Ángel & $\mathrm{m}$ & África & moreno & Bartolomé R. Sampedro & $\mathrm{m}_{\mathrm{e}}$ & 14 \\
\hline 446. & libro 15 & $28-02-1867$ & Mercedes & $\mathrm{f}$ & conga & morena & Francisco Sosa & soltera & 50 \\
\hline 447. & libro 15 & 01-03-1867 & Silvestra & $\mathrm{f}$ & criolla & no se dice & Manuela Almendaris & no se dice & 19 \\
\hline 448. & libro 15 & 01-03-1867 & Crescencia & $\mathrm{f}$ & criolla & morena & Eduardo García & no se dice & 32 \\
\hline 449. & libro 15 & $02-03-1867$ & Isidro & $\mathrm{m}$ & congo & moreno & Eloy Navia & no se dice & 50 \\
\hline 450. & libro 15 & 03-03-1867 & Domingo & $\mathrm{m}$ & criollo & moreno & Domingo Páez y Mora & soltero & 27 \\
\hline 451. & libro 15 & 04-03-1867 & Manuel & $\mathrm{m}$ & no se dice & moreno & Miguel Dama & soltero & 25 \\
\hline 452. & libro 15 & $05-03-1867$ & Manuel & $\mathrm{m}$ & congo & moreno & Bernardo Curvelo & no se dice & 40 \\
\hline 453. & libro 15 & $07-03-1867$ & Juan de Dios & $\mathrm{m}$ & gangá & moreno & Josefa Maner & soltero & 60 \\
\hline 454. & libro 15 & 08-03-1867 & Francisco & $\mathrm{m}$ & criollo & no se dice & Agustín N. Madan & $\mathrm{m}_{\mathrm{e}}$ & 8 \\
\hline 455. & libro 15 & $08-03-1867$ & David & $\mathrm{m}$ & congo & moreno & Francisco Alballo & no se dice & 20 \\
\hline 456. & libro 15 & $10-03-1867$ & Encarnación & f & criolla & no se dice & Sres. Casimiro y Reconco & no se dice & $\mathrm{a}$ \\
\hline 457. & libro 15 & $10-03-1867$ & Guadalupe & $\mathrm{f}$ & conga & morena & Miguel Cuní y Compañía & soltero & 20 \\
\hline 458. & libro 15 & $12-03-1867$ & Esteban & $\mathrm{m}$ & criollo & no se dice & Antonio Lena & soltero & 45 \\
\hline 459. & libro 15 & $17-03-1867$ & Francisco & $\mathrm{m}$ & criollo & moreno & Julián Hernández Campos & soltero & 18 \\
\hline 460. & libro 15 & 21-03-1867 & Narciso & $\mathrm{m}$ & criollo & moreno & Francisco Aballí & no se dice & 38 \\
\hline 461. & libro 15 & 23-03-1867 & Pedro & $\mathrm{m}$ & gangá & moreno & Bernardo Márquez & soltero & 44 \\
\hline 462. & libro 15 & 02-04-1867 & Antonio & $\mathrm{m}$ & congo & moreno & Miguel Cuní y Compañía & soltero & 22 \\
\hline 463. & libro 15 & 03-04-1867 & Leonarda & $\mathrm{f}$ & criolla & no se dice & Bernardo Junco & soltera & 18 \\
\hline 464. & libro 15 & 04-04-1867 & Enrique & $\mathrm{m}$ & carabalí & moreno & Pedro Sala & soltero & 80 \\
\hline
\end{tabular}




\begin{tabular}{|c|c|c|c|c|c|c|c|c|c|}
\hline 465. & libro 15 & 08-04-1867 & Anastasio Pendas & $\mathrm{m}$ & congo & moreno & Sres. Pendas y Compañía & no se dice & 20 \\
\hline 466. & libro 15 & 08-04-1867 & Genaro Días & $\mathrm{m}$ & criollo & no se dice & José Francisco Días & $\mathrm{m}_{\mathrm{e}}$ & 1 \\
\hline 467. & libro 15 & 08-04-1867 & $\begin{array}{ll}\text { María } & \text { Regla } \\
\text { Casabuena } & \end{array}$ & $f$ & criolla & morena & Catalina Pérez & no se dice & 42 \\
\hline 468. & libro 15 & $12-04-1867$ & Lucas Torres & $\mathrm{m}$ & criollo & moreno & Julián Rodríguez & no se dice & 38 \\
\hline 469. & libro 15 & $12-04-1867$ & Gonzalo & $\mathrm{m}$ & gangá & moreno & Pablo Hernández & no se dice & 54 \\
\hline 470. & libro 15 & $12-04-1867$ & Marcelina Pérez & $\mathrm{f}$ & no se dice & morena & Gabriel Pérez & no se dice & 80 \\
\hline 471. & libro 15 & $13-04-1867$ & Margarita Gómez & $\mathrm{f}$ & criolla & parda & Juan Luis Gómez & no se dice & 22 \\
\hline 472. & libro 15 & $18-04-1867$ & José Colomina & $\mathrm{m}$ & gangá & moreno & Vicente Colomina & no se dice & 55 \\
\hline 473. & libro 15 & $26-04-1867$ & Leocadia Días & $\mathrm{f}$ & lucumí & morena & Juan José Días & no se dice & 40 \\
\hline 474. & libro 15 & $30-04-1867$ & Elogio Cuní & $\mathrm{m}$ & gangá & moreno & Miguel Cuní y Compañía & soltero & 32 \\
\hline 475. & libro 15 & $03-05-1867$ & Felicia & $\mathrm{f}$ & no se dice & no se dice & Zacarías A. & no se dice & 40 \\
\hline 476. & libro 15 & $04-05-1867$ & Rafael Palencia & $\mathrm{m}$ & congo & moreno & Josefa Palencia & soltero & 90 \\
\hline 477. & libro 15 & $14-05-1867$ & Susana Calvar & $\mathrm{f}$ & no se dice & morena & Victoria Calvar & $\mathrm{m}_{\mathrm{e}}$ & 3 \\
\hline 478. & libro 15 & $23-05-1867$ & Filomena Pintado & f & carabalí & morena & Tomás Pintado & soltera & 60 \\
\hline 479. & libro 15 & $27-05-1867$ & Guillermo & $\mathrm{m}$ & criollo & moreno & Sres. Pendas y Compañía & no se dice & 35 \\
\hline 480. & libro 15 & $05-06-1867$ & Rita Buadas & f & gangá & morena & Magdalena Buadas & no se dice & 40 \\
\hline 481. & libro 15 & 08-06-1867 & José Interian & $\mathrm{m}$ & criollo & no se dice & Pedro Interian & no se dice & 35 \\
\hline 482. & libro 15 & $10-06-1867$ & Antonio Lavayen & $\mathrm{m}$ & congo & moreno & Sres. Lavayen y Compañía & no se dice & 26 \\
\hline 483. & libro 15 & $15-06-1867$ & Luis Aballí & $\mathrm{m}$ & no se dice & pardo & Francisco Aballí & $\mathrm{m}_{\mathrm{e}}$ & 2 \\
\hline 484. & libro 15 & $21-06-1867$ & Justo Salord & $\mathrm{m}$ & criollo & moreno & Adeosdato Salord & soltero & 28 \\
\hline 485. & libro 15 & $20-06-1867$ & Augusto & $\mathrm{m}$ & criollo & moreno & Rosa Escudero & no se dice & 30 \\
\hline 486. & libro 15 & 28-06-1867 & Flora & f & criolla & parda & Petrona Milian y García & soltera & 26 \\
\hline 487. & libro 15 & $05-07-1867$ & Manuel & $\mathrm{m}$ & criollo & no se dice & Vicente C. & $\mathrm{m}_{\mathrm{e}}$ & 0 \\
\hline 488. & libro 15 & 05-07-1867 & Agustín García & $\mathrm{m}$ & criollo & moreno & Jaime García y Juan Fanjul & soltero & 30 \\
\hline 489. & libro 15 & 06-07-1867 & Justa Vallenilla & f & lucumí & morena & Manuel Vallenilla & no se dice & 40 \\
\hline 490. & libro 15 & $09-77-1867$ & Luisa Gutiérrez & f & criolla & parda & José Gutiérrez & $\mathrm{m}_{\mathrm{e}}$ & 0 \\
\hline 491. & libro 15 & $11-07-1867$ & Filomena & $f$ & criolla & no se dice & Micaela Marcotegui & soltera & 17 \\
\hline 492. & libro 15 & $15-07-1867$ & Celestino & $\mathrm{m}$ & carabalí & moreno & Benito Fernández y Compañía & no se dice & 110 \\
\hline
\end{tabular}




\begin{tabular}{|c|c|c|c|c|c|c|c|c|c|}
\hline 493. & libro 15 & $17-07-1867$ & Luisa Coll & $\mathrm{f}$ & conga & morena & Rosa Pedrosa de Coll & soltera & 50 \\
\hline 494. & libro 15 & $17-07-1867$ & Martina Arteaga & $\mathrm{f}$ & criolla & morena & Juan Bautista Arteaga & no se dice & 30 \\
\hline 495. & libro 15 & $19-07-1867$ & Arturo Fuentes & $\mathrm{m}$ & criollo & moreno & Isabel de Fuentes de Jimeno & $\mathrm{m}_{\mathrm{e}}$ & 0 \\
\hline 496. & libro 15 & $25-07-1867$ & Manuel & $\mathrm{m}$ & gangá & moreno & Carmen Espericueta & no se dice & 50 \\
\hline 497. & libro 15 & $27-07-1867$ & Carlos Pereira & $\mathrm{m}$ & congo & moreno & José Miguel Pereira & soltero & 50 \\
\hline 498. & libro 15 & $29-07-1867$ & Nicolás Rodríguez & $\mathrm{m}$ & gangá & moreno & José María Rodríguez & no se dice & 50 \\
\hline 499. & libro 15 & $11-08-1867$ & Pedro Milian & $\mathrm{m}$ & criollo & no se dice & Juan Milian & soltero & 50 \\
\hline 500. & libro 15 & $19-08-1867$ & Francisca García & f & lucumí & morena & Genoveva García & no se dice & 80 \\
\hline 501. & libro 15 & $21-08-1867$ & Lucía Anciano & $\mathrm{f}$ & lucumí & morena & Ciriaco Anciano & no se dice & 35 \\
\hline 502. & libro 15 & $22-08-1867$ & Trinidad Blay & $\mathrm{m}$ & gangá & moreno & Herederos de Pablo Blay & no se dice & 50 \\
\hline 503. & libro 15 & $25-08-1867$ & Julián Mayor & $\mathrm{m}$ & criollo & moreno & Pablo Mayor & no se dice & 50 \\
\hline 504. & libro 15 & $25-08-1867$ & Gonzalo Alfonso & $\mathrm{m}$ & África & moreno & Pedro Antonio Alfonso & no se dice & 60 \\
\hline 505. & libro 15 & $28-08-1867$ & Federica Jiménez & $\mathrm{f}$ & criolla & no se dice & R. M. Alandete & no se dice & 16 \\
\hline 506. & libro 15 & $31-08-1867$ & Ruperto Santo & $\mathrm{m}$ & mina & moreno & Ambrosio Concepción Santo & soltero & 50 \\
\hline 507. & libro 15 & $12-09-1867$ & Joaquín & $\mathrm{m}$ & no se dice & pardo & José Salas & no se dice & a \\
\hline 508. & libro 15 & $16-09-1867$ & Fernando & $\mathrm{m}$ & África & moreno & Nicolasa Compen (morena libre) & no se dice & 70 \\
\hline 509. & libro 15 & $19-09-1867$ & Dorotea & $\mathrm{f}$ & criolla & morena & Massimo Famargo & soltera & 19 \\
\hline 510. & libro 15 & $22-09-1867$ & Agustín & $\mathrm{m}$ & criollo & moreno & Salvador Alcina & soltero & 60 \\
\hline 511. & libro 15 & 29-09-1867 & José & $\mathrm{m}$ & criollo & pardo & Pedro Fullá & no se dice & 24 \\
\hline 512. & libro 15 & $01-10-1867$ & Cornelio & $\mathrm{m}$ & criollo & no se dice & José Buigas & $\mathrm{m}_{\mathrm{e}}$ & 0 \\
\hline 513. & libro 15 & $02-10-1867$ & Andrea & $\mathrm{f}$ & criolla & morena & no se dice & $\mathrm{m}_{\mathrm{e}}$ & 6 \\
\hline 514. & libro 15 & 02-10-1867 & Juan & $\mathrm{m}$ & carabalí & moreno & Isabel Viciedo y Cartaya & no se dice & 70 \\
\hline 515. & libro 15 & 03-10-1867 & Teodoro & $\mathrm{m}$ & criollo & moreno & Federico Molina & $\mathrm{m}_{\mathrm{e}}$ & 0 \\
\hline 516. & libro 15 & $11-10-1867$ & José & $\mathrm{m}$ & gangá & moreno & Nicolás Vehil & soltero & 50 \\
\hline 517. & libro 15 & $20-10-1867$ & Luis & $\mathrm{m}$ & África & moreno & Jaime Puig & soltero & 50 \\
\hline 518. & libro 15 & $21-10-1867$ & Eduardo Knight & $\mathrm{m}$ & criollo & pardo & Rita Knight & $\mathrm{m}_{\mathrm{e}}$ & 0 \\
\hline 519. & libro 15 & $21-10-1867$ & Isabel & $\mathrm{f}$ & gangá & morena & Herederos de Francisco Sevilla & soltera & 55 \\
\hline 520. & libro 15 & $27-10-1867$ & Wencesla & $\mathrm{f}$ & no se dice & parda & Marta del Diestro & no se dice & $\mathrm{a}$ \\
\hline 521. & libro 15 & 03-11-1867 & Eugenio & $\mathrm{m}$ & criollo & moreno & Rita Martínez & no se dice & 20 \\
\hline
\end{tabular}




\begin{tabular}{|c|c|c|c|c|c|c|c|c|c|}
\hline 522. & libro 15 & $05-11-1867$ & Matías & $\mathrm{m}$ & gangá & moreno & Basilio Fosca & soltero & 45 \\
\hline 523. & libro 15 & $12-11-1867$ & Lucila & $\mathrm{f}$ & criolla & no se dice & Lucas Francés & $\mathrm{m}_{\mathrm{e}}$ & 0 \\
\hline 524. & libro 15 & $14-11-1867$ & Martín Carbonell & $\mathrm{m}$ & criollo & pardo & Ana Carbonell & $\mathrm{m}_{\mathrm{e}}$ & 0 \\
\hline 525. & libro 15 & $17-11-1867$ & Juana & $\mathrm{f}$ & conga & morena & Manuel del Portillo & soltera & 78 \\
\hline 526. & libro 15 & $23-11-1867$ & Esteban & $\mathrm{m}$ & criollo & pardo & Ramón Font & $\mathrm{m}_{\mathrm{e}}$ & 2 \\
\hline 527. & libro 15 & 24-11-1867 & Flora & $\mathrm{f}$ & criolla & no se dice & Gabriela Mendoza & $\mathrm{m}_{\mathrm{e}}$ & 0 \\
\hline 528. & libro 15 & $25-11-1867$ & Faustina & $\mathrm{f}$ & criolla & morena & Eugenio Coffigny & $\mathrm{m}_{\mathrm{e}}$ & 0 \\
\hline 529. & libro 15 & $27-11-1867$ & Enrique & $\mathrm{m}$ & criollo & no se dice & Enrique Lluria & $\mathrm{m}_{\mathrm{e}}$ & 0 \\
\hline 530. & libro 15 & $28-11-1867$ & Abraham & $\mathrm{m}$ & criollo & pardo & Josefa Sosa & $\mathrm{m}_{\mathrm{e}}$ & $\mathrm{p}$ \\
\hline 531. & libro 15 & $30-11-1867$ & Hilario & $\mathrm{m}$ & congo & moreno & Vicente Capote & no se dice & 75 \\
\hline 532. & libro 15 & $07-12-1867$ & Eulogio & $\mathrm{m}$ & carabalí & moreno & J. Ferrer & soltero & 24 \\
\hline 533. & libro 15 & $07-12-1867$ & Nicolasa & $\mathrm{f}$ & criolla & no se dice & Francisco Menocal & no se dice & 20 \\
\hline 534. & libro 15 & $12-12-1867$ & Andrés & $\mathrm{m}$ & no se dice & no se dice & Pedro Romero & $\mathrm{m}_{\mathrm{e}}$ & 8 \\
\hline 535. & libro 15 & $14-12-1867$ & Martina & $\mathrm{f}$ & criolla & morena & José M. Prin & soltera & 42 \\
\hline 536. & libro 15 & $05-01-1868$ & Ildefonsa & $\mathrm{f}$ & criolla & morena & Petrona Milian y García & viuda & 42 \\
\hline 537. & libro 15 & $10-01-1868$ & María & $\mathrm{f}$ & conga & morena & Miguel Abrina & no se dice & 19 \\
\hline 538. & libro 15 & $05-02-1868$ & Tomas Aballí & $\mathrm{m}$ & criollo & moreno & Francisco Aballí & soltero & 26 \\
\hline 539. & libro 15 & $15-02-1868$ & Pedro & $\mathrm{m}$ & congo & moreno & Rosa Escudero de Andricain & soltero & 40 \\
\hline 540. & libro 15 & $15-02-1868$ & Alejandro & $\mathrm{m}$ & criollo & moreno & Josefa Sosa & soltero & 32 \\
\hline 541. & libro 15 & $19-02-1868$ & José Castillo & $\mathrm{m}$ & no se dice & moreno & Rosa Pedrosa & soltero & 50 \\
\hline 542. & libro 15 & $26-02-1868$ & Anastasia & $\mathrm{f}$ & criolla & no se dice & Ignacio Cañizares & viuda & 38 \\
\hline 543. & libro 15 & $29-02-1868$ & Manuel Macabí & $\mathrm{m}$ & criollo & moreno & Francisca Palles & no se dice & 26 \\
\hline 544. & libro 15 & $02-03-1868$ & Tranquilina & $\mathrm{f}$ & criolla & morena & Elena Martínez & no se dice & no \\
\hline 545. & libro 15 & $05-03-1868$ & Isabel & $\mathrm{f}$ & macua & morena & Francisco Aballí & no se dice & 30 \\
\hline 546. & libro 15 & $05-03-1868$ & Gregoria & $\mathrm{f}$ & criolla & morena & Ramón Russinyol & soltera & 25 \\
\hline 547. & libro 15 & 08-03-1868 & Andrés & $\mathrm{m}$ & congo & moreno & Rosa Escudero de Andricain & soltero & 60 \\
\hline 548. & libro 15 & 09-03-1868 & Margarita & $\mathrm{f}$ & criolla & no se dice & Juan Vivó & no se dice & 25 \\
\hline 549. & libro 15 & 09-03-1868 & $\begin{array}{l}\text { Pio Antonio María } \\
\text { Junquera }\end{array}$ & $\mathrm{m}$ & África & moreno & Salvador Junquera & no se dice & 55 \\
\hline
\end{tabular}




\begin{tabular}{|c|c|c|c|c|c|c|c|c|c|c|}
\hline 550. & libro 15 & $10-03-1868$ & Tomasa Torres & $\mathrm{f}$ & criolla & morena & Margarita Torres de Delmonte & soltera & 25 & \\
\hline 551. & libro 15 & $14-03-1868$ & Manuel & $\mathrm{m}$ & congo & moreno & Francisco Aballí & no se dice & 24 & \\
\hline 552. & libro 15 & $15-03-1868$ & Justa & $\mathrm{f}$ & criolla & morena & José Pon & soltera & 20 & \\
\hline 553. & libro 15 & $18-03-1868$ & Sabino Hernández & $\mathrm{m}$ & no se dice & moreno & Isidoro Hernández & soltero & 35 & \\
\hline 554. & libro 15 & $20-03-1868$ & Nicomedes & $\mathrm{m}$ & arará & moreno & Juan de Fuentes y Pérez & soltero & 40 & \\
\hline 555. & libro 15 & $22-03-1868$ & Carlos & $\mathrm{m}$ & gangá & moreno & Úrsula de los Ríos de Parga & no se dice & 62 & \\
\hline 556. & libro 15 & $23-03-1868$ & José Sains & $\mathrm{m}$ & criollo & moreno & Sres. Gómez y Ortiz & soltero & 28 & \\
\hline 557. & libro 15 & $26-03-1868$ & Rosario Almendro & $\mathrm{f}$ & criolla & morena & Antonio Almendro & no se dice & 50 & \\
\hline 558. & libro 15 & $27-03-1868$ & Pio Motino & $\mathrm{m}$ & congo & moreno & Luis Motino & soltero & 50 & \\
\hline 559. & libro 15 & $28-03-1868$ & Dolores & $\mathrm{f}$ & conga & morena & Fermín Martínez & no se dice & 30 & \\
\hline 560. & libro 15 & $30-03-1868$ & Paulino & $\mathrm{m}$ & macua & moreno & Sres. Morales y Benet & soltero & 36 & \\
\hline 561. & libro 15 & 01-04-1868 & José Matarell & $\mathrm{m}$ & criollo & moreno & Alejandro José Matarell & no se dice & 18 & \\
\hline 562. & libro 15 & 04-04-1868 & Filomeno Lorest & $\mathrm{m}$ & criollo & no se dice & Carmen de la Calle & no se dice & 15 & \\
\hline 563. & libro 15 & 07-04-1868 & Asunción Ramos & $\mathrm{f}$ & criolla & morena & Ignacio Ramos & soltera & 35 & \\
\hline 564. & libro 15 & $10-04-1868$ & Eustasio Zubieta & $\mathrm{m}$ & criollo & moreno & María de Jesús Ortega & soltero & 26 & \\
\hline 565. & libro 15 & $10-04-1868$ & Cándido & $\mathrm{m}$ & macua & moreno & Pelegrin Fialo & no se dice & 30 & \\
\hline 566. & libro 15 & $13-04-1868$ & Juana de la Cruz & $\mathrm{f}$ & criolla & no se dice & Agustina Arebí & no se dice & 49 & \\
\hline 567. & libro 15 & $18-04-1868$ & Manuel & $\mathrm{m}$ & congo & moreno & José Mir & no se dice & no & se \\
\hline 568. & libro 15 & 21-04-1868 & Dolores Solano & $\mathrm{f}$ & criolla & morena & Manuel Solano & soltera & 90 & \\
\hline 569. & libro 15 & 29-04-1868 & Teresa Perdomo & $\mathrm{f}$ & no se dice & morena & Manuel Domínguez & soltera & 32 & \\
\hline 570. & libro 15 & $30-04-1868$ & Carlos García & $\mathrm{m}$ & congo & moreno & Fabián García & no se dice & 40 & \\
\hline 571. & libro 15 & $03-05-1868$ & Belén Roque & $\mathrm{f}$ & criolla & morena & Josefa Roque & soltera & 19 & \\
\hline 572. & libro 15 & $05-05-1868$ & Justo Zayas & $\mathrm{m}$ & gangá & moreno & Fernando Zayas & no se dice & 50 & \\
\hline 573. & libro 15 & 07-05-1868 & Joaquina Ferrera & $\mathrm{f}$ & carabalí & morena & Calixto Ferrera & no se dice & 76 & \\
\hline 574. & libro 15 & $08-05-1868$ & $\begin{array}{l}\text { Félix Hernández } \\
\text { Piloto }\end{array}$ & $\mathrm{m}$ & gangá & moreno & Domingo Hernández Piloto & no se dice & 50 & \\
\hline 575. & libro 15 & $09-05-1868$ & Martin Capó & $\mathrm{m}$ & macua & moreno & Pedro Capó & soltero & 34 & \\
\hline 576. & libro 15 & $10-05-1868$ & Tomasa Martínez & $\mathrm{f}$ & criolla & morena & Elena Martínez & soltera & 34 & \\
\hline 577. & libro 15 & $11-05-1868$ & Carlos Benites & $\mathrm{m}$ & criollo & pardo & Salvador Alcina & soltero & 33 & \\
\hline
\end{tabular}




\begin{tabular}{|c|c|c|c|c|c|c|c|c|c|c|}
\hline 578. & libro 15 & $11-05-1868$ & María Candelaria & $\mathrm{f}$ & criolla & morena & Gregorio Gumá & soltera & 26 & \\
\hline 579. & libro 15 & $11-05-1868$ & Catalina & $\mathrm{f}$ & carabalí & morena & Ramón Silveira & viuda & 55 & \\
\hline 580. & libro 15 & $12-05-1868$ & Carlos & $\mathrm{m}$ & criollo & moreno & José Joaquín & soltero & 24 & \\
\hline 581. & libro 15 & $14-05-1868$ & Eduardo Alcina & $\mathrm{m}$ & congo & moreno & Salvador Alcina & soltero & 21 & \\
\hline 582. & libro 15 & $14-05-1868$ & Felicia & $\mathrm{f}$ & gangá & morena & Julio & soltera & 63 & \\
\hline 583. & libro 15 & $15-05-1868$ & Gregorio Alcina & $\mathrm{m}$ & criollo & moreno & Salvador Alcina & soltero & 22 & \\
\hline 584. & libro 15 & $18-05-1868$ & María & $\mathrm{f}$ & gangá & morena & José María Olmo & soltera & 40 & \\
\hline 585. & libro 15 & $18-05-1868$ & Margarita & $\mathrm{f}$ & criolla & morena & Domingo Hernández Piloto & soltera & 32 & \\
\hline 586. & libro 15 & $19-05-1868$ & Gregorio Fuentes & $\mathrm{m}$ & criollo & moreno & Andrés Calín & no se dice & 80 & \\
\hline 587. & libro 15 & $22-05-1868$ & Sofía & $\mathrm{f}$ & mandinga & morena & Julio & soltera & 67 & \\
\hline 588. & libro 15 & 23-05-1868 & Petrona & $\mathrm{f}$ & conga & morena & Julián Maresma & soltera & no & se \\
\hline 589. & libro 15 & $24-05-1868$ & Paula Govín & f & criolla & no se dice & Desideria Govín & soltera & 40 & \\
\hline 590. & libro 15 & $26-05-1868$ & $\begin{array}{l}\text { María de los } \\
\text { Ángeles Martínez }\end{array}$ & $\mathrm{f}$ & no se dice & parda & Miguel Martínez & $\mathrm{m}_{\mathrm{e}}$ & 5 & \\
\hline 591. & libro 15 & $26-05-1868$ & Telesfora & $\mathrm{f}$ & conga & morena & Pedro Camerón & soltera & 20 & \\
\hline 592. & libro 15 & $30-05-1868$ & Margarita & $\mathrm{f}$ & conga & morena & Juan Nento & soltera & 25 & \\
\hline 593. & libro 15 & $30-05-1868$ & German & $\mathrm{m}$ & criollo & moreno & María Ortega & soltero & 46 & \\
\hline 594. & libro 15 & $30-05-1868$ & Mónica & $\mathrm{f}$ & criolla & morena & Agustín Madan & soltera & 46 & \\
\hline 595. & libro 15 & 01-06-1868 & Manuela Acosta & $\mathrm{f}$ & mina & morena & Ignacio María de Acosta & soltera & 40 & \\
\hline 596. & libro 15 & 03-06-1868 & Gabriel & $\mathrm{m}$ & arará & moreno & Pedro Sala & soltero & 50 & \\
\hline 597. & libro 15 & 04-06-1868 & Luisa & $\mathrm{f}$ & carabalí & morena & José Martínez & soltera & 47 & \\
\hline 598. & libro 15 & 04-06-1868 & Valentina & $\mathrm{f}$ & criolla & morena & Miguel Martínez & $\mathrm{m}_{\mathrm{e}}$ & 0 & \\
\hline 599. & libro 15 & 06-06-1868 & Carlos & $\mathrm{m}$ & mina & moreno & Isabel & soltero & 45 & \\
\hline 600. & libro 15 & 07-06-1868 & Juan Martínez & $\mathrm{m}$ & macua & moreno & Tomas Martínez & soltero & 30 & \\
\hline 601. & libro 15 & 09-06-1868 & Antonio Vega & $\mathrm{m}$ & criollo & moreno & José Vega & soltero & 27 & \\
\hline 602. & libro 15 & $10-06-1868$ & Juan & $\mathrm{m}$ & criollo & moreno & Guadalupe del Junco de Gener & soltero & 50 & \\
\hline 603. & libro 15 & 09-06-1868 & Bonifacio Alfonso & $\mathrm{m}$ & criollo & pardo & no se dice & $\mathrm{m}_{\mathrm{e}}$ & 1 & \\
\hline 604. & libro 15 & $12-06-1868$ & Serafín Junco & $\mathrm{m}$ & criollo & pardo & Tomás Junco & soltero & 40 & \\
\hline 605. & libro 15 & $12-06-1868$ & Irvina & $\mathrm{f}$ & criolla & morena & Ramón Larrién & soltera & 37 & \\
\hline
\end{tabular}




\begin{tabular}{|c|c|c|c|c|c|c|c|c|c|}
\hline 606. & libro 15 & 14-06-1868 & Francisco & $\mathrm{m}$ & criollo & moreno & Ignacio de Arellano & soltero & 60 \\
\hline 607. & libro 15 & $16-06-1868$ & María Labade & $\mathrm{f}$ & criolla & morena & Santos Piloto & soltera & 35 \\
\hline 608. & libro 15 & $17-06-1868$ & Isabel & $\mathrm{f}$ & criolla & morena & Pastora Fernández & $\mathrm{m}_{\mathrm{e}}$ & 12 \\
\hline 609. & libro 15 & $17-06-1868$ & Lorenzo & $\mathrm{m}$ & macua & moreno & Juana Peraza & soltero & 60 \\
\hline 610. & libro 15 & $17-06-1868$ & Francisca & $\mathrm{f}$ & no se dice & morena & Carlota Govín & no se dice & 50 \\
\hline 611. & libro 15 & $17-06-1868$ & Juan de la Cruz & $\mathrm{m}$ & criollo & moreno & Avelina Fernández & $\mathrm{m}_{\mathrm{e}}$ & 5 \\
\hline 612. & libro 15 & $18-06-1868$ & Antonia & $\mathrm{f}$ & lucumí & morena & Juan José Días & soltera & 45 \\
\hline 613. & libro 15 & $18-06-1868$ & Clara & $\mathrm{f}$ & gangá & morena & José Cano & soltera & 50 \\
\hline 614. & libro 15 & $18-06-1868$ & Eugenio Escoto & $\mathrm{m}$ & criollo & pardo & Luisa Escoto & no se dice & 20 \\
\hline 615. & libro 15 & $18-06-1868$ & Margarita & $\mathrm{f}$ & criolla & no se dice & Matilde y Cristina Piedra & soltera & 40 \\
\hline 616. & libro 15 & 19-06-1868 & Lorenza & $\mathrm{f}$ & criolla & morena & Manuel del Portillo & soltera & 40 \\
\hline 617. & libro 15 & $20-06-1868$ & Amalia & $\mathrm{f}$ & criolla & morena & Avelina Maso & soltera & 16 \\
\hline 618. & libro 15 & $21-06-1868$ & Antonio & $\mathrm{m}$ & gangá & moreno & Ignacio López & soltero & 70 \\
\hline 619. & libro 15 & 21-06-1868 & Cirilo Vidal & $\mathrm{m}$ & gangá & moreno & Ignacio Vidal & no se dice & 54 \\
\hline 620. & libro 15 & 21-06-1868 & Alejandro Valera & $\mathrm{m}$ & criollo & moreno & no se dice & soltero & 34 \\
\hline 621. & libro 15 & 22-06-1868 & José Monserrat & $\mathrm{m}$ & criollo & pardo & José Sala & soltero & 22 \\
\hline 622. & libro 15 & 23-06-1868 & María & $\mathrm{f}$ & Nueva Orleans & morena & Miguel Dama & soltera & 30 \\
\hline 623. & libro 15 & 23-06-1868 & Luciano Salas & $\mathrm{m}$ & Puerto Rico & moreno & José Salas & soltero & 50 \\
\hline 624. & libro 15 & $23-06-1868$ & María Regla & $\mathrm{f}$ & África & morena & María del Toro & soltera & 40 \\
\hline 625. & libro 15 & $23-06-1868$ & Patricio & $\mathrm{m}$ & no se dice & moreno & Felipe Chartrand & soltero & 50 \\
\hline 626. & libro 15 & $25-06-1868$ & María Teresa & f & criolla & morena & Cecilia Díaz & soltera & 60 \\
\hline 627. & libro 15 & $25-06-1868$ & Ramón & $\mathrm{m}$ & gangá & moreno & Rita Mano & soltero & 50 \\
\hline 628. & libro 15 & $26-06-1868$ & Florencio & $\mathrm{m}$ & lucumí & moreno & Miguel Dama & soltero & 50 \\
\hline 629. & libro 15 & $27-06-1868$ & Ignacia & $\mathrm{f}$ & conga & morena & Miguel Cuní y Compañía & soltera & 50 \\
\hline 630. & libro 15 & 28-06-1868 & Juan & $\mathrm{m}$ & criollo & no se dice & Manuel Delgado & soltero & 50 \\
\hline 631. & libro 15 & $28-06-1868$ & $\begin{array}{l}\text { Florencia García } \\
\text { Díaz }\end{array}$ & f & gangá & morena & Juana García Díaz & no se dice & 50 \\
\hline 632. & libro 15 & 28-06-1868 & José Rosario Sala & $\mathrm{m}$ & criollo & moreno & José Sala & soltero & 19 \\
\hline 633. & libro 15 & 28-06-1868 & Leopolda & $\mathrm{f}$ & criolla & morena & Gabriela Mendosa & soltera & 16 \\
\hline
\end{tabular}




\begin{tabular}{|c|c|c|c|c|c|c|c|c|c|c|}
\hline 634. & libro 15 & $30-06-1868$ & Josefa Aballí & $\mathrm{f}$ & criolla & morena & Francisco Aballí & soltera & 30 & \\
\hline 635. & libro 15 & 01-07-1868 & Guillermo & $\mathrm{m}$ & criollo & moreno & Campos & soltero & 28 & \\
\hline 636. & libro 15 & 01-07-1868 & Romualdo & $\mathrm{m}$ & Curasao & pardo & Ramón Brufan & soltero & 38 & \\
\hline 637. & libro 15 & $02-07-1868$ & Roque & $\mathrm{m}$ & lucumí & moreno & Pedro Sala & soltero & 54 & \\
\hline 638. & libro 15 & 03-07-1868 & Andrea Oliva & $\mathrm{f}$ & criolla & parda & Rafael Oliva & soltera & 19 & \\
\hline 639. & libro 15 & 04-07-1868 & Manuela & $\mathrm{f}$ & carabalí & morena & Catalina López Villavicencio & soltera & 70 & \\
\hline 640. & libro 15 & 04-07-1868 & Domingo & $\mathrm{m}$ & mandinga & moreno & José María Martínez & soltero & 45 & \\
\hline 641. & libro 15 & $07-07-1868$ & Lusiano & $\mathrm{m}$ & no se dice & moreno & Pedro Sala & $\mathrm{m}_{\mathrm{e}}$ & no & se \\
\hline 642. & libro 15 & 07-07-1868 & Pedro & $\mathrm{m}$ & gangá & moreno & Sres. Gómez y Ortiz & soltero & 90 & \\
\hline 643. & libro 15 & 09-07-1868 & Ramón Sala & $\mathrm{m}$ & carabalí & moreno & Pedro Sala & no se dice & 50 & \\
\hline 644. & libro 15 & $11-07-1868$ & Carmen Soloni & $\mathrm{f}$ & gangá & morena & Félix Soloni & soltera & 88 & \\
\hline 645. & libro 15 & $11-07-1868$ & Justa Soloni & $\mathrm{f}$ & criolla & morena & Félix Soloni & soltera & 75 & \\
\hline 646. & libro 15 & $11-07-1868$ & Carlota Soloni & $\mathrm{f}$ & criolla & morena & Félix Soloni & $\mathrm{m}_{\mathrm{e}}$ & 8 & \\
\hline 647. & libro 15 & $13-07-1868$ & Josefa Pino & $\mathrm{f}$ & gangá & morena & Antonia Pino & soltera & 48 & \\
\hline 648. & libro 15 & $14-07-1868$ & Francisco & $\mathrm{m}$ & mandinga & moreno & Rita Olano & no se dice & 44 & \\
\hline 649. & libro 15 & $14-07-1868$ & Dolores Chartrand & $\mathrm{f}$ & criolla & parda & Felipe Chartrand & no se dice & 18 & \\
\hline 650. & libro 15 & $15-07-1868$ & Manuel Jiménez & $\mathrm{m}$ & gangá & moreno & Tránsito Jiménez & soltero & 80 & \\
\hline 651. & libro 15 & $20-07-1868$ & Justo Borges & $\mathrm{m}$ & criollo & moreno & Antonia Borges & no se dice & 23 & \\
\hline 652. & libro 15 & 21-07-1868 & Miguel Portillo & $\mathrm{m}$ & lucumí & moreno & Manuel del Portillo & soltero & 65 & \\
\hline 653. & libro 15 & $22-07-1868$ & Juan Casanovas & $\mathrm{m}$ & gangá & moreno & Pablo Casanovas & no se dice & 48 & \\
\hline 654. & libro 15 & $24-07-1868$ & Felipe & $\mathrm{m}$ & lucumí & moreno & Valentín de la Villa & no se dice & 37 & \\
\hline 655. & libro 15 & $26-07-1868$ & Pablo Escudero & $\mathrm{m}$ & congo & moreno & Rosa Escudero & soltero & 37 & \\
\hline 656. & libro 15 & $26-07-1868$ & Francisca & $\mathrm{f}$ & criolla & no se dice & Nicomedes Fleita & no se dice & 76 & \\
\hline 657. & libro 15 & $28-07-1868$ & Juan Manuel & $\mathrm{m}$ & criollo & moreno & Bernardo Junco & soltero & 40 & \\
\hline 658. & libro 15 & $29-07-1868$ & Pilar & $\mathrm{f}$ & arará & morena & Cecilio Rodríguez & soltera & 25 & \\
\hline 659. & libro 15 & 06-08-1868 & Severina Rion & $\mathrm{f}$ & criolla & morena & José Rion & no se dice & 27 & \\
\hline 660. & libro 15 & 08-08-1868 & Pablo & $\mathrm{m}$ & África & moreno & José Coll & soltero & 64 & \\
\hline 661. & libro 15 & 09-08-1868 & Cristina Rion & $\mathrm{f}$ & no se dice & morena & José Rion & no se dice & 25 & \\
\hline 662. & libro 15 & $10-08-1868$ & Victoria & $\mathrm{f}$ & conga & morena & Félix Cobarroca & soltera & 30 & \\
\hline
\end{tabular}




\begin{tabular}{|c|c|c|c|c|c|c|c|c|c|}
\hline 663. & libro 15 & $16-08-1868$ & Juana de la Cruz & $\mathrm{f}$ & criolla & parda & Manuel Cagigas & soltera & 16 \\
\hline 664. & libro 15 & $18-08-1868$ & Alejandro García & $\mathrm{m}$ & criollo & moreno & Pedro Figueredo & soltero & 32 \\
\hline 665. & libro 15 & $18-08-1868$ & Fabián de Lima & $\mathrm{m}$ & congo & moreno & Agueda de Lima & no se dice & 45 \\
\hline 666. & libro 15 & $21-08-1868$ & Narciso López & $\mathrm{m}$ & gangá & moreno & Gabriel López & soltero & 50 \\
\hline 667. & libro 15 & $22-08-1868$ & Francisco Fialo & $\mathrm{m}$ & no se dice & moreno & Pelegrin Fialo & no se dice & 60 \\
\hline 668. & libro 15 & $23-08-1868$ & José León & $\mathrm{m}$ & lucumí & moreno & Pelegrin Fialo & no se dice & 50 \\
\hline 669. & libro 15 & $23-08-1868$ & Tranquilino & $\mathrm{m}$ & mandinga & moreno & Celedonio Días & no se dice & 40 \\
\hline 670. & libro 15 & 24-08-1868 & Marcelino & $\mathrm{m}$ & no se dice & moreno & Salvador Junquera & no se dice & 75 \\
\hline 671. & libro 15 & $27-08-1868$ & Hilario Hernández & $\mathrm{m}$ & Puerto Rico & pardo & Martin Eduardo Hernández & soltero & 81 \\
\hline 672. & libro 15 & $29-08-1868$ & Teresa Valdés & $\mathrm{f}$ & gangá & morena & Miguel Valdés & soltera & 54 \\
\hline 673. & libro 15 & 01-09-1868 & Antonio & $\mathrm{m}$ & gangá & moreno & Ramón de Aldasabal & soltero & 55 \\
\hline 674. & libro 15 & 02-09-1868 & Andrés Hernández & $\mathrm{m}$ & criollo & moreno & José Hernández & soltero & 26 \\
\hline 675. & libro 15 & 07-09-1868 & Manuel & $\mathrm{m}$ & criollo & moreno & Manuel Enrique & soltero & 80 \\
\hline 676. & libro 15 & $10-09-1868$ & Pio Pérez & $\mathrm{m}$ & congo & moreno & Domingo Pérez & soltero & 22 \\
\hline 677. & libro 15 & $10-09-1868$ & Gregorio Días & $\mathrm{m}$ & no se dice & moreno & José Coll & no se dice & 28 \\
\hline 678. & libro 15 & 14-09-1868 & José Ferrer & $\mathrm{m}$ & carabalí & moreno & Francisco Ferrer & no se dice & 70 \\
\hline 679. & libro 15 & $15-09-1868$ & Filomena & $\mathrm{f}$ & criolla & no se dice & Claudia Hernández & soltera & 50 \\
\hline 680. & libro 15 & $15-09-1868$ & Eustaquio Soloni & $\mathrm{m}$ & criollo & moreno & Félix Soloni & soltero & 16 \\
\hline 681. & libro 15 & $15-09-1868$ & Gonsala & $\mathrm{f}$ & criolla & morena & Salvador Cejas & soltera & 22 \\
\hline 682. & libro 15 & $18-09-1868$ & Zacarías Centena & $\mathrm{m}$ & criollo & moreno & Juan Wandeputter & soltero & 40 \\
\hline 683. & libro 15 & $20-09-1868$ & Cecilia Fernández & $\mathrm{f}$ & conga & morena & José Fernández & soltera & 50 \\
\hline 684. & libro 15 & $22-09-1868$ & Guadalupe & $\mathrm{f}$ & criolla & morena & Mercedes Carbonell & soltera & 38 \\
\hline 685. & libro 15 & $23-09-1868$ & Pio Govín & $\mathrm{m}$ & no se dice & pardo & José Govín & soltero & 30 \\
\hline 686. & libro 15 & 28-09-1868 & Cristóbal Simpson & $\mathrm{m}$ & gangá & moreno & Antonio María Simpson & soltero & 42 \\
\hline 687. & libro 15 & 29-09-1868 & Juana Sánchez & $\mathrm{f}$ & criolla & morena & Antonio Sánchez & $\mathrm{m}_{\mathrm{e}}$ & 13 \\
\hline 688. & libro 15 & $19-10-1868$ & José Joaquín & $\mathrm{m}$ & gangá & moreno & Isabel de la O Madan & soltero & 60 \\
\hline 689. & libro 15 & 20-10-1868 & Trinidad & $\mathrm{f}$ & criolla & no se dice & Benito Acosta & no se dice & 37 \\
\hline 690. & libro 15 & $25-10-1868$ & Nieves & $\mathrm{f}$ & conga & morena & María Cortes & no se dice & 45 \\
\hline
\end{tabular}




\begin{tabular}{|c|c|c|c|c|c|c|c|c|c|}
\hline 691. & libro 15 & $25-10-1868$ & $\begin{array}{l}\text { José del Carmen } \\
\text { del Portillo }\end{array}$ & $\mathrm{m}$ & gangá & moreno & Bernabé del Portillo & no se dice & 55 \\
\hline 692. & libro 15 & $31-10-1868$ & Modesto & $\mathrm{m}$ & criollo & moreno & Rafael Rodríguez & no se dice & 15 \\
\hline 693. & libro 15 & 07-11-1868 & José Arias & $\mathrm{m}$ & criollo & moreno & Manuel Arias & soltero & 16 \\
\hline 694. & libro 15 & $11-11-1868$ & Carlota Gómez & f & criolla & no se dice & Juan L. Gómez & no se dice & 35 \\
\hline 695. & libro 15 & $17-11-1868$ & Ynes Otí & $\mathrm{f}$ & conga & morena & Celedonio Otí & soltera & 38 \\
\hline 696. & libro 15 & $18-11-1868$ & Tomas Gil & $\mathrm{m}$ & congo & moreno & Federico Gil & no se dice & 60 \\
\hline 697. & libro 15 & $18-11-1868$ & Herculana del & $f$ & criolla & morena & Clara del Castillo & $\mathrm{m}_{\mathrm{e}}$ & 0 \\
\hline 698. & libro 15 & 24-11-1868 & Pablo Fialo & $\mathrm{m}$ & criollo & moreno & Pelegrin Fialo & soltero & 24 \\
\hline 699. & libro 15 & $25-11-1868$ & Longina & $\mathrm{f}$ & criolla & no se dice & Francisco Betancourt & soltera & 26 \\
\hline 700. & libro 15 & $26-11-1868$ & Estefanía & $\mathrm{f}$ & criolla & no se dice & Esteban Rodríguez & no se dice & 45 \\
\hline 701. & libro 15 & 28-11-1868 & Jaime Dubrog & $\mathrm{m}$ & congo & moreno & Antonia Dubrog & soltero & 20 \\
\hline 702. & libro 15 & $29-11-1868$ & Clemente Casado & $\mathrm{m}$ & criollo & pardo & Pedro Casado & $\mathrm{m}_{\mathrm{e}}$ & 0 \\
\hline 703. & libro 15 & 29-11-1868 & Lucia Castell Florit & f & carabalí & morena & Marquesa de Castell Florit & soltera & 65 \\
\hline 704. & libro 15 & $30-11-1868$ & Ramón del Portillo & $\mathrm{m}$ & gangá & moreno & Bernabé del Portillo & soltero & 60 \\
\hline 705. & libro 15 & $04-12-1868$ & Irene García & f & no se dice & no se dice & José Oña & soltera & 28 \\
\hline 706. & libro 15 & $09-12-1868$ & Desideria Viciedo & f & criolla & morena & Francisca Almenteros & no se dice & 23 \\
\hline 707. & libro 15 & $10-12-1868$ & Felipe Domínguez & $\mathrm{m}$ & congo & moreno & Manuel Domínguez & no se dice & 50 \\
\hline 708. & libro 15 & $13-12-1868$ & Dolores Velasco & f & criolla & morena & Francisco Velasco & soltera & 34 \\
\hline 709. & libro 15 & $18-12-1868$ & Manuel Matos & $\mathrm{m}$ & Caracas & moreno & Manuel del Portillo & soltero & 84 \\
\hline 710. & libro 15 & $19-12-1868$ & Juan Castell Florit & $\mathrm{m}$ & mandinga & moreno & Marquesa de Castell Florit & soltera & 85 \\
\hline 711. & libro 15 & $22-12-1868$ & Eusebio Castellá & $\mathrm{m}$ & criollo & no se dice & no se dice & $\mathrm{m}_{\mathrm{e}}$ & 0 \\
\hline 712. & libro 15 & $27-12-1868$ & Ignacio & $\mathrm{m}$ & lucumí & moreno & Francisco Días & soltero & 50 \\
\hline 713. & libro 15 & $29-12-1868$ & Susana Días Pérez & f & criolla & morena & José Días Pérez & soltera & 22 \\
\hline 714. & libro 15 & $31-12-1868$ & Marcelina & $\mathrm{f}$ & criolla & no se dice & Juan Eugenio & soltera & 34 \\
\hline 715. & libro 15 & $31-12-1868$ & Adolfo Castell & $\mathrm{m}$ & gangá & moreno & Marquesa de Castell Florit & soltero & 49 \\
\hline 716. & libro 15 & $10-01-1869$ & José Jesús & $\mathrm{m}$ & criollo & moreno & María Elena O'Farril (morena & $\mathrm{m}_{\mathrm{e}}$ & 0 \\
\hline 717. & libro 15 & $17-01-1869$ & José María & $\mathrm{m}$ & gangá & moreno & Lucas Francés & soltero & 50 \\
\hline 718. & libro 15 & $17-01-1869$ & Agustín Torre & $\mathrm{m}$ & criollo & pardo & Francisco Torre & soltero & 15 \\
\hline
\end{tabular}




\begin{tabular}{|c|c|c|c|c|c|c|c|c|c|}
\hline 719. & libro 15 & 29-01-1869 & Luis Betancourt & $\mathrm{m}$ & criollo & pardo & Francisco Betancourt & soltero & 45 \\
\hline 720. & libro 15 & 29-01-1869 & Juan Fullá & $\mathrm{m}$ & criollo & moreno & Pedro Fullá & $\mathrm{m}_{\mathrm{e}}$ & 6 \\
\hline 721. & libro 15 & 29-01-1869 & Juliana & $\mathrm{f}$ & criolla & no se dice & Leonarda Fernández & $\mathrm{m}_{\mathrm{e}}$ & 0 \\
\hline 722. & libro 15 & $31-01-1869$ & Andrea & $\mathrm{f}$ & criolla & morena & María Teresa Iribarren de Oliva & soltera & 18 \\
\hline 723. & libro 15 & 03-02-1869 & Lugarda Rovira & $\mathrm{f}$ & criolla & no se dice & Miguel Rovira & soltera & 26 \\
\hline 724. & libro 15 & $10-02-1869$ & Evaristo & $\mathrm{m}$ & criollo & no se dice & Paula Gonzalez & no se dice & $\mathrm{a}$ \\
\hline 725. & libro 15 & $10-02-1869$ & Marcelino & $\mathrm{m}$ & criollo & moreno & Rafael Navias & no se dice & 30 \\
\hline 726. & libro 15 & 23-02-1869 & Isabel Castell & $\mathrm{f}$ & lucumí & morena & Marquesa de Castell Florit & soltera & 50 \\
\hline 727. & libro 15 & 26-02-1869 & Guillermo Ferreiro & $\mathrm{m}$ & criollo & no se dice & Lino Ferreiro & soltero & 23 \\
\hline 728. & libro 15 & 03-03-1869 & Tomás & $\mathrm{m}$ & congo & moreno & Tomás W. & soltero & 38 \\
\hline 729. & libro 15 & 04-03-1869 & Desiderio Gavilán & $\mathrm{m}$ & criollo & pardo & Joaquín de los Reyes Gavilán & soltero & 34 \\
\hline 730. & libro 15 & 07-03-1869 & Ramón & $\mathrm{m}$ & criollo & pardo & Guillermo & no se dice & 34 \\
\hline 731. & libro 15 & 09-03-1869 & Rosa & $\mathrm{f}$ & gangá & morena & $\begin{array}{l}\text { Tomas Campo y Bienvenido } \\
\text { Caballol }\end{array}$ & no se dice & 90 \\
\hline 732. & libro 15 & $18-03-1869$ & Manuela & $\mathrm{f}$ & arará & morena & Vicente de la Nuez & soltera & 50 \\
\hline 733. & libro 15 & $21-03-1869$ & $\begin{array}{l}\text { María del Loreto } \\
\text { Junco }\end{array}$ & f & criolla & morena & Petrona Junco & soltera & 30 \\
\hline 734. & libro 15 & 29-03-1869 & Facunda Santana & $\mathrm{f}$ & criolla & morena & Francisco Santana & soltera & 30 \\
\hline 735. & libro 15 & 29-03-1869 & Dorotea Santos & $\mathrm{f}$ & gangá & morena & Felicia Santos & soltera & 70 \\
\hline 736. & libro 15 & 04-04-1869 & Juliana García & $\mathrm{f}$ & criolla & morena & Lorenzo García & soltera & 23 \\
\hline 737. & libro 15 & 06-04-1869 & Toribio Martin & $\mathrm{m}$ & congo & moreno & Marquesa de Castell Florit & soltero & 30 \\
\hline 738. & libro 15 & 09-04-1869 & Emilio García & $\mathrm{m}$ & criollo & moreno & Pablo García & soltero & 19 \\
\hline 739. & libro 15 & 19-04-1869 & Santiago Simpson & $\mathrm{m}$ & mina & moreno & Antonio María Simpson & soltero & 80 \\
\hline 740. & libro 15 & 20-04-1869 & Altagracia & $\mathrm{f}$ & mandinga & morena & Julio Daprés & soltera & 40 \\
\hline 741. & libro 15 & 20-04-1869 & Gabriela Chávez & $\mathrm{f}$ & criolla & parda & Felipa Chávez & no se dice & 25 \\
\hline 742. & libro 15 & 24-04-1869 & Emilio Roa & $\mathrm{m}$ & criollo & moreno & Felicitas Roa & soltero & 26 \\
\hline 743. & libro 15 & 28-04-1869 & Bibiana Gil & $\mathrm{f}$ & criolla & morena & Lugarda Gil & soltera & 42 \\
\hline 744. & libro 15 & 04-05-1869 & Antonio Agis & $\mathrm{m}$ & criollo & no se dice & Juan Eugenio Agis & $\mathrm{m}_{\mathrm{e}}$ & 12 \\
\hline 745. & libro 15 & $10-05-1869$ & Santiago Hero & $\mathrm{m}$ & criollo & moreno & Flora Hero (morena libre) & soltero & 25 \\
\hline
\end{tabular}




\begin{tabular}{|c|c|c|c|c|c|c|c|c|c|}
\hline 746. & libro 15 & $14-05-1869$ & Francisco Fialo & $\mathrm{m}$ & criollo & moreno & Pelegrin Fialo & soltero & 60 \\
\hline 747. & libro 15 & $15-05-1869$ & Martina & $\mathrm{f}$ & criolla & parda & María Úrsula de los Ríos & soltera & 30 \\
\hline 748. & libro 15 & $20-05-1869$ & Josefa & $\mathrm{f}$ & criolla & parda & José Peirano & soltera & 25 \\
\hline 749. & libro 15 & $27-05-1869$ & Lorenza & $\mathrm{f}$ & criolla & morena & Francisco Rowier & soltera & 45 \\
\hline 750. & libro 15 & 04-06-1869 & María de la & $\mathrm{f}$ & criolla & morena & María Irene Morejón & soltera & 38 \\
\hline 751. & libro 15 & $05-06-1869$ & Catalina & $\mathrm{f}$ & macua & morena & Antonio Barbanza & soltera & 60 \\
\hline 752. & libro 15 & 12-06-1869 & Saturnino & $\mathrm{m}$ & criollo & moreno & Gerónimo Rosique & no se dice & 23 \\
\hline 753. & libro 15 & $12-06-1869$ & Carlos García & $\mathrm{m}$ & gangá & moreno & Jaime García & soltero & 60 \\
\hline 754. & libro 15 & $15-06-1869$ & Rosa & $\mathrm{f}$ & gangá & morena & Ángela Riverón (morena libre) & soltera & 45 \\
\hline 755. & libro 15 & $15-06-1869$ & Rosa Solano & $\mathrm{f}$ & carabalí & morena & Manuel Solano & soltera & 80 \\
\hline 756. & libro 15 & $16-06-1869$ & $\begin{array}{l}\text { Florencio Castell } \\
\text { Florit }\end{array}$ & $\mathrm{m}$ & congo & moreno & Marquesa de Castell Florit & soltero & 39 \\
\hline 757. & libro 15 & 17-06-1869 & Manuel & $\mathrm{m}$ & congo & moreno & $?$ & soltero & 23 \\
\hline 758. & libro 15 & 18-06-1869 & Ambrosia & $\mathrm{f}$ & criolla & morena & María Encarnación Lamadrid & soltera & 52 \\
\hline 759. & libro 15 & 24-06-1869 & Salomé & $\mathrm{f}$ & México & parda & Joaquín Marill & soltera & 60 \\
\hline 760. & libro 15 & $30-06-1869$ & Santiago Salbá & $\mathrm{m}$ & gangá & moreno & Francisco Salbá & soltero & 90 \\
\hline 761. & Def.-F. G. P. M. & 04-08-1869 & Juana & $\mathrm{f}$ & criolla & morena & Domingo Aldama & $\mathrm{m}_{\mathrm{e}}$ & 5 \\
\hline 762. & Def.-F. G. P. M. & 01-08-1869 & Concepción & $\mathrm{f}$ & lucumí & morena & Sres. Setien y hermano & no se dice & $\mathrm{a}$ \\
\hline 763. & Def.-F. G. P. M. & $15-07-1868$ & Cayetano & $\mathrm{m}$ & carabalí & moreno & $\begin{array}{l}\text { Rafael L. Sánchez y Francisco } \\
\text { Hernández }\end{array}$ & soltero & 50 \\
\hline 764. & Def.-F. G. P. M. & $15-07-1868$ & Pedro & $\mathrm{m}$ & criollo & moreno & Petrona Milian y García & $\mathrm{m}_{\mathrm{e}}$ & 4 \\
\hline 765. & Def.-F. G. P. M. & $05-07-1868$ & $\begin{array}{ll}\text { María } & \text { Luisa } \\
\text { Plutarca } & \end{array}$ & $\mathrm{f}$ & criolla & morena & Gonzalo Pérez & $\mathrm{m}_{\mathrm{e}}$ & 0 \\
\hline 766. & Def.-F. G. P. M. & $24-07-1868$ & Carolina & $\mathrm{f}$ & macua & morena & Francisco Morales & no se dice & 47 \\
\hline 767. & Def.-F. G. P. M. & $24-07-1868$ & Félix Sotolongo & $\mathrm{m}$ & no se dice & moreno & Dolores Ugarte de Sotolongo & no se dice & 20 \\
\hline 768. & Def.-F. G. P. M. & $16-07-1868$ & Alejandro & $\mathrm{m}$ & lucumí & moreno & Antonio García de Villalta & soltero & 45 \\
\hline 769. & Def.-F. G. P. M. & $21-07-1868$ & Cayetano & $\mathrm{m}$ & gangá & moreno & León Crespo & soltero & 60 \\
\hline 770. & Def.-F. G. P. M. & $23-07-1868$ & Sofía & $\mathrm{f}$ & criolla & morena & José de la Portilla & $\mathrm{m}_{\mathrm{e}}$ & 6 \\
\hline 771. & Def.-F. G. P. M. & $13-07-1868$ & Dominga & $\mathrm{f}$ & criolla & morena & Francisco Balbona & $\mathrm{m}_{\mathrm{e}}$ & 14 \\
\hline
\end{tabular}




\begin{tabular}{|c|c|c|c|c|c|c|c|c|c|}
\hline 772. & Def.-F. G. P. M. & 30-08-1868 & Isidora & $\mathrm{f}$ & criolla & morena & Catalina E. de Abreu & $\mathrm{m}_{\mathrm{e}}$ & 9 \\
\hline 773. & Def.-F. G. P. M. & 23-07-1868 & Juan Hernández & $\mathrm{m}$ & congo & moreno & no se dice & no se dice & 48 \\
\hline 774. & Def.-F. G. P. M. & $05-11-1868$ & Josefa & $\mathrm{f}$ & mina & morena & Domingo Aldama & soltera & 28 \\
\hline 775. & Def.-F. G. P. M. & 03-11-1868 & Oracio & $\mathrm{m}$ & criollo & moreno & Petrona Milian y García & soltero & 25 \\
\hline 776. & Def.-F. G. P. M. & $26-05-1869$ & Ubaldo & $\mathrm{m}$ & criollo & moreno & Juan Poey & $\mathrm{m}_{\mathrm{e}}$ & 0 \\
\hline 777. & Def.-F. G. P. M. & $12-07-1868$ & Vicente & $\mathrm{m}$ & carabalí & moreno & Francisco Morales & no se dice & 30 \\
\hline 778. & Def.-F. G. P. M. & $13-07-1868$ & Máximo & $\mathrm{m}$ & criollo & moreno & Domingo Aldama & $\mathrm{m}_{\mathrm{e}}$ & 10 \\
\hline 779. & Def.-F. G. P. M. & $24-07-1868$ & Felipe & $\mathrm{m}$ & lucumí & moreno & Valentín de la Villa & no se dice & 37 \\
\hline 780. & Def.-F. G. P. M. & 06-07-1868 & José de la Luz & $\mathrm{m}$ & gangá & moreno & Isidra García & soltero & 31 \\
\hline 781. & Def.-F. G. P. M. & 13-08-1868 & Tranquilino & $\mathrm{m}$ & congo & moreno & Catalina E. de Abreu & soltero & 32 \\
\hline 782. & Def.-F. G. P. M. & 03-08-1868 & Cecilio & $\mathrm{m}$ & lucumí & moreno & Sres. Drake y hermano & soltero & 60 \\
\hline 783. & Def.-F. G. P. M. & 03-07-1868 & Mamerto & $\mathrm{m}$ & lucumí & moreno & Cosme de la Torriente & soltero & 50 \\
\hline 784. & Def.-F. G. P. M. & $07-07-1868$ & Genoveva & $\mathrm{f}$ & criolla & morena & Roberto Bennatyne & $\mathrm{m}_{\mathrm{e}}$ & 1 \\
\hline 785. & Def.-F. G. P. M. & $30-11-1868$ & Manuela & $\mathrm{f}$ & conga & morena & León Crespo & no se dice & 20 \\
\hline 786. & Def.-F. G. P. M. & 04-01-1859 & José & $\mathrm{m}$ & criollo & moreno & $\begin{array}{l}\text { Sres. Arganegui Gonzalez y } \\
\text { Compañía }\end{array}$ & no se dice & $\begin{array}{ll}\text { no } & \text { se } \\
\text { dice } & \end{array}$ \\
\hline 787. & Def.-F. G. P. M. & $15-03-1859$ & Mauricio & $\mathrm{m}$ & congo & moreno & Compañía Territorial Cubana & no se dice & $\mathrm{a}$ \\
\hline 788. & Def.-F. G. P. M. & 24-09-1859 & Manuel & $\mathrm{m}$ & no se dice & moreno & Sres. Lavayen y Compañía & $\mathrm{m}_{\mathrm{e}}$ & $\mathrm{p}$ \\
\hline 789. & Def.-F. G. P. M. & 08-03-1859 & María de Jesús & $\mathrm{f}$ & no se dice & parda & Pedro La Rudeé & no se dice & $\mathrm{a}$ \\
\hline 790. & Def.-F. G. P. M. & $14-12-1859$ & Doroteo & $\mathrm{m}$ & no se dice & moreno & Antonio Gutiérrez & $\mathrm{m}_{\mathrm{e}}$ & $\mathrm{p}$ \\
\hline 791. & Def.-F. G. P. M. & 08-06-1859 & Luis & $\mathrm{m}$ & lucumí & moreno & Ignacio Cárdenas & no se dice & 70 \\
\hline 792. & Def.-F. G. P. M. & $27-06-1869$ & Antonio Abad & $\mathrm{m}$ & carabalí & moreno & José R. de Cárdenas O'Farril & no se dice & $\mathrm{a}$ \\
\hline 793. & Def.-F. G. P. M. & $30-08-1868$ & Juan Bautista & $\mathrm{m}$ & criollo & moreno & José Gutiérrez & $\mathrm{m}_{\mathrm{e}}$ & 0 \\
\hline 794. & Def.-F. G. P. M. & $08-08-1868$ & Pablo & $\mathrm{m}$ & África & moreno & Herederos de José Coll & soltero & 64 \\
\hline 795. & Def.-F. G. P. M. & $16-05-1869$ & Felino & $\mathrm{m}$ & no se dice & moreno & Juan Poey & $\mathrm{m}_{\mathrm{e}}$ & $\mathrm{p}$ \\
\hline 796. & Def.-F. G. P. M. & $17-05-1869$ & Bernabé & $\mathrm{m}$ & congo & moreno & Herederos de José Ramón Febles & no se dice & $\mathrm{a}$ \\
\hline 797. & Def.-F. G. P. M. & 08-06-1869 & Dionisio & $\mathrm{m}$ & gangá & moreno & Herederos de Catalina Calvo & soltero & 70 \\
\hline 798. & Def.-F. G. P. M. & 23-05-1869 & Cándido & $\mathrm{m}$ & África & moreno & José María Ramírez & soltero & 40 \\
\hline 799. & Def.-F. G. P. M. & $30-05-1869$ & Verena & $\mathrm{f}$ & criolla & morena & Juan Poey & $\mathrm{m}_{\mathrm{e}}$ & 1 \\
\hline
\end{tabular}




\begin{tabular}{|c|c|c|c|c|c|c|c|c|c|}
\hline 800. & Def.-F. G. P. M. & 03-08-1869 & Anastasio & $\mathrm{m}$ & criollo & moreno & José R. de Cárdenas O'Farril & $\mathrm{m}_{\mathrm{e}}$ & 3 \\
\hline 801. & Def.-F. G. P. M. & $21-05-1869$ & $\begin{array}{l}\text { María de los } \\
\text { Ángeles Florentina }\end{array}$ & f & criolla & morena & Tomás Pintado & $\mathrm{m}_{\mathrm{e}}$ & 0 \\
\hline 802. & Def.-F. G. P. M. & 26-04-1869 & Esteban & $\mathrm{m}$ & gangá & moreno & Petrona Milian y García & no se dice & 30 \\
\hline 803. & Def.-F. G. P. M. & $25-07-1869$ & Félix & $\mathrm{m}$ & criollo & moreno & Evelina L. de Biart & soltero & 25 \\
\hline 804. & Def.-F. G. P. M. & 03-08-1869 & Alejo & $\mathrm{m}$ & gangá & moreno & Francisco Gumá & soltero & 80 \\
\hline 805. & Def.-F. G. P. M. & $16-07-1869$ & Cristóbal & $\mathrm{m}$ & criollo & moreno & Catalina E. de Abreu & soltero & 75 \\
\hline 806. & Def.-F. G. P. M. & $12-05-1869$ & Antonio & $\mathrm{m}$ & lucumí & moreno & Antonio García de Villalta & soltero & 50 \\
\hline 807. & Def.-F. G. P. M. & 21-07-1869 & Silvestre & $\mathrm{m}$ & congo & moreno & Rosa Escudero & soltero & 48 \\
\hline 808. & Def.-F. G. P. M. & $11-07-1869$ & María Sabina & $\mathrm{f}$ & criolla & parda & Antonio Fernández Vallin & $\mathrm{m}_{\mathrm{e}}$ & 1 \\
\hline 809. & Def.-F. G. P. M. & $16-06-1869$ & Florencio & $\mathrm{m}$ & congo & moreno & Marquesa de Castell Florit & soltero & 39 \\
\hline 810. & Def.-F. G. P. M. & 06-08-1869 & María Magdalena & $\mathrm{f}$ & criolla & morena & Gregorio Estupiñan & $\mathrm{m}_{\mathrm{e}}$ & $\mathrm{p}$ \\
\hline 811. & Def.-F. G. P. M. & $17-07-1869$ & Desiderio & $\mathrm{m}$ & criollo & moreno & Petrona Milian y García & $\mathrm{m}_{\mathrm{e}}$ & 1 \\
\hline 812. & Def.-F. G. P. M. & $15-06-1859$ & Rosa & $\mathrm{f}$ & conga & morena & no se dice & no se dice & 40 \\
\hline 813. & Def.-F. G. P. M. & 08-09-1869 & Elías & $\mathrm{m}$ & congo & moreno & Herederos de Antonio Beltrán & soltero & 27 \\
\hline 814. & Def.-F. G. P. M. & $30-07-1869$ & Concepción & $\mathrm{f}$ & lucumí & morena & Sres. Setien y hermano & no se dice & 100 \\
\hline 815. & Def.-F. G. P. M. & $20-07-1868$ & León & $\mathrm{m}$ & congo & moreno & León Crespo & soltero & 66 \\
\hline 816. & Def.-F. G. P. M. & $05-06-1868$ & Rosa & $\mathrm{f}$ & criolla & morena & Herederos José Ignacio Estenoz & casada & 55 \\
\hline 817. & Def.-F. G. P. M. & 08-08-1868 & Alejandra & $\mathrm{f}$ & criolla & morena & Fulgencio García & $\mathrm{m}_{\mathrm{e}}$ & 0 \\
\hline 818. & Def.-F. G. P. M. & $16-07-1868$ & Cornelia & $\mathrm{f}$ & criolla & morena & Domingo Aldama & no se dice & 25 \\
\hline 819. & Def.-F. G. P. M. & $28-05-1868$ & Filomeno & $\mathrm{m}$ & carabalí & moreno & Juan N. Montenegro & soltero & 45 \\
\hline 820. & Def.-F. G. P. M. & $18-08-1868$ & Lorenzo & $\mathrm{m}$ & criollo & pardo & Petrona Junco de Gener & $\mathrm{m}_{\mathrm{e}}$ & 0 \\
\hline 821. & Def.-F. G. P. M. & $19-08-1868$ & Alejandro García & $\mathrm{m}$ & criollo & moreno & Pedro Figueras & soltero & 32 \\
\hline 822. & Def.-F. G. P. M. & $23-11-1868$ & Antonio María & $\mathrm{m}$ & carabalí & moreno & Simón López & soltero & $\mathrm{a}$ \\
\hline 823. & Def.-F. G. P. M. & 01-11-1868 & Mariana & $\mathrm{f}$ & gangá & morena & Bernardo García & soltera & 39 \\
\hline 824. & Def.-F. G. P. M. & $30-05-1868$ & Olindo & $\mathrm{m}$ & macua & moreno & Juan N. Montenegro & soltero & 80 \\
\hline 825. & Def.-F. G. P. M. & $18-05-1869$ & Entropía & $\mathrm{f}$ & criolla & morena & Juan Poey & $\mathrm{m}_{\mathrm{e}}$ & 1 \\
\hline 826. & Def.-F. G. P. M. & 07-07-1868 & Eusebio & $\mathrm{m}$ & lucumí & moreno & Domingo Aldama & no se dice & 80 \\
\hline 827. & Def.-F. G. P. M. & 29-11-1868 & Casimiro & $\mathrm{m}$ & criollo & moreno & Marqués de Montelo & soltero & 25 \\
\hline
\end{tabular}




\begin{tabular}{|c|c|c|c|c|c|c|c|c|c|}
\hline 828. & Def.-F. G. P. M. & $06-11-1868$ & Nicolasa & $\mathrm{f}$ & gangá & morena & $\begin{array}{l}\text { Rafael L. Sánchez y Francisco } \\
\text { Hernández }\end{array}$ & casada & 40 \\
\hline 829. & Def.-F. G. P. M. & $18-07-1868$ & Dolores & f & mandinga & morena & José Serrate & no se dice & 70 \\
\hline 830. & Def.-F. G. P. M. & $30-10-1863$ & Antonio & $\mathrm{m}$ & macua & moreno & Agustín Baró & no se dice & $\mathrm{a}$ \\
\hline 831. & Def.-F. G. P. M. & $10-05-1863$ & Isidro & $\mathrm{m}$ & no se dice & moreno & Julia Alfonso de Moliner & no se dice & $\mathrm{a}$ \\
\hline 832. & Def.-F. G. P. M. & $09-07-1863$ & Santiago & $\mathrm{m}$ & macua & moreno & Antonio María Rodríguez & no se dice & $\mathrm{a}$ \\
\hline 833. & Def.-F. G. P. M. & $16-07-1863$ & Juan de Dios & $\mathrm{m}$ & lucumí & moreno & no se dice & no se dice & $\mathrm{a}$ \\
\hline 834. & Def.-F. G. P. M. & $26-04-1863$ & Benito & $\mathrm{m}$ & congo & moreno & no se dice & no se dice & $\mathrm{a}$ \\
\hline 835. & Def.-F. G. P. M. & $30-09-1863$ & Gonzalo & $\mathrm{m}$ & criollo & moreno & Gonzalo Alfonso & no se dice & $\mathrm{a}$ \\
\hline 836. & Def.-F. G. P. M. & 01-08-1863 & María Magdalena & $\mathrm{f}$ & criolla & morena & Gregorio Estupiñan & $\mathrm{m}_{\mathrm{e}}$ & 0 \\
\hline 837. & Def.-F. G. P. M. & $28-01-1863$ & Juan & $\mathrm{m}$ & mandinga & moreno & no se dice & no se dice & $\mathrm{a}$ \\
\hline 838. & Def.-F. G. P. M. & $16-08-1863$ & Seferino & $\mathrm{m}$ & carabalí & moreno & Martín Ayllón y Testa & no se dice & $\mathrm{a}$ \\
\hline 839. & Def.-F. G. P. M. & $25-04-1864$ & Justo & $\mathrm{m}$ & lucumí & moreno & María Antonia Calvo & no se dice & $\mathrm{a}$ \\
\hline 840. & Def.-F. G. P. M. & $23-10-1864$ & Luis Choe & $\mathrm{m}$ & China & asiático & Martín García & no se dice & $\mathrm{a}$ \\
\hline 841. & Def.-F. G. P. M. & $25-02-1864$ & Vicente & $\mathrm{m}$ & no se dice & moreno & no se dice & no se dice & $\mathrm{a}$ \\
\hline 842. & Def.-F. G. P. M. & $30-12-1866$ & Felicia & $\mathrm{f}$ & criolla & morena & no se dice & $\mathrm{m}_{\mathrm{e}}$ & 0 \\
\hline 843. & Def.-F. G. P. M. & 21-11-1867 & Gregorio & $\mathrm{m}$ & carabalí & moreno & Antonio Benítez & soltero & 40 \\
\hline 844. & Def.-F. G. P. M. & $12-07-1868$ & Josefa & f & criolla & morena & Domingo Aldama & no se dice & 100 \\
\hline 845. & Def.-F. G. P. M. & $10-07-1868$ & Gil & $\mathrm{m}$ & criollo & moreno & Domingo Aldama & $\mathrm{m}_{\mathrm{e}}$ & 1 \\
\hline 846. & Def.-F. G. P. M. & $17-08-1868$ & Juana de la Cruz & $\mathrm{f}$ & criolla & parda & Manuel de las Cagigas & soltera & 16 \\
\hline 847. & Def.-F. G. P. M. & $30-08-1868$ & Teresa & $f$ & conga & morena & Miguel Valdés & soltera & 54 \\
\hline 848. & Def.-F. G. P. M. & $23-08-1868$ & Tranquilino & $\mathrm{m}$ & mandinga & moreno & Celedonio Días & no se dice & 40 \\
\hline 849. & Def.-F. G. P. M. & $17-07-1868$ & Silvestre & $\mathrm{m}$ & lucumí & moreno & Sres. Bolet y Pages & no se dice & 80 \\
\hline 850. & Def.-F. G. P. M. & $21-07-1868$ & Nicasio & $\mathrm{m}$ & lucumí & moreno & Domingo Aldama & soltero & 60 \\
\hline 851. & Def.-F. G. P. M. & $26-08-1868$ & Máxima & f & criolla & morena & Domingo Aldama & $\mathrm{m}_{\mathrm{e}}$ & 4 \\
\hline 852. & Def.-F. G. P. M. & $19-07-1868$ & Justo & $\mathrm{m}$ & congo & moreno & Sres. Barenecena y Gamuri & soltero & 33 \\
\hline 853. & Def.-F. G. P. M. & 07-07-1868 & Ciriaco & $\mathrm{m}$ & congo & moreno & León Crespo & soltero & 20 \\
\hline 854. & Def.-F. G. P. M. & $26-08-1868$ & Mauricia & $\mathrm{f}$ & criolla & morena & $\begin{array}{l}\text { Herederos de María Antonia } \\
\text { Calvo }\end{array}$ & soltera & 30 \\
\hline
\end{tabular}




\begin{tabular}{|c|c|c|c|c|c|c|c|c|c|}
\hline 855. & Def.-F. G. P. M. & $10-08-1868$ & Victoria & $\mathrm{f}$ & conga & morena & no se dice & soltera & 30 \\
\hline 856. & Def.-F. G. P. M. & $11-08-1868$ & $\begin{array}{lll}\text { María de los } \\
\text { Ángeles }\end{array}$ & $\mathrm{f}$ & criolla & parda & no se dice & $\mathrm{m}_{\mathrm{e}}$ & 0 \\
\hline 857. & Def.-F. G. P. M. & $16-07-1868$ & Andrés & $\mathrm{m}$ & congo & moreno & Rafael Valera & no se dice & 70 \\
\hline 858. & Def.-F. G. P. M. & 07-07-1868 & José & $\mathrm{m}$ & criollo & moreno & León Crespo & soltero & 35 \\
\hline 859. & Def.-F. G. P. M. & 07-07-1868 & Francisca & $\mathrm{f}$ & conga & morena & León Crespo & soltera & 20 \\
\hline 860. & Def.-F. G. P. M. & 08-11-1868 & Severo & $\mathrm{m}$ & criollo & moreno & Domingo Aldama & soltero & 24 \\
\hline 861. & Def.-F. G. P. M. & 07-11-1868 & José & $\mathrm{m}$ & criollo & moreno & Manuel Arias & soltero & 16 \\
\hline 862. & Def.-F. G. P. M. & 11-11-1868 & Carlota & $\mathrm{f}$ & criolla & morena & Juan Luis Gómez & no se dice & 35 \\
\hline 863. & Def.-F. G. P. M. & $30-11-1868$ & Margarita & $\mathrm{f}$ & criolla & morena & León Crespo & $\mathrm{m}_{\mathrm{e}}$ & 6 \\
\hline 864. & Def.-F. G. P. M. & $16-07-1868$ & Andrés & $\mathrm{m}$ & gangá & moreno & Rafael Valera & soltero & 70 \\
\hline 865. & Def.-F. G. P. M. & $22-07-1868$ & Leoncio & $\mathrm{m}$ & criollo & moreno & Domingo Aldama & soltero & 19 \\
\hline 866. & Def.-F. G. P. M. & $19-07-1868$ & Camilo & $\mathrm{m}$ & lucumí & moreno & Domingo Aldama & soltero & 60 \\
\hline 867. & Def.-F. G. P. M. & $18-07-1868$ & Toribio & $\mathrm{m}$ & lucumí & moreno & Martín Ayllón y Testa & soltero & 56 \\
\hline 868. & Def.-F. G. P. M. & $16-08-1863$ & Simón & $\mathrm{m}$ & no se dice & moreno & Antonio Madan Alfonso & no se dice & $\mathrm{a}$ \\
\hline 869. & Def.-F. G. P. M. & 23-07-1868 & Hilario & $\mathrm{m}$ & gangá & moreno & Domingo Aldama & no se dice & 40 \\
\hline 870. & Def.-F. G. P. M. & 09-07-1868 & Dominga & $\mathrm{f}$ & criolla & morena & León Crespo & soltera & 70 \\
\hline 871. & Def.-F. G. P. M. & $01-12-1868$ & Manuela & $\mathrm{f}$ & conga & morena & León Crespo & soltera & 20 \\
\hline 872. & Def.-F. G. P. M. & $17-06-1869$ & Antonio Abad & $\mathrm{m}$ & carabalí & moreno & José R. de Cárdenas O'Farril & no se dice & $\mathrm{a}$ \\
\hline 873. & Def.-F. G. P. M. & $27-05-1869$ & Plácido & $\mathrm{m}$ & criollo & no se dice & Julia Alfonso de Moliner & $\mathrm{m}_{\mathrm{e}}$ & 0 \\
\hline 874. & Def.-F. G. P. M. & $25-06-1869$ & Caciano & $\mathrm{m}$ & carabalí & moreno & Andrés de Torres & soltero & 50 \\
\hline 875. & Def.-F. G. P. M. & 07-05-1869 & Remigio & $\mathrm{m}$ & criollo & moreno & Pedro La Rudeé & $\mathrm{m}_{\mathrm{e}}$ & 6 \\
\hline 876. & Def.-F. G. P. M. & $18-06-1869$ & Simón & $\mathrm{m}$ & carabalí & moreno & Francisco Hernández Morejón & soltero & 70 \\
\hline 877. & Def.-F. G. P. M. & $20-06-1869$ & Evarista & $\mathrm{f}$ & criolla & morena & Ambrosio María Rendón & $\mathrm{m}_{\mathrm{e}}$ & 2 \\
\hline 878. & Def.-F. G. P. M. & 09-06-1869 & Benita & $\mathrm{f}$ & criolla & morena & Domingo Belaustre & $\mathrm{m}_{\mathrm{e}}$ & 1 \\
\hline 879. & Def.-F. G. P. M. & 28-06-1869 & Carmen & $\mathrm{f}$ & criolla & morena & Pedro La Rudeé & soltera & 26 \\
\hline 880. & Def.-F. G. P. M. & 14-07-1868 & Dominga & $\mathrm{f}$ & no se dice & morena & Francisco Balbona & no se dice & 14 \\
\hline 881. & Def.-F. G. P. M. & 21-01-1855 & Labrador & $\mathrm{m}$ & gangá & moreno & Sres. Domínguez y Jener & no se dice & no \\
\hline 882. & Def.-F. G. P. M. & $11-01-1855$ & Rafael & $\mathrm{m}$ & lucumí & moreno & José Gilberto Zamora & no se dice & no \\
\hline
\end{tabular}




\begin{tabular}{|c|c|c|c|c|c|c|c|c|c|c|}
\hline 883. & Def.-F. G. P. M. & $19-01-1855$ & Antonio & $\mathrm{m}$ & gangá & moreno & Francisco de la Torriente & no se dice & no & se \\
\hline 884. & Def.-F. G. P. M. & 09-03-1855 & Tiburcio & $\mathrm{m}$ & criollo & pardo & Domingo Aldama & no se dice & no & se \\
\hline 885. & Def.-F. G. P. M. & $23-10-1856$ & Pastor & $\mathrm{m}$ & lucumí & moreno & Domingo Aldama & no se dice & no & se \\
\hline 886. & Def.-F. G. P. M. & 03-08-1856 & Alejandro & $\mathrm{m}$ & criollo & moreno & José R. de Cárdenas O'Farril & no se dice & no & se \\
\hline 887. & Def.-F. G. P. M. & 08-07-1868 & Ana & $\mathrm{f}$ & criolla & morena & Domingo Aldama & soltera & 16 & \\
\hline 888. & Def.-F. G. P. M. & $07-07-1868$ & Luciano & $\mathrm{m}$ & congo & moreno & Marquesa de Castell Florit & soltero & 40 & \\
\hline 889. & Def.-F. G. P. M. & $02-07-1868$ & Agueda & $\mathrm{f}$ & criolla & parda & Ambrosio Fernández & $\mathrm{m}_{\mathrm{e}}$ & 4 & \\
\hline 890. & Def.-F. G. P. M. & 06-07-1868 & Bartolo & $\mathrm{m}$ & congo & moreno & Esteban Santa Cruz de Oviedo & soltero & 40 & \\
\hline 891. & Def.-F. G. P. M. & $05-07-1868$ & Paula & $\mathrm{f}$ & lucumí & morena & León Crespo & soltera & 30 & \\
\hline 892. & Def.-F. G. P. M. & $05-07-1868$ & Teófila & $\mathrm{f}$ & criolla & morena & León Crespo & $\mathrm{m}_{\mathrm{e}}$ & 3 & \\
\hline 893. & Def.-F. G. P. M. & $06-07-1868$ & Julia & $\mathrm{f}$ & conga & morena & León Crespo & soltera & 20 & \\
\hline 894. & Def.-F. G. P. M. & $07-07-1868$ & Catulo & $\mathrm{m}$ & criollo & moreno & León Crespo & soltero & 35 & \\
\hline 895. & Def.-F. G. P. M. & $08-07-1868$ & Carlos & $\mathrm{m}$ & criollo & moreno & León Crespo & soltero & 45 & \\
\hline 896. & Def.-F. G. P. M. & $11-07-1868$ & Lorenzo & $\mathrm{m}$ & congo & moreno & León Crespo & soltero & 90 & \\
\hline 897. & Def.-F. G. P. M. & 04-07-1868 & Romualdo & $\mathrm{m}$ & criollo & moreno & León Crespo & soltero & 46 & \\
\hline 898. & Def.-F. G. P. M. & 04-07-1868 & Manuela & $\mathrm{f}$ & gangá & morena & Cosme de la Torriente & soltera & 51 & \\
\hline 899. & Def.-F. G. P. M. & 23-07-1868 & Pascuala & $\mathrm{f}$ & criolla & morena & Domingo Aldama & soltera & 18 & \\
\hline 900. & Def.-F. G. P. M. & 23-07-1868 & José & $\mathrm{m}$ & congo & moreno & Manuel Fernández & soltero & 20 & \\
\hline 901. & Def.-F. G. P. M. & 21-07-1868 & Martina & $\mathrm{f}$ & gangá & morena & Domingo Aldama & soltera & 26 & \\
\hline 902. & Def.-F. G. P. M. & $10-07-1868$ & Luis & $\mathrm{m}$ & congo & moreno & Domingo Aldama & soltero & 50 & \\
\hline 903. & Def.-F. G. P. M. & $16-07-1868$ & Marino & $\mathrm{m}$ & criollo & moreno & Domingo Aldama & $\mathrm{m}_{\mathrm{e}}$ & 2 & \\
\hline 904. & Def.-F. G. P. M. & $25-05-1866$ & Santiago & $\mathrm{m}$ & mandinga & moreno & Santiago Rosié & soltero & 71 & \\
\hline 905. & Def.-F. G. P. M. & 14-06-1866 & Torcuato & $\mathrm{m}$ & gangá & moreno & Petrona Milian y García & no se dice & no & se \\
\hline 906. & Def.-F. G. P. M. & $01-06-1866$ & Vicente & $\mathrm{m}$ & criollo & moreno & Domingo Aldama & no se dice & no & se \\
\hline 907. & Def.-F. G. P. M. & $30-05-1869$ & Rafaela & $\mathrm{f}$ & conga & morena & Marqués de Montelo & no se dice & 50 & \\
\hline 908. & Def.-F. G. P. M. & 26-10-1869 & Amador & $\mathrm{m}$ & congo & moreno & José Baró & soltero & 70 & \\
\hline 909. & Def.-F. G. P. M. & 07-08-1869 & Jorge & $\mathrm{m}$ & congo & moreno & Antonia Madan de Alfonso & no se dice & 81 & \\
\hline 910. & Def.-F. G. P. M. & $15-07-1869$ & Rafaela & $\mathrm{f}$ & criolla & morena & José R. de Cárdenas O'Farril & $\mathrm{m}_{\mathrm{e}}$ & 1 & \\
\hline 911. & Def.-F. G. P. M. & 20-04-1869 & Gabriela & $\mathrm{f}$ & criolla & morena & Felipa Chávez & no se dice & 25 & \\
\hline
\end{tabular}




\begin{tabular}{|c|c|c|c|c|c|c|c|c|c|}
\hline 912. & Def.-F. G. P. M. & $20-05-1869$ & Josefa & $\mathrm{f}$ & criolla & morena & $?$ & soltera & 23 \\
\hline 913. & Def.-F. G. P. M. & 02-05-1869 & Juan & $\mathrm{m}$ & criollo & no se dice & Herederos de Andrea Lemasny & $\mathrm{m}_{\mathrm{e}}$ & 0 \\
\hline 914. & Def.-F. G. P. M. & 28-04-1869 & Bibiana Gil & $\mathrm{f}$ & criolla & morena & Lugarda Gil & soltera & 42 \\
\hline 915. & Def.-F. G. P. M. & 20-04-1869 & Altagracia & $\mathrm{f}$ & mandinga & morena & Julio Daprés & no se dice & 40 \\
\hline 916. & Def.-F. G. P. M. & 21-03-1869 & María de Loreto & $\mathrm{f}$ & criolla & morena & Petrona Junco de Gener & soltera & 30 \\
\hline 917. & Def.-F. G. P. M. & $11-04-1869$ & Caridad & $\mathrm{f}$ & criolla & no se dice & Narciso Hernández & $\mathrm{m}_{\mathrm{e}}$ & 3 \\
\hline 918. & Def.-F. G. P. M. & 16-04-1869 & Gerónimo & $\mathrm{m}$ & criollo & moreno & Marqués de Esteves & soltero & 20 \\
\hline 919. & Def.-F. G. P. M. & $23-05-1869$ & Valentín & $\mathrm{m}$ & gangá & moreno & $?$ & soltero & 90 \\
\hline 920. & Def.-F. G. P. M. & 08-05-1869 & Isidora & $\mathrm{f}$ & criolla & no se dice & Marqués de Montelo & $\mathrm{m}_{\mathrm{e}}$ & 0 \\
\hline 921. & Def.-F. G. P. M. & 30-08-1869 & Serapio & $\mathrm{m}$ & gangá & moreno & $\begin{array}{l}\text { Rafael Sánchez y Francisco } \\
\text { Hernández }\end{array}$ & soltero & 70 \\
\hline 922. & Def.-F. G. P. M. & $11-03-1868$ & Marcelino & $\mathrm{m}$ & gangá & moreno & Pánfila Sardiñas & soltero & 57 \\
\hline 923. & Def.-F. G. P. M. & 06-03-1868 & Bartolo & $\mathrm{m}$ & lucumí & moreno & Domingo Aldama & no se dice & 100 \\
\hline 924. & Def.-F. G. P. M. & 02-03-1868 & Isidoro & $\mathrm{m}$ & lucumí & moreno & María Antonia Calvo & casado & 100 \\
\hline 925. & Def.-F. G. P. M. & 04-03-1868 & Matilde & $\mathrm{m}$ & lucumí & moreno & Domingo Aldama & no se dice & 50 \\
\hline 926. & Def.-F. G. P. M. & $14-07-1868$ & Jorge & $\mathrm{m}$ & mandinga & moreno & Rafael Valera & no se dice & 55 \\
\hline 927. & Def.-F. G. P. M. & $15-07-1868$ & Magdaleno & $\mathrm{m}$ & criollo & moreno & $?$ & $\mathrm{~m}_{\mathrm{e}}$ & 3 \\
\hline 928. & Def.-F. G. P. M. & $16-07-1868$ & Manuel & $\mathrm{m}$ & criollo & pardo & Domingo Aldama & soltero & 25 \\
\hline 929. & Def.-F. G. P. M. & $14-07-1868$ & Coleta & $\mathrm{f}$ & conga & morena & Cosme de la Torriente & soltera & 46 \\
\hline 930. & Def.-F. G. P. M. & $14-07-1868$ & Pedro & $\mathrm{m}$ & congo & moreno & Ramona Reyes & no se dice & 25 \\
\hline 931. & Def.-F. G. P. M. & $16-07-1868$ & José María & $\mathrm{m}$ & lucumí & moreno & Isidra García & soltero & 56 \\
\hline 932. & Def.-F. G. P. M. & $15-07-1868$ & Luis & $\mathrm{m}$ & congo & moreno & José Serrate & soltero & 35 \\
\hline 933. & Def.-F. G. P. M. & 24-11-1868 & Ambrosio & $\mathrm{m}$ & $\operatorname{mina}$ & moreno & Marqués de Montelo & soltero & 80 \\
\hline 934. & Def.-F. G. P. M. & $16-11-1868$ & Basilio & $\mathrm{m}$ & gangá & moreno & Domingo Aldama & soltero & 80 \\
\hline 935. & Def.-F. G. P. M. & $25-09-1868$ & Ciriaco & $\mathrm{m}$ & no se dice & moreno & Lorenzo Delgado y Compañía & no se dice & 40 \\
\hline 936. & Def.-F. G. P. M. & 28-09-1868 & Eustaquio & $\mathrm{m}$ & criollo & pardo & Isabel Madan & $\mathrm{m}_{\mathrm{e}}$ & 0 \\
\hline 937. & Def.-F. G. P. M. & $16-09-1868$ & Eustaquio & $\mathrm{m}$ & criollo & moreno & Félix Soloni & $\mathrm{m}_{\mathrm{e}}$ & 17 \\
\hline 938. & Def.-F. G. P. M. & 11-09-1868 & Pio Pérez & $\mathrm{m}$ & congo & moreno & Domingo Pérez & soltero & 22 \\
\hline 939. & Def.-F. G. P. M. & $10-08-1868$ & Marcelina & $\mathrm{f}$ & criolla & morena & Sres. Drake y hermano & $\mathrm{m}$ & 1 \\
\hline
\end{tabular}




\begin{tabular}{|c|c|c|c|c|c|c|c|c|c|}
\hline 940. & Def.-F. G. P. M. & $17-08-1868$ & Esteban & $\mathrm{m}$ & criollo & no se dice & Eustasia Fuentes & $\mathrm{m}_{\mathrm{e}}$ & 0 \\
\hline 941. & Def.-F. G. P. M. & $19-08-1868$ & Fabián & $\mathrm{m}$ & congo & moreno & Agueda de Lima & no se dice & 45 \\
\hline 942. & Def.-F. G. P. M. & 23-08-1868 & Francisco & $\mathrm{m}$ & no se dice & moreno & Pelegrin Fialo & no se dice & 60 \\
\hline 943. & Def.-F. G. P. M. & 05-07-1868 & Dominga & $\mathrm{f}$ & criolla & no se dice & León Crespo & $\mathrm{m}_{\mathrm{e}}$ & 5 \\
\hline 944. & Def.-F. G. P. M. & $06-07-1868$ & Federico & $\mathrm{m}$ & criollo & moreno & León Crespo & soltero & 15 \\
\hline 945. & Def.-F. G. P. M. & $23-08-1868$ & José León & $\mathrm{m}$ & lucumí & moreno & Pelegrin Fialo & no se dice & 50 \\
\hline 946. & Def.-F. G. P. M. & 27-08-1868 & Pía & f & criolla & morena & Francisco Hernández Morejón & $\mathrm{m}_{\mathrm{e}}$ & 2 \\
\hline 947. & Def.-F. G. P. M. & 02-07-1869 & Amalia & $\mathrm{f}$ & criolla & morena & Domingo Aldama & $\mathrm{m}_{\mathrm{e}}$ & 3 \\
\hline 948. & Def.-F. G. P. M. & $11-07-1869$ & Ramón & $\mathrm{m}$ & lucumí & moreno & José R. de Cárdenas O'Farril & no se dice & 57 \\
\hline 949. & Def.-F. G. P. M. & $14-07-1869$ & Isabel & $\mathrm{f}$ & criolla & parda & Francisca Díaz & $\mathrm{m}_{\mathrm{e}}$ & 0 \\
\hline 950. & Def.-F. G. P. M. & $17-07-1869$ & María de Jesús & $\mathrm{f}$ & criolla & morena & Esteban Santa Cruz de Oviedo & no se dice & 30 \\
\hline 951. & Def.-F. G. P. M. & $17-07-1869$ & Pedro & $\mathrm{m}$ & criollo & moreno & Antonia Madan de Alfonso & no se dice & 21 \\
\hline 952. & Def.-F. G. P. M. & $07-07-1868$ & Jacinta & $\mathrm{f}$ & criolla & morena & León Crespo & soltera & 35 \\
\hline 953. & Def.-F. G. P. M. & 06-07-1868 & Andrés & $\mathrm{m}$ & congo & moreno & León Crespo & soltero & 30 \\
\hline 954. & Def.-F. G. P. M. & $07-07-1868$ & Vicente & $\mathrm{m}$ & criollo & pardo & León Crespo & soltero & 25 \\
\hline 955. & Def.-F. G. P. M. & $07-07-1868$ & Leonor & $\mathrm{f}$ & criolla & morena & León Crespo & $\mathrm{m}_{\mathrm{e}}$ & 2 \\
\hline 956. & Def.-F. G. P. M. & 08-07-1868 & Felipe & $\mathrm{m}$ & criollo & moreno & León Crespo & $\mathrm{m}_{\mathrm{e}}$ & 12 \\
\hline 957. & Def.-F. G. P. M. & 09-07-1868 & Cecilio & $\mathrm{m}$ & lucumí & moreno & Domingo Aldama & soltero & 60 \\
\hline 958. & Def.-F. G. P. M. & $07-07-1868$ & Daniel & $\mathrm{m}$ & criollo & moreno & León Crespo & $\mathrm{m}_{\mathrm{e}}$ & 3 \\
\hline 959. & Def.-F. G. P. M. & $28-12-1868$ & Agustín & $\mathrm{m}$ & congo & moreno & Salvador Baró & no se dice & 90 \\
\hline 960. & Def.-F. G. P. M. & $10-07-1868$ & Claudio & $\mathrm{m}$ & lucumí & moreno & Miguel Armona & no se dice & 50 \\
\hline 961. & Def.-F. G. P. M. & $06-07-1868$ & Inés & f & criolla & morena & León Crespo & soltera & 80 \\
\hline 962. & Def.-F. G. P. M. & 18-04-1868 & Antonio & $\mathrm{m}$ & carabalí & moreno & Herederos de Agustín Ibarra & soltero & 33 \\
\hline 963. & Def.-F. G. P. M. & $18-07-1868$ & Casimiro & $\mathrm{m}$ & carabalí & moreno & Miguel Armona & no se dice & 95 \\
\hline 964. & Def.-F. G. P. M. & $17-07-1868$ & Francisco & $\mathrm{m}$ & criollo & moreno & Miguel Armona & $\mathrm{m}_{\mathrm{e}}$ & 2 \\
\hline 965. & Def.-F. G. P. M. & $28-07-1868$ & Bonifacio & $\mathrm{m}$ & criollo & moreno & Juan Rodríguez & $\mathrm{m}_{\mathrm{e}}$ & 6 \\
\hline 966. & Def.-F. G. P. M. & $25-07-1868$ & Beatriz & $\mathrm{f}$ & carabalí & morena & Domingo Echevarría & no se dice & 80 \\
\hline 967. & Def.-F. G. P. M. & $22-12-1868$ & Ramona & $\mathrm{f}$ & criolla & morena & $?$ & $\mathrm{~m}_{\mathrm{e}}$ & 7 \\
\hline 968. & Def.-F. G. P. M. & $09-12-1868$ & Juan & $\mathrm{m}$ & criollo & moreno & Pedro Hernández Morejón & $\mathrm{m}_{\mathrm{e}}$ & 2 \\
\hline
\end{tabular}




\begin{tabular}{|c|c|c|c|c|c|c|c|c|c|c|}
\hline 969. & Def.-F. G. P. M. & 21-06-1868 & Tomás & $\mathrm{m}$ & criollo & moreno & José Baró & no se dice & no & se \\
\hline 970. & Def.-F. G. P. M. & $17-06-1869$ & Andrea & $\mathrm{f}$ & criolla & morena & José García & $\mathrm{m}_{\mathrm{e}}$ & 0 & \\
\hline 971. & Def.-F. G. P. M. & $21-07-1869$ & Tomás & $\mathrm{m}$ & congo & moreno & Francisco Aballí & soltero & 25 & \\
\hline 972. & Def.-F. G. P. M. & $26-12-1868$ & Dámaso & $\mathrm{m}$ & mandinga & moreno & $\begin{array}{l}\text { Herederos de Martín de Zayas y } \\
\text { Varona }\end{array}$ & soltero & 50 & \\
\hline 973. & Def.-F. G. P. M. & 02-07-1869 & Miguel & $\mathrm{m}$ & gangá & moreno & Herederos de Manuel del Junco & soltero & 80 & \\
\hline 974. & Def.-F. G. P. M. & $25-07-1868$ & Antonio & $\mathrm{m}$ & congo & moreno & Justo de Lamar & soltero & 60 & \\
\hline 975. & Def.-F. G. P. M. & $25-07-1868$ & Clemente & $\mathrm{m}$ & mandinga & moreno & Domingo Belaustre & soltero & 36 & \\
\hline 976. & Def.-F. G. P. M. & 21-07-1869 & María Isabel & $\mathrm{f}$ & criolla & no se dice & José R. de Cárdenas O'Farril & $\mathrm{m}_{\mathrm{e}}$ & 0 & \\
\hline 977. & Def.-F. G. P. M. & $15-07-1869$ & Guadalupe & $\mathrm{f}$ & criolla & morena & Antonio García de Villalta & soltera & 50 & \\
\hline 978. & Def.-F. G. P. M. & $22-08-1868$ & Narciso & $\mathrm{m}$ & gangá & moreno & Gabriel López & soltero & 50 & \\
\hline 979. & Def.-F. G. P. M. & $18-07-1869$ & Francisco & $\mathrm{m}$ & criollo & moreno & Domingo Aldama & $\mathrm{m}_{\mathrm{e}}$ & 5 & \\
\hline 980. & Def.-F. G. P. M. & $25-11-1868$ & Perfecto & $\mathrm{m}$ & mina & moreno & Domingo Aldama & viudo & 95 & \\
\hline 981. & Def.-F. G. P. M. & 05-10-1869 & Ramón & $\mathrm{m}$ & congo & moreno & Francisco Marrero & soltero & 40 & \\
\hline 982. & Def.-F. G. P. M. & $26-08-1868$ & Agapito & $\mathrm{m}$ & criollo & moreno & José Gutiérrez & $\mathrm{m}_{\mathrm{e}}$ & 0 & \\
\hline 983. & Def.-F. G. P. M. & $11-09-1868$ & Gregorio Días & $\mathrm{m}$ & no se dice & moreno & José Coll & soltero & 28 & \\
\hline 984. & Def.-F. G. P. M. & $05-07-1868$ & Bárbara & $\mathrm{f}$ & conga & morena & León Crespo & soltera & 20 & \\
\hline 985. & Def.-F. G. P. M. & 24-08-1868 & Sebastiana & $\mathrm{f}$ & criolla & morena & Petrona Milian y García & $\mathrm{m}_{\mathrm{e}}$ & 0 & \\
\hline 986. & Def.-F. G. P. M. & $26-07-1868$ & Diego & $\mathrm{m}$ & criollo & moreno & Miguel Armona & soltero & 25 & \\
\hline 987. & Def.-F. G. P. M. & 25-04-1869 & María Nieve & $\mathrm{f}$ & criolla & morena & León Crespo & $\mathrm{m}_{\mathrm{e}}$ & 0 & \\
\hline 988. & Def.-F. G. P. M. & 03-04-1869 & Lucía & $\mathrm{f}$ & criolla & parda & Pedro La Rudeé & soltera & 36 & \\
\hline 989. & Def.-F. G. P. M. & $12-07-1868$ & Jorge & $\mathrm{m}$ & criollo & moreno & León Crespo & soltero & 25 & \\
\hline 990. & Def.-F. G. P. M. & 29-06-1869 & Benita & $\mathrm{f}$ & criolla & parda & Domingo Belaustre & soltera & 18 & \\
\hline 991. & Def.-F. G. P. M. & $17-04-1869$ & Pedro José & $\mathrm{m}$ & criollo & moreno & Mariano Rivera & $\mathrm{m}_{\mathrm{e}}$ & 12 & \\
\hline 992. & Def.-F. G. P. M. & 19-07-1869 & Lugarda & $\mathrm{f}$ & criolla & morena & José R. de Cárdenas O'Farril & soltera & 18 & \\
\hline 993. & Def.-F. G. P. M. & 30-10-1869 & Trinidad & $\mathrm{m}$ & mina & moreno & Sres. Drake y hermano & viudo & 73 & \\
\hline 994. & Def.-F. G. P. M. & 28-09-1869 & Antonio María & $\mathrm{m}$ & lucumí & moreno & Patricia Ponce de León & no se dice & 45 & \\
\hline 995. & Def.-F. G. P. M. & $14-07-1869$ & Cristóbal & $\mathrm{m}$ & lucumí & moreno & José Govín & no se dice & 60 & \\
\hline 996. & Def.-F. G. P. M. & $20-07-1868$ & Bienvenido & $\mathrm{m}$ & gangá & moreno & Narciso Hernández & soltero & 75 & \\
\hline
\end{tabular}




\begin{tabular}{|c|c|c|c|c|c|c|c|c|c|}
\hline 997. & Def.-F. G. P. M. & $07-07-1868$ & Mercedes & $\mathrm{f}$ & gangá & morena & Miguel Armona & soltera & 60 \\
\hline 998. & Def.-F. G. P. M. & 21-07-1869 & Guillermo & $\mathrm{m}$ & criollo & no se dice & Juan Hernández & $\mathrm{m}_{\mathrm{e}}$ & 0 \\
\hline 999. & Def.-F. G. P. M. & 09-07-1869 & Odón & $\mathrm{m}$ & criollo & no se dice & Antonio García de Villalta & $\mathrm{m}_{\mathrm{e}}$ & 0 \\
\hline 1000. & Def.-F. G. P. M. & 16-06-1868 & Bernardo & $\mathrm{m}$ & criollo & moreno & Domingo Aldama & $\mathrm{m}_{\mathrm{e}}$ & 3 \\
\hline
\end{tabular}

$\left(\mathrm{m}_{\mathrm{e}}\right)$ Menores de 15 años. (? ) Ilegible. Elaboración propia a partir de la información disponible en: SSDA y Defunciones, Fondo Gobierno Provincial, AHPM. 
APÉNDICE DOCUMENTAL 


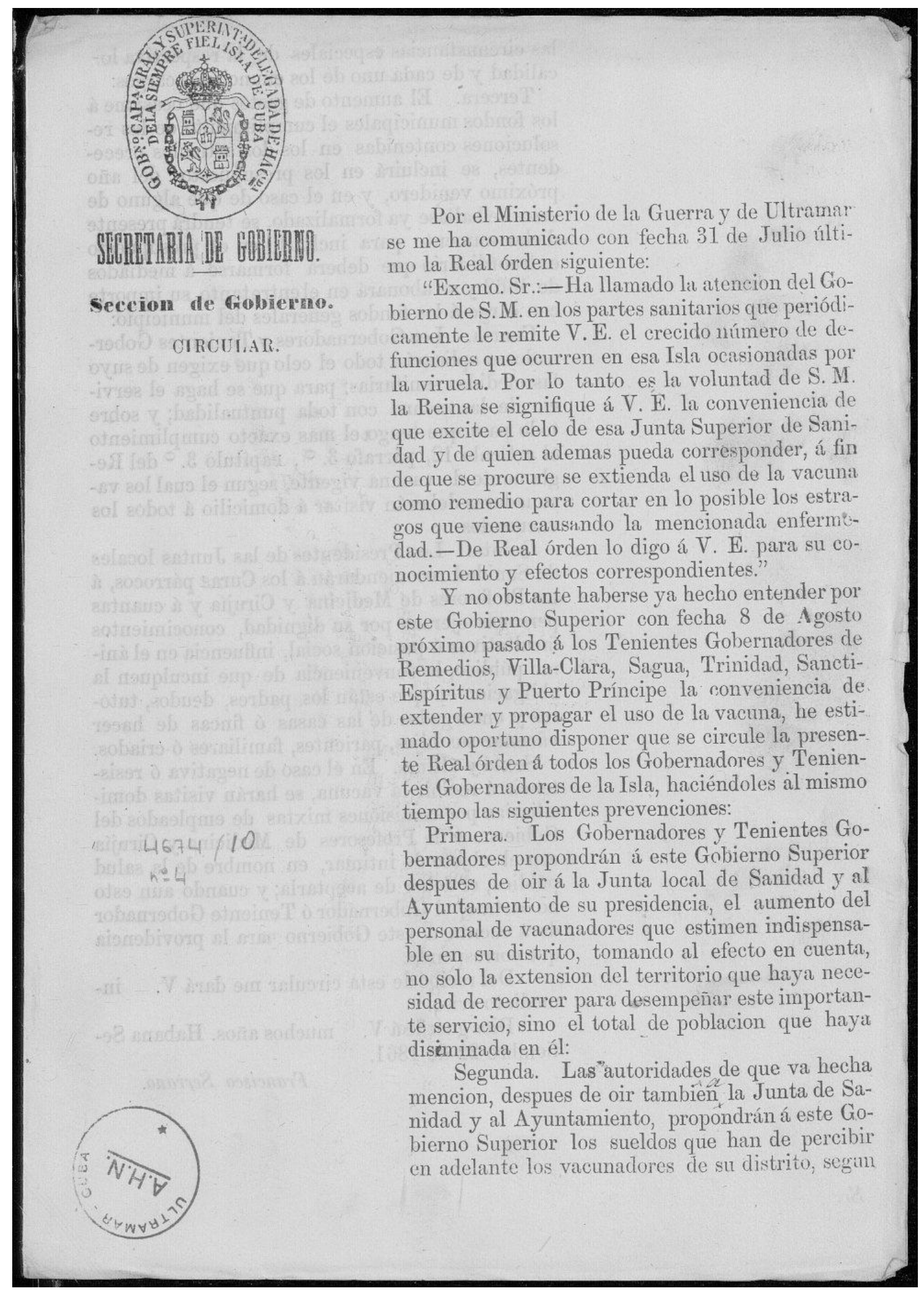




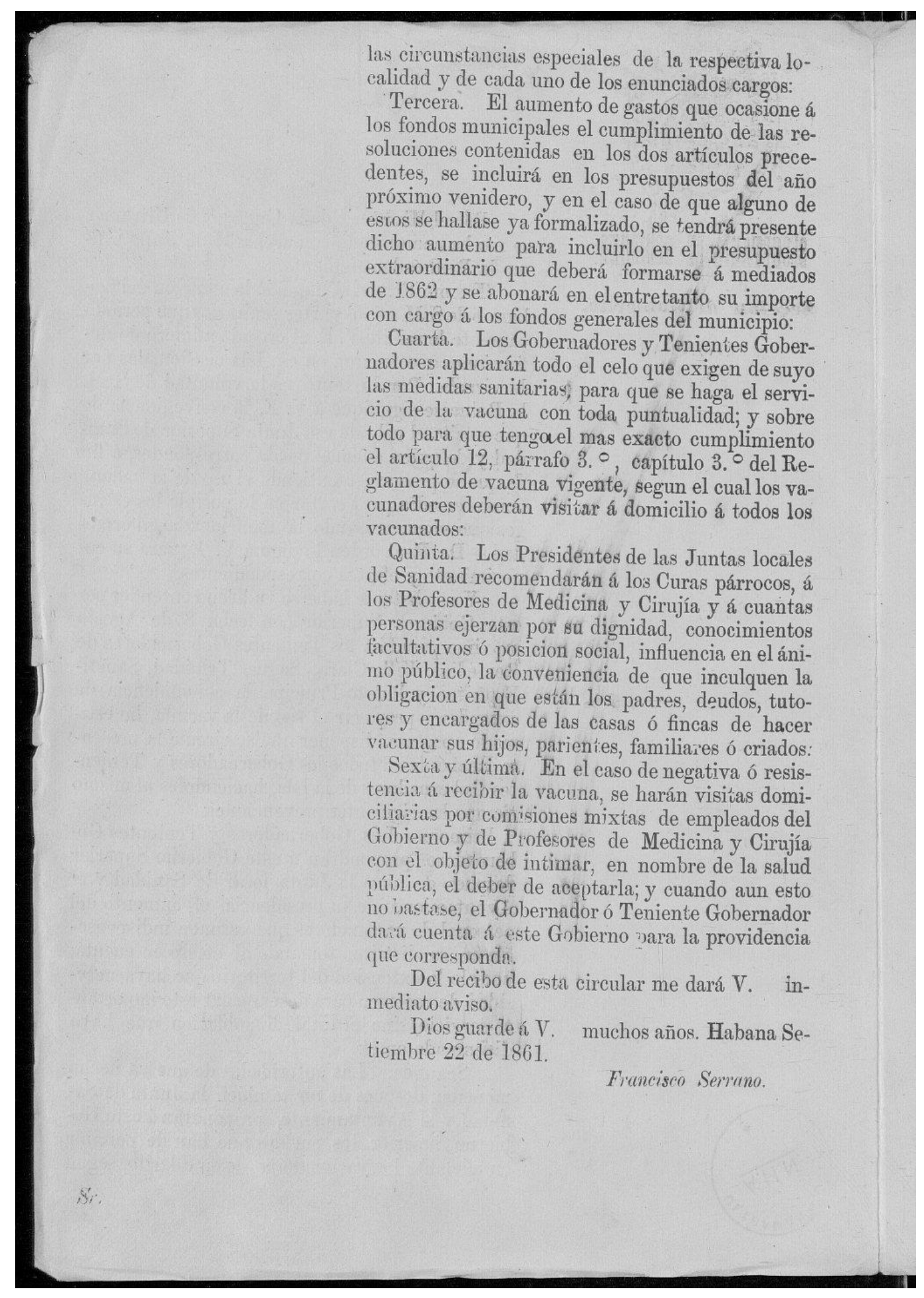

Fuente: "Se recomienda que la vacuna de la viruela sea obligatoria en Cuba", AHN, Ultramar, Leg. 4674, No. 10,1861 . 
II- DOCUMENTO FIRMADO POR CARLOS MANUEL DE CÉSPEDES NOTIFICANDO A LAS AUTORIDADES LA MUERTE DE JUAN MARÍA, ESCLAVO DE 61 AÑOS, DE NACIÓN CARABALÍ, A CONSECUENCIA DE UNA TISIS PROLONGADA.

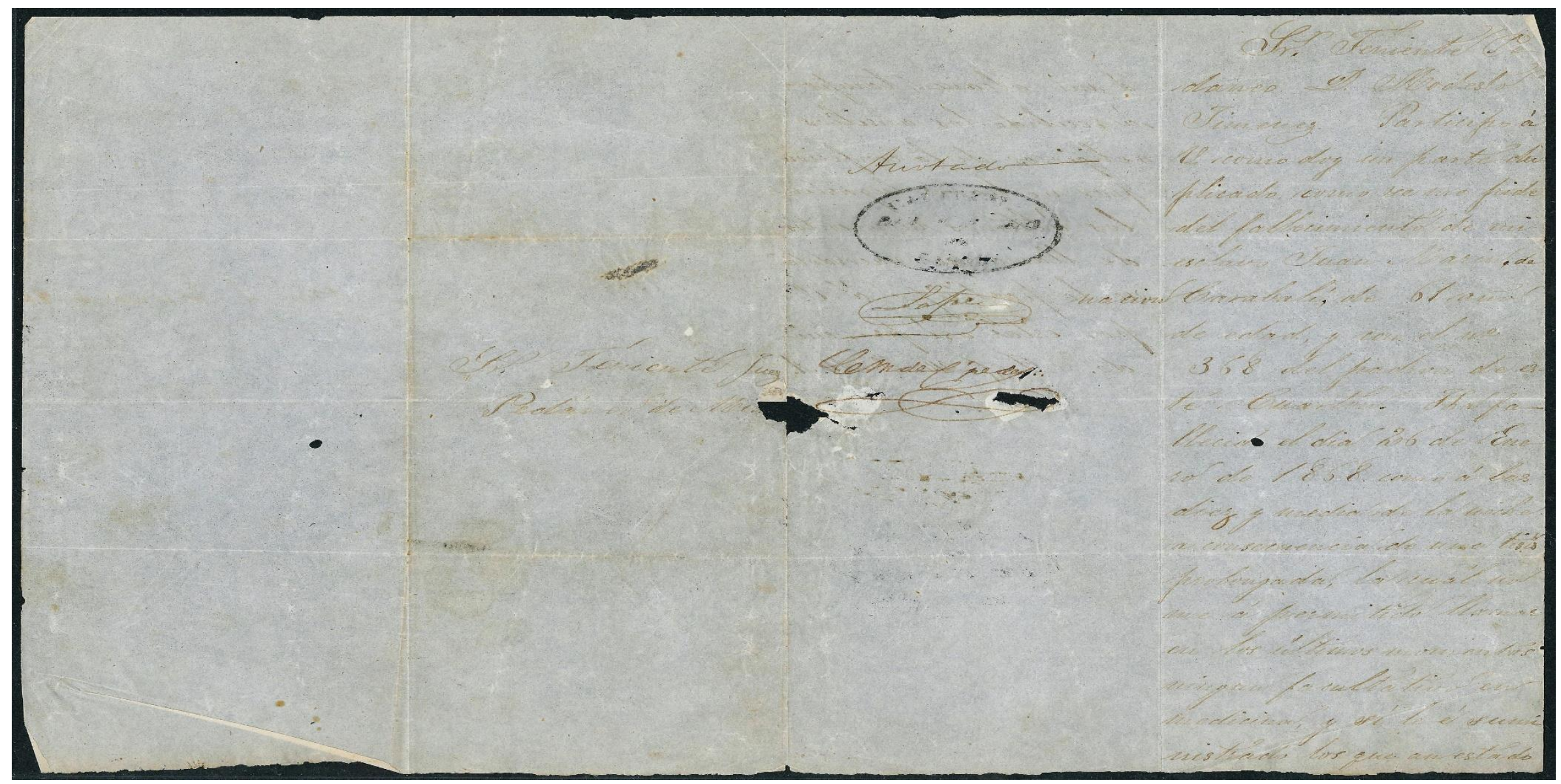




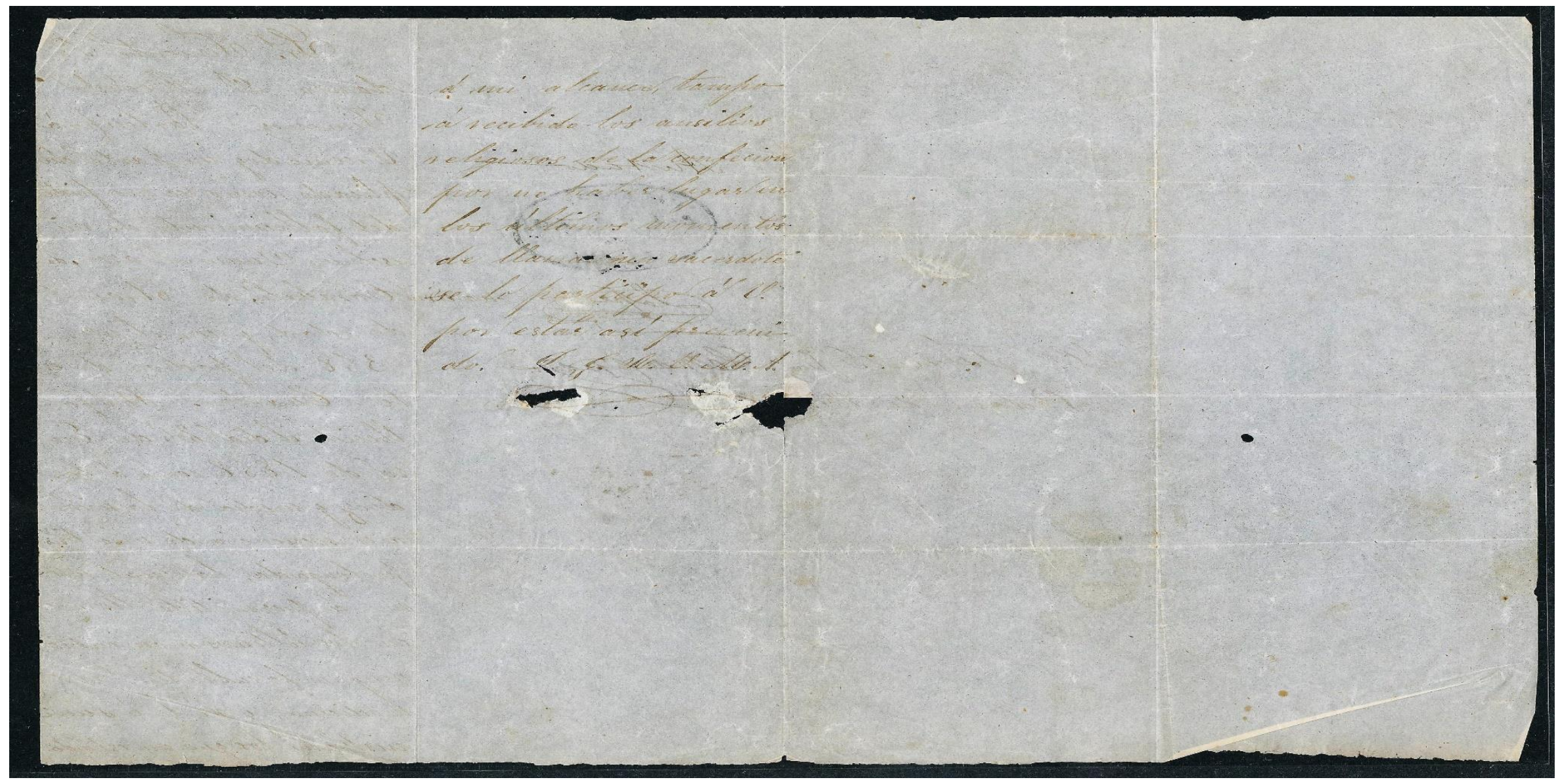

Fuente: Cuban Heritage Collection. University of Miami. 
Sr. Teniente Pedáneo D. Modesto Jiménez. Participo á U. como doy un parte duplicado como se me pide del fallecimiento de mi esclavo Juan María, de nación Carabalí, de 61 años de edad, y con el no 368 del padrón este Cuartón. Ha fallecido el día 26 de Enero de 1868 como a las diez y media de la noche a consecuencia de una tisis prolongada, la cual no me á permitido llamar en los últimos momentos ningún facultativo en medicina, y sí le é suministrado los que an estado á mí alcance, tampoco á recibido los ausilios religiosos de la confeción por no haber lugar en los últimos momentos de llamar un sacerdote, se lo participo á U. por esta, así prevenido.

(firma) 
III- FOTOGRAFÍA DEL INTERIOR DE UN INGENIO CUBANO, TOMADA POR GEORGE NORMAN BARNARD EN ALGÚN MOMENTO DE LA DÉCADA DE 1860.

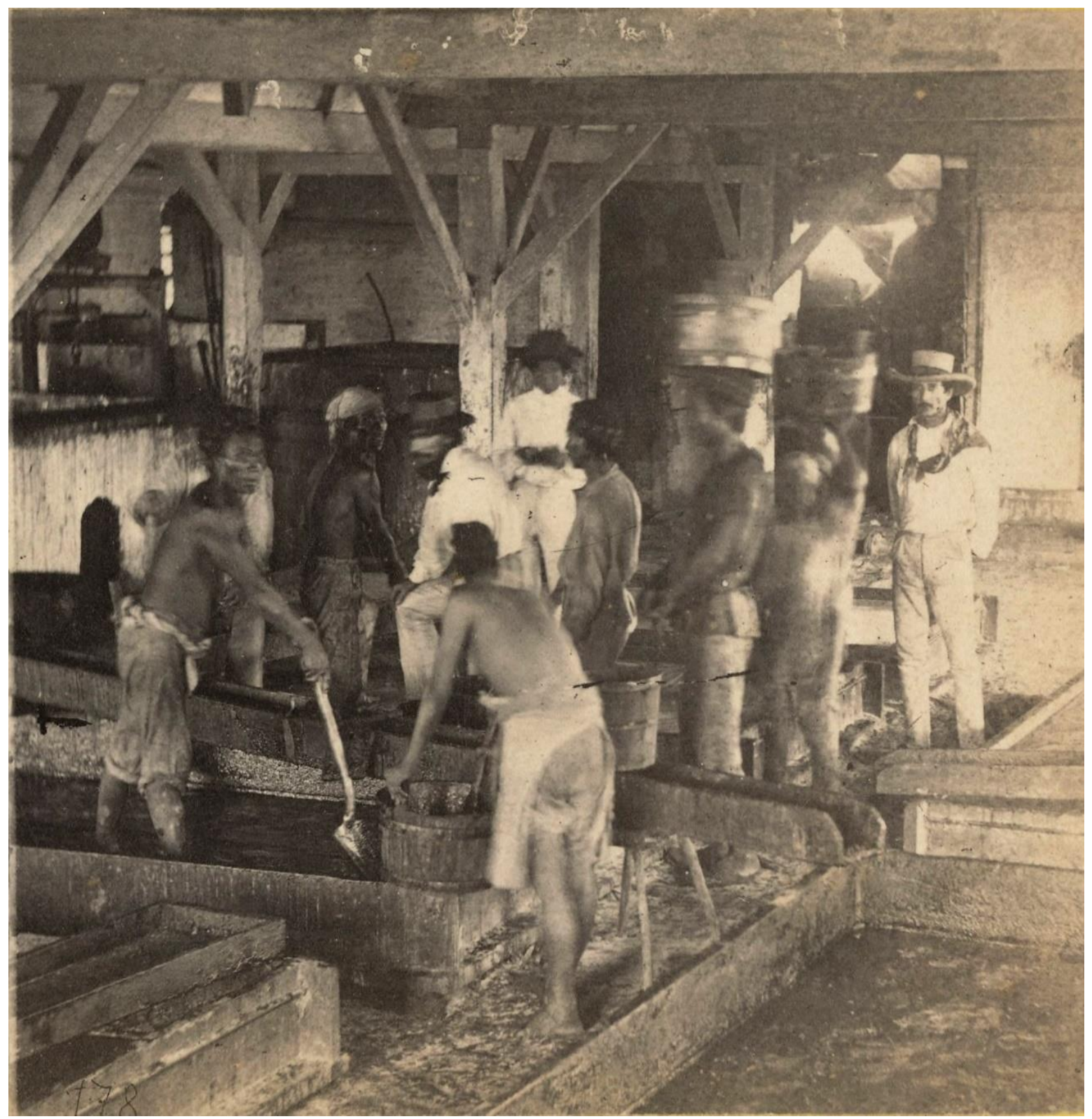

Fuente: Cuban Heritage Collection. University of Miami. 
IV- NOTA EN LA QUE SE INFORMA AL BRIGADIER GOBERNADOR DE MATANZAS LAS DEFUNCIONES DE VARIOS ESCLAVOS CORRESPONDIENTES A LA DOTACIÓN DEL INGENIO SANTA ROSA, PROPIEDAD DE DOMINGO ALDAMA.

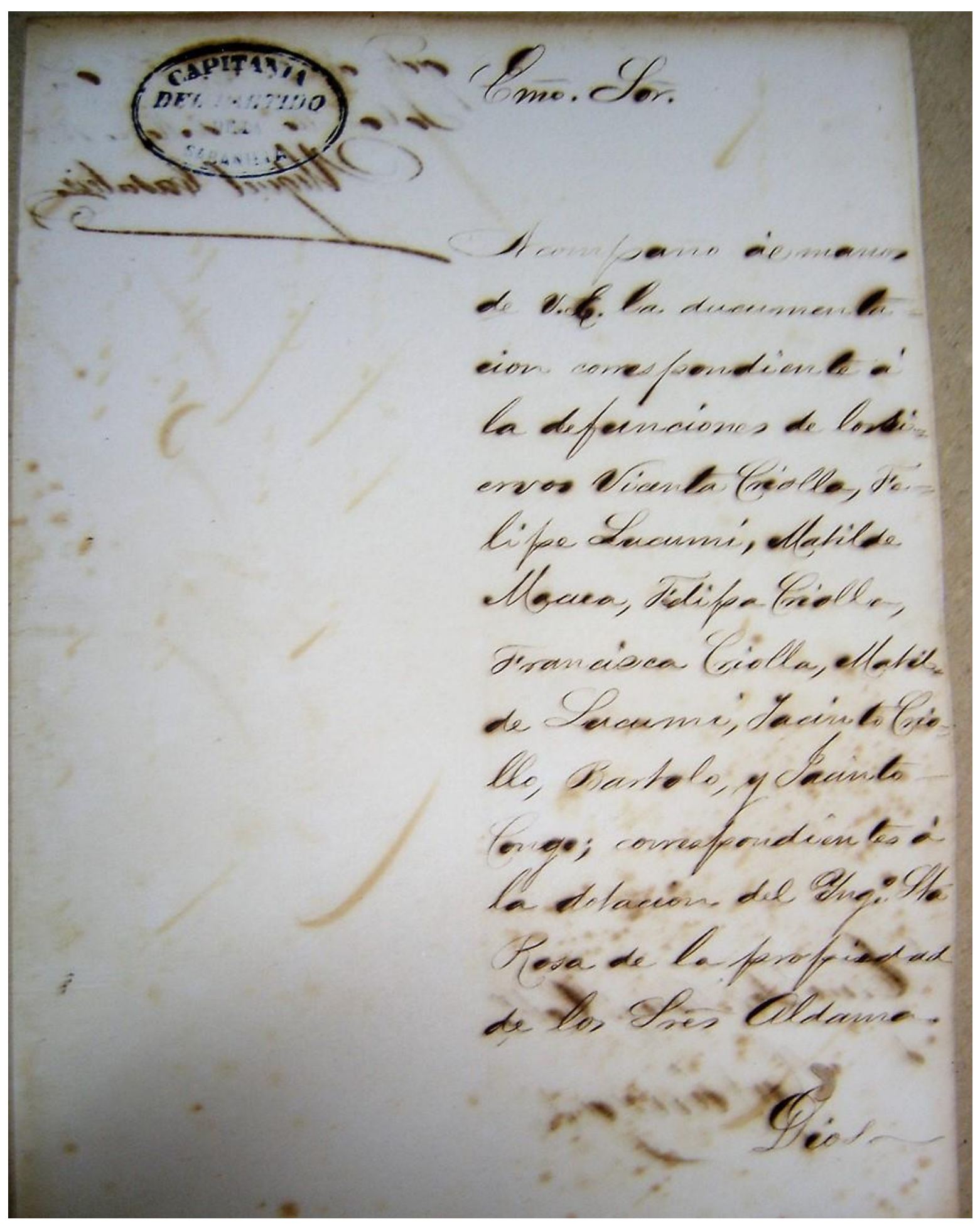




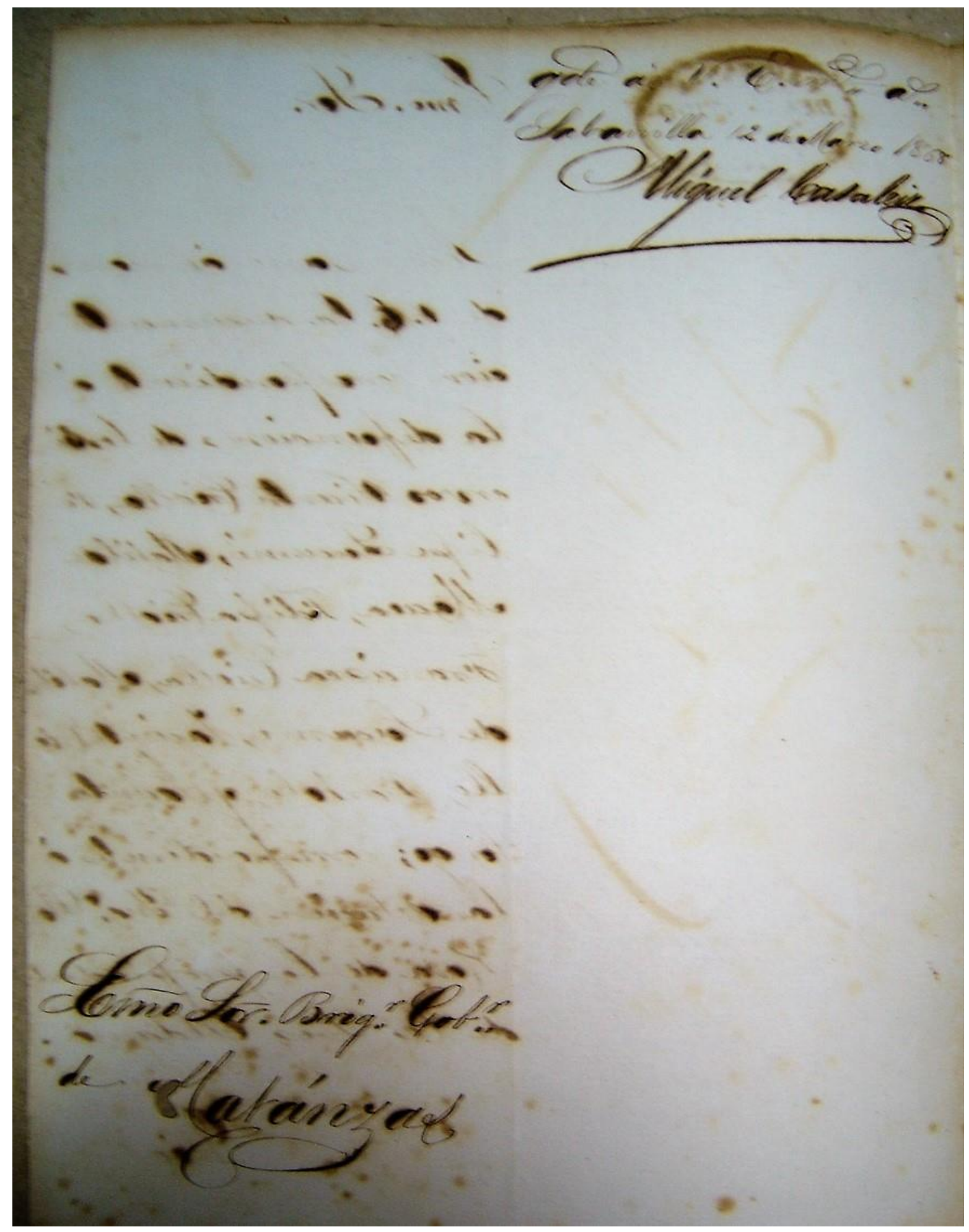

Los esclavos nombrados son Vicenta criolla, Felipe lucumí, Matilde macua, Felipa criolla, Francisca criolla, Matilde lucumí, Jacinto criollo, Bartolo, y Jacinto congo. La nota está firmada el 12 de marzo de 1868. Fuente: Defunciones, Fondo Gobierno Provincial, AHPM. 
V- IMÁGENES DEL LIBRO DE REFACCIÓN DE INGENIOS DE JULIÁN ZULUETA EN EL QUE SE REGISTRA EL NACIMIENTO (2 DE AGOSTO DE 1876) Y LA INMEDIATA DEFUNCIÓN (3 DE AGOSTO DE 1876) DE CÁNDIDO, HIJO DE JUANA MACUA. TAMBIÉN SE NOTIFICA LA DEFUNCIÓN DEL CRIOLLITO GERARDO, HIJO DE SAGUNTA LUCUMÍ.

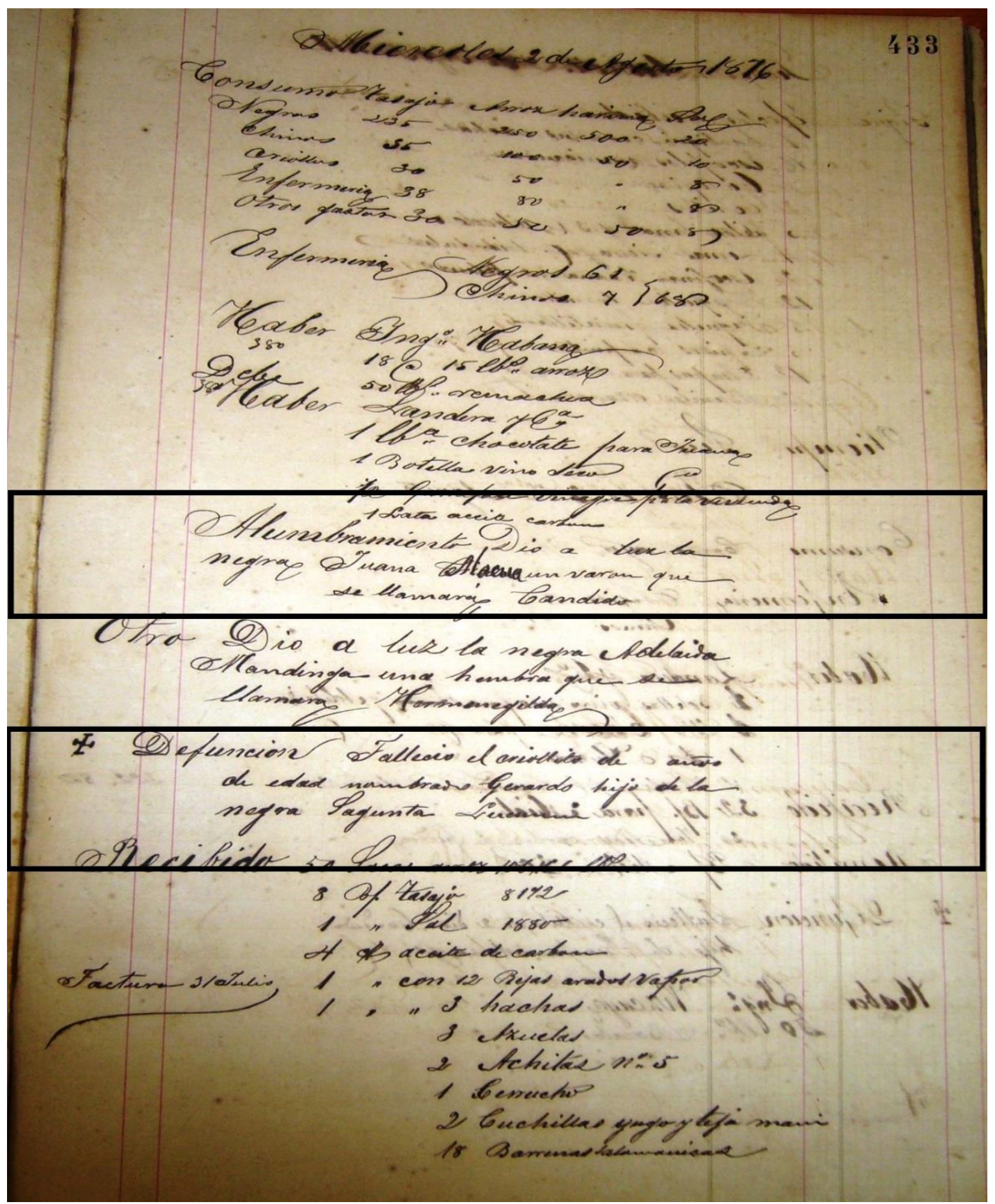




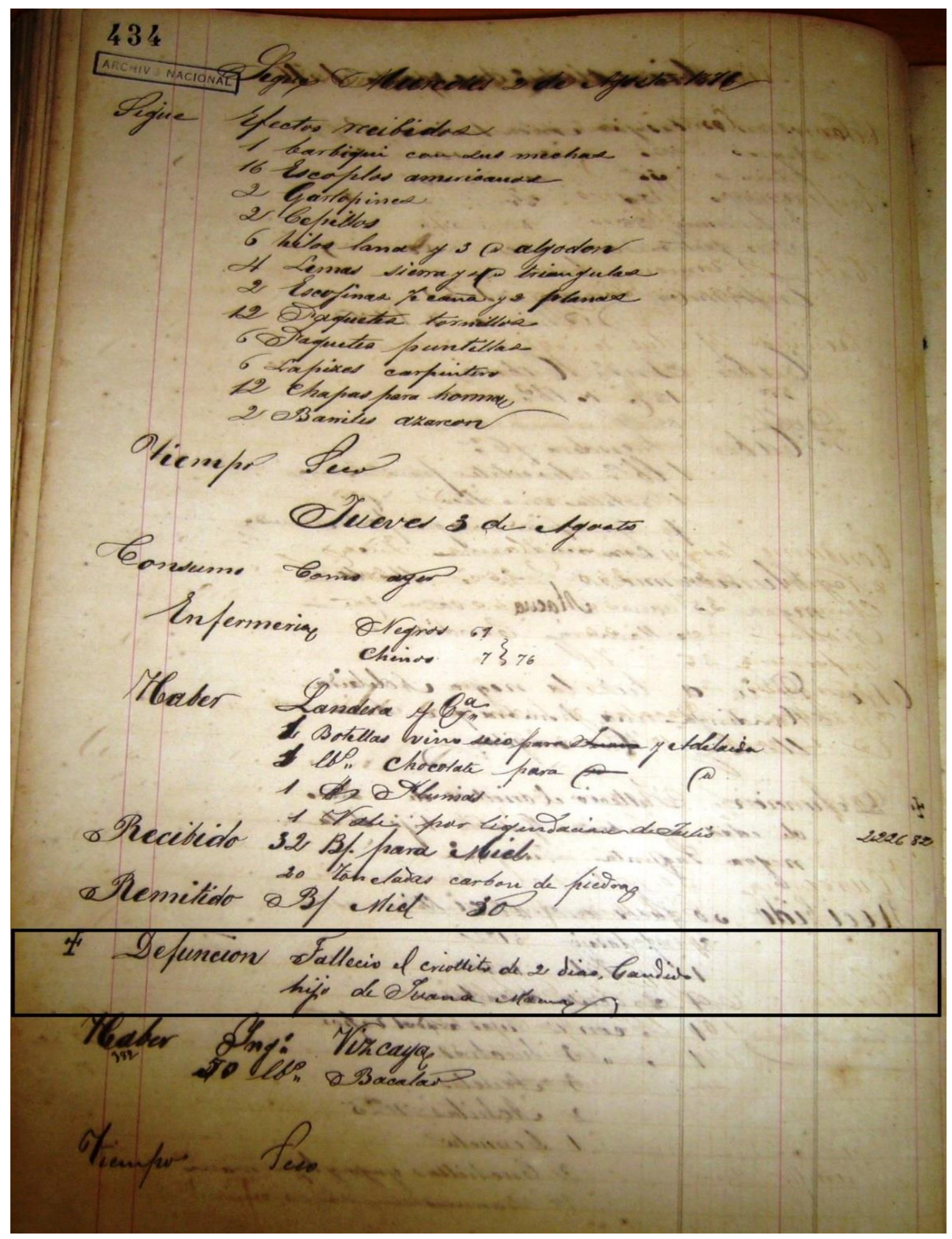

Fuente: Libro de refacción de los ingenios Vizcaya, Habana, España, Álaba (sic) y otros ubicados en la provincia de Matanzas, propiedad de Julián de Zulueta correspondiente a los años 1874-1876, ANC, Donativos y Remisiones, Leg. 140, No. 1, folios 433 y 434. 
VI-PRIMERA PÁGINA DEL MANUSCRITO INVESTIGACIONES SOBRE LAS RAZAS QUE NO PADECEN LA FIEBRE AMARILLA Y ESTUDIO PARTICULAR DE LA ENFERMEDAD HINCHAZÓN DE LOS NEGROS Y CHINOS.

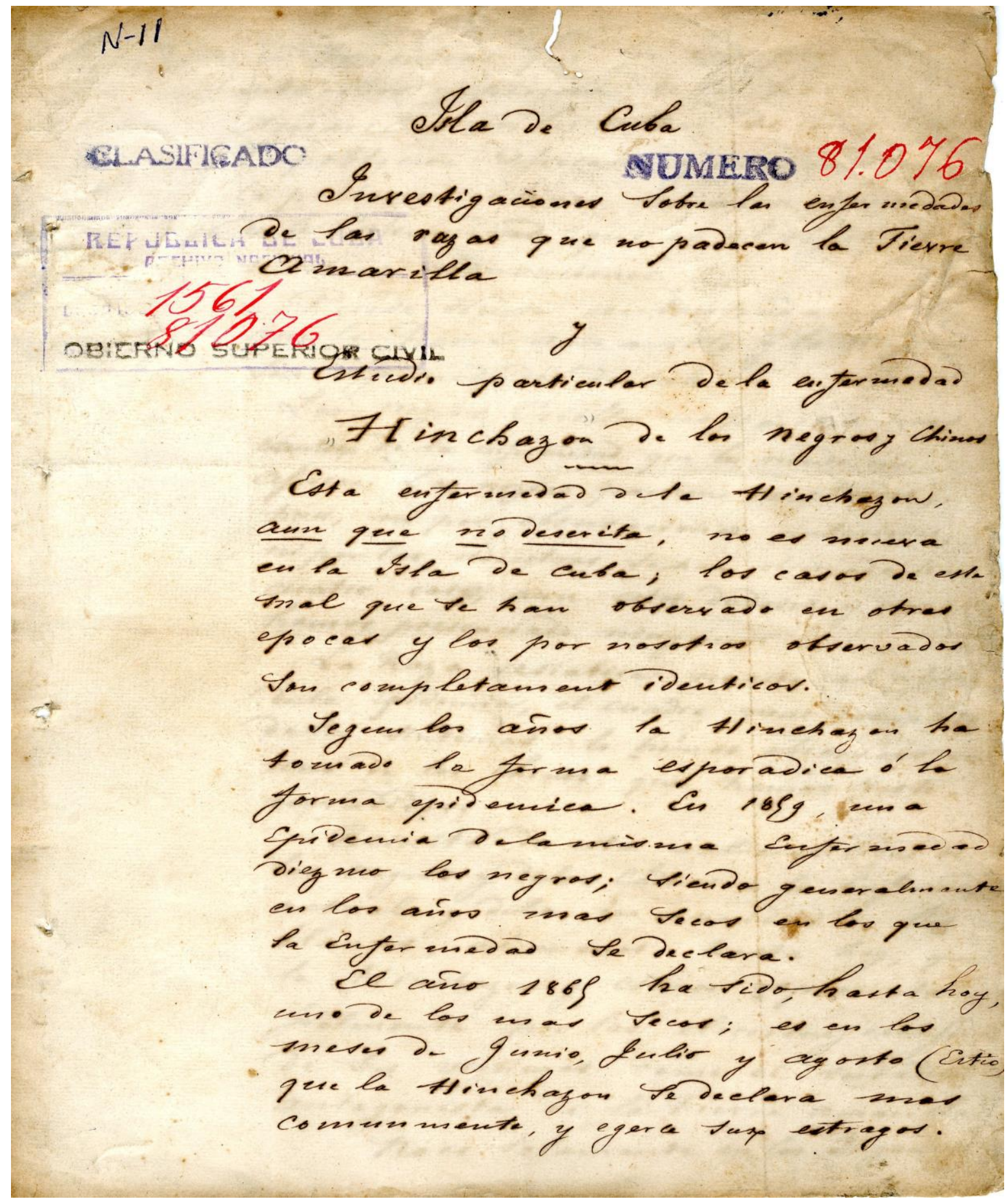

Encontramos el manuscrito durante una estancia de investigación en el Archivo Nacional de Cuba. Hasta la fecha no teníamos conocimiento, ni referencia alguna, de su existencia. Henri Dumont lo publicó en 1865 en Cárdenas y posteriormente en los Anales de la Academia de Ciencias de La Habana. Fuente: ANC, Gobierno Superior Civil, leg. 1561, exp. 81076, 1865. 
VII- PORTADA DE LA PRIMERA EDICIÓN DE INVESTIGACIONES GENERELAES..., DE HENRI DUMONT.

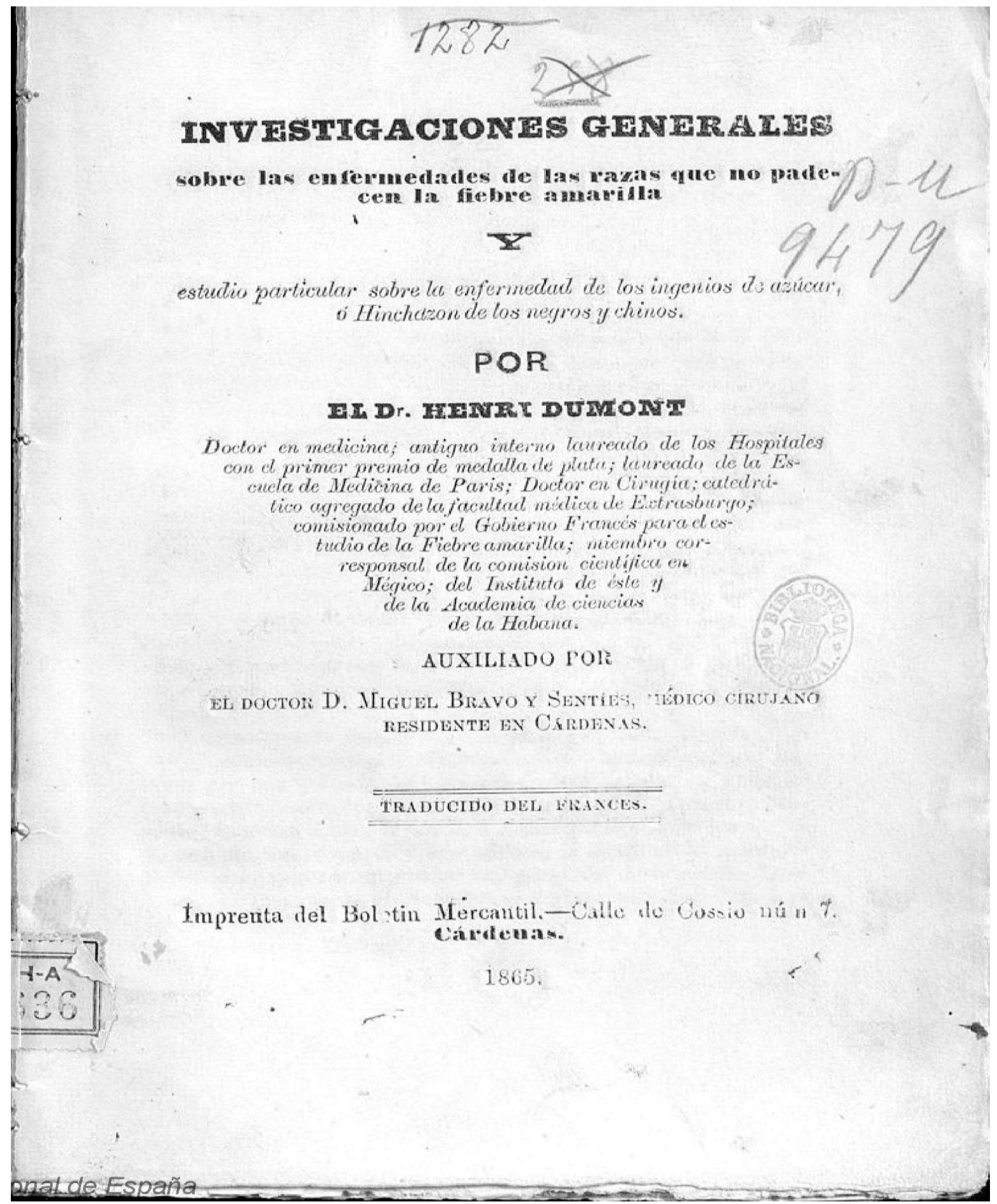

Fuente: Biblioteca Digital Hispánica. 


\section{FUENTES DOCUMENTALES}

\section{ARCHIVO NACIONAL DE CUBA}

Fondo Gobierno Superior Civil

Fondo Junta Superior de Sanidad

Fondo Miscelánea de Expedientes

Fondo Reales Órdenes y Cédulas

Fondo Donativos y Remisiones

Fondo Real Audiencia Pretorial de La Habana

\section{ARCHIVO HISTÓRICO PROVINCIAL DE MATANZAS}

Fondo Gobierno Provincial

Fondo Miscelánea de Expedientes

\section{ARCHIVO HISTÓRICO NACIONAL-ESPAÑA}

Fondo Ultramar

\section{BIBLIOTECA NACIONAL DE CUBA}

Fondo Manuscritos

Colección Cubana Antonio Bachiller y Morales

PUBLICACIONES PERIÓDICAS (años consultados)

Anales de la Real Academia de Ciencias Médicas, Físicas y Naturales de La Habana (1868-1898)

Anales de la Academia de Ciencias de La Habana (1899-1930)

Anales de Ciencias, Agricultura, Comercio y Artes (1829)

Boletín de la Sociedad Cubana de Pediatría (1939) 
Cuba Contemporánea (1913-1927)

Crónica Médico Quirúrgica de La Habana (1875)

Archivos del Folklore Cubano (1924-1930)

Diario de la Marina (1844-1882)

El Eco de Galicia (1878)

El Ingenio. Semanario Agrícola-Industrial (1878-1879)

Gaceta de La Habana (1851)

Gaceta Médica de La Habana (1879-1881)

Gaceta de Madrid (1838-1884)

Guía de Forasteros de la Isla de Cuba $(1844,1866)$

La Aurora (1865)

La Correspondencia de España (1897)

La Época (1897)

La Lucha (1886)

Memorias de la Sociedad Económica de Amigos del País (1836-1861)

Revista de Jurisprudencia, Administración y Comercio (1856-1863)

Revista Bimestre Cubana $(1916,1923)$

Revista de Sanidad Militar (1896)

Sanidad y Beneficencia (1909-1930)

\section{PELÍCULAS}

Sergio Giralt: El otro Francisco (1974)

Tomás Gutiérrez Alea: La última cena (1976)

\section{RECURSOS WEB}

American Geographical Society Library

Archivo General de la Nación-Colombia

Bases de datos de Gwendolyn M. Hall

Baptismal Record Database for Slave Societies

Biblioteca Digital Cubana

Biblioteca Digital Hispánica 
Biblioteca Virtual de la Real Academia Nacional de Medicina-España

Centro de Documentación de la Universidad Jaume I

Cuban Heritage Collection (Universidad de Miami)

Digital Public Library of America

Europeana Colletions

HathiTrust's Digital Library

Internet Archive

JSTOR

Library of Congress (Estados Unidos)

Our World In Data

Portal de Archivos Españoles (Pares)

Slave Societies Digital Archive

The Human Mortality Database

The Internet Archive

The National Archives (Reino Unido)

The New York Public Library. Digital Collections

U.S. National Library of Medicine

Voyages. The Trans-Atlantic Slave Trade Database 


\section{BIBLIOGRAFÍA}

ADAMS, David P.: "Malaria, Labor, and Population Distribution in Costa Rica: A Biohistorical Perspective", The Journal of Interdisciplinary History, vol. 27, $\mathrm{N}^{\circ} .1$, verano, 1996, pp. 75-85.

APTHEKER, Herbert: Las revueltas de los esclavos negros norteamericanos, Siglo XXI, Madrid, 1978.

ARIAS, Salvador: Esclavitud y narrativas en el siglo XIX cubano. Enfoques recientes, Editorial Academia, La Habana, 1991.

ARNALTE, Arturo: Los últimos esclavos de Cuba, Alianza Editorial, Madrid, 2001.

AUSTIN, Gareth, Joerg Baten y Bas van Leeuwen: "The biological standard of living in early $19^{\text {th }}$-century West Africa: new anthropometric evidence", The Economic History Review, vol. 65, N .4 , noviembre, 2012, pp. 1280-1302.

BALBOA Navarro, Imilcy: Los brazos necesarios. Inmigración, colonización y trabajo libre en Cuba, 1878-1898, Fundación Instituto de Historia Social, Valencia, 2000.

----- (ed.): La reinvención colonial de Cuba, Ediciones Idea, Santa Cruz de Tenerife, 2012.

BARCIA PAZ, Manuel: Con el Látigo de la Ira: legislación, represión y control en las plantaciones cubanas, 1790-1870, Editorial de Ciencias Sociales, La Habana, 2000.

-----: La resistencia esclava en las plantaciones cubanas (1790-1870), Rábida, №. 17, 1998, pp. 121-138.

-----: The Great African Slave Revolt of 1825: Cuba and the Fight for Freedom in Matanzas, Louisiana State University Press, Baton Rouge, 2012.

-----: West African Warfare in Bahia and Cuba: Soldier Slaves in the Atlantic World, 18071844, Oxford University Press, Oxford, 2014.

BARCIA ZEQUEIRA, María del Carmen: La otra familia. Parientes, redes y descendencia de los esclavos en Cuba, Editorial Oriente, Santiago de Cuba, 2009. 
-----: "El tema negro en la historiografía cubana del siglo XX", Revista del Caribe, $\mathrm{N}^{\circ} .44$, 2004, pp. 102-110.

BARNET, Miguel: Biografía de un cimarrón, Instituto de Etnología y Folklore, La Habana, 1966.

BARRERA Y DOMINGO, Francisco: Reflexiones histórico físico naturales médico quirúrgicas. Prácticos y especulativos entretenimientos acerca de la vida, usos, costumbre, alimentos, bestidos (sic), color y enfermedades a que propenden los negros de África, venidos a las Américas, Ediciones C. R., La Habana, 1953.

BASHFORD, Alison y Claire Hooker (eds.): Contagion. Historical and cultural studies, Routledge, Londres y Nueva York, 2001.

BERGARD, Laird W: Cuban Rural Society in the Nineteenth Century. The Social and Economic History of Monoculture in Matanzas, Princeton University Press, Princeton, 1990.

-----, Fe Iglesias García y María del Carmen Barcia: The Cuban Slave Market (1700-1880), Cambridge University Press, Cambridge, 1995.

BALDWIN, Peter: Contagion and the State in Europe (1830-1930), Cambridge University Press, Cambridge, 1998.

BELDARRAÍN CHAPLE, Enrique: "Medicina y esclavitud", Catauro, Año. 4, No. 7, enero-junio, 2003, p. 53-78.

BLACKBURN, Robin: The Making of New World Slavery: From the Baroque to the Modern, 1492-1800, Verso, Londres, 1997.

BOLÍVAR AROSTEGUI, Natalia y Carmen González Díaz de Villegas: Mitos y leyendas de la comida afrocubana, Editorial Plaza Mayor, San Juan, 2000.

BOYDEN, Stephen V.: Biohistory. The Interplay Between Human Society and the Biosphere, Unesco, Paris, 1992.

BURNARD, Trevor y Richard Follett: "Caribbean Slavery, British Anti-Slavery, and the Cultural Politics of Venereal Disease", The Historical Journal, vol. 55, No. 2, junio, 2012, pp. 427-451.

BYNUM, Helen: Spitting Blood: The History of Tuberculosis, Oxford University Press, Oxford, 2012. 
BYNUM, William: The History of Medicine: A Very Short Introduction, Oxford University Press, Oxford, 2008.

CARNEY, Judith: Black Rice: The African Origins of Rice Cultivation in the Americas, Harvard University Press, Cambridge, 2001.

CARRERA, Julio Ángel: Esclavitud, abolición y racismo, Editorial de Ciencias Sociales, La Habana, 1985.

CEPERO BONILLA, Raúl: Azúcar y abolición, Editorial de Ciencias Sociales, La Habana, 1971.

CHANDLER, David C.: Health and Slavery in Colonial Colombia, Arno Press, Nueva York, 1981.

CHATEAUSALINS, Honorato Bernard de: El vademécum de los hacendados cubanos o guía práctica para curar la mayor parte de las enfermedades, Imprenta de Manuel Soler, La Habana, 1854.

CHILDS KOHN, George (ed.): Encyclopedia of Plague and Pestilence. From ancient times to the present, Facts On File Inc., Nueva York, 2008.

COCKBURN, Aidan: The Evolution and Eradication of Infectious Diseases, The Johns Hopkins University Press, Baltimore, 1963.

COELHO, Philip R. y Robert A. McGuire: "Biology, Diseases, and Economics: And Epidemiological History of Slavery in the American South", Journal of Bionomics, No. 1, 1999, pp. 151-190.

----: “Diets Versus Diseases: The Anthropometrics of Slave Children", The Journal of Economic History, vol. 60, №. 1, marzo, 2000, pp. 232-246.

COLECTIVO DE AUTORES: Historia de Cuba. La colonia, evolución socioeconómica y formación nacional de los orígenes hasta 1867, Editora Política, La Habana, 1994.

CROSBY, Alfred W.: Imperialismo Ecológico. La expansión biológica de Europa 9001900, Crítica, Barcelona, 1998.

----: America's Forgotten Pandemic. The Influenza of 1918, Cambridge University Press, Cambridge, 2003.

CURTIN, Philip D.: "Epidemiology and the Slave Trade", Political Science Quarterly, vol. 83 , No. 2, junio, 1968, pp. 190-216. 
-----: The Atlantic Slave Trade: A Census, The University of Wisconsin Press, Madison, 1969.

-----: Death by Migration: Europe's Encounter with the Tropical World in the Nineteenth Century, Cambridge University Press, Cambridge, 1989.

-----: Disease and Imperialism Before the Nineteenth Century, Cambridge University Press, Cambridge, 1990.

-----: Disease and Empire: The Health of European Troops in the Conquest of Africa, Cambridge University Press, Cambridge, 1998.

-----: Migration and Mortality in Africa and the Atlantic World 1700-1900, Routledge, Aldershot, 2001.

DAVID COOK, Noble: Born to Die: Disease and New World Conquest 1492-1650, Cambridge University Press, Cambridge, 1998.

DEATON, Angus: El gran escape. Salud, riqueza y los orígenes de la desigualdad, Fondo de Cultura Económica, Madrid, 2015.

DE BARROS, Juanita, Steven Palmer y David Wright: Health and medicine in the circumCaribbean, 1800-1968, Routledge, Nueva York, 2009.

DE LABRA, Rafael M.: La abolición de la esclavitud en el orden económico, Imprenta de J. Naguera, Madrid, 1873.

DE LA FUENTE GARCÍA, Alejandro: “Índices de morbilidad e incidencia de enfermedades entre los esclavos en La Habana, 1580-1699”, Asclepio, No. 2, vol. 43, 1991, pp. 7-22.

-----: “El mercado esclavista habanero 1580-1699: las armazones de esclavos”, Revista de Indias, vol. L, N. 189, 1990, pp. 371-396.

-----: Una nación para todos. Raza, desigualdad y política en Cuba 1900-2000, Imagen Contemporánea, La Habana, 2014.

DE LA SAGRA, Ramón: Historia económica-política y estadística de la Isla de Cuba, Imprenta de las viudas de Arazoza y Soler, La Habana, 1831.

-----: Estudios coloniales con aplicación a la Isla de Cuba, Imprenta de D. Dionisio Hidalgo, Madrid, 1845. 
DE SOLANO, Francisco y Agustín Guimerá Ravina: Esclavitud y derechos humanos: la lucha por la libertad del negro en el siglo XIX, Consejo Superior de Investigaciones Científicas, Madrid, 1990.

DESCHAMPS CHAPEAUX, Pedro: El negro en la economía habanera del siglo XIX, Editorial de Ciencias Sociales, La Habana, 1971.

DRESCHER, Seymour: Econocide. British slavery in the era of abolition, The University of North Carolina Press, 2010.

DUBOS, Rene y Jean Dubos. The White Plague. Tuberculosis, Man and Society, Rutgers University Press, New Jersey, 1987.

DUMONT, Henri: Investigaciones generales sobre las enfermedades de las razas que no padecen la fiebre amarilla y estudio particular sobre la enfermedad de los ingenios de azúcar o hinchazón de los negros y chinos, Imprenta del Boletín Mercantil, Cárdenas, 1865.

-----: Ensayo de una historia médico-quirúrgica de la Isla de Puerto Rico, Imprenta La Antilla, La Habana, 1875.

-----: Antropología y patología comparada de los negros esclavos, Colección Cubana de Libros y Documentos Inéditos o Raros, La Habana, 1922.

DUPIERRIS, Marcial: Memorias sobre la topografía médica de La Habana y sus alrededores, y sobre el estudio físico y moral de los colonos asiáticos, Imprenta La Habanera, La Habana, 1857.

ELTIS, David: "Nutritional Trends in Africa and the Americas: Heights of Africans, 18191839", The Journal of Interdisciplinary History, vol. 12, №. 3, 1982, pp. 453-475.

----- y David Richardson: Atlas of the Transatlantic Slave Trade, Yale University Press, New Haven y Londres, 2010.

----, Frank D. Lewis y Kenneth L. Sokoloff (eds.): Slavery in the development of the Americas, Cambridge University Press, Nueva York, 2004.

-----: The Rise of African Slavery in the Americas, Cambridge University Press, Nueva York, 2006.

ENTRALGO, Elías: La liberación étnica cubana, Imprenta de la Universidad de La Habana, La Habana, 1953. 
ESPINOSA, Mariola: Epidemic Invasions. Yellow Fever and the limits of Cuban Independence 1878-1930, The University of Chicago Press, Chicago, 2009.

ESPINOSA VALDÉS, Mabel: Comportamiento sociocultural de los esclavos africanos y sus descendientes en la región de Cárdenas (1800 - 1880), CD de Monografías, Universidad de Matanzas, 2011, consultado en http://monografias.umcc.cu/monos/2011/FUM\%20CARDENAS/mo11sc27.pdf.

FERRER DE COUTO, José: Los negros en sus diversos estados y condiciones; tales como son, como se supone que son y cómo deben ser, Imprenta de Hallet, Nueva York, 1864.

FLANDRIN, Jean-Louis y Massimo Montanari (eds.): Historia de la Alimentación, Ediciones Trea, S. L., Gijón, 2004.

FLORES GUZMAN, Ramiro Alberto: "The feeding of slave population in the United States, the Caribbean, and Brazil; some remarks in the state of the art", América Latina en la Historia Económica, Año. 20, №. 2, mayo-agosto, 2013, pp. 5-35.

FOGEL, Robert W. y Stanley L. Engerman: Tiempo en la cruz. La economía esclavista en los Estados Unidos, Siglo XXI, Madrid, 1981.

FOGEL, Robert W: Escapar del hambre y la muerte prematura. Europa, América y el Tercer Mundo 1700-2100, Alianza Editorial, Madrid, 2009.

FOLLETT, Richard: "Heat, sex, and sugar: pregnancy and childbearing in the slave quarters", Journal of Family History, vol. 28, №. 4, 2003, pp. 510-539.

-----: 'Lives of living death': The reproductive lives of slave women in the cane world of Louisiana", Slavery and Abolition, vol. 26, No. 2, 2005, pp. 289-304.

-----: The Sugar Masters: Planters and Slaves in Louisiana's Cane World, 1820-1860, Louisiana State University Press, Baton Rouge, 2005.

FORSTER, Martin y S. D. Smith: "Surviving slavery: mortality at Mesopotamia, a Jamaican sugar estate, 1762-1832”, Journal of the Royal Statistical Society, vol. 174, No. 4, octubre, 2011, pp. 907-929.

FRANCO, José Luciano: Esclavitud, comercio y tráfico negreros, Academia de Ciencias de Cuba, La Habana, 1972.

-----: Los palenques de negros cimarrones, Departamento de Orientación Revolucionaria del Comité Central, La Habana, 1973. 
-----: Contrabando y trata negrera en el Caribe, Editorial de Ciencias Sociales, La Habana, 1976.

----: Comercio clandestino de esclavos, Editorial de Ciencias Sociales, La Habana, 1980.

FREYRE, Gilberto: Casa grande y Senzala, Biblioteca Ayacucho, Caracas, 1977.

FUNES MONZOTE, Reinaldo: Despertar del asociacionismo científico en Cuba 18761920, Centro de Investigación y Desarrollo de la Cultura Cubana "Juan Marinello", La Habana, 2005.

-----: "Plantaciones esclavistas azucareras y transformación ecológica en Cuba", Revista Historia, $\mathrm{N}^{\circ}$. 59-60, enero-diciembre, 2009, pp. 35-54.

-----: De los bosques a los cañaverales. Una historia ambiental de Cuba (1492-1926), Editorial de Ciencias Sociales, La Habana, 2010.

GARCÍA, Armando y Consuelo Naranjo: Racismo e inmigración en Cuba en el siglo XIX, Doce Calles, Aranjuez, 1996.

-----: El estigma del color: saberes y prejuicios sobre las razas en la ciencia hispano cubana del siglo XIX, 2 vols, Ediciones Idea, Tenerife, 2008.

GARCÍA, Gloria: La esclavitud desde la esclavitud. La visión de los siervos, Centro de Investigación Científica "Ing. Jorge L. Tamayo”, México, 1996.

GARRIDO, Santiago y otros: Tráfico marítimo de esclavos: cambios tecnológicos y mortalidad. Un análisis socio-técnico, Primeras Jornadas Nacionales de Historia Social, La Falda-Córdoba, 30, 31 de mayo y 1ro de junio de 2007.

GONZÁLEZ DEL VALLE, Ambrosio: Tablas obituarias, Establecimiento Tipográfico de la Viuda de Soler, La Habana, 1882.

GONZÁLEZ-RIPOLL, Ma Dolores y Izaskun Álvarez Cuartero, (eds.): Francisco Arango y la invención de la Cuba azucarera, Ediciones Universidad de Salamanca, Salamanca, 2010.

GROB, Gerald N.: The Deadly Truth. A History of Disease in America, Harvard University Press, Cambridge, 2002.

GUERRA, Ramiro: Azúcar y población en las Antillas, Editorial de Ciencias Sociales, La Habana, 1970. 
JODA ESTEVE, Beatriz: "El comercio de esclavos a Cuba (1790-1840): una proporción femenina", Anuario Colombiano de Historia Social y de la Cultura, vol. 41, №. 2 , julio-diciembre, 2014, pp. 107-130.

-----: Mujer y esclavitud doméstica: La Habana (1790-1844), Tesis Doctoral, Universitat Jaume I, Castellón de la Plana, 2014.

HALL, Gwendolyn M.: Social Control in Slave Plantation Societies: A Comparison of St. Domingue and Cuba, Johns Hopkins Press, Baltimore, MD, 1971.

HANDLER, Jerome S. y Robert S. Corruccini: "Plantation Salve Life in Barbados: A Physical Anthropological Analysis", The Journal of Interdisciplinary History, vol. $14, \mathrm{~N}^{\circ} .1$, verano, 1983 , pp. 65-90.

-----: "Weaning among West Indian Slaves: Historical and Bioanthropological Evidence from Barbados", The William and Mary Quarterly, vol. 43, №. 1, enero, 1986, pp. 111-117.

HART, Richard: Esclavos que abolieron la esclavitud, Casa de las Américas, La Habana, 1984.

HEVIA LANIER, Oilda: Prácticas Religiosas de los negros en la Colonia, Ediciones Rizo, Instituto de Historia de Cuba, La Habana, 2010.

HIGMAN, Barry W.: Slave Populations of the British Caribbean, 1807-1834, The Press University of West Indies, Kingston, 1995.

HOFFMAN, Frederic L.: "The Negro in the West Indies", Publications of American Statistical Association, vol. 4, Nº. 30, junio, 1895.

HUMPHREYS, Margaret: Yellow Fever and The South, The Johns Hopkins University Press, Baltimore y Londres, 1999.

----: Malaria: Poverty, Race, and Public Health in the United States, The Johns Hopkins University Press, Baltimore, 2001.

IBARRA CUESTA, Jorge: Marx y los historiadores ante la hacienda y la plantación esclavistas, Editorial de Ciencias Sociales, La Habana, 2008.

IGLESIAS UTSET, Marial: "Los Despaigne en Saint-Domingue y Cuba: narrativa microhistórica de una experiencia atlántica”, Revista de Indias, vol. LXXI, №. 251, 2011, pp. 77-107. 
INSTITUTO DE CIENCIAS HISTÓRICAS: La esclavitud en Cuba, Editorial Academia, La Habana, 1986.

INSTITUTO DE HISTORIA DE CUBA: La historiografía en la Revolución cubana. Reflexiones a 50 años, Editora Historia, La Habana, 2010.

KARASCH, Mary C.: Slave Life in Rio de Janeiro, 1808-1850, Princeton University Press, Princeton, 1987.

KARRAS, Alan y J. R. McNeill (eds.): Atlantic American Societies. From Columbus through abolition (1492-1888), Routledge, Londres, 1992.

KENNETH STAMP, Milton: La esclavitud en los Estados Unidos. La institución peculiar, Ediciones Oikos-Tau, Barcelona, 1966.

KIPLE, Kenneth F.: Blacks in colonial Cuba, 1774-1899, University Presses of Florida, Gainesville, 1976.

-----: “Deficiency Diseases in the Caribbean” The Journal of Interdisciplinary History, vol. $11, \mathrm{~N}^{\mathrm{o}} .2,1980$, pp. 197-215.

----- and Virginia H. K: "The African Connection: Slavery, Disease and Racism", Phylon, vol. 41, No. 3, 1980, pp. 211-222.

---- y Virginia H. K.: Another Dimension to the Black Diaspora: Diet, Disease, and Racism, Cambridge University Press, Cambridge, 1981.

-----: The Caribbean Slave: A Biological History, Cambridge University Press, Cambridge, 1984.

-----: "Cholera and Race in the Caribbean", Journal of Latin American Studies, vol. 17, mayo, 1985, pp. 157-177.

-----: "The nutritional link with slave infant and child mortality in Brazil", The Hispanic American Historical Review, vol. 69, No. 4, noviembre, 1989, pp. 677-690.

----- (ed.): The Cambridge World History of Human Disease, Cambridge University Press, Cambridge, 1993.

----- y Kriemhild Coneé Ornealas (eds.): The Cambridge World History of Food, vol. I y II, Cambridge University Press, Cambridge, 2000.

---- (ed.): The Cambridge Historical Dictionary of Disease, Cambridge University Press, Cambridge, 2003. 
KLEIN, Herbert S. y Stanley L. Engerman: "Fertility Differentials between Slaves in the United States and the British West Indies: A Note on Lactation Practices and Their Possible Implications", The William and Mary Quarterly, vol. XXXV, No. 2, abril, 1978, pp. 357-374.

-----, Stanley L. Engerman, Robin Haines y Ralph Shlomowitz: “Transoceanic Mortality:

The Slave trade in Comparative Perspective", The William and Mary Quarterly, vol. LVIII, No. 1, enero, 2001, pp. 93-118.

-----: La esclavitud africana en América Latina y el Caribe, Alianza Editorial, Madrid, 1986.

-----: The Atlantic Slave Trade, Cambridge University Press, Nueva York, 2010.

----- y Francisco Vidal Luna: Slavery in Brazil, Cambridge University Press, Cambridge, 2010.

KNIGHT, Franklin W.: Slave society in Cuba during the Nineteenth Century, Wisconsin University Press, Madison, 1970.

LAVIÑA, Javier y José Luis Ruiz-Peinado: “Alimentación y cimarronaje en Vuelta Abajo. Notas sobre el diario de un rancheador”, Boletín Americanista, No. 37, 1987, pp. 203214.

-----: Resistencias esclavas en las Américas, Ediciones Doce Calles, Madrid, 2006.

-----: Cuba. Plantación y adoctrinamiento, Ediciones Idea, Santa Cruz de Tenerife, 2006.

LE RIVEREND, Julio: Historia económica de Cuba, Instituto Cubano del Libro, La Habana, 1971.

LEE, Anne S. y Everett S. Lee: "The Health of Slaves and the Health of Freedmen: A Savannah Study", Phylon, vol. 38, N. 2, 1977, pp. 170-180.

LEE DAWDY, Shannon: ““.A Wild Taste”: Food and Colonialism in Eighteenth-Century Louisiana”, Ethnohistory, vol. 57, No. 3, verano, 2010, pp. 389-414.

LEE, Debbie: "Yellow Fever and the Slave Trade: Coleridge's The Rime of the Ancient Mariner", English Literary History, vol. 65, №. 3, otoño, 1998, pp. 675-700.

LÓPEZ DENIS, Adrián: Saco, Sagra y el cólera morbo, Ediciones Vitral, Pinar del Río, 2002.

----: "Higiene pública contra higiene privada: cólera, limpieza y poder en La Habana colonial”, Estudios Interdisciplinarios de América Latina y el Caribe, vol. 14, №. 1, 
enero-junio,

2003,

disponible

en

http://eial.tau.ac.il/index.php/eial/article/view/928/964.

-----: "Melancholia, Slavery and Racial Pathology in Eighteenth Century Cuba", Science in Context, vol. 18, №. 2, 2005, pp. 179-200.

----: Disease and Society in Colonial Cuba, 1790-1840, Tesis Doctoral, University of California, Los Angeles, 2007.

LÓPEZ ESPINOSA, José Antonio y otros: "El tema nutrición y alimentación en la bibliografía médica cubana del período colonial”, Acimed, vol. 14, No. 5, 2006, pp. 114.

LÓPEZ, Manuel B.: El garrote en Cuba, Imprenta “América Arias”, La Habana, 1927.

LÓPEZ SÁNCHEZ, José: La Medicina en La Habana, Publicación del Consejo Científico del Ministerio de Salud Pública, La Habana, 1970.

----: Cuba. Medicina y Civilización siglos XVII y XVIII, Editorial Científico-Técnica, La Habana, 1997.

MADDEN, Richard: La isla de Cuba, sus recursos, progresos y perspectivas, Consejo Nacional de Cultura, La Habana, 1964.

MALAVASSI, Ana Paulina: "Miscelánea cubana sobre el entorno sanitario de los africanos esclavizados", Intercambio, Año. 6, Nº. 7, 2009, pp. 129-156.

MARGO, Robert A. y Richard H. Steckel: "The Heights of American Slaves. New Evidence on Slave Nutrition and Health”, Social Science History, vol. 6, No. 4, 1982, pp. 516-538.

MARQUÉS DE ARMAS, Pedro: Ciencia y poder en Cuba. Racismo, homofobia, nación (1790-1970), Editorial Verbum, Madrid, 2014.

-----: "Exclusiones post mortem. Esclavitud, suicidio y derecho de sepultura", Revista Tunecina de Estudios Hispánicos, №. 2, 2015, pp. 49-63.

MARRERO, Levi: Cuba: Economía y Sociedad 1510-1868, (Obra en 15 volúmenes), Editorial Playor, Madrid, 1988.

MCNEILL, John R.: "El vómito negro y la geopolítica. El medio ambiente, las epidemias y las batallas por el imperio en los trópicos americanos", en: Reinaldo Funes (ed.), Naturaleza en declive. Miradas a la historia ambiental de América Latina y el Caribe, Fundación Instituto de Historia Social, Valencia, 2008. 
----: Mosquito Empires: Ecology and War in the Greater Caribbean 1620-1914, Cambridge University Press, Cambridge, 2010.

MCNEILL, William H.: Plagues and Peoples, Anchor, New York, 1976.

MESA, Roberto: El colonialismo en la crisis del XIX español: esclavitud y trabajo libre en Cuba, Ediciones de Cultura Hispánica, Madrid, 1990.

MILLER, Joseph C.: Way of Death: Merchant Capitalism and the Angolan Slave Trade, 1730-1830, University of Wisconsin Press, Madison, 1988.

-----: The Problem of Slavery as History: A Global Approach, Yale University Press, New Haven y Londres, 2012.

MINTZ, Sidney W.: Dulzura y poder. El lugar del azúcar en la historia moderna, Siglo XXI, Madrid, 1996.

-----: Tasting food, Tasting Freedom: Excursions into eating, culture, and the past, Beacon Press, Boston, 1996.

MORENO FRAGINALS, Manuel: El ingenio. Complejo económico-social cubano del azúcar, Editorial de Ciencias Sociales, La Habana, 2014.

----- (relator): África en América Latina, Siglo XXI, Madrid, 1996.

----: La historia como arma y otros estudios sobre esclavos, ingenios y plantaciones, Crítica, Barcelona, 1999.

MÖRNER, Magnus (ed.): Race and Class in Latin American, Columbia University Press, Nueva York, 1971.

-----: "Buy or breed"? Alternative sources of slave supply in the plantation societies of the New World, Institute of Latin American Studies, Stockholm, 1980.

MURRAY, David R.: Odious Commerce. Britain, Spain and the abolition of the Cuban slave trade, Cambridge University Press, Cambridge, 2002.

MUSTAKEEM, Sowande: "I Never Have Such a Sickly Ship Before: Diet, Disease, and Mortality in 18th-Century Atlantic Slaving Voyages", The Journal of African American History, vol. 93, N. 4, otoño, 2008, pp. 474-496.

NARANJO, Consuelo y Armando García, "Antropología, "raza" y población en Cuba en el último cuarto del siglo XIX”, Anuario de Estudios Americanos, vol. 55, №. 1, 1998, pp. 267-289. 
-----: "La cuestión racial durante la transición al trabajo libre en Cuba (1860-1890)", en: José A. Piqueras (coord.), Azúcar y esclavitud en el final del trabajo forzado, Fondo de Cultura Económica, Madrid, 2002, pp. 308-330.

-----: "La aclimatación a los trópicos y el trabajo esclavo en Cuba" en: Justo Cuño Bonito (ed.), Palabras para el intendente: un libro-homenaje al historiador Juan Andreo García, Editorial Renacimiento, Sevilla, 2014, pp. 160-181.

---- (ed.): Esclavitud y diferencia racial en el Caribe hispano, Ediciones Doce Calles, Madrid, 2016.

NAVARRO AZCUE, Concepción; La abolición de la esclavitud negra en la legislación española 1870-1886, Instituto de Cooperación Iberoamericana, Madrid, 1987.

NEWSON, Linda A. y Susie Minchin: From Capture to Sale: The Portuguese Slave Trade to Spanish South America in the early seventeenth century, Brill Academic Publishers, Leiden y Boston, 2007.

NUNN, Nathan y Nancy Qian: "The Columbian Exchange: A History of Disease, Food, and Ideas", The Journal of Economic Perspectives, vol. 24, №. 2, primavera, 2010, pp. 163-188.

NÚÑEZ JIMÉNEZ, Antonio: Los esclavos negros, Fundación de la Naturaleza y el Hombre, La Habana, 1998.

O'CONNELL, Heather A.: "The Impact of Slavery on Racial Inequality in Poverty in the Contemporary U.S. South", Social Forces, vol. 90, N. 3, marzo, 2012, pp. 713-734.

ORTIZ, Fernando: Los negros esclavos, Editorial de Ciencias Sociales, La Habana, 1975.

PACHECO, Francisco: Facetas del esclavo africano en América Latina, Academia de Ciencias de Cuba-Instituto de Historia, La Habana, 1970.

PATTERSON, Orlando: Slavery and Social Death. A comparative Study, Harvard University Press, Cambridge, 1982.

PERALTA, José: La esclavitud en América Latina, Publicaciones de la Universidad de Cuenca, Panamá, 1961.

PERERA DÍAZ, Aisnara y María de los Ángeles Meriño Fuentes: Esclavitud, familia y parroquia en Cuba: Otra mirada desde la microhistoria, Editorial Oriente, Santiago de Cuba, 2006. 
-----: Un café para la microhistoria. Estructura de posesión de esclavos y ciclo de vida en la llanura habanera (1800-1886), Editorial de Ciencias Sociales, La Habana, 2007.

PÉREZ DE LA RIVA, Juan: El barracón y otros ensayos, Editorial de Ciencias Sociales, La Habana, 1975.

-----: Para la historia de la gente sin historia, Ariel, Barcelona, 1976.

PERRET BALLESTER, Alberto: El azúcar en Matanzas y sus dueños en La Habana: apuntes e iconografía, Editorial de Ciencias Sociales, La Habana, 2007.

PIÑA Y PEÑUELA, Ramón: Topografía médica de la Isla de Cuba, Imprenta y Encuadernación del Tiempo, La Habana, 1855.

PIQUERAS, José Antonio: "El azúcar en Cuba y las fuentes para su estudio", América Latina en la Historia Económica, vol. 6, Nº. 11, enero-junio, 1999, pp. 35-47.

----- (comp.): Azúcar y esclavitud en el final del trabajo forzado, Fondo de Cultura Económica, Madrid, 2002.

----- "Coacción, voluntariedad y libertad en el trabajo colonial: una historia atlántica", en: José Antonio Piqueras (ed.): Trabajo libre y coactivo en sociedades de plantación, Siglo XXI, Madrid, 2009, pp. 3-50.

-----: La esclavitud en las Españas: un lazo transatlántico, Libros de la Catarata, Madrid, 2011.

-----: "Censos lato sensu. La abolición de la esclavitud y el número de esclavos en Cuba", Revista de Indias, vol. LXXI, No. 251, 2011, pp. 193-230.

----- (coord.): Esclavitud y capitalismo histórico en el siglo XIX, Brasil, Cuba y Estados Unidos, Editorial del Caribe, Santiago de Cuba, 2016.

----- (ed.): Orden político y gobierno de esclavos, Fundación Instituto de Historia Social, Valencia, 2016.

PORTO, Ángela: "Fontes e debates em torno da saúde do escravo no Brasil do século XIX”, Revista Latinoamericana de Psicopatologia Fundamental, São Paulo, vol. 11, $\mathrm{N}^{\circ} .4$, diciembre, 2008, pp. 726-734.

PUIG-SAMPER, Miguel Ángel: "El suicidio esclavo en el Mundo Atlántico”, en: Consuelo Naranjo (ed.), Esclavitud y diferencia racial en el Caribe hispano, Ediciones Doce Calles, Madrid, 2016, pp. 71-88. 
RANGEL RIVERO, Armando: Antropología en Cuba: Orígenes y desarrollo, Fundación Fernando Ortiz, La Habana, 2012.

REDIKER, Markus: El barco de esclavos. Una historia humana, Imagen Contemporánea, La Habana, 2014.

RILEY, James C.: Rising Life Expectancy: A Global History, Cambridge University Press, Cambridge, 2001.

RODNEY, Walter: De cómo Europa subdesarrollo a África, Editorial de Ciencias Sociales, La Habana, 1982.

ROIG, Emilio: Médicos y Medicina en Cuba. Historia, Biografía, Costumbrismo, Academia de Ciencias de Cuba, La Habana, 1964.

ROSENBERG, Charles E.: The Cholera Years, The United States in 1832, 1849, and 1866, The University of Chicago Press, Chicago, 1987.

ROTHMAN, Sheila M.: Living in the Shadow of Death: Tuberculosis and the Social Experience of Illness in American History, Basic Books, New York, 1994.

SALAS-SALVADÓ, Jordi y otros (eds.): La alimentación y la nutrición a través de la historia, Editorial Glosa, Barcelona, 2005.

SACO, José Antonio: Carta sobre el cólera morbo asiático, Imprenta del Gobierno, La Habana, 1833.

-----: La supresión del tráfico de esclavos en la Isla de Cuba. Examinada con relación a su agricultura y su seguridad, Imprenta de Panckoucke, París, 1845.

-----: Historia de la esclavitud desde los tiempos más remotos hasta nuestros días, Imprenta Jaime Jepús, Barcelona, 1877.

-----: Colección póstuma de papeles científicos, históricos, políticos y otros ramos sobre la isla de Cuba, Editor Miguel de Villa, La Habana, 1881.

SARMIENTO RAMÍREZ, Ismael: Cuba: Entre la opulencia y la pobreza, S. L. Agualarga Editores, Madrid, 2004.

SCHEPER-HUGHES, Nancy: La muerte sin llanto. Violencia y vida cotidiana en Brasil, Ariel, Barcelona, 1997.

SCOTT, Rebecca J.: La emancipación de los esclavos en Cuba: la transición al trabajo libre (1860-1899), Fondo de Cultura Económica, México D. F., 1989. 
SCHWARTZ, Stuart B., Sugar plantations in the formation of Brazilian society: Bahia, 1550-1835, Cambridge University Press, Cambridge, 1985.

SILVERSTEIN, Arthur M.: A History of Immunology, Elsevier Inc., Londres, 2009.

SOLOW, Barbara L. (ed.): Slavery and the Rise of the Atlantic System, Cambridge University Press, Nueva York, 2002.

STARR, Paul: The Social Transformation of American Medicine, Basic Books, New York, 1982.

STECKEL, Richard H.: "A Peculiar Population. The Nutrition, Health, and Mortality of American Slave from Childhood to Maturity", The Journal of Economic History, vol. 46, N. 3, septiembre, 1986, pp. 721-741.

-----: "A dreadful childhood: the excess mortality of American slaves", Social Science History, vol. 10, N . 4, 1986, pp. 427-466.

----: "Diets Versus Diseases in the Anthropometrics of Slave Children: A Reply" The Journal of Economic History, vol. 60, №. 1, marzo, 2000, pp. 247-259.

----- y Jerome C. Rose (eds.): The Backbone of History: Health and Nutrition in the Western Hemisphere, Cambridge University Press, Cambridge, 2005.

STOLCKE, Verena: Racismo y sexualidad en la Cuba colonial, Alianza Editorial, Madrid, 1992.

SUTCH, Richard: "The Treatment Received by American Slaves: A Critical Review of the Evidence Presented in Time on the Cross", Explorations in Economic History, Elsevier, vol. 12, № 4, octubre, 1975, pp. 335-438.

TADMAN, Michael: “The Demographic Cost of Sugar: Debates on Slave Societies and Natural Increase in the Americas", The American Historical Review, vol. 105, №. 5, diciembre, 2000, pp. 1534-1575.

TANNENBAUM, Frank: El negro en las Américas. Esclavo y ciudadano, Paidós, Buenos Aires, 1968.

THODE JENSEN, Niklas: For the Health of the Enslaved. Slaves, Medicine and Power in the Danish West Indies, 1803-1848, Museum Tusculanum Press, Copenhagen, 2012.

THOMAS, Hugh: La trata de esclavos. Historia del tráfico de seres humanos de 1440 a 1870, Editorial Planeta, Barcelona, 1998.

-----: Cuba. La lucha por la libertad, Debate, Barcelona, 2004. 
TOMICH, Dale W.: Through the Prism of Slavery: Labor, Capital, and World Economy, Rowman \& Littlefield, Lanham-Oxford, 2004.

-----: "La segunda esclavitud y el capitalismo mundial: una perspectiva para la investigación histórica", Historia Social, Nº. 90, 2018, pp. 149-164.

-----: Espacios de esclavitud: tiempo/tiempos del capital, Fundación Instituto de Historia Social, Valencia, 2019.

TORNERO, Pablo: Crecimiento económico y transformaciones sociales. Esclavos, hacendados y comerciantes en la Cuba colonial 1790-1840, Ministerio de Trabajo y Seguridad Social, Madrid, 1996.

TORRES CUEVA, Eduardo: Esclavitud y sociedad: notas y documentos para la historia de la esclavitud negra en Cuba, Editorial de Ciencias Sociales, La Habana, 1986.

TURNBULL, David: Travels in the West, Cuba, with notices of Porto Rico and the slave trade, Imprenta Longman, Londres, 1840.

VARELLA, Claudia: Esclavos a sueldo. La coartación cubana en el siglo XIX, Tesis Doctoral, Universitat Jaume I, Castellón de la Plana, 2010.

-----: "El fracaso de las compañías de seguros de esclavos: Cuba a partir de la experiencia norteamericana", International Journal of Cuban Studies, vol. 10, № . 1, primavera, 2018, pp. 93-113.

VERANOB, John W. y Douglas H. Ubelaker: Disease and demography in the Americas, Smithsonian Institution Press, Washington, 1992.

WATTS, Sheldon: Disease and Medicine in World History, Routledge, New York y Londres, 2003.

WILLIAMS, Eric: Capitalismo y esclavitud, Editorial de Ciencias Sociales, La Habana, 1975.

WHOOLEY, Owen: Knowledge in the Time of Cholera. The Struggle Over American Medicine in the Nineteenth Century, The University of Chicago Press, Chicago, 2013.

ZANETTI, Oscar y Alejandro García: Caminos para el azúcar, Editorial de Ciencias Sociales, La Habana, 1987.

-----: “La historiografía de temática social (1959-1984)", Revista de la Biblioteca Nacional José Martí, №. 1, enero-abril, 1985, pp. 5-17. 
